\title{
América Latina ante el cambio geoeconómico-político mundial: entre la crisis de hegemonía y las nuevas asimetrías del Sur global
} Sergio Ordóñez Víctor Ramiro Fernández Carlos Brandão [Coordinadores]
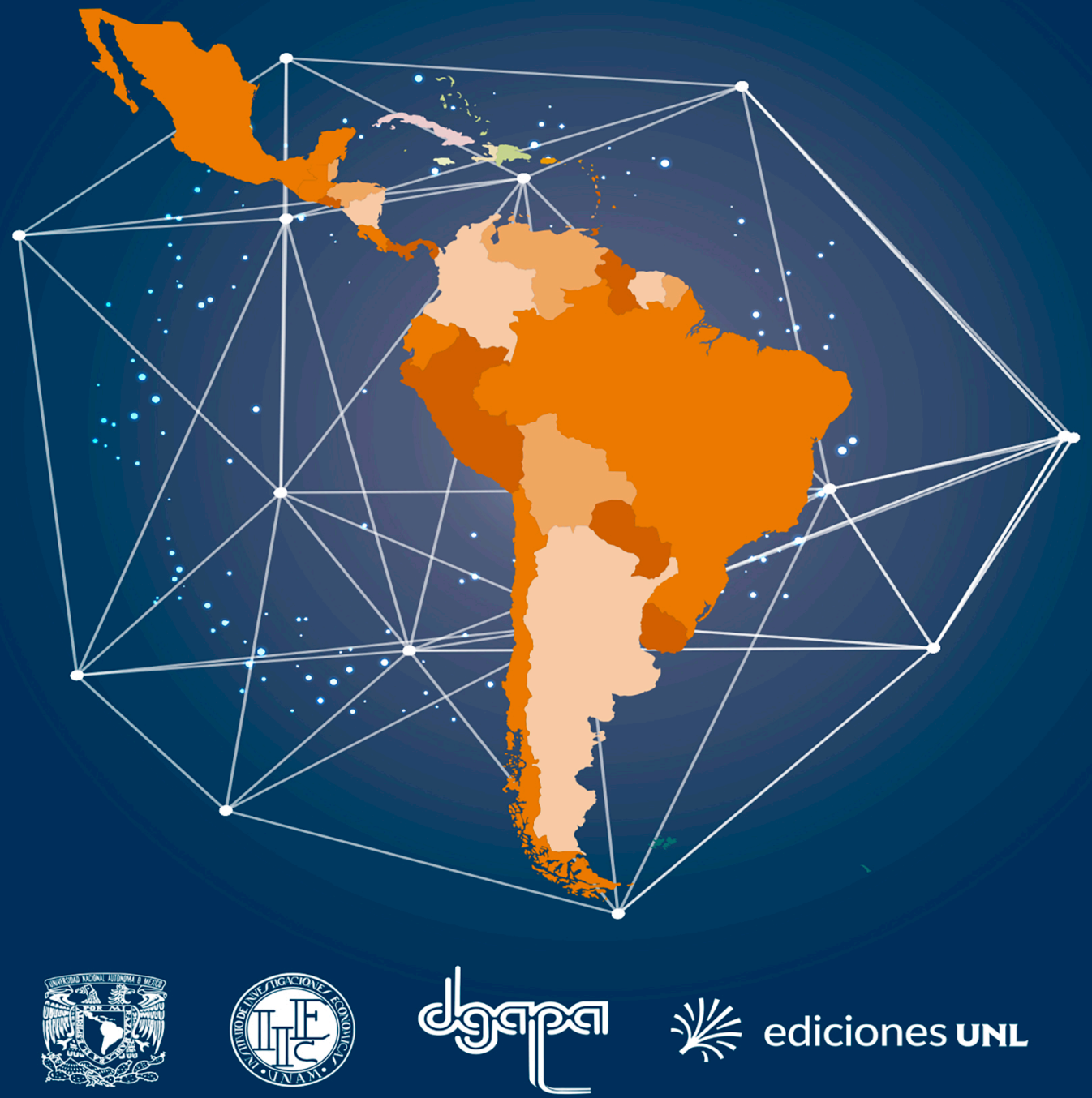

谈 ediciones UNL 
AMÉRICA LATINA ANTE EL CAMBIO GEOECONÓMICO-POLÍTICO MUNDIAL:

ENTRE LA CRISIS DE HEGEMONÍA Y LAS NUEVAS ASIMETRÍAS DEL SUR GLOBAL 

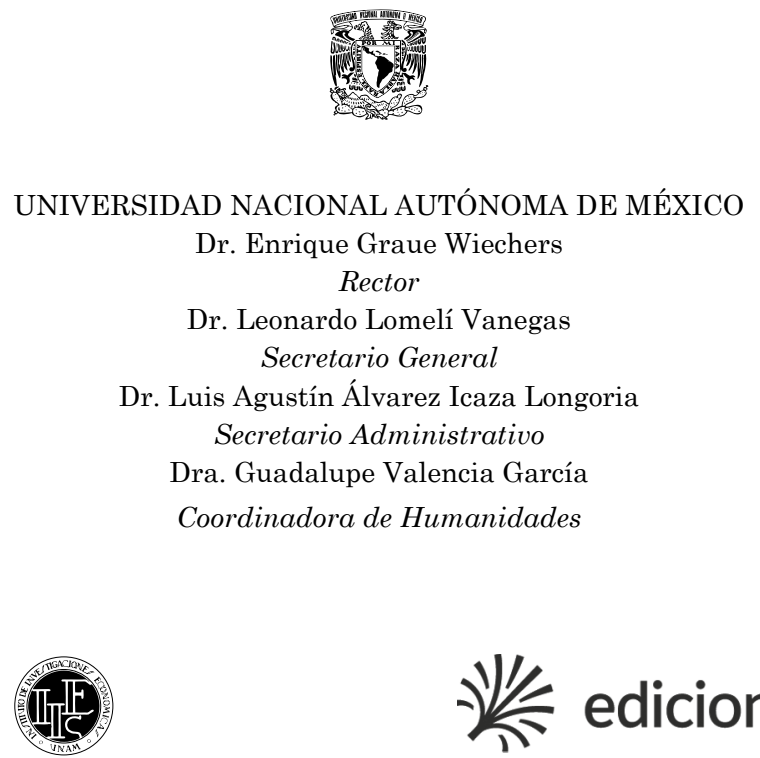

监 ediciones UNL

INSTITUTO DE INVESTIGACIONES ECONÓMICAS

Dr. Armando Sánchez Vargas

Director

Dra. Isalia Nava Bolaños

Secretaria Académica

Ing. Patricia Llanas Oliva

Secretaria Técnica

Mtra. Graciela Reynoso Rivas

Jefa del Departamento de Ediciones
UNIVERSIDAD NACIONAL DEL LITORAL

Enrique Mammarella

Rector

Miguel Irigoyen

Secretario de Planeamiento

Institucional y Académico

Ivana Tosti

Directora Ediciones UNL 


\title{
AMÉRICA LATINA ANTE EL CAMBIO GEOECONÓMICO-POLÍTICO MUNDIAL: ENTRE LA CRISIS DE HEGEMONÍA Y LAS NUEVAS ASIMETRÍAS DEL SUR GLOBAL
}

\author{
Sergio Ordóñez \\ Víctor Ramiro Fernández \\ Carlos Brandão \\ (Coordinadores)
}


Primera edición digital en pdf, febrero 2021.

D.R. C Universidad Nacional Autónoma de México

Ciudad Universitaria, Coyoacán, 04510, Ciudad de México.

Instituto De InVESTIGACIONES ECONÓMICAS

Circuito Mario de la Cueva s/n,

Ciudad de la Investigación en Humanidades,

04510, Ciudad de México.

D.R. (C) Universidad Nacional del Litoral

Boulevard Pellegrini 2750

de la Ciudad de Santa Fe, Provincia de Santa Fe, 3000, Argentina.

ISBN UNAM: 978-607-30-4363-2

ISBN UNL: 978-987-749-264-4

PAPIIT IN301519 "Nuevo ciclo industrial y redes productivas globales ante el actual curso proteccionista internacional: repercusiones para México”.

La investigación de la que esta obra es resultado fue realizada en el marco de la colaboración de los autores en la Red del Desarrollo Socioeconómico Espacial Latinoamericano.

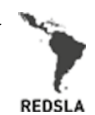

La edición de esta obra ha sido parcialmente financiada por una subvención de la Universidad Nacional de General Sarmiento.

Diseño de portada: Manuel Alejandro Tufiño Orozco

Cuidado de la edición: Hélida De Sales Y.

Prohibida la reproducción total o parcial por cualquier medio sin la autorización escrita del titular de los derechos patrimoniales.

Hecho en México 


\section{AGRADECIMIENTOS}

Los coordinadores de este libro expresan su agradecimiento a la Fundación Antípode, la que generosamente financió el taller "Re-thinking Latin America development beyond neoliberalism: Toward a rediscovering/recreation of the Latin American thought on development", el cual tuvo lugar en México los días 25 a 27 de marzo de 2015. Dicho encuentro actuó como plataforma fundamental para la formación de nuestra Redsla (Red del Desarrollo Socioeconómico-Espacial Latinoamericano), con base en la cual se formuló el presente proyecto editorial. Expresamos también nuestro agradecimiento al Consejo Latinoamericano de Ciencias Sociales (Clacso) por apoyar el trabajo de investigación de los integrantes de nuestra red por medio del grupo Desarrollo, espacio y capitalismo global, que formó parte del programa de dicha institución en el periodo 2016 a 2019.

Así mismo, agradecemos el trabajo de los estudiantes-becarios del proyecto PAPIIT IN301519 de la UNAM que participaron directamente en la preparación de los materiales del libro: Mónica Valdez, Ricardo Fregoso y Agustín Calderón. 



\title{
ÍNDICE
}

Introducción

\section{PARTE I \\ CAmbio GeOeCONÓMICO-POLÍtICO MUNDIAL y AMÉRICA LATINA}

1. América Latina ante su gran encrucijada histórica de cara al mundo del siglo XxI Alejandro Dabat y Paulo Leal

2. Cambios geoeconómicos y políticos mundiales y su impacto en la crisis brasileña reciente

Valéria Lopes Ribeiro

3. Brasil después del 2000: un caso de neoliberalismo realmente existente y emancipación restringida

Deborah Werner

4. ¿Prebisch renace en el nuevo capitalismo?

Sebastián Sztulwark

\author{
PARTE II \\ ReEXAMEN DE LA PRESENCIA Y EL ACCIONAR DEL ESTADO \\ EN EL NUEVO ESCENARIO Y LOS DESAFÍOS DE SU CONSTRUCCIÓN \\ EN LOS PAÍSES EN DESARROLLO
}

5. Estado y desarrollo en América Latina contemporánea.

Dinámicas y balance del ciclo posneoliberal, 2002-2015

Pablo Míguez 
6. Estado argentino y la promoción del desarrollo industrial.

Un análisis de las experiencias recientes (2003-2018)

201

María Jimena García Puente, Carolina Lauxmann

y Emilia Ormaechea

7. Estado asociativo y cadenas de valor en México

al inicio del siglo xxi: el caso de Jalisco

Paty Montiel y Seyka Sandoval

8. Mutaciones del Estado en la periferia:

el anclaje del centro-oeste formoseño

entre los años noventa y el nuevo milenio

273

Ernesto Fabián Giuliano

9. Estado, desarrollo y minería en América Latina.

Indagaciones sobre las capacidades del Estado

para una estrategia de desarrollo

Alejandro Federico Casalis

PARTE III

TRANSFORMACIONES SUBNACIONALES Y DESAFÍOS URBANO-REGIONALES

BAJO EL PROCESO DE REESTRUCTURACIÓN MULTIESCALAR

DEL CAPITALISMO Y LOS CAMBIOS EN LA REGIÓN

10. Políticas nacionales de desarrollo regional en América Latina:

lecciones y retos de los años 2000

Fábio Lucas Pimentel de Oliveira

11. Enfermedad holandesa regional-subnacional

en la América del Sur del siglo xxi: casos regionales

en Brasil, Colombia y Perú

Luis E. Reina-Bermúdez, Didier Alejo-Barrera, Robson Dias da Silva y Lino Santa 
12. Integración sudamericana, proyectos de gran escala y glocalizaciones: la encrucijada de la Hidrovía Paraguay-Paraná y el Corredor Bioceánico Central en el segundo ciclo extractivista

Gisela Ariana Rausch y Estefanía Szupiany 



\section{INTRODUCCIÓN}

EL PUNTO DE PARTIDA Y PRECISIONES CONCEPTUALES: HACIA UN DISPOSITIVO ANALITICO-PROPOSITIVO

El presente libro es resultado de un esfuerzo colectivo de la Red del Desarrollo Socioeconómico Espacial Latinoamericano (Redsla) y el Grupo de Trabajo Clacso Desarrollo, espacio y capitalismo global, los cuales se plantean el análisis de la actual realidad latinoamericana relacionando dialécticamente el proceso de transformación estructural del capitalismo global con los condicionantes derivados de las trayectorias y los bloques históricos, las estructuras de clases y las correlaciones de fuerzas políticosociales de los países de la región, para avanzar en la generación de un dispositivo conceptual de tipo analítico-propositivo.

Desde una perspectiva gnoselógica general se trata de trascender la aproximación del estudio del capitalismo en términos de una historicidad del modo de producción, que prepara las condiciones históricas del socialismo científico (la dimensión bajo la que lo estudia Marx), para, sin romper con esa perspectiva, incorporar una dimensión histórico-espacial más concreta en términos de unidades cambiantes entre economía, política, ideología, cultura e instituciones, y sus respectivas espacialidades, las cuales constituyen fases históricas de desarrollo en el seno del modo de producción que implican la "superación momentánea de los límites inmanentes al modo de producción capitalista” en la visión de Chesnais [2002: 1].

La incorporación de esa dimensión histórico-espacial más concreta nos lleva a reconocer que la actual transfomación estructural del capitalismo implica la emergencia de una nueva fase de desarrollo que se traduce en el despliegue desigual global de una nueva base tecnológico-productiva desde los años ochenta del siglo anterior, resultante de la revolución tecnológica-industrial de la electrónica-informática y las telecomunicaciones, en la que los procesos de conocimiento, aprendizaje e innovación cobran 
una inédita preeminencia económica y se constituyen en una fuerza productiva principal [Ordóñez, 2004].

La dimensión espacial de ese fenómeno es la conformación de un nuevo espacio global resultado del proceso de trasnacionalización del capital que originaría una creciente superposición y preeminencia de una nueva división interindustrial y trasnacional del trabajo (diferenciación de empresas OEM, ODM, CM y CS) ${ }^{1}$ en un amplio conjunto de industrias, en relación con la (antigua) división internacional del trabajo. Lo anterior se desarrollaría por medio de un amplísimo proceso de relocalización productiva y subcontratación internacionales (offshoring-outsourcing), y el consiguiente despliegue de redes productivas globales (RPG) que configuraron el fundamento material de ese nuevo espacio global [Ordóñez, 2018a].

En ese marco histórico y conceptual, vía de desarrollo o variaciones de capitalismo [Jessop, 2018] dan cuenta de la vía específica, modalidad o variación por la que cada país emprende el pasaje a la fase de desarrollo, ${ }^{2}$ la cual se relaciona con la originalidad de cada país y encuentra su explicación en los conceptos articulados de estructura de clases, trayectoria y bloque histórico nacionales, así como correlación de fuerzas político-sociales, mismos que se sintetizan en una trama socioespacial e institucional propia o matriz socioinstitucional de actores [Ordóñez, 2018b].

Por tanto, la especificidad de la forma o variación de emprendimiento de la fase de desarrollo en un país está determinada por la originalidad de los compromisos, acuerdos y alianzas entre las clases y los grupos sociales que le son distintivos, y que tienen lugar en torno a un proyecto histórico común único, acorde con los requerimientos de la fase y con una trayectoria (histórica) propia, en relación con la cual podrá haber más o menos elementos de continuidad y ruptura dependiendo de la correlación de fuerzas entre el impulso del cambio proveniente "desde arriba", por parte de

${ }^{1}$ Original Equimpment Manufacturing, Original Design Manufacturing, Contract Manufacturers y Contract Services.

${ }^{2}$ El concepto se retoma de Marx pero adaptado a un horizonte temporal del capitalismo considerado en términos de sucesión de fases de desarrollo. Marx distingue entre la vía farmer (progresista) de desarrollo del capitalismo, basada en la disolución de la propiedad terrateniente y la constitución de la pequeña propiedad capitalista, seguida por países como Inglaterra o Estados Unidos, y la vía yunker (reaccionaria), caracterizada por la transformación de la gran propiedad terrateniente en gran propiedad capitalista, que se acompaña de un intervencionismo estatal más activo y coercitivo (sustitución de la clase por el Estado) en la acumulación originaria, seguido por países como Alemania y Rusia, posteriormente. 
las clases dominantes y el Estado, y el originado "desde abajo", por parte de las clases y los grupos sociales subalternos, quienes podrán tener una mayor o menor representatividad en el Estado [Ordóñez, 2020].

En consecuencia, en sentido estricto, cada país implica una vía de desarrollo o variación específica, aun cuando existen grupos de países con estructuras de clases, bloques y trayectorias históricos similares que posibilitan conceptualizar vías de desarrollo más amplias que involucran grupos de naciones.

Así, las diversas vías de desarrollo o variaciones de capitalismo se distinguen entre sí por las características y el grado de desarrollo de la nueva base tecnológico-productiva asentada en los espacios nacionales, y su articulación con tramas socioespaciales e institucionales o matrices socioinstitucionales de actores diferenciadas, pero con aspectos comunes entre grupos de países.

En la actualidad, pueden reconocerse por lo menos tres vías de desarrollo o variaciones operantes del tránsito a la nueva fase de desarrollo del capitalismo: el neoliberalismo, la vía escandinava y la de los países asiáticos [Ordóñez, 2020].

No es aquí el lugar para estudiar con detalle esas vías o variaciones reconocibles, aunque sí nos detendremos en algunos particulares del neoliberalismo porque es la variación predominantemente emprendida por los países y en torno a la cual se ha reconstituido el sistema de hegemonía de Estados prevaleciente, además de que ha sido la vía tomada inicialmente por los países latinoamericanos.

El neoliberalismo puede entenderse como un proceso de liberalización de las fuerzas materiales y "espirituales" del capital, bajo los nuevos fundamentos de la revolución tecnológico-industrial de la electrónicainformática y las telecomunicaciones, y la trasnacionalización del capital, lo que explica su enorme capacidad transformadora en el terreno tecnológico-productivo y financiero, y en la reconfiguración del espacio mundial a partir de los años ochenta [Ordóñez, 2020].

La liberalización de las fuerzas del capital en el marco de la revolución tecnológica y luego industrial hacia finales de los años setenta y ochenta posibilitó el desarrollo de un nuevo capital financiero a partir de la informatización y consecuente automatización e incremento inusitado de la 
velocidad de la circulación dineraria, con la consecuente ampliación de la esfera de valorización financiera, que trajo consigo la diversificación y el carácter más complejo de los nuevos instrumentos y agentes financieros [Dabat, 2009]. En tales condiciones, el nuevo capital financiero se constituyó inicialmente como una enorme palanca para el despliegue mundial de la nueva base tecnológica-productiva hasta la crisis del índice Nasdaq de 2001-2002 [Ordóñez, 2018a: 209].

Tal proceso devendría después en una autonomización del capital financiero respecto del capital productivo, la formación de una enorme plétora de aquel y el predominio de prácticas especulativas y parasitarias que han conllevado a un proceso de desvinculación y disfunción del capital ficticio (como forma del nuevo capital financiero) en relación con los requerimientos de la acumulación real [Carcanholo, 2011], que a su vez expresa una profunda disociación entre el proceso de apropiación de valor y su generación, lo que alcanza su punto extremo en la crisis financieroproductiva global de 2007-2009. De ese proceso tiende a dar cuenta, en lo fundamental, la llamada financiarización, aunque sin distinguirlo de los cambios en la forma histórica de articulación e imbricación del capital financiero con el capital productivo que son consustanciales al pasaje a la nueva fase de desarrollo del capitalismo.

Derivado de lo anterior, el periodo actual se caracteriza por un lento proceso de acumulación y bajas tasas de inversión y ganancia ligados a altos grados de concentración y centralización del capital que impiden a los Estados de los países avanzados dejar operar procesos de "destrucción creativa" resultantes en un elevamiento de la rentabilidad del capital productivo, lo que conduce a nueva manera de mantener la rentabilidad vía la referida financiarización y búsqueda de nuevos espacios de acumulación [Choonara, 2018].

La liberalización de las fuerzas materiales y "espirituales" del capital tiene lugar en el seno de la trama socioespacial e institucional o matriz socioinstitucional de actores emergida del New Deal en Estados Unidos, que en la segunda posguerra se extendería bajo modalidades nacionales propias al conjunto de países avanzados de Occidente, y en América Latina asumiría la forma específica de un corporativismo de Estado en torno al proyecto histórico de la industrialización por sustitución de importaciones. 
En el espacio internacional, la liberación de las fuerzas del capital se verifica en el marco del complejo institucional del sistema de hegemonía de Estados dirigido por Estados Unidos, pero implicaría una ruptura de los antiguos compromisos históricos distributivos, y en cierta medida de los corporativos también, con las clases y grupos subalternos del fordismokeynesianismo y la sustitución de importaciones en América Latina, así como de la centralidad espacial de la escala nacional, además de un intento de dimensiones históricas de asimilación de aquellas clases y grupos sociales unilateralmente a la racionalidad del capital a partir de su derrota, sin la incorporación de objetivos históricos y elementos suyos [Ordóñez, 2018a].

Muy distante de la narrativa liberal conservadora, la realidad concreta es que promover el proceso de neoliberalización requiere una gran y potente intervención en conjunto con cambios amplios y profundos en el accionar del Estado que implican una verdadera ola de asalto y reapropiación privada de los fondos públicos para su redistribución entre las clases y grupos dominantes, apertura de nuevas fuentes de valorización del capital, privatización de los servicios públicos, ataque predatorio a los derechos civiles y la ciudadanía, etc.; lo anterior supone una amplia reorganización de la potencia estatal para ser ejercida de manera autoritaria, por lo que los valores democráticos no forman parte de sus atributos o, mejor, la antidemocracia o ademocracia es su marca creciente.

Por ello el neoliberalismo implica la imposición sin mediaciones de la racionalidad del capital al conjunto de la sociedad, lo que supone el desdoblamiento y la proyección de la racionalidad empresarial y del mercado en el conjunto de la trama socioespacial e institucional heredada del fordismo-keynesianismo (incluidas las instituciones no económicas) [Brown, 2003: 40], la sustitución de las clases y los grupos sociales por el individuo aislado, y la conformación de un nuevo sentido común del hombre racional cuyo accionar está regido por el cálculo económico en términos de costos y beneficios, lo que culmina en la asimilación de lo ético-moral a lo económico [Harvey, 2005: 48, 78 y Brown, 2003: 42].

A este respecto, Peck, Brenner y Theodore [2019] hacen una importante contribución al caracterizar el neoliberalismo como un proceso siempre incompleto, contradictorio, contestado y complejo de experimentaciones sociopolítico-espaciales. Elaboraron una interpretación en la que aquel debe ser 
tratado por su naturaleza fungible, híbrida, maleable, dependiente de la trayectoria pasada y con futuro abierto, que se desarrolla e impregna en y de cada ambiente, e implica un permanente cambio de los contornos institucionales que se van rediseñando en cada tiempo coyuntural. Nunca es unidireccional, pero siempre es adherente y adaptable a contextos variados [Berndt et al., 2020].

En esa perspectiva, no obstante heredar y racionalizar la antigua trama socioespacial e institucional del fordismo-keynesianismo y de sustitución de importaciones en América Latina, en el marco del sistema de hegemonía de Estados de Estados Unidos, el neoliberalismo sí implica una nueva construcción institucional que no remplaza sino se superpone a aquellos. La nueva construcción institucional está constituida por las redes económicas y políticas globales (REPG) [en las que los organismos de financiamiento internacional (OFI) y las empresas trasnacionales (ETN) desempeñan un papel destacado], que tienen su fundamento en el despliegue de las RPG y atraviesan transversalmente los Estados nacionales, reasignando competencias, recursos y funciones a actores de escalas trans, supra y sub nacionales, y promoviendo así una nueva espacialidad "glocalizadora", consistente en la tendencia a la articulación/subordinación directa de las escalas regional y local respecto de las escalas trans y supranacionales, sin la mediación de la escala nacional, por lo que el proceso implica la tendencia a la fragmentación y el desmantelamiento de los espacios nacionales [Fernández, 2017: 29].

\section{CAmbio geoeconómico-Político mundial y América Latina}

De lo desarrollado previamente se sigue que la actual situación -caracterizada por una profunda disociación entre el proceso de apropiación de valor y su generación, que se traduce en un lento proceso de acumulación y bajas tasas de inversión y ganancia, en el marco de una desvinculación y disfunción creciente del capital financiero respecto de los requerimientos de la acumulación real- expresa una crisis multifacética del neoliberalismo como vía de emprendimiento predominante de la nueva fase de desarrollo del capitalismo. 
En su dimensión escalar más amplia, se trata de una crisis de la globalización en su modalidad neoliberal y unipolar, centrada en el sistema de hegemonía de Estados de Estados Unidos, que abre un dramático periodo de cambio geoeconómico-político mundial orientado a una nueva modalidad multipolar de la globalización, donde los rasgos más distintivos son el desplazamiento del centro dinámico de la economía mundial al Este Asiático y la irrupción de China y los BRICS, y donde, por tanto, las geometrías del poder Norte-Sur se han visto modificadas de la mano de un inédito crecimiento reciente del Sur global (convertido hasta hace poco en principal fuente de dinamismo de la acumulación a nivel mundial) [Ordóñez y Sánchez, 2016; Fernández, 2017].

El conjunto del proceso encierra una disputa entre vías de desarrollo o variaciones del emprendimiento del pasaje a la nueva fase de desarrollo del capitalismo, sobre todo entre el neoliberalismo predominante en el Norte y América Latina, y la vía asiática, en tanto que el Este Asiático, y en especial China, han sido las fuentes principales del dinamismo reciente del Sur global vis-à-vis del Norte global, lo que incluye nuevas asimetrías en el Sur global observables claramente entre el posicionamiento del Este Asiático en comparación con el de América Latina.

Así, mientras en el Este Asiático se ha desarrollado una estructura productiva interna socialmente más cohesiva (menos desigual, hasta la irrupción de China), y al exterior una inserción creciente en las actividades dinámicas del mercado mundial, así como en actividades y exportaciones con alto contenido tecnológico, en América Latina subsiste una estructura productiva más primarizada y menos cohesiva en términos sociales, que se complementa con una inserción internacional más endeble y subordinada, carente de marcas globales, y salvo México, sujeta a operar en la provisión de recursos naturales en las RPG, no solo reafirmando una histórica relación con el Norte, sino también extendiéndola con el Este Asiático [Fernández, 2017].

El cambio geoeconómico-político mundial se desarrolla en diversos frentes: en el Atlántico Norte se caracteriza por un distanciamiento económico-político y militar entre Estados Unidos y sus principales aliados occidentales; en Oriente Medio, por un retiro relativo de aquel país en favor de una acrecentada presencia político-militar de Rusia y la emergencia de potencias regionales como Irán, Arabia Saudita y Turquía; y en 
Asia Pacífico, por un retiro relativo de Estados Unidos, el aislamiento de sus aliados y nuevos conflictos entre ellos, en particular Japón y Corea del Sur, además de la presencia político-militar creciente de China.

En ese marco tiene lugar en la actualidad un enfrentamiento geoeconómico-político entre Estados Unidos y China, y la disputa por la presencia en el Sur global y, sobre todo, en la región; tales procesos están llamados a acentuarse en los próximos años.

Ante la crisis de la globalización en su modalidad neoliberal y unipolar, Estados Unidos busca reposicionarse replegando su hegemonía internacional para priorizar el apuntalamiento de sus bases nacionales de expansión bajo la fórmula (contradictoria) de un "neoliberalismo-nacionalista", que consiste en una profundización de las políticas neoliberales en el espacio nacional (desregulaciones financiera, ambiental y a industrias ligadas a fuentes energéticas fósiles, reducciones impositivas empresariales, marcha atrás en la neutralidad de internet, etc.), combinada con una defensa e intento de redespliegue de ese espacio en la escala internacional, lo que resulta en un nuevo curso proteccionista, la formulación de un proyecto de inversión en infraestructura nacional, de iniciativas de reposicionamiento estatal en la formulación y promoción de tecnologías de punta como las redes $5 \mathrm{G}$, el cierre de fronteras a la inmigración y un nuevo discurso xenofóbico.

El neoliberalismo nacionalista de Estados Unidos conlleva al enfrentamiento con China, cuya expresión más clara es la actual guerra comercial entre ambos países, y a la búsqueda de un reposicionamiento del primero en la región que rearticule sus bases de expansión geoeconómico-políticas ante el repliegue de la hegemonía internacional, y capitalice el retroceso de las experiencias neodesarrollistas y el avance neoliberal en el sur del continente, como se desarrolla con detalle en el capítulo 1.

Por su parte, China emprende un posicionamiento geoeconómico inicial orientado a asegurar la provisión internacional de materias primas para mantener su economía en crecimiento, que involucró principalmente a África y América Latina. Con posterioridad a ello y con el ascenso de Xi Jinping, inicia un proceso de posicionamiento como gran potencia mundial que implica, además del ya referido incremento de su presencia políticomilitar en Asia Pacífico, la promoción de grandes proyectos de infraestructura en el Sur global y la región, cuyo resultado es el posicionamiento 
internacional de su moneda como medio de pago, de sus bancos y empresas, además de un nuevo poder de condicionamiento internacional hacia esos países.

En ese escenario, América Latina emerge de un pasado reciente de búsqueda de vías alternativas al neoliberalismo que se concretó en las experiencias neodesarrollistas del sur de la región, las cuales, no obstante las mejoras socioeconómicas operadas, experimentaron persistentes dificultades para transformar la dinámica de acumulación (histórico-estructurales y agravadas por el neoliberalismo previo), por lo que se mantuvieron: a) la prevalencia de los requerimientos de la valorización financiera sobre la valorización productiva; b) la centralización del capital productivo y el peso creciente del capital extranjero en las ramas dinámicas, lo que supone la persistencia y agudización de la heterogeneidad estructural y la fragmentación y desmantelamiento de encadenamientos productivos a escala nacional; c) la falta de competitividad industrial y su dependencia de la subvaluación cambiaria; d) el rezago infraestructural, tanto de infraestructura física-energética como informática y de las telecomunicaciones; e) la asimetría escalar-territorial y la producción de un desarrollo espacialmente desigual, resultante de una superposición de la fragmentación e integración desigual de las escalas y el territorio nacionales; y f) la falta de generación de procesos sustentables de explotación de los recursos naturales [Ordóñez, 2017].

El neodesarrollismo incluyó el uso de la potencia externa acentuada del Estado, a partir de la gestión de la renta agro-minera-petrolera internacional, para desplegar una política de posicionamiento y realineamiento internacional que involucró una creciente formalización de una relación geoeconómica-política estratégica con China, resultante en montos de préstamos de ese país a América Latina que sobrepasan los del Banco Interamericano de Desarrollo desde 2009, y en fecha más reciente, en una fuerte presencia regional china como prestamista de último recurso, sobre todo en los últimos riesgos de default y reducción de las reservas internacionales de países como Venezuela y Argentina antes del fin de los gobiernos Kirchner ${ }^{3}$ [Ordóñez, 2017].

\footnotetext{
${ }^{3}$ China y Argentina establecen un acuerdo de reconocimiento recíproco de la integralidad de su soberanía (una sola China/Taiwán/Tíbet y Argentina continental e Islas Malvinas) y la promoción de la multipolaridad, y
} 
Ese posicionamiento y realineamiento internacional de la región se complementó con una diversificación del comercio internacional, orientada a la disminución de la dependencia hacia Estados Unidos y Europa, y la reorientación hacia Asia y China en particular, además del Mercosur y Latinoamérica en general. En ese proceso, los países del sur del continente inauguraron una relación comercial "de periferia" con Asia y China (exportadores de materias primas y alimentos e importadores de productos industriales), mientras Brasil y Argentina sostienen una relación de "centro" con el Mercosur y América Latina (la composición comercial inversa) [Kleef et al., 2012: 22-32; Fernández y Vigil, 2010: 99-158].

De modo complementario, ambos países llevaron a cabo una política de impulso y proyección internacional del Sur global, y del Sur latinoamericano en particular, en el seno de la Unasur, que incluyó un acercamiento político internacional con los países del Sur global y la búsqueda conjunta, por parte de Brasil, de una reforma de las instituciones económicopolíticas del sistema estadounidense de hegemonía de Estados, como el FMI y la oNU, que implicara el reconocimiento político internacional del nuevo peso económico de los países del Sur en esas instancias institucionales de gobierno [Ordóñez, 2017].

Con ese antecedente cercano, América Latina se debate ahora entre el actual viraje neoliberal bajo formas e intensidad renovadas en Brasil, Uruguay y Bolivia, además de la reciente experiencia argentina, y el arribo de un gobierno progresista en México sumado al retorno del neodesarrollismo en Argentina, que vuelve a plantear la problemática de la ruptura con el neoliberalismo en países de la región. Entre esos dos extremos se encuentran las experiencias nacionales inspiradas en el neodesarrollismo subsistentes en los países más pobres de Centro y Sudamérica, y el cambio y la ruptura con el gobierno precedente en Ecuador.

Esa nueva realidad latinoamericana conlleva a la necesidad tanto teórica como política de hacer un balance crítico de las recientes experiencias neodesarrollistas del sur del continente en términos de una aproximación a las consecuencias que la incapacidad de los gobiernos progresistas

declaran su relación como de carácter "estratégico" [Paz, 2014: 152-186]. Por su parte, Brasil y China, en el marco de la Comisión para la Coordinación y Cooperación Chino-Brasileña de Alto Nivel (Cosban), elevan el nivel de su relación de "asociación estratégica" a "asociación global estratégica" en 2013 [Bendur, 2014: 125-152]. 
para cambiar las bases tecnológico-productivas y lograr transformaciones profundas en el orden político-institucional, en el Estado y su accionar, así como en la espacialidad de esos tres procesos combinados, ha tenido en el viraje bajo formas renovadas hacia el neoliberalismo en el Sur, y las lecciones que de ello pueden extraerse ante el ascenso de un gobierno progresista en México y el retorno del neodesarrollismo en Argentina en términos de las posibilidades de ruptura con el neoliberalismo.

En particular, el nuevo escenario presenta una situación propicia para profundizar las reflexiones sobre el Estado hechas por los estudios en la región. Ello reviste importancia, ya que tanto las reflexiones de posguerra que lo ubicaban como un actor cuasi libre de conflictos como aquellas que luego lo entendían como condensación de la lucha política y social poseen en general un alcance limitado para captar las implicaciones de las formaciones estatales bajo las complejidades y transformaciones producidas por el advenimiento de las REPG y su tentativa de ejercicio de una gobernanza global propias del neoliberalismo [Fernández, 2017].

En este marco, y considerando las perspectivas futuras que recién parecen abrirse para algunos países de la región, problematizar el Estado implica explorar en qué medida hubo coincidencias entre las recientes experiencias "neodesarrollistas" y el neoliberalismo en cuanto al accionar estatal en términos de: a) la ya indicada reasignación de competencias, recursos y funciones a actores de escalas trans, supra y sub nacionales, en concordancia con las estrategias de las REPG; y b) una asimilación de programas y políticas públicas difundidos por los ofi y la adopción de marcos conceptuales que propiciaron, antes que alterarlos, escenarios de reproducción del capital globalizado [Fernández, 2017].

La problematización del Estado en términos de ruptura con el neoliberalismo en un sentido progresista debe incluir la necesidad de readquirir una capacidad estratégica de promoción del desarrollo, pero en términos del pasaje a la nueva fase de desarrollo del capitalismo.

El accionar estatal con esa orientación general supone un cambio de la forma estatal misma con las siguientes características: a) tránsito de una forma de organización patrimonial hacia una meritocrática; b) cambio en la perspectiva conceptual-operativa de la burocracia desde una que prioriza la respuesta y satisfacción de demandas de clases y grupos sociales internos y externos hacia una en la que la prioridad sea la formulación de 
estrategias y proyectos de desarrollo endógeno y competitivo de la base tecnológico-productiva, aunada a formas meritocráticas de reclutamiento del personal estatal; c) tránsito desde una fragmentación institucional interna de las instancias ligadas a la promoción del desarrollo hacia la integración centralizada que posibilite un direccionamiento coherente y fluido; d) desarrollo de capacidades de obtención, control y direccionamiento de financiamiento a la base tecnológico-productiva y a la reconfiguración multiescalar del espacio nacional e integración del territorio; y e) cambio multiescalar de la organización institucional misma del Estado [Fernández, 2017: 188-89].

En términos espaciales, esta aproximación marca un aspecto diferencial respecto de teorizaciones previas acerca del desarrollo que centraron su análisis priorizando (aunque no de modo exclusivo) una noción espacialescalar intra e inter "nacional", poco dinámica interescalarmente, como el estructuralismo latinoamericano de posguerra, o bien haciendo énfasis en el ámbito local/regional y su vínculo con la escala global manteniendo cierta desconexión con la escala nacional, como las teorizaciones realizadas durante la última década del siglo xx y la primera del presente referidas al nuevo regionalismo.

Así, el Estado ha sido atravesado por un profundo proceso de reescalamiento que coloca en activo protagonismo las instancias supra y subnacionales, al tiempo que, bajo el neoliberalismo, se torna en un facilitador de la valorización del capital en una disputada interrelación de espacios y una compleja confrontación de intereses y estrategias.

En los espacios subnacionales se trata de investigar estructuras, dinámicas, relaciones y procesos. Es necesario entender cuáles son sus intereses concretos movilizados y sus instrumentos y lógicas de acción activados; cuestionar cómo se constituyen los territorios de la destitución, como lo son muchos espacios regionales latinoamericanos en los que agrupaciones conservadoras bloquean las posibilidades de romper con el atraso estructural en los espacios regionales y urbanos.

Por consiguiente, la teorización de los vínculos entre espacio y desarrollo amerita incorporar los cambios espaciales esbozados desde América Latina y superar dicotomías del tipo "nacional vs. local/global” para avanzar hacia una comprensión y planificación multiescalar del desarrollo que incluya directrices para la acción y estrategias políticas con las clases y 
los grupos sociales, además de las regiones económica, política, social y espacialmente subalternas.

Abordar la problemática esbozada demanda la recuperación del debate en la región acerca del desarrollo, el cambio estructural, el Estado y el espacio, alzándose sobre este legado para revalorarlo y tributar en él, pero también con un sentido superador y una clara intención de actualizarlo en función de las transformaciones acaecidas, en tanto que ello posibilita la reconstrucción de una visión de conjunto e integral de la actual problemática latinoamericana que aspira a ser diagnóstica pero al mismo tiempo propositiva, además de que permite la integración de diversos referentes teóricos con el análisis histórico bajo una perspectiva de presente y futuro.

Más allá del legado del pensamiento de la región, la nueva aproximación propuesta posibilita, al tiempo que hace necesaria, una articulación adaptativa y creativa también de referentes teóricos críticos provenientes de otras latitudes, como los notables aportes gramscianos, neogramscianos, institucionalistas, neomarxistas, neoshumpeterianos, entre otros, así como aportes desde el amplio campo de la geografía humana crítica.

\section{LA ORGANIZACIÓN DEL LIBRO}

El libro consta de tres partes, que a su vez constituyen ejes temáticos de la problemática antes desarrollada: I. Cambio geoeconómico-político mundial y América Latina, II. Reexamen de la presencia y el accionar del Estado en el nuevo escenario y los desafíos de su construcción en los países en desarrollo, y III. Transformaciones subnacionales y desafíos urbanoregionales bajo el proceso de reestructuración multiescalar del capitalismo y los cambios en la región.

La primera parte aborda la ubicación y el análisis de algunas de las principales transformaciones sufridas en fecha reciente por la región y algunos países, esbozadas en el apartado anterior, en el marco del cambio geoeconómico-político mundial.

En esa perspectiva, Alejandro Dabat y Paulo Leal, en el capítulo "América Latina ante su gran encrucijada histórica de cara al mundo del siglo xxi”, caracterizan el periodo actual como de crisis del orden mundial neoliberal y 
una nueva polarización internacional, que incluye el contraataque de Estados Unidos para recuperar su patio trasero regional, y la lucha más general de los pueblos por la construcción de un mundo multipolar, pacífico, inclusivo, multicultural y sustentable.

Después de presentar un panorama de la declinación de los países neoliberales y del sistema de hegemonía de Estados dirigido por Estados Unidos, los autores analizan el papel ascendente de un bloque internacional de países de características distintas al neoliberalismo que conceptualizan como social-productivistas, en el cual destacan China, Rusia y el Sur global, así como el reciente realineamiento internacional de América Latina en el marco de las experiencias neodesarrollistas. A partir de ello plantean lo que denominan la encrucijada histórica de la región ante la búsqueda de Estados Unidos de reposicionarse en ella como zona de influencia "natural" para el apuntalamiento de sus bases nacionales de expansión internacional ante el repliegue hegemónico.

En ese proceso, ven la posibilidad de un nuevo curso social-productivista en la región, que supondría una modalidad de desarrollo más intensiva en inversión pública, tecnología avanzada, trabajo calificado y cooperativismo, mayor diversificación de la producción y modernización de las pymes, e integración económica regional, sobre todo en infraestructuras, industrias avanzadas, banca de desarrollo con regulación monetaria-financiera, desarrollo científico tecnológico y financiamiento externo no convencional.

Retomando el aspecto de la irrupción de China, los BRICs y el Sur global en el cambio geoeconómico-político mundial, Valéria Lopes Ribeiro, en el capítulo "Cambios geoeconómicos y políticos mundiales y su impacto en la crisis brasileña reciente", avanza una explicación de la actual crisis en Brasil como resultado de la confluencia de elementos externos derivados de ese cambio mundial, con elementos ligados con una trayectoria interna propia.

Así, plantea la llamada financiarización, característica del neoliberalismo, como nueva causa de crisis en los países del Norte global, lo que está asociado con la búsqueda por parte del capital de nuevos espacios de acumulación y el ascenso de las economías en desarrollo, en particular China.

En ese contexto, la trayectoria brasileña reciente ha estado marcada por una inserción internacional reprimarizadora ligada al crecimiento del Este Asiático y específicamente de China; por su integración al circuito 
del nuevo capital financiero que se tradujo, aun en el periodo neodesarrollista, en un crecimiento fuertemente apoyado en el consumo a crédito que carecía de sustentabilidad a largo plazo; y por el fracaso de la llamada nueva matriz económica como tentativa de cambiar la modalidad de crecimiento a favor de la industria por parte del gobierno de D. Rousseff.

Con base en esa perspectiva, la autora polemiza con visiones actuales de la crisis brasileña inspiradas en un nacionalismo metodológico que solo consideran los determinantes internos inmediatos heredados del periodo neodesarrollista.

Por su parte, Deborah Werner, en el capítulo "Brasil después del 2000: un caso de neoliberalismo realmente existente y emancipación restringida", retoma el concepto de Peck, Brenner y Theodore [2018] de "neoliberalismo realmente existente" para caracterizar la trayectoria reciente de Brasil al plantear que el periodo neodesarrollista en realidad consistió en la conciliación de la dinámica neoliberal de inserción internacional en los circuitos de valorización financiera y como proveedor de commodities agrícolas y minerales, particularmente a China, con procesos redistributivos y de inclusión social en los que el Estado promueve incluso esa dinámica estructural -y carece, por tanto, de un accionar de ruptura con sus fundamentos- y en cambio atenúa el conflicto social. Por ello el proyecto político encabezado por los gobiernos de centro-izquierda logró solo una emancipación restringida basada en conquistas sociales sobre bases frágiles que se agotó a partir de 2014 con la crisis económico-política, cuyo trasfondo fue la finalización del ciclo expansivo de los precios internacionales de los commodities.

La solución a la crisis en el primer año del gobierno de Bolsonaro, sostiene la autora, implica una radicalización neoliberal que no solo cancela las conquistas sociales recientes, sino que atenta incluso contra el acuerdo social en la base de la Constitución Federal de 1988, al implicar un posicionamiento contra la política educativa y el conocimiento académico científico, las conquistas democráticas y las desregulaciones medioambientales, así como un realineamiento internacional con Estados Unidos y su sistema de hegemonía de Estados.

En el capítulo “¿Prebisch renace en el nuevo capitalismo?”, Sebastián Sztulwark [2019] introduce la interrogante del significado del cambio estructural en la nueva fase de desarrollo del capitalismo, reactualizando la 
preocupación de Prebisch por la necesidad de avanzar en la región hacia la industrialización a partir de los años treinta del siglo anterior e indaga acerca de las implicaciones actuales de ese cambio para América Latina.

Tras diferenciar entre el desarrollo de capacidades productivas, que reproducen conocimiento ya existente, y capacidades de innovación, que generan nuevo conocimiento, el autor concluye que en la actualidad el cambio estructural significa el desarrollo de este último tipo de capacidades, que es lo que ha posibilitado a los países del Este Asiático generar rentas de aprendizaje y ascender en las RPG y en la jerarquía internacional de países, a diferencia de América Latina, que ha generado fundamentalmente capacidades productivas.

De ello se desprenden lecciones de las recientes experiencias neodesarrollistas, las cuales a pesar de promover políticas industriales, no lo hicieron en una escala y orientación adecuadas, y sobre todo carecieron de una articulación orgánica con políticas de creación y fortalecimiento de un sistema de conocimiento y ascenso industrial en las RPG de las nuevas actividades dinámicas.

La segunda parte reexamina el Estado y su accionar en el marco de las transformaciones recientes de la región y de algunas experiencias nacionales, con las experiencias neodesarrollistas del sur de la región como referente inmediato y buscando avanzar hacia un balance crítico centrado en el Estado.

En el capítulo "Estado y desarrollo en América Latina contemporánea. Dinámicas y balance del ciclo posneoliberal, 2002-2015”, Pablo Míguez avanza en un balance crítico de las experiencias neodesarrollistas del sur de la región, teniendo como eje el estudio de las principales experiencias políticas y su relación con los cambios en los modos de acumulación y el accionar estatal.

Tras un repaso de las experiencias de Brasil, Argentina, Paraguay, Uruguay, Venezuela, Ecuador y Bolivia, concluye que el Estado, a diferencia del desarrollismo clásico, no debía desentenderse del corto plazo y del mantenimiento de los equilibrios macroeconómicos como condición para accionar en políticas de mediano plazo como las industriales, de inversión infraestructural y comerciales. Pero el intento es fallido al no poder revertir la reprimarización y posicionar, la industria como actividad dinámica, y no poder escapar del circuito financiero internacional que posibilitaba 
un crecimiento sustentado en un consumo a crédito a pesar del incremento del poder adquisitivo del salario y los procesos de inclusión social.

En el capítulo "Estado argentino y la promoción del desarrollo industrial. Un análisis de las experiencias recientes (2003-2018)", Jimena García Puente, Carolina Lauxmann y Emilia Ormaechea estudian la experiencia neodesarrollista argentina y el periodo posterior al triunfo de la Alianza Cambiemos bajo la óptica de la organización y el accionar estatal dirigidos a la estrategia de acumulación y en particular a la promoción del desarrollo industrial.

Desde la premisa de que el cambio en la correlación de fuerzas políticas entre un periodo y otro resultó en una transformación de la organización institucional y las formas de implicación estatales hacia la industria, las autoras realizan un análisis pormenorizado de ambas dimensiones de la estatalidad en los dos periodos. A partir de ello, concluyen que en ninguno se logró conformar una estatalidad coherente y cohesionada en la que las instancias vinculadas con la industria tuvieran una participación relevante, así como tampoco presentaron modalidades de implicación capaces de impulsar la conformación de una actividad manufacturera nacional compleja y dinámica, impulsora del desarrollo.

En el capítulo "Estado asociativo y cadenas de valor en México al inicio del siglo xxi: el caso de Jalisco", Paty Montiel y Seyka Sandoval abordan el estudio de la reconfiguración del Estado regional en Jalisco, en términos de su accionar dirigido a la inserción y el ascenso del sector electrónicoinformático y de las telecomunicaciones (SE-IT) regional en las RPG.

Las autoras destacan la originalidad de esa experiencia regional tras reconocer que la misma tiene lugar en el marco de la vía de desarrollo neoliberal seguida por el país. Su originalidad radica en un relativo posicionamiento del Estado-región orientado a la inserción y el ascenso del SE-IT en las RPG, donde el accionar de aquel se acompaña de actividades colectivas organizadas bajo un liderazgo empresarial de ejecutivos mexicanos de las principales empresas trasnacionales del sector en la región, las cuales han posibilitado el desarrollo de procesos de aprendizaje institucional y la reducción de costos de transacción.

En el capítulo "Mutaciones del Estado en la periferia: el anclaje del centro-oeste formoseño entre los años noventa y el nuevo milenio", Ernesto 
Fabián Giuliano estudia las transformaciones del Estado-región en el centro-oeste formoseño argentino inspiradas en las directrices de la nueva ortodoxia regionalista de 1990 a 2015.

La nueva ortodoxia regional consiste en un conjunto de contribuciones académicas originadas en los países desarrollados que hacia mediados de los años noventa se fueron instalando en los países en desarrollo hasta convertirse en un referente común de políticas regionales. Sus directrices propician una espacialidad "glocalizadora": los ámbitos locales están determinados por las dinámicas globales y lo local adquiere un nuevo significado en la configuración de los procesos globales, en el marco de relaciones asimétricas e inestables, donde las estrategias locales se subordinan a los dictados de la competencia global al favorecer la libertad de acción del capital. Asimismo, entre las regiones se alientan relaciones competitivas que consolidan y acentúan los procesos fragmentarios de reproducción socioespacial y de este modo provocan nuevos desequilibrios y desigualdades.

En el caso del anclaje formoseño, aun bajo el neodesarrollismo se potencia y proyecta la alianza entre grupos ganaderos y de agroindustrias locales con organizaciones globales, que penetran y presionan a grupos subalternos como las poblaciones originarias y los pequeños productores bajo la promesa incumplida de un desarrollo endógeno y mayor bienestar en una óptica comunitario-localista.

En el capítulo "Estado, desarrollo y minería en América Latina. Indagaciones sobre las capacidades del Estado para una estrategia de desarrollo", Alejandro Federico Casalis estudia los condicionamientos que el Estado enfrenta en América Latina para impulsar estrategias de desarrollo a partir de la utilización e industrialización de los recursos naturales, con la minería como punto de referencia.

A partir de la desregulación de la minería, la apertura a la inversión extranjera directa (IED) y la erosión de las capacidades estatales para promover una estrategia nacional de desarrollo en el neoliberalismo, el autor estudia las experiencias neodesarrollistas y plantea como características distintivas la búsqueda de un incremento de la capacidad de regulación del Estado, la ampliación de derechos sociales y la búsqueda de mayor autonomía en la inserción regional y global, que tuvieron en la explotación minera una fuente de financiamiento. En ese proceso, destacaron algunas 
iniciativas orientadas a la mayor participación estatal en la renta minera, políticas para la industrialización de los recursos y la promoción de políticas industriales y científico-tecnológicas, aun cuando no se logró modificar la estructura productiva reprimarizada de la región, alterar las relaciones asimétricas de poder y cambiar el tipo de inserción en el comercio internacional.

Como lección para el impulso de una estrategia de desarrollo a futuro, el autor desprende la necesidad de incrementar las capacidades estatales de accionar en la minería en términos de una mayor regulación económica y ambiental; ampliar la participación en la renta minera mediante la creación de una empresa pública nacional (o en asociación mayoritaria con el capital privado) que desarrolle capacidades productivas, industriales, tecnológicas y de control, e incremente la habilidad de negociación frente a las empresas transnacionales, y a partir de ello identificar actividades para la sustitución de importaciones, el desarrollo de una industria de bienes de capital que abastezca la minería y la diversificación de la estructura productiva para disminuir la dependencia de recursos no renovables en el mediano y largo plazos.

En la tercera parte se aborda el estudio de la dimensión subnacional de las transformaciones recientes de la región y los desafíos urbanorregionales con la perspectiva de una reestructuración multiescalar del capitalismo.

En el capítulo "Políticas nacionales de desarrollo regional en América Latina: lecciones y retos de los años 2000”, Fábio Lucas Pimentel hace una descripción de los rasgos generales de las políticas de desarrollo regional desde la escala nacional propuestas en América Latina en el marco de la sustitución de importaciones, identifica sus aspectos clave y aporta consideraciones que van desde las posibilidades de ejecución hasta los principales límites y brechas. En seguida, en el contexto del reforzamiento del localismo y la adopción de estrategias autonomistas por parte de los agentes públicos y privados de los territorios que se inaugura con la emergencia del neoliberalismo, el autor rescata el estatuto del subdesarrollo, la multiescalaridad en las políticas, la actuación del mercado en las regiones, las capacidades estatales y el grado de participación social articulado al proceso de planificación, es decir, en términos de gobernanza territorial. A partir de ello, sintetiza los principales hallazgos, apunta los desafíos derivados de la experiencia de políticas regionales en los años 2000 
e imagina cómo pueden ser útiles en su (re)diseño bajo el contexto de una profundización del neoliberalismo.

En el capítulo "Enfermedad holandesa regional-subnacional en la América del Sur del siglo xxI: casos regionales en Brasil, Colombia y Perú”, Luis E. Reina-Bermúdez, Didier Alejo-Barrera, Robson Dias da Silva y Lino Santa exploran el efecto comparado sobre la composición de la estructura productiva de tres regiones: Río de Janeiro en Brasil, Orinoquía en Colombia y la región Sur de Perú, del auge de los precios del petróleo y los commodities de 2003 a 2014, de los que las tres regiones cuentan con una abundante provisión, bajo la hipótesis de la enfermedad holandesa regional-subnacional.

Los autores llevan a cabo un estudio de corte transversal y un análisis de las series de tiempo del producto interno bruto por sectores en las tres regiones, para luego comparar el contexto y los resultados en cada una, reflexionando sobre los aspectos que generaron una mayor profundización de la enfermedad o su contención en el tiempo.

A partir de ello concluyen que las tres regiones evidencian diferentes momentos de desarrollo económico inicial, lo que resulta importante para rastrear los efectos de la enfermedad holandesa. Cuando se presenta un auge de un recurso natural, este modifica la estructura productiva de la región destruyendo, disminuyendo el ritmo o impidiendo que se desarrollen los demás productos transables. El impacto negativo sobre los diferentes factores de producción (capital, trabajo, tierra) ocasionó una disminución de la competitividad a nivel internacional vía precios.

Por último, en el capítulo "Integración sudamericana, proyectos de gran escala y glocalizaciones: la encrucijada de la Hidrovía ParaguayParaná y el Corredor Bioceánico Central en el segundo ciclo extractivista”, Gisela Ariana Rausch y Estefanía Szupiany analizan, desde una perspectiva crítica y con un objetivo territorial, los proyectos de gran escala vinculados con la integración latinoamericana, expresados por los acuerdos del Mercosur y la Iniciativa para la Integración Regional Sudamericana (IIRSA-Cosiplan). Resaltando su orientación destinada a impulsar la explotación de recursos naturales en distintos países de la región, se examinan, como materialización territorial de esos proyectos, los casos del corredor fluvial Norte-Sur, denominado HPP, y del eje vial Este-Oeste, conocido como CBC, los cuales conforman una encrucijada en el área central de Argentina al recuperar 
la traza colonial. El enfoque crítico, al tiempo que con mirada multidisciplinar, se basa en aportes de la geografía humana y la ecología política para considerar desde la línea de los estudios urbanos y regionales: a) las condiciones histórico-geográficas que hicieron posible la emergencia de ambos proyectos de gran escala (PGE) durante la década de 1990; b) el papel de este tipo de proyectos en la vinculación con el lugar asignado internacionalmente a los países de América Latina como productores de materias primas; y c) las discusiones y legitimaciones en el ámbito local y regional de los proyectos en relación con las ideas de integración, crecimiento económico y desarrollo regional.

REFERENCIAS

Bárcena, Alicia y Miguel Torres [2019], Del estructuralismo al neoestructuralismo. La travesía intelectual de Osvaldo Sunkel. Santiago, Naciones Unidas, CEPAL.

Bendur, A. [2014], "Brazil-Asia Trade: Emerging Configurations", en C. Arnson (ed.), Reaching across the Pacific Washington, Woodrow Wilson International Center for Scholars, pp. 125-152.

Berndt, Christian, Jamie Peck y Norma Rantisi (eds.) [2020], Market/ place: exploring spaces of Exchange. Newcastle upon Tyne, Agenda Publishing.

Brown, Wendy [2003], Neoliberalism and the end of liberal democracy. San Diego, University of California-San Diego, p. 23.

Carcanholo, D. Marcelo [2011], "Conteúdo e forma da crise atual do capitalismo: lógica, contradições e posibilidades", Crítica e Sociedade: revista de cultura política, Uberlândia, Universidade Federal de Uberlândia, vol. 1, núm. 3, pp. 73-84.

Chesnais, F. [2002], La globalización y sus crisis: interpretaciones desde la economía crítica. Madrid, Los libros de la catarata, p. 1.

Choonara, Joseph [2018], "A economia política da grande depressào", en International Socialism, Reino Unido, núm. 158, pp. 1-29.

Dabat, Alejandro [2009], Economía del conocimiento y capitalismo informático. Notas sobre estructura, dinámica y perspectivas de desarrollo, en A. Dabat y J. Rodríguez (coords.), Globalización, conocimiento y 
desarrollo. La nueva economía del conocimiento. Estructura y problemas, tomo I. México, IIEc-UnAM, pp. 57-73.

Dabat, Alejandro, Miguel A. Rivera R. y Sebastián Sztulwark [2007], "Rentas económicas en el marco de la globalización: desarrollo y aprendizaje”, en Problemas del Desarrollo, México, IIEc-UnAM, octubrediciembre, vol. 38, núm. 151, pp. 13-36.

Dosi, Giovanni [1998], "Opportunities, incentives and the collective patterns of technological change", en The Economic Journal, vol. 107, núm. 444, pp. 1530-1547.

Fajnzylber, Fernando [1983], La industrialización trunca de América Latina. México, Editorial Nueva Imagen, 416 pp.

Fernández, Víctor Ramiro [2017], La trilogía del erizo-zorro: redes globales, trayectorias nacionales y dinámicas regionales desde la periferia. Barcelona, Anthropos Editorial, 383 pp.

Fernández, V. y J. Vigil [2010], "Estrategias de desarrollo y reconstrucción estatal: obstáculos y desafíos en la Argentina del bicentenario", en A. Dabat (coord.), Estado y desarrollo, México, unam, Problemas del Desarrollo, 99-158 pp.

Gramsci, Antonio [1931-1932], Quaderni del carcere. Italia, EinaudiIstituto Gramsci.

Harvey, D. [2005], A Brief History of Neoliberalism, Estados Unidos, Oxford University Press, $247 \mathrm{pp}$.

Jessop, Bob [2018], "Capitalismo: ¿diversidad, variedad o abigarramiento?", en Matthias Ebenau y Víctor Ramiro Fernández, coords., Variedades de capitalismo entre centro y periferia. Buenos Aires, Miño y Dávila, pp. 29-52.

Kleef, P. et al. [2012], Global Brazil and the Political Economy of the Brazilian model, Roskilde, ISG Roskilde University.

Mallorquín, Carlos [2019], Breve historia del espíritu del desarrollo latinoamericano. México, Colofón.

Ordóñez, Sergio [2004], "La nueva fase de desarrollo y capitalismo del conocimiento: elementos teóricos", en Comercio Exterior, México, vol. 54, núm. 1, pp. 4-17.

[2009a], "La crisis global actual y el sector electrónico-informático", en Problemas del desarrollo, México, IIEc-Unam, julio-septiembre, vol. 40, núm. 158, pp. 55-90. 
[2017], "La nueva fase de desarrollo del capitalismo, más allá del neoliberalismo y América Latina”, en Carlos Brandão, Víctor Ramiro Fernández y Sergio Ordóñez, coords., Desarrollo socio-económico espacial en América Latina, México, IIEc-UNAM.

[2018a], "A nova fase de desenvolvimiento do capitalismo, para além do neoliberalismo, e a América Latina”, en Carlos Antonio Brandão, org., Teorias e políticas do desenvolvimento latino-americano. Río de Janeiro, Contraponto/Centro Internacional Celso Furtado de Políticas para o desenvolvimento, pp. 195-231.

[2018b], "Nuevo ciclo industrial y el neoliberalismo como variedad actual del capitalismo en México", en Matthias Ebenau y Víctor Ramiro Fernández, coords. Variedades de capitalismo entre centro y periferia. Buenos Aires, Miño y Dávila, 185 pp.

[2020], Nuevo ciclo industrial, el sector electrónico-informático y de las telecomunicaciones y vías de desarrollo. México, IIEc-UnAM, 219 pp. y C. Sánchez [2016], "Knowledge capitalism, globalization and hegemony: towards a socio-spatial approach", en World Review of Political Economy, Estados Unidos, Pluto Journals, vol. 7, núm. 1, pp. 4-28.

Paz, G. [2014], “Argentina and Asia: China's Remergence, Argentina's recovery", en C. Arnson (edit.), Reaching across the Pacific Washington, Woodrow Wilson International Center of Scholars, pp. 152-186.

Peck, Jamie, Neil Brenner y Nik Theodore [2019], "Actually existing neoliberalism", en Damien Cahill et al., eds., The Sage Handbook of Neoliberalism, Los Angeles, Sage.

Pinto, Aníbal [1970], "Naturaleza e implicaciones de la 'heterogeneidad estructural' de la América Latina”, en El Trimestre Económico, Ciudad de México, Fondo de Cultura Económica, enero-marzo, vol. 37, núm. 145.

Shumpeter, J. A. [1939], Business Cycles: A Theoretical, Historical and Statistical Analysis of the Capitalist Process, 2 vols., Nueva York, McGraw Hill, 1905 pp.

Sunkel, Osvaldo [1978], "La dependencia y la heterogeneidad estructural”, en El Trimestre Económico, Ciudad de México, Fondo de Cultura Económica, enero-marzo, vol. 45, núm. 177. 
Sztulwark, Sebastián [2019], "The center and the periphery in the structural logic of the new capitalism", en Víctor Ramiro Férnandez y Gabriel Brondino, Development in America Latina, Santa Fe, Universidad del Litoral. 
PARTE I

CAMBIO GEOECONÓMICO-PolítICO MUNDIAL

Y AMÉRICA LATINA 



\section{AMÉRICA LATINA ANTE SU GRAN ENCRUCIJADA HISTÓRICA DE CARA AL MUNDO DEL SIGLO XXI}

Alejandro Dabat y Paulo Leal*

INTRODUCCIÓN

El objetivo general de este capítulo es analizar el papel de América Latina en las transformaciones económicas y políticas mundiales, considerando que la región se encuentra ante un panorama muy difícil y complejo de gran agudización y polarización de sus conflictos sociales, políticos y culturales a partir de la brutal ofensiva de Estados Unidos y los sectores más poderosos y reaccionarios del poder económico interno contra los gobiernos y sectores progresistas de la sociedad. Tal fenómeno, además de las expresiones propias en cada país y grupo de países, es parte de la crisis del orden mundial neoliberal, la nueva polarización internacional, el contraataque de Estados Unidos para recuperar su patio trasero regional y la lucha más general de los pueblos por la construcción de un mundo multipolar, pacífico, inclusivo y multicultural.

Con este sentido, el capítulo consta de tres secciones: en la primera se presenta un panorama de la declinación de los países neoliberales que han detentado el poder desde la segunda posguerra, pero que se encuentran en un proceso de descomposición; en la segunda sección se analiza el papel

* Alejandro Dabat es Investigador Titular C Tiempo Completo en el IIEC-UnAm y Paulo Leal es ProfesorInvestigador Asociado C Tiempo Completo en la Facultad de Economía de la misma universidad. Este capítulo contó con el apoyo de los proyectos de investigación a cargo de los autores: UNAM-DGAPA-PAPIIT IN 304019"El siglo XX en perspectiva actual" y UNAM-DGAPA-PAPIIT IN 310720 "Evolución de la economía estadounidense y su impacto en México en el periodo 1990-2020". Agradecemos el apoyo bibliográfico y de sistematización de la información a Enrique Arriola y Luis Romero. 
de un bloque de países de características distintas al neoliberalismo que conceptualizamos como social-productivistas, en el que destacan China, Rusia e Irán. En la tercera sección, se expone el desenvolvimiento reciente de América Latina ante las transformaciones mundiales mencionadas. El advenimiento del nuevo capitalismo tuvo para América Latina características propias dentro del contexto mundial, lo que se manifestó en tiempo y espacio en tres periodos históricos diferentes desde fines del siglo pasado, los cuales se analizan en esta sección.

Dentro del último periodo, cobra relevancia fundamental la llegada de Donald Trump a la presidencia de Estados Unidos, que sin duda afecta la conformación geopolítica de la región con consecuencias muy importantes para todos los países latinoamericanos en general y en especial para México, aunque de una magnitud y un carácter aún difíciles de precisar. Las posturas nacionalistas de ultraderecha de Trump, si bien bastantes diferentes en distintos campos a la ortodoxia neoliberal-globalista que ha gobernado el mundo en los últimos treinta años, han repercutido gravemente en toda América Latina, alterando e incluso agudizando problemas coyunturales y estructurales en toda la región, lo que nos permite reflexionar acerca de una nueva etapa de relación y conflicto con Estados Unidos.

Sin embargo, este tipo de problemas así expresados tiene consecuencias diferentes para las grandes subregiones de América Latina. En el caso de México y de parte de los países de América Central y el Caribe incorporados de hecho al espacio económico y político estadounidense, existe una mayor integración a la economía estadounidense vía la industria maquiladora, los tratados de libre comercio y las presiones para brindar más seguridad a la inversión extranjera, con el supuesto combate formal al crimen organizado y la corrupción (cuestiones estas últimas sobre las que existen diferencias entre las agencias especializadas estadounidenses como la DEA o la CIA). En el caso de países no alineados al declive hegemónico estadounidense, la política exterior de Trump ha sido muy clara en torno a endurecer las sanciones con Venezuela, al ataque frontal a los movimientos progresistas de América del Sur o al endurecimiento del cerco contra Cuba.

De todas maneras, este conjunto de circunstancias adversas para la región se da en un contexto mundial más general, como el debilitamiento de la hegemonía mundial de Estados Unidos y otras condiciones que pueden 
ayudar a la región a superar la difícil coyuntura actual, por ejemplo, el nuevo papel internacional de China y sus políticas de inversión externa, y el papel complementario de Rusia en el sector energético y militar.

\section{EL DECLIVE DE Estados UNIDOS Y DEL BLOQUe NEOLIBERAL}

En la conformación del bloque neoliberal existen dos grupos de países: un núcleo duro constituido por aquellos que históricamente han sido leales a los intereses de Estados Unidos, pero que por diversas razones algunos han iniciado un proceso de relativo distanciamiento, y otro grupo con características pragmáticas que en ocasiones se alinea de forma importante con Estados Unidos y a veces se distancia.

El primer grupo está conformado por los "Cinco ojos": Reino Unido, Canadá, Australia y Nueva Zelanda; ${ }^{1}$ además, existe, un grupo intermedio que ha mostrado un importante apoyo: Israel, Japón, Arabia Saudita, Alemania, Corea del Sur, México, República Dominicana y Colombia. Dentro del tercer grupo podemos mencionar diversas experiencias de alineación temporal de países como Chile, Ecuador, Argentina, Brasil, Perú, Polonia, Panamá y Kuwait, entre otros. ${ }^{2}$

El neoliberalismo es la trama institucional que ha revestido este conjunto de países en mayor o menor medida dependiendo de la coyuntura histórica, en la cual se ha otorgado importancia fundamental a la libre empresa, al papel central de los mercados financieros, al debilitamiento de los sindicatos y de las prestaciones sociales, y en general a dotar de espacios de rentabilidad a la gran empresa trasnacional a costa de incrementar la desigualdad.

En términos de política económica, las bases del neoliberalismo se centraban en el combate a la inflación, la reducción del déficit fiscal, la

\footnotetext{
1 La alianza de los "Cinco ojos" (FveY, abreviatura de Five Eyes) surge después de la Segunda Guerra Mundial e implica la colaboración en tareas de espionaje e inteligencia a nivel global.

${ }^{2}$ En países como Colombia, Chile, México y Perú, en los que la derecha dominaba toda la esfera política hasta hace unos años, existen actualmente partidos progresistas que representan una gran fuerza política nacional capaz de disputar el poder en cada país. A su vez, en los países donde el neoliberalismo retornó, en realidad el enfrentamiento social se polarizó cada vez más; tales son los casos de Argentina, Brasil y Ecuador. Finalmente, en países donde la izquierda gobierna también se han agudizado los conflictos, como en Bolivia, Nicaragua y Venezuela.
} 
caída del gasto y la inversión pública, el debilitamiento del Estado, el libre comercio y la desregulación. Sin embargo, es importante mencionar que como consecuencia de las crisis económicas de 2001 y 2008, incluso el bloque neoliberal ha matizado sus posiciones de política económica para enfrentar el desastre económico que el propio neoliberalismo ha generado. Así, encontramos posiciones contrarias al libre comercio (Estados Unidos en la era de Trump o la muy posible salida del Reino Unido de la Unión Europea, Brexit), políticas monetarias expansivas (quantitative easing, en Japón, Estados Unidos, Reino Unido y la Eurozona), política de endeudamiento expansiva (Estados Unidos, Japón, Reino Unido, Canadá, Alemania y Australia) y hasta un nuevo Estado intervencionista en materia económica con Estados Unidos coercionando a varias empresas automotrices para que regresen a producir desde el suelo de ese país.

La razón de estas prácticas de política económica es que las crisis han dejado al descubierto que la burda reducción del papel del Estado en la economía no solo genera mayor desigualdad, sino que es nociva para la economía en su conjunto. Las tasas de crecimiento de la economía mundial han sido con mucho menores en la era neoliberal que con la presencia del Estado de Bienestar. Mientras que el crecimiento de la economía mundial durante el Estado de Bienestar (1950-1980) fue de 4.5\% promedio anual, en el periodo neoliberal de 1980 a 2018 apenas alcanzó 2.9\% [Maddison, 2018 y Banco Mundial, 2020a].

Estados Unidos promovió la práctica institucional del neoliberalismo porque así convenía a sus intereses, pero a raíz de la crisis de 2001 se generó un viraje en su política económica porque el declive de su economía y su hegemonía persistió en las últimas dos décadas.

Este proceso de declinación de la hegemonía estadounidense es un fenómeno histórico no lineal que se agudizó en 2001 a partir de tres acontecimientos independientes: la crisis de las punto com, el abierto desafío militar de los ataques del 11 de septiembre y la entrada de China a la Organización Mundial del Comercio (OMC); es decir, la declinación de la hegemonía de Estados Unidos ha avanzado con base en su descomposición y el fortalecimiento paulatino de China.

Desde 2001, Estados Unidos ha buscado, sin éxito, recomponer su situación económica, política y social. La recuperación económica del periodo 2002 2007 solo sirvió como caldo de cultivo para una crisis aún más profunda 
en 2008-2009. A partir de 2010 ha crecido de forma moderada, pero no se ha logrado fortalecer el proceso de acumulación en el interior del país y ya se habla de la posibilidad de una nueva recesión.

La proyección en el plano internacional de esta declinación es una pérdida de liderazgo mundial. Varios países han alcanzado o rebasado a Estados Unidos en distintos rubros. Podemos afirmar que ya no detenta una hegemonía absoluta, sino que su liderazgo es cada vez más cuestionable y en franca decadencia. Su participación en el producto interno bruto (PIB) mundial ha venido cayendo; las combinaciones de altos salarios y consumismo que no corresponden a importantes incrementos en la productividad han dejado un estado de deterioro en su competitividad mundial que se expresa en el déficit estructural de cuenta corriente, en el proceso de internacionalización de la producción de sus principales empresas y en la búsqueda desesperada de la administración de Trump por repatriar empresas, lo que genera una guerra comercial con China y amenazas de eliminar el TLCAN y cancelar la posibilidad de los acuerdos Transpacífico y Transatlántico.

$\mathrm{Al}$ interior de Estados Unidos el deterioro de su base económica se observa en el debilitamiento de su núcleo endógeno de acumulación que propicia la internacionalización de la producción de sus empresas manufactureras. Este proceso ha dejado cierre de fábricas, pérdida de empleos de tiempo completo y caída de la participación tanto de los salarios en el PIB como de la inversión productiva y el PIB manufacturero en las cuentas nacionales.

Ante la descomposición de la base económica, también el aspecto social se ha deteriorado. Estados Unidos es un país que mantiene cierto nivel de vida gracias al crédito; hoy su nivel de deuda es de más de $100 \%$ del PIB y este equilibrio inestable se mantiene gracias al papel que el dólar aún desempeña como moneda de reserva a nivel mundial. Ante la falta de oportunidades laborales y educativas, se ha recrudecido la desigualdad social y se han profundizado las expresiones xenófobas, excluyentes y violentas.

Este malestar social fue capitalizado en términos electorales por Trump, que busca reelegirse en el año 2020 con una campaña que profundiza la división en su país. Se observa claramente una descomposición de la institucionalidad neoliberal que la administración de Trump no ha sido 
capaz de revertir, aunque sí ha implementado medidas de política económica contrarias al dogma neoliberal.

En lo político, el mandato de cuatro años de Trump está concluyendo en medio de una profunda crisis política con pérdida de aprobación de la población, escándalos de corrupción y pérdida de liderazgo en el entorno internacional.

Pero la crisis política no es privativa de Estados Unidos; desde sus orígenes, la Unión Europea se conformó en lo económico como un grupo de países en torno al liderazgo de Alemania, y aunque se fijaron reglas económicas (de nivel de endeudamiento público y déficit fiscal), se ha observado su falta de cumplimiento.

Diversos analistas (Bloomberg, Goldman Sachs, cNn y The Economist, entre otros) plantean la alta probabilidad de una nueva recesión en 2020 con epicentro en Estados Unidos y Europa occidental, pero esta vez sin la posibilidad de implementar las políticas contracíclicas ya planteadas porque esas herramientas se agotaron.

Las opciones que Estados Unidos ha utilizado ante la incapacidad de liderar la economía son variadas: el uso del Big Data, los bloqueos económicos, el empleo de la posverdad, los intentos de golpes blandos y hasta las provocaciones bélicas. El conjunto de estos elementos ha colocado al mundo ante una posibilidad, aún remota, de una nueva guerra mundial que dirima de una vez la lucha por el liderazgo económico entre el decadente Estados Unidos y el naciente grupo de países social-productivistas que veremos a continuación.

\section{América Latina en el avance de China y Rusia}

Como se planteó en el apartado anterior, la expansión de la vía neoliberal de desarrollo del capitalismo informático-global dirigida por los países innovadores de punta como Estados Unidos (potencia hegemónica mundial) o sus aliados Reino Unido o la Eurozona, se ha visto muy afectada por sus limitaciones internas, pero también por el gran ascenso geopolítico de China, Rusia, Irán, India, la actual Corea del Sur y la mayoría de los países sudamericanos que tendieron a converger en un frente mundial muy amplio, aunque disperso, contra el neoliberalismo y la hegemonía de 
Estados Unidos, que ha profundizado y extendido el conflicto entre vías alternativas de desarrollo confrontadas hasta abarcar el mundo entero.

De los años 2011-2015 en adelante, y sobre todo de 2015, la pugna política, social y cultural entre estas vías alternativas de desarrollo opera a partir de una inestabilidad política creciente y de conflictos y eventos catastróficos de gran magnitud, que convierten la crisis económica del neoliberalismo en una crisis orgánica de la globalización neoliberal. Grandes conflictos militares como la destrucción de Libia, la guerra siria, las ulteriores guerras ucraniana o yemenita y las múltiples guerras locales yihadistas se han conjugado con hechos económicos como la repercusión tardía de la crisis económica mundial en China, la contracción del comercio y las transacciones financieras mundiales o el derrumbe del precio internacional de los commodities. A ello se agrega la proliferación de "golpes blandos" y el uso del lawfare, ${ }^{3}$ así como las enormes oleadas migratorias de desplazados y refugiados desde los países en desarrollo más frágiles o destruidos, en especial hacia Europa Occidental y Estados Unidos, pero también el vertiginoso ascenso de una derecha xenófoba y filofascista que tiende a combinar el neoliberalismo y el autoritarismo interno con el proteccionismo económico externo, que alcanza su máxima expresión mundial con el advenimiento de Trump a la presidencia de Estados Unidos y acentúa la tendencia hacia la contracción del mercado mundial de mercancías y capitales derivada de la crisis.

La contracción del comercio y la inversión internacional más las nuevas políticas proteccionistas llevan a muchos autores a considerar que estamos ante el comienzo del fin de la globalización. Sin embargo, esto nos parece solo parcialmente correcto (nada más en lo que hace a la "globalización neoliberal") porque la infraestructura tecnológica y material de la globalización no deja de extenderse tanto por el revolucionario ascenso de la "banda ancha" de internet (gráfica 1) como por las grandes inversiones en infraestructura de transporte y comunicación impulsadas fundamentalmente por la construcción de la Ruta de la Seda por parte de China, los grandes gasoductos y oleoductos euroasiáticos (rusos o iraníes) que unen

${ }^{3}$ Entendemos como lawfare la judicialización de la política como mecanismo de golpe blando aplicado por la derecha reaccionaria conservadora, que pasó a ser un instrumento fundamental de lucha contra los movimientos progresistas de América Latina [Zanin et al., 2018]. 
los grandes yacimientos energéticos de Asia Central y el Medio Oriente con el corazón de la Europa occidental y China, o los países de la Asociación de Naciones del Sudeste Asiático (ASEAN) y las grandes construcciones ferroviarias, viales o portuarias en los países africanos más importantes.

\section{Gráfica 1. Indicadores internacionales de comercio e inversión y redes de comunicación (1990-2017)}

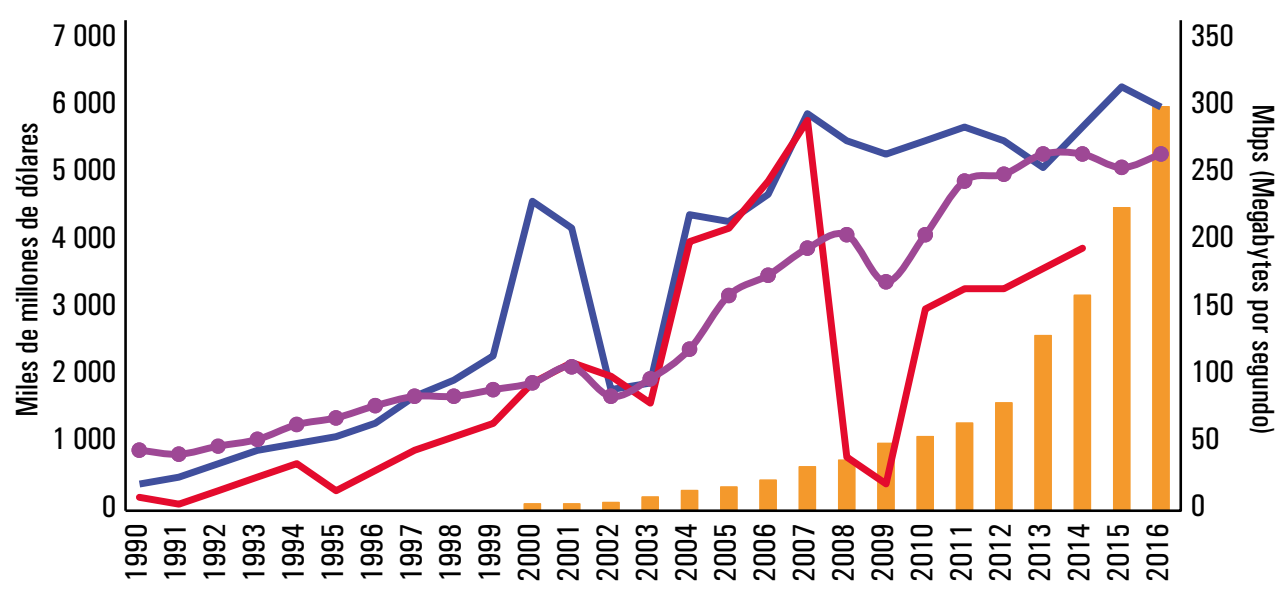

Fuente: Cepal [2019].

Esto plantea una fuerte contradicción, que se muestra en la gráfica 1, entre el comportamiento declinante o estacionario de los principales flujos comerciales o de capital mundial (particularmente grande en el sector financiero) frente al vertiginoso ascenso de la infraestructura de comunicaciones (en este caso banda ancha de internet, ya que, por su diversidad, no es posible cuantificar la infraestructura física de transporte ferroviario o por ductos) a partir de 2008-2009.

Lo que es cierto es que el grupo de países más dinámicos en la economía mundial ha dejado de ser el alineado con Estados Unidos, y cada vez se ve mayor dinamismo y participación en la economía por parte de los países social-productivistas, según se observa en el cuadro 1. 


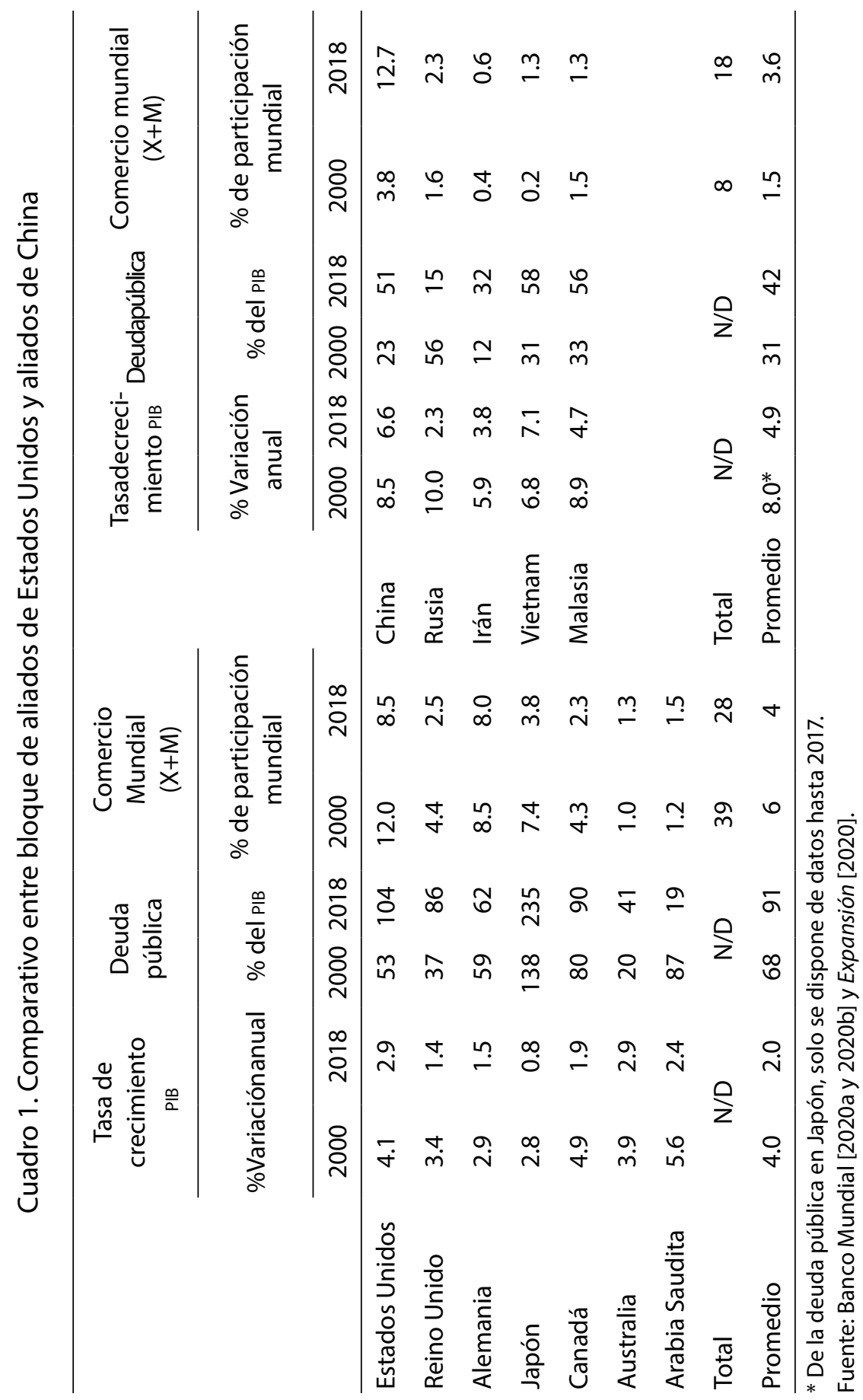


Esta dicotomía sería mucho más clara si se incorporan las grandes inversiones y obras de infraestructura material que hemos expuesto, lo que demuestra que no estamos ante el fin de lo globalización sino en vísperas de un nuevo tipo de globalización productiva y multipolar, no dominada por el neoliberalismo, en la que América Latina podría desempeñar un papel fundamental.

\section{El respaldo de China y Rusia}

El nuevo papel económico, financiero y tecnológico que China y Rusia han comenzado a desempeñar en América Latina favoreció el crecimiento económico de estos países, la intensificación del conflicto mundial y la mucha mayor presencia económica y geopolítica de la región. En este sentido destaca la vertiginosa y creciente participación de la inversión china (mayor que la de su comercio), que se dio sobre todo desde 2010 [Cepal, 2015], y en particular desde 2014-2015 (como parte de los recientes acuerdos intergubernamentales), que llevó a ese país a convertirse en el segundo inversor en la región. ${ }^{4}$ Junto al caso chino también tiene mucha importancia la presencia rusa, que si bien menor, fue muy complementaria de la del país asiático por su peso en otras actividades centrales como las energéticas, las aeroespaciales o de abastecimiento militar.

Durante los dos últimos años, los países de América Latina y el Caribe celebraron importantísimos acuerdos con China y Rusia que exceden por mucho el tipo inicial de acuerdos basados casi de modo exclusivo en producción y exportación minera y de combustibles fósiles (caso chino) o de productos alimenticios (Rusia). Hasta 2011-2012, China había sido el segundo inversor directo en América Latina a través fundamentalmente de sus empresas públicas, cerca de $90 \%$ de las cuales se dirigía a la minería y a otros recursos naturales [Dussel, 2012]. Pero a partir de 20122013, este cuadro se amplía con la fuerte irrupción de Rusia. Al lado de la

${ }^{4}$ Es difícil estimar con precisión el monto de las inversiones directas chinas por la naturaleza tanto de las propias estadísticas chinas (muchas de las inversiones son realizadas desde Hong Kong o por filiales de empresas chinas radicadas en el exterior) como de las latinoamericanas. Perú, por ejemplo, no publica el origen de la inversión extranjera directa (IED) que recibe [CEPAL, 2015]. Pero a pesar de ello, la CEPAL ya sitúa la inversión directa china en la región en un segundo lugar cercano al estadounidense. 
inversión directa tradicional aparecieron otras en industria pesada y obras de infraestructura básica, créditos a largo plazo en condiciones favorables, acuerdos monetarios tipo swap o de pago en monedas nacionales de las transacciones comerciales y múltiples acuerdos de cooperación científica-técnica, cultural o aun militar, sobre todo en el caso de Venezuela. Empresas chinas acordaron dos enormes obras de transporte interoceánico como el canal que está en construcción en Nicaragua desde fines de 2014 o el ferrocarril transamazónico que unirá el océano Atlántico con el Pacífico a través de Brasil, Bolivia y Perú; también se halla en estudio la construcción de una tercera vía interoceánica en Colombia de un ferrocarril que una sus dos litorales oceánicos [BBC, 2015], y en el caso de México, China otorgó a Pemex una línea de crédito por 600 millones de dólares que se hará efectiva en 2020.

Además, se cuenta con los enormes créditos a Venezuela (la mitad de los muy grandes otorgados a la región) pagados en gran parte en petróleo, un convenio en swaps con Argentina de 11000 millones de dólares, más un préstamo de 7000 millones para represas y la modernización de los ferrocarriles, entre otros muchos compromisos. En el caso de Brasil, la asistencia financiera consistirá en un fondo equivalente a 53000 millones de dólares, parte de los cuales se adjudicarán sus principales empresas en apuros (7 000 millones de dólares para Petrobras y 4000 para Vale, la principal productora mundial de mineral de hierro). ${ }^{5}$ Este tipo de inversiones, créditos y acuerdos alcanzarán de una u otra manera a la mayoría de los países de América del Sur, México, Cuba y Nicaragua, y se enmarcarán en el Plan de Cooperación CELAC-China 2015-2019 [Bárcena, 2015], una de cuyas primeras medidas sería el compromiso chino de elevar la inversión directa en la región a unos 250000 millones de dólares en el próximo decenio [La Nación, 2015].

Rusia también hará aportes muy importantes pese a su difícil situación económica debida en gran parte a los embargos estadounidenses y de la Unión Europea por su postura en el conflicto de Ucrania. Mientras el aporte chino se dará sobre todo en inversión directa, préstamos y swaps

${ }^{5}$ Los acuerdos de China con Brasil serán muy amplios e incluirán cuestiones como la adquisición de un banco privado brasileño por el quinto banco público de China o la construcción de una base científica con bandera brasileña en la Antártida [Turdera, 2015]. 
monetarios (como los casos de Brasil y Argentina) o en infraestructura de transportes y una gama muy amplia de actividades, la aportación rusa estaría más centrada en nichos económicos, tecnológicos o de aprovisionamiento militar (esto último, sobre todo en Venezuela, Brasil y Nicaragua), aunque también en la condonación de la deuda cubana por más de 30000 millones de dólares. A un nivel más general, los principales sectores beneficiados serán petróleo y gas, energía hidráulica y nuclear, industria aeroespacial (en especial, Argentina y Brasil), enriquecimiento de uranio (Argentina) o industria aeronáutica y naval en el caso brasileño. A nivel energético destaca la aportación a Venezuela (petróleo pesado del Orinoco), Brasil (asistencia a Petrobras), Argentina (hidrocarburos no convencionales de Vaca Muerta), Cuba (explotación de aguas profundas del Golfo de México), Ecuador (petróleo y gas) o Bolivia (gas natural). Ello incluye inversiones en refinerías petroleras o plantas nucleares en Argentina, Brasil o Ecuador, en la industria aeroespacial argentina o en el remozamiento de la industria y el equipo bélico cubano, dada la tecnología militar heredada de la relación con la Unión Soviética.

América Latina en el ConteXto mundial de deCLiVe del neOliberalismo

Desde la fundación de la Organización de los Estados Americanos (OEA) en 1948, la organización regional más antigua, la región latinoamericana se encontraba bajo dominio político, comercial e ideológico de las posiciones estadounidenses y sus intereses en la región. En pleno proceso de conformación del nuevo capitalismo, América Latina se insertó en la globalización como un gran bloque regional, aunque con grandes diferencias entre países y sin romper por completo con la hegemonía de Estados Unidos. Así se fueron creando organizaciones principalmente comerciales como los tratados de libre comercio, el Mercado Común del Sur (Mercosur), el Sistema de Integración Centroamericana (SICA), la Comunidad Andina de Naciones (CAN) y la Comunidad del Caribe (Caricom).

Con la llegada de los gobiernos progresistas, la geopolítica latinoamericana cambió radicalmente [Dabat et al., en prensa]. Durante la primera década de nuestro siglo, la región quedó partida en dos grandes bloques: a) la mayoría de los países de América del Sur, parte de América Central 
y la mayoría de los países del Caricom agrupados contra Estados Unidos y el neoliberalismo gracias al papel del ALBA y la CELAC (bloque opuesto al neoliberalismo), y b) los países que no rompieron con el neoliberalismo y siguieron sometidos a la hegemonía estadounidense en plena decadencia, como México y otros centroamericanos y sudamericanos con alto nivel de integración a la economía de Estados Unidos. Estos nuevos organismos regionales dieron mayor estabilidad económica, política y social a la región.

Por ejemplo, en 2005 Venezuela comenzó el apoyo económico a 13 países caribeños con el programa Petrocaribe (Haití, República Dominicana, Antigua y Barbuda, El Salvador y Nicaragua, entre otros) que implica formas de pago preferenciales sobre los energéticos (petróleo, gas y electricidad) con el objetivo de promover el avance del desarrollo económico, cultural y social de la región. Aunque la nueva integración latinoamericana jugó un papel muy importante en la estabilidad de los gobiernos progresistas, también existieron fuertes limitaciones como la nula inversión e integración regional en ciencia, tecnología e innovación, y la escasa inversión en infraestructura. Precisamente en el rubro de infraestructura, el financiamiento por parte de Rusia y China ha jugado un papel importante en la región.

A continuación analizamos ambas regiones de América Latina a partir del progresismo de América del Sur, el fin del auge de las exportaciones primarias y la nueva contraofensiva neoliberal.

\section{Los principales motores y orientaciones del progresismo latinoamericano}

El desarrollo de movimientos populares democráticos con instituciones y políticas públicas diferentes a las del neoliberalismo hizo posible el crecimiento económico y las transformaciones sociales, políticas, culturales e incluso ideológicas de los países progresistas de América del Sur. En prácticamente todos los casos se establecieron economías de mercado reguladas, con aperturas externas controladas y estrategias propias del desarrollo [Ordóñez y Sánchez, 2016] impulsadas por un fuerte activismo estatal, poderosas empresas públicas y empresas privadas nacionales competitivas con mercados internos en desarrollo; amplias políticas de educación, salud, seguridad social y culturales; altos niveles de inversión en inversión y desarrollo (I+D); fuertes reservas de divisas y débil exposición a los aspectos 
más especulativos del sistema financiero, o por lo menos (salvo el caso de Brasil), con fuertes contrapesos de banca pública. En este sentido, contaron con sistemas bancarios muy regulados y en gran parte públicos, y con fuertes reservas internacionales [Lane y Schmukler, 2007].

La inserción de esos países a la nueva división global del trabajo y las cadenas productivas globales fue muy superior con respecto al periodo anterior a partir de estrategias de desarrollo heterodoxas, movilización masiva de la población para el desarrollo económico, inversión masiva con fines estratégicos de desarrollo y regulación pública de su inserción al mercado.

En el plano económico, el incremento del comercio internacional de productos básicos junto con las mejoras en los términos de intercambio permitió que la región latinoamericana tuviera una alta tasa de crecimiento anual entre 2000 y 2008 [Cepal, 2014], y en casos como los de Venezuela y Argentina, la economía creció a un promedio de más de $7 \%$, mientras que países como México se mantuvieron a un ritmo de crecimiento de $2 \%$ (cuadro 2).

Cuadro 2. Tasa de crecimiento del PIB para las principales economías de América Latina, periodos seleccionados

\begin{tabular}{lccccc} 
& \multicolumn{1}{c}{$1980-1989$} & $1990-1999$ & $2000-2008$ & $2009-2015$ & $2016-2018$ \\
\hline México & 2.3 & 3.5 & 2.2 & 2.1 & 2.3 \\
Brasil & 3.0 & 1.9 & 3.8 & 1.9 & -0.4 \\
Argentina & -0.3 & 4.0 & 3.5 & 1.7 & -0.6 \\
Colombia & 3.4 & 2.9 & 4.2 & 4.2 & 2.0 \\
Chile & 3.6 & 6.1 & 4.8 & 3.4 & 2.3 \\
Venezuela* & -0.2 & 2.5 & 4.8 & -0.5 & -16.9 \\
Bolivia & -0.4 & 4.0 & 3.7 & 5.0 & 4.2 \\
Perú & 0.4 & 3.2 & 5.5 & 4.8 & 3.5 \\
Ecuador & 2.6 & 2.3 & 4.3 & 3.8 & 0.8 \\
-DR & 1.2 & 3.9 & 4.0 & 3.3 & 3.5 \\
Promedio & 1.6 & 3.4 & 4.3 & 3.0 & 0.1 \\
A. Latina & & & & & \\
\hline
\end{tabular}

*Nota: los datos de 2015-2018 se basan en las estimaciones de datosmacro.com debido a la falta de información oficial del PIB de Venezuela.

Fuente: Banco Mundial [2020a] y Expansión [2019]. 
Las exportaciones de la región crecieron a más de $150 \%$ en esos años, con casos como el brasileño de $260 \%$ y otros como Bolivia, Ecuador y Perú con más de $300 \%$. Aunque la crisis económica mundial de 2008 tuvo impactos negativos en la región, se mantuvieron tasas de crecimiento promedio de $3 \%$ durante el periodo de 2009-2015.

En el plano financiero, los grandes saldos comerciales favorables se tradujeron en la ampliación de las reservas internacionales para toda la región en 200 \%, destacando Ecuador y Argentina, que redujeron drásticamente la deuda externa por restructuraciones con los organismos internacionales [Leal, 2016]. En el caso de Venezuela, se aprovecharon los altos precios del petróleo para desarrollar internamente programas sociales (las misiones) y promover los procesos de integración regional, sobre todo en relación con el ALBA.

En el plano social, los gobiernos progresistas crearon grandes programas que permitieron reducir de forma sustancial los niveles de pobreza. En 2012, las tasas de pobreza e indigencia cayeron a los niveles más bajos desde 1990 (de $21.4 \%$ a $7.1 \%$ ) y entre 2003 y 2012, 70 millones de personas salieron de la pobreza en la región [Ferreira et al., 2013].

El desarrollo científico y tecnológico tuvo avances significativos, aunque aún muy limitados. En promedio, los gobiernos progresistas invirtieron proporcionalmente más en I+D que lo gastado en la época neoliberal anterior: pasaron de menos de $0.3 \%$ del PIB a $0.7 \%$ a lo largo de la región [Banco Mundial, 2019].

Por último, en el plano político se da una verdadera ampliación democrática y de empoderamiento de los sectores populares, sea por la vía sindical, de movimientos sociales o vía partidos políticos [García, 2017], que pone fin al dominio político de las viejas élites políticas representadas en los partidos políticos tradicionales en la mayoría de los países de América del Sur.

Limitaciones internas y externas de la primera oleada progresista

Los logros mencionados, en particular los de carácter social, no bastaron para resolver los grandes estragos del desempleo y la marginalidad social generados por el neoliberalismo [Bárcena, 2010] y se hicieron a costa de 
otras necesidades a largo plazo, aunque no tan urgentes (porque existía el colchón de los altos ingresos de exportación), como la modernización tecnológica de la economía, la diversificación del aparato productivo o el pasaje a un nuevo tipo de acumulación de naturaleza intensiva y compleja en capital, ${ }^{6}$ infraestructura, tecnología, conocimiento y desarrollo nacional y regional de industrias de alta tecnología, que pudieran traducirse en fuertes logros de productividad del trabajo y competitividad internacional en sucesivos y múltiples sectores de las economías nacionales tanto empresariales privados, como públicos (estatales) y sociales.

Lo cierto es que por esta y otras razones (restos de la herencia ideológica populista, entre otras) los principales países de América Latina avanzaron muy poco en el pasaje al nuevo tipo de acumulación de capital intensiva y compleja y de desarrollo tecnológico y económico-social seguido por países asiáticos como Corea, China o India. Ello hizo que las naciones más progresistas de la región no lograran modificar su perfil nacional de exportadores de commodities hacia exportadores de manufactureras, software o servicios avanzados (cuadro 3), salvo el caso discutible de México, gran exportador mundial de productos industriales de alta tecnología pero basada en una industria maquiladora controlada totalmente por grandes trasnacionales, que aunque opera en territorio mexicano por razones de bajo costo salarial, importa sus insumos del exterior (sin cadenas productivas internas de importancia), utiliza tecnología importada y no paga impuestos.

Como se observa en el cuadro anterior, los productos agrícolas, los combustibles y los productos de minería son los que dominan en nuestras exportaciones; solo en el caso de México es muy importante la manufactura, pero la gran mayoría es maquiladora, como ya se planteó. Lo anterior implica que no hemos logrado salir del atraso de ser economías productoras de bienes primarios o exportadoras de mano de obra barata (como México).

'Llamamos acumulación "intensiva y compleja" (a diferencia de "extensiva" de puro elevamiento proporcional de trabajo y capital tradicional) al tipo de acumulación que además de incrementar cuantitativamente la inversión para elevar el monto del producto, también eleva la capacidad cognitiva y productiva del trabajo y la tecnología empleada tanto a nivel nacional como local, regional y supranacional. 
Cuadro 3. Estructura y principal destino de exportaciones de países latinoamericanos seleccionados

\begin{tabular}{|c|c|c|c|c|}
\hline Origen & Destino & $\%$ s/total & Estructura \% & \\
\hline \multirow{3}{*}{ Argentina } & \multirow{3}{*}{ Brasil } & \multirow{3}{*}{18.3} & Productos agrícolas & 84.5 \\
\hline & & & Combustiblesy productos deminería & 6.4 \\
\hline & & & Manufacturas & 9.1 \\
\hline \multirow{3}{*}{ Brasil } & \multirow{3}{*}{ China } & \multirow{3}{*}{26.8} & Productos agrícolas & 42.7 \\
\hline & & & Combustiblesy productos deminería & 33.0 \\
\hline & & & Manufacturas & 24.3 \\
\hline \multirow{3}{*}{ Colombia } & \multirow{3}{*}{ EstadosUnidos } & \multirow{3}{*}{26.53} & Productos agrícolas & 17.4 \\
\hline & & & Combustiblesy productos deminería & 76.3 \\
\hline & & & Manufacturas & 6.3 \\
\hline \multirow{3}{*}{ México } & \multirow{3}{*}{ EstadosUnidos } & \multirow{3}{*}{76.5} & Productos agrícolas & 3.8 \\
\hline & & & Combustiblesy productos de minería & 10.1 \\
\hline & & & Manufacturas & 86.1 \\
\hline \multirow{3}{*}{ Venezuela } & \multirow{3}{*}{ EstadosUnidos } & \multirow{3}{*}{$\mathrm{N} / \mathrm{D}$} & Productos agrícolas & 0.8 \\
\hline & & & Combustiblesy productos de minería & 97.4 \\
\hline & & & Manufacturas & 1.9 \\
\hline
\end{tabular}

Fuente: Trade Map [2020].

El fin de la bonanza de las exportaciones de bienes primarios

El rápido crecimiento de las economías de América del Sur se apoyó en gran parte en las favorables condiciones del comercio internacional, sobre todo en los precios muy elevados de las exportaciones de bienes primarios. Ello, junto con otras condiciones internas y externas, posibilitó el crecimiento de la economía e importantes logros sociales y de diversa índole. Pero 
tal nivel de precios comenzó a deteriorarse a lo largo de 2014 para convertirse en un derrumbe casi general durante los primeros meses de 2015, que afectó sobre todo al petróleo y el mineral de hierro (caídas cercanas o superiores a $50 \%$ en relación con 2013), seguidos muy de cerca por el maíz y con menores niveles (entre 20 y 30 \%) por el trigo, la soya, el arroz, el cobre, el carbón, el azúcar y los plátanos, en un proceso del que solo se salvaron (entre los principales productos de exportación) la carne de res, el aluminio, el níquel o el algodón, y en cierto sentido, por su leve caída, el gas natural, el café o el oro [FMI, 2016].

Este proceso obedeció a un conjunto de factores como la desaceleración y reorientación hacia el mercado interno de China, la persistencia de la crisis europea o el incremento de la producción mundial ante los altos precios precedentes, agravados por fenómenos coyunturales como el cambio de tendencias de la especulación con los precios futuros (que exacerbó en buena medida la caída), o la ruptura de hecho de la OPEP por el aumento de las ventas de Arabia Saudita destinado a golpear sobre todo a las economías iraní y rusa.

En términos generales, y aunque resulte aún muy temprano para extraer conclusiones definitivas, los datos del cuadro 4, complementados con otras fuentes, apuntan a dos hechos básicos: a) que los precios de los commodities más afectados parecerían ser los de los más relacionados con la elaboración de medios de producción o producción de infraestructuras tradicionales (precios del petróleo, el hierro o numerosos metales), más que los de los productos alimenticios y materias primas de origen agrícola, cuya caída promedio estuvo entre 10 y $15 \%$ en el periodo estudiado [FMI, 2016] por razones aparentemente muy vinculadas con las nuevas características de la demanda china; y b) que dentro del rubro combustibles y metales, los precios que conservaron mayor estabilidad relativa al parecer fueron los más relacionados con las tecnologías informáticas, como el gas natural o el cobre (materiales fundamentales para la electricidad y el equipo electrónico), o los metales más maleables y necesarios para las nuevas aleaciones y aplicaciones, como el aluminio, el níquel o el plomo.

En general, podría decirse que la fuerte caída del precio de los commodities es un fenómeno indudable que aunque puedan revertirlo en parte 
factores como una reducción de la producción de las mismas, un rebote hacia el alza de las operaciones especulativas con ellas, una eventual recuperación de la economía europea o un incendio político-militar en Medio Oriente (para el caso del petróleo), tiene visos de ser el comienzo de un nuevo ciclo depresivo internacional relativamente duradero. Aunque tal fenómeno pudiera ayudar a la economía de ciertos países y regiones importadores de algunos de estos bienes, sobre todo de petróleo y mineral de hierro, significa un golpe muy fuerte para la gran mayoría de los países latinoamericanos, sobre todo para aquellos muy dependientes de los productos más afectados por la caída de precios, lo que lastima tanto sus balanzas comerciales como los productos internos y los ingresos fiscales en especial.

Cuadro 4. Precios mundiales de bienes primarios, años seleccionados

\begin{tabular}{|c|c|c|c|c|c|c|c|}
\hline Año & $\begin{array}{l}\text { Algodón } \\
\text { (USDÇ/lb) }\end{array}$ & $\begin{array}{l}\text { Aluminio } \\
\text { (USD\$/ton) }\end{array}$ & $\begin{array}{l}\text { Azúcar } \\
\text { (USDÇ/lb) }\end{array}$ & $\begin{array}{l}\text { Café } \\
\text { y otras } \\
\text { arábicas } \\
\text { suaves } \\
\text { (USDÇ/lb) }\end{array}$ & $\begin{array}{c}\text { Carne } \\
\text { de res } \\
\text { (USDÇ/lb) }\end{array}$ & $\begin{array}{c}\text { Cobre } \\
\text { (USD\$/ton) }\end{array}$ & $\begin{array}{c}\text { Gas natural } \\
\text { ruso en } \\
\text { Alemania } \\
\text { (USD\$/mmbtu) }\end{array}$ \\
\hline 2000 & 59 & 1551.5 & 8.1 & 85 & 87.79 & 1814.5 & 3.5 \\
\hline 2005 & 55.2 & 1900.5 & 10.1 & 114.3 & 118.73 & 3676.5 & 5.9 \\
\hline 2010 & 103.5 & 2173 & 20.9 & 194.4 & 152.47 & 7538.4 & 8.2 \\
\hline 2011 & 154.6 & 2400.6 & 26.2 & 273.2 & 183.18 & 8823.5 & 10.6 \\
\hline 2012 & 89.2 & 2022.8 & 21.4 & 187.6 & 187.94 & 7958.9 & 12 \\
\hline 2013 & 90.4 & 1846.7 & 17.7 & 141.1 & 183.59 & 7331.5 & 11.2 \\
\hline 2014 & 83.1 & 1867.4 & 17.1 & 202.8 & 224.06 & 6863.4 & 10.5 \\
\hline 2015 & 70.4 & 1664.7 & 13.2 & 160.5 & 200.49 & 5510.5 & 7.3 \\
\hline 2016 & 74.2 & 1604.1 & 18.1 & 164.5 & 178.2 & 4867.9 & 4.3 \\
\hline 2017 & 83.6 & 1968 & 15.8 & 152.4 & 191.51 & 6169.9 & 5.7 \\
\hline 2018 & 91.4 & 2108.5 & 12.2 & 137.4 & 183.5 & 6529.8 & 7.9 \\
\hline 2019 & 82.9 & 1842.9 & 12.5 & 130.5 & 195.5 & 6227 & 5.5 \\
\hline
\end{tabular}


(Continuación del cuadro 4)

\begin{tabular}{cccccccc}
\hline Año & $\begin{array}{c}\text { Maíz } \\
\text { (USD\$/ton) }\end{array}$ & $\begin{array}{c}\text { Mineral } \\
\text { de hierro } \\
\text { (USD\$/ton) }\end{array}$ & $\begin{array}{c}\text { Oro } \\
\text { (USD\$/ozt) }\end{array}$ & $\begin{array}{c}\text { Petróleo } \\
\text { crudo } \\
\text { (USD\$/barril) }\end{array}$ & $\begin{array}{c}\text { Uranio } \\
\text { (USD\$/lb) }\end{array}$ & $\begin{array}{c}\text { Soya } \\
\text { (USD\$/ton) }\end{array}$ & $\begin{array}{c}\text { Trigo } \\
\text { (USD\$/ton) }\end{array}$ \\
\hline 2000 & 88.2 & 12.5 & 279 & 28.2 & 8.3 & 183.1 & 100.7 \\
2005 & 98.4 & 28.1 & 444.8 & 53.4 & 27.9 & 223.1 & 129.9 \\
2010 & 186 & 146.7 & 1224.7 & 79 & 46 & 384.9 & 194.5 \\
2011 & 291.8 & 167.8 & 1568.3 & 104 & 56.2 & 484.2 & 280 \\
2012 & 298.4 & 128.5 & 1668.8 & 105 & 48.9 & 537.8 & 276.1 \\
2013 & 259 & 135.4 & 1411.5 & 104.1 & 38.6 & 517.2 & 265.8 \\
2014 & 192.9 & 96.8 & 1265.6 & 96.2 & 33.5 & 457.8 & 242.5 \\
2015 & 169.8 & 55.2 & 1160 & 50.8 & 36.8 & 347.4 & 185.6 \\
2016 & 159.2 & 58.5 & 1248.3 & 42.8 & 26.5 & 362.7 & 143.2 \\
2017 & 154.6 & 71.1 & 1257.1 & 52.8 & 22 & 358.8 & 145.3 \\
2018 & 164.5 & 70.1 & 1269.1 & 68.3 & 24.5 & 342.5 & 186.1 \\
2019 & 167.1 & 89.2 & 1296.6 & 63.3 & 27 & 325.4 & 172.6 \\
\hline
\end{tabular}

Nota: precios promedio anuales calculados con base en datos mensuales.

*Promedio de precio a junio de 2019.

Fuente: FMI [2019].

Lo expuesto no solo afectó el crecimiento de América Latina y el Caribe, sino que también obligó a los gobiernos progresistas a realizar grandes cambios en sus políticas económicas y a recurrir mucho más a acuerdos internacionales para estar en condiciones de afrontar la crisis, las asechanzas de la restauración conservadora y las exigencias de participación de la región en la pugna por el cambio en el orden mundial contra el neoliberalismo y la hegemonía de Estados Unidos.

Los primeros golpes blandos y ataques desestabilizadores

Durante este periodo de ascenso, la derecha de la región más reaccionaria y parasitaria, proclive a los intereses del gobierno estadounidense, buscó 
desestabilizar por cualquier método a los gobiernos de izquierda. En los primeros intentos de desestabilización, desarrollaron golpes fallidos con gran violencia. El primer caso fue contra Hugo Chávez en 2002, después vinieron intentos de golpes en Ecuador y Bolivia.

Sin embargo, los esfuerzos de desestabilización-restauración neoliberalconservadora apoyados por Estados Unidos complejizaron los instrumentos destituyentes a partir de los golpes "blandos", 7 que también se dieron en otros países del mundo. Los primeros ocurrieron en dos naciones donde los gobiernos de izquierda eran más débiles: Paraguay y Honduras. Aunque dichos golpes fueron condenados por los organismos regionales como CELAC, Unasur y aun Mercosur, poco o nada pudo hacerse contra ellos, lo que mostró la debilidad de dichos organismos regionales. Los cambios en la economía regional a partir de 2013 , aprovechando las consecuencias de la crisis internacional y la posterior declinación del precio de las materias primas, aunados a las debilidades socioinstitucionales mencionadas, permitieron que los grupos más retrógradas de la derecha latinoamericana comenzaran un gran contraataque desestabilizador contra los avances de los últimos 15 años.

\section{El agotamiento del modelo de crecimiento}

De nuevo en el plano económico, al problema del derrumbe de los precios de las materias primas se agrega otro más grave aún que Fajnzylber [1983] señaló hace más de tres décadas, y que por su naturaleza estructural requiere grandes cambios científico-tecnológicos, económicos, educativos y socioinstitucionales de largo plazo. De acuerdo con las nuevas condiciones históricas, esto implica el pasaje de un tipo de crecimiento basado en materias primas e industrias intensivas en trabajo con escasa incorporación de capital fijo y tecnología, a otro mucho más productivo y diversificado

\footnotetext{
${ }^{7}$ Ejercicio del soft power a nivel internacional se refiere a acciones convergentes de las grandes cadenas mundiales y nacionales amigas de comunicación de masas, de las instituciones internacionales del neoliberalismo, de las fundaciones $\mathrm{y}$ oNG financiadas por ellas o directamente por gobiernos que sobornan a dirigentes y amplifican movimientos opositores, de entidades de inteligencia como la CIA, el M-16 o el Mosad o medios de información financiera que promueven fugas de capitales, como también decisiones judiciales o arbitrales externas.
} 
sustentado en una mayor y más moderna infraestructura física, social y científica-tecnológica que haga posible la producción industrial y de servicios avanzados intensiva en capital, tecnología, innovación y mayor calificación de la fuerza de trabajo. Las condiciones comerciales favorables en el plano internacional, conjugadas con la necesidad imperiosa de superar rápidamente las catastróficas condiciones sociales heredadas de los gobiernos neoliberales de la década anterior, condujeron casi de manera espontánea a los nuevos gobiernos progresistas de la región (sobre todo en América del Sur) a privilegiar en el nuevo siglo los requerimientos sociales más apremiantes (empleo, salario, jubilación, seguridad social, servicios educativos, médicos y urbanísticos para las barriadas más marginadas, embriones de economías solidarias, etc.), sobre la necesidad de afrontar un decidido proceso de modernización, creación de infraestructura y logística moderna, diversificación productiva e incremento de la productividad del trabajo, teniendo en cuenta que esta última se encuentra muy por debajo de la lograda por los países emergentes de Asia Oriental (gráfica 2).

Gráfica 2. Productividad promedio por hora trabajada, 1990-2017:

América Latina y Pacífico Asiático

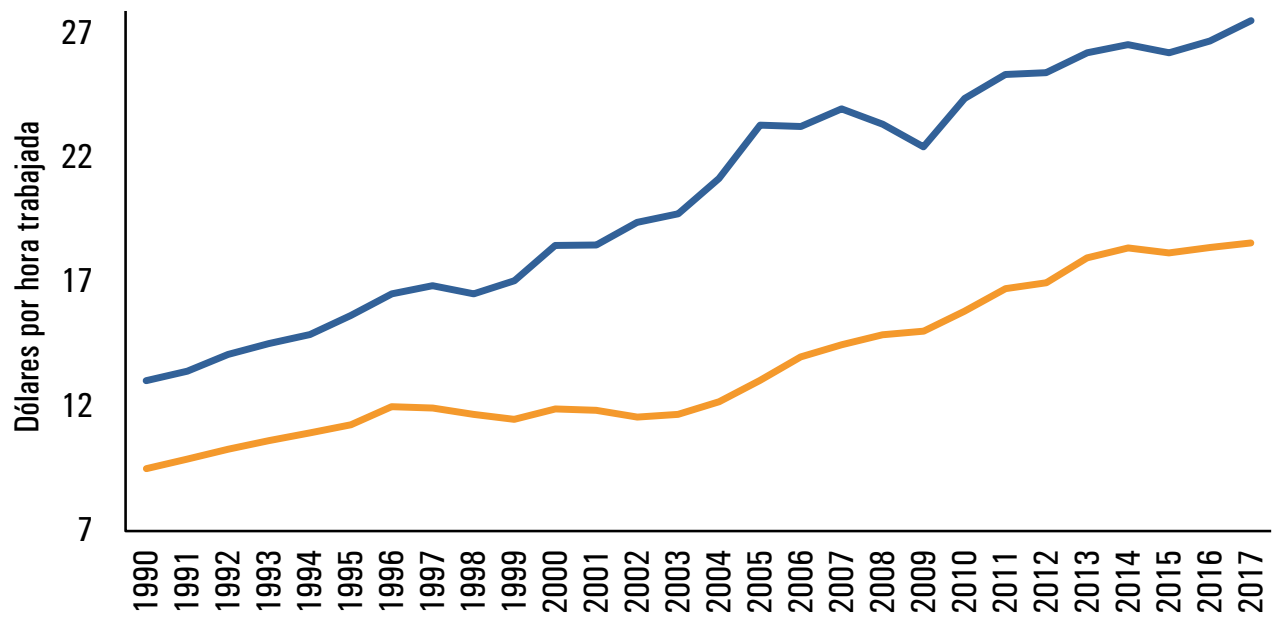
América Latina Pacífico Asiático

Fuente: Our World in Data [2019]. 
Reflujo económico, contraataque neoliberal y derrotas del progresismo

La recesión económica y los grandes problemas sociales no pudieron resolverse en el corto plazo, si bien los gobiernos progresistas lograron avances significativos en corrupción, concentración monopólica de la información, derechos sociales de los sectores más vulnerables y desigualdad social, entre otras demandas. Pero las nuevas fuerzas conservadoras comenzaron a organizarse, ya no bajo los partidos políticos tradicionales, sino en movimientos reaccionarios sectarios que promueven de nuevo la ortodoxia neoliberal en términos económicos, aunque bajo la supuesta bandera de la anticorrupción, y que muestran en realidad su rostro cavernario y retrógrada, con posturas racistas, homofóbicas, machistas y elitistas, todo ello con base en un discurso enmarcado en la llamada "posverdad", respaldada por los monopolios privados de la opinión pública.

A partir de 2013, si bien los intentos de golpes blandos de la etapa anterior tuvieron pocos o nulos efectos en toda la región (salvo los casos de Paraguay y Honduras) para este nuevo contexto, los gobiernos progresistas carecían de un gran respaldo popular como había acontecido antes. La confusión teórica y la ambigüedad del discurso de los sectores más avanzados en la academia, el atraso de los sectores más oscuros de la izquierda latinoamericana, la manipulación de la información que llega a los sectores más populares de la población, aunados a los errores tácticos de la izquierda en el gobierno, permitieron lentamente que el discurso anticorrupción llegase a ser una bandera de la derecha fascista para empezar a posicionarse como un actor relevante en la política nacional. ${ }^{8}$

Con la muerte de Hugo Chávez y Néstor Kirchner y la sucesión de Lula por Dilma Rousseff, se fueron perdiendo referentes simbólicos importantes de los liderazgos nacionales de los movimientos progresistas y la integración regional. Así, el reflujo de la derecha neoliberal abrió dos frentes: la desestabilización interna con movilizaciones manipuladas por una información alterada (posverdad) como las movilizaciones violentas en Venezuela en 2013 y 2017, en 2015 en Ecuador contra la llamada Ley

8 "Prefiero un gobierno homofóbico, clasista y racista que un gobierno corrupto se puede leer en la actual disputa en Brasil" [вВС, 2018]. Este ejemplo nos muestra la falta de claridad de los objetivos políticos que permean en los sectores más vulnerables de la región. 
de plusvalía y los paros del sector cocalero y las manifestaciones en contra de la candidatura de Evo Morales en Bolivia. En 2012 tuvo lugar en Argentina el conflicto agropecuario por la resolución 125, que duró casi cuatro meses e incluyó cortes de ruta y movilizaciones multitudinarias que significaron un gran revés del kirchnerismo. En Brasil, tras las primeras grandes movilizaciones contra la realización de la Copa Confederaciones y la Copa Mundial de Futbol, aunque fueron de gran cantidad de personas, el gobierno del Partido del Trabajo (РT) pudo salir victorioso en las elecciones dando un segundo mandato a Dilma Rousseff por encima del candidato de derecha aliado con los ambientalistas. Sin embargo, como veremos más adelante, el golpe de Estado cambió drásticamente la geopolítica latinoamericana. El caso brasileño y la derrota electoral del Frente para la Victoria por una mínima diferencia en Argentina ampliaron los problemas políticos de la región.

Aprovechando esta coyuntura, las campañas violentas de los medios de comunicación generaron una polarización sin precedentes en la región; así, con la derrota electoral en Argentina y el golpe de Estado en Brasil vinieron dos frentes de la derecha muy importantes hasta ahora producto de la derechización de gobiernos de izquierda como Chile con Bachelet y Ecuador con Lenin Moreno. A su vez, los organismos regionales perdieron un peso significativo, y no solo ello, sino que dichos organismos empezaron a influir en la condena y las sanciones a los países de izquierda; son los casos del Mercosur y la suspensión de Venezuela en dicho órgano, o el ataque de la OEA en Bolivia.

Ante este panorama tan complicado, en cada país se gestaron conflictos que polarizaron a casi toda la sociedad. Si bien la derecha ha ganado espacios fundamentales, no se debe a un proceso hegemónico o de derrota completa del progresismo, sino que es una oleada que en los casos de Argentina y Brasil ha demostrado que no tiene alternativa de desarrollo, sino se anida de los errores del progresismo [García, 2017] y manipulaciones mediáticas.

En el transcurso de 2015 y 2016, las denuncias anticorrupción (el caso de Odebrecht es el ejemplo paradigmático al respecto) y las acusaciones al progresismo de debilidad frente a la delincuencia posicionaron el discurso más reaccionario en la opinión pública y la política regional y latinoamericana, y se convirtieron en un ataque frontal destituyente. En países 
como Argentina ese discurso apenas logró el triunfo electoral por muy escaso margen debido en gran medida a la complicidad directa o indirecta de una parte de la izquierda y el movimiento popular. ${ }^{9}$ Sin embargo, en los demás países de la región las fuerzas más reaccionarias se hicieron del control del gobierno a partir de la violencia, el sabotaje y la complicidad internacional, la manipulación de la información y la judicialización de la política, como el golpe parlamentario en Brasil, o en su defecto, llevaron a una violencia sin precedentes en estos últimos años en la región a naciones como Venezuela, Bolivia y Nicaragua por querer tirar a los gobiernos elegidos democráticamente, y a los asesinatos de líderes sociales en México y Colombia. Esta compleja realidad llevó al poder a Macri y Temer en Argentina y Brasil, respectivamente, y después condujo al golpe de Estado en Bolivia. ${ }^{10}$ En términos generales, el nuevo proceso histórico que se abrirá para América del Sur y los países de la región de América que estamos estudiando será un esfuerzo en extremo temporal y de muy débil sustentabilidad histórica (por su orientación opuesta del todo a las tendencias históricas del desarrollo mundial), orientado por tres objetivos fundamentales: a) restablecer el dominio del gran capital sobre los países afectados por el proceso bajo su actual forma neoliberal de economías desreguladas de libre mercado; b) en paralelo, realinear internacionalmente, esos países dentro del bloque mundial neoliberal hegemonizado por Estados Unidos; y c) instituir entidades estatales de emergencia contrarrevolucionaria de destrucción de los aún débiles Estados de derecho de esos países, a fin de convertirlos en aparatos arbitrarios de excepción esforzados en aplastar por medios ilegales los logros populares, nacionales y progresistas de los mismos para alcanzar los dos objetivos anteriores.

${ }^{9}$ Por ejemplo, en Argentina Macri ganó con la votación mayoritaria de la sociedad argentina no con un voto propio, sino con un voto prestado. Macri por sí mismo no sacó más de $25 \%$ en la primera vuelta y fue completado por el radicalismo de izquierda [Gambina y Hernández, 2017].

${ }^{10} \mathrm{El} 10$ de noviembre de 2019, bajo un supuesto fraude electoral y con clara participación de la OEA, se orquestó un golpe de Estado por parte de las fuerzas armadas que llevó a la renuncia del presidente Evo Morales y del vicepresidente Álvaro García Linera. Jeanine Añez se autoproclamó presidenta con claros cuestionamientos sobre la legalidad y legitimidad del proceso. 
La importancia de la región radica en que se proyecta (después de Medio Oriente) como uno de los escenarios principales en el estadio actual de lucha por el nuevo orden mundial entre el Occidente neoliberal y los países social-productivistas del sur del mundo. En este sentido, la enorme dotación de recursos naturales, la potencialidad de los mercados internos, la ubicación geográfica y la disponibilidad de mano de obra con niveles medios de productividad, crean en conjunto una región muy importante en la disputa geopolítica actual que se sitúa en una coyuntura histórica en la que Estados Unidos, tras sus derrotas económicas y militares en otras partes del mundo, trata de refugiarse entre sus reales o supuestos amigos, entre los que no podrían faltar los incondicionales de su histórico "patrio trasero".

La coyuntura histórica abre escenarios para la región que presentan posibilidades reales de avance hacia una senda progresista que logre responder exitosamente a la contraofensiva del imperio del Norte y al neoliberalismo, y que permita solidificar en lo económico una estructura social-productivista que prevalezca sobre la especulación y la exclusión social, mediante la diversificación y el fortalecimiento de su comercio internacional y flujos de capital, con énfasis en la incorporación masiva de la población a un nuevo proyecto de nación propio que considere las particularidades de la región y en el que se enfatice la generación de empleos, el combate a la desigualdad, el avance tecnológico, la protección del medio ambiente y la reinserción de la región en el mercado mundial a partir de un núcleo endógeno de acumulación basado en el incremento de la productividad y la menor dependencia de la renta del suelo.

En lo político, la coyuntura actual abre la posibilidad del arribo o la concreción de bloques progresistas de poder nacionales que derroten a las fuerzas opresoras y entreguistas y avancen hacia una relación más adecuada y solidaria con los países emergentes de Asia como China, Corea del Sur, Rusia o Irán, la nueva África, y sobre todo, consigo mismo a través del restablecimiento de la unidad regional de nuestros países que incluya la recuperación de la OEA para las causas progresistas y una futura incidencia regional conjunta dentro del nuevo orden mundial en construcción.

Aunque las actuales condiciones sean favorables para el avance de los gobiernos progresistas alternos al neoliberalismo, podemos establecer las siguientes tesis centrales: 
1. Que cualquiera que haya sido el nivel de los logros económicos, sociales, culturales, institucionales y más modestamente tecnológicos que obtuvieron algunos países de la región a comienzos de la presente década, está aún muy lejos de resolver los grandes problemas históricos de la región y que dichos avances requieren una gran profundización tanto a nivel interno como internacional; en particular es necesario que estos avances se expresen en términos de elevamiento de la productividad.

2. Que los avances progresistas logrados son reversibles por su insuficiente base de consolidación si no logran derrotarse los avances restauradores del neoliberalismo, porque su preservación, aun sea parcial, seguirá afectando las funciones sociales del Estado y a las organizaciones solidarias de la sociedad civil a costa del empleo, los salarios, las prestaciones, la seguridad social, la educación, el conocimiento tecnológico endógeno, la salud pública o la equidad de género [Dabat, en prensa] bajo formas más conservadoras y racistas tipo Trump o Bolsonaro.

3. Que para recuperar los avances anteriores, consolidarlos y profundizarlos, debe pasarse a una fase de modalidad de desarrollo económico más intensiva en inversión pública, tecnología avanzada, trabajo calificado y cooperativismo, mayor diversificación de la producción y modernización de las pymes e integración económica regional, sobre todo en infraestructuras, industrias avanzadas, banca de desarrollo con regulación monetaria-financiera, desarrollo científico-tecnológico y financiamiento externo no convencional.

En este contexto cobra fundamental relevancia el actuar de Donald Trump, de la oEA y de los gobiernos afines a los intereses estadounidenses. Los conflictos sociales se han polarizado en torno a dos bloques claramente marcados: los gobiernos apoyados por los intereses de Estados Unidos y los gobiernos progresistas en mayor o menor medida respaldados por los bloques social-productivistas del mundo. Al respecto sostenemos que después de las derrotas en Medio Oriente, Trump busca refugiarse en América Latina tratando de atenuar los conflictos más graves con la región, como sería neutralizar o moderar los procesos brasileño, argentino, 
boliviano, cubano o aun venezolano, para concentrar sus fuerzas políticas, militares y diplomáticas en la contención directa de China y Rusia.

Finalmente, para el caso de México, al conjugarse los problemas externos con el contexto de debilidad y enfermedad de la economía nacional en lo interno, se produce un escenario de fuerte posibilidad de crisis en México. Ante lo cual Andrés Manuel López Obrador no tiene un proyecto que resuelva los problemas de producción y desarrollo, y menos ante la coyuntura mundial de bajo crecimiento económico y emergencia sanitaria por el coronavirus. No se han creado instituciones para afianzar el combate a la corrupción ni el apoyo a la ayuda social, por lo que el fin del sexenio podría significar el fin de estas políticas. Entre sus logros se cuenta una política social incluyente, pero no tiene el dinero para sostenerla.

En conjunto, por una u otra razón, México también precisa un proceso de modernización productivo nacional propio que le otorgue verdaderas posibilidades de un desarrollo nacional mucho más autónomo, dentro de los imperativos geográficos impuestos por su vecindad e interdependencia con Estados Unidos, que le permitan desempeñar un papel geopolítico independiente dentro del futuro mundo bipolar en construcción.

\section{REFERENCIAS}

Banco Mundial (BM) [2019], "Gasto en investigación y desarrollo (\% del PIB)”, en Banco Mundial. <https://cutt.ly/jgkZEri>.

[2020a], “Crecimiento del PIB (\% anual)", en Banco Mundial. <https:// cutt.ly/9fXWwQW>.

[2020b], "Exportaciones de mercaderías (US\$ a precios actuales)", en Banco Mundial Datos. <https://cutt.ly/ogkZT9S>.

Bárcena, Alicia [2010], "Restricciones estructurales del desarrollo en América Latina y el Caribe: una reflexión postcrisis", en Revista Cepal, núm. 100.

[2015], "Diversificación es la palabra clave", en Pagina 12, Buenos Aires, 24 de junio.

BBC [2015], "El polémico tren Atlántico-Pacífico que China quiere construir en Sudamérica", en BBC News, Sección Mundo, 18 de mayo de 2015. $<$ https://cutt.ly/Rhsx5qa>. 
[2018], "Brasil: ¿por qué voto a Bolsonaro? Prefiero un presidente homófobico o racista a uno que sea ladrón", en $B B C$ News. Sección Mundo, 8 de octubre. $<$ https://cutt.ly/UhscwCg>.

Comisión Económica para América Latina y el Caribe (Cepal) [2014], Panorama de la inserción internacional de América Latina y el Caribe. $<$ https://cutt.ly/igkZOlZ>.

[2015], La inversión extranjera directa en América Latina y el Caribe. <https://cutt.ly/7gkZA47>.

[2019], "Bases de datos y publicaciones estadísticas", en CEPALSTAT. $<$ https://cutt.ly/fgkZGop>.

Dabat Alejandro [en prensa], El agotamiento del neoliberalismo hacia un mundo multipolar e inclusivo. México, Instituto de Investigaciones Económicas-UNAM.

Dabat Alejandro, Paulo Leal y Jorge Hernández [en prensa], "Capítulo quince: La encrucijada actual de América latina en el contexto internacional", en El agotamiento del neoliberalismo hacia un mundo multipolar e inclusivo. México, Instituto de Investigaciones Económicas-UNAM.

Dussel, Enrique [2012], "Chinese FDI in Latin America: Does Ownership Matter?", en Working Group on Development and Environment in the Americas, Discussion Paper Number 33.

Expansión [2019], "PIB de Venezuela", en DatosMacro.com. <https://cutt. ly/ogkZJUR>.

[2020], "Deuda pública", en DatosMacro.com. <https://cutt.ly/lgkZZjF>.

Fajnzylber, Fernando [1983], La industrialización trunca de América Latina. México, Nueva Imagen.

Ferreira, Francisco et al. [2013], Panorámica general: La movilidad económica y el crecimiento de la clase media en América Latina. Washington, DC, Banco Mundial.

Fondo Monetario Internacional (FMI) [2016], "Primary Commodity Prices". <https://cutt.ly/XgkXrC0>.

[2019], "Datos básicos", <https://cutt.ly/NgkXuPd>.

Gambina, Julio y Mario Hernández [2017], "Por primera vez en la historia política de la Argentina gana la presidencia alguien que no es radical ni peronista", en ContrahegemoníaWeb, Sección Argentina, 6 de abril. <https://cutt.ly/DgkXaap>. 12 de marzo de 2020. 
García Linera, Álvaro [2017], ¿Qué es una revolución? De la revolución rusa de 1917 a la revolución de nuestros tiempos. Bolivia, Vicepresidencia del Estado Plurinacional de Bolivia.

Lane, Philip R. y Sergio L. Schmukler [2007], "The International Financial Integration of China and India", en World Bank, Research Working Papers 4132, febrero.

La Nación [2015], "China promete invertir US\$250.000 millones en América Latina en diez años", <https://cutt.ly/IgkXk9p>.

Leal, Paulo [2016], "Latinoamérica ante las transformaciones del Orden Monetario y Financiero Mundial", en Economía Informa, México, Facultad de Economía, UNAM, enero-febrero, núm. 396.

Maddison, Angus [2018], "Angus Maddison (1910-2016)", en Groningen Grown \& Development Centre. <https://cutt.ly/ogkXEA4.

Ordóñez, Sergio y Carlos Sánchez [2016], "Knowledge Capitalism, Globalization and Hegemony: Towards a socio-spatial approach", en Revista Procesos, Ecuador, núm. 7, pp. 4-28. <https://cutt.ly/CgkXIv0>.

Our World in Data [2019], "Productivity per hour worked". <https://cutt. ly/MgkXAWI>.

Trade Map [2020], "Trade statistics for international business development". <www.trademap.org/Index.aspx>.

Turdera, Carlos [2015], "China se lanza a la conquista de Brasil", en Dirigentes Digital. <https://cutt.ly/AgkXJKQ>.

Zanin Martins, Cristiano, Valeska Zanin Martins y Rafael Valim [2018], Lawfare: The Law as a political weapon. Brasil, Editora Contracorrente. 


\section{CAMBIOS GEOECONÓMICOS Y POLÍTICOS MUNDIALES Y SU IMPACTO EN LA CRISIS BRASILEÑA RECIENTE}

Valéria Lopes Ribeiro*

INTRODUCCIÓN

Las últimas décadas del siglo xx y las casi dos décadas del siglo xxi pueden caracterizarse como un periodo de varias transformaciones del capitalismo contemporáneo que han impuesto una serie de desafíos tanto en el campo teórico-metodológico como en la acción política de los Estados nacionales.

El final del siglo xx se distinguió por profundos cambios en los procesos de acumulación de capital, ya sea por la expansión y consolidación de los instrumentos de acumulación financiera o por los avances tecnológicos, con el incremento de los sistemas de comunicación, los nuevos regímenes de producción y el crecimiento del sector de servicios. Tales cambios impusieron nuevas formas y lugares de producción material.

Aliado de los cambios en la base material capitalista, se consolidó también en este periodo el neoliberalismo, es decir, la respuesta política a los ajustes necesarios al nuevo patrón de acumulación. Mientras que los países del Norte se especializaban en nuevos arreglos tecnológicos, en la expansión del sector de servicios y la consolidación de una elite financiera rentista, la mayoría de los países periféricos aceptaba las condiciones impuestas por las instituciones financieras internacionales que restringían la capacidad del Estado para adoptar políticas favorables al

* Doctora en Economía Política Internacional. Profesora adjunta del Programa de Posgrado en Economía Política Mundial, Universidad Federal de ABC (UFABC), Sao Paulo, Brasil. 
crecimiento mientras imponían la apertura de estas economías al capital internacional.

Sin embargo, a partir de estas transformaciones de las últimas décadas del siglo xx se establecieron, al mismo tiempo, nuevas bases sobre las cuales el capitalismo contemporáneo se presentaría en el siglo XXI.

Sin romper con la hegemonía del capital financiero y el neoliberalismo, el capitalismo contemporáneo se caracteriza por la profundización de las contradicciones vinculadas con la capacidad de expandir los niveles de crecimiento económico, lo que algunos han llamado "gran estancamiento"; la intensificación de la desigualdad de ingresos, incluso en las economías centrales; y la dificultad permanente para mejorar las condiciones de vida de las poblaciones, sobre todo en el Occidente. Además, al moverse geográficamente en busca de espacios de acumulación en las últimas décadas del siglo xx, la expansión capitalista terminó por desplazar el centro de la acumulación productiva mundial a Asia, en particular a China, y encontró un modelo de acumulación que generó resultados significativos en términos de elevación de los niveles de ingresos y producción material.

$\mathrm{Al}$ abrir su economía y hacer una transición gradual de un régimen socialista cerrado al "socialismo del siglo xxI", según la visión del Partido Comunista Chino, China logró expandir su economía por medio de la fuerte capacidad del Estado para promover el crecimiento, un camino que es muy diferente del que se utilizó en las periferias de América Latina y África. Con esto ese país se convierte en una de las economías más grandes del mundo y hace que, además de los cambios tecnológicos y la continuidad del patrón de acumulación financiera, no sea posible entender el siglo XXI sin comprender la importancia de la ascensión de su economía.

En medio de estas transformaciones que caracterizan el capitalismo del siglo XXI y representan continuidades y rupturas en relación con el capitalismo de las últimas décadas del siglo xx, la economía brasileña se insertará de una manera diferente.

Como es bien sabido, durante las décadas de los ochenta y noventa el país abandonó por completo la trayectoria desarrollista que marcaría casi todo el siglo xx. Las contradicciones de la gestión desarrollista, en especial las vinculadas con los regímenes dictatoriales que llevaron al país a seguir el camino de la modernización conservadora, alcanzaron su límite ya a fines de la década de los setenta, estableciendo un periodo de crisis 
de deuda, alta inflación y fuerte concentración de ingresos. Los cambios en la política monetaria estadounidense, como las altas tasas de interés y la ruptura con el estándar monetario de Bretton Woods, tuvieron un impacto decisivo en la profundización de la crisis brasileña al contribuir a la crisis definitiva del Estado [Tavares, 1985]. A partir de entonces, ya en la década de los ochenta y sobre todo en la de los noventa, Brasil entró en una fase de abandono completo del proyecto desarrollista, comenzó a adoptar medidas liberales, abdicó del papel del Estado como promotor del crecimiento y se abrió de forma abrupta al capitalismo internacional, con resultados desastrosos para la economía y la sociedad.

A partir del siglo xxI, a pesar del mantenimiento de los pilares que sostienen el neoliberalismo hay un cambio de dirección. Entre 2003 y 2011, con un escenario internacional más favorable, el país experimenta un periodo de crecimiento económico que se reflejó en la mejora de varios indicadores, como el ingreso y el empleo. ${ }^{1}$

Las razones que explican la reanudación del crecimiento brasileño en el siglo XXI se han debatido con amplitud, y aunque con diferentes énfasis, pueden estar relacionadas con aspectos como la coyuntura internacional de términos de intercambio favorables para las periferias, aliados a los flujos de capital internacional más baratos; la mejora del marco macroeconómico nacional que resultó de esta coyuntura, reflejada en la mejora de la balanza de pagos; las políticas para incrementar la inversión estatal (en especial la vinculada con el sector primario, como el petróleo, pero no solo); y las políticas para estimular la demanda interna mediante la expansión de los salarios reales y políticas para la transferencia de ingresos [Corrêa y Dos Santos, 2013; Pochmann, 2012; Medeiros, 2015].

Desde una perspectiva a más largo plazo, es posible decir que incluso frente a la continuidad del ciclo de acumulación financiera (una marca de la trayectoria de los países occidentales al menos desde la década de los setenta), en la primera década del siglo Xxi se estableció un marco externo más favorable al crecimiento de los países periféricos. Esto permitió la adopción de políticas económicas y sociales en ciertas naciones, lo que

${ }^{1}$ La tasa de crecimiento promedio del PIB en ese periodo fue de $4.06 \%$ por año [Banco Mundial, 2019] y el número de empleos formales creció $53.6 \%$ entre 2003 y 2010. A fines de 2010, Brasil tenía 44.07 millones de personas empleadas en puestos formales y el aumento en el empleo representó un crecimiento anual promedio de $5.51 \%$ [Guimarães, 2012]. 
condujo a la expansión de las tasas de crecimiento, aunque dentro de los límites de una política monetaria muy ortodoxa. En el caso de Brasil, la coyuntura externa favorable permitió la ampliación del mercado interno mediante el aumento del consumo y la expansión de las inversiones. Es importante señalar que a pesar del peso del consumo, la reanudación de las inversiones en algunos sectores, como las empresas estatales (Petrobras) y la infraestructura, fue un aspecto crucial del crecimiento [Corrêa y Dos Santos, 2013].

Esta mejora económica se reflejó en la elevación de los indicadores de ingresos y la formalización del trabajo, lo que junto con las políticas de expansión de la educación superior y la acción afirmativa, permitió que el crecimiento se reflejara en una importante inclusión social. Vale la pena mencionar que dicha inclusión en términos de ingresos y empleo se limitó a ampliar la base de la pirámide del mercado laboral y no se estableció en todas las capas del mismo [Pochmann, 2012].

Un punto importante de este periodo de crecimiento brasileño es que no fue un caso aislado en todo el mundo. Países de América Latina y África, además de Asia, por supuesto, también experimentaron un crecimiento económico, principalmente mediante la inserción externa más favorable. Según Nayyar [2014], el reciente crecimiento de los llamados países "en desarrollo" refleja un cambio histórico marcado por su mayor participación en el producto global en comparación con la de los países centrales e industrializados. Para el autor, desde finales del siglo xx ha habido una "convergencia", es decir, las naciones en desarrollo comienzan a incrementar su participación en la absorción de la riqueza global, en un movimiento que difiere del que prevaleció entre el comienzo del siglo XIX y $1950 .^{2}$

A pesar del crecimiento y el optimismo de la primera década del siglo XXI, a partir de 2011 el proceso de expansión del producto interno bruto (PIB)

2 Según el autor, con base en los datos de Maddison, en los precios actuales y el tipo de cambio del mercado, entre 1970 y 2010 la participación de los países en desarrollo en el PIB mundial se duplicó de 1/6 a 1/3 [Nayyar, 2014]. Resulta esencial aclarar que la llamada "convergencia" puede cuestionarse mucho porque la mejora fue extremadamente desigual dentro del grupo de los países en desarrollo. Uno de los puntos es que la mejora fue impulsada sobre todo por Asia y China en particular, y no se reflejó en cambios importantes en términos de ingreso per cápita. Otro punto es que el crecimiento fue mucho más modesto o inexistente en los países de América Latina y África, y se reflejó en una mayor participación en el comercio mundial y no en términos de industrialización, por ejemplo. 
se interrumpió en Brasil, un movimiento que también puede observarse en otros países.

La tasa de crecimiento del PIB brasileño cayó de $7.5 \%$ a $3.98 \%$ en 2011 y a $1.93 \%$ en 2012 [Banco Mundial, 2019]. De 2011 a 2017, la tasa de crecimiento promedio de Brasil fue de solo $0.4 \%$ por año. La dificultad para mantener las tasas de crecimiento se reflejó en la disminución de los indicadores sociales, lo que abrió un periodo de reversión de crecimiento y contracción del ingreso que continúa hasta nuestros días. Este momento de fuerte crisis económica se ha acompañado de una amplia crisis política que involucró una secuencia de eventos, entre ellos manifestaciones políticas urbanas con demandas de derechos y descontento colectivo con el gobierno (2013); una amplia campaña orquestada por la Policía Federal que investiga las denuncias de corrupción en empresas estatales, como Petrobras y otras empresas nacionales, la llamada operación LavaJato (2014); una elección presidencial marcada por la polarización (2014); la destitución de la presidenta Dilma Rousseff (2016); y el ascenso de un partido conservador a la presidencia de la República en 2018.

Desde 2011, Brasil experimenta un periodo de crisis económica y política cuyas interpretaciones han adquirido diferentes dimensiones, ya sea en el campo de la economía política, de los economistas ortodoxos y de los politólogos. La mayoría de estos análisis se centró en aspectos internos que habrían llevado a la crisis, como los errores de política macroeconómica del equipo económico del gobierno de la presidenta Dilma Rousseff [Carvalho, 2018], el conflicto distributivo interno generado por el periodo de crecimiento [Serrano y Summa, 2018] o aun la disputa entre las fracciones de la burguesía que habría roto una especie de pacto de clases anterior [Boito Jr., 2018].

En trabajos como el de Serrano y Summa [2018], hay una interpretación del estancamiento brasileño basada en la idea de que el crecimiento generó una especie de "revolución no deseada" en el mercado laboral entre 2004 y 2014 al aumentar el poder de negociación de los trabajadores -con salarios reales que crecían por encima de la productividad-, lo que profundizó el conflicto distributivo y la caída en el margen de beneficio de las empresas. Este movimiento generó a su vez un efecto fundamental, aunque indirecto, en la interrupción del crecimiento: a partir de estos 
cambios, la clase capitalista ejerció presión política sobre el gobierno, que luego actuó alterando la política económica que interrumpió el crecimiento. Dichas medidas se consideran el resultado de un "error de diagnóstico".

También en Carvalho [2018] es posible observar un análisis de las causas de la crisis vinculada con los intentos fallidos del gobierno de Dilma Rousseff de estimular la economía con incentivos a la industria, exenciones e intervenciones de intercambio, y de 2014 en adelante un ajuste fiscal en extremo contraproducente para la economía. Incluso teniendo en cuenta el factor externo del agotamiento del ciclo internacional de los commodities, del precio del petróleo y del mineral de hierro, según Carvalho, hay un cambio en la política económica que está equivocado en términos de diagnóstico y timing [Carvalho, 2018].

Aunque dichos análisis han sido fundamentales para comprender la crisis, en el presente trabajo tratamos de argumentar que no tienen en cuenta elementos esenciales en torno a la crisis brasileña relacionados con aspectos externos, o más específicamente, con las transformaciones del capitalismo contemporáneo y las relaciones interestatales.

Como sugiere Medeiros [2010], en la mayoría de los estudios críticos puede observarse un predominio de lo que llamó nacionalismo metodológico, que hace referencia a la nación como una unidad autosuficiente e insertada en un entorno internacional indiferenciado. Medeiros analiza cómo los diferentes enfoques del desarrollo, ya sea en su perspectiva heterodoxa $\mathrm{u}$ ortodoxa, fueron rehenes de un nacionalismo metodológico que restringió el análisis del desarrollo periférico a elementos internos relacionados con variables políticas o económicas.

Aunque los autores de diferentes vertientes, como Prebisch [2009] y también la teoría de la dependencia (de una manera diferente), intentasen superar estos límites en relación con los pioneros del desarrollo (y en relación con la propia Cepal, en el caso de la teoría de la dependencia), dependiendo del contexto histórico que permite o no un mayor alcance para el desarrollo endógeno, el análisis centrado en un nacionalismo metodológico excesivo siempre resurge. Según Medeiros [2010]:

No solo existe una relación bidireccional entre el Estado y las clases sociales y los grupos de interés en el país, que limita y condiciona las estrategias de desarrollo, sino también una relación política entre los Estados territoriales, 
que conduce, en los exámenes de las trayectorias nacionales de desarrollo, a un diálogo necesario con los temas examinados en la economía política internacional (traducción de la autora).

Para contribuir al debate sobre la reciente crisis brasileña y tratar de escapar del nacionalismo metodológico, el objetivo de este capítulo es comprender la crisis brasileña a partir de un análisis de la inserción del país en un contexto específico del capitalismo mundial, buscando relacionar de manera equilibrada y en su dimensión correcta las condiciones externas e internas que explican el periodo actual.

\section{CRISIS DEL CAPITALISMO Y CAMBIOS GEOECONÓMICOS Y POLITICOS GLOBALES}

El propósito de esta sección es discutir las transformaciones del capitalismo contemporáneo y sus contradicciones fundamentales a fin de apoyar el debate de las causas externas de la crisis brasileña.

Desde mediados de la década de los setenta en adelante, se observó en Occidente un periodo de crisis del capitalismo marcado por la reducción de las tasas de crecimiento económico en diferentes partes del mundo. Las causas de esta crisis pueden señalarse como: una fuerte caída de la tasa de beneficio, que muestra la tendencia descrita por Marx en el libro 3 de $E l$ Capital; ${ }^{3}$ la crisis del patrón de acumulación de tipo fordista y la transición a un patrón flexible [Harvey, 1992]; o incluso el resultado de una serie de acciones unilaterales llevadas a cabo por la economía estadounidense en torno a la búsqueda de mantener su hegemonía [Tavares, 1985].

Por tanto, la crisis de la década de los setenta puede verse como una expresión de la capacidad de reafirmación de la supremacía estadounidense mediante la sumisión de sus competidores y aliados a la aceptación del dólar no solo como moneda clave en las transacciones comerciales, sino

\footnotetext{
${ }^{3}$ Vale la pena recordar que la ley de la tendencia a la caída de la tasa de beneficio también debe analizarse en función de sus tendencias contrarias, es decir, los mecanismos de intensificación de la extracción de valor adoptados para compensar la tendencia a la caída de la tasa de beneficio. Por tanto, la ley en sí misma no garantiza una caída de la tasa de beneficio, dadas las tendencias contrarias. Como señala Kliman [2015], esta tendencia no conduce a un estado estable, sino a la formación de ciclos de crecimiento y declive que entonces no pueden ser la causa directa de las desaceleraciones, sino indirecta, lo que reduce la disposición de los capitalistas a invertir en la producción. Veremos más sobre esta tendencia, según Kliman, más adelante.
} 
también como moneda de referencia para el sistema financiero internacional. Esta centralización del dólar, a su vez, se combina con la expansión de la globalización financiera que surge de la desregulación de los mercados de capitales. Todo este proceso resulta (o se fortalece) de la política de diplomacia del dólar. Esto se debe a que el afianzamiento de la posición del dólar en el comercio internacional significa que los gobiernos de los países, ante la necesidad de reciclar sus reservas en dólares, sobre todo las que resultan de las exportaciones de las empresas, permiten el reciclaje privado de dichas reservas mediante el sector financiero internacional (dado que el reciclaje público implicaría apreciación cambiaria). En consecuencia, las empresas con excedentes en dólares invierten en activos financieros cada vez más diversificados. Este movimiento provoca una expansión del uso de la moneda estadounidense al extender su influencia como referencia básica no solo en las transacciones comerciales, sino también en el sistema financiero internacional.

Además de la afirmación de la hegemonía estadounidense y la creación de la hegemonía del capital financiero, según Streeck [2018], en la década de los setenta los capitalistas rompieron de modo brutal el proceso de expansión productiva iniciado en el periodo de posguerra porque este modelo fue volviéndose demasiado caro. Según el autor, una huelga de inversión kaleckiana habría sido la razón fundamental de la crisis, representada por una acción coordinada entre empresas y empresarios que lograron organizarse colectivamente en torno a las críticas del "exceso de empleo y regulación” [Streeck, 2018]. De esta manera, la crisis no estaría relacionada con la presión de los sindicatos que exigían salarios altos, sino con los capitalistas que interrumpieron de forma deliberada las inversiones. Para el autor, "en épocas de bajo crecimiento, como después del final de la fase de reconstrucción en la década de los setenta, el conflicto distributivo se acentúa, y por lo tanto se hace más difícil para la política garantizar la respectiva paz social" [Streeck, 2018: 20].

Con base en esta discusión sobre la crisis de los años setenta, Streeck afirma que la crisis financiera y fiscal observada en el capitalismo actual, principalmente desde 2008, debe entenderse con una perspectiva de continuidad donde se observa el proceso de disolución del régimen capitalista de posguerra. A partir de ese periodo, el autor identifica la existencia de 
una tensión fundamental entre la vida social y una economía dominada por los imperativos de la apreciación y multiplicación del capital. Dicha tensión se transmite con el tiempo y a veces se establece un equilibrio, aunque siempre provisional.

El principal argumento de Streeck es que la crisis que comenzó desde la década de los setenta -que pone de relieve la tensión entre trabajadores y capitalistas, lleva al empeoramiento de la contradicción que rodea la continuación de la acumulación de capital y empeora las condiciones de vida y los salarios de los trabajadores-, en lugar de resolverse solo se pospuso para contener los conflictos sociales. Este aplazamiento tuvo lugar mediante: "inflación; luego por el endeudamiento del Estado; luego, por la expansión de los mercados privados de crédito; y, finalmente, hoy día, por la compra de deudas de Estados y bancos por parte de bancos centrales" [Streeck, 2018: 28]. Estos intentos de posponer la crisis están vinculados con los procesos que llamamos financiarización [Chesnais, 1996]. Esta relación entre los instrumentos para posponer la crisis y el ámbito financiero se transforma de modo progresivo en un nuevo elemento de crisis.

Por lo tanto, un tipo de aplazamiento de la crisis puede ser la raíz de la explicación de la de 2008, es decir, la creación de mecanismos de endeudamiento que generen efectos de especulación financiera y que en un momento determinado exploten en forma de burbujas, como en el caso del mercado inmobiliario de América del Norte.

La contradicción fundamental en la caída de la rentabilidad observada desde la década de los setenta no se resuelve, sino que la acción del Estado y su relación con el capital la evitan. Esto es lo que dice Choonara [2018]; según este autor, a diferencia de las crisis anteriores del capitalismo, que promovieron una violenta aniquilación del capital para reanudar el punto de expansión, la actual concentración y centralización del capital y los riesgos de una crisis llevan a los Estados a comenzar a "ahorrar" capital por medio de préstamos y financiación de grandes bancos, asegurando que no haya "limpieza" de unidades no rentables. Con esto hay menos contracciones repentinas, pero al mismo tiempo observamos lo que se llama gran moderación, es decir, un crecimiento más lento, además de nuevas formas de mantener la rentabilidad mediante la financiarización y la búsqueda de nuevos espacios de acumulación. 
Para Carcanholo [2011], la crisis actual del capitalismo contemporáneo también sería un desarrollo dialéctico de las contradicciones que surgieron en esta fase histórica. Para el autor, la lógica del proceso de acumulación del capitalismo contemporáneo es una consecuencia de las formas en que emergió de su última crisis estructural a fines de la década de los sesenta, que resultó de la sobreproducción de capital (sobreacumulación) y la reducción de la tasa de beneficio, una consecuencia del valor-capital que se ha producido en exceso [Carcanholo, 2011].

En este sentido, el capitalismo contemporáneo se construyó históricamente a partir de una respuesta a esa crisis. Así,

las posibilidades, los límites, la lógica, solo son inteligibles considerando: (i) el proceso de reestructuración productiva que, entre otros aspectos, promovió la reducción de los tiempos de rotación de capital y, por lo tanto, aumentó la tasa anual o periódica de plusvalía; en consecuencia, la tasa de beneficio anual o periódica (Marx, 1988, vol. III, sección II); (ii) las reformas estructurales en los mercados laborales que llevaron a un aumento en la tasa de plusvalía, tanto en los países centrales de la acumulación de capital mundial como en los países periféricos; (iii) el aumento en la porción del valor producido por el capitalismo periférico para la apropiación/acumulación en los países centrales, ya sea por medio de mecanismos vinculados a la competencia dentro y entre sectores que producen bienes, o incluso mediante formas de remitir recursos como un servicio de deuda externa y transferencia de beneficios y dividendos, debido a la inversión extranjera directa; (iv) la expansión de los mercados, dada la intensificación de los procesos de apertura comercial y liberalización financiera, que están en la raíz del proceso dado en (iii); (v) el cambio en la lógica de la apropiación/acumulación de capital, de acuerdo con las determinaciones dadas por lo que Marx llamó capital ficticio [Carcanholo, 2011].

Según este mismo autor, cada uno de estos elementos puede verse como una respuesta del capital a la crisis estructural. Una de estas respuestas analizadas por él con mayor profundidad es el cambio en la lógica de la apropiación/acumulación de capital, que Marx llamó “capital ficticio", y que representa una promesa de apropiación de valor por medio de instrumentos financieros que en ciertos momentos no se cumple. Esto se debe a que, en el capitalismo contemporáneo, una masa creciente de capital se especializa en la mera apropiación del valor, un valor que no se produce a la misma magnitud. Prevalece la disfuncionalidad del capital 
ficticio para el modo de producción capitalista. Esto sería, según Carcanholo [2011], la dialéctica del capital ficticio, en su funcionalidad y disfuncionalidad para el capital total.

Así, la nueva crisis estructural del capital se refiere a esta disfuncionalidad del capital ficticio, ya que la apropiación del valor no es compatible con la producción de valor. Este elemento es fundamental en la comprensión del elemento de crisis presente en Marx relacionado con la contradicción fundamental entre apropiación y acumulación.

Bajo esta perspectiva de la reciente crisis, que parte de una interpretación estructural, podríamos decir que la crisis actual del capitalismo (la crisis del mercado inmobiliario de América del Norte y la crisis de 2008) no solo está relacionada con la expansión del capital ficticio en sí, o con el proceso de financiarización, sino con la producción y generación de valor (o no generación de valor) en lo que podemos llamar la economía real.

Como muestra Choonara [2009], dentro del marxismo hubo varias interpretaciones para la crisis de 2008 que aclararon las contradicciones del capitalismo contemporáneo. Algunos autores trataron de interpretar la crisis a partir de la idea de que refleja un tipo de autonomía de las finanzas en relación con la economía real, como Costas Lapavitsas, según el cual "las finanzas se han vuelto relativamente autónomas de las empresas productivas y han crecido rápidamente" [Lapavitsas, 2008 apud Choonara, 2009]. ${ }^{4}$

Por otro lado, autores como David McNally argumentaron que la crisis no puede entenderse solo mirando la financiarización, y que sería "incapaz de explicar por qué esta crisis no se ha restringido a los mercados financieros, o investigar su interconexión con los problemas de sobreacumulación global” [McNally, 2008 apud Choonara, 2009]. ${ }^{5}$

A partir de las perspectivas de interpretación de la crisis que apuntan a una fuerte relación entre las finanzas y la producción, entendemos que el capitalismo contemporáneo revela, sobre todo en los países centrales, una contradicción que hace que la disfuncionalidad del capital ficticio sea cada vez más aguda para la acumulación de capital. O sea,

${ }^{4}$ Traducción de la autora.

${ }^{5}$ Traducción de la autora. 
Cuando una masa creciente de capital se especializa en la mera apropiación del valor, y este valor no se produce a la misma magnitud, prevalece la disfuncionalidad del capital ficticio para el modo de producción capitalista. [...] Mientras prevaleció la funcionalidad, junto con los otros elementos de la respuesta del capitalismo a su crisis, el capitalismo mostró algunas dinámicas de acumulación. La nueva crisis estructural del capitalismo, a principios del siglo XXI, se explica precisamente por el predominio de la disfuncionalidad de la lógica del capital ficticio para la acumulación de capital total [Carcanholo, 2011].

Esta nueva crisis estructural del capital reflejaría, además de un desarrollo dialéctico basado en la teoría marxista de la crisis, el resultado de un momento histórico específico marcado por un amplio desapego entre la apropiación del valor y la generación de valor. Esto se refiere, en nuestra opinión, a un cambio profundo en la división internacional del trabajo determinado por la carrera del capital hacia lugares de producción fuera de las ubicaciones tradicionales de las economías centrales, en regiones de Asia principalmente, que promueve lo que Nayyar llama "convergencia", o al menos una expansión de la generación de valor de los países del Sur, en especial de Asia y sobre todo de China.

Como ya se señaló, la respuesta del capitalismo para superar (o posponer) la crisis de la década de los setenta también fue, junto con la financiarización, un cambio profundo en la producción de valor fuera de los centros tradicionales. A lo largo de los años ochenta y noventa, este cambio fue funcional al proceso de acumulación en el centro, ya que representaba principalmente la posibilidad de ampliar la apropiación del valor, evitando en parte la caída de la rentabilidad, con la expansión de la transferencia de utilidades y el uso de mano de obra barata para la producción. Sin embargo, en el siglo xxi existe una disfuncionalidad de este proceso para la acumulación de capital en el centro, ya que algunos países como China, por ejemplo, aumentan su participación en la generación y apropiación de valor mediante un proceso de acumulación de capital marcada no solo por la presencia de empresas extranjeras que envían beneficios, sino también, y cada vez más, por empresas nacionales que, a partir de un proceso de acumulación conducido por el Estado, promovieron una expansión económica sin precedentes, con ganancias de productividad y expansión del ingreso interno. 
Por tanto, si en un momento dado el desplazamiento productivo de capital hacia nuevas áreas de valorización fue funcional para superar la crisis de acumulación, hoy este movimiento ya no lo es porque, al expandir la generación y apropiación de valor en áreas periféricas, notablemente solo en Asia y China, las contradicciones en el centro del capitalismo vinculadas con la disfuncionalidad del capital ficticio se intensificaron.

En las economías centrales existe una creciente contradicción entre la apropiación del valor y la generación de valor, dada la dificultad de expandir la acumulación productiva. Este tema puede entenderse dentro del debate actual sobre el llamado "estancamiento secular", un término presentado por Summers [2015] que explicaría la dificultad de las economías centrales para reanudar las tasas de crecimiento después de la crisis de 2008.

Como señala Kliman [2015], este "estancamiento secular" reflejaría la dificultad de expansión en el centro y la debilidad a largo plazo que se observa en las economías centrales. Según este autor, la tasa de beneficio de las corporaciones estadounidenses tendió a caer en casi todo el periodo posterior a la Segunda Guerra Mundial. Para Kliman, esta caída de la rentabilidad condujo a una caída de la tasa de acumulación de capital (tasa de crecimiento de la inversión productiva). Esta disminución, a su vez, ha llevado, y lleva, a una caída de las tasas de crecimiento económico.

Un punto que quizás rara vez se menciona en este debate es el hecho de que al mismo tiempo que se observa la caída de la rentabilidad de las corporaciones estadounidenses y la dificultad para expandir la esfera productiva, en países como China hay una fuerte expansión material a lo largo de las últimas décadas. Este es el resultado de una alianza estatal entre la industrialización y la regulación financiera que sometió a esta última a las pautas para la expansión del capital productivo, ya sea mediante el mantenimiento de los bancos públicos o con el control, e incluso el cierre del sistema financiero, al menos durante la mayor parte del periodo de crecimiento.

Según Choonara [2018], China sería el ejemplo de que a pesar de las tendencias de posponer la crisis característica del capitalismo contemporáneo, no hay parálisis en el sistema, sino un dinamismo que promueve una reorganización competitiva. En respuesta a la recesión en los mercados mundiales en 2008, China ha expandido fuertemente el crédito para 
mantener la inversión, con un aumento de la deuda total de $160 \%$ del PIB en 2008 a $260 \%$ en 2017, acompañado de una expansión de las instituciones financieras, con un sistema bancario que ya es el más grande del mundo.

INTENSIFICACIÓN DE LA COMPETENCIA INTERESTATAL-IMPERIALISMO

Como afirma Foster,

It will be argued here that the globalization of production (and finance) which emerged along with neoliberalism out of the economic stagnation of the mid-1970s and then accelerated with the demise of Soviet-type societies and China's reintegration into the capitalist world system - has generated a more generalized monopoly capitalism, theorized by thinkers such as Magdoff, Baran, Sweezy, and Amin. This ushered in what can be called late imperialism. Late imperialism refers to the present period of monopolyfinance capital and stagnation, declining U.S. hegemony and rising world conflict, accompanied by growing threats to the ecological bases of civilization and life itself. It stands at its core for the extreme, hierarchical relations governing the capitalist world economy in the twenty-first century, which is increasingly dominated by mega-multinational corporations and a handful of states at the center of the world system [Foster, 2019].

Según se señala en la cita previa, la crisis del capitalismo contemporáneo que presentamos en la sección anterior también está marcada por la intensificación de la competencia entre los Estados y el avance del imperialismo. De hecho, la crisis del capital y las relaciones interestatales no pueden entenderse por separado, ya que ambas caracterizan las contradicciones de un momento histórico específico del capitalismo contemporáneo.

Así, la intensificación de la competencia interestatal es resultado de un momento específico del capitalismo contemporáneo determinado por la profundización de la crisis y su postergación eterna.

Más de diez años después de la crisis de 2008, la economía mundial aún no ha logrado recuperar grandes niveles de crecimiento. Incluso en las economías avanzadas existe un escenario de bajo crecimiento acompañado de un aumento de las desigualdades sociales y económicas, además 
de la continua adopción de medidas de austeridad como la única respuesta al creciente déficit gubernamental [UNCTAD, 2017].

A pesar de los recortes en el gasto público, el periodo posterior a la crisis se distinguió por algunos movimientos como el rescate de grandes bancos por parte de bancos centrales, flexibilización cuantitativa y la adopción de tasas de interés bajas o incluso negativas en las economías centrales. Aun cuando mantuvieron vivo el capitalismo en el periodo posterior a la crisis, estas medidas destinadas a reanudar la producción no tuvieron efecto en los países centrales de Occidente. La baja rentabilidad prevaleciente, o "gran moderación", todavía es una característica fundamental del capitalismo contemporáneo, lo que refleja la dificultad para reanudar las inversiones. En lugar de aumentar la producción, el dinero se está transformando en inversión financiera [Choonara, 2018]. Como se vio antes, esta dificultad para expandirse a grandes niveles se debe a la intensificación de contradicciones y cambios estructurales en el capitalismo contemporáneo.

En este contexto, la crisis establece, cada vez más dentro de las propias economías avanzadas, la dificultad de incrementar los niveles de empleo, los salarios y el ingreso a los más pobres. Una de las consecuencias fundamentales es precisamente el aumento de la concentración de ingreso en el centro del capitalismo y la dificultad de expandir los ingresos en las capas medias de la población.

El análisis de Milanovic [2016] sobre la desigualdad dentro de los países enfatiza las consecuencias de la globalización para las economías centrales, como la estadounidense, y para las economías emergentes, como la china. Según el autor, en los últimos años el ingreso de las clases medias ha disminuido no solo en Estados Unidos, sino también en otras economías centrales, como la inglesa. Ocurrió una fuerte concentración de riqueza en la parte superior de estas economías, mientras que el ingreso promedio se mantuvo estancado, lo que formó un grupo que según el autor sería el de los "perdedores de la globalización".

La concentración de la riqueza es sin duda una de las consecuencias de la crisis del capitalismo contemporáneo. Y, contrariamente a lo que cabría esperar, cuanto más empeora la crisis en los países centrales, mayor es la dificultad de proponer cambios profundos para este escenario. Por tanto, podríamos pensar en el aumento de la austeridad y la dificultad de 
los Estados para llevar a cabo la política fiscal; el aumento de la tasa de explotación laboral en forma de salarios reducidos, retirada de derechos e inseguridad; y otros reflejos sobre el Estado, como la destrucción del presupuesto estatal para abrir espacios para la acumulación privada: fondos de pensiones, privatización, etcétera.

Por lo tanto, los intentos de responder a las contradicciones en el proceso de acumulación de capital se manifiestan mediante la lucha de clases y la articulación de la burguesía en torno a satisfacer sus intereses a expensas del trabajo.

Sin embargo, además de las contradicciones internas observadas en los países centrales, la crisis del capitalismo contemporáneo también se observa en la intensificación de la competencia interestatal y en el fortalecimiento del nacionalismo y de las estrategias de control sobre otros Estados.

Como señaló Foster [2019] al comienzo de esta sección, la globalización de la producción, que surgió junto con el neoliberalismo y el estancamiento económico a mediados de la década de los setenta, generó un capitalismo monopolista más generalizado, teorizado por pensadores como Magdoff, Baran, Sweezy y Amin, que inició lo que puede llamarse imperialismo tardío. Imperialismo tardío se refiere al periodo actual de capital financiero-monopolista, estancamiento y creciente conflicto mundial. Está en el centro de las relaciones que gobiernan la economía mundial capitalista en el siglo xxI, cada vez más dominada por empresas multinacionales y Estados en el centro del sistema mundial.

Por tanto, las contradicciones del capitalismo contemporáneo, cuando se expresan en una dificultad creciente para superar la caída de la rentabilidad y la gran moderación, también se manifiestan en una reanudación de la competencia interestatal que coloca a los países periféricos en una posición central, como representantes de áreas y espacios para la acumulación de capital.

A diferencia de periodos anteriores, una de las características de esta competencia actual es justo la entrada de nuevos Estados (semiperiféricos), como China, que han avanzado en términos de acumulación productiva (en un escenario de desplazamiento de producción) y ahora comienzan a disputar espacios de acumulación de capital fuera de sus propias fronteras al entrar en la competencia con los Estados occidentales tradicionales. 
La expansión del capital chino en todo el mundo es uno de los fenómenos más importantes del siglo Xxi. Durante más de treinta años China ha recibido una cantidad cada vez mayor de inversión extranjera: entre 1979 y 2010 absorbió más de mil millones de dólares en investigación extranjera directa (IED). Pero después de la consolidación del crecimiento económico, la situación se invierte y los chinos avanzan expandiendo sus propias inversiones extranjeras: las empresas del país se extendieron a diferentes partes del mundo respaldadas por un volumen sustancial de reservas acumuladas.

Una de las expresiones de este avance chino es el reciente proyecto de la Belt and Road Initiative. Anunciado en 2013, el programa prevé una serie de inversiones gigantescas en proyectos de infraestructura en Asia Central, Europa, África, Asia Oriental y otros. Con contribuciones de capital de más de un trillón de dólares estadounidenses y varias instituciones financieras chinas participantes, el proyecto ya está en marcha con subproyectos en gran progreso como puertos, ferrocarriles, plantas hidroeléctricas, carreteras y puentes. Todos estos proyectos representan un esfuerzo por parte del gobierno chino, empresas y gobiernos de diferentes países para acceder a financiamiento para la ejecución de grandes obras.

Todavía es difícil ubicar la exportación de capital chino dentro del marco conceptual marxista en relación con el concepto de imperialismo, ya que el término abarca varias dimensiones además de la económica.

Sin embargo, el avance del capital chino se alía a una coyuntura caracterizada por la continua expansión del capital financiero en todo el mundo, por el avance de las exportaciones de capital a regiones periféricas, como el continente africano, en busca de compra de tierras, explotación de recursos naturales e incluso ataques militares en regiones como Siria, Libia y Venezuela.

Esta situación ha despertado el interés académico y general en el tema del imperialismo, que había desaparecido del debate en la década de los setenta, cubierto por la tesis liberal de la globalización.

En contraste con la famosa tesis presentada por Hardt y Negri de que tanto el imperialismo como la importancia de los Estados nacionales habían perdido relevancia, varios autores han estado desconstruyendo esta idea mediante sus propias interpretaciones del imperialismo actual [Patnaik, 1990, apud Amaral, 2012]. 
Panitch y Gindin [2006], por ejemplo, presentan la idea de que aunque las tesis clásicas del imperialismo no sirvan para explicar el periodo reciente, es posible argumentar a favor de la existencia de un imperio informal estadounidense que tiene la habilidad de incorporar rivales e integrar todas las regiones dentro de un sistema de coordinación efectivo bajo su autoridad. Este no es el fin de la capacidad de acción de los Estados, sino una forma de dominar por medio de los mismos, hecha posible por la amplia capacidad imperial estadounidense [Panitch y Guindin, 2006].

Por otro lado, para Callinicos [2005] la etapa actual del imperialismo, después de la Guerra Fría, se caracterizaría por un mundo política y económicamente multipolar, con las teorías clásicas del imperialismo recuperando su capacidad de explicación y con una competencia mucho más feroz. Después de 1989 aparecieron las potencias subimperialistas y nuevos centros de acumulación de capital, aunque con el apoyo del centro, para intensificar la competencia. Para Callinicos, Estados Unidos, aunque aún sea hegemónico, enfrenta una fuerte competencia en la esfera económica, por lo que el potencial desestabilizador y las rivalidades entre estos Estados no pueden subestimarse.

Panitch y Guindin [2013] hacen un análisis esencial de la forma de acción de lo que llaman imperio informal estadounidense y destacan la fuerza con la que Estados Unidos sigue siendo hegemónico mediante la búsqueda de gobernar por medio de los Estados. Sin embargo, los autores parecen dar poca importancia a la ascensión de los países emergentes en la intensificación de la disputa interestatal, sobre todo luego de la crisis de 2008.

Como se dijo antes, después de la crisis, China, el país que parece subvertir la lógica global de la gran moderación, sintió los efectos de la recesión económica mundial, en especial por la caída de la demanda externa de los países industrializados, como los de Europa y Estados Unidos [Ocampo y Erten, 2013].

No obstante, a pesar de la discusión acerca del aumento del déficit y las posibles burbujas en la economía china, su crecimiento es cada vez más sostenido gracias a la expansión de las inversiones combinada con la expansión del mercado interno. El país ha intentado gradualmente separar su propio crecimiento del crecimiento de Estados Unidos con la expansión del PIB por medio del consumo interno, la diversificación del uso de reservas 
en dólares, además de los títulos estadounidenses, y una fuerte expansión de las inversiones extranjeras.

El tema fundamental a este respecto es la comprensión de cómo la ascensión de nuevos actores, como China, influye en el escenario del imperialismo global. En este punto es esencial comprender la respuesta estadounidense a este escenario global, en particular con respecto a las contradicciones de su capitalismo, fundado en la crisis estructural del capital y la disfuncionalidad del capital ficticio, que genera cada vez más dificultades para aumentar el ingreso interno de las capas medias.

La actitud estadounidense actual de romper con la narrativa liberal que había asumido desde la década de los noventa, basada en el discurso de que cualquier expansión estadounidense resultaría en una expansión de la prosperidad global, es innegable. Esta ruptura refleja, según Fiori [2019], la nueva doctrina de la seguridad nacional en Estados Unidos, que expresa claramente la posición de defender los intereses nacionales utilizando los instrumentos más diversos: guerra convencional, guerra híbrida y el papel de la moneda en el rompimiento de economías mediante la imposición de sanciones, como lo ha estado haciendo en el caso de Irán.

INTERPRETACIÓN DE LA CRISIS BRASILEÑA

¿Cómo entender la crisis brasileña a partir de todas estas transformaciones del capitalismo contemporáneo, vinculadas, como dijimos, con un momento histórico marcado por el empeoramiento de la disfuncionalidad del capital ficticio mediante la desconexión entre la apropiación y la generación de valor y por la intensificación de las disputas interestatales? ¿Cuáles son los impactos de esta configuración para Brasil?

Estas preguntas no son fáciles de responder. Aquí tenemos la intención, si no de responderlas, al menos de señalar algunos nexos lógicos que pueden ampliar la comprensión.

La primera pregunta a entender es que aunque el periodo de expansión brasileña entre 2004 y 2010 sea reflejo de la adopción de políticas sociales y de inversión, también debe ser visto dentro del escenario más extenso de la dificultad de las economías occidentales para ampliar las inversiones productivas e industriales. Además, es fundamental recordar la importancia 
del escenario externo de aumento de los precios de los productos primarios y los abundantes flujos de capital que proporcionaron crecimiento sin grandes desequilibrios externos.

Este perfil del crecimiento brasileño y la situación de amplia mejora en el sector externo, incluso después de la crisis, plantea un desafío para la interpretación de las causas externas de la crisis y del clásico debate estructuralista sobre las discontinuidades históricas de la industrialización y los límites del desarrollo periférico. Esto se debe a que la buena situación externa, muy diferente de la que marcó las economías periféricas en la década de los noventa, por ejemplo, refuerza la lectura de la crisis brasileña basada solo en factores internos, y en especial vinculada con la política económica adoptada por el gobierno de Dilma Rousseff.

En este sentido, el desafío es precisamente mostrar que a pesar de la mejora de la posición brasileña en el sector externo -reflejada en la amplia formación de reservas, por ejemplo-, los aspectos más estructurales de la crisis internacional desempeñaron un papel importante en la interrupción del crecimiento brasileño. Como queremos mostrar, este impacto de la crisis externa en la economía brasileña se produjo no solo por medio del comercio, sino también de las finanzas, además del efecto de dimensiones políticas e interestatales relacionadas con la posición estratégica de Brasil en el contexto de disputas entre las grandes potencias.

Ya es importante afirmar que incluso creciendo en la década de 2000 sobre la base de la expansión del consumo, como señala Paulani [2009], en las últimas décadas la economía brasileña estuvo firmemente integrada al circuito de expansión del régimen de acumulación con dominio de la valorización financiera [Chesnais, 1996, 1997 apud Paulani, 2009]. Nuestro crecimiento en la primera década del siglo xxI, por tanto, debe verse desde esta perspectiva. Según la autora,

el consumo no tiene el dinamismo para impulsar la economía, como lo hace la inversión, y el consumo impulsado por el crédito no es sostenible a largo plazo, como muestra el espejo estadunidense [...] este arreglo típico de un proceso de acumulación en el que las finanzas están a cargo, fomentando el crecimiento de la riqueza ficticia [Paulani, 2009: 35].

En este contexto de crecimiento, la economía crece en función de la extensión de las exportaciones de productos primarios, en el escenario 
externo de aumento de precios mediante políticas internas de expansión salarial, inversiones y principalmente del sector servicios. Los salarios crecen más que la productividad, ya que los sectores productivos, como el industrial, se mantienen con un bajo crecimiento. El escenario externo de la demanda de exportaciones, el crecimiento de las importaciones junto con el dólar bajo y la atracción de capital impidieron que el aumento de los salarios provocara presiones inflacionarias y permitieron el crecimiento con incremento de los salarios [Carvalho, 2018].

En este sentido, el crecimiento brasileño siempre ha tenido una base frágil, no en el sentido de no reflejarse en una mejora en las condiciones de vida, sino porque imposibilita cualquier cambio estructural. Una de las contradicciones es exactamente que al ayudar a contener la inflación y permitir el acceso barato a productos importados, el acuerdo brasileño priorizó el dinamismo interno por medio del consumo y el sector de servicios, debilitando la expansión de la industria, aún más en un escenario de tipo de cambio valorado.

En vista de la crisis de 2008, estas contradicciones aparecen de manera explícita a pesar de las medidas anticíclicas adoptadas en el gobierno de Lula en el periodo posterior a la crisis, que tienen algún efecto para evitar la disminución del crecimiento.

Sin embargo, ya en el gobierno de Dilma Rousseff, la adopción de la llamada nueva matriz económica en 2011, un intento de transformar este modelo de crecimiento, es absolutamente ineficaz en el contexto de la nueva situación internacional.

El comienzo de la administración de Dilma Rousseff estuvo marcado por una política macroeconómica más restrictiva, con la caída de la inversión pública y el gasto de las empresas estatales. La intención sería una política fiscal más estricta que proporcionaría la base para una política monetaria más "flexible", reduciendo las tasas de interés y mejorando el tipo de cambio, de modo que se reanudaran el sector exportador y también la industria. Sin embargo, el escenario externo estaba bastante deteriorado, lo que hizo que las medidas de interrupción del crédito, la caída de la inversión y la contingencia se manifestaran en un decremento del crecimiento.

El Banco Central comenzó a reducir la tasa Selic en agosto de 2011 y continuó este movimiento hasta octubre de 2012, cuando Brasil alcanzó una tasa de interés básica de $7.25 \%$, pero el crecimiento no se reanudó. 
En otras palabras, los intentos de disminuir las tasas de interés, el ajuste fiscal más las exenciones de impuestos, en lugar de promover la reanudación del crecimiento mediante la expansión de la inversión privada, no muestran el resultado esperado. Por el contrario, las medidas agravaron la crisis, abriendo el periodo de caída de las tasas de crecimiento observado hasta hoy.

A partir de 2015, en el segundo gobierno, las medidas de ajuste son aún más fuertes, incluida una reducción del gasto de inversión y aumentos de las tasas de impuestos y de la tasa de interés a $14.5 \%$, lo que creó un escenario de fuerte recesión. A partir de entonces la economía brasileña entró en un periodo sumamente recesivo, abriendo espacio para articulaciones políticas que culminaron con la destitución de la presidenta en 2016. Desde ese momento el país no ha podido reasumir los niveles de crecimiento económico y mejora de las condiciones de ingresos de la población.

De acuerdo con la propuesta para comprender este movimiento con base en causas externas vinculadas con las transformaciones del capitalismo internacional, señalaremos la existencia de dos canales de explicación: a) los impactos mediante de medios financieros y la respuesta de los países centrales a la crisis, y b) el cambio del eje de apropiación del valor de Occidente a Asia, principalmente a China.

\section{Impactos mediante medios financieros y la respuesta de los países centrales a la crisis}

Aunque las medidas adoptadas por el gobierno de Dilma Rousseff contribuyeron a profundizar la recesión, las transformaciones de la economía internacional posterior a la crisis de 2008 relacionadas con la intensificación de las contradicciones del capitalismo mundial alteraron profundamente el escenario que hizo posible el breve crecimiento brasileño. En este sentido sería muy poco probable que la recesión se evitara, ya que reflejaba no solo el modelo en su conjunto sino también la forma frágil en la que se sostenía.

Como se describió, la crisis de 2008 puede verse como una manifestación de la crisis capitalista, marcada por la dificultad de expandir la 
tasa de rentabilidad y por el aplazamiento recurrente de la resolución de la crisis mediante la exacerbación de los propios instrumentos de financiarización.

El periodo posterior a la crisis de 2008 está determinado por una respuesta de las naciones centrales a la crisis con un amplio programa de rescate de los bancos, junto con una política fiscal austera que ha fallado (y aún no puede) para estimular la expansión de la demanda agregada con inversiones y empleo.

Esta realidad de la respuesta de los países centrales a la crisis, más el bajo dinamismo de estas mismas economías, desplazó de forma considerable el escenario externo para las economías periféricas.

Como afirma Akyuz [2013], el crecimiento de los países en desarrollo antes de la crisis de 2008 llevó a muchos a defender la tesis de que habría un desacoplamiento (decoupling) entre el crecimiento del Sur y el del Norte. La idea era que las naciones en desarrollo, aunque dependientes de las centrales, habrían encontrado formas de crecer sin importar las posiciones cíclicas de los países avanzados, aplicando políticas internas y neutralizando las conmociones externas. Según Akyuz, esta tesis no tuvo en cuenta el hecho de que el crecimiento en el Sur siempre se ha relacionado con el ciclo del Norte, no solo mediante las exportaciones primarias sino también en el boom de los flujos de capital, el rápido crecimiento de la liquidez internacional y las bajas tasas de interés históricas [Akyuz, 2013: 18].

Después del colapso de Lehman Brothers en septiembre de 2008, el entorno económico mundial se ha deteriorado de diversas maneras que antes sostuvieron el crecimiento en el mundo en desarrollo, lo que resultó en una grave crisis en varias naciones.

A pesar de este impacto, ocurrió una rápida recuperación desde 2009, gracias a una respuesta política anticíclica en las economías en desarrollo, posible incluso por las mejores posiciones fiscales y de balanza de pagos durante la expansión anterior. Además, la respuesta de la política monetaria de Estados Unidos y Europa a la crisis también ayudó a la recuperación al dirigir los flujos de capital hacia ellos después de un alto repentino y una fuerte reversión provocada por el colapso de Lehman [Akyuz, 2013].

Pero esta aparente recuperación no pudo sostenerse. A mediados de 2009, el aumento de los flujos de capital y los precios de los commodities 
llegó a su fin y las exportaciones a los países centrales se redujeron de modo considerable. Además, los efectos puntuales de las políticas anticíclicas en las naciones en desarrollo han comenzado a desaparecer y el espacio político para nuevas acciones expansionistas ha disminuido de forma notable. Con la excepción de China, que respondió con rapidez a la crisis con una mayor inversión, las restricciones fiscales y los problemas de balanza de pagos comenzaron a aparecer en la mayoría de los principales países en desarrollo como resultado del cambio al crecimiento liderado por la demanda interna, lo que llevó al aprieto fiscal.

La crisis de 2008, aunque no genera una crisis cambiaria, ocasiona un cambio importante en el escenario anterior. Desde 2011 y 2012, se produce una caída en la cuenta de capital y financiera, lo que refleja una transformación en el escenario anterior de crecimiento de los flujos de capital. Además de la fuerte crisis de la balanza comercial, desde 2008 ha habido déficits significativos que comprometen el resultado de la balanza de pagos. Este movimiento condujo a una inestabilidad importante en el tipo de cambio brasileño, que se vuelve inestable y tiende a apreciarse. Este escenario compromete aún más la situación de la balanza comercial, ya en crisis. Como explica Akyuz,

The financial crisis in AEs has led to considerable instability of private capital inflows, yield spreads, equity prices and exchange rates in DCs. The surge in capital inflows to DCs that had begun in the early years of the 2000s with sharp cuts in interest rates and rapid expansion of liquidity in AEs continued unabated in the early months of the crisis. However, the flight to safety triggered by the Lehman collapse led to a sudden stop and reversal, resulting in strong downward pressures on exchange rates and asset prices.16 Closer and deeper integration with major financial centres and rapidly growing gross asset and liabilities positions of DCs with the AEs intensified the transmission of financial stress to asset, banking and currency markets. The crisis also led to a contraction of credit in DCs due to cut-back in international bank lending and local lending by foreign banks' affiliates in DCs as well as declines in inter-bank cross-border lending for funding by domestic banks [Akyuz, 2013: 18].

Cada país responderá de manera diferente a este nuevo escenario con base en su apertura y exposición a la economía internacional; Brasil quizás 
no fue el más afectado. Sin embargo, aunque no causó una crisis cambiaria importante, la caída de los flujos internacionales de capital junto con la crisis en la balanza comercial cambió profundamente el escenario para los intentos de adoptar políticas internas de fomento del crecimiento económico. El tipo de cambio que tiende a apreciarse empeoró aún más la situación de la balanza comercial al modificar el ímpetu de la inversión a las importaciones y comprometer aún más el escenario de la balanza de pagos, que empeora en gran medida en 2013 y 2014.

El cambio en el escenario externo muestra cuán estrechamente vinculada estaba la economía brasileña con el crecimiento de los países centrales (más los emergentes, como China) en lo que respecta tanto a la balanza comercial como al escenario de fuerte expansión de los flujos de capital.

En este marco general, la respuesta de las economías centrales para resolver la crisis en sus propias economías no ha llevado a la recuperación del crecimiento y al mantenimiento de la demanda de productos importados de la periferia, además de promover nuevas restricciones al desarrollo periférico mediante la posible expansión de la producción industrial nacional y las exportaciones industriales. Esto se debe a que el intento de devaluar la moneda brasileña para reanudar las inversiones y acrecentar las exportaciones con mayor valor agregado fue bloqueado por la inestabilidad cambiaria generada desde 2008 para varios países emergentes.

En este escenario sería posible afirmar que las respuestas de las naciones a la crisis de 2008, al no recuperar la demanda agregada o recomponer las importaciones y seguir presionando por la desaceleración de otros países, como China, tuvieron un efecto extremadamente negativo en las economías periféricas como la brasileña.

El escenario externo posterior a la crisis, incluso con un retraso en términos de impacto en la caída del crecimiento, terminó exacerbando las contradicciones del frágil modelo brasileño.

Aunado a estas respuestas económicas debe considerarse el hecho de que la no resolución de la crisis en los países centrales acentúa la dificultad para incrementar la demanda y los ingresos de las capas medias de la población en las naciones centrales, como ya se mencionó. Por esta razón surge de nuevo la pregunta acerca de cómo avanzan los Estados nacionales en los países periféricos en busca de espacios de acumulación tanto en recursos naturales y energéticos como en mercados de consumo. 


\section{Cambio del eje de apropiación del valor de Occidente a Asia, principalmente a China}

Como se discutió antes, si el desplazamiento productivo de capital hacia nuevas áreas de valorización fue funcional para superar la crisis de acumulación en los años ochenta y noventa, este movimiento ya no lo es porque al expandir la generación y apropiación del valor en Asia, en especial en China, promovió no solo la intensificación de las contradicciones en el centro del capitalismo y la disfuncionalidad del capital ficticio, sino también la dificultad de otras economías periféricas para acrecentar su capacidad de generar y apropiarse del valor.

Este cambio histórico altera profundamente la cuestión del desarrollo periférico con el cambio estructural en los términos de Prebisch [2009]. Esto se debe a que el surgimiento de Asia y China como grandes centros comerciales mundiales contrarresta la centralidad de América del Norte como el principal centro cíclico. En el caso de China, hay una economía que acrecienta cada vez más su participación mundial en la producción industrial, exportando a todo el mundo a precios baratos, y por tanto, imponiendo diversos desafíos para la expansión de la industria y los ingresos en los países periféricos. No solo se ejerce presión sobre la primarización de las economías con el objetivo de satisfacer la demanda china de recursos primarios, sino también se presiona para competir con productos manufacturados con alta productividad y que llegan al mercado a precios muy bajos.

Esta nueva realidad histórica del capitalismo cambia de modo radical la idea de desarrollo. El crecimiento brasileño, si bien reflejaba políticas internas fundamentales, habría sido imposible sin la coyuntura del aumento de los precios de los productos primarios y la caída de los precios de los productos manufacturados baratos de Asia. La posibilidad misma de expandir el consumo estaba relacionada con este cambio estructural en la economía global, no solo en Brasil sino en varios países periféricos.

Como consecuencia, en cierto sentido la crisis brasileña misma se estaba posponiendo dada la capacidad de mantener el crecimiento mediante escenarios externos y políticas internas, pero eso no podría sostenerse sin un escenario externo favorable. Estas contradicciones se manifestaron de manera severa con el cambio en la situación externa y la caída de las exportaciones. 
La crisis económica brasileña, que también es una crisis política, representa una inversión de un periodo de expansión, aunque breve, observado entre los años en que los gobiernos del Partido de los Trabajadores estuvieron en vigor, en especial el gobierno de Lula. En ese periodo, y con un contexto internacional favorable, fue posible crecer con la distribución del ingreso y el aumento de los salarios, con resultados fundamentales en términos de reducción de la pobreza.

Sin embargo, incluso en ese lapso de crecimiento ya había varias contradicciones en el modelo, que reflejaban a su vez contradicciones del propio capitalismo contemporáneo.

Como hemos tratado de demostrar, el capitalismo contemporáneo se encuentra ahora en un contexto de crisis profunda, una crisis que refleja las contradicciones de su propio movimiento de generación y expansión de valor. El aplazamiento recurrente de la resolución de la crisis de rentabilidad desde la década de los sesenta amplió los mecanismos de acumulación por medio de medios financieros, lo que intensificó la contradicción entre las promesas de apropiación y la generación de valor. Este aplazamiento de la resolución de la crisis conduce a otras crisis financieras de grandes proporciones, que nuevamente imponen limitaciones a la expansión económica.

$\mathrm{Al}$ mismo tiempo, el capitalismo encontró formas de superar esta crisis buscando nuevos espacios de acumulación, como Asia. Si por un momento este movimiento fue funcional para la continuación de la acumulación, en fecha más reciente trajo nuevas contradicciones porque las regiones que generan valor, como Asia, se convierten cada vez más no solo en un centro de producción sino también de apropiación del valor, lo que exacerba la disfuncionalidad del capital ficticio e impone amplias contradicciones a las economías occidentales.

En este contexto, las economías centrales responden a su propia recesión manteniendo políticas de austeridad que solo contribuyen al crecimiento letárgico.

Hasta 2010 la economía brasileña se insertó de manera beneficiosa en esta situación, expandiendo sus exportaciones de productos primarios, importando productos industrializados baratos y mediante políticas internas 
exitosas. No obstante, cuando la situación internacional cambia, las contradicciones salen a la luz e imponen una fuerte retracción del crecimiento brasileño.

Con esta interpretación, no tenemos la intención de afirmar que las decisiones de política económica del gobierno de Dilma Rousseff no desempeñaron un papel en la crisis brasileña. Ciertamente pudieron ser más adecuadas para el escenario externo. Sin embargo, nuestra interpretación busca dar un significado más amplio al grave momento que está viviendo Brasil, buscando entenderlo en una unidad de análisis más amplia.

Las restricciones al crecimiento brasileño son estructurales, y como hemos visto, están vinculadas con una situación de profunda crisis económica y de acumulación global, pero sobre todo en el centro del capitalismo, en las economías centrales.

Estos cambios implican nuevas determinaciones políticas que intensifican las disputas interestatales y vuelven a plantear la cuestión del imperialismo.

Como se dijo, cuanto más empeore la crisis en los países centrales, mayor será la tendencia a continuar los intentos de superarla, no solo aumentando la tasa de explotación laboral en forma de salarios reducidos, retiro de derechos, precariedad o presiones al Estado, sino también con la búsqueda del control político de las regiones periféricas y espacios de acumulación y extracción de valor, generando mayor presión competitiva y volviendo a plantear la cuestión del imperialismo en primer plano.

En contraste con periodos anteriores, una de las características de esta competencia actual es precisamente la entrada de nuevos Estados (semiperiféricos), como China, que han avanzado en términos de acumulación productiva, en un escenario de desplazamiento de producción y que ahora compiten por espacios de acumulación de capital fuera de sus propias fronteras, entrando así en la disputa con los Estados occidentales tradicionales. 
Akyuz, Yilmaz [2013], "Waving or drowning: developing countries after the financial crisis", en South Centre, Research Paper, junio. <https://cutt. ly/5gkXX52>.

Amaral, Marisa Silva [2012], Teorias do imperialismo e da dependência: a atualização necessária ante a financeirização do capitalismo. Sao Paulo. Tesis, Facultad de Economía, Administración y Contabilidad.

Banco Mundial [2019], <https://cutt.ly/hs9rseH>. [2020], <https://cutt.ly/hs9rseH>.

Boito Jr., Armando [2012], "Governos Lula: A nova burguesia nacional no poder", en Armando Boito Jr. y Andreia Galvão, Política e classes sociais no Brasil dos anos 2000. Sao Paulo, Editora Alameda.

Callinicos, Alex [2005], "Imperialism and global political economy", en International Socialism, Reino Unido, núm. 108.

Carcanholo, Marcelo [2011], "Conteúdo e forma da crise atual do capitalismo: lógica, contradições e possibilidades”, en Crítica e Sociedade: revista de cultura política, vol. 1, núm. 3, Edição Especial - Dossiê: A crise atual do capitalismo, dez.

Carvalho, Laura [2018], Valsa Brasileira - do boom ao caos econômico, Sao Paulo, Editora Todavia.

Chesnais, François [2016], Finance Capital Today: Corporations and Banks in the Lasting Global Slump. Boston, Brill Academic Pub. [1996], A mundialização do capital. Sao Paulo, Editora Xamã.

Choonara, Joseph [2018], "A economia política da grande depressão", en International Socialism, abril, núm. 158.

[2009], "Marxist accounts of the current crisis", International Socialism, núm. 123, Londres.

Corrêa, Vanessa Petrelli y Claudio Hamilton Dos Santos [2013], "Modelo de crescimento brasileiro e mudança estrutural - avanços e limites", en Vanessa Petrelli Corrêa (org.), Padrão de acumulação e desenvolvimento brasileiro, Sao Paulo, Editora Fundação Perseu Abramo, pp. 17-56.

Fiori, Jose Luis [2019], "A síndrome de babel e a nova doutrina de segurança dos Estados Unidos", en Revista Tempo do mundo, vol. 4, núm. 2, pp. 47-56. <https://cutt.ly/VgkXNRc>. 
Foster, John Bellamy [2019], "Late imperialism - fifty years after Harry Magdoff's The Age of Imperialism”, en Monthly Review, julio, 20. Guimarães, José Ribeiro Soares [2012], Perfil do Trabalho Decente no Brasil: um olhar sobre as Unidades da Federação durante a segunda metade da década de 2000. Brasília, Organização Internacional do Trabalho (oit), Escritório no Brasil, 416 pp.

Harvey, David [1992], Condição pós-moderna. Sao Paulo, Edições Loyola. Kliman, Andrew [2015], "A Grande Recessão e a teoria da crise de Marx", en Revista Outubro, segundo semestre, núm. 24.

Marx, Karl [1984], O Capital, vol. 3, Sao Paulo, Abril Cultural.

Medeiros, Carlos Aguiar de [2015], Inserção externa, crescimento e padrões de consumo na economia brasileira. Brasilia, IPEA.

[2010], "Instituições e desenvolvimento econômico: uma nota crítica ao "nacionalismo metodológico", en Economia e Sociedade, Campinas, vol. 19, núm. 3 (40), pp. 637-645.

Milanovic, Branko [2016], Global Inequality - A New Approach for the Age of Globalization. Cambridge, Harvard University Press.

Nayyar, Deepak [2014], A Corrida Pelo Crescimento: Países em Desenvolvimento na Economia Mundial. Río de Janeiro, Editora Contraponto.

OCDE [2020], OECD <https://data.oecd.org/>.

Ocampo, José A. y Bilge Erten [2013], "The global implications of falling commodity prices" <https://cutt.ly/0s9qDml>.

Panitch, Leo y Sam Gindin [2013], The Making of Global Capitalism: The Political Economy of American Empire. Verso.

Panitch, Leo y Sam Gindin [2006], "Capitalismo global e império norte americano", en Leo Panitch y Colin Leys (eds.), Socialist Register 2004: o novo desafio imperial. Buenos Aires, Clacso y Londres, Merlin.

Paulani, Leda Maria [2009], "A crise do regime de acumulação com dominância da valorização financeira e a situação do Brasil”, en Estudos Avançados, vol. 23, núm.66.

Pereira, Lia Baker Valls [2015], "A volta das restrições externas ao crescimento econômico?", en Conjuntura Econômica, vol. 69, núm. 2.

Pochmann, Márcio [2012], Nova classe média? O trabalho na base da pirâmide social brasileira. Sao Paulo, Editora Boitempo.

Prebisch, Raúl [2009 (1949)], "O Desenvolvimento Econômico da América Latina e seus Principais Problemas", en Ricardo Bielshowsky, Cinqüenta anos de pensamento na cepal. Río de Janeiro, Editora Record. 
Serrano, Franklin y Ricardo Summa [2018]. "Conflito distributivo e o fim da 'breve era de ouro' da economia brasileira”, en Novos Estudos Cebrap, Sao Paulo, mayo-agosto, vol. 37, núm. 2.

Streeck, Wolfgang [2018], Tempo Comprado - A crise adiada do capitalismo democrático. Sao Paulo, Editora Boitempo.

Summers, Larry [2015], "Reflection on Secular Stagnation", discurso en Julius-Rabinowitz Center, Princeton, Universidad de Princenton.

Tavares, Maria da Conceição [1985], "A retomada da hegemonia norteamericana", en Revista de Economia Política, abril-junio, vol. 5, núm. 2. Torres Filho, Ernani Teixeira [2014], "A crise do sistema financeiro globalizado contemporâneo", en Revista de Economía Política, julio-septiembre, vol. 34, núm. 3 (136), pp. 433-450.

UNCTAD [2017], Trade and development report 2017. Beyond austery: towards a global news deals, Nueva York y Ginebra, Naciones Unidas. 



\section{BRASIL DESPUÉS DEL 2000: UN CASO DE NEOLIBERALISMO REALMENTE EXISTENTE Y EMANCIPACIÓN RESTRINGIDA}

Deborah Werner*

INTRODUCCIÓN

En este capítulo nos proponemos analizar, con carácter ensayístico, la economía brasileña y el papel del Estado en los gobiernos de Luiz Inácio Lula da Silva (2003-2010), Dilma Rousseff (2011-2016) y Jair Bolsonaro (2018-2022) a partir del proceso de neoliberalización [Brenner et al., 2012] y desde la perspectiva del neoliberalismo realmente existente [Theodore et al., 2009]. Estos enfoques permiten relativizar las interpretaciones que atribuyen al periodo 2003-2016 el carácter del neodesarrollo, el nuevo desarrollo y el social desarrollismo [Bresser-Pereira, 2009; Bastos, 2012; Paulani, 2017].

En contraposición con esta interpretación, se argumenta la incapacidad de romper con el patrón de acumulación impreso por las reformas posteriores al Consenso de Washington (1989), que privilegió la inserción del país en la economía global como plataforma de acumulación financiera y proveedora de commodities agrícolas y minerales [Paulani, 2013]. Las políticas anticíclicas viabilizadas poscrisis de 2008 y el papel activo del Estado en la planificación, las inversiones y las políticas sociales, al no romper con el actual patrón de acumulación en curso, permitieron un proceso de emancipación restringido de la sociedad brasileña por los dictámenes neoliberales y sus consecuencias.

* Instituto de Pesquisa e Planejamento Urbano e Regional, Universidade Federal do Rio de Janeiro. 
La acción del Estado, por tanto, no promovió rupturas estructurales con el patrón de acumulación y con la forma de distribución de excedentes en el país, sino que contribuyó a viabilizar el acceso de las exportaciones primario-exportadoras a los mercados globales -con especial atención en el mercado chino-, intensificó la dinámica financiera y ayudó a amortiguar los conflictos de clases, una estrategia que se agota a partir de 2014 .

La primera sección rescata la concepción de neodesarrollo analizada a la luz del proceso de neoliberalización y de la perspectiva del neoliberalismo verdaderamente existente. La segunda sección presenta de forma breve la trayectoria de la economía brasileña desde la década de los noventa, evidenciando sus principales características. Enseguida se argumenta que los beneficios económicos y sociales verificados entre 2003 y 2014 pueden entenderse como un proceso de emancipación restringido que resultó del intento de reconciliar el proyecto neoliberal y las demandas emprendidas por los gobiernos de centro-izquierda, los cuales muestran su fragilidad en el contexto de crisis política y económica a partir de 2014, dada la incapacidad de internalizar las decisiones para conducir la economía política.

La última sección está reservada para las notas finales, que resumen las medidas de intensificación de la agenda recesiva económica y conservadora. El escenario actual exige el rescate de la política como camino para superar el carácter apenas reactivo que han marcado las fuerzas contrahegemónicas frente al proyecto neoliberalizador, llamándolas a la tarea de reconstruir los fundamentos sociales, económicos e ideológicos de un nuevo proyecto societario.

NEODESARROLLO, NUEVO-DESARROLLO, SOCIAL-DESARROLLO VERSUS NEOLIBERALISMO REALMENTE EXISTENTE

En contraste con las expectativas derivadas de las primeras elecciones de Luiz Inácio Lula da Silva (2003-2006), su política económica repite aún más incisivamente los parámetros macroeconómicos que guiaron la década de los noventa, con énfasis en el trípode de altas tasas de interés, alto superávit primario y metas inflacionarias, además de profundizar la apertura financiera de la economía brasileña con medidas favorables a esta fracción de capital, el ejemplo de la reforma de la ley de falencias y de la ampliación de la reforma de las pensiones a los servidores públicos [Paulani, 2017]. 
A partir del segundo periodo (2007-2010) se modificaron algunos aspectos, como el lanzamiento del Programa de Aceleración del Crecimiento (PAC) en 2007, que estableció inversiones públicas en los sectores de infraestructura por el orden de $13 \%$ del producto interno bruto (PIB), articulado al crédito del Banco Nacional de Desarrollo Económico y Social (BNDES), y el Programa Mi Casa Mi Vida en 2009, cuyo objetivo fue construir viviendas populares a tasas de interés subvencionadas por medio de la Caja Económica Federal (CEF). En términos generales, el gobierno promovió programas de exoneración de impuestos, reducción de las tasas de interés para inversiones específicas, ampliación de las líneas de crédito y aumento real del salario mínimo, entre otras medidas que posibilitaron la reanudación de las inversiones públicas y privadas y el consumo de las familias [Carvalho, 2018].

La reanudación de la acción estatal en la planificación, las inversiones en infraestructura, la concesión de crédito y las políticas sociales generó el crecimiento del PIB y el empleo, y condujo a una interpretación del contexto del término neodesarrollo en referencia a un nuevo periodo de intervención estatal en la economía en alusión al periodo de desarrollo de los años cuarenta y cincuenta.

El Neodesarrollo pasó a ser asociado con las políticas que, contrariando al actual canon liberal, apelaban a considerables programas de inversión pública (PAC, Mi Casa Mi Vida) y para expedientes de intervención en la actividad económica Lula había ampliado el crédito al consumidor a una escala sin precedentes -considerando implícitamente su papel como impulsor del mercado interno- y concedió la exoneración fiscal a algunos sectores de la industria en respuesta a la crisis internacional [crisis de 2008] [Paulani, 2017: 139].

El debate sobre una posible alteración de un modelo neoliberal para las políticas neodesarrollistas se dividió en dos grandes corrientes conceptuales que reivindicaron el término desarrollismo: el nuevo-desarrollismo y el social-desarrollismo, cuyas características también están asociadas con un tercer grupo, el nuevo-desarrollismo poskeynesiano. En el cuadro 1 se resumen estas contribuciones [Paulani, 2017: 142]. 


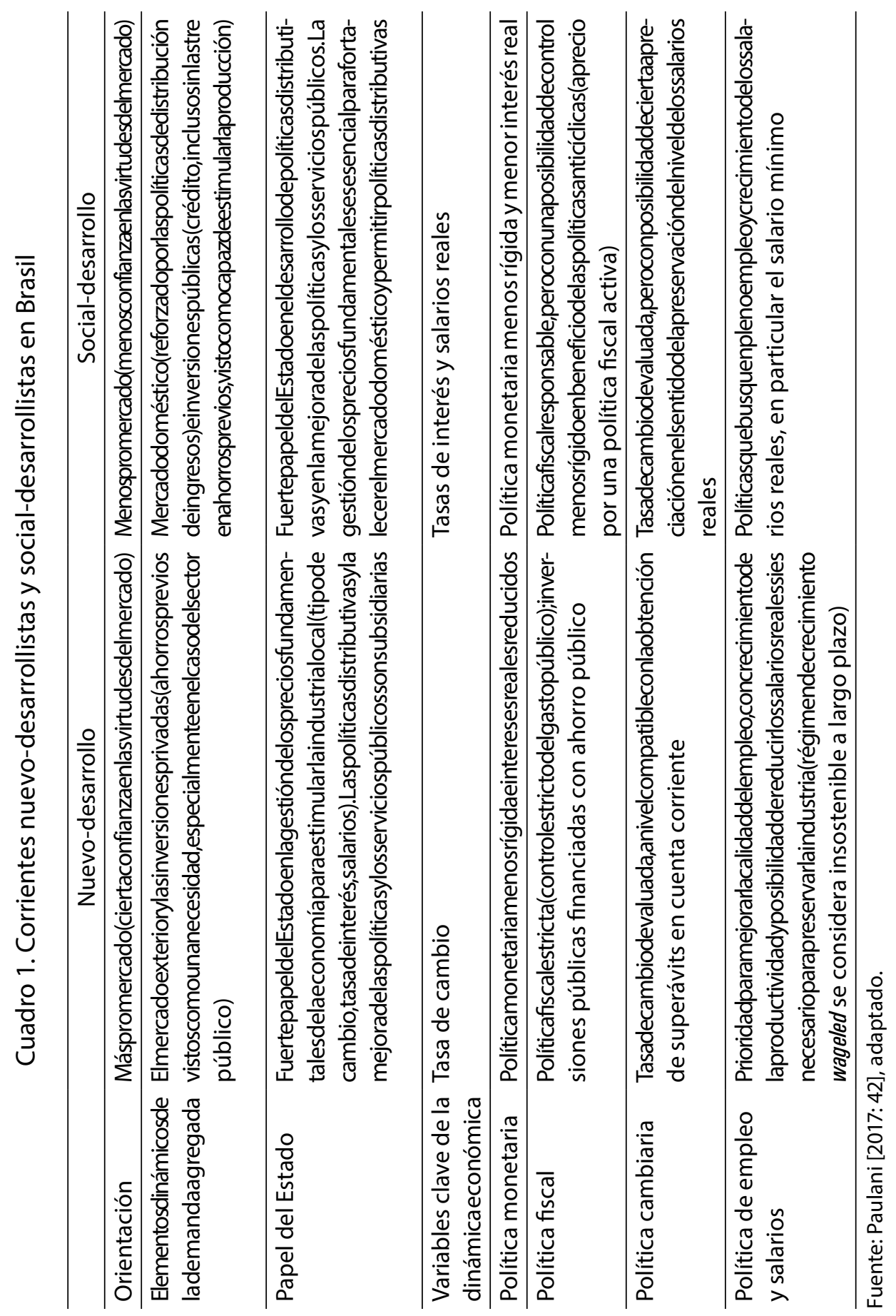


Una estrategia para considerarse desarrollista debe comprender los siguientes elementos: a) la existencia de un proyecto deliberado o estrategia que tenga como objeto y epicentro de la propuesta a la nación y su futuro, es decir, un proyecto nacional, aunque no signifique rechazo al capital extranjero o ruptura con el orden internacional; b) la intervención consciente y decidida del Estado con miras a habilitar el proyecto, lo que requiere agentes capaces de ejecutarlo en el aparato estatal y con el apoyo social y político de segmentos y clases de la sociedad en su conjunto; y c) la industrialización como un proceso capaz de acelerar el crecimiento económico, la productividad y la difusión del progreso técnico, incluso para el sector primario [Fonseca, 2015]. A partir de los tres elementos extraídos del análisis de varias estrategias nacionales, el autor elabora el concepto de desarrollismo:

Se entiende por desarrollismo la política económica formulada y/o ejecutada, deliberadamente, por los gobiernos (nacionales o subnacionales) para, a través del crecimiento de la producción y la productividad, bajo el liderazgo del sector industrial, transformar a la sociedad con miras a lograr propósitos deseables, destacadamente la superación de sus problemas económicos y sociales, dentro de los marcos institucionales del sistema capitalista [Fonseca, 2015: 40].

Adhiriéndose a la conceptualización propuesta por Fonseca [2015], Paulani [2017] argumenta que ninguna de las corrientes que reivindican el término pos-2000 puede considerarse desarrollista.

En el nuevo-desarrollismo, a pesar del fuerte énfasis en el sector industrial, hay mucha confianza en el mercado y el sector privado (débil intervención del gobierno, centrada únicamente en la gestión de los precios fundamentales, en particular el tipo de cambio, las inversiones públicas sin protagonismo), así como la falta de un proyecto nacional. En el social-desarrollismo, a pesar del fuerte énfasis en la intervención gubernamental y el papel del sector público, hay poca preocupación por la industria y también carece de un proyecto nacional [Paulani, 2017: 143].

Según la autora, la acción del Estado verificada en el periodo comprendido entre 2003 y 2014 no buscó la ruptura con la división internacional del trabajo, vigorizando la inserción internacional de bienes y servicios, las 
transacciones con factores de producción y la inserción financiera del periodo anterior (1990-2002). En este sentido, no se trata de una planificación de intervención estatal a favor de un proyecto nacional guiado por la industrialización, ya que la subalternidad de los mercados financieros internacionales, la condición de exportación primaria y la dependencia tecnológica permanecieron.

El marco institucional que hoy en día encuadra el funcionamiento del capitalismo brasileño fue construido, de esa manera, sobre la base del principio mayor de responder con prontitud y precisión a los intereses de la riqueza financiera, en particular de los acreedores e inversores externos. ${ }^{1}$ El ascenso del Partido de los Trabajadores al gobierno federal, con la elección de Lula en el 2002, despertó la esperanza de que habría alguna reversión en la agenda liberal en curso, pero [...], esto no sucedió. Este rasgo permanece, por lo tanto, prácticamente intacto en todos los gobiernos de Fernando Henrique Cardoso y Lula/Dilma, a pesar de las diferencias que los separan [Paulani, 2017: 145].

Como interpretación alternativa, la reanudación de la acción estatal en la planificación y las inversiones de forma concomitante con el mantenimiento de la división internacional del trabajo vinculada con la exportación de commodities agrícolas y minerales, y el predominio de la macroeconomía centrada en la esfera financiera pueden entenderse desde el proceso de neoliberalismo y la noción de neoliberalismo verdaderamente existente [Brenner et al., 2012; Theodore et al., 2009].

El proceso de neoliberalización surge como una de las diversas tendencias regulatorias desencadenadas a partir de la década de los setenta en la que las respuestas basadas en el mercado son priorizadas, orientadas al mercado o disciplinadas por el mercado para los problemas regulatorios. El objetivo es intensificar la comodificação creciente en amplias áreas de la vida social, para lo cual se movilizan instrumentos financieros especulativos y

${ }^{1}$ La autora se refiere a la apertura financiera sin control sobre los flujos internacionales de capital; la internacionalización del mercado brasileño de bonos; las concesiones fiscales a los propietarios de acciones y ganancias financieras de no residentes; los cambios legales para dar mayor seguridad a los acreedores del Estado (Ley de Responsabilidad Tributaria) y del sector privado (Ley de Falencias); las enmiendas al régimen general de seguridad social (INSS) y a los propios regímenes de los funcionarios públicos; y la adopción de una prescripción macroeconómica centrada en el beneficio de la riqueza financiera (austeridad fiscal y altas tasas de interés). 
se abren nuevas arenas para la realización capitalista de lucros [Brenner et al., 2012].

En el campo teórico, el pensamiento neoliberal tiene como presupuesta la creencia en mercados abiertos, competitivos y no regulados, no sometidos a interferencias estatales o acciones de colectivos sociales, lo que representa el óptimo mecanismo para el desarrollo económico. Se trata de una visión utópica de la supremacía del mercado, de reducción del papel del Estado, una visión arraigada en una concepción del individualismo competitivo que refuta las diferentes formas de solidaridad social e institucional [Peck y Theodore, 2019].

Entre las políticas basadas en doctrinas neoliberales se encuentran: desregulación del control estatal sobre la industria, ofensivas contra el trabajo organizado, reducción de los impuestos corporativos, contracciones y/o privatización de los servicios públicos, desmantelamiento de los programas de bienestar social, ampliación de la movilidad del capital internacional e intensificación de la competencia entre localidades [Theodore et al., 2009].

La doctrina neoliberal presenta los Estados y mercados como si fueran principios de organización social y económica diametralmente opuestos, en lugar de reconocer el carácter políticamente construido de todas las relaciones económicas. Tiene como premisa la existencia de un modelo único de aplicación de políticas que supone que la imposición de reformas orientadas al mercado siempre tendrá los mismos resultados, sin reconocer las variaciones que desencadena la instalación de reformas neoliberales en escenarios institucionales y sistemas políticos diferentes y específicos.

La ideología neoliberal tiene como uno de sus presupuestos que las fuerzas del mercado operan de acuerdo con leyes inmutables, sin considerar el lugar donde se realizan. Este entendimiento se diferencia de la noción de "neoliberalismo verdaderamente existente", que considera la inserción contextual de los proyectos de reestructuración neoliberal y la dependencia de la trayectoria heredada, de la superposición entre las políticas neoliberales y los marcos reglamentarios precedentes, en las diferentes formaciones sociales [Theodore et al., 2009].

Con base en esta noción se establece una base analítica a partir de la cual es posible comprender la producción de tales proyectos dentro de contextos nacionales, regionales y locales determinados, cuya especificidad 
está dada por el legado de marcos institucionales, políticas estatales, prácticas regulatorias y conflictos políticos que se transmiten a lo largo del tiempo.

Por tanto, es necesario comprender el neoliberalismo realmente existente a partir de interacciones dependientes de la trayectoria y contextualmente específicas que tienen lugar entre los escenarios regulatorios heredados y los proyectos emergentes de reformas neoliberales orientadas por el mercado. No basta con captar los fundamentos político-ideológicos de los proyectos, hay que examinar las diferentes formas institucionales, las direcciones en las que se desarrollan los diversos efectos sociopolíticos y sus múltiples contradicciones.

El proceso de neoliberalización nunca se manifiesta en una forma pura, como un todo regulatorio integral, como lo desea su marco teórico. Las tendencias de la neoliberalización solo pueden articularse en modalidades incompletas, híbridas, que se cristalizan en ciertas formaciones reguladoras, pero que se reelaboran de manera continua y ecléctica en contextos específicos [Brenner et al., 2012; Peck y Theodore, 2019].

A diferencia de la caricatura neoliberal de reducir o vaciar el Estado como resultado necesario y deseable de la globalización económica, surge una concepción de transescalación en la que las funciones crecientes del Estado, en sus diferentes niveles de gobierno, no se sustituyen simplemente, sino que se someten a un proceso de transformación cualitativa mediante el reescalonamiento, del que surgen nuevas normas o esquemas interescalares [Peck, 2010].

El carácter creativo y destructivo se enfatiza a lo largo del proceso de neoliberalización, a medida que nuevas formas de construcción institucional acompañan o siguen a la desregulación. Peck [2010] se refiere a dos dinámicas temporales de neoliberalización: los movimientos de rollback y los de roll-out. La fase de roll-back se refiere al inicio del proceso de neoliberalización, cuando la reestructuración de los procesos se centra en la implementación de fundamentos básicos del neoliberalismo, desmantelando instituciones y desorganizando centros de poder básicos, zonas de control burocrático, mientras que se disciplinan asuntos potencialmente indisciplinados a la luz de la lógica de mercado.

La fase roll-out suele estar asociada con la implementación de normativas de conformidad con los mercados, como las privatizaciones, las 
asociaciones público-privadas y las regulaciones. Esta fase envuelve una lógica interna provocada por simples fallas regulatorias y una lógica externa ocasionada por la creciente dependencia de los apoyos internacionales y los mecanismos de ajustes políticos. Es en este contexto que los procesos de neoliberalización puestos en marcha se comprenden como respuestas a crisis estructurales y al amplio apoyo de agencias e instituciones multilaterales para su implementación, como el Banco Mundial y el Fondo Monetario Internacional.

Por el carácter histórico y dependiente de contextos sociales y políticos específicos, es posible el surgimiento del proceso de neoliberalización concomitante a la intervención del Estado, que ocurrirá en pro o se subordinará, en última instancia, a los dictámenes de la acumulación vinculada con el capital financiero. Aunque tal concomitancia puede resultar tensa y contradictoria, con avances y contratiempos por parte de los agentes sociales en disputa, como se ha visto en Brasil, al ser engendrada dentro de un gobierno de centro-izquierda, esta tensión no es suficiente para asumir la superación de la neoliberalización. Por lo tanto, en este aspecto, la reanudación de la acción estatal por sí sola no garantiza un compromiso con los elementos que caracterizan el desarrollo.

Los movimientos de neoliberalización en Brasil iniciados en la década de los noventa promovieron mecanismos e instrumentos de experimentaciones re-reguladoras, con diversas repercusiones. En el gobierno de Fernando Henrique Cardoso (1994-2002) se buscó establecer políticas basadas en el Consenso de Washington, con privatizaciones, apertura comercial y financiera, una política macroeconómica orientada a los mercados financieros globales [Brandão, 2017].

De 2003 a 2015, en los gobiernos de Luiz Inácio Lula da Silva (20032010) y Dilma Rousseff (2011-2015), predominaron la macroeconomía conservadora, el mantenimiento de metas inflacionarias, tasas de interés y superávit primario elevados, compitiendo para mantener alianzas intactas con grupos conservadores relacionados con la renta y especialización en commodities, sin la debida confrontación de la cuestión urbana y regional a pesar de las políticas progresistas. Con Michel Temer (20162018) se reinauguran las políticas neoliberales de la década de los noventa, con profundas consecuencias para el estándar regulatorio nacional 
vinculado con las tres mercancías ficticias: tierra, dinero y trabajo [Polanyi, 1980], capaz de alterar la relación capital-trabajo.

En el gobierno de Jair Bolsonaro (2018-2022), el movimiento iniciado con su predecesor se consolida al promover la alineación del país con los deseos de la agenda global, de exacerbada coerción competitiva intercapitalista e interestados territoriales, y extraordinaria reordenación jerárquica y hegemónica escalar-espacial en el plan mundial, como afirma Brandão [2017].

Este proceso se deriva de la reorganización y reconstrucción de nuevas coherencias estructuradas de carácter económico, político y social que, por medio de ciclos acelerados de experimentación regulatoria derivados de la crisis de 2008, han cambiado los marcos de la reproducción social-clasista, "con repercusiones de naturaleza estructural, distribuidas de manera desigual en el sistema capitalista, en sus relaciones interescalares, con diferentes 'variaciones' temporales y espaciales 'de las' y 'en las' varias periferias del sistema" [Brandão, 2017: 47].

Los diferentes movimientos regulatorios en Brasil compiten para promover la estrategia de inserción periférica del país a los mercados globales posteriores a 1990. La diferencia entre los gobiernos estuvo en la capacidad o no de conciliar el proyecto con los deseos de las clases subalternas con respecto a la distribución de los beneficios económicos y el papel más o menos activo del Estado en la economía, a veces regulatorio y a veces invirtiendo y aprovisionando crédito.

El carácter de inserción en los circuitos mundiales de valoración financiera, sin embargo, no se modificó con el ascenso al poder de los gobiernos de centro-izquierda a partir de 2003; por el contrario, se exacerbaron las medidas que profundizaron esta posición, como la ampliación de la reforma de las pensiones al servicio civil público, la reforma de la ley de falencias con el fin de priorizar los intereses de los acreedores financieros y la adopción de medidas para aumentar el grado de apertura financiera [Paulani, 2013], lo que posibilitó e intensificó el dominio de esta fracción de capital sobre las demás.

Con respecto a la estructura productiva, la consecuencia es la desindustrialización ${ }^{2}$ y la reprimarización de la agenda exportadora del país.

\footnotetext{
${ }^{2}$ La desindustrialización es un proceso normal en las economías centrales, después de la consolidación del proceso de industrialización, en el que la estructura productiva y el empleo avanzan hacia la expansión,
} 
Para este aspecto, se argumenta que el caso brasileño expresa un tipo de neoliberalismo que buscó conferir a la acción del Estado el sentido de promover la inserción internacional del país en la reestructuración del capitalismo global. El agotamiento de esta estrategia profundizaría las medidas neoliberalizantes a partir del gobierno de Michel Temer (2016-2018) y Jair Bolsonaro (2019-2022).

TRAYECTORIA DE LA ECONOMÍA BRASILEÑA: 1990-2018

La crisis monetaria, fiscal y cambiaria de la década de los ochenta y las políticas adoptadas para su superación (alta tasa de interés, valorización del tipo de cambio y superávit primario) dieron lugar, en la década siguiente, a un aporte masivo de dólares debido a las altas tasas de interés, que contribuyó a una permanente valorización del tipo de cambio. El rebatimiento de esta estrategia en la estructura productiva fue el proceso de desindustrialización y reprimarización de la agenda de exportación del país [Cano, 2012; Paulani, 2013].

La desindustrialización que sufrió Brasil se expresa en la caída de la participación de la industria de transformación en el PIB y está justificada por las siguientes razones: a) cambio valorizado implementado desde el Plan Real; b) apertura comercial sin mediaciones capaces de permitir que la industria nacional enfrentase a la competencia extranjera; c) altas tasas de interés, lo que significa que el empresario opte por la aplicación en los títulos de la deuda; d) inversión extranjera directa dirigida principalmente a inversiones en la cartera y títulos de deuda pública y privada, es decir, por lo general especulativa; y e) desaceleración de la economía desde 2007 y la crisis de 2008, que hizo que las economías desarrolladas (Estados Unidos y la Unión Europea) más China implementaran políticas agresivas de exportación de productos industriales [Cano, 2012].

La reprimarización de la agenda de exportación es la otra cara de la nueva forma de vincular la economía brasileña con el circuito global de

modernización y diversificación, aún más en los servicios, más que la agricultura y la industria de transformación, pasando el peso relativo de la caída de esta, que pierde posición respecto de los servicios. Sin embargo, en los países subdesarrollados la desindustrialización se produce con un decremento de la participación de la industria de transformación, que desaparece [Cano, 2012]. 
acumulación por medio del suministro de productos de bajo valor agregado y commodities, al tiempo que garantiza grandes ganancias en moneda fuerte al resto del mundo, absorbiendo continuamente el ahorro externo, con el fin de actuar como agente activo del proceso financiero [Paulani, 2013]. Como resultado, el país pierde la capacidad de conquistar los mercados de consumo extranjeros al revertir lo que se había logrado a principios de la década de los ochenta, cuando la matriz industrial se completó a partir del II Plan Nacional de Desarrollo (II PND). Cabe destacar que esta era la matriz industrial fordista, mientras que el mundo ya se introducía a la dinámica de la acumulación flexible.

La devaluación de la moneda en 1999, junto con el aumento de la demanda de commodities como resultado del efecto China a partir de los años 2000, dio lugar a resultados positivos en las transacciones corrientes en el primer gobierno de Lula (2003-2006). Sin embargo, la continua revaloración de la moneda combinada con la disminución relativa de los precios de los commodities después de la crisis de 2008 culminó con el retorno de los déficits en las transacciones corrientes. Así, la segunda administración de Lula (2007-2010) ya presenta las consecuencias de la conducción de la política económica del primer mandato, la ortodoxa.

Las altas tasas de interés asociadas con el fuerte movimiento de la revalorización monetaria produjeron crecientes déficits en las transacciones corrientes y una fuerte atracción de los flujos de capital externo mediante la cuenta financiera de la balanza de pagos. Respecto de las fracciones de capital, las políticas de altos intereses afectaron directamente los intereses del sector bancario-financiero, que dio poder a esta fracción, cuya importancia es cada vez más creciente dada la continuidad de las políticas ortodoxas relacionadas con el trípode económico [Gonçalves, 2013; Paulani, 2013].

Con esto se afirma la forma prioritaria de inserción de la economía brasileña en el proceso de acumulación de capital en todo el mundo, la cual es la de funcionar como una plataforma internacional de valoración financiera (fuente permanente de ganancias financieras pulposas para el capital gitano internacional), que no está exenta de consecuencias para la forma de su inserción productiva [...]. Por ahora vale la pena añadir que esta forma de inserción es característica de la etapa madura de las finanzas, donde la intermediación bancaria pierde fuerza siendo reemplazada por la llamada financiación directa, 
que tiene como protagonistas los fondos de inversión y los fondos de pensiones, bolsas y mercados secundarios de títulos, procesos de securitización y derivados [Paulani, 2013: 244].

En lo que respecta a la tasa de inversión, ya estaba muy deprimida desde la década de los ochenta, cuando cae aún más hasta 2005, recupera una pequeña parte y aumenta en 2008 a $16.9 \%$ y cerca de $19 \%$ en 2010 y 2011, en lo cual contribuyó el PAC 2007. Brasil no recuperó el nivel necesario alcanzado en la década de los setenta, del orden de $25 \%$ del PIB (Cano, 2012). Esto se refleja en el carácter de la inversión, en la que predominan la allocation de servicios, sobre todo en el sector financiero, la construcción, los negocios inmobiliarios, el agropecuario y el minero, y se reduce la participación en la industria manufacturera.

Esto es comprensible, pues la productividad y la competitividad de la industria brasileña se han contenido, y en muchos casos, cayeron, y fue bien percibido por el capital. Al mismo tiempo, hubo el giro predominantemente americano y asiático de IDE para China en busca de trabajo barato, tipo de cambio devaluado y alta competitividad. Por esta razón, se trasladó en gran medida a China con el fin de producir más barato, abandonando o disminuyendo su presencia en áreas antiguas donde había tenido una gran expresión [Cano, 2012: 9].

Por su parte, el crecimiento del PIB, visto a partir de 2003, se justifica debido al aumento del consumo familiar estimulado por el incremento del crédito al consumidor; el incremento del salario mínimo real y de las políticas sociales como Bolsa Família; las decisiones a favor de la expansión del financiamiento de inversiones (público y privado), sobre todo para la Petrobras después del descubrimiento del pré-sal, a pesar de la política fiscal restrictiva; y la expansión del sector exportador, debido al auge internacional entre 2004 y 2008, con el fuerte aumento de los precios de las materias primas y el aumento de la demanda física causado principalmente por la economía china [Orair, 2015; Medeiros, 2015; Carvalho, 2018].

Una vez que la inserción productiva internacional de Brasil se produjo mediante commodities, el país se benefició del "efecto China", un aumento de la demanda y los precios de estos bienes (gráfica 1), que comenzó a revertirse con la crisis de 2008, pero la intensa caída se produce a partir de 2014. 
Gráfica 1. Evolución de los índices medios de precios de commodities conforme a tipología: 2000-2019 $(2016=100)$

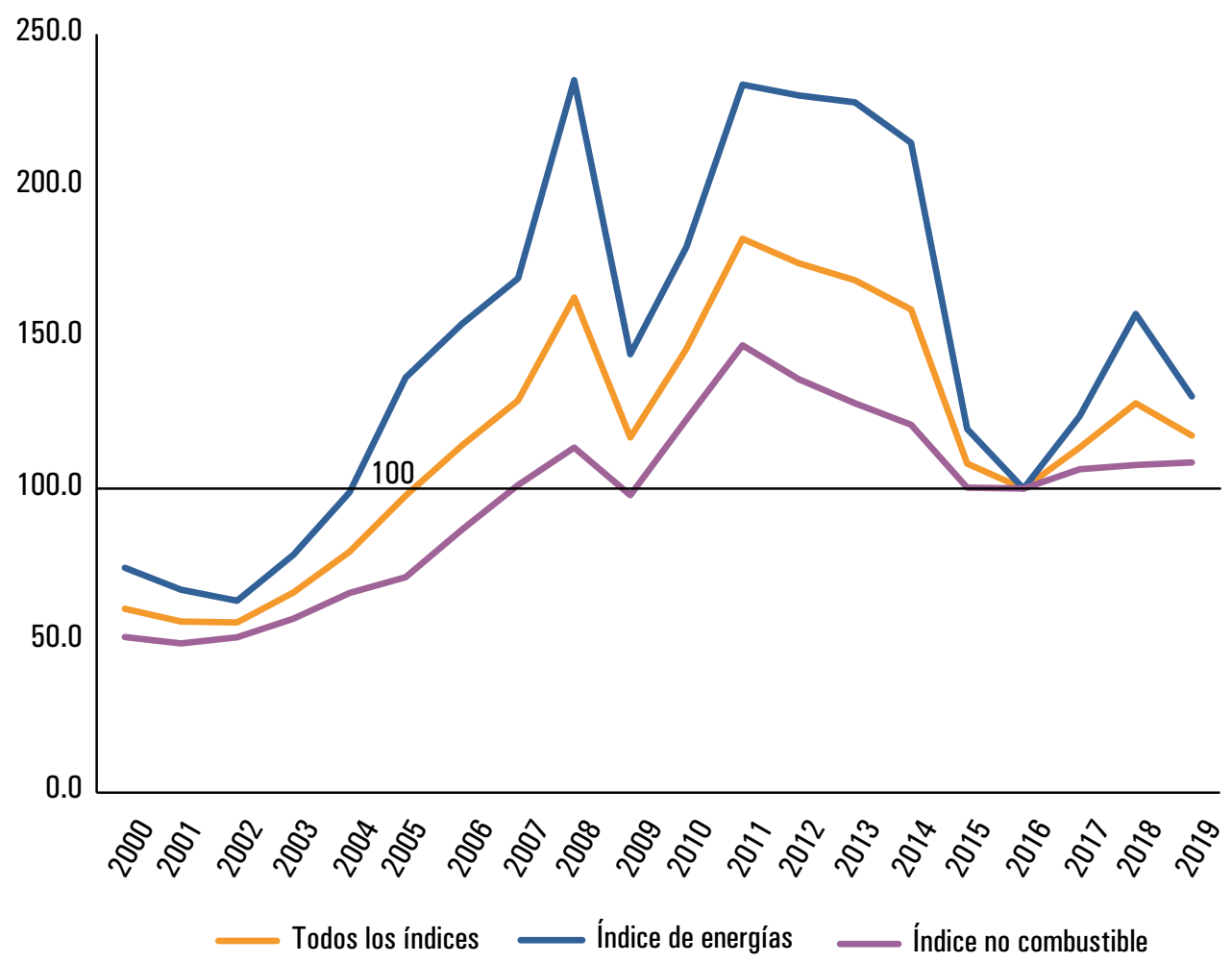

Fuente: FMI, 2020.

La reanudación del papel del Estado en las inversiones en infraestructura, los aumentos reales del salario mínimo, el boom de los commodities, el incremento del crédito a los sectores productivos y las familias, y las exenciones fiscales a sectores específicos justifican el buen desempeño de la economía brasileña en el periodo 2003-2010 [Carvalho, 2018]. Como advierte la autora, la reserva seguida en los años de Lula no tendría el mismo efecto en el periodo siguiente. La reversión cíclica de la crisis de 2008 y la caída de los precios de los commodities se suman a las condiciones macroeconómicas internas: el decremento de las reservas públicas causado por las exenciones, la desaceleración de las inversiones y el proceso inflacionario [Carvalho, 2018]. 
La adopción de políticas contraccionistas en la primera administración de Dilma Rousseff (2011-2014), el recorte de las inversiones estatales, la ampliación de las exenciones fiscales y la reducción de los tipos de interés por parte de los bancos públicos no tuvieron el efecto esperado de reversión de la crisis; por el contrario, profundizaron la caída de la Unión y limitaron la demanda efectiva. El intento de legar a los capitales privados la reanudación de las inversiones y la adopción de la Agenda Fiesp contribuyeron a hacer de la crisis económica una crisis política, compitiendo por el impeachment en 2016 bajo el alegato de delito fiscal: la tristemente célebre "pedalada fiscal". Además de la crisis económica, los efectos de la parálisis de las inversiones causada por las investigaciones de la Operación Lava-Jato impactó en los planes de inversión de Petrobras y otras empresas investigadas [Gentil y Hermann, 2017; Carvalho, 2018].

La inserción comercial y financiera que se consolida a partir de 1990 en Brasil expresa nuevas relaciones centro-periferia frente a las transformaciones del capitalismo contemporáneo. Estas transformaciones repercuten en nuevas formas de relación entre el Estado y la economía, que pasan a responder a los diseños de acumulación financiera. Además de la reducción, minimización o debilitamiento del Estado, presenta nuevas funciones en razón de la dinámica de acumulación vinculada con las finanzas, un aspecto coherente con la perspectiva del neoliberalismo verdaderamente existente.

Componen el papel de desregulaciones ocurridas desde la década de los noventa y están en línea con el neoliberalismo verdaderamente existente, los cambios en el código del agua, el código forestal, el código de minería, la flexibilización de los procesos de legislación ambiental, la reforma laboral, la reforma de las pensiones, la aprobación de la Enmienda Constitucional del 95, la reforma educativa (Ensino Médio y Future-se), entre otras medidas, que pueden entenderse como permisivas a la apropiación privada de los recursos territoriales y del fondo público por los procesos de acumulación global [Almeida, 2012; Acselrad et al., 2012; Brandão, 2017].

Por tanto, a pesar de que desde 2003 los gobiernos hayan estado encabezados por fuerzas de oposición al marco neoliberal, esto no fue suficiente para romper el dominio financiero en la conducción del bloque en el poder, de modo que la política económica mantuvo las medidas neoliberalizantes y prevaleció la ortodoxia monetaria y financiera por medio del 
trípode macroeconómico: a) superávit primario, b) metas inflacionarias y c) tipo de cambio valorado, que profundizó la inserción comercial por medio de ventajas competitivas y la sumisión de los Estados a la acumulación financiera.

\section{EMANCIPACIÓN RESTRINGIDA ${ }^{3}$ POSTERIOR A 1988}

Si bien la acción del Estado ha sido fundamental para el proceso de industrialización y acumulación en el país, también restringió y frenó, mediante la dictadura civil-militar (1964-1985), los numerosos intentos de involucrar a las clases trabajadoras y los grupos subalternos y contrahegemónicos que buscaban cambiar esta condición en la disputa para proyectos alternativos, aunque dentro de los marcos del capitalismo. Para este aspecto, el carácter autoritario del Estado enfrió las posibilidades de establecer un patrón de apropiación más igualitario del excedente, lo que potenciaría las transformaciones institucionales, culturales y valorativas en la sociedad brasileña, tomando como referencia la perspectiva del desarrollo de Furtado de ampliar los horizontes de posibilidad y aspiración de la colectividad [Brandão, 2012].

Por su parte, la Constitución de 1988 daría inicio a un nuevo capítulo de la historia nacional al expresar la necesidad de garantizar las condiciones de ciudadanía, materiales y políticas en el preámbulo de la Carta Magna "derechos sociales, individuales, libertad, seguridad, bienestar, desarrollo, igualdad y justicia como valores supremos de una sociedad fraterna, pluralista y sin prejuicios, fundada en la armonía social y comprometida, en el orden interno e internacional, con la solución pacífica de controversias" [Constituição Federal de 1988, Preâmbulo].

Estos aspectos expresan los objetivos de la República Federativa del Brasil, los cuales son: construir una sociedad libre, justa y solidaria; garantizar el desarrollo nacional; erradicar la pobreza y la marginación y reducir las desigualdades sociales y regionales; y promover el bien de todos, sin

${ }^{3}$ Como analogía de la idea de la industrialización restringida como característica de la economía brasileña entre 1930 y 1956 [Cardoso de Mello, 1984]. 
prejuicios de origen, raza, sexo, color, edad y cualquier otra forma de discriminación [Constituição Federal de 1988, art. $3^{\circ}$ ].

De estos valores surge el compromiso con la universalización de la salud, la educación pública libre y de calidad, la seguridad social, el fortalecimiento de la cooperación y la solidaridad entre entidades federadas, la reforma urbana y la agraria, entre otros. La incorporación de cuestiones ambientales innovadoras enunciaría y firmaría el compromiso con el tema de la sostenibilidad como precepto constitucional.

Dado que el proceso de industrialización no estuvo acompañado por la consolidación del Estado de bienestar social en Brasil, sino que, por el contrario, promovió la centralización de la riqueza y la eliminación de derechos, sobre todo a partir de 1964, la Constitución Federal de 1988, resultado de las luchas al final de la dictadura militar, buscaría corregir la herencia histórica de desigualdad y consolidar el Estado democrático de derecho en Brasil. Abre, por tanto, la posibilidad de hacer frente a las condiciones de dependencia, exclusión, subalternidad, violencia y opresión que marcaron el proceso de modernización conservadora en el país.

Su promulgación coincidió, sin embargo, con el momento de profundas transformaciones del capitalismo global, de ruptura con el patrón de acumulación dominado por la fracción de capital industrial (acumulación fordista) y el abandono de los valores que habían guiado a las sociedades y el desempeño mismo de los Estados nacionales en la búsqueda de conciliar los deseos de acumulación de las clases dominantes con las aspiraciones de las clases subalternas: el Estado de bienestar social, que en Brasil se abre como una posibilidad con la Constitución de 1988 [Fagnani, 2017].

En consecuencia, la ola neoliberal de la década de los noventa limitaría estas aspiraciones al imponer reformas estructurales para la mercadificación de las relaciones sociales y los bienes públicos, la apertura comercial y financiera, las privatizaciones, las desnacionalizaciones y la restricción a la acción planificadora y proveedora del Estado en el ámbito de los servicios públicos [Cano, 2000; Fagnani, 2005]. El bajo crecimiento económico, el enfoque en la estabilización monetaria, la posición subalterna en la división internacional del trabajo como exportador de commodities agrícolas y minerales y una plataforma para la valoración financiera de capitales especulativos comenzaron a caracterizar la economía brasileña desde la década de los noventa, como se señaló antes. 
Los años 2000 fueron testigo de un contraste con los gobiernos neoliberales que marcaron no solo a Brasil sino a otros países latinoamericanos. ${ }^{4}$ Los movimientos sociales organizados, después de años de representatividad democrática seguidos de la neoliberalización, promovieron protestas a escala mundial, como el Foro Social Mundial -que reunió a varios movimientos sociales y organizaciones no gubernamentales que se oponían a la agenda neoliberalizante de 2001 en Porto Alegre, a diferencia del Foro Económico Mundial, que se celebra anualmente en Davos-, las manifestaciones del Movimiento de Trabajadores Sin Tierra, el Movimiento de Afectados por las Presas y el Movimiento de Trabajadores Sin Hogar, entre otros, que cuestionaron la agenda hegemónica en curso de privatizaciones y reformas contraccionistas destinadas a desmantelar las políticas acordadas en 1988. A nivel internacional, en el centro económico mundial destacó la Batalla de Seattle contra la reunión de la Organización Mundial del Comercio en 1999, explicitando los cuestionamientos contra la agenda de los mercados.

Tales luchas se articularon y legitimaron en múltiples escalas promoviendo lo que Swyngedouw [1997] refiere como "salto escalar" de las luchas contrahegemónicas y contribuyeron a la promoción de cambios en las direcciones políticas y económicas de Brasil y América Latina, que culminaron con la llegada al poder de grupos políticos vinculados con las agendas de izquierda y centro-izquierda.

En Brasil, desde 2003 la victoria de Luiz Inácio Lula da Silva inaugura este periodo y busca reposicionar el papel del Estado, la reanudación de las acciones de planificación regional y urbana, las inversiones públicas y las políticas sociales. En términos económicos, el crecimiento observado en el periodo está relacionado con la demanda china de productos primarios, las inversiones públicas en infraestructura con el PAC, el aumento del empleo formal, las ganancias reales del salario mínimo, la jubilación rural, la transferencia de ingresos y las políticas de crédito a la inversión y

${ }^{4}$ En los demás países de América Latina, el descontento social con las políticas neoliberales llegó con las elecciones, en Argentina, de Néstor Kirchner (2003-2007) y Cristina Kirchner (2007-2015); en Ecuador, de Rafael Correa (2007-2017); en Paraguay, de Fernando Lugo (2008-2012); en Uruguay, de Pepe Mujica (2010-2015); en Bolivia, de Evo Morales (2006-2019); y en Venezuela, de Hugo Chávez (1999-2013), sucedido por Nicolás Maduro (desde 2013). 
el consumo a partir del desempeño de los bancos públicos (Banco Nacional de Desarrollo Económico y Social, Banco do Brasil y Caixa Económica Federal).

Esta posición requirió la reestructuración de las carreras estatales con el fin de obtener las condiciones institucionales y políticas para la ejecución del proyecto, tales como concursos en diversas áreas, creación del Ministerio de Ciudades, preparación del Plan Nacional de Desarrollo Regional (PNDR) en el marco del Ministerio de Integración Nacional y las políticas sociales para la diversidad de género, étnica y cultural. Las políticas en el área de educación pusieron el énfasis en la educación superior con la expansión de las vacantes en las universidades públicas, la creación de nuevos campus y cursos con el Reuni, la financiación mediante el FIES y el programa de becas (Prouni), además de la reanudación de concursos para la composición del personal docente y técnico.

El margen de maniobra, desde la reanudación de la acción estatal por medio de las inversiones públicas, la expansión del crédito, el cumplimiento de las políticas sociales y la valoración del salario mínimo, se derivaba tanto del escenario externo favorable (combinación de los altos precios de los commodities y la creciente demanda de China), como de las presiones de los diversos grupos sociales insatisfechos con los años de neoliberalización, lo que permitió a los gobiernos, a partir de 2003, estructurar sus políticas públicas para articular los dictámenes de acumulación que sostuvo el proyecto hegemónico neoliberal a la adhesión de las demandas de fracciones de la clase industrial nacional (construcción civil y agronegocios) y clases subalternas, una base que sustentó el proyecto de poder del Partido de los Trabajadores (РT) hasta 2014.

La llegada de los gobiernos del PT, con énfasis en los de Lula (20032006 y 2007-2010) pero que puede extenderse a los de Dilma $^{5}$ (2011-2014 y 2015-2016), estableció lo que Oliveira [2010] llama "hegemonía a la inversa”. Con el término, el autor caracteriza las relaciones de poder en la era de la globalización: la nueva dominación invierte, según él, los términos gramscianos, aunque funcionales para el capitalismo mundializado. En la hegemonía a la inversa,

${ }^{5}$ El segundo gobierno de Dilma fue interrumpido en mayo de 2016 en medio de la crisis económica y política que legitimó por parte de la oposición la apertura de un proceso de impedimento bajo la justificativa de crimen fiscal cometido por la presidenta. 
[p]arece que los dominados dominan, pues proporcionan la "dirección moral" y, físicamente, incluso, están al frente de las organizaciones del Estado, directa o indirectamente, y de las grandes estatales. Parece que ellos son los propios capitalistas, pues los grandes fondos de pensiones del Estado son el corazón del nuevo sistema financiero brasileño y financian fuertemente la deuda pública interna. Parece que comandan la política porque disponen de poderosos bancos en la Cámara de Diputados y del Senado. Parece que la economía está finalmente estabilizada, que se dispone de una sólida moneda y que tal hazaña se debió a la política de gobierno, principalmente, en el primer mandato de Lula. El conjunto de apariencias esconde otra cosa, para lo cual todavía no tenemos nombre o tal vez concepto [...]. [Según Gramsci] El consentimiento siempre fue el producto de un conflicto de clases en el que los dominantes, al elaborar la ideología, que se convierte en la ideología dominante, trabajan la construcción de las clases dominadas a su imagen y semejanza [...]. Estamos en frente de una nueva dominación: los dominados realizan la "revolución moral" - derrota del apartheid en Sudáfrica y la elección de Lula y Bolsa Família en Brasil- que transforma y se deforma, en capitulación ante la explotación desenfrenada. En términos de Marx y Engels, de la ecuación "fuerza + consentimiento" que forma la hegemonía desaparece el elemento "fuerza". Y el consentimiento se convierte en su inverso: ya no son los dominados que consienten su propia explotación; es el dominante -capitalistas y capital, es explícito- que consiente ser conducido políticamente por los dominados, con la condición de que la "dirección moral" no cuestione la forma de explotación capitalista [Oliveira, 2010: 26-27].

Paulani interpreta la "hegemonía a la inversa" como el resultado de una separación inusual entre los papeles atribuidos a la clase hegemónica, tal como es concebida por Gramsci [Paulani, 2010]. Mientras que una clase hegemónica ejerce el liderazgo moral e intelectual, su opuesto ejerce el liderazgo material. Tal situación es cómoda para las clases burguesas, que pueden ejercer su liderazgo material (explotar) sin pagar el precio de las concesiones y reformas, eximidas que están de funcionar como liderazgo moral de la sociedad.

El hecho de que el liderazgo moral sea ejercido por la clase dominada es más funcional para el ejercicio del liderazgo que importa, el material, en comparación con el caso en el que ambos liderazgos son ejercidos por 
la clase dominante, como en la referencia gramsciana. ${ }^{6}$ En opinión de la autora, la hegemonía sigue siendo de los dominantes, pero es operada por los dominados, que están a cargo del Estado y obedientes a la lógica de la acumulación financiera.

Por este aspecto es que fue posible atender determinadas reivindicaciones de otras fracciones de capital y clases subalternas mediante programas como el Programa Luz para Todos, de 2003 [Camargo, 2010; Werner, 2016]; Programa Bolsa Família, de 2003 [Jannuzzi y Rodrigues, 2013; Cohn, 2013]; Programa de Aceleración del Crecimiento, de 2007 [Jardim y Silva, 2015]; Mi casa Mi vida, de 2009 [Cardoso, 2013; Mioto, 2015]; políticas relacionadas con la educación técnica y universitaria [Araújo, 2013]; cambio en la estrategia geopolítica, como lo demuestra el proyecto Unión de Naciones Sudamericanas (Unasur) [Amorim, 2015], entre otras acciones gubernamentales que marcan los gobiernos de Lula (2003-2006 y 2007-2010) y Dilma (20112014), incluso bajo políticas macroeconómicas favorables a la acumulación financiera.

A pesar de estas políticas, a lo largo de todo el periodo se mantuvo una estructura tributaria regresiva [Receita Federal, 2018]; la reducción de la desigualdad de ingresos se produjo, pero sin priorizar estrategias capaces de cambiar estructuralmente la condición y el nivel de insuficiencia socioeconómica en términos de acceso a bienes y servicios: saneamiento básico, cañerías para agua potable y transporte público, entre otros [Trovão, 2015]. Tanto el aumento real del salario mínimo verificado en el periodo como el de la formalización contribuyeron a la caída de la desigualdad de ingresos, aunque la mayoría de los empleos formales generados por la actividad económica en Brasil se caracterizaron por ser de bajos salarios [DIEESE, 2014; Baltar et al., 2017].

En consecuencia, se verifica que el patrón de acumulación que se estableció a partir de 2003, vinculado con los sectores financieros y la inserción

${ }^{6}$ Paulani [2010: 126] destaca el concepto original de hegemonía en Gramsci: "La hegemonía de la clase dominante (la burguesía), es ejercida principalmente a través de un liderazgo moral e intelectual, que opera dentro de la sociedad civil y engendra el consentimiento. El precio a pagar por este tipo de alianza es la desvinculación de la clase hegemónica de sus intereses materiales más inmediatos y la realización de concesiones y reformas que atienden los intereses de otras clases. Por lo tanto, el liderazgo se da a cierta clase, pero también se le atribuye la responsabilidad por el avance de la sociedad como un todo". 
pasiva comercial, permitió consolidar la hegemonía financiera en conciliación con las demandas de las clases subalternas y las fracciones de clase no hegemónica, y que correspondió al Estado actuar para asegurar los intereses a largo plazo de la clase dominante [Poulantzas, 2013]. En este sentido, la dinámica proporcionada por el auge de los commodities posibilitó llevar a cabo las intenciones del gobierno de centro-izquierda de mejorar la vida de las poblaciones más pobres sin cambiar estructuralmente los determinantes económicos, que se conservaron neoliberales.

Se argumenta, por tanto, que la inercia de los determinantes de la desigualdad y el mantenimiento de la inserción internacional primario-exportadora y de las políticas neoliberalizantes contribuyeron a promover un proceso de emancipación restringido por estos mismos elementos liberalizantes. A pesar de una posible reconciliación entre la neoliberalización y los beneficios sociales en el periodo de ascensión económica, el proyecto se vuelve insostenible cuando se revierte cíclicamente. Esto es emancipación restringida porque sus resultados fueron restringidos por la inserción periférica internacional, por la dependencia del mercado exterior y por la estructura productiva reprendida. Además, la capacidad fiscal del Estado estaba limitada por la macroeconomía financiera, lo que hacía imposible que el excedente económico del periodo se dirigiera a la provisión de bienes de consumo colectivos.

NotAS FINALES. De LA REVERSIÓN CíCLICA A LA PROFUNDIZACIÓN DEL PROCESO DE NEOLIBERALIZACIÓN

La heteronomía y la dependencia que marcan el desarrollo brasileño [Paulani, 2013] limitarían la sustentación del proyecto hegemónico, con la desaceleración del mercado exterior y las consecuencias de la crisis financiera global, en especial a partir de 2010. La crisis de 2008 en los países centrales, que sacudió el sistema financiero internacional, no fue capaz de revertir la hegemonía financiera, y ante los efectos en la economía brasileña, sobre todo desde 2013, culminaría en los cuestionamientos de las políticas en curso.

El proceso de desarrollo capitalista en Brasil, caracterizado por largos periodos autoritarios y por el rechazo de conciliar los intereses de la acumulación de capital con la ampliación de los horizontes de posibilidades 
para parcelas crecientes de la población, alcanzó elevadas tasas de crecimiento económico concomitante con la producción de una "máquina de desigualdad" [Tavares, 1999; Brandão, 2007]. Se consolidó una sociedad desigual en términos económicos, políticos y sociales, donde la mayoría de la población fue destituida de las mínimas condiciones emancipatorias, con espacios restrictos de acción en cuanto sujeto político para presionar y reivindicar derechos junto a las élites políticas y económicas -conservadoras y retrogradas-, lo que posibilitaría condiciones de ejercicio de ciudadanía plena.

Las contradicciones de una sociedad compleja y desigual no estarían ausentes ni en el contexto de las transformaciones en curso ni en el presente análisis. Lo que se encuentra es que el periodo posterior a 2003 no rompió con los marcos del proceso de neoliberalización en curso, lo que remite al "neoliberalismo realmente existente" tratado por Theodore et al. [2009].

Sobre este aspecto, se destaca el mantenimiento de la macroeconomía de las finanzas: altas tasas de interés, tipos de cambio valorados y altos superávit primarios; el mantenimiento de la desvinculación de las recetas de la unión que retira recursos de gasto primario; la intensificación de las asociaciones público-privadas, cuyo socio mayoritario corresponde a los agentes privados, mientras que los recursos técnicos y financieros provendrían de empresas públicas y de bancos públicos; y reformas de pensiones que priorizan a los agentes financieros privados.

En términos productivos, se profundiza en el proceso de desindustrialización y reprimarización de la agenda exportadora. El cambio de China en la jerarquía mundial y su búsqueda de proveedores de commodities agrícolas y minerales favorecieron las exportaciones brasileñas, pero nos colocaron en la posición de exportadores de productos primarios e importadores de manufacturas [Fernández, 2017], una situación contra la cual se empeñaron las políticas de desarrollo nacional, desde mediados del siglo xx, a partir de las contribuciones de los pensadores de la tradición históricoestructural de la Cepal.

En términos de división regional del trabajo, si las desigualdades regionales oriundas derivadas del proceso de industrialización e integración productiva buscaron ser subsanadas mediante la creación de agencias de planificación regional, así como la experiencia de la Superintendencia 
de Desarrollo del Noreste (Sudene, 1959) [Oliveira y Werner, 2014], el proceso de neoliberalización fue testigo de la inserción de las regiones brasileñas en la dinámica de la acumulación global, destacando las especializadas en productos agrícolas y minerales, como la agroindustria en el centro-oeste y la minería en el norte, además de las regiones petroleras.

Así, la agroindustria y la minería dinamizaron las ciudades medias al impulsar los vínculos local-globales y suscitaron análisis que denunciaban la fragmentación de la nación [Pacheco, 1998; Vainer, 2007], mientras había aquellos que elogiaban la panacea de lo local como una escala apropiada para las políticas de desarrollo, criticadas por Brandão [2007].

En cuanto a las inversiones estatales, el PAC trató de dar competitividad a las exportaciones de commodities con inversiones en logística (autopistas, puertos y ferrocarriles), parques eólicos e hidroeléctricas, incluida la exploración de la frontera hidroenergética del país, la Amazonía, y garantizando la viabilidad económica a los sectores electrointensivos como la minería, la siderurgia, el papel, la celulosa y el cemento. Con este fin, se aceleró la flexibilización de las normas y los reglamentos ambientales y sociales para la especialización regresiva.

Así, la inserción productiva internacional se distinguió por el vínculo con la explotación de los recursos naturales que agudizó conflictos por los fundos (tierras), conflictos sociales y ambientales en torno del modo de apropiación de territorios, como ocurrió en los casos de las usinas hidroeléctricas (UHE) de Santo Antonio, Jirau y Belo Monte, y en fecha más reciente, los delitos ambientales de Mariana, Brumadinho y los quemados en la Amazonía, revelando procesos de desigualdad ambiental y chantaje de arrendamiento [Acselrad, 2013] perpetrado por el gran capital articulado con las élites nacionales y locales vinculadas con los sectores primario-exportadores, la construcción civil y el capital financiero. Estos procesos exponen los conflictos entre la acumulación capitalista desregulada y las formas tradicionales de ocupación territorial.

La ausencia de reforma tributaria, política y de la mídia, faltante en el proyecto iniciado en 2003, expuso la fragilidad del proyecto en la crisis financiera de 2008, con los primeros signos de reversión cíclica en Brasil que se produjo a partir de 2011. Entre 2009 y 2014, el gobierno brasileño todavía fue capaz de estimular la dinámica económica por medio de inversiones públicas, estímulos a la inversión y el consumo mediante el crédito 
de los bancos públicos, inversiones en programas de vivienda popular (MCMv) y con los megaeventos.

Sin embargo, tanto la desaceleración de la economía inicialmente debida a la caída de los precios de los commodities, como las renuncias y exenciones fiscales promovidas por el gobierno como remedio contra la reversión cíclica, que causarían una caída de las reservas por exportaciones y después una caída de las reservas fiscales del gobierno [Gentil y Hermann, 2017], dificultaron la estrategia del gobierno de sustentar la demanda, y en consecuencia las políticas de desarrollo sin promover la ruptura con las estructuras pasadas.

La crisis económica y política que se instaura a partir de 2015 revela contradicciones del proyecto iniciado en 2003 que, a pesar de buscar la implementación de políticas progresistas en términos sociales, pretendió conciliarlas con la agenda neoliberal y los aliados políticos relacionados con el periodo de confinamiento de las aspiraciones democráticas y emancipadoras de años anteriores. En cuanto hubo crecimiento económico fue posible conciliar altas tasas de ganancias y ganancias rentistas con algunas concesiones sociales, que si bien generaron transformaciones y rupturas generacionales, no se arraigaron como valores societarios innegociables, de manera que no se tornaron perennes en la sociedad brasileña.

Se evidenció, por tanto, la fragilidad en la que se basaban las transformaciones de los últimos años. Delante de la no convergencia entre las ganancias económicas de las élites rentistas, financistas y primario-exportadoras, el siguiente paso fue no solo socavar las frágiles conquistas sociales en marcha desde 2003, sino que, y de manera relevante, se empeñaron en contra del mismo pacto societario expresado en la constitución federal de 1988 al imponer como solución de la crisis la profundización de la agenda neoliberal, aspecto que se evidencia en los cambios introducidos en la política fiscal a partir de la Enmienda Constitucional de 1995 [Dweck et al., 2018].

En la búsqueda de recomponer las pérdidas económicas y políticas, los sectores ricos de la sociedad, con el apoyo de la clase media y los medios de comunicación, presionan para una mayor apropiación del fondo público, lo que daría lugar a la Enmienda Constitucional del 95, la deslegitimación de las políticas sociales, la reforma laboral, la reforma de las pensiones, el posicionamiento contra las políticas educativas y los conocimientos 
académico-científicos en una clara ofensiva contra la educación básica, alta y universitaria, y la flexibilización del marco ambiental, entre otros reveses, marcas del primer año del gobierno de Jair Bolsonaro (2018-2022).

El discurso contra las libertades individuales, la pérdida de los derechos sociales y el resurgimiento de la violencia del Estado fueron aspectos legitimados en las elecciones y evidencian tanto la deslegitimación de la política como la incapacidad de las fuerzas progresistas para articular a las clases privilegiadas como aliadas en la transformación social.

En términos de política exterior, el país se niega a ocupar un papel de liderazgo en el escenario internacional al asumir una posición subordinada ante los deseos de la potencia hegemónica. Este posicionamiento debilita los recientes logros internacionales, de mayor protagonismo en los espacios multilaterales, así como el liderazgo regional adquirido después del 2000, lo que contribuyó a la estabilidad presenciada en América Latina [Amorim, 2015]. La crisis económica en Venezuela y la crisis política en Bolivia y Chile frente a la posición brasileña ya revelan las consecuencias nefastas del abandono de Brasil como líder regional.

Una negativa similar se percibe en el debate medioambiental, ya que Brasil ha protagonizado, desde el Eco-92, una posición destacada en los foros internacionales, así como ha ocupado un papel importante en las articulaciones de los Acuerdos de París en beneficio del clima. La posición de desmantelar la agenda ambiental y las instituciones nacionales y la amenaza misma de abandonar los Acuerdos de París ponen en riesgo el protagonismo alcanzado en las últimas décadas y colocan a Brasil en confrontación con los socios internacionales.

Por todos los puntos señalados, se concluye que el término neoliberalismo realmente existente se considera el más apropiado para caracterizar a Brasil en el periodo posterior al 2000, en el que se trató de conciliar los logros sociales sin romper con los determinantes del proceso de neoliberalización. Los efectos de la crisis de 2008 destacarían la fragilidad del proyecto, que se revela como una emancipación restringida para la sociedad brasileña a pesar de la interpretación de un modelo de crecimiento económico de sesgo desarrollista.

Por tanto, el momento vivido requiere reflexiones capaces de rescatar el deseado proyecto societario de emancipación, los instrumentos a 
movilizar por los sujetos sociales colectivos, las posibles escalas de acción de los individuos y sus respectivas fuerzas a ser empeñadas. Requiere resistirse y reexistir para preparar los cimientos que permitan la reconducción de los destinos de la nación de manera democrática, soberana e igualitaria, y que seamos capaces de hacer justicia al legado crítico latinoamericano del cual somos herederos políticos e intelectuales.

\section{REFERENCIAS}

Acselrad, Henri et al. [2012], "Desigualdade ambiental e acumulação por espoliação: o que está em jogo na questão ambiental?", en E-cadernos Ces, 17. <http://eces.revues.org/1138>. Consulta: 05 de septiembre de 2012.

Acselrad, Henri [2013], "Desigualdade ambiental, economia e política", en Astrolabio, Buenos Aires, vol. 11, pp. 105-123.

Almeida, Alfredo Wagner [2012], "Entre a 'proteção' e o 'protecionismo", en Le Monde Diplomatique, Sao Paulo, 4 de mayo.

Amorim, Celso [2015], Teerã, Ramalá e Doha: Memórias da política externa ativa e altiva. Sao Paulo, Benvirá, 513 pp.

Araújo, Tania B. de [2013], "Tendências do desenvolvimento regional recente no Brasil", en Carlos Brandão e Hipólita Siqueira, orgs., Pacto federativo, integração nacional e desenvolvimento regional. Sao Paulo, Editora Fundação Perseu Abramo.

Baltar, Paulo Eduardo de A., Jacqueline A. Souen y Guilherme C. de Souza Campo [2017], "Emprego e distribuição de Renda", en Texto para discussão. Instituto de Economía, Unicamp, núm. 298, mayo. <http:// www.eco.unicamp.br/docprod/downarq.php?id=3527\&tp=a>, 6 de octubre de 2019.

Bastos, Pedro Paulo Zahluth [2012], "A economia política do novo-desenvolvimentismo e do social desenvolvimentismo", en Economia e Sociedade [online], Campinas, vol. 21, núm. spe, diciembre, pp. 779-810. $<$ https://cutt.ly/ggkX7m7>, noviembre de 2019.

Brandão, Carlos Antônio [2007], Território e desenvolvimento: as múltiplas escalas entre o local e o global. Campinas, Unicamp, 238 pp. 
[2012], "Celso Furtado: subdesenvolvimento, dependência, cultura e criatividade", en Revista de Economía Política de las Tecnologías de la Información y de la Comunicación, vol. 14, núm. 1, pp. 94-110.

[2017], "Crise e rodadas de neoliberalização: impactos nos espaços metropolitanos e no mundo do trabalho no Brasil”, en Cadernos $\mathrm{Me}$ trópole, vol. 19, núm. 38, pp. 45-69.

Brenner, Neil, Jamie Peck y Nik Theodore [2012], “Após a neoliberalização?”, en Cadernos Metrópole, Estados Unidos, vol. 14, núm. 27, pp. 15-39.

Bresser-Pereira, Luis Carlos [2009], "O novo-desenvolvimentismo", en Globalização e Competição, Río de Janeiro, Campus-Elsevier, pp. 75-94. Camargo, E. J. S. [2010], "Programa luz para todos - da eletrificação rural à universalização do acesso à energia elétrica - da necessidade de uma política de Estado", disertación en maestría de Energía, Universidad de São Paulo, São Paulo, <www.teses.usp.br>, doi:10.11606/ D.86.2010. tde-22092010-010215

Cano, Wilson [2000], Soberania e Política na América Latina, Sao Paulo, Unesp, $582 \mathrm{pp}$.

[2012], "A desindustrialização no Brasil", en Economia e Sociedade, Campinas, vol. 21, núm. spe, pp. 831-851. <https://dx.doi.org/10.1590/ S0104-06182012000400006>.

Cardoso, Adauto Lucio (org.) [2013], O programa Minha Casa Minha Vida e seus efeitos territoriais. Río de Janeiro, Letra Capital.

Cardoso de Mello, João Manuel [1984], O Capitalismo Tardio: contribuição à revisão crítica da formação e do desenvolvimento da economia brasileira. Sao Paulo, Brasiliense, $182 \mathrm{pp}$.

Carvalho, Laura [2018], Valsa brasileira: do boom ao caos econômico. Sao Paulo, Todavia, $192 \mathrm{pp}$.

Cohn, A. [2013], "Desafios de uma trajetória de êxito: dez anos do PBF", en Tereza Campello y Marcelo Côrtes Neri (org.), Programa Bolsa Família uma década de inclusão e cidadania, Brasilia, IPEA.

Constituição Federal de 1988. <https://cutt.ly/5gkCtfw>, 3 de diciembre de 2019.

Departamento Intersindical de Estatística e Estudos Socioeconômicos (DIEESE) [2014], "Política de Valorização do Salário Mínimo", en Nota técnica, núm. 132, enero. <https://cutt.ly/MgkCiah>, 10 de noviembre de 2019. 
Dweck, Esther, Ana Luísa Mattos de Oliveira y Pedro Rossi [2018], Austeridade e Retrocesso: Impactos Sociais da Política Fiscal no Brasil, Sao Paulo: Brasil Debate y Fundação Friedrich Ebert.

Fagnani, Eduardo [2005], Política social no Brasil (1964-2002): entre a cidadania e a caridade. Campinas. Tesis, Universidade Estadual de Campinas, Instituto de Economía, 614 pp. <http://www.repositorio. unicamp.br/handle/REPOSIP/285940>.

[2017], "O fim do breve ciclo da cidadania social no Brasil (19882015)", en Texto para discussão, núm. 308, Campinas, Instituto de Economía, Unicamp. <https://cee.fiocruz.br>, 6 de diciembre de 2019.

Fernández, Víctor Ramiro [2017], La trilogía del erizo-zorro. Redes globales, trayectorias nacionales y dinámicas regionales desde la periferia, Barcelona, Anthropos/Editoral, Santa Fe, Ediciones UnL, 400 pp.

Fonseca, Pedro Correa Dutra [2015], Desenvolvimentismo: a construção do conceito. Brasilia-Río de Janeiro, Instituto de Pesquisa Econômica Aplicada.

Fondo Monetario Internacional [2020], Evolução de índices médios de preços de commodities, conforme tipologia. 2000-2019 (2016=100). $<$ https://data.imf.org>, 16 de enero de 2020.

Gentil, Denise y Jennifer Hermann [2017], "A política fiscal do primeiro governo Dilma Rousseff: ortodoxia e retrocesso", en Economia e Sociedade, vol. 26, núm. 3, pp. 793-816.

Gonçalves, Reinaldo [2013], Desenvolvimentismo às avessas: verdade, má-fé e ilusão no atual modelo brasileiro de desenvolvimento. Río de Janeiro, LTC, $212 \mathrm{pp}$.

Jannuzzi, Paulo y Alejandro Rodrigues Pinto [2013], "Bolsa Família e seus impactos nas condições de vida da população brasileira: uma síntese dos principais achados da pesquisa de avaliação de impacto do Bolsa Família”, en Tereza Campello y Marcelo Côrtes Neri, org., Programa Bolsa Família uma década de inclusão e cidadania. Brasilia, IPEA.

Jardim, M. C. y M. R. Silva [2015], Programa de Aceleração do Crescimento: neodesenvolvimentismo?, Sao Paulo, Unesp.

Medeiros, Carlos Aguiar de [2015], Inserção externa, crescimento e padrões de consumo na economia brasileira. Brasilia, IPEA.

Mioto, B. [2015], As políticas habitacionais no subdesenvolvimento: os casos do Brasil, México e Venezuela (1980/2013). Campinas. Tesis, Unicamp. 
Oliveira, Francisco de [2010], "Hegemonia às avessas", en Cibele Saliba Rizek, Ruy Braga y Francisco de Oliveira, Hegemonia às avessas: economia, política e cultura na era da servidão financeira. <https://cutt.ly/ Xs9vhmZ>.

Oliveira, Fabio Lucas Pimentel y Deborah Werner [2014], Perspectiva histórica do planejamento regional no Brasil. Santiago, Ilpes-Cepal, $32 \mathrm{pp}$.

Orair, Rodrigo Octávio [2015], "Notas sobre a trajetória do investimento público no Brasil”, en Gabriel Coelho Squeff (org.), Dinâmica Macrossetorial Brasileira. Brasilia, IPEA.

Pacheco, Carlos Américo [1998], A fragmentação da Nação. Campinas, IE/ Unicamp.

Paulani, Leda [2017], "A experiência brasileira entre 2003 e 2014: Neodesenvolvimentismo?”, en Cadernos do Desenvolvimento, Río de Janeiro, vol. 12, núm. 20, pp. 135-155.

[2010], "Capitalismo financeiro, estado de emergência econômico e hegemonia às avessas", en Cibele Saliba Rizek, Ruy Braga y Francisco de Oliveira, Hegemonia às avessas: economia, política e cultura na era da servidão financeira, São Paulo, Boitempo: 109-136.

[2013], "Acumulação sistêmica, poupança externa e rentismo: observações sobre o caso brasileiro", en Estudos Avançados, vol. 27, núm. 77, pp. 237-264.

Peck, Jamie [2010], Constructions of Neoliberal Reason. Oxford, Oxford University Press, 324 pp.

Peck, Jamie y Nik Theodore [2019], "Still Neoliberalism?", en The South Atlantic Quarterly, Duke University Press, abril, vol. 118, issue 2.

Polanyi, Karl [1980], A grande transformação. Sao Paulo, Editora Campus. $306 \mathrm{pp}$.

Poulantzas, Nicos [2013 (1978)], L'Etat, le pouvoir et le socialisme, París, Les Prairies Ordinaires, $400 \mathrm{pp}$.

Receita Federal [2018], Carga Tributária no Brasil, 2017. Análise por Tributos e Bases de Incidência. Ministério da Fazenda.

Swyngedouw, Erik [1997], "Neither Global Nor Local: 'Glocalization' and the Politics of Scale", en Spaces of Globalization: Reasserting the Power of the Local, Nueva York-Londres, Guilford/Longman, p. 137-166. 
Tavares, Maria da Conceição [1999], "Império, território e dinheiro", en José Luís Fiori (org.), Estado e moedas no desenvolvimento das nações. Petrópolis, Vozes, 496 pp.

Theodore, Nik, Jamie Peck y Neil Brenner [2009], "Urbanismo neoliberal: la ciudad y el imperio de los mercados", Temas Sociales, marzo, vol. 66 .

Trovão, Cassiano José Bezerra Marques [2015], Desigualdade multidimensional: uma abordagem Keynesiana para o seu enfrentamento. Campinas, SP. Tesis, Universidade Estadual de Campinas, Instituto de Economía, 241 pp. <http://www.repositorio.unicamp.br>, 20 de octubre de 2019.

Vainer, Carlos [2007], "Fragmentação e projeto nacional: Desafios para o planejamento territorial", en Célio Campolina Diniz (org.), Políticas de desenvolvimento regional: desafios e perspectivas à luz da experiência da União Europeia e do Brasil, Ministério da Integração Nacional, vol.1, pp. 103-130.

Werner, Deborah [2016], "Estado, capitais privados e territórios no processo de reconfiguração do setor elétrico brasileiro pós-1990", tesis doctoral, Carlos Bernardo Vainer (dir.), Río de Janeiro, Universidad Federal de Río de Janeiro, 434 pp., <https://cutt.ly/ls9msW6>. 



\title{
4. ¿PREBISCH RENACE EN EL NUEVO CAPITALISMO?'
}

\author{
Sebastián Sztulwark*
}

INTRODUCCIÓN

La potencia del pensamiento estructuralista latinoamericano de posguerra emanaba de su apelación a desnaturalizar el discurso del libre comercio como única opción para el desarrollo económico de nuestros países. En el marco de un sistema económico mundial polarizante, la política de transformación productiva, la industrialización, constituía el camino necesario para romper con el carácter periférico de nuestra inserción internacional. Como contracara, su comprensión del proceso de desarrollo, de los actores y las fuerzas concretas que impulsan y bloquean el cambio fue más débil [Fernández y Brondino, 2019].

El debate se reactualiza con la crisis del neoliberalismo en América Latina y la experiencia de los llamados "gobiernos progresistas" en algunos países de la región, cuyo discurso y programa se orientaron a retomar una agenda de desarrollo desde una perspectiva heterodoxa. ${ }^{2}$ Lo que se verificó en algunas de estas experiencias fue una renovada capacidad para intervenir en la disputa por la apropiación del excedente económico. Sin embargo, a pesar de esta base diferente respecto de los gobiernos

* Investigador de la Universidad Nacional de General Sarmiento y del Conicet (Argentina). Correo electrónico: <sztulwark@campus.ungs.edu.ar>.

${ }^{1}$ Este trabajo es una reelaboración de una ponencia presentada con el mismo título en el taller "Alternativas al neoliberalismo en América Latina: Explorando potencialidades y limitaciones del pensamiento latinoamericano sobre el desarrollo", realizado en el Instituto de Investigaciones Económicas de la unAm, Ciudad de México, del 23 al 25 marzo de 2015.

${ }^{2}$ Las principales experiencias políticas asociadas con esta denominación fueron (o son) las del PT en Brasil, el kirchnerismo en Argentina, el Frente Amplio en Uruguay y los gobiernos de Hugo Chávez en Venezuela, de Rafael Correa en Ecuador y de Evo Morales en Bolivia. 
neoliberales de los años noventa, no se registraron avances de una magnitud significativa en materia de transformación productiva. En efecto, a pesar de la existencia de algunas iniciativas orientadas a la diversificación y diferenciación productiva, el núcleo fundamental de la inserción internacional de la región continúa basado en la exportación de commodities primarios e industriales y de servicios de escasa complejidad productiva [Cepal, 2016]. A la luz de estas experiencias recientes, sigue abierta la cuestión de cómo avanzar en un proceso de cambio estructural en América Latina. Una pregunta propiamente estructuralista.

Un interrogante de este tipo implica considerar cuál debería ser la dirección de la transformación productiva en nuestros países para lograr un cambio en la jerarquía de la economía mundial. Una problemática que remite a la figura de Raúl Prebisch, que en este trabajo consideramos no en toda la amplitud de su obra ni de su controvertida actuación como "hombre político", sino de un modo más limitado, pero también más preciso: como el significante del cambio estructural. ${ }^{3}$ La pregunta fundamental es, por lo tanto, qué significa el cambio estructural en el nuevo capitalismo. ${ }^{4}$

El trabajo considera tres núcleos conceptuales para pensar históricamente este problema. En primer lugar, la concepción de Prebisch de posguerra que plantea una diferenciación centro-periferia en torno a la polarización mundial entre estructuras que producen bienes industriales y primarios. En segundo lugar, la síntesis estructural-schumpeteriana, que propone un esquema de divergencia internacional en torno al contenido tecnológico de los bienes y las barreras a la entrada que se constituyen en

\footnotetext{
${ }^{3}$ Prebisch fue considerado como un dependentista por ciertas lecturas ortodoxas y como un ortodoxo por el dependentismo más radical. El título de este trabajo, sin embargo, se inspira en un artículo de Alice Amsden publicado en la revista de la Cepal en el año 2004, "La sustitución de importaciones en las industrias de alta tecnología: Prebisch renace en Asia". En este trabajo la autora plantea que el despliegue en estos países de una nueva generación de políticas de promoción de la alta tecnología puede interpretarse como una superación de las políticas de sustitución de importación de posguerra y, al mismo tiempo, como una reactualización de las ideas fundamentales de Prebisch sobre el desarrollo económico. Es en este sentido que podemos asociar el nombre de Prebisch con el significante del cambio estructural.

${ }^{4}$ La noción de "nuevo capitalismo" alude a una transformación interna al modo de producción capitalista que tiene como rasgo fundamental el pasaje de un "régimen de reproducción", en el que la valorización reposaba esencialmente sobre el dominio del tiempo de reproducción de mercancías estandarizadas, a un "régimen de invención", en el que el proceso de valorización se apoya principalmente en un tiempo de creación de nuevos conocimientos [Corsani, 2003]. El carácter novedoso de la etapa actual radica, por lo tanto, en una forma singularmente nueva de articular la producción de conocimiento con la producción de valor.
} 
torno de ellos. En tercer lugar, se incorpora la perspectiva de un "nuevo capitalismo". El punto fundamental a considerar es una nueva articulación, de naturaleza postschumpeteriana, entre invención e innovación. El cambio estructural remite a la articulación de esta doble dimensión, entre conocimiento y producción pero también entre economía y cultura, que cobra una particular significación en el nuevo capitalismo.

Sobre esta base conceptual, que podría denominarse como la de un estructuralismo cognitivo, se argumenta que el déficit principal de las políticas de cambio estructural aplicadas por los llamados "gobiernos progresistas" de América Latina no se ubica necesariamente en la ausencia de esquemas de promoción productiva sino, más bien, en la escala y orientación de los recursos aplicados y en la desarticulación entre las políticas de creación y fortalecimiento de un sistema de conocimiento, por un lado, y de ascenso industrial (o upgrading) en determinadas cadenas globales, por el otro.

En las páginas que siguen se desarrolla históricamente el concepto de cambio estructural y se plantean, de modo preliminar, algunas implicaciones para el desarrollo latinoamericano en el marco del nuevo capitalismo.

\section{El significado del CAMbio estructural en Prebisch}

El concepto de cambio estructural tiene dos vertientes. Una primera cuya preocupación es cómo afecta el cambio en la composición del producto al crecimiento de una economía representativa. Es una línea que se remonta a los trabajos pioneros, en los años treinta y cuarenta, de autores como Fisher [1939] o Clark [1967 (1940)] y continúa tanto en una perspectiva neoclásica como poskeynesiana [Syrquin, 1988]. La segunda tiene como antecedente los aportes clásicos del desarrollismo de posguerra y, a diferencia de la anterior, sostiene que ese proceso de cambio difiere en su naturaleza según se trate de una economía desarrollada o subdesarrollada. En esta última línea ubicamos, por supuesto, a Prebisch y el estructuralismo latinoamericano de posguerra.

En esta perspectiva, el cambio en la estructura productiva de un determinado territorio solo puede comprenderse como parte de la dinámica de la macroestructura de la economía mundial. De la estructura del capitalismo. El concepto de estructura realza los aspectos invariantes de un 
determinado modo de funcionamiento. En el estructuralismo latinoamericano ese aspecto invariante es el carácter jerárquico que asume la relación entre un polo central (dominante) y un polo periférico (subordinado). Esta asimetría es la que sustenta, como diría Prebisch, el "carácter centrípeto" del capitalismo, dado que es el polo central el que retiene los "frutos del progreso técnico" [Prebisch, 1963 (1949)].

¿Cómo es este modo de funcionamiento? Hay que mirar la diferencia en las estructuras productivas de ambos polos. En el polo central, núcleo del dinamismo tecnológico mundial, la estructura es homogénea y diversificada. Esto es, todas las actividades productivas tienen niveles de productividad cercanas a la frontera internacional y su dinámica económica externa no depende de un solo sector productivo. En contraste, el polo periférico se incorpora tardíamente a la difusión del cambio tecnológico, y de ese proceso, su estructura adquiere un carácter heterogéneo (actividades de alta productividad conviviendo con otras de muy baja eficiencia) y especializado (su inserción internacional se apoya unilateralmente en la exportación de bienes de escasa elaboración y baja integración económica interna). El rasgo específico de la crisis de la periferia es, en consecuencia, la falta de acumulación de capital y no su exceso.

¿Por qué hay falta de acumulación en la periferia? No porque en ella no se genere un excedente suficiente. Tomemos la argumentación del Prebisch maduro, el del Capitalismo periférico [1981]. Allí Prebisch sostiene que el excedente de la periferia tiene una naturaleza diferente al generado en el centro. Mientras en aquel la fuente del excedente se vincula con los beneficios extraordinarios que surgen del cambio tecnológico, en la periferia este se constituye sobre la base de la desigualdad. El argumento es que a medida que el progreso técnico se difunde hacia la periferia, y se desplaza mano de obra de los sectores de baja a los de alta productividad, el salario no evoluciona, aun en un marco competitivo, de manera equivalente al aumento de la productividad (como presupone la teoría neoclásica). El problema radica en las características de la estructura productiva de la periferia. En su carácter subdesarrollado. En la existencia de una masa enorme de trabajadores de baja productividad empleada en las actividades primarias, que provoca una competencia regresiva que tiende a inhibir el aumento del salario a medida que se incrementa la productividad por la propagación del progreso técnico del centro a la periferia. 
El problema, entonces, es que hay excedente pero falta acumulación de capital. Prebisch [1981] plantea tres causas: a) la sociedad privilegiada de consumo, b) la hipertrofia del Estado y c) la succión de los centros. Las tres implican un lugar subordinado en una estructura mundial. Las dos primeras aluden a un desajuste entre el ritmo deseable de la acumulación de capital y su nivel efectivo, que surge en el marco de las conductas y demandas sociales de la periferia. En ambos casos, por detrás existe un "efecto demostración" de la dinámica social del centro. En el caso de la sociedad privilegiada de consumo, se trata de que los propietarios del excedente tienden a imitar el patrón de consumo de sus pares del centro, sin contar aún con una base de acumulación suficiente. Esto es, se produce un desequilibrio entre la proporción destinada a ese consumo "privilegiado" y las necesidades de acumulación en la periferia. Algo similar ocurre con la "hipertrofia del Estado". Acá el problema no es que el Estado asuma funciones de bienestar, sino que las asuma tempranamente, sin que aún se hayan desplegado en la periferia las bases de la acumulación que le den un fundamento más consistente. En ambos casos existe excedente, pero no se utiliza con los fines de la acumulación.

La tercera causa apunta a una dimensión diferente. Es la acción directa de los centros apropiándose del excedente de la periferia y orientándolo hacia su propio desarrollo. Dos mecanismos principales menciona el autor. Uno tiene que ver con la inversión directa (el giro de utilidades) y otro con el comercio (el deterioro de los términos de intercambio). Los autores tercermundistas y dependentistas han visto en este mecanismo el fundamento de la propia acumulación del centro. ${ }^{5}$ Pero en Prebisch (y en el estructuralismo en general), las cosas son diferentes. El desarrollo del centro tiene que ver con su constitución como polo difusor del "progreso técnico" mundial (centro de la Revolución industrial). La periferia en cambio debe su carácter a su integración tardía a ese proceso. La succión de los centros, en todo caso, refuerza el carácter centrípeto del capitalismo, pero no lo explica. Es la posición en la estructura lo que permite la succión y no la succión la que explica el lugar en la estructura.

Tomemos el caso de la explicación del deterioro de los términos de intercambio. La famosa tesis Prebisch (1963 [1949])-Singer [1950]. El fenómeno

\footnotetext{
${ }^{5}$ Para una versión crítica del paradigma tercermundista-dependentista, ver Dabat [1994].
} 
del deterioro alude a una tendencia por la cual el precio de los bienes exportados por la periferia (productos primarios) tiende a evolucionar desfavorablemente en relación con el precio de los bienes exportados por el centro (productos industriales). Las causas del deterioro tienen que ver, por supuesto, con razones de estructura. El excedente de mano de obra en la periferia presiona hacia abajo los salarios y los precios de los bienes primarios. ${ }^{6}$ En cambio, el centro posee una escasez relativa de fuerza de trabajo que, además, está mejor organizada y cuenta con una estructura empresarial de menor atomización que domina los segmentos de alta tecnología. Todos estos elementos proveen al centro de un mayor control oligopólico sobre los precios de sus productos.

Pero estas causas por el lado de la oferta tienden a verse reforzadas por las que surgen del lado de la demanda. El hecho que verifican Prebisch y Singer es el menor dinamismo de la demanda de bienes primarios en relación con el de los bienes industriales. Ese dinamismo diferencial se expresa en una menor elasticidad ingreso de la demanda de estos bienes. Mientras que la demanda de bienes primarios se comporta según lo establecido por la ley de Engel (una vez satisfechas ciertas necesidades básicas provistas por los bienes primarios, el consumo tiende a orientarse hacia los bienes más diferenciados), la demanda de bienes industriales, por el contrario, tiende a aumentar en una intensidad mayor conforme el ingreso de una determinada sociedad crece.

La implicación fundamental de la tesis Prebisch-Singer es que la disparidad de ingresos en la economía mundial no tiene que ver únicamente con las diferencias de productividad que separan el centro de la periferia, como enuncia el pensamiento más ortodoxo. Hay algo más. En el caso del comercio internacional, este plus tiene que ver con la succión de excedente que se verifica mediante el deterioro de los términos de intercambio. Aun aumentando la eficiencia en la producción de bienes primarios (mediante la incorporación de tecnología y formas modernas de organización), la brecha centro-periferia puede no cerrarse como consecuencia del deterioro de la relación de precios. De lo que se trata es de cambiar el patrón de especialización internacional hacia actividades que no estén sujetas al deterioro de los términos de intercambio, de modo tal de combinar el aumento

${ }^{6} \mathrm{~A}$ su vez, hay factores tecnológicos que inducen la baja del precio de los bienes primarios, como la sustitución de estos por productos sintéticos, por ejemplo. 
de productividad con la apropiación de los frutos de ese progreso técnico. En otras palabras, el problema es el subdesarrollo y la solución, el cambio estructural.

Ahora bien, cómo pensar el cambio estructural en una estructura que se considera invariante -ahí la riqueza del concepto de estructura-. El cambio estructural debe pensarse no como una transformación del modo de funcionamiento del capitalismo sino más bien como un cambio en la posición que una determinada región periférica puede ocupar dentro de esa estructura. En esto consiste el optimismo estructuralista. ${ }^{7}$ En la existencia de un muy estrecho sendero de cambio a partir de políticas públicas que sean capaces de contrarrestar las tendencias polarizantes que efectivamente tienden a prevalecer en la economía mundial.

Durante el periodo de posguerra, ese estrecho sendero de cambio estuvo asociado con el carácter específico que el proceso de industrialización asumió en los países de la región. En efecto, tal como lo explicara Albert Hirschman [1996], el proceso de industrialización latinoamericano no seguiría el patrón de los países pioneros, que fueron desarrollando de modo simultáneo las industrias de bienes de consumo y las de bienes de producción. La condición "tardía" de la industrialización latinoamericana se verificaba en un proceso de tipo secuencial, que implicaba un pasaje gradual desde las fases más simples (como la elaboración de bienes de consumo no durables) hacia las actividades industriales de mayor complejidad, como los bienes durables de consumo, la industria "pesada", y finalmente, los bienes de capital. La clave estaba en la posibilidad de superar los estrangulamientos tecnológicos que dicho pasaje implicaba. Industrialización sustitutiva fue el nombre del programa de reformas que se puso en marcha en la mayoría de los países de la región para avanzar en ese proceso de cambio estructural.

El proceso avanzaba en esa dirección, dando algunos frutos no desdeñables, al menos para los países más grandes de la región [Katz y Kosacoff, 1998]. Pero en uno de los nudos de mayor tensión que puso en marcha

\footnotetext{
${ }^{7}$ En un artículo publicado hace unos años en la revista de la Cepal, Aldo Ferrer, un referente de aquel viejo estructuralismo latinoamericano, afirma que uno de los mensajes fundamentales que conforman el legado de Raúl Prebisch es "que la transformación es posible, que sobre la base de una visión realista de los problemas se puede transformar la realidad, desplegar el potencial y lograr, con el resto del mundo y en primer lugar con los centros de poder mundial, una relación simétrica no subordinada" [Ferrer, 2010: 9].
} 
aquel proceso, y vinculado con ciertos movimientos en la geopolítica mundial, advino una terrible derrota política que se llevó consigo tanto el programa de reformas como el de investigación en el que este se apoyaba. El proyecto fue interrumpido, de la mano del triunfante programa de la globalización neoliberal.

En el abordaje estructuralista del cambio estructural, del significante Prebisch, existe un problema referente a su historicidad: en qué medida este esquema teórico sobrevive el momento histórico de auge del estructuralismo y del propio Prebisch, y puede ser apropiado, reutilizado para pensar el cambio estructural en el nuevo capitalismo.

Podemos abordar este fenómeno mediante la evolución del debate acerca de los términos de intercambio. Un trabajo fundamental en este caso es el de Kaplinsky [2006], que retoma a su vez las contribuciones del economista alemán Hans Singer (el coautor, junto con Prebisch, de la tesis del deterioro).

El principal aporte de Singer al debate posterior al de su contribución original sobre los términos de intercambio fue la conexión que estableció entre la perspectiva estructuralista y la schumpeteriana. En esta perspectiva, afirma Kaplinsky, Singer destaca el papel que desempeñan las barreras a la entrada en la determinación del ingreso y en el creciente papel de la innovación en ese proceso. De este modo, el paso fundamental que da Singer [1971] es abrir la posibilidad de que no todas las manufacturas necesariamente estén sujetas a términos de intercambio crecientes. Pero será veinte años después que Singer explorará en un trabajo empírico la posibilidad de que los precios de la manufactura exportada por la periferia se deterioren en relación con los precios de la manufactura exportada por los países del centro [Sakar y Singer, 1991]. El foco, como se ve, se modifica: los términos de intercambio se deterioran contra la periferia, pero esto no reproduce necesariamente un patrón de intercambio primarioindustrial, sino que se verifica también en el comercio intraindustrial.

Finalmente, Kaplinsky revisa un trabajo de Maizels del año 2003 en el que se constata que el deterioro de los términos de intercambio de la 
manufactura en contra de las naciones en desarrollo es menor en el caso de los tigres asiáticos que en el de otros países en desarrollo, lo que constituye, para el autor, una confirmación de la hipótesis schumpeteriana de Singer del año 1971, en relación con que los términos de intercambio están asociados con el nivel tecnológico de las manufacturas que se exportan.

A la contribución de Singer, el propio Kaplinsky agrega que este cambio al interior del sector manufacturero presagia un cambio en los términos de intercambio entre manufacturas y commodities. ${ }^{8}$ El autor presenta tres tendencias estructurales para sustentar esta afirmación.

En primer lugar, la "descomoditización" (en el original, de-commodification) de algunos productos primarios. Un commodity se define como un producto con bajas barreras a la entrada, en el que existe una intensa competencia que fuerza a la baja los márgenes de rentabilidad. ${ }^{9}$ Por el contrario, descomoditizar refleja un proceso en el que la rentabilidad de un producto crece conforme se erigen sobre él barreras a la entrada. En el caso de los commodities agrícolas (como el té, el café o la horticultura) se verifica un proceso efectivo de descomoditización, esto es, de creación de barreras a la entrada que permiten a sus productores constituir nichos de mercado diferenciados para evitar la caída general de los precios en los momentos de sobreproducción. Esta tendencia implicaría, al menos en parte, una reversión de la ley de Engel, uno de los pilares de la originaria tesis Prebisch-Singer, en la medida que esta dinámica de diferenciación asociaría una demanda creciente de bienes primarios (descomoditizados) con el crecimiento del ingreso per cápita de una sociedad.

La segunda tendencia refiere a la creciente concentración de los compradores globales de manufactura. En este punto, Kaplinsky se apoya en el enfoque de cadenas globales, sobre todo en la figura de la "cadena comandada por el comprador" de Gereffi [1996], que verifica la existencia de una segmentación global al interior de una cadena constituida por una gama de fabricantes de manufactura a bajo costo en la periferia con el comando de empresas de marca, los "compradores globales de manufactura", que poseen

${ }^{8}$ El autor diferencia manufacturas de commodities aunque, al mismo tiempo, sostiene que estas categorías no se excluyen mutuamente.

${ }^{9}$ Esta definición de commodity no es del todo operativa para los bienes primarios, en los que existen restricciones naturales en la oferta, y por lo tanto, pueden estar sujetos a elevación de las barreras a la entrada sin perder su condición de bien indiferenciado desde un punto de vista tecnológico [Sztulwark y Girard, 2016]. 
como atributos competitivos fundamentales la capacidad para el diseño de producto y el desarrollo de canales de comercialización, lo que les permite controlar el acceso a los consumidores de los mercados de mayores ingresos. Esta situación refleja la organización global de industrias como las de indumentaria, muebles y juguetes, pero (esta es la tesis fundamental del enfoque) es un modo de organización que en la globalización deviene dominante. Sobre esta base, Kaplinsky afirma que este creciente poder de los compradores globales en relación con unos proveedores globales con menor poder de mercado incide sobre los términos de intercambio de la manufactura, en detrimento de los países de la periferia.

Finalmente, el tercer factor es el impacto de China en la economía mundial. Este factor afectaría la evolución de los términos de intercambios entre manufactura y commodities en dos sentidos: por un lado, afirma el autor, los rubros en los que China participa en el comercio de manufactura son los que tienen una mayor caída de precio (hecho que afecta su propia rentabilidad pero también la de sus competidores en la periferia); segundo, por medio del impacto de la demanda de China sobre el precio de las materias primas y algunos commodities industriales.

Para Kaplinsky [2006], el corolario de estas tendencias sobre el análisis de los términos de intercambio es: a) que hay espacio para crear barreras a la entrada incluso en algunos bienes primarios; b) que hay un importante grupo de productos manufacturados cuyo precio tiende a caer, resultado de un aumento de la oferta pero también de la concentración de la demanda; y c) que el precio de algunos hard commodities, como los minerales, que históricamente ha tendido a declinar, estaba creciendo a partir del año 2000 con base en el dinamismo de la demanda y de ciertas restricciones por el lado de la oferta.

La explicación de la posibilidad de que estas tendencias sigan operando de modo efectivo tiene que ver con un análisis estructural: la cuestión de los términos de intercambio no es finalmente un problema de productos, sino de estructuras. Siguiendo la línea Prebisch-Singer, Kaplinsky plantea que lo fundamental es el pasaje de buena parte de la manufactura global a países con estructuras heterogéneas, en los que existe una fuerza de trabajo abundante, crecientemente educada y con competencias laborales, con cuya base puede incrementarse la productividad en una proporción mayor que el costo de la mano de obra. 
Lo que hay que notar en términos de ruptura con la tesis Prebisch-Singer es que la polarización entre territorios de la economía mundial no siempre responde a un patrón de especialización por productos (industriales o primarios) sino a una diferenciación de procesos en el marco de cadenas globales. La nueva división internacional del trabajo tiene bases cognitivas, entre procesos productivos tecnológicamente diferenciados (alta capacidad de innovación) y procesos de baja diferenciación, donde lo "comoditizado", como explica Kaplinsky [2006], es el propio trabajo involucrado.

La obtención de la máxima renta de innovación para la firma líder de una cadena depende de la posibilidad de segmentar las distintas etapas de una cadena global entre territorios que tienen altas capacidades de innovación (adquisición, creación, procesamiento y acumulación de nuevo conocimiento) y las que ofrecen ventajas en las capacidades de producción (uso y adaptación del conocimiento existente), para utilizar la distinción elaborada por Bell y Pavitt [1995]. Esta sería una forma propiamente schumpeteriana de pensar el problema del cambio estructural.

SOBRE EL NUEVO CAPITALISMO

La perspectiva estructural-schumpeteriana de Singer y Kaplinsky es un punto de referencia importante para pensar el problema del cambio estructural. Su principal atractivo, lo mismo que su debilidad, deriva de un mismo elemento: el estudio focalizado en la temática de la innovación, sin problematizar los elementos de estructura relacionados con la dinámica histórica del capitalismo. Lo que no está pensado, en esta perspectiva, es la ruptura en la dinámica de largo plazo del capitalismo, en tanto transformación más profunda que un cambio institucional o tecnológico que habilite el despliegue y la difusión de nuevas tecnologías y principios organizacionales flexibles o "en red". No es este el lugar para hacer una descripción exhaustiva de esta nueva etapa histórica, ${ }^{10}$ sino que tomaremos de ella algunos elementos que nos sirvan de base para pensar el cambio estructural.

${ }^{10}$ Al respecto, ver Dieuaide et al. [2007], Castells [1999], Vercellone [2011], Dabat [2006], Ordóñez [2009] y Míguez y Sztulwark [2013]. 
El nudo de la cuestión puede plantearse a partir de la distinción schumpeteriana entre invención e innovación. Como se sabe, para Schumpeter la innovación es el hecho fundamental de la dinámica capitalista, es el mecanismo que reforma o revoluciona el sistema económico "desde adentro". ${ }^{11} \mathrm{En}$ cambio, la invención es un fenómeno económicamente subordinado, y en buena medida, exógeno o autónomo del sistema económico. Es la función empresarial, la introducción de innovaciones, la que le da sentido económico a una invención. Pero, para Schumpeter, la invención por sí sola no tiene ninguna significación económica. ${ }^{12}$

El elemento fundamental a considerar en este punto es que esta forma schumpeteriana de concebir la relación entre invención e innovación ha dejado de ser operativa para pensar la dinámica de la acumulación en el nuevo capitalismo. No es que la invención se haya vuelto endógena al sistema económico o que la frontera entre uno y otro se haya vuelto indistinguible. Eso implicaría que la invención finalmente hubiese devenido innovación. No se trata de eso. Es más bien el hecho de que la potencia de la innovación de un capital particular depende, cada vez más, del grado de complejidad del sistema de conocimiento local (que incluye tanto la ciencia como la cultura) en el que se apoya como base del proceso de acumulación de capital.

La corriente del capitalismo cognitivo realizó algunos aportes fundamentales a esta cuestión. Nos referiremos brevemente a algunos autores que presentan de una manera muy clara la relación que se establece entre empresa (en tanto locus de la innovación) y sociedad (espacio de la invención) en esta etapa histórica. Fumagalli [2010: 85] sostiene que el elemento fundamental a considerar es la generalización y centralidad que tiene el conocimiento dentro de "una organización de la producción que tiende cada

${ }^{11}$ En Schumpeter, la innovación está definida como "cualquier forma de hacer las cosas de una manera diferente en la esfera de la actividad económica" como, por ejemplo, la introducción de nuevos productos, la modificación de mercancías que ya se encuentran en uso, la apertura de nuevos mercados, el hallazgo de nuevas fuentes de aprovisionamiento o la introducción de nuevas formas de organización, entre otros [Schumpeter, 2002 (1939): 63].

12 "La innovación es posible sin algo que identificaríamos como un invento, y el invento no induce necesariamente la innovación, solo produce por sí mismo un efecto que no es económicamente relevante en absoluto [...] Destacar el elemento de invento, o definir la innovación por medio del invento no solo significaría subrayar un elemento sin importancia para el análisis económico, sino que también reduciría el fenómeno relevante a lo que realmente no es sino una parte del mismo" [Schumpeter, 2002 (1939): 63]. 
vez más a superar los límites de las empresas y a convertirse en producción social”. Esto implica, como sostiene Vercellone [2011], que es cada vez más "atrás" de la esfera del trabajo asalariado y del universo mercantil, en la sociedad, y en particular en el sistema de formación e investigación, donde se encuentran la clave de la productividad y el desarrollo de la riqueza social.

Desde el punto de vista de Dieuaide et al. [2007: 81-82] este fenómeno remite a un "desbordamiento" de la producción de recursos en relación con el marco de la empresa, espacio de acumulación propio del capitalismo industrial.

Ello no solamente -continúan los autores- porque el consumo y lo que se encuentra detrás, la subjetividad, constituyen procesos centrales. Sino también a causa de que la unidad técnica y cognoscitiva del ser social engloba la esfera de la producción en la empresa, el consumo y las relaciones privadas. La cultura técnica (en un sentido amplio) constituye un todo indivisible.

En un sentido similar, Virno [2003: 108-109] sostiene que

la cooperación productiva de la que participa la fuerza de trabajo es cada vez más amplia y rica que la puesta en acción en el proceso laboral. Comprende también el no-trabajo, las experiencias y conocimientos madurados fuera de la fábrica y del oficio. La fuerza de trabajo valoriza al capital solamente porque no pierde ya su calidad de no trabajo - es decir su inherencia a una cooperación productiva más rica que aquella integrada al proceso laboral estrechamente acordado.

En esta perspectiva, la ruptura en la propia naturaleza del proceso de creación de valor respecto al capitalismo industrial se verifica en este desacople entre "tiempo de producción" y "tiempo de trabajo". ${ }^{13}$

Este creciente proceso de socialización de la producción plantea, como sostiene Corsani [2003], un problema sobre el control de los recursos cognitivos. La empresa, un capital crecientemente desterritorializado, tiene

13 “En el posfordismo -sostiene Virno [2003: 119]-, el 'tiempo de producción' comprende el tiempo de no trabajo, la cooperación social que enraíza en él. Denomino entonces 'tiempo de producción' a la unidad indisoluble entre vida retribuida y vida no retribuida, trabajo y no trabajo, cooperación social manifiesta y cooperación social sumergida. El 'tiempo de trabajo' es solo un componente, y no necesariamente el más relevante, de 'tiempo de producción' así entendido". 
que valorizar la riqueza producida por redes que están ligadas a la dinámica de un territorio. Lo que se presenta es un problema de apropiación que gira en torno a la asimetría entre los elevados costos de la invención, de la creación de conocimiento (la envergadura de la inversión colectiva en infraestructura de formación e investigación), y los relativamente bajos costos de reproducción de esos conocimientos una vez que pueden ser codificados.

En el marco de estas condiciones históricas, la innovación, en un sentido schumpeteriano, como función empresarial de explotación económica de un nuevo conocimiento, no puede pensarse por fuera de la esfera de la invención, del sistema de creación de conocimiento. ¿Cómo opera este vínculo? Existe una relación entre el grado de complejidad del conocimiento que se genera en un territorio y el potencial de innovación que una firma puede obtener por operar en un sistema de este tipo. Pero, a su vez, en un mismo sistema de conocimiento, dos empresas pueden desarrollar capacidades diferenciales para explotar económicamente el conocimiento existente, es decir, para innovar. Podemos pensar el nuevo capitalismo como una etapa en la que los territorios se diferencian por sus capacidades para crear nuevo conocimiento (invención) y las empresas por su capacidad de explotarlo económicamente (innovación), y que entre estas dos dimensiones existe un vínculo de creciente complejidad.

Ahora bien ¿es posible extraer de estas consideraciones sobre la dinámica del nuevo capitalismo elementos de significación para pensar estratégicamente la cuestión del cambio estructural? Creemos que sí. Que la clave para pensar el cambio estructural en la periferia no responde más a la dicotomía primario/industrial (tesis Prebisch-Singer). Lo que se requiere es considerar la compleja articulación entre la creación de conocimiento y su explotación económica. En otros términos, entre el sistema de invención (la cooperación social que desborda los límites de la empresa) y la cadena global (en el sentido de Kaplinsky y Gereffi). La cadena articula la jerarquía entre territorios cognitivamente diferenciados, bajo el comando de una firma líder, esto es, de una empresa que tiene la capacidad de articular invención, innovación y producción con vistas a captar una renta específicamente global. ${ }^{14}$

\footnotetext{
${ }^{14}$ Para el concepto de renta global, ver Dabat et al. [2007].
} 
El cambio estructural, en este sentido, puede pensarse como un proceso de complejización del conocimiento generado en un determinado territorio sobre cuya base se construyen capacidades de innovación (en el sentido de explotación económica) que permiten un reposicionamiento (upgrading) en la jerarquía mundial al interior de una o varias cadenas globales. El cambio estructural se genera en la base cognitiva pero se verifica en el lugar en la cadena. Las políticas de cambio estructural son una combinación, una articulación entre la política científica, tecnológica y cultural de un país, aquellas que modifican la base cognitiva del sistema, y las políticas específicas orientadas a una segunda instancia, la de fomentar la capacidad empresarial (que incluye cuestiones organizacionales, financieras, tecnológicas y, ¿por qué no?, políticas) necesaria para explotar el conocimiento a una escala global.

Retomando las categorías de Prebisch, podríamos afirmar que la heterogeneidad estructural de la periferia del nuevo capitalismo refiere ya no a las diferencias de productividad entre un sector moderno y otro tradicional, sino más bien al grado de difusión de las capacidades de invención (o de creación) que existe en una determinada sociedad. Marazzi [2003: 65-66] lo plantea con claridad:

La definición clásica de la productividad, esto es, el valor de los productos acabados en relación con el coste de los factores de producción (trabajo y/o capital invertido), ya no tiene ningún significado operativo [...] Lo que mide la productividad, por el contrario, es un conjunto de factores que caracterizan el espacio socio-regional y que trascienden, pues, al trabajador aislado, permitiéndole ser creador de riqueza en tanto que miembro de una colectividad.

IMPLICACIONES PARA AMÉRICA LATINA

Lo que tenemos, por tanto, son algunos elementos conceptuales para pensar cómo se ha venido constituyendo la estructura económica mundial en los últimos años. En este abordaje se propone considerar una polarización de la economía mundial de base cognitiva, esto es, entre sistemas de conocimiento que se articulan entre sí bajo la figura, no exclusiva pero sí dominante, de cadenas globales de producción. La cadena es el constructo organizacional que expresa esta jerarquía mundial entre territorios 
que tienen diferencias significativas a la hora de crear conocimiento y explotarlo económicamente.

En términos geográficos, el centro de la economía mundial tiende a desplazarse desde la zona del Atlántico norte, espacio que constituyó el núcleo de la economía mundial durante el capitalismo industrial, hacia la zona del Pacífico, que incluye tanto la costa oeste de Estados Unidos (principal atractor mundial del conocimiento científico y tecnológico pero también del estético-expresivo) como la costa oriental de Asia, donde se concentran las principales capacidades de producción. Lo que hay por detrás son dos sistemas de conocimiento diferentes: uno, orientado a la creación de nuevo conocimiento para la diferenciación de productos y procesos (trabajo reflexivo, diseño-intensivo); el otro, subordinado a la actividad de producción a gran escala de productos ya diseñados y construidos como dominantes por un discurso empresarial (trabajo de naturaleza repetitiva, de reproducción, cuya clave competitiva es la reducción del costo unitario de producción). Como se ve, la vieja división del trabajo fordista-taylorista entre tareas de concepción y de ejecución al interior de la fábrica ahora se reproduce a escala global como base de una división internacional del trabajo dentro de cadenas globales de producción. Este patrón mundial de acumulación tiene un carácter dinámico, y por tanto, admite que determinados territorios modifiquen su función en el sistema. Lo importante, sin embargo, es que esos cambios de posición se dan en el marco de una jerarquía que tiene cierta estabilidad, al menos durante un periodo histórico significativo.

Así, ¿qué podemos decir de los países asiáticos que apoyados en sus capacidades de producción están construyendo nuevas capacidades de innovación? Corea del Sur, que sigue en algún sentido el sendero abierto unos años antes por Japón, es probablemente el caso paradigmático de un cambio estructural en la dirección señalada [Kim, 2001]. ¿Cómo considerar los fenómenos de China e India? Son países que se insertan en la globalización, como señala Kaplinsky [2006], en línea con Prebisch, sobre la base de la constitución de un excedente por desigualdad, en actividades que combinan incrementos de productividad con competencia regresiva de la fuerza de trabajo. No obstante, a diferencia de la época de Prebisch, esta inserción se produce no sobre la base de sectores económicos de bajo 
dinamismo estructural (productos primarios o de baja elaboración) sino en el núcleo mismo de la economía mundial: la electrónica en el caso chino y la informática en el de la India. La entrada es por el límite inferior de la cadena (capacidades simples de ejecución) y la dirección es hacia actividades más complejas.

¿En qué medida lo están logrando? Las evidencias aún no son concluyentes. ${ }^{15}$ De acuerdo con Altenburg et al. [2008], la situación se puede caracterizar de la siguiente manera: los esfuerzos de redireccionar el excedente desde una base de conocimiento a otra son muy significativos, más en China que en la India. Los resultados, en cambio, eran, al menos hasta ese momento, aún modestos. Esto se debe, según los autores, a la lenta maduración que este tipo de proceso tiene por su propia naturaleza y al punto de partida, que es, en términos comparativos con los sistemas de conocimiento más desarrollados, muy bajo. Algunos trabajos más recientes confirman la dirección del cambio, aunque con una serie de avances significativos en materia de innovación mundial en algunos campos específicos en el caso de China [Zenglein y Hollzman, 2019].

Vayamos finalmente a nuestro foco de interés, América Latina. La realidad de estos países es muy heterogénea. Una distinción básica es entre los países de América Central y el Caribe, más bien integrados de una manera subordinada a la economía de Estados Unidos, y los de América del Sur, más articulados con el auge del precio de los commodities primarios y con Asia-Pacífico. Pero también en estos países la realidad actual y la historia hacen difícil la comparación. Aunque hay algunos elementos en común. Uno es el proceso trunco de industrialización sustitutiva. Otro, pero articulado con el anterior, la hegemonía del neoliberalismo. En este marco tendió a consolidarse el carácter periférico de nuestros países en la economía mundial. Economías sujetas a grados considerables de heterogeneidad estructural y especialización en productos de baja elaboración y de escasa integración en el territorio. Un patrón productivo que ejerce muy bajas demandas sobre el sistema de conocimiento.

A pesar de este panorama general esencialmente negativo, vale la pena considerar la experiencia reciente de algunos países de la región.

\footnotetext{
${ }^{15}$ Ver, por ejemplo, Ernst [2011] y Breznitz y Murphree [2011].
} 
Esta tiene que ver, sobre todo, con la emergencia de gobiernos progresistas en América del Sur, que han logrado, aprovechando el ciclo de auge de los precios de los bienes primarios, una novedosa y muy interesante capacidad de intervenir en la disputa por el excedente económico. Capacidad que no se verificaba en la magnitud que se presentó en estos años desde, al menos, la época de los gobiernos nacional-desarrollistas de posguerra del siglo pasado. Desde el punto de vista del cambio estructural, la pregunta fundamental es por el destino de ese excedente económico, por la naturaleza del proceso de acumulación. No es este el espacio para un abordaje exhaustivo de ese proceso. Pero se pueden establecer, sobre la base de los conceptos previamente expuestos, dos observaciones generales.

En primer lugar, parte de ese excedente se orientó a la redistribución del ingreso, cumpliendo una demanda histórica de reducción de la desigualdad con base en la base de la recomposición o establecimiento de las funciones de welfare que el neoliberalismo había desmontado (en el caso de Argentina y Uruguay) o que solo se habían constituido de una manera limitada (como en Ecuador o Bolivia). A diferencia de Prebisch, que en su crítica al peronismo pensaba en la temprana función de bienestar del Estado argentino y su contradicción con la profundización del proceso de acumulación de capital, y a la luz de las transformaciones del nuevo capitalismo, estas funciones de bienestar social representan un hecho, como en el pasado, de reparación social, pero, además, constituyen una base indispensable para el cambio estructural en tanto las capacidades del sistema de formación y de investigación, que no son independientes, por ejemplo, del sistema de salud, devienen recurso crítico para cualquier estrategia de reposicionamiento basado en la complejización de las tareas productivas desarrolladas en el territorio.

Segundo, estas funciones de bienestar, con todo lo necesarias que son, resultan insuficientes como base de una política de cambio estructural. En efecto, lo que se verifica en términos generales es una muy baja capacidad de estos gobiernos para establecer políticas que logren torcer el perfil productivo de nuestros países y, por tanto, su inserción en la economía mundial. Esto no se debe, sin embargo, a la ausencia de políticas de promoción industrial o de fomento de la ciencia y la tecnología. En efecto, a pesar de la gran heterogeneidad que existe en este terreno entre los diferentes 
países de la región, se verifica la puesta en marcha de una serie importante de iniciativas en el plano productivo y, en particular, de promoción de la innovación [Cepal, 2012; Rivas y Rovira, 2014; Crespi y Dutrénit, 2013].

Si bien desde los años 2000 se presenta un nuevo modelo de políticas de impulso a la ciencia, la tecnología y la innovación en la región, que pretende superar los enfoques orientados a la "demanda" propios del momento "duro" del consenso neoliberal de la década previa, a partir de una visión más sistémica del proceso de innovación, de un más sostenido compromiso de financiamiento a las instituciones públicas de producción de conocimiento y de una mayor prioridad a las políticas verticales y de impulso a tecnologías específicas, entre otros elementos ${ }^{16}$ desde la perspectiva del cambio estructural presentada en los apartados previos es posible identificar dos límites fundamentales en el propio modelo de intervención.

En primer lugar, en la escala y orientación de la inversión en infraestructura de investigación y formación, que es la base principal sobre la cual se apoya la producción de conocimiento de una sociedad. Así, aun cuando hubo algunos avances parciales, sobre todo en países como Argentina, Brasil, Uruguay o Ecuador, no se logró reducir de un modo significativo la brecha existente con los países de mayor desarrollo relativo. A su vez, la falta de focalización de la inversión impidió alcanzar los umbrales mínimos necesarios para avanzar en una estrategia ofensiva de escala global sobre campos de conocimiento estratégicos. En segundo lugar, en los casos en los que hubo una política más focalizada en el plano de la invención, como Argentina y Brasil, no se consiguió desarrollar una buena articulación con las etapas de producción y comercialización, lo que provocó trayectorias truncas de innovación aun en un marco de expansión de la inversión pública nacional en ciencia y tecnología [Ramírez y Sztulwark, 2018; Casas et al., 2014; Bianchi y Guarga, 2018].

En realidad, lo que se verifica en el programa de reformas del llamado "progresismo latinoamericano" no es solo un problema de escala de recursos aplicados a la promoción del desarrollo o de límites políticos en el plano de las relaciones de fuerza. Restricciones mayores que efectivamente operaron. En este trabajo, sin embargo, se presenta la idea de que

\footnotetext{
${ }^{16}$ Para un análisis más exhaustivo, ver Crespi y Dutrénit [2013].
} 
en los momentos de mayor fertilidad política y financiera de esos gobiernos, cuando coincidió, sobre todo en América del Sur, la ampliación y fortalecimiento del Mercosur y la conformación de Unasur con la disponibilidad de recursos derivados del alza del precio de los commodities primarios e industriales, el proceso de cambio estructural no avanzó lo suficiente por un déficit que hay que buscar también en otro plano: en el de la propia concepción del modelo de reformas.

Es preciso ubicar este déficit en el plano del pensamiento. En la ausencia de un programa de investigación sistemático sobre la especificidad del desarrollo latinoamericano, y por tanto, de una escuela de pensamiento que sea capaz de movilizar la inteligencia colectiva en función de un proyecto de transformación productivo y social de alcance regional. La declinación de la Comisión Económica para América Latina y el Caribe (Cepal) como fuente de inspiración para una tarea de esta naturaleza, y la creciente relevancia e influencia de organismos de crédito como el Banco Interamericano de Desarrollo (BID) y el Banco Mundial, son solo una muestra de dónde tendió a concentrarse la capacidad de imponer los criterios dominantes para el diseño de políticas en el plano del conocimiento y la producción durante estos años.

Como reflexión final vale la pensar insistir en el hecho de que los cambios en la economía mundial de las últimas décadas señalan un nuevo escenario para el desarrollo de nuestros países. La existencia de una renovada capacidad para intervenir en la disputa por el excedente en la región es una base necesaria pero insuficiente para avanzar en un proceso de cambio estructural. La discusión es necesariamente amplia, porque no solo se requiere una visión de lo que significa hoy el cambio estructural sino también el poder y la capacidad para llevarlo adelante, entendiendo que estos procesos implican confrontar con estructuras de privilegio históricamente arraigadas y con capacidad para bloquear las iniciativas de cambio. En todo caso, y a la luz de la experiencia de la región en los últimos años, el significante Prebisch no debería estar ausente. 
Altenburg, T., H. Schmitz y A. Stamm [2008], "Breakthrough? China's and India's transition from production to innovation", en World Development, vol. 36, issue 2, pp. 325-344.

Amsden, Alice [2004], "La sustitución de importaciones en las industrias de alta tecnología: Prebisch renace en Asia”, en Revista Cepal, núm. 82, abril. Bell, Martin y Keith Pavitt [1995], "The development of technological capabilities", en Irfan ul Haque, ed., Trade and international competitiveness. Economic Development Institute, Washington, The World Bank.

Bianchi, Carlos y Rafael Guarga [2018], "Ciencia, tecnología, innovación y desarrollo: el papel de las universidades en América Latina”, en Rafael Guarga, A cien años de la reforma universitaria de Córdoba. Hacia un nuevo manifiesto de la educación superior latinoamericana. Caracas, Unesco, pp. 113-130.

Breznitz, Dan y Michael Murphree [2011], Run of the Red Queen: Government, Innovation, Globalization, and Economic Growth in China. New Haven, Yale University Press.

Casas, Rosalva, Juan M. Corona y Roxana Rivera [2014], "Políticas de ciencia, tecnología e innovación en América Latina: entre la competitividad y la inclusión social", en P. A. Kreimer et al. (eds.), Perspectivas latinoamericanas en el estudio social de la ciencia, la tecnología y el conocimiento. México, Siglo XxI.

Castells, Manuel [1999], La era de la información. Economía, sociedad y cultura, vol. 1, "La sociedad red", Buenos Aires, Siglo Veintiuno Editores. Comisión Económica para América Latina y el Caribe (Cepal) [2012], Cambio estructural para la igualdad: Una visión integrada del desarrollo. Santiago, Cepal.

[2016], Panorama de la inserción internacional de América Latina y el Caribe 2016. Santiago, Cepal.

Clark, Colin [1967 (1940)], Las condiciones del progreso económico. Madrid, Alianza.

Corsani, Antonella [2003], "Elementos de uma ruptura: a hipótese do capitalismo cognitivo", en G. Cocco, A. Patez Galvao y G. Silva (orgs.), Capitalismo cognitivo. Trabalho, redes e inovacao. Río de Janeiro, DP\&A editora. 
Crespi, Gustavo y Gabriela Dutrénit [2013], Políticas de ciencia, tecnología e innovación para el desarrollo. La experiencia latinoamericana. México, Foro Consultivo Científico y Tecnológico, A. C.

Dabat, Alejandro [1994], Capitalismo mundial y capitalismos nacionales. México, Facultad de Economía-unam y Fondo de Cultura Económica. [2006], "Capitalismo informático y capitalismo industrial. Acercamiento al perfil histórico del nuevo capitalismo", en Economía Informa, México, unaM, enero-febrero, núm. 338.

Dabat, Alejandro, Miguel Ángel Rivera Ríos y Sebastián Sztulwark [2007], "Rentas económicas en el marco de la globalización: desarrollo y aprendizaje", en Problemas del Desarrollo, México, IIEc-unam, vol. 38, núm. 51.

Dieuaide, Patrick, Bernard Paulré y Carlo Vercellone [2007], "Introducción al capitalismo cognoscitivo", en Miguel Ángel Rivera Ríos y Alejandro Dabat, Cambio histórico mundial, conocimiento y desarrollo. Una aproximación a la experiencia de México. México, UNAM.

Ernst, Dieter [2011], "China innovation policy is a wake-up call for America”, en Asia Pacific Issues, East-West Centre, mayo, núm. 100.

Fernández, Víctor R. y Gabriel Brondino [2019], Development in Latin America: Critical Discussions from the Periphery. Londres, Palgrave Macmillan.

Ferrer, Aldo [2010], "Raúl Prebisch y el dilema del desarrollo en el mundo global”, en Revista Cepal, agosto, núm. 101.

Fisher, Allan G. B. [1939], "Production, primary, secondary and tertiary", en Economic Record, vol. 15, pp. 24-38.

Fumagalli, Andrea [2010], Bioeconomía y capitalismo cognitivo. Madrid, Traficantes de Sueños.

Gereffi, Gary [1996], "Global Commodity Chains: New Forms of Coordination and Control among Nations and Firms in International Industries", en Competition \& Change, vol. 1, núm. 4.

Hirschman, Albert O. [1996], "La economía política de la industrialización a través de la sustitución de importaciones en América Latina", en El Trimestre Económico, México, FCE, vol. 63, núm. 250.

Kaplinsky, Raphael [2006], "Revisiting the Revisited Terms of Trade: Will China Make a Difference?", en World Development, vol. 34, núm. 6, pp. 981-995. 
Katz, Jorge y Bernardo Kosacoff [1998], “Aprendizaje tecnológico, desarrollo institucional y la microeconomía de la sustitución de importaciones", en Desarrollo Económico, Buenos Aires, IDEs, enero-marzo, vol. 37, núm. 148.

Kim, Linsu [2001], "The dynamics of technological learning in industrialization”, en International Social Science Journal, junio, vol. 53, núm. 168. Marazzi, Cristiano [2003], El sitio de los calcetines. Madrid, Akal.

Míguez, Pablo y Sebastián Sztulwark [2013], "Knowledge valorization in cognitive capitalism", en Knowledge Cultures, Nueva York, Addleton Academic Publishers, vol. 1, núm. 4.

Ordóñez, Sergio [2009], "La crisis global actual y el sector electrónico-informático", en Problemas del Desarrollo, México, Instituto de Investigaciones Económicas-UnAM, vol. 40, núm. 148.

Prebisch, Raúl [1963 (1949)], "El desarrollo económico de América Latina y algunos de sus principales problemas", en Boletín Económico de la América Latina, febrero, vol. 7, núm. 1.

[1981], Capitalismo periférico. Crisis y transformación. México, Fondo de Cultura Económica.

Ramírez, René y Sebastián Sztulwark [2018], "América Latina: De la inmovilidad estructural al cambio en la matriz cognitiva”, en Estado y Políticas Públicas, Buenos Aires, Flacso, núm. 10.

Rivas, Gonzalo y Sebastián Rovira [2014], Nuevas instituciones para la innovación: prácticas y experiencias en América Latina, Santiago, Cepal. Sarkar, Prabirjit y Hans Singer [1991], "Manufactured exports of developing countries and their terms of trade", World Development, vol. 19, núm.4, pp. 333-340.

Schumpeter, Joseph [2002 (1939)], Ciclos económicos. Análisis teórico, histórico y estadístico del proceso capitalista. Zaragoza, Prensas Universitarias de Zaragoza.

Singer, Hans [1950], "The Distribution of Gains between Investing and Borrowing Countries", en American Economic Review, Papers and Proceedings, vol. 40, núm. 2, pp. 473-485.

[1971], The distribution of gains revisited. The Strategy of International Development. Londres, Macmillan.

Syrquin, Moshe [1988], "Patterns of Structural Change", en H. Chenery y T. N. Srinivasan (eds.), Handbook of Development Economics, vol. I. Amsterdam, North-Holland, pp. 203-273. 
Sztulwark, Sebastián y Melisa Girard [2016], "Genetically modified seeds and the de-commodification of primary goods", en International Journal of Biotechnology, vol. 14, núm. 2.

Vercellone, Carlo [2011], Capitalismo cognitivo. Renta, saber y valor en la época posfordista. Buenos Aires, Prometeo.

Virno, Paolo [2003], Gramática de la multitud. Buenos Aires, Colihue.

Zenglein, Max y Anna Holzmann [2019], "Evolving made in China 2025. China's industrial policy in the quest for global tech leadership", en MERICS Papers on China, julio, núm. 8. 


\section{PARTE II}

ReEXAMEN DE LA PRESENCIA Y EL ACCIONAR DEL Estado EN EL NUEVO ESCENARIO Y LOS DESAFÍOS DE SU CONSTRUCCIÓN EN LOS PAÍSES EN DESARROLLO 



\section{ESTADO Y DESARROLLO EN AMÉRICA LATINA CONTEMPORÁNEA. DINÁMICAS Y BALANCE DEL CICLO POSNEOLIBERAL, 2002-2015}

Pablo Míguez*

INTRODUCCIÓN

En América Latina, desde comienzos del siglo xxI, se extendió por más de una década una etapa posneoliberal que muestra signos claros de agotamiento y una preocupante crisis de alternativas a la vista. La mayor parte de los países latinoamericanos se vieron afectados por el reflujo del pensamiento y las políticas neoliberales. Importantes procesos políticos y económicos tuvieron lugar, mismos que imponen hacer un balance crítico y un análisis de su grado de profundidad y del alcance de la reversión de las políticas del periodo neoliberal. Los significativos cambios en materia de política económica supusieron, no obstante, la consolidación de un modo de acumulación centrado en una nueva inserción del capitalismo doméstico en el mercado mundial sustentada en la producción y exportación de commodities de escaso valor agregado. Desde 2015 en adelante, se verifica un resurgimiento de regímenes políticos antagónicos a las experiencias políticas y al ideario distributivo asociado con el periodo posneoliberal -más retórico que real y más efímero que duradero-que muestran analogías y diferencias con el periodo neoliberal precedente de finales del siglo xx.

Diversos procesos políticos, como los iniciados por Hugo Chávez en Venezuela, Luiz Inácio Lula da Silva en Brasil, Néstor Kirchner en Argentina,

\footnotetext{
* Universidad Nacional General Sarmiento (UNGS), Instituto de Industria, Argentina.
} 
Evo Morales en Bolivia o Rafael Correa en Ecuador, intentaron poner fin a los proyectos neoliberales consolidados en la década previa en América Latina. Con un objetivo compartido y con políticas económicas, sociales y de relaciones exteriores afines entre sí, las principales dinámicas de la ofensiva neoliberal, que hoy está relanzada, solo parecen haberse suspendido. El ascenso de Macri en Argentina a fines de 2015 y la caída del gobierno de Dilma Rouseff en 2016 supusieron el final de un ciclo de gobiernos de las fuerzas progresistas y el anuncio de un cierre de ciclo para los regímenes políticos vigentes en América Latina, que suponen también una crisis del "neodesarrollismo" como proyecto de reconstrucción del tejido económico y social deteriorado por el ascenso neoliberal de la década de los años noventa. Con la notable excepción de México con la llegada a la presidencia de López Obrador en 2018, asistimos a un renovado avance de proyectos de la "nueva derecha" en América Latina, que se entusiasma con el acceso al gobierno en numerosos países, en especial en aquellos donde fueron importantes las experiencias posneoliberales a comienzos del siglo XXI.

En este trabajo analizamos las principales experiencias políticas asociadas con las transformaciones en la dinámica de acumulación del capital y en las lógicas de intervención del Estado en los países latinoamericanos. Aquí describiremos el contenido de estos procesos a la luz de las transformaciones más generales de la dinámica capitalista contemporánea, con las limitaciones que ello ha impuesto a las tentativas de transformación de la matriz productiva y de la lógica de integración de la región en el mercado mundial en el inicio del siglo xxi caracterizado por el gran aumento de los precios de las materias primas, el posterior ascenso de China como demandante de los commodities de las economías latinoamericanas y un alejamiento parcial de la esfera de influencia norteamericana sobre América Latina.

El “NeOdesarrollismo” en el Ciclo ascendente posneoliberal (2003-2013)

El mito del Estado desarrollista siempre estuvo presente en América Latina, alimentado desde los años cincuenta tanto por las "teorías del desarrollo" 
económico como por las versiones de la economía política latinoamericana que se proponían discutir el "subdesarrollo", esto es, el "estructuralismo" de la Comisión Económica para América Latina (Cepal), y desde posiciones más críticas, como las diferentes versiones de la teoría de la dependencia [Míguez, 2017]. El diagnóstico del subdesarrollo tenía una solución al alcance de la mano de los regímenes políticos latinoamericanos, en línea con la atmósfera del pensamiento keynesiano: la industrialización (entendida como el desarrollo de las industrias básicas) y la redistribución del ingreso (para activar la demanda agregada por medio del desarrollo del mercado interno). El Estado debía llevar adelante ambas tareas dada la insuficiencia de la acumulación del capital (en la versión estructuralista) o el desinterés, por diferentes razones según los países, de las burguesías internas de América Latina en avanzar en esa dirección (para las teorías de la dependencia).

En una línea similar, el modelo "neodesarrollista" surge a comienzos del siglo XxI estimulado por un ciclo ascendente de los precios de las materias primas originado por la demanda china de alimentos y por la llegada en Brasil y Argentina de gobiernos populares como los de Lula y Kirchner. Luis Carlos Bresser Pereira en Brasil y Aldo Ferrer en Argentina son los economistas que plantean recuperar los planes desarrollistas de las décadas previas pero ajustándolos a las nuevas circunstancias políticas posneoliberales derivadas de la crisis del neoliberalismo en el continente y buscando evitar los errores que impidieron el buen desenvolvimiento de la industrialización sustitutiva de importaciones (ISI) en los años del viejo desarrollismo.

En los años 2000, una estrategia alternativa tanto al viejo desarrollismo como a las fallidas ideas neoliberales debía sostenerse en un cuidadoso manejo de las políticas económicas de corto, mediano y largo plazos, combinando políticas macroeconómicas sustentadas en un tipo de cambio competitivo y políticas industriales y de infraestructura profundas sobre la base de un Estado eficiente que no incurra en déficits fiscales ostensibles y acelere los procesos de integración regional en el Cono Sur.

Estas ideas eran compartidas, en mayor o menor medida, por casi todos los países de la región, aunque en los hechos las políticas y estrategias de intervención fueron sumamente disímiles tanto en relación con el desarrollo como con las iniciativas de integración regional. A continuación analizamos las circunstancias condicionantes del periodo en los principales países 
del Cono Sur de América Latina: Brasil, Argentina, Uruguay, Paraguay, Venezuela, Ecuador y Bolivia

BRASIL: LOS DOS MANDATOS DE LULA Y LA CONTINUIDAD CON DILMA ROUSEFF

Brasil es un caso especial por tratarse, junto con México, de uno de los países de mayor desarrollo industrial en América latina y una de las economías de mayor tamaño de la periferia capitalista. Allí se despliegan con mucha fuerza desde el comienzo del gobierno de Lula (2001-2006) las ideas neodesarrollistas tras el periodo neoliberal de dos mandatos de Fernando Henrique Cardoso (1994-2002). Con una política fiscal expansiva y una política monetaria ortodoxa, el primer periodo de Lula procura mejorar la enorme desigualdad del ingreso con políticas sociales con planes como el Bolsa Familia, destinado a casi 25 \% de la población (unas 50 millones de personas).

En 2003, los precios de los commodities comienzan un ciclo alcista que favorece las exportaciones brasileñas de materias primas, como el hierro y la soja, así como la acumulación de reservas internacionales a niveles inéditos. Ello habilitó a plantear políticas de más largo plazo -de infraestructura e industriales- que permitían llevar adelante las ideas neodesarrollistas así como un distanciamiento de la potencia estadounidense en el plano internacional. Este alejamiento de Estados Unidos por parte de Brasil dejó allanado el camino, a nivel continental, para rechazar el proyecto del ALCA (Área de Libre Comercio para América Latina) a finales de 2005 y presentar a Brasil como una economía en ascenso dispuesta a ofrecer un contrapeso al dominio estadounidense junto con China y Rusia, India y Sudáfrica en el marco de los BRICS.

Las iniciativas neodesarrollistas alcanzan su máxima expresión durante el segundo mandato de Lula (2006-2010). El crecimiento económico permitió un boom del consumo y también del crédito, con una expansión del sistema financiero, como se estudió en los capítulos 2 y 3 de esta obra, y una euforia desatada desde 2009 con los descubrimientos de yacimientos del pré-sal, un área de $160000 \mathrm{~km}^{2}$ de petróleo fundamental para alentar los planes neodesarrollistas de convertir el país en una potencia 
petrolera tardía [Mercadante, 2013: 77-83]. La institución clave de las políticas era el Banco Nacional de Desarrollo Económico y Social (BNDES), que impulsó y financió numerosas políticas industriales y de infraestructura en Brasil y todo el Cono Sur.

Las políticas industriales más relevantes se sostenían con créditos del BNDES o del Banco do Brasil destinados a hacer de empresas públicas como Embraer y Embrapa “campeones nacionales". Petrobras también adoptó estas iniciativas para el desarrollo de proveedores locales a partir de elevados requisitos de contenido nacional para comprar plataformas, naves, insumos para las refinerías, etcétera.

En las políticas de infraestructura era clave otro proyecto a financiar por el BNDES y a ejecutar por constructoras privadas brasileñas por medio de IIRSA (Integración de Infraestructura Regional Sud-Americana), que nació en el gobierno de Cardoso como un intento de expansión de Brasil sobre su propia región, en el contexto del avance del ALCA [Santos, 2013: 40]. Se trata de un proyecto de grandes obras de infraestructura, rutas, puentes, usinas, centros de acopio y distribución, para lograr la interconexión de la región, que históricamente se insertaba en el mercado mundial siempre a partir de cada puerto nacional.

El boom de las materias primas impulsó también la expansión del sector agrícola y de las exportaciones primarias brasileñas. La producción de granos, cereales y oleaginosas aumento $51 \%$ entre 2002 y 2008 mientras que las exportaciones pasaron de 25000 a 72000 millones de dólares en ese mismo periodo, convirtiendo a Brasil en el segundo mayor exportador de materias primas (soja y hierro) y alimentos (carne bovina, pollo, azúcar, café y jugo de naranja), por delante de China y Canadá y detrás de Estados Unidos. En 2013, la producción agropecuaria ya representaba alrededor de $6 \%$ de la producción mundial y se sostenía que Brasil -coloso industrial de América Latina y ejemplo de desarrollismo- iba camino en realidad a una reprimarización de su economía y a un modelo de acumulación que mostraba la asociación del capital agroindustrial y la gran propiedad terrateniente con las estrategias económicas del capital financiero. El área plantada de soja aumentó en promedio 169 \% entre 2000 y 2014 al pasar de 13.6 a 30.3 millones de hectáreas y de 32.8 a 86.7 millones de toneladas en todo el país [Bernardes y Maldonado, 2017: 74-78]. 
La exposición de Brasil al capital financiero quedó en evidencia después de la crisis financiera internacional de 2007-2008, que inicialmente afectó de manera leve a un Brasil que había acumulado reservas internacionales y formaba parte de los BRICs. Todavía en 2008 se llevaban adelante políticas neodesarrollistas como las de desarrollo productivo, parte decisiva de la política de aceleración del crecimiento, que fueron importantes para compensar la caída de la inversión privada con la naciente crisis financiera internacional [Mercadante, 2013: 189].

En el año 2009 se evidencian algunos síntomas de la crisis con una leve caída del PIB de 0.2 \% y el cierre de algunos mercados de exportación, pero la economía se recuperó muy rápido en 2010 con el crecimiento de 7 \% del PIB y la acumulación de reservas por 287000 millones de dólares al final del segundo mandato de Lula, que había iniciado su gobierno con apenas 16000 millones de reservas en 2002. Los déficits fiscales y externos empezaban a incrementarse y el crecimiento económico a desacelerarse en los años siguientes, creciendo a $4 \%$ en 2011, $1.9 \%$ en $2012,3 \%$ en 2013 y apenas $0.5 \%$ en 2014, lo que marcó el primer gobierno de Dilma Rouseff (2010-2014) con un menor crecimiento relativo que el de Lula pero con el incremento de las reservas internacionales (registraron $353000 \mathrm{y}$ 373000 millones en 2011 y 2012 , y desde allí se mantienen en torno a ese nivel hasta la actualidad).

La recesión asociada con la crisis financiera internacional se manifiesta en 2010 con amenazas de fugas masivas de capitales y suspensión de inversiones [Sampaio, 2010]. Desde finales de los años noventa Brasil se había transformado, según Leda Paulani, en una "plataforma internacional de valorización financiera" a lo largo de los gobiernos de Cardoso y del Partido del Trabajo (РT) que, con sus diferencias, mantuvieron ese rasgo en el formato de la política económica. Ello se da a partir de la apertura financiera y la ausencia de control sobre los flujos internacionales de capital, con exenciones impositivas y garantías a los tenedores de bonos públicos además de una política macroeconómica basada en la austeridad fiscal y tasas de interés absurdamente elevadas para beneficio del capital financiero. Además, la especulación sobre el tipo de cambio se vuelve habitual a causa del enorme mercado de derivativos que se consolida [Paulani, 2017]. La crisis mostraba la subordinación del Estado brasileño 
a los intereses del capital rentista nacional e internacional, con una política económica que suponía expandir el mercado interno sobre la base del endeudamiento de unas familias que enfrentaban la creciente precarización del mercado de trabajo al tiempo que aumentaba el riesgo de insolvencia del sistema bancario [Sampaio, 2010]. De forma simultánea, el gobierno otorgaba grandes subsidios y exenciones al gran capital, estimulaba procesos de regresión industrial vía la producción de productos primarios o semimanufacturados y aumentaba peligrosamente la deuda externa [Sampaio, 2010].

En el primer mandato de Dilma Rouseff comienza a avizorarse un desgaste político y una desaceleración económica, así como un mayor acercamiento con China, que ya era el principal socio comercial y el primero en proyectos de inversión extranjera directa en Brasil. Este mandato estará signado por la impronta de Lula, pero la pérdida de popularidad se hace presente y se evidencia en las protestas callejeras y manifestaciones de julio de 2013, ampliadas luego en 2014, y que condicionan una reelección que consigue por escaso margen y también su segundo mandato.

\section{ARGENTINA DURANTE LA DÉCADA KIRCHNERISTA}

Después de una recesión de tres años, la crisis de diciembre de 2001 terminó con el modelo neoliberal de la convertibilidad de los años noventa e inició una de las más profundas crisis económicas y políticas de la historia argentina. "Crisis del 2001" remite a la crisis económica y social de diciembre de 2001 que puso fin al plan económico de la convertibilidad del peso por el dólar iniciado 10 años antes. Entre 2002 y 2005 implicó, más que la instauración de una nueva forma de Estado, la reconstrucción del Estado a partir de las ruinas de la forma neoliberal impuesta en los años noventa [Bonnet, 2015: 119].

La reactivación posterior a la gran crisis vino de la mano del gran aumento de los precios de los commodities, que favoreció las exportaciones de todas las economías latinoamericanas y la salida devaluacionista de la crisis, lo que permitió recuperar la rentabilidad, afianzar la reactivación 2002-2005 y estabilizar el crecimiento en 2006-2007 [Bonnet, 2015: 184]. La convertibilidad fue un sistema de conversión automática de la moneda local con el dólar estadounidense promovido por economistas liberales y 
adoptado por Argentina en 1991 para, supuestamente, "poner fin" al problema de la hiperinflación. La enorme devaluación del peso derivada de la salida de la convertibilidad permitió un tipo de cambio competitivo y un importante superávit comercial, fortalecido por la cuasi imposibilidad de importar bienes en el periodo 2002-2003, que se mantendrá hasta el año 2012. La devaluación promovió cierto proceso de sustitución de importaciones -apoyándose en salarios reducidos en dólares, utilización "plena" de la capacidad instalada y trabajo en negro [Piva, 2015a]-que se articuló con las exportaciones de la burguesía agroindustrial. El default de la deuda externa pública permitió que no drenaran recursos para el pago de intereses, y con una inflación muy moderada que no llegaba a $10 \%$, posibilitó superávits fiscales importantes entre 2002 y 2005 . Con el aumento de la demanda interna de bienes, la recuperación de la capacidad instalada ociosa de la industria y ciertos incrementos en construcción y obra pública se produjo una recuperación importante de los indicadores económicos durante el gobierno de Néstor Kirchner entre 2003 y 2007.

Subsistía la desconfianza hacia los bancos en los primeros periodos de la posconvertibilidad y se verificaba una retracción de esa actividad. El gobierno había realizado una pesificación asimétrica de depósitos en dólares y crédito bancarios y emitió bonos para compensar las pérdidas a los bancos. Se reconstituirá cierta dinámica de las finanzas y cierta articulación de la lógica de la intervención del Estado entre distintos sectores, como el sector financiero o el industrial.

El periodo más auspicioso de la década kirchnerista fue el de 20052008, que inició con la exitosa reestructuración de la deuda externa: un periodo optimista en el que se hablaba del "modelo de crecimiento con inclusión social”. Se alentaba el debate sobre las características que debía tener "el modelo productivo" en simultáneo con el auge del neodesarrollismo en Brasil. Según la lectura del gobierno, este proceso permitiría retomar el fallido proceso de industrialización por sustitución de importaciones interrumpido por la dictadura militar en 1976, dejando de lado o minimizando la transformación radical de la economía internacional en esos treinta años. Había una estrategia de "cambio de la matriz productiva" -la idea asociada con una serie de encadenamientos positivos derivados de la industrialización, sinónimo de expansión de la demanda agregada y de absorción del desempleo- y toda una serie de circunstancias positivas 
que hacían pensar que, con el contexto internacional favorable, era un momento propicio para impulsar esa estrategia.

El crecimiento económico a tasas chinas del periodo 2005-2008 es el mejor momento de la posconvertibilidad y la acumulación de reservas internacionales (9\%, $8.4 \%$ y $8 \%$, respectivamente, en 2005,2006 y 2007 ). El impulso se ve detenido por la tentativa de aumentar los impuestos a las exportaciones primarias que deriva en el denominado "conflicto del campo" a comienzos de 2008, un punto de quiebre del periodo posneoliberal en Argentina. Las reservas internacionales habían alcanzado 46000 millones de dólares después de quedar en apenas 10000 millones tras la crisis de diciembre de 2001 , pero no como resultado de un cambio en la matriz productiva o un cambio estructural, sino a resultas de los excepcionales precios de las materias primas. No había un cambio estructural ni un auge industrial sino apenas una recuperación de la capacidad instalada, que todavía no se estaba usando de manera plena [Porta y Fernández, 2008]. Existía una reticencia inversora producto de diversas razones entre las cuales debe resaltarse la recuperación de la lucha sindical y de los salarios reales a partir de las negociaciones paritarias relanzadas desde 2007, con muchas diferencias entre los trabajadores registrados y entre estos últimos y los trabajadores "en negro", que se observa entre 2007 y 2012 [Piva, 2015a: 42-43].

El aumento de los precios internos y la recuperación salarial afectan la competitividad externa y los superávits comerciales y de pagos empiezan a reducirse. La fuga de capitales se reinicia, vuelve deficitarias la cuenta de capital y la balanza de pagos y habilita la implementación, al comienzo del segundo mandato de Cristina Fernández de Kirchner, de fuertes controles de cambio y limitaciones para la adquisición de divisas, el denominado "cepo cambiario". Por su parte, la industria empezaba a mostrar los límites de su expansión inicial. El problema de la industria es el déficit externo de divisas que registra por los insumos importados que requiere y que no se implementó una política industrial adecuada a esa situación. Según Schoor y Wainer, hubo un afianzamiento de la "dualidad estructural" del sector fabril argentino que "se expresa en que un puñado de rubros productivos ligados con el procesamiento de recursos básicos presenta una balanza comercial positiva, mientras que los restantes son deficitarios [Schoor y Wainer, 2015: 41]. Como señala Sztulwark, a pesar de que existen 
múltiples políticas e iniciativas, la política industrial desplegada se muestra descoordinada de las de ciencia y técnica y con un bajo impacto en la productividad, como fue el caso de las grandes apuestas industriales del kirchnerismo, el caso del Régimen de Promoción de Tierra del Fuego para la electrónica de consumo y el sector automotriz, que sigue mostrando una inserción pasiva en las cadenas regionales coordinadas desde Brasil [Sztulwark, 2015: 90].

El kirchnerismo se propone establecer una mediación compleja entre las diferentes fracciones de capital para favorecer al sector industrial -grande, mediano y pequeño- generador de empleo y de valor agregado en desmedro de las otras fracciones, sobre todo el financiero y el agrario. La retórica del gobierno va en este sentido pero la práctica concreta no siempre toma esa dirección. Aunque los bancos y estos sectores no se adhieran al programa del gobierno, la salida de la crisis de 2001 reconstituye también la dinámica de la acumulación financiera por el solo hecho de reconstituir sus bases de acumulación. Las ganancias del sector financiero durante el periodo kirchnerista fueron superiores incluso a las de la década de los noventa, según Alan Cibils y Cecilia Allami [2013], con resultados por prestación de servicios que superan los resultados por intereses y resultados de préstamos al sector público que superan al sector privado. En este último caso, las ganancias están vinculadas con el crédito al consumo de corto plazo (33 \% del crédito en 2009) más que con la inversión de largo plazo, impulsando una lógica del endeudamiento de los sectores populares [Gago, 2014].

La compleja mediación del gobierno kirchnerista con las diferentes fracciones del capital venía bien hasta que encontró un punto de no retorno con el "conflicto del campo" por las retenciones a las exportaciones agrarias en 2008, cuando esta mediación dejó de verse convalidada por las fracciones dominantes. El kirchnerismo creyó poder conducir el proceso a favor de la fracción industrial mercado-internista en desmedro de las demás, mientras las restantes fracciones -dado el incierto contexto poscrisisfueron apoyando la política del gobierno o al menos no la impugnaron. A partir de la resistencia de los sectores rurales al aumento de las retenciones a las exportaciones agrarias en el conflicto del campo esa relación se quiebra, lo que cambiará de forma definitiva el porvenir de esa lógica 
de mediación del Estado con las fracciones del capital, que de todas maneras va a quedar velada por la continuación del éxito de la acumulación (luego del conflicto de 2008, el crecimiento económico continuó en 2009 y hasta 2010-2011).

El gobierno mantenía la iniciativa política y avanzaba con la ley de medios y con políticas sociales como la asignación universal por hijo. A pesar del golpe recibido en 2008 con la crisis del campo, con este impulso Cristina Fernández de Kirchner terminó su mandato en 2011 y consiguió su reelección. Se observaba un aumento importante de la inflación, cercana a $27 \%$ en 2008 , a $15 \%$ en 2009 y por encima de $20 \%$ y de modo permanente entre 2010 y 2012 . Es evidente la reticencia inversora, el aumento de la fuga de capitales -que tiene un máximo en 2011-y el fin de los superávits fiscales y de la balanza de pagos. La restricción externa y la fuga de capitales no redujeron tanto las reservas porque también el saldo exportable seguía siendo importante. Pero generó una señal de alarma habilitada por la utilización del cepo cambiario que se instaló ni bien fue reelecta Cristina Kirchner y que condicionó bastante todo su segundo mandato. Las tasas de crecimiento de ese periodo son débiles (en 2011 se creció más de $8 \%$ pero $2012-2015$ ya son años de alternancia entre crecimientos y caídas del PIB) e incluso se registra una gran caída de las reservas: en 2011 estaban en 46000 millones de dólares y terminarán en 30000 millones de dólares en 2013.

El kirchnerismo fracasaba en esa tentativa de mediación compleja entre las fracciones del capital agrario, industrial y financiero. Y ese fracaso se evidenció cuando el capital productivo orientado a la exportación tuvo la capacidad de convertirse en dominante al interior del "bloque en el poder" e hizo coincidir su reproducción como fracción con la reproducción del capital en general y del conjunto social [Piva, 2015b: 34]. Teniendo capacidad política de imponerse después de "la crisis del campo", esta fracción dominante aún no había encontrado una articulación política "por derecha" para disputarle el control sobre ese arbitraje al kirchnerismo. Por su parte, este fracasó en el intento de disciplinar al capital agrario, avaló, por acción u omisión, el crecimiento de las rentas financieras e inmobiliarias al tiempo que falló en restablecer la ganancia industrial. El kirchnerismo se había desgastado enormemente y preparaba así el camino para su posterior derrota electoral en 2015. 
El subdesarrollo, el aislamiento de los mercados internacionales y los regímenes políticos autoritarios -la dictadura de Alfredo Stroessner se extendió por 35 años hasta 1989- han condicionado históricamente a un país pequeño de apenas siete millones de habitantes como Paraguay. Una altísima concentración de la tierra, una estructura política autoritaria y una industrialización casi inexistente han caracterizado al país durante esas cuatro décadas. En los años sesenta, y en línea con la "Alianza para el progreso", se crea el Instituto de Bienestar Rural para distribuir tierras fiscales que no implicaban expropiaciones ni una reforma agraria en sentido estricto. Ya en los años setenta la industria reconoce un crecimiento importante con las obras de construcción de las grandes represas hidroeléctricas para aprovechar el gran caudal del río Paraná, junto con industrias del cemento y siderúrgicas como Aceros Paraguay.

Paraguay no tuvo siquiera un proyecto de sustitución de importaciones, pero en 1973 inició la construcción de la represa hidroeléctrica binacional Yacyretá con Argentina, y en 1975 la represa de Itaipú con Brasil, lo que supuso una inyección de dinero desde Brasil para la industria de la construcción y llevó al crecimiento de los sectores obreros hasta 1982. La energía eléctrica es la única actividad de exportación además del algodón y algo de soja. En los años ochenta la crisis de la deuda externa coincide con el regreso al campo de los asalariados de Itaipú y la toma de tierras comienza a volverse un factor fundamental en la caída de Stroessner en 1989. Los terratenientes, los "barones de Itaipú" y los militares son los actores relevantes de un régimen paraguayo en el que la corrupción seguía presente aún en el periodo democrático de Andrés Rodríguez (1989-1993), Juan Carlos Wasmosy (1993-1998), Luis Gonzáles Macchi (1999-2003) y Nicolás Duarte Frutos (20004-2008).

Las rebeliones militares (1996,1999 y 2000) estaban a la orden del día y en 2005 convertían Paraguay en el tercer país más desigual de América Latina [Nickson, 2008: 8]. Incluso Stroessner es derrocado por la vía del golpe de Estado de parte de Andrés Rodríguez, que luego será electo y promoverá las reducciones arancelarias para el sector agroexportador (la soja transgénica es introducida tempranamente en 1989) y la privatización de empresas públicas como las Líneas Aéreas Paraguayas. En la década 
de los noventa los gobiernos adoptaron las recetas neoliberales pero mostraron un bajo crecimiento económico y enfrentaron numerosas crisis financieras entre 1995 y 2002 ya que se vieron afectados por la crisis en Brasil y Argentina.

En 2003, la crisis política termina con el bipartidismo del Partido Colorado y el Partido Liberal. Ese mismo año aparecen por primera vez nuevos partidos políticos en el parlamento y comienza también el auge de la soja y el crecimiento económico que habilitó la aparición de una nueva clase media. Pero el agronegocio de la soja está controlado por capitales extranjeros, en especial argentinos y brasileños. Los beneficios económicos del auge agrícola se concentraron en la élite de productores de soja, ganaderos y profesionales urbanos, y a pesar de la prosperidad de los precios agrícolas, la pobreza extrema aumento de $15.5 \%$ a $19.4 \%$ entre 2005 y 2007 , lo que incrementó el descontento de los movimientos campesinos contra los latifundios, sobre todo los de propiedad de agricultores brasileños que adquirían enormes extensiones de tierra para la producción de soja [Nickson, 2008: 10].

La expansión del cultivo de soja desplazó al algodón como actividad económica dominante, que llegó a representar 30 \% del PIB y benefició al gobierno de Nicolás Duarte Frutos entre 2004 y 2008. Este gobierno se ocupó también de iniciar con el FMI una renegociación de la deuda externa; sin embargo, el descontento iba en aumento. El "obispo de los pobres", Fernando Lugo, encabezó en 2006 un movimiento de resistencia ciudadana a la reelección de Duarte Frutos. Lugo, en acuerdo con el Partido Liberal, creó la "Alianza Patriótica para el Cambio" y ganó las elecciones de 2008, lo que significó un quiebre institucional de enorme relevancia. La elección de Lugo como presidente puso fin a seis décadas de hegemonía del Partido Colorado, que históricamente nucleaba a representantes de los terratenientes, la Iglesia y el ejército. Paraguay es ahora el cuarto productor mundial de soja y Lugo impulsa una reforma agraria. Pero el gobierno de Lugo debe enfrentar muy tempranamente los efectos de la crisis internacional, para lo cual cuenta con el apoyo de Ecuador y los restantes países latinoamericanos con gobiernos progresistas.

El gobierno de Lugo tiene margen para endeudarse dado el bajo ratio de deuda/PIB cercano a $20 \%$, lo que le permite emitir bonos, promover la 
inversión externa directa y planificar la realización de obras de infraestructura mediante alianzas público-privadas. El año 2010 es un año de enorme crecimiento económico, cercano a $10 \%$, y así serán también los años posteriores. No obstante, Lugo será destituido por razones poco claras por medio de un golpe institucional parlamentario en julio de 2012, luego de la masacre de Curuguaty, jaqueado en el parlamento por el Partido Liberal y el Partido Colorado y por las movilizaciones patronales de la Unión de Gremios de la Producción (UGP) tras solo cuatro años de gobierno. Con una inversión externa de 400 millones de dólares en los sectores agrario y forestal, el intento de frenar el avance del algodón transgénico parece haber condicionado el gobierno de Lugo. Los plantadores de soja "brasiguayos" también se oponían a Lugo, con apoyo del gobierno brasileño [Barbosa, 2014:22]. Luego de cinco años de interrupción de su poder, el Partido Colorado retorna de la mano del empresario tabacalero Horacio Cartes, quien constituye un gabinete de técnicos formados en Estados Unidos y seguirá aprovechándose de los beneficios del auge de la sojización y el agronegocio.

Uruguay durante las presidenCias del Frente Amplio

La crisis del neoliberalismo en Uruguay se precipita a partir del impacto que recibe de la crisis de Argentina del año 2002. Este impacto se refleja en una crisis del sistema bancario entre 2002 y 2004, y una crisis económica, con un desempleo que alcanza a 17 \% de la población económicamente activa. El Frente Amplio (FA) llega al poder de la mano de Tabaré Vázquez desplazando al Partido Colorado y el Partido Nacional, lo que significó un gran quiebre institucional que dio inicio al periodo posneoliberal en Uruguay y que se mantuvo por cuatro mandatos consecutivos.

La movilización popular contra el neoliberalismo facilitó la promoción de un proyecto alternativo que culminó con el ascenso del FA al gobierno e inauguró un periodo neodesarrollista en Uruguay orientado a dinamizar el crecimiento económico con base en la inversión externa directa. Entre 2004 y 2011 la inversión externa directa ascendió de 330 a 2700 millones de dólares y pasó de representar 2 a $6 \%$ del PIB, lo que supone el doble del promedio para América Latina, según la Cepal [Santos et al., 2013: 15]. 
Para un país pequeño con una población de apenas 3.5 millones de habitantes y con un desempleo cercano a $10 \%$ en 2002, las expectativas en torno a un gobierno de izquierda eran altas dados los niveles de pobreza de casi $27 \%$. El boom agrícola iniciado en 2003 por el auge de los precios de las materias primas y el dinamismo de sectores como el forestal, las telecomunicaciones, la construcción y el transporte sostuvieron el avance del neodesarrollismo. Aunque en el periodo 2005-2012 aumentaron los salarios reales $36 \%$ y cayeron fuertemente la pobreza (de 36 a $13 \%$ ) y la indigencia (de 4 a $0.5 \%$ ), así como el desempleo a su mínimo histórico de $6 \%$, el subempleo de 17 a $7 \%$ y la informalidad de 38 a $28 \%$, el régimen de acumulación seguía sosteniéndose en la exportación de commodities de bajo valor agregado con una fuerte extranjerización de la propiedad y la producción en el sector agroindustrial. Entre 2001 y 2011, al calor del auge del agronegocio forestal y sojero, los propietarios uruguayos de tierras redujeron su participación de 90 a 54 \% de las propiedades y las sociedades anónimas pasaron de tener 1 a 43 \% de las tierras [Santos et al., 2013: 15].

La política fiscal fue el eje de numerosas reformas durante los gobiernos del FA. Las reformas fiscales de un sistema impositivo antiguo establecieron la supresión de numerosos impuestos, la reducción del impuesto al valor agregado (IVA) de 23 a $21 \%$ y la creación del Impuesto a la Renta de Personas Físicas (IRPF). En esa línea se impulsó un notable aumento del gasto público social, así como la creación del Ministerio de Desarrollo Social en 2005 y políticas focalizadas para la reducción de la pobreza y la indigencia [Santos et al., 2013: 18-19]. En educación, el presupuesto aumentó de modo notable a $4.5 \%$ del PIB y en el sector salud destaca el nuevo Sistema Nacional Integrado de Salud (SNIS), que afilió a 1.5 millones de uruguayos. Uno de los mentores de las políticas era el ministro de Economía Danilo Astori, quien perderá la interna con el exlíder de los Tupamaros, José Pepe Mujica, para las elecciones presidenciales de 2010. Electo Mujica como presidente con 53 \% de los votos para el periodo 2010-2014, de todos modos Astori será su vicepresidente y luego nuevamente ministro de Economía en el segundo mandato de Tabaré (2014-2018).

El gobierno de Mujica inicia su gestión con un nivel bajo de desempleo -en torno a $5 \%$ - y con perspectivas de mejorar la relación con Argentina, tensada durante el conflicto por la instalación de las pasteras en la costa uruguaya que contaminaban el río Uruguay. Con la aprobación de un 
nuevo código minero en diciembre de 2010, Mujica apuesta por la minería para agregar el hierro a las exportaciones tradicionales de carne, soja, arroz y celulosa, lo que supone enfrentarse a productores rurales y a movimientos ambientalistas. Las luchas contra la minería de cielo abierto y el agronegocio serán encabezadas por pobladores y productores de las zonas afectadas antes que por organizaciones clásicas del campo popular, como el movimiento sindical o cooperativo frente a los numerosos proyectos mineros que se proponen para el periodo 2010-2013 [Elizalde et al., 2013: 48]. Uno de los más importantes es el proyecto minero Aratirí, previsto para la explotación de hierro por 12 años (unos 18 millones de toneladas al año) para abastecer la siderurgia de China por parte de la empresa india Zamin Ferrous. Este proyecto supone una inversión de 3000 millones de dólares, la mayor inversión externa de la historia uruguaya. También se impulsaba el desarrollo de proyectos de infraestructura como un puerto de aguas profundas para embarcar el hierro y la pasta de celulosa de Botnia.

El estímulo a las actividades extractivistas fue compensado con leyes de corte "progresista", como la Ley del aborto (2012), la Ley de matrimonio igualitario y la regulación del consumo de marihuana. Uruguay se transforma en un país donde proliferan actividades rentísticas, acciones nuevas que involucran enclaves de actividades extractivas, el agronegocio y la especulación con títulos mineros, pero llevadas adelante en el marco de gobiernos progresistas. Los "enclaves informacionales" gozan de excepciones fiscales y aduaneras para el outsourcing de servicios informáticos, de atención a clientes y servicios financieros bajo el encuadre de las zonas francas y complementan la actividad bancaria offshore [Falero, 2013].

Uruguay es uno de los dos socios pequeños del Mercosur y mantenía vínculos muy estrechos con la economía de Argentina, pero la relación va a deteriorarse a raíz del conflicto ambiental alrededor de la instalación de la pastera Botnia de capitales finlandeses sobre el río Uruguay. El conflicto entre Argentina y Uruguay condicionó las relaciones bilaterales entre ambos países durante los gobiernos de Tabaré y Kirchner. El interés de Uruguay en aumentar la inversión externa y el empleo, vinculado con la construcción y puesta en marcha de la planta, chocaba con los efectos sobre el ambiente derivados del propio funcionamiento de la pastera, sumamente contaminante. La empresa inició su producción en 2007, pero muy lejos estuvo de haber generado el desarrollo de proveedores o el 
aumento del empleo esperado. No obstante, la economía se recuperaba acompañada de una serie de medidas en los planos fiscal, social y educativo.

Venezuela: el gobierno de la revolución bolivariana de Hugo Chávez

El régimen de acumulación en Venezuela se encuentra totalmente dominado por la actividad petrolera y la distribución de su renta constituye el eje de todas las políticas de distribución. El sector no petrolero muestra una alarmante volatilidad en relación tanto con los volúmenes de producción como con sus precios fijados en el mercado mundial, lo que pone de relieve la necesidad de transformar y diversificar esa matriz productiva como paso previo a cualquier estrategia de desarrollo. El petróleo se descubre tempranamente en Venezuela en 1914, cuando el grueso de las exportaciones era de café (50 \%). La primera ley del petróleo es de 1922 y en los años treinta es el segundo país productor, después de Estados Unidos. En 1960, se crea la Organización de Países Exportadores de Petróleo (OPEP), $\mathrm{y}$, en los años setenta, en medio del boom, se nacionaliza el petróleo en 1976, durante el primer gobierno de Carlos Andrés Pérez, cuando nace Petróleos de Venezuela, S. A. (PDVsa). Pero en los años ochenta, persisten la dependencia petrolera y el endeudamiento externo, que terminan en 1983 con la crisis de la deuda y en 1989 con el "caracazo".

En Venezuela, el neoliberalismo comienza con el segundo gobierno de Carlos Andrés Pérez, quien lleva la pobreza de 53 a 71 \% en 1992, lo que amerita un intento de golpe de Estado por parte del entonces coronel Hugo Chávez Frías, que al año siguiente será destituido por la Corte Suprema. Luego de numerosas manifestaciones, enfrentamientos y tentativas de golpes de Estado, accede al poder Rafael Caldera (1993-1999), que inicialmente se pronuncia contra las reformas neoliberales sugeridas por el Consenso de Washington, pero que las retomará pronto en 1994. La deuda externa aumentó de 3000 a 20000 millones de dólares entre 1991 y 1996. Ante la severidad de la crisis, Caldera buscó abrir el sector petrolero, cuyo monopolio correspondía al Estado desde 1976, a la inversión privada. Hugo Chávez se presenta a elecciones y gana en 1998. Chávez permanecerá 14 años en el poder, desde 1999 hasta su muerte en 2013, y cambiará la dinámica económica, política y social históricamente dominante en el 
país, al tiempo que se proyectará a nivel internacional como un líder regional y de los países petroleros organizados en torno a la OPEP.

Venezuela fue fundamental en el desplazamiento hacia la izquierda de América del Sur. Chávez crea la Alianza Bolivariana para los Pueblos de Nuestra América (ALBA) en 2004, impulsa el rechazo al Área de Libre Comercio de las Américas (ALCA) en 2005 y atraviesa sucesivamente el auge de los precios del petróleo de 2004 a 2008 y su caída en 2008 de 147 a 30 dólares. Venezuela sufre la hegemonía del sector petrolero y la influencia de una burguesía importadora que impone la crisis del bolívar y sucesivas devaluaciones, recurrentes desde 2010 y explosivas a partir de 2016, ante la baja del precio del petróleo. Al menos hasta 2012, con innumerables contradicciones, errores y limitaciones, las condiciones de vida de los sectores populares mejoraron, la pobreza y la desigualdad se redujeron, y el acceso a la salud, la educación y la seguridad social se acrecentó, con un aumento de la organización social de base y de la participación política. Sin embargo, Venezuela tampoco ha podido salir de la dependencia petrolera y desde 2013 -luego de la muerte de Chávez- atraviesa no solo una severa recesión sino una de las peores crisis de su historia.

Chávez sufrió un intento de golpe de Estado fallido en abril de 2002 y un "paro petrolero" de dos meses en diciembre de ese año a raíz de la iniciativa de reformar la Ley de hidrocarburos para aumentar el porcentaje de participación del Estado en las empresas mixtas del sector. La política petrolera se daba en el marco de un paquete de 49 leyes que incluyen la Ley de hidrocarburos y la Ley de tierra y desarrollo agrario, la cual plantea la posibilidad de expropiar tierras ociosas para entregarlas a los campesinos. La actividad económica se detuvo y el PIB cayó de manera estrepitosa en 2002 y 2003; también disminuyó la inversión, y el desempleo y la inflación aumentaron. La reducción de las reservas internacionales obliga a adoptar controles de cambio y a devaluar el bolívar.

La economía se recupera, aprovecha la subida de los precios del petróleo y crece un increíble $18 \%$ en 2004 y a una tasa de $8 \%$ interanual entre 2005 y 2008, lo que le permitió triplicar los ingresos por exportaciones [Sutherland, 2018: 144]. Sin embargo, estos enormes ingresos van a sobrevaluar el tipo de cambio y a generar un auge importador voraz, muy superior al de las exportaciones, que licuará buena parte de la renta petrolera. Entre 2003 y 2012, las importaciones, muchas de ellas fraudulentas, 
se quintuplican: pasan de 14000 a 80000 millones de dólares, y no se traducen en ningún incremento sustantivo de la producción [Sutherland, 2018: 146]. La importación de maquinaria y equipo indispensable para la formación bruta de capital se quintuplicó y el producto interno bruto (PIB) industrial registró un notable incremento entre 2004 y 2008, pero luego se desplomó a los niveles de 1997. Las numerosas estatizaciones supusieron pagar mucho dinero por empresas técnicamente obsoletas. Desde 2005, Chávez expropió latifundios y tierras improductivas (unos tres millones de hectáreas de tierras cultivables a partir de 2007, alegando razones de soberanía alimentaria) y desde 2006 algunas empresas estratégicas como la empresa de electricidad de Caracas, lo que le permitirá al Estado tener un control clave en los sectores de electricidad y agua. En el marco del Plan de Desarrollo Económico y Social de la Nación (2007-2013), se nacionalizaron los sectores considerados estratégicos como el hierro, el acero, el cemento, las telecomunicaciones y la electricidad, por unos 24000 millones de dólares en expropiaciones y nacionalizaciones entre 2007 y 2009 [Vera, 2018: 91]. En 2008, se nacionaliza Siderúrgica del Orinoco (Sidor), empresa del grupo argentino Techint, y el Banco de Venezuela, perteneciente al Banco Santander de España, que recibió 1050 millones de dólares por 51 \% de las acciones de un banco del que había adquirido $93 \%$ por apenas 300 millones [Sutherland, 2018: 148].

Las mejores condiciones internacionales permitieron implementar políticas sociales y expandir el gasto público social, lo que contrastaba con las políticas sociales focalizadas del periodo neoliberal. Las "Misiones" se despliegan desde 2003 en educación, salud, vivienda y también en el campo productivo. Chávez impulsó políticas de transferencias directas a los sectores más empobrecidos y favoreció la participación comunitaria de los consejos comunales y subsidios enormes a los servicios públicos, pero diluyó la renta petrolera a favor del capital importador y en contra del agro, la industria y el comercio.

La baja de los precios del petróleo en 2008, que pasó de 147 a 30 dólares, implicó un golpe muy fuerte para mantener el ritmo de las importaciones y el nivel de las reservas. El sector que controlaba la importación y la distribución de alimentos regulaba con su poder oligopólico la abundancia o escasez de los mismos. Los intentos de recuperar la soberanía alimentaria llevaron a buscar el control de empresas del sector en 2009, 
año en que se produce una caída de $3 \%$ del PIB luego de cinco años de crecimiento continuo. La crisis energética se hace sentir en 2009 tras una decena de años en los que la demanda de energía eléctrica aumentó mucho más que la capacidad instalada y en los que la actividad petrolera cae $6 \%$ y $25 \%$ la producción de gas.

La bonanza petrolera habilitó el endeudamiento externo y la deuda externa -sobre todo con los bancos de desarrollo de China- se cuadruplicó en apenas seis años (entre 2006 y 2012), hasta alcanzar 113000 millones de dólares y dejar casi agotadas sus reservas internacionales líquidas $\mathrm{u}$ operativas, que pasaron de 15000 millones de dólares durante el periodo 2005-2011 a apenas 3500 millones en 2012 [Vera, 2018: 87]. Mucho de esta caída se explica por el manejo discrecional de PDVSA como una agencia de desarrollo por afuera de controles presupuestarios fiscales (que según Vera suponía un pasivo de 65000 millones con el Banco Central a fines de 2013) y por una reforma del Banco Central realizada en 2005 que habilitó la transferencia a un fondo para las inversiones del sector público (Fondo para el Desarrollo Nacional) de casi 53000 millones de dólares entre 2005 y 2013. A su vez, el servicio de la deuda ya llegaba a 15500 millones de dólares en 2011 y suponía 17 \% de las exportaciones (y seguirá subiendo hasta alcanzar 20000 millones, $54 \%$ de las mismas en 2015) [Vera, 2018: 88]. A partir de allí comienza una espiral descendente de la economía que combinará aumento de la emisión monetaria, devaluación del bolívar e inflación, en una caída libre que lleva a la presente crisis. La inflación, que desde 2007 supera sistemáticamente $20 \%$ anual, y el desabastecimiento ponían en jaque al bolívar, que se devaluó de forma sucesiva en 2009, 2010 y 2013, y pasó de 2 a 6 bolívares por dólar. En 2012 un Chávez enfermo es reelecto pero fallece a los pocos meses de iniciar su último mandato y deja como sucesor a Nicolás Maduro.

\section{Ecuador: el gobierno de la revolución ciudadana de Rafael Correa}

Al igual que Venezuela o México, en la década de los setenta Ecuador se verá beneficiado por el alza de los precios del petróleo y dará comienzo el "boom petrolero". Sobre ese boom va a circular el grueso de la generación 
de excedentes económicos en una economía escasamente industrializada que se había organizado a partir de la exportación del cacao desde fines del siglo XIX hasta la tercera década del xx y luego de la de bananas en el decenio de 1940 [Acosta, 2012: 76-135]. El despegue de la actividad petrolera en los años setenta significará un punto de inflexión en la historia económica del Ecuador y aquella se convertirá en el sector económico más determinante del régimen de acumulación ecuatoriano, al menos hasta la crisis de mediados de los años ochenta [Acosta, 2012:158-196]. De allí en adelante el boom se amortiguó y la euforia disminuyó. La década de los noventa es la del neoliberalismo, con el gobierno de Durán Ballén (1992-1996) y la seguidilla de Abdalá Bucaram, Fabián Alarcón y Jamil Mahuad. Durante el gobierno de este último, Ecuador recibe los efectos de la crisis del sudeste asiático y de la caída de los precios del petróleo, que en 1999 se traducen en una caída de 7 \% del PIB y una crisis financiera fenomenal que lleva a la emigración de un millón de ecuatorianos en un país con 14 millones de habitantes (5.4 millones en la pobreza) y a la eliminación y el reemplazo de la moneda nacional, el sucre, por el dólar en el año 2000 [Acosta, 2012: 243-265].

La dolarización fue una medida extrema en un país que además buscará renegociar la deuda externa de 7000 millones de dólares en un canje de bonos y un ajuste acordado con el Fondo Monetario Internacional (FMI). En 2004, se sanciona la Ley Trole I, que incluye una flexibilización laboral. La crisis y el aumento de la deuda a casi 10000 millones de dólares colaboran a la salida del coronel Lucio Gutiérrez y la llegada de Rafael Correa al poder, en el marco de un aumento de los precios del petróleo, facilitado por la opEP, de 18 a 35 dólares. Correa propone luego una auditoría de la deuda externa y en 2009 obtiene una quita muy importante de $70 \%$ de la misma. El repunte de los precios del petróleo iniciado en 2003 señala el comienzo de uno de los mayores ciclos ascendentes de la economía ecuatoriana, el cual coincidirá en tiempo con la consolidación de Rafael Correa en el poder.

La Asamblea Constituyente de Montecristi confirma a Correa y el gobierno presenta su Plan Nacional de Desarrollo 2007-2011. De la mano de la asamblea y del concepto indígena del Buen vivir surge la iniciativa Yasuní-ITT para no explotar el petróleo en zonas protegidas para las poblaciones originarias, así como el mandato de eliminar las concesiones 
mineras, lo que se expresa en la Constitución de 2008. La Constitución de Montecristi subraya el carácter multiétnico del país y consagra expresamente el concepto indígena del Buen vivir, con lo que se consolida la alianza del gobierno con el sector indígena. El mismo camino seguirán las constituciones sancionadas en Bolivia y Venezuela a inicios de 2009. La Confederación de Nacionalidades Indígenas del Ecuador (Conaie) apoyó a Correa y los diputados indígenas de Pachakutik se aliaron con Acuerdo País, aunque en 2009 rompieron con él a raíz de su rechazo a la consulta a los indígenas acerca de la explotación minera y debilitaron así la legitimidad originaria de su gobierno [Trujillo, 2010: 17-20].

El gobierno de Correa procura garantizar el control estratégico de los recursos naturales e impulsar la salud y la educación. El gobierno impulsa el Plan Nacional del Buen Vivir 2009-2013 y el Plan Nacional de Desarrollo del Sector Minero 2011-2015 para la realización de una "minería sustentable" en un contexto de enorme crecimiento de las exportaciones petroleras, que entre 2007 y 2011 aportan unos 30000 millones de dólares, crecimientos importantes del PIB y una reducción de la desigualdad y la pobreza considerable. Pero, además, la nueva constitución permite a Correa presentarse a la reelección por otros dos mandatos consecutivos de cuatro años en 2009 y 2013.

En el segundo mandato de Correa, la pobreza pasa de $38 \%$ en 2006 a $25 \%$ en 2011 . El año 2010 le supone gestionar los precios más bajos y la caída de las remesas del exterior, la otra variable relevante para una economía dolarizada. Los logros en los indicadores sociales son notables: la pobreza extrema será menor de un dígito (8.6\% en 2013 según el Banco Central de Ecuador) por primera vez en la historia del Ecuador; 2012 es el punto más alto del correísmo, con un crecimiento de $5 \%$ del PIB. Ese año los precios del petróleo superaron 120 dólares luego de haber caído estrepitosamente en 2009 del máximo de 130 a 40 dólares por la crisis financiera internacional.

Por tratarse de un país pequeño, dolarizado y dependiente del petróleo se recuperó muy rápido de la crisis internacional de 2008 y emprendió un ambicioso plan de desarrollo o "cambio de la matriz productiva", en línea con las ideas posestructuralistas de la Cepal, para las que la extracción de recursos naturales debe intensificarse en vistas de la transición a 
una economía basada en el conocimiento, como sostenía el Plan Nacional del Buen Vivir. Al margen de la recepción de los debates reciente sobre el desarrollo y las virtudes de la valorización del conocimiento, se tomaron muchas iniciativas en un país con un desarrollo industrial muy embrionario de los sectores tendientes a fortalecer.

En todo el periodo 2006-2013 Ecuador se benefició de ingresos por exportaciones que fueron el triple de los de cualquier gobierno ecuatoriano de la historia y de nuevos contratos de operación con 99 \% de las ganancias para el Estado. La quita de la deuda colaboró también a que esos ingresos no se destinaran especialmente a pagar acreencias y se canalizaran al mercado interno, con importaciones del sector privado y sobre todo con un aumento de la inversión pública y social sin precedentes en un contexto de bajas tasas de interés internacionales [Purcell et al. 2015: 44]. La inversión pública se realizó en construcción de autopistas, puertos, aeropuertos y proyectos hidroeléctricos para cubrir las necesidades de infraestructura de una sociedad dependiente del petróleo con niveles de desarrollo históricamente bajos, asociada de forma complementaria con los proyectos de la IIRSA. Estos proyectos fueron iniciados por el Banco Interamericano de Desarrollo en los 2000, apoyados por Brasil desde el inicio y financiados por el BNDEs y el Banco de Desarrollo de América Latina (CAF), y desde 2009 respaldados por Unasur como parte de un "regionalismo posneoliberal". La inversión en infraestructura y capital fijo por parte del Estado alcanzó los 7500 millones de dólares entre 2006 y 2012 [Purcell et al. 2015: 45]; así mismo, la nueva matriz energética basada en la construcción de ocho empresas hidroeléctricas fue pensada para alcanzar la independencia energética y permitir el avance de un proceso industrializador que promovía una sustitución selectiva de importaciones, no indiscriminada, para no reeditar los problemas de la industrialización sustitutiva de importaciones.

Hasta 2013 Ecuador registró un periodo de bonanza, sostenido en el aumento del PIB y de las exportaciones petroleras que permitieron encauzar la inversión pública y los proyectos de infraestructura para unir la Costa, la Sierra y la Amazonía. No obstante, la dependencia de los precios de los commodities condicionó este desempeño en los años posteriores. 
Bolivia fue tradicionalmente un país relegado con una situación de alta pobreza y distribución del ingreso muy regresiva a pesar de contar con enormes reservas de hidrocarburos: la mayor reserva de gas y petróleo en América Latina detrás de Venezuela. La dictadura militar encabezada por Hugo Banzer en los años setenta dio paso en 1982 a una democracia relativamente débil, que pronto se vio jaqueada por un proceso hiperinflacionario que terminó con el gobierno de Hernán Siles Suazo y habilitó el comienzo de los gobiernos neoliberales a partir de la administración de Víctor Paz Estenssoro. El inicio del neoliberalismo en Bolivia puede situarse en la decisión de desnacionalizar la minería, esto es, la Comibol. Ello trajo aparejado el despido de 27000 mineros entre 1985 y 1987, que resistieron y formaron cooperativas (que luego serán relevantes para comprender los conflictos distributivos en los años de Evo Morales).

Ya en los años noventa, el gobierno de Sánchez de Losada (1993-1997) impulsó el avance de las privatizaciones, la creación de fondos de pensión y los proyectos de descentralización del Estado, que permitieron la politización a nivel de los municipios y el aumento de la participación de los movimientos sociales indígenas y campesinos [Villarroel, 2014]. En 1996 las reservas de gas y petróleo comprendían alrededor de 47 \% del territorio boliviano; el sector representaba $7 \%$ del PIB y $50 \%$ de los ingresos fiscales bolivianos, pero la producción solo se usaba para satisfacer el mercado interno y vender algo de petróleo a Chile. Por dicha razón se promovió una nueva ley de inversiones extranjeras (Ley 1689), pensada en especial para el sector de hidrocarburos, que establece los "contratos de riesgo compartido", por lo que se da a los inversores la propiedad de los recursos.

En el año 2000, el aumento de las tarifas de agua generó la denominada "guerra del agua" y la subida del gas ocasionó la "guerra del gas", que terminó con el segundo gobierno de Sánchez de Losada. En las elecciones de 2002, se convirtió en la segunda fuerza política del país el Movimiento al Socialismo (MAS), encabezado por Evo Morales -proveniente de la Federación de Productores de Coca- y participante activo de las luchas de 2003 y 2005 encabezadas por movimientos campesinos e indígenas agrupados en la Coordinadora del Agua y la Coordinadora del Gas. Carlos Mesa 
asumió la presidencia en 2003 y propuso un referéndum vinculante sobre los hidrocarburos que no cuestionaba la propiedad de los hidrocarburos, no afectaba los contratos de riesgo compartido ni reconstituía la empresa estatal Yacimientos Petrolíferos Fiscales Bolivianos (YPFB).

En 2005, después de tres semanas de cerco sobre La Paz, el presidente Mesa renuncia y asciende el presidente de la Corte Suprema Eduardo Rodríguez Veltze. Se promulga la nueva Ley 3058 de hidrocarburos que deja sin efecto la Ley 1689 sobre inversión extranjera directa y se convoca a elecciones, las cuales gana Evo Morales con más de $53 \%$ de los votos [Allende y Boido, 2014: 157].

En su primer gobierno, Evo Morales pretende crear un Estado fuerte y desarrollado en el marco de lo que su vicepresidente Álvaro García Linera denominó en 2006 "capitalismo andino amazónico". Quedaron conformados dos bloques de poder en pugna por un proyecto de país a decidirse en la Asamblea Constituyente convocada ya en 2004: el vinculado con los movimientos sociales indígenas y campesinos (del altiplano y Cochabamba), que establecen el Pacto de Unidad; y el de los sectores tradicionales y los prefectos del oriente del país, la autodenominada "medialuna opositora" de los departamentos de las tierras bajas y la Amazonía (Santa Cruz, Pando, Beni y Tarija), pujando por la definición del nuevo Estado plurinacional y por dos cuestiones centrales, esto es, la distribución del excedente de los hidrocarburos recién nacionalizados y el proyecto de reforma agraria. El 10 de agosto tanto el gobierno nacional como los prefectos pusieron en juego sus cargos y el voto avaló ambos proyectos en lo que García Linera caracterizó como un "empate catastrófico” (el MAs ganó de forma abrumadora a nivel nacional, pero perdió en la medialuna opositora) y que derivó en la "masacre de Pando" organizada por los prefectos que, según Unasur, culminó en el asesinato de más de 20 campesinos. Evo declaró el estado de sitio, expulsó al embajador de Estados Unidos por considerarlo cómplice del plan separatista e incorporó las autonomías departamentales en el texto constitucional, que sería aprobado en referéndum en enero de 2009. En ese año, se sanciona una nueva constitución que da lugar a un Estado plurinacional, multilingüe, laico y con jurisdicción exclusiva sobre los recursos naturales. En ese mismo año, se produce la reelección de Evo Morales, lo que da lugar a una hegemonía inédita 
desde los años cincuenta. En un giro pragmático, Morales se concentró en ganarle a la derecha en sus territorios y obtener la reelección para un segundo periodo (2010-2015).

Morales nacionalizó los hidrocarburos en mayo de 2006 y firmó más de 40 acuerdos con empresas trasnacionales en un proceso que, a diferencia de los acuerdos con la Standard Oil en 1937 y la Gulf Oil en 1969, no implicó la confiscación de la propiedad sino la asociación y producción compar-tida con YPFB [Allende y Boido, 2014: 163]. Aunque se discute el alcance de la nacionalización, según García Linera el Estado se queda con $90 \%$ de la ganancia del sector hidrocarburífero, lo que constituye uno de los porcentajes de participación más altos del mundo [García, 2011: 50-51]. Ello permitió también ampliar los ingresos tributarios, que por primera vez superan los recursos provenientes de la cooperación internacional. Es así como se consolidaron políticas sociales bajo la forma de transferencias a partir de los ingresos derivados del auge de los hidrocarburos (Bono Juancito Pinto para la educación primaria, Renta Dignidad para los mayores de 60 años en condición de pobreza extrema y Bono Juana Azurduy para madres sin seguro de salud) [Schneider, 2014: 170]. El aumento de los precios internacionales y las exportaciones de gas dieron lugar a un crecimiento económico inédito: el PIB se duplicó en apenas tres años, entre 2007 y 2010, de 10000 a 20000 millones de dólares y en 2014 alcanzó 30000. Al mismo tiempo se acrecientan las reservas de divisas, de 3200 millones de dólares a 13000 en 2012, lo que representa alrededor de $50 \%$ del PIB, algo inédito en la historia económica boliviana.

Luego de los primeros años de posneoliberalismo, el proceso se mostraba algo debilitado en el frente interno. En 2008 sufrió las tentativas separatistas de los grupos autonomistas del Oriente petrolero, que impulsaban un federalismo tendiente a romper la unidad del país. En el segundo gobierno los cuestionamientos provinieron de las propias bases más que de los grupos políticos antagónicos. El crecimiento sostenido del sector minero generó pugnas entre los asalariados, las cooperativas (surgidas luego de la desestructuración de la Comibol en los años ochenta, con el cierre de minas de estaño y el éxodo de asalariados) y las grandes empresas trasnacionales del sector minero. La política minera del MAs fue ambivalente; se 
apoyó en diferentes sectores según las tensiones de la coyuntura: en algunos casos en las cooperativas, que pretendían recibir concesiones y limitar los efectos sobre ellas de los impuestos que se aplican al sector, y en otros en los mineros asalariados, que aumentaron la visibilidad y el papel de la Central Obrera Boliviana, que se acercó al gobierno de Morales sobre el final del primer mandato [Allende y Boido, 2014: 162-166].

En Bolivia también tomó nuevo impulso la reforma agraria con el gobierno del MAs. Desde los años cincuenta las titulaciones se habían realizado de manera individual para consolidar la pequeña propiedad campesina en los valles y el altiplano, mientras que en el Oriente se permitieron las grandes extensiones de tierras, favorables a la exportación. En los noventa, se había sancionado la Ley INRA para el reconocimiento de tierras comunitarias, pero apenas se habían repartido pocas hectáreas, unos 10 millones, entre 1996-2006. Morales saneará más de 30 millones de hectáreas en apenas tres años, entre 2006-2009 (completó casi 40 \% del territorio boliviano), aunque buena parte de ellas (18 millones de hectáreas) bajo la modalidad colectiva de tierras comunitarias de origen (TCO). Sin embargo, las mejores tierras han quedado en mano de los grandes propietarios y las disputas entre indígenas y campesinos por la forma de la propiedad se dan por tierras de menor capacidad productiva [Allende y Boido, 2014: 155-161].

A 10 años de Evo Morales en el poder, el crecimiento y el avance de los derechos de indígenas y campesinos en relación con la etapa previa es notable. No obstante, las disputas por el control de las minas en tierras de las comunidades generaron conflictos de todo tipo, ya sea por el incumplimiento de acuerdos sobre las concesiones de yacimientos como respecto a la preservación de áreas protegidas, como es el caso de la construcción de una ruta en el Territorio Indígena y Parque Nacional Isiboro Securé (TIPNIS). Los conflictos se traducen en enfrentamientos que condicionan la mediación estatal ya que dos centrales campesinas rompieron con el gobierno y el Pacto de Unidad creado en mayo de 2007 para apoyar la primera gestión del primer presidente indígena. A pesar de ello, Evo Morales fue reelecto por segunda vez y atraviesa su tercer mandato consecutivo, lo que supone una aprobación del modelo económico social, comunitario y productivo. 
El ciclo descendente (2013-2015) y el renovado avance neoliberal en América Latina

\section{Brasil desde 2013: recesión, crisis política y caída del PT}

El segundo periodo de gobierno de Dilma Rouseff inicia en 2014 con una gran pérdida de popularidad a causa de las manifestaciones de 2013 . Aunque Dilma había conseguido su reelección, lo había hecho por muy poco margen y al precio de una pérdida de legisladores del PT que dejaba un Congreso muy desfavorable al gobierno. En un intento de ganar confianza en los mercados, encaró un ajuste fiscal que fragilizó los apoyos en la sociedad y abrió el camino para que los sectores dominantes y los partidos de derecha tuvieran la oportunidad de crecer en términos de visibilidad y legitimidad electoral. El programa del PT no quiso ni pudo alterar los intereses estructurales de dichos sectores, que estaban dispuestos a tomar el poder en sus manos tras el agotamiento de un programa que, no obstante, significó una mejora sustantiva en las condiciones de vida de los sectores populares. Desempleo, inflación y recesión desde 2014 facilitaron un dudoso proceso de impeachment en 2016 sobre la base del mal manejo de las cuentas públicas tras un déficit fiscal de $9 \%$ del PIB y acusaciones de corrupción derivadas de las causas judiciales de la "Operación Lava Jato" y el "caso Odebrecht".

Como subraya Paulani [2017], la diferencia de los gobiernos del PT con la etapa previa consiste en que los primeros, a raíz de las condiciones internacionales, lograron conciliar las ganancias de las élites económicas, en especial la financiarizada, con políticas sociales y la elevación del consumo vía endeudamiento de las clases populares, en una tesis parecida a la del "neoliberalismo realmente existente" desarrollada en el capítulo 3. Se trata de una conciliación cada vez más dificultosa por la disputa de los fondos públicos y la cada vez menor disposición de las élites a que la conducción la realice un partido de izquierda y la encabece un líder obrero, y su pretensión de hacerlo directamente y por cuenta propia. Dilma Rouseff será reemplazada por su vicepresidente Michel Temer luego de su destitución fraudulenta; este hace suya la agenda de las élites de la derecha, retoma la retórica del ajuste inexorable y condiciona la inversión social a la inflación. De la mano de Temer, se realizan numerosos cambios de 
ministros y se busca reducir beneficiarios del programa Bolsa Familia y avanzar con el programa de privatizaciones (aeropuertos, Eletrobrás).

En julio de 2017, Temer consigue aprobar una reforma laboral para debilitar a los sindicatos y procurar una reforma provisional. En los primeros meses de 2018 se apoya en los sectores militares, decreta la intervención en Río de Janeiro y permite alimentar el descrédito del PT. El Tribunal Superior de Justicia ordena el encarcelamiento de Lula acusado de corrupción y se llega a las elecciones de 2018 en un clima social profundamente fragmentado, con una derecha en crecimiento, agitando los fantasmas con su discurso racista, militarista, nacionalista y contrario a la continuidad de la integración con los países sudamericanos. El triunfo de Jair Bolsonaro en las elecciones confirmó el tremendo giro a la derecha de Brasil y el retorno al alineamiento con los Estados Unidos de Trump, que por su importancia en el continente condicionará el rumbo de muchos procesos latinoamericanos, como se estudió en el capítulo 1.

Buscando retomar el ideario neoliberal, Bolsonaro en Brasil y Macri en Argentina ya promovieron a fines de 2018 el acuerdo del Mercosur con la Unión Europea, cuyas negociaciones estaban estancadas desde muchos años atrás y que supone un problema para el desarrollo industrial de los países de la región. Sin embargo, todavía debe ser ratificado por los parlamentos de los países europeos, algunos de los cuales no quieren ver expuesto su sector agrario a la competencia sudamericana.

ARGENTINA DESPUÉS DE 2013: EL DESGASTE DEL KIRCHNERISMO Y EL ASCENSO DEL MACRISMO

El segundo mandato de Cristina Fernández, tras el gran triunfo de octubre de 2011, no debe engañar respecto de la complejidad de la situación. Con importante fuga de capitales en 2011 y 2012, 2013 es un año de bajo crecimiento, caída de reservas y alta inflación que da las primeras señales de alarma al kirchnerismo acerca de las dificultades por llegar. La especulación sobre el dólar llevó la divisa a cotizar al doble de su valor oficial en el mercado paralelo del "dólar blue" y obligó a una fuerte devaluación en enero de 2014 y a una subida de la tasa de interés de $30 \%$. Con ello se da comienzo a un ciclo recesivo del cual nunca se volvió a salir. Este segundo turno de Cristina Fernández convive con mayores controles 
cambiarios, crecimiento del dólar paralelo y un incremento de las importaciones de energía. La necesidad de promover el ingreso de inversiones y las búsquedas de capitales conduce al gobierno en 2015 a retomar los pagos a los acreedores del Club de París y los tenedores de bonos que no habían aceptado la reestructuración de la deuda externa. Resolver los conflictos que habían quedado pendientes llevó al gobierno a un conflicto nuevo, el conflicto con los fondos buitres que se negaban a negociar sus acreencias y buscaban una salida judicial con apoyo de la justicia estadounidense. El periodo 2011-2015 fue de alternancia entre crecimiento bajo y caídas del PIB, y culminó con la derrota electoral del kirchnerismo, si bien por escaso margen, a manos de Mauricio Macri y su proyecto neoliberal actualizado a las nuevas circunstancias.

El macrismo buscaba retomar el crecimiento ajustando las cuentas públicas y fomentando la inversión externa. La economía se venía debilitando desde 2013 y Macri se proponía relanzarla sobre la base de un programa económico de cuño neoliberal. El gobierno liberó el tipo de cambio, con lo cual se produjo un aumento exponencial del dólar (que subió de 12 a 20 pesos en los primeros dos años, en 2018 alcanzó 40 pesos y orilla los 60 pesos en 2019) y la megadepreciación del peso elevó la deuda externa a niveles inéditos (de 240000 a 350000 millones de dólares entre comienzos de 2016 y fines de 2018). Como a su vez actualizó las tarifas de los servicios públicos a los niveles del dólar, los efectos sobre los precios no se hicieron esperar y la inflación no paró de incrementarse, alcanzando un $53.8 \%$ en 2019, el último año del mandato de Macri. La corrida cambiaria de 2018 amenazaba las reservas internacionales del Banco Central y el gobierno decidió recurrir al FMI en su rescate, que se comprometió a aportar unos 57000 millones de dólares (lo que elevó la deuda externa, que ya supone $95 \%$ del PIB cuando en el comienzo del macrismo era de $53 \%$ y condicionó su asistencia a la profundización del ajuste que el macrismo ya había iniciado. Los años 2017 y 2018 fueron de caída del PIB y gran aumento de la inflación y el desempleo; con un endeudamiento interno y externo más que preocupante, el gobierno perdió las elecciones presidenciales de 2019 y se produjo el retorno de un gobierno kirchnerista de la mano de Alberto Fernández. La coyuntura electoral de agosto de 2019 precipitó la crisis económica y la disparada del dólar, así como la salida de depósitos bancarios y el descrédito del gobierno de Macri, en franca retirada. 


\section{Paraguay: la consolidación del "modelo sojero" con Horacio Cartes}

El avance del modelo sojero tras 15 años de la sojización (2003-2018) posibilitó un crecimiento económico considerable en el mandato de Horacio Cartes (2013-2018): se alcanzó un PIB de 30 mil millones de dólares (se triplicó en 20 años desde 1995). El crecimiento permitió la cuasi duplicación de la clase media sin una mayor inclusión social pero con una reducción de la pobreza que pasó de $50 \%$ en 2003 a $28 \%$ en 2018.

Aunque el crecimiento basado en la sojización apenas necesita mano de obra dada la automatización de las plantaciones, contribuyó al desarrollo de infraestructura para la exportación y al boom inmobiliario en Asunción, en manos de capitales argentinos, brasileños y españoles. Paraguay es un paraíso financiero para capitales de Argentina y Brasil, y numerosos empresarios brasileños invierten también en maquilas para la producción de bienes de consumo destinados a su país. Según Jorge González [2016], entre 2013 y 2016 el acaparamiento de las tierras indígenas y campesinas por medios legales e ilegales -tanto pacíficos como violentos- produjo un aumento de la superficie sembrada de soja y una mayor deforestación, consolidando el modelo sojero frente al de la agricultura familiar campesina. Muchas familias campesinas terminaron vendiendo sus lotes a empresarios sojeros, sobre todo brasileños, bajo la presión de fumigaciones, amedrentamientos y ofrecimientos de compra de tierra [González, 2016: 2].

En 2018 Mario Abdo Benítez, el candidato de Cartes, ganó la interna del Partido Colorado y luego las elecciones presidenciales, por escaso margen, a la alianza formada por el Partido Liberal y el expresidente Lugo, por lo que se espera la continuidad en la expansión del modelo sojero.

\section{Uruguay frente a los dilemas no resueltos del Frente Amplio}

$\mathrm{Al}$ calor del auge de los precios de los commodities y las inversiones externas, Uruguay inició desde 2003 uno de los periodos de mayor crecimiento económico de su historia, con un fuerte incremento del PIB, la inversión (en especial la externa) y las exportaciones, así como una significativa mejoría en la distribución del ingreso, un descenso del desempleo y una importante reducción de la pobreza (de $39.9 \%$ en 2004 a $9.7 \%$ en 2014) y la indigencia (de 4.7 a $0.3 \%$ en el mismo periodo) [Caetano, 2017: 15]. 
Durante el segundo mandato de Tabaré Vázquez (2014-2018) se generaron algunas tensiones en el Frente Amplio. El gobierno dio marcha atrás a algunas decisiones de Mujica y en materia de relaciones exteriores, por ejemplo, impulsó un tratado de libre comercio con Chile -único país de Sudamérica que no es miembro pleno de alguno de los bloques económicos y que suele firmar esta clase de acuerdos con un tipo de política exterior diferente de la encabezada por los países sudamericanos- que ya fue aprobado por el parlamento uruguayo.

Desde 2015 el conflicto social se muestra en ascenso y en el segundo gobierno de Tabaré comienza a sentirse el clima de descontento marcado por diversos paros generales de los trabajadores del Plenario Intersindical de Trabajadores-Convención Nacional de Trabajadores (PIT-CNT) en reclamo de mejoras salariales [Caetano, 2017: 22]. El contexto regional signado por triunfos electorales de la derecha y los múltiples descontentos habilitaron el final del ciclo progresista en Uruguay con el triunfo del conservador Partido Nacional de Luis Lacalle Pou en las elecciones de finales de noviembre de 2019.

\section{Venezuela: la muerte de Chávez y el ocaso de la revolución bolivariana}

El modelo rentista petrolero desde la nacionalización del petróleo en 1976, en medio del boom, encontró sus límites. Chávez y los precios del petróleo de los años 2000 parecían la clave para el desarrollo de Venezuela, pero no se cambió la matriz productiva, sino que se profundizó la dependencia del sector (hasta alcanzar 96 \% de las exportaciones de Venezuela en 2013). En 2013-2014, cayeron dos pilares fundamentales del modelo venezolano: Chávez muere en marzo de 2013 y se asiste a una nueva caída estrepitosa de los precios del petróleo, de 100 a alrededor de 25 dólares. Desde el año 2013 se derrumba el PIB y en 2017 fue $40 \%$ del que era en 2014. Venezuela atraviesa una de las peores crisis de su historia: la economía se derrumba tras cinco años seguidos de caída del PIB y aumentan la pobreza, la desnutrición y la emigración forzada de venezolanos (desde 2014 emigran más de dos millones de personas de una población de alrededor de 30 millones); sufre además el bloqueo internacional y la amenaza de intervención de los Estados Unidos de Donald Trump. 
En abril de 2013, Nicolás Maduro llega al poder con menos apoyo y legitimidad que Chávez (gana por solo $1.5 \%$ por encima de Henrique Capriles de la Mesa de la Unidad Democrática-Mud). Ante un 2013 signado por la inflación y un 2014 por el comienzo de una megadevaluación del bolívar, lo más sencillo y urgente fue imponer un severo recorte de importaciones de $13 \%$ en $2013,17 \%$ en $2014,30 \%$ en 2016 y $51 \%$ en 2017 , lo que las redujo de 66000 a 12300 millones de dólares entre 2012 y 2017, y contribuyó a la recesión por escasez de insumos y a una crisis grave por falta de alimentos y medicinas [Vera, 2018: 89]. El escaso ingreso de divisas y las presiones en el mercado paralelo disparan el precio del dólar, que se convierte en el más importante de la economía y en un indexador automático de precios, lo que estimula el aumento desbocado de la inflación.

En este contexto, las condiciones socioeconómicas y el desgaste político del gobierno de Maduro llevarán a que en diciembre de 2015 se produzca una derrota electoral a manos de la oposición en las elecciones parlamentarias, con la que esta alcanza los dos tercios de la Asamblea Nacional. Maduro le adjudica el triunfo electoral a la derecha, al imperialismo y a la "guerra económica", que no son suficientes para explicar la crisis y el descontento de la población. En vez de reconocer la derrota e iniciar una autocrítica, desde 2016 busca preservar el poder a cualquier precio. Nombra magistrados para el Tribunal Superior de Justicia (TSJ) que sentenciarán la Asamblea Nacional con cargos de desacato por promover el referéndum revocatorio, lo que inicia un ciclo de protestas y movilizaciones entre abril y julio de 2017, con aumento de la represión mediante la incorporación de grupos armados paraestatales, numerosos muertos y heridos [Llorens, 2018: 75]. Los militares, que constituyen el gran sostén de Maduro, aumentaron su participación en la economía al convertirse no solo en actores políticos sino en empresarios que controlan sectores importantes de la economía, incluso PDVSA [Jácome, 2018: 125].

El TSJ fue el que autorizó a Maduro a abrir la minería y el petróleo a las empresas trasnacionales, lo que estaba prohibido por la constitución y la Ley de hidrocarburos. En 2017 se crea de manera inconsulta una zona denominada Arco Minero del Orinoco (AMO) que abarca $12 \%$ del territorio nacional, un espacio de extraordinaria biodiversidad en el estado de Bolívar en el que se prevé la explotación de oro, diamantes, coltán, cobre, hierro y bauxita con la participación de 150 empresas provenientes de 35 países, 
lo que constituye, en palabras de Ruiz, una "diversificación del extractivismo ante la imposibilidad de diversificación de la matriz productiva venezolana" [Ruiz, 2018: 129]. Esta iniciativa se complementa con la creación de una corporación militar-empresarial de industrias mineras, petrolíferas y de gas (Compañía Anónima Militar para las Industrias Mineras, Petrolíferas y de Gas -Camimpeg) en 2016 y una nueva ley de inversiones extranjeras sancionada por la Asamblea Nacional Constituyente en 2017 dejando libre el camino al capital trasnacional, a nuevos actores nacionales y al pranato mafioso minero local [Ruiz, 2018: 134].

En mayo de 2017, con una hiperinflación galopante y una deuda externa de 70 \% del PIB, Maduro convocó a una Asamblea Nacional Constituyente (ANC) sin referéndum consultivo al pueblo y creando un sistema de doble representación (territorial y sectorial). Aunque 60 \% de la población no votó, la ANC se instala de todas maneras con 545 miembros oficialistas que asumen con poderes legislativos y sancionan leyes autoritarias y represivas como los delitos de "instigación al odio". La elección de la ANC desinfló las protestas y el contexto de crisis institucional indefinido tiñó de ilegitimidad también a la Asamblea Nacional. Después de cinco años de recesión, desde 2013, con una caída acumulada del PIB de 40 \% (3.9 \% en 2014, $6.2 \%$ en $2015,16.5 \%$ en 2016 y $12.9 \%$ en 2017 ), un aumento de la deuda de 112000 a 140000 millones de dólares, una hiperinflación con emisión descontrolada y la cuasi desaparición de las reservas internacionales aunada a escasos ingresos petroleros, el panorama para Venezuela es desolador: escasez de alimentos y medicinas y emigración forzada. En las elecciones presidenciales de mayo de 2018 ganó Maduro con $68 \%$ de los votos, pero la abstención fue altísima ya que votó solo 40 \% de la población.

\section{Ecuador: final de ciclo para el correísmo y cuestionamientos al proceso} al interior de Alianza País

Aunque en 2013 seguirá un crecimiento moderado de $4 \%$, ya comienzan a asomar problemas propios de una tendencia a la baja de los precios del petróleo, que se desplomarán desde mediados de 2014 hasta 2017, cuando vuelven a los niveles de 2005, previos al boom. En ese año, el déficit comercial no petrolero alcanzó 9000 millones de dólares, 9.7 \% del PIB, 
que si bien fue compensado por el superávit petrolero dejó un saldo de déficit comercial de 1000 millones en una economía dolarizada en la que no es posible hacer política monetaria como devaluar o emitir dinero.

La caída de los precios de las materias primas en 2014 perjudicó también los ingresos por exportaciones de bananas, camarones y cacao, al margen del sector petrolero. Los subsidios recibidos por la industria se ocuparon en producir bienes sencillos como juguetes y se dejó de lado el incentivo a la innovación. El deterioro de la situación económica comienza a expresarse en 2015. Por otro lado, los sectores de punta que se buscaba dinamizar, como la biotecnología, la nanotecnología o la industria farmacéutica, tenían un desarrollo muy escaso para alcanzar un impacto relevante en todo el régimen de acumulación. En 2014, en este contexto que ya mostraba signos de desaceleración, la inversión en educación superior alcanzó 2.12 \% del PIB, el más alto de América Latina, y se crearon parques tecnológicos como la Universidad Yachay en un intento de acercar Ecuador a participar de los desarrollos científicos y tecnológicos de punta inspirados en los parques tecnológicos surcoreanos [Ramírez, 2014].

El deterioro del proceso económico llevó a reconsiderar la abstención de la explotación de territorios indígenas y las colisiones con las organizaciones indígenas erosionaron las bases de apoyo del correísmo. El desgaste tras 10 años en el poder -algo único en Ecuador-y el desistimiento de Correa a presentarse a una nueva elección facilitan la ascensión del candidato de Alianza País designado como su sucesor, Lenin Moreno, en mayo de 2017. A poco de iniciar su gestión, Moreno decide diferenciarse del expresidente avalando las investigaciones por corrupción del gobierno de Correa ligada al proceso de Lava Jato y al caso Odebrecht, desatado en noviembre de 2014 en Brasil, que alcanzan incluso al vicepresidente Jorge Glas. En menos de seis meses en el poder Moreno denuncia alrededor de 640 obras por sobreprecios e iniciativas como Yachay o Refinerías del Pacífico en Manabí (en la que se han gastado 1200 millones de dólares y aún no existe como tal) serán señaladas como símbolo de despilfarro por el gobierno entrante, así como la corrupción vinculada con el boom petrolero y Petroecuador [Labarthe y Saint-Upéry, 2017: 38-39].

En enero de 2018 Lenin Moreno lanzó y ganó una consulta para reformar la constitución y eliminar la reelección indefinida (incluso discontinua), que en los hechos significa la imposibilidad de retornar al poder para 
Correa, junto con un conjunto de medidas para contentar pragmáticamente a diversos sectores, como la reducción del área de explotación petrolera en el parque Yasuní o la prohibición de practicar la minería metalífera en áreas protegidas para los sectores indígenas, así como la derogación de la ley de plusvalía, que ponía un impuesto sobre el valor especulativo del suelo, a favor del sector de la construcción. El triunfo en esta consulta tampoco es un cheque en blanco para Moreno puesto que las medidas para la reactivación no han dado demasiado resultado todavía, aunque prometió reducir el déficit fiscal a $1 \%$ para 2020, lo que se ve como determinante para mantener la dolarización porque el nivel de la deuda pública también se está cuestionando. El gobierno de Correa decía que esta alcanzaba apenas $28 \%$ del PIB y los nuevos funcionarios le atribuyen el doble, lo cual excede el límite de $40 \%$ que establece la ley de finanzas públicas impulsada por el propio correísmo [Labarthe y Saint-Upéry, 2017: 35].

El periodo posneoliberal parece haber terminado y el gobierno de Moreno muestra su alineamiento pragmático con los nuevos proyectos políticos emergentes en América Latina. Lenin Moreno pidió un paquete de ayuda de 4000 millones de dólares al FMI que compromete a cumplir condicionalidades como la sanción de una reforma laboral, lo que permite avizorar el comienzo de resistencias populares más significativas.

\section{Bolivia: el proyecto de Evo Morales se sostiene con múltiples tensiones}

En Bolivia, el auge exportador se mantuvo durante los años finales del segundo gobierno de Evo Morales, lo que permitió alcanzar unas reservas internacionales de más de 15000 millones de dólares, el punto más alto de la historia económica de ese país, cuyo PIB creció a la tasa más alta de toda América Latina entre 2013 y 2018. Al calor de este crecimiento basado en el aumento de la inversión pública se redujeron aún más la pobreza (que pasó de 40 a $20 \%$ entre 2005 y 2017) y el desempleo (que descendió de $8.1 \%$ en 2005 a $4.5 \%$ en 2017) a partir de la incorporación de unas tres millones de personas al grupo de ingresos medios (de 3.3 a 6.5 millones). Sin embargo, desde 2015 el aumento del valor del peso boliviano favoreció el déficit comercial 2015-2018, en especial con países que vieron devaluadas sus monedas, como Argentina y Brasil, lo que sumado 
a cinco años de déficit fiscal (2013-2018) contribuyó a mermar las reservas internacionales de manera significativa en apenas tres años, desde 2015 hasta 2018, las cuales quedaron en unos 9000 millones de dólares, pero que aún representan $27 \%$ del producto interno bruto.

A pesar de este dato, el crecimiento anual por encima de $4 \%$ de los últimos años ha permitido alcanzar un PIB de 40000 millones de dólares, con inversiones en carreteras, puentes y almacenes que suponen una mayor integración del país y un menor desempleo en un contexto de desarrollo de proyectos de industrialización de sus recursos naturales como el gas y el litio, de intentos de exportar energía eléctrica, de desarrollar el petrolero y la petroquímica, y de expandir el agro. La industrialización del gas en Cochabamba, la exportación de gas licuado o la industrialización de los recursos del salar de Uyuni y del litio para producir baterías en 2021 supone contratos de lo más diversos con empresas de China y Alemania cuyo saldo final está por verse.

Evo Morales apostaba por la continuidad del proceso y había conseguido aprobar - de manera cuestionable- por la vía del Tribunal Constitucional Plurinacional la posibilidad de ser reelecto por cuarta vez consecutiva, luego de que el referéndum para modificar la Constitución fuera rechazado en febrero de 2016 [Molina, 2018: 5]. Tras el cuestionamiento del resultado electoral, el golpe encabezado por la oposición de derecha terminó de manera abrupta con el proceso liderado por Evo Morales tras doce años en el poder. Así inicia un proceso incierto para Bolivia, en un retroceso inesperado para uno de los países latinoamericanos donde las transformaciones fueron mayores.

Balance Crítico del “NeOdesarrollismo” en el CierRe del Ciclo posneoliberal

El "neodesarrollismo" de los años 2000 es un proyecto de modelo económico para los países latinoamericanos que encarna el espíritu del viejo desarrollismo, pero que incluye a sectores que en principio se encontraban fuera de su alcance por tratarse de sectores atrasados o "rentistas" con respecto al sector dinámico por antonomasia que era el industrial. El neodesarrollismo incluirá el sector agrario y la minería, además de la industria, como objeto de políticas públicas específicas que debe llevar adelante 
un Estado que esta vez no debía incurrir en los problemas del desarrollismo clásico, esto es, desentenderse del corto plazo y de la necesidad de ponderar los equilibrios macroeconómicos como condición de posibilidad de políticas de mediano plazo, como son las políticas industriales, de desarrollo de infraestructuras y comerciales.

A comienzos del siglo xxi, la situación de la economía mundial es completamente distinta del periodo del capitalismo de posguerra correspondiente a "los treinta años gloriosos", en los que se concibieron los diagnósticos desarrollistas. La producción en masa con pleno empleo y el consumo masivo del periodo keynesiano benefactor no parecen ser reeditables. En la actualidad la industria no puede cumplir la promesa de ser el motor de un desarrollo económico que de manera endógena tire del carro de la acumulación. Los cambios en la propia lógica de la valorización del capital resultantes de cierto rechazo de la fuerza de trabajo a la disciplina de la fábrica industrial fordista se combina con las limitaciones propias de un modo de producir bienes industriales - por medio de economías de tiempo y rendimientos a escala- que ya mostraban mercados saturados y cuellos de botella en los años setenta. La valorización del trabajo cognitivo y la apropiación privada del conocimiento socialmente construido es el anuncio de la emergencia de un acentuado capitalismo cognitivo y financiarizado en desmedro del clásico capitalismo industrial y en el que la acumulación a escala global y la mundialización del capital se muestran en línea con la hipertrofia del capital financiero. En los años setenta se produjo una reestructuración de la fábrica en los países industrialmente avanzados que significó la fragmentación de la producción a escala global junto con una transformación de la lógica misma de la valorización del capital [Míguez, 2014, 2016].

Las explicaciones para el crecimiento del periodo posneoliberal latinoamericano deben buscarse en el aumento de la demanda china que facilitó liquidez y algunas inversiones directas, en el boom de los precios de los commodities y en los movimientos de las grandes masas de capitales financieros especulativos (que en su fuga hacia delante abandonaron los países centrales en busca de nuevas oportunidades de valorización). Como señala Sampaio [2012], el neodesarrollismo procura conciliar los aspectos "positivos" del neoliberalismo (compromiso con la estabilidad de la moneda, austeridad fiscal y búsqueda de competitividad) con los aspectos 
"positivos" del viejo desarrollismo (integración social mediante la industrialización, el crecimiento y el papel interventor del Estado) y evita sus efectos "negativos" (nacionalismo anacrónico, gasto desmedido e inflación). El neodesarrollismo se apoya sobre logros importantes en el contexto de los países latinoamericanos pero que se mostraron a su vez efímeros y reversibles, como la lenta recuperación del poder adquisitivo de los salarios, una ligera mejora en la distribución de la renta y un boom de consumo financiado por el endeudamiento de las familias [Sampaio, 2012].

Identificada por el neodesarrollismo con el avance del neoliberalismo, la hipertrofia de las finanzas va a asociarse sin más con un régimen de valorización financiera en desmedro de una industria que se verá desplazada del centro de la acumulación y que, de ese modo, no podrá cumplir con el papel de conducir el proceso de desarrollo que tiene asignado. Sin embargo, si bien la teoría buscará reponer la centralidad de la industria dentro de un esquema de acumulación virtuosa, en la práctica concreta de estos regímenes autodenominados neodesarrollistas las políticas fueron mucho más ambivalentes en este sentido.

Debemos diferenciar la propuesta neodesarrollista en la teoría de la práctica efectiva de los gobiernos latinoamericanos en los años 2000. El rápido ascenso de nuevas derechas que retoman el proyecto neoliberal que se había suspendido a comienzos de esos años y la facilidad con que se impusieron estas nuevas coaliciones permiten poner en duda la obtención de una verdadera reversión del neoliberalismo por parte de los gobiernos "progresistas", cuyo final anunciaron de forma más pomposa y retórica que real.

REFERENCIAS

Acosta, Alberto [2012], Breve historia económica del Ecuador. Quito, Corporación Editora Nacional.

Allende, Santiago y Federico Boido [2014], "La Bolivia de Evo Morales. Conflictos, tensiones y ambivalencias durante el primer gobierno del MAS (2006-2009)", en Alejandro Schneider (comp.), América Latina hoy. Integración, procesos políticos y conflictividad en su historia reciente. Buenos Aires, Imago Mundi. 
Andreani, Fabrice [2018], "Las vías enmarañadas del autoritarismo bolivariano", en Nueva Sociedad, marzo-abril, núm. 274, pp. 44-58.

Barbosa dos Santos, Fabio Luis [2014], "A problemática brasiguaia e os dilemas de projecao regional brasileira", en Walter Desiderá Neto (org.), O Brasil e Novas Dimensiones da Integracao regional. Brasilia, IPEA. [2017], "Seis hipóteses para ler a cojuntura brasileira", en Cadernos IHU ideias, Instituto Humanitas Unisinos, año 15, vol. 15, núm. 263.

Bernardes, Julia y Gabriela Maldonado [2017], "Estrategias do capital na fronteira agrícola moderna brasileira e argentina", en Julia A. Bernardes et al., orgs., Globalizacao do agronegocio e Land Grabbing. A atuacao das megaempresas argentinas no Brasil. Río de Janeiro, Lamparina.

Bonnet, Alberto [2015], La insurrección como restauración. El kirchnerismo, 2002-2015, Prometeo, Buenos Aires.

Caetano, Gerardo [2017], “iMilagro en Uruguay? Apuntes sobre los gobiernos del Frente Amplio", en Nueva Sociedad, noviembre-diciembre, núm. 272.

Cibils, Alan y Cecilia Allami [2013], "Financialisation vs. Development Finance: the Case of the Post-Crisis Argentine Banking System", en Revue de la Régulation. Capitalisme, Institutions, Pouvoirs, París, núm. 13.

Elizalde, Lucía, Mariana Menéndez y María Noel Sosa [2013], "Cronología sobre el conflicto minero en Uruguay 2010-2013”, en Contrapunto, Montevideo, núm. 2.

Falero, Alfredo [2013], "El desarrollo de enclaves y la ilusión del desarrollo", en Contrapunto, Montevideo, núm. 2.

Gago, Verónica [2014], La razón neoliberal: economías barrocas y pragmática popular. Buenos Aires, Tinta Limón.

García Linera, Á. [2011], El "Oenegismo", enfermedad infantil del derechismo (O cómo la "reconducción" del Proceso de Cambio es la restauración neoliberal). La Paz, Vicepresidencia del Estado PlurinacionalPresidencia de la Asamblea Legislativa Nacional.

González, Jorge [2016], "Paraguay: el 'nuevo rumbo' apura el acaparamiento de tierras campesinas e indígenas al cumplir sus tres años", en BASE Investigaciones Sociales, Asunción, núm. 5.

Gray Molina, George [2007], "El reto posneoliberal de Bolivia", en Nueva Sociedad, mayo-junio, núm. 209, pp. 119-129. 
Jácome, Manuel [2018], "Los militares en la política y la economía de Venezuela”, en Nueva Sociedad, núm. 274, marzo-abril, pp. 119-128.

Labarthe, Sunniva y Marc Saint-Upéry [2017], "Leninismo versus correísmo: la 'tercera vuelta' en Ecuador”, en Nueva Sociedad, noviembrediciembre, núm. 272.

Llorens, Maule [2018], "Dolor país, versión Venezuela. Las protestas de 2017 y sus secuelas", en Nueva Sociedad, marzo-abril, núm. 274, pp. 71-82.

Mercadante, Aloizio [2013], Brasil: de Lula a Dilma (2003-2013). Clave Intelectual, pp. 221-317.

Míguez, Pablo [2014], "Del General Intellect a las tesis del 'Capitalismo Cognitivo': aportes para el estudio del capitalismo del siglo xxI”, Bajo el Volcán Revista de Sociología de la Benemérita Universidad Autónoma de Puebla, Puebla, México, 13(21), septiembre de 2013febrero de 2014.

[2016], "El desarrollo y los bienes comunes en América Latina. Una mirada desde las tesis del Capitalismo Cognitivo", en Mariano Féliz, Emiliano López y Matías García (coords.), Desarmando el Modelo. Desarrollo, conflicto y cambio socia tras una década de neodesarollismo en Argentina, Ed. El Colectivo, 237-259 pp.

[2017], "Estado y desarrollo en la economía política latinoamericana”, en Márgenes. Revista de Economía Política, Instituto de Industria, UNGs, núm. 3, agosto, Los Polvorines, Argentina, 113-132.

Molina, Fernando [2018], "Tendencias socioelectorales en la Bolivia del caudillismo", en Nueva Sociedad, enero-febrero, núm. 273, pp. 4-13.

Nickson, Andrew [2008], "Una oportunidad para Paraguay. Los desafíos de Fernando Lugo", en Nueva Sociedad, julio-agosto, núm. 216.

Paulani, Leda [2017], "Não há saída sem a reversão da financeirização", en Estudos Avançados, vol. 31, núm. 89, pp. 29-35.

Piva, A. [2015a], "Los límites económicos de una lógica política", en A. Piva, Economía y politica en la Argentina kirchnerista. Buenos Aires, Batalla de Ideas, pp. 37-49.

[2015b], "Modo de acumulación y hegemonía en Argentina: continuidades y rupturas después de la crisis de 2001", en A. Piva, Economía y política en la Argentina kirchnerista. Buenos Aires, Batalla de Ideas, pp. 19-34. 
Porta, F. y C. Fernández Bugna [2008], "El crecimiento reciente de la industria argentina. Cambio de régimen sin cambio estructural", en Realidad Económica, núm. 233.

Purcell, Thomas, Nora Fernández y Estefanía Martínez [2015], Cambio de la matriz productiva en Ecuador: rentas, conocimiento y neoestructuralismo. Documento de trabajo núm. 2, CENEDET-IAEN.

Ramírez, René [2014], La virtud de los comunes. De los paraísos fiscales al paraiso de los conocimientos abiertos. Quito, Ediciones Abya Yala.

Ruiz, Francisco [2018], "El Arco Minero del Orinoco. Extractivismo y nuevos regímenes biopoliticos”, en Nueva Sociedad, marzo-abril, núm. 274, pp. 129-141.

Sampaio Junior, Plinio de A. [2010], "O Brasil não é maior do que a crise", en Jornal dos economistas, Río de Janeiro, núm. 255.

[2012], "Desenvolvimentismo e neodesenvolvimentismo: tragédia e farsa”, en Serviço Social \& Sociedade, Sao Paulo, diciembre, núm. 112.

Santos, Carlos et al. [2013], "Seis tesis urgentes sobre el neodesarrollismo en Uruguay", en Contrapunto, Montevideo, núm. 2.

Schneider, Alejandro [2014], "Dificultades políticas y tensiones sociales durante el segundo gobierno de Evo Morales", en Alejandro Schneider (comp.), América Latina Hoy. Integración, procesos políticos y conflictividad en su historia reciente. Buenos Aires, Imago Mundi.

Schoor, M. y A. Wainer [2015], "Algunos determinantes de la restricción externa en Argentina”, en Márgenes. Revista de Economía Política, Los Polvorines, Universidad Nacional General Sarmiento, núm. 1, pp. $55-80$.

Sutherland, Manuel [2018], "La ruina de Venezuela no se debe al socialismo ni a la revolución", en Nueva Sociedad, núm. 274, marzo-abril de 2018, pp. 142-151.

Sztulwark, S. [2015], "El kirchnerismo y la concepción del cambio estructural”, en Márgenes. Revista de Economía Política, Los Polvorines, Universidad Nacional General Sarmiento, núm. 1, pp. 81-94.

Trujillo, Jorge [2010], "Las organizaciones indígenas y el gobierno de Rafael Correa", en Íconos. Revista de Ciencias Sociales, Ecuador, flacso; núm. 37, pp. 13-23. 
Vera, Leonardo [2018], ¿Cómo explicar la catástrofe económica venezolana?”, en Nueva Sociedad, marzo-abril, núm. 274, pp. 83-96.

Villarroel Castro, Patricia [2014], Estado Plurinacional de Bolivia: acerca de las transformaciones del Estado y la gestión de desarrollo. Cepal. 



\title{
6. ESTADO ARGENTINO Y LA PROMOCIÓN DEL DESARROLLO INDUSTRIAL. UN ANÁLISIS DE LAS EXPERIENCIAS RECIENTES (2003-2018)
}

\author{
María Jimena García Puente, ${ }^{*}$ Carolina Lauxmann** \\ y Emilia Ormaechea***
}

INTRODUCCIÓN

Desde inicios de este siglo, el papel del Estado en la promoción del desarrollo volvió a colocarse en el centro de los debates académicos y políticos de América Latina. Esto se dio en consonancia con el triunfo de coaliciones políticas en diversos países de la región (como Argentina, Bolivia, Brasil, Chile, Ecuador, Uruguay y Venezuela) que reposicionaron -al menos discursivamente- a los Estados como actores centrales de las estrategias de desarrollo. Diversos autores denominaron este periodo neodesarrollista [Araníbar y Rodríguez, 2013; Bresser-Pereira, 2006 y 2007; Gaitán, 2013], en tanto retomaba, con las especificidades del nuevo contexto, la tradición desarrollista latinoamericana del periodo de posguerra.

En particular para el caso argentino, la recuperación de la centralidad del Estado bajo los gobiernos de Néstor Kirchner (2003-2007) y Cristina Fernández de Kirchner (2007-2015) estuvo asociada con la promoción de la actividad industrial. Ello permitió, en un primer momento, la reactivación

\footnotetext{
* Instituto de Humanidades y Ciencias Sociales del Litoral (UNL/Conicet).

** Facultad de Ciencias Económicas, Universidad Nacional del Litoral.

*** Instituto de Humanidades y Ciencias Sociales del Litoral (UNL/Conicet).
} 
económica vinculada con la redinamización del sector manufacturero. Sin embargo, luego se presentaron diversas dificultades para continuar traccionando de la economía y la generación de empleo. Este contexto habilitó, años más tarde, el triunfo electoral de la Alianza Cambiemos, presidida por Mauricio Macri (2015-2019), con un discurso que presentaba cuestionamientos tanto a la intervención estatal como a la importancia de la actividad industrial para la promoción del desarrollo.

Frente a este escenario, el presente capítulo examina la importancia del Estado para el desarrollo industrial en la periferia latinoamericana. Se analiza en especial la incidencia de su configuración organizativa particular y de su lógica de implicación en la conformación de un determinado proyecto estatal desde el cual es posible viabilizar estrategias de acumulación. Centrando el análisis en la experiencia reciente de Argentina, se consideran las características de los distintos proyectos estatales que se configuraron primero en el contexto neodesarrollista y luego bajo el gobierno de la Alianza Cambiemos, y se examinan las estrategias de acumulación resultantes en cada caso.

Para avanzar en este sentido, el trabajo se organiza de la siguiente manera. En un primer apartado se hacen algunas precisiones teóricasconceptuales sobre el Estado y la noción de proyecto estatal. Luego se analiza la gravitación de la estructura del aparato estatal y su forma de implicación para impulsar estrategias de acumulación que viabilicen el desarrollo. A este último respecto, se repara de forma central en la importancia del desenvolvimiento del sector manufacturero. En un segundo apartado se estudia la experiencia neodesarrollista. Se pone el foco en el análisis de las relaciones de fuerzas y su vinculación con el proyecto estatal de este periodo mediante el análisis de la estructura organizativa del Estado y su lógica implicativa. Luego se estudia la estrategia de acumulación resultante. En un tercer apartado se examina la configuración del Estado y su lógica implicativa bajo el gobierno de Mauricio Macri (2015-2019), en el marco de una cambiante relación de fuerzas. Se trata, asimismo, la modificación de la estrategia de acumulación y la incidencia en el desenvolvimiento del sector industrial. Por último, se presentan las conclusiones. 


\section{Estado y proyecto estatal}

En el presente trabajo abordamos al Estado en relación con sus características estructurales y sus lógicas implicativas para el desarrollo. Es decir, consideramos la configuración material del aparato estatal y sus políticas públicas, y cómo esos aspectos inciden en estrategias de acumulación que eventualmente permitan salir de posicionamientos periféricos.

Partimos de considerar la dimensión organizacional del Estado en tanto un conjunto diferenciado de estructuras, recursos y poder que, mediante su implicación, configuran e influyen en las dinámicas de los distintos actores sociales [Skocpol, 1991; Mann, 1991]. En ese sentido, las cualidades de las estructuras y políticas estatales pueden generar transformaciones estructurales y promover el desarrollo económico [Evans, 1995 y 1996].

La consideración de la especificidad del Estado y de la potencialidad de su accionar para incidir en los diversos actores y aspectos de la organización social, política y económica en un momento determinado se aleja de las concepciones del Estado que lo consideran un simple reflejo de las relaciones de fuerzas de la sociedad, así como de aquellas que lo entienden como un mero administrador de intereses o un receptor pasivo o neutral de presiones.

Por el contrario, entendemos que la estructura organizacional y las acciones estatales reflejan "una condensación institucionalmente mediada del equilibrio cambiante de las fuerzas políticas" [Jessop, 2014: 35]. Tal condensación material de las relaciones de fuerza entre clases y fracciones [Poulantzas, 2005 (1978)] se expresa, en palabras de Jessop [1990], en un proyecto estatal. ${ }^{1}$ Por proyecto estatal aludimos a una particular conformación organizativa del Estado que lo dota de coherencia y coordinación organizacional, funcional y operacional e implica una modalidad de intervención socioeconómica específica en un espacio y momento determinados

\footnotetext{
${ }^{1}$ Las particulares formas organizativas y funcionales del Estado, y de los diferentes patrones de acumulación que habilita, no se resuelven exclusivamente en los límites territoriales dentro de los cuales ejerce su jurisdicción, sino que se trata de un proceso que tiene lugar en múltiples escalas y en el que intervienen diferentes actores políticos, sociales, económicos e institucionales, todos inmersos dentro de la dinámica de la reproducción sistémica -y desigual- del capitalismo a nivel global.
} 
[Jessop, 2008 y 2017; Brenner, 2013]. La configuración de un proyecto estatal está asociada con la potencialidad del mismo para viabilizar u obturar determinadas estrategias de acumulación, entendidas estas como modelos de crecimiento económico específico [Jessop, 1990].

De este modo, proponemos estudiar el Estado como una expresión institucional de las relaciones de fuerza dominantes en un momento y espacio determinados que, en tanto proyecto estatal, se expresa en una modalidad de organización e implicación con potencialidad para habilitar una particular estrategia de acumulación de capital.

\section{Estado y desarrollo}

La consideración de la importancia de los Estados en las estrategias de desarrollo recobró relevancia en el marco de los estudios de las recientes experiencias exitosas del Este asiático [Amsden, 1989; Anglade y Fortin, 1989; Chibber, 1999; Evans, 1995; Kohli, 2004 y 2009; Wade, 1999]. En ese sentido, diversos autores señalan que la excepcionalidad de la performance de ciertos países del este de Asia, que lograron mejorar sus formas de inserción internacional y abandonar una posición periférica, se explica por el papel central que los Estados asumieron en la definición y el condicionamiento de la estrategia de desarrollo. De esta manera, sin desconocer otros elementos coyunturales de relevancia para la comprensión de la excepcionalidad de estas estrategias, ${ }^{2}$ las características que los Estados del Este asiático adoptaron son un factor central para explicar el exitoso desenvolvimiento del sector industrial.

En términos generales pueden destacarse diversos aspectos que estos Estados presentan. Por un lado, la existencia de áreas organizacionales vinculadas con el desarrollo de la industria que adquieren un lugar específico y relevante [Amsden, 2004; Chibber, 2003]. Por otro, la presencia de una nodalidad estratégica [Chibber, 2003] que coordina las distintas instancias que están relacionadas con el sector industrial para evitar el conflicto intraorganizacional y adecuarlas a los requerimientos del proceso

\footnotetext{
${ }^{2}$ Principalmente el interés geopolítico de Estados Unidos de conformar baluartes defensivos ante la amenaza comunista [Stubbs, 2009].
} 
de industrialización. La relevancia de esas cualidades y las propiedades organizacionales del Estado se funda en que habilitan la emergencia de políticas cohesivas, bien diseñadas y consistentes con una estrategia de desarrollo [Kolhi, 2010].

Asimismo, en los debates recientes sobre el desarrollo en América Latina [Bresser-Pereira, 2007; Gaitán, 2014], se encuentran argumentaciones y propuestas que recuperan el papel del Estado junto con las contribuciones del estructuralismo latinoamericano y que refuerzan la importancia de la industrialización para alcanzar posiciones de centro dentro del sistema capitalista mundial.

\section{Estrategia de acumulación para el desarrollo. La importancia de la manufactura}

Retomando los postulados del estructuralismo latinoamericano, podemos considerar que las manufacturas, aún hoy, son centrales para impulsar procesos de transformación estructural que viabilicen la salida de posicionamientos periféricos.

Diversas razones permiten dar cuenta de ello. En primer lugar, interesa resaltar la importancia de la manufactura como correa de transmisión entre las oportunidades científicas y técnicas y el resto del sistema productivo. Es decir, la actividad manufacturera es la que tiene la capacidad de producir insumos, por ejemplo, máquinas o productos químicos o biológicos, que explican la aplicación de técnicas y los aumentos de productividad en otros sectores [Szirmai, 2013]. Además, el desarrollo del sector manufacturero estimula la demanda de servicios cada vez más complejos, como servicios de ingeniería, diseño, investigación y desarrollo, impulsando la generación continua de innovaciones y progreso técnico, lo que permite mantener el conjunto de la estructura productiva en la frontera tecnológica [Lavarello, 2017]. Por último, pero no por ello menos importante, las manufacturas aún tienen un peso central en la generación de empleo de elevada productividad, ya sea de manera directa o bien a través del estímulo al desarrollo del sector servicios [Hersh y Weller, 2003].

Particularmente, en función de la experiencia de los países que alcanzaron el desarrollo en fecha reciente podemos advertir que resultan relevantes las actividades manufactureras de base endógena, compleja y dinámica 
[Amsden, 2004; Hikino y Amsden, 1995; Fernández, 2017]. Es decir, aquellas actividades en las que prima el capital doméstico, el cual tiene la capacidad de establecer eslabonamientos intrasectoriales y que para su reproducción lleva adelante prácticas vinculadas con el desarrollo de innovaciones y nuevas tecnologías. Esta preferencia por el capital nacional no implica despreciar la presencia del capital extranjero en las estructuras productivas domésticas de los países periféricos, pero lo típico es que el capital extranjero vaya a la zaga del desarrollo industrial en lugar de ponerse a la cabeza de él e incentivar la innovación en los países periféricos [Hikino y Amsden, 1995]. Por tanto, si lo que se pretende es incentivar el dinamismo del sector manufacturero, las empresas nacionales son las que presentan mejores oportunidades de hacerlo [Amsden, 2004]. Algo similar pasa con los encadenamientos. La inversión extranjera tiende a presentar escasa capacidad de generar articulaciones -hacia atrás o hacia adelante- entre las distintas actividades del sector en las economías periféricas en las que ingresa [Gallagher et al., 2008], por lo que el capital endógeno también presenta ventajas a la hora de contribuir a la complejidad del entramado productivo.

Luego de haber planteado estas consideraciones, vamos a examinar los proyectos estatales en el neodesarrollismo y en la gestión de la Alianza Cambiemos, teniendo en cuenta su configuración organizacional y las formas de implicación y las estrategias de acumulación resultante.

\section{El proyecto estatal bajo el NeOdeSARROLLISMo (2003-2015)}

En el presente apartado se analiza el periodo neodesarrollista, que comprende el gobierno de Néstor Kirchner (2003-2007) y los dos mandatos consecutivos de Cristina Fernández de Kirchner (2008-2015). Se examina, en primer lugar, el proyecto estatal en ese periodo a partir de considerar la correlación de fuerzas y los actores dominantes durante el mismo, la configuración organizacional del Estado y su modalidad de implicación a través de las políticas públicas de fomento a la actividad industrial. En segundo lugar, se aborda la estrategia de acumulación resultante. 
Las correlaciones de fuerzas y los actores dominantes bajo el neodesarrollismo

A partir de la crisis de 2001, se inició un proceso de modificación de la correlación de fuerzas en Argentina, lo que implicó la reconfiguración de la estrategia de acumulación dominante hasta entonces vinculada con la valorización financiera [Basualdo, 2011], hacia otra que, luego de la devaluación de 2002, privilegió la lógica productiva. Ello se dio sobre la base de lo que algunos autores denominan "alianza devaluacionista" [Basualdo, 2011] o "grupo productivo" [López y Catamutto, 2017]. Este grupo estuvo compuesto por los grandes exportadores y el capital productivo y comercial orientado al mercado interno, integrado principalmente por los grandes grupos económicos locales y algunos extranjeros, y algunos actores vinculados con la producción primaria [Wainer, 2018]. En consonancia con ello se fue construyendo un consenso en torno a la relevancia de la industria y el desarrollo en vastos sectores políticos, académicos y empresariales [Azpiazu y Schorr, 2010].

Durante los primeros años del kirchnerismo, este grupo resultó favorecido por la reactivación de la actividad productiva, en especial de la manufacturera, a la par que las condiciones de vida de los sectores populares fueron mejorando [Wainer, 2018; Basualdo, 2011]. Sin embargo, el año 2008 marcó el inicio de un nuevo cambio en la correlación de fuerzas. Ello se vio atravesado por la presencia de diversos obstáculos en la economía argentina, algunos de carácter estructural y otros coyunturales. Entre ellos, pueden mencionarse la crisis internacional de 2008-2009, el conflicto del gobierno con el sector agropecuario en torno a la Resolución $\mathrm{N}^{\circ} 125$, la disminución de las tasas de crecimiento económico, el aceleramiento de la inflación, la reducción de los superávits de cuenta corriente y fiscal, la aparición del clásico problema asociado con la restricción externa y la mayor dificultad, en este contexto, de generar nuevas fuentes de empleo formal y mejorar las condiciones de vida de los trabajadores. En este marco, el modelo económico orientado a lo productivo comenzó a ser disputado por las fracciones vinculadas con la actividad agropecuaria y los grandes grupos económicos locales [Manzanelli y Basualdo, 2016].

En ese entorno, el proyecto estatal configurado bajo el kirchnerismo se orientó a sostener la demanda por medio del fomento al consumo. En un 
contexto de crecientes disputas con los sectores económicos más concentrados, la estrategia se dirigió a asentar su base de apoyo en los capitales mercado-internistas y las clases subalternas, entre ellos, gran parte del movimiento sindical, movimientos sociales y capas medias [Wainer, 2018].

\section{La configuración organizacional del proyecto estatal bajo el neodesarrollismo³}

El aparato estatal argentino fue creciendo en términos de estructura organizativa durante los años 2003-2015. Ejemplo de ello es el incremento en volumen e importancia de la estructura ministerial, en procura de la jerarquización de determinadas funciones a realizar por el aparato estatal, mediante la creación de ministerios, secretarías y subsecretarías.

En esta expansión del aparato estatal puede advertirse la intención de implicarse en el fomento de la actividad productiva-industrial para estimular el desarrollo a partir de ello. En ese sentido, en 2002 se creó el Ministerio de la Producción, con oficinas vinculadas específicamente al impulso de la industria; luego, durante los años 2003-2008, esa cartera ministerial y las dependencias relacionadas con la industria pasaron a estar bajo la órbita del Ministerio de Economía y Producción. En 2008, se creó de nuevo el Ministerio de Producción, el cual asumió una vez más las instancias asociadas con la actividad manufacturera. Por último, en 2009 tuvo lugar la instauración del Ministerio de Industria. Este operó bajo la denominación de Industria y Turismo durante un breve interregno de ese mismo año, para finalmente consolidarse como Ministerio de Industria entre 2010 y 2015.

Ahora bien, a pesar de que esas modificaciones y rejerarquizaciones de las áreas concernientes al desenvolvimiento del sector industrial conformaron un espacio específico de intervención, no se consolidaron como un lugar central dentro del conjunto de la estructura del Estado nacional. En ese sentido, los ministerios que durante ese periodo tuvieron bajo su órbita de influencia las oficinas relacionadas con la actividad industrial contaron con escasos recursos económicos. Esta poca gravitación se observa con claridad luego de 2009, cuando se creó el Ministerio de Industria

\footnotetext{
${ }^{3}$ En este aparatado se retoma el análisis realizado en García Puente et al. [2019].
} 
como cartera diferenciada del Ministerio de la Producción, tal como se muestra en la gráfica 1.

Gráfica 1. Evolución del gasto público de los ministerios que tuvieron bajo su órbita de influencia oficinas vinculadas con el desarrollo industrial (2003-2015, \% del gasto total)

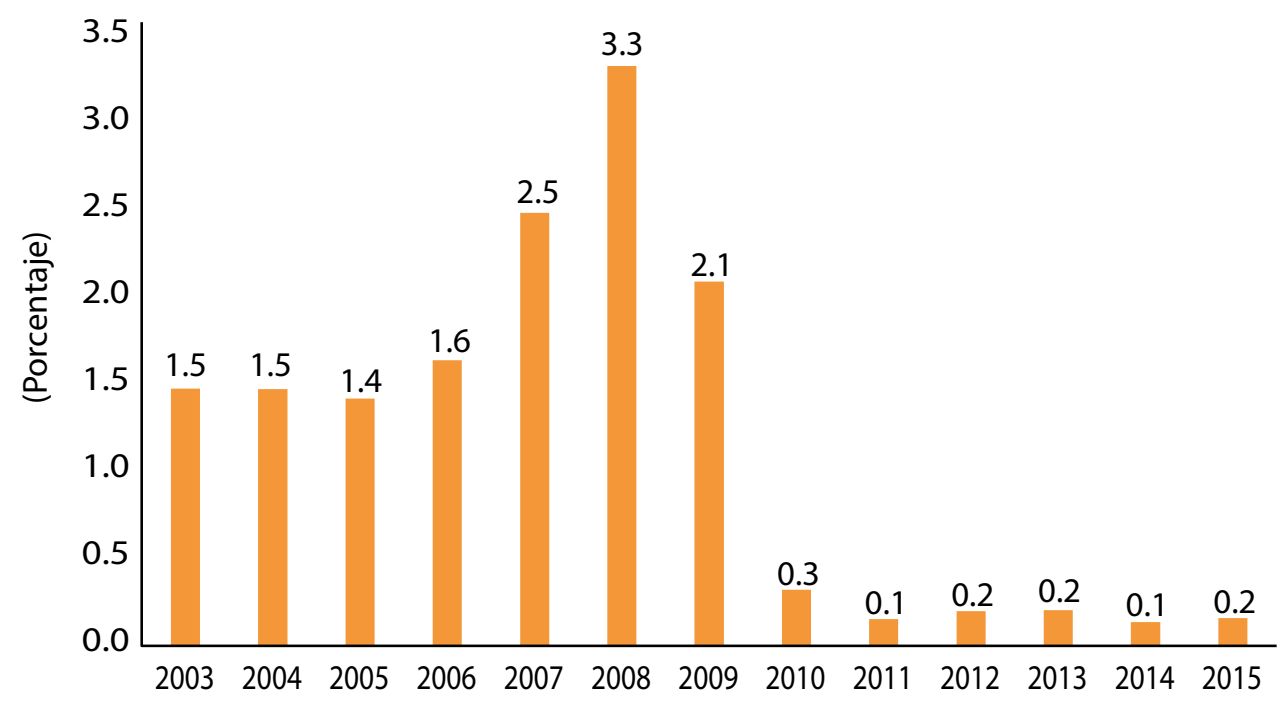

Fuente: elaboración propia con base en datos de la Oficina Nacional de Presupuesto del Ministerio de Economía de la Nación.

Por otra parte, cuando se analiza más allá de las instancias ministeriales y se realiza un examen del gasto por finalidades, se advierte un importante crecimiento de la participación de servicios económicos dentro del total del gasto público nacional (gráfica 2). En 2003, el gasto en servicios económicos representaba $9.30 \%$ del total del presupuesto nacional, dicho porcentaje ascendió a 41.09 \% en 2014 y en 2015 fue de 33.15 por ciento. 
Gráfica 2. Gasto público nacional por finalidades, porcentajes de participación (2003-2015)

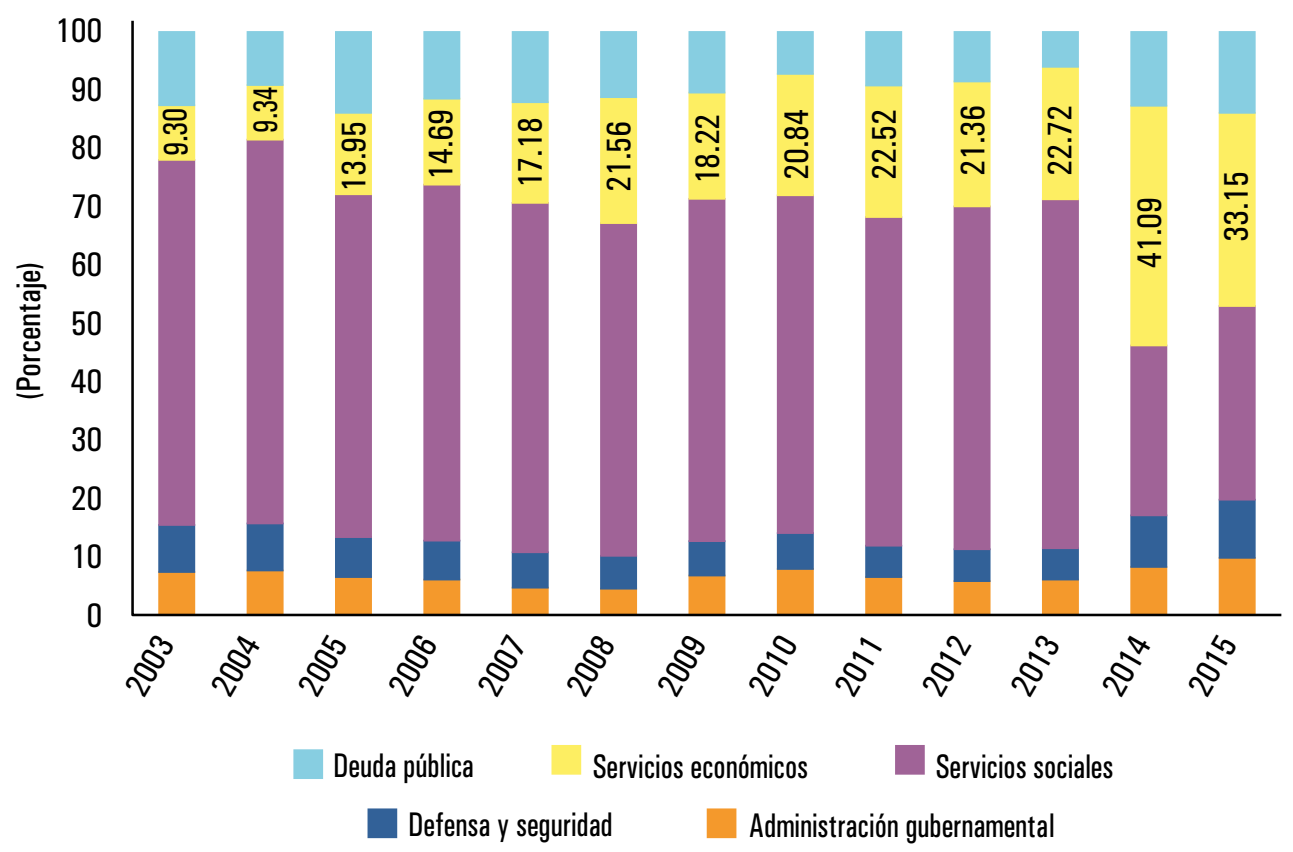

Fuente: elaboración propia con base en datos de la Oficina Nacional de Presupuesto del Ministerio de Economía de la Nación.

Sin embargo, al profundizar el análisis al interior de servicios económicos se observa que los flujos destinados específicamente a la actividad industrial revisten poca importancia: para el periodo 2003-2015 representan, en promedio, solo $1.8 \%$ del total de dicha finalidad. El grueso del gasto público de servicios económicos durante esos años estuvo vinculado con las funciones de energía, combustible y minería, y transporte, que representó 79.3 \% del total del presupuesto (gráfica 3). Ello se asocia con la existencia de importantes subsidios al consumo de electricidad y/o de transporte vigentes durante el periodo mencionado. 
Gráfica 3. Gasto público nacional en servicios económicos desagregado por funciones (2003 a 2015)

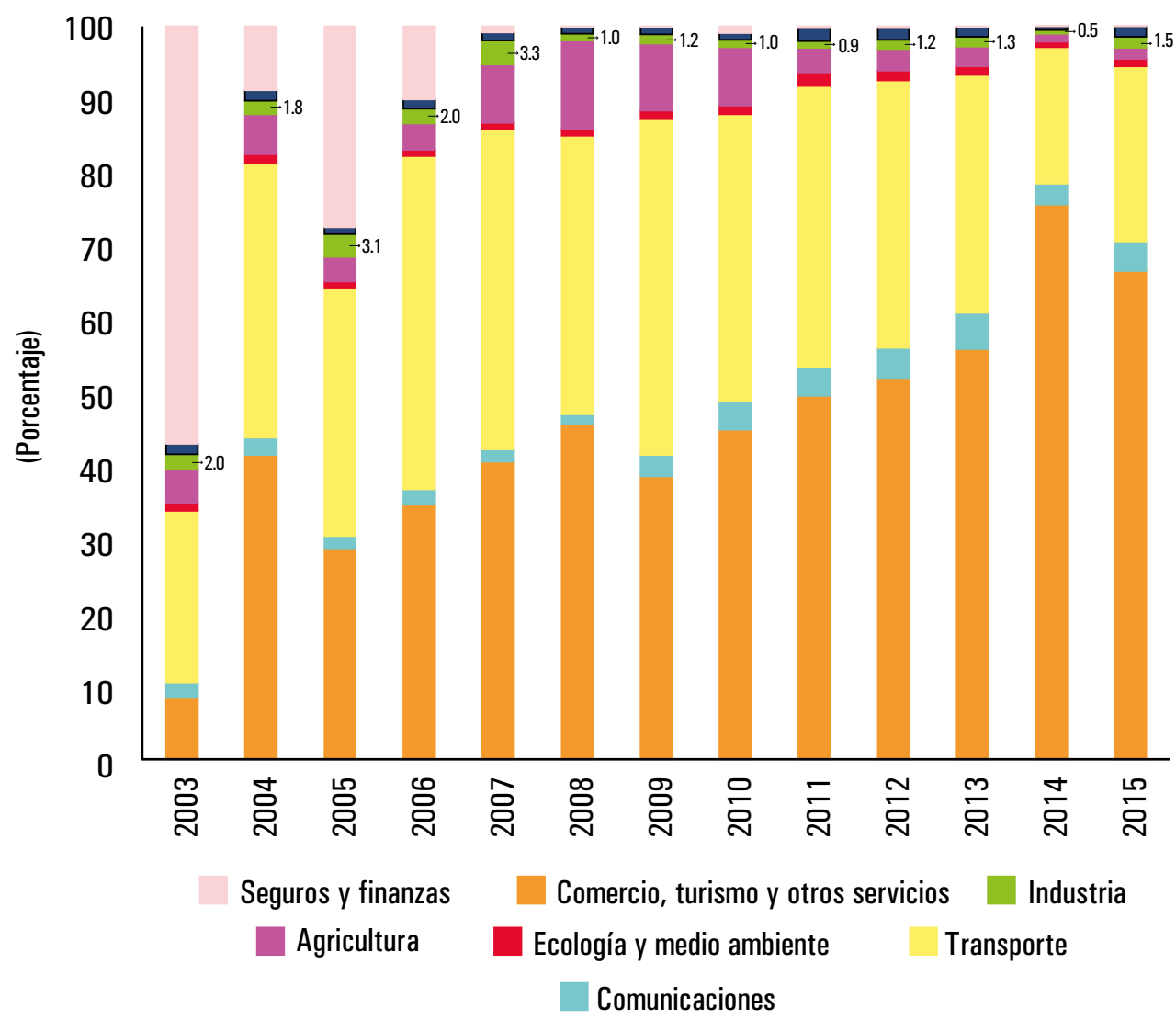

Fuente: elaboración propia con base en datos de la Oficina Nacional de Presupuesto del Ministerio de Economía de la Nación.

Así, en el organigrama se observa que se jerarquizaron las dependencias destinadas a incidir en la actividad productiva-industrial, asumiendo especificidad y rango ministerial; no obstante, tales oficinas no adquirieron centralidad dentro de la estructura del Estado. El examen de los recursos financieros con los que estas instancias contaron para hacer frente a las actividades tendientes a cumplir sus objetivos no muestra una tendencia a su empoderamiento, dado los bajos porcentajes que se evidencian conforme 
a la clasificación institucional del gasto público. Resta resaltar que cuando se analiza el presupuesto por finalidad, si bien se advierte una creciente participación de los servicios económicos dentro del total, al examinar las funciones específicas del gasto público se observa la baja gravitación que el estímulo al sector industrial presenta.

\section{Las políticas públicas de fomento a la actividad industrial bajo el neodesarrollismo}

En referencia a las formas de implicación del Estado bajo el neodesarrollismo, a inicios del periodo se destacan las condiciones que generó el Estado en la macroeconomía, que incidieron de manera positiva en la actividad industrial. En este sentido, una de las principales medidas fue la devaluación y el mantenimiento de un tipo de cambio elevado o "dólar alto" [Azpiazu y Schorr, 2010; Schorr, 2013]. Esa política cambiaria protegió el mercado interno, dotó de un elevado margen de ganancia al sector y promovió las exportaciones industriales [Kulfas, 2016]; a su vez, junto con el tipo de cambio diferencial, mediante el establecimiento de alícuotas menores para la exportación de manufacturas de origen industrial [Lavarello y Sarabia, 2015], favoreció el crecimiento del sector manufacturero. La rentabilidad del sector también se vio beneficiada por el rezago del salario real y el congelamiento de las tarifas de servicios públicos [Costantino, 2017; Varesi, 2010].

Ahora bien, ante la aparición de los mencionados obstáculos económicos en 2008 se pusieron en marcha distintas acciones estatales orientadas a sostener la actividad industrial, tales como la restricción a las importaciones, los aumentos de aranceles y el direccionamiento de inversiones productivas con la implementación de políticas públicas específicas de fomento al sector. A pesar de ello, gran cantidad de autores [Azpiazu y Schorr, 2010; Baruj et al., 2009; Couto, 2010; Fernández Bugna y Porta, 2007; Kulfas, 2009; Lavarello y Sarabia, 2015; Rougier y Schorr, 2012] señalan la ausencia de un abordaje estratégico, integrado y global hacia el sector, y marcan la presencia de un conjunto fragmentado y descoordinado de políticas y programas específicos que, con éxito dispar, se desarrollaron durante la fase neodesarrollista. 
La mayoría de ese conjunto de políticas se formuló en los años noventa para resolver "fallas" del mercado y limitaciones de algunas empresas. A su vez, tuvieron un alcance horizontal, es decir, sus destinatarios eran las empresas independientemente de su inserción sectorial o actividad, sin definiciones de sectores prioritarios [Couto, 2010; Kulfas, 2009; Lavarello y Goldstein, 2011]. Pero tales programas incrementaron sus recursos fiscales y financieros [Lavarello y Sarabia, 2015] y aumentaron sus destinatarios [García Puente, 2016] en el periodo bajo análisis.

Junto con ello, también se llevaron adelante acciones sectoriales y de fomento de competencias tecnológicas y modernización, aunque ocuparon un lugar menor que las políticas horizontales. Las mismas se orientaron a: a) promover sectores vinculados con la investigación, el desarrollo y la exportación, como el caso de software y la biotecnología; b) actividades con potencial crecimiento de la demanda o el empleo -el mantenimiento del régimen de privilegio para el sector automotor y de motopartes-; c) segmentos con ventajas naturales de gran escala, como la minería metálica o el sector forestal; y d) atender situaciones de crisis, por ejemplo, la maquinaria agrícola o el tabaco [Baruj y Porta, 2006; Couto, 2010].

Los regímenes de promoción sectoriales se presentaron por medio de incentivos fiscales y arancelarios. Asimismo, se implementaron regímenes de promoción industrial ${ }^{4}$ y se mantuvieron los de promoción regional para las radicaciones industriales, y se extendió el régimen ensamblador de Tierra del Fuego y el estímulo a las exportaciones por puertos patagónicos.

En referencia al sector de pequeñas y medianas empresas (pymes), en el marco de la ley de pymes del año 2000 (Ley 25.300) se crearon nuevos programas y se modificaron algunos existentes, que comenzaron a implementarse y ejecutarse presupuestariamente a partir de 2006 . No obstante, las políticas públicas hacia las pymes tuvieron un alcance limitado, no estaban coordinadas y no se establecían prioridades de recursos para ese sector [Sztulwark, 2010]. Tampoco estaban articuladas conceptualmente con el resto de las intervenciones industriales y de desarrollo productivo, y operaron de manera fragmentada [Kulfas, 2009].

${ }^{4}$ Régimen de incentivos para los fabricantes nacionales de bienes de capital (decreto 379/01) y, luego, con la Ley de promoción industrial (Ley 25.924 del año 2004); en 2008, se continuaron con la Ley de promoción de inversiones en bienes de capital y obras de infraestructura (Ley 26.360 ). 
Por otro lado, se identifican esfuerzos por extender las políticas de acceso al financiamiento para la inversión y el desarrollo, entre las que se destacan el Programa del Financiamiento Productivo del Bicentenario (decreto 783/2010); la reforma de la carta orgánica del Banco Central de la República Argentina, en marzo de 2012 (Ley 26.739); y el Fondear (Fondo para el Desarrollo Económico Argentino).

La creación del Ministerio de Industria, que se organizó en tres secretarías (Secretaría de Industria, Secretaría de Planeamiento Estratégico Industrial y Secretaría de la Sepyme y Desarrollo Regional), generó un espacio específico de gestión de políticas. Destacamos de esa cartera, por un lado, las acciones de fomento a parques industriales mediante la constitución de un registro y el otorgamiento de aportes no reembolsables (ANR) para infraestructura y créditos a pymes para que se instalen allí. Por otro lado, lo novedoso fue el diseño del Plan Industrial 2020. Algunos autores remarcan que fue la primera iniciativa explícita de formulación de una política industrial desde un ministerio [Lavarello y Sarabia, 2015] con una planificación más orientada hacia lo sectorial [Stumpo y Rivas, 2013]. Sin embargo, las falencias y debilidades fueron tantas que no se avanzó en su implementación. Entre ellas se observa que el plan se organizó en torno a 11 cadenas productivas, pero no contó con un criterio explícito de priorización por sectores estratégicos [Rougier y Schorr, 2012]. Además, el plan no se articuló con otros planes estratégicos desarrollados durante esos años (como el Plan Estratégico Territorial, el Plan Agroalimentario y Agroindustrial y el Plan Argentina Innova) ni tampoco contó con la participación de las instancias estatales provinciales para su elaboración [García, 2016]. También se señala la debilidad de la estructura organizativa responsable de implementarlo, ya que era una secretaría carente de recursos e instrumentos propios [Lavarello y Saravia, 2015].

De acuerdo con lo indicado, puede considerarse que la modalidad de implicación estatal en referencia a las políticas públicas orientadas al sector productivo industrial se caracterizó por ser un conjunto de acciones heterogéneas sin prioridades establecidas, que operaron de forma fragmentada y descoordinada desde estructuras estatales marginales. 
La estrategia de acumulación y la industrialización de los años 2003-2015

La configuración organizacional, la capacidad de fuego y las modalidades de implicación del Estado argentino durante los años 2003-2015 no han permitido conformar una estrategia de acumulación que permita viabilizar el desarrollo sobre la base del avance del sector manufacturero. Sostenemos lo anterior a pesar de las importantes tasas de crecimiento del producto bruto interno (PBI) durante el periodo señalado, motorizadas en gran medida por la recuperación del sector manufacturero. ${ }^{5}$

Como se puede advertir en la gráfica 4, tomando la serie del Banco Mundial en unidades de moneda nacional (UMN) a precios constantes, el crecimiento del sector manufacturero fue muy importante en la recuperación de la actividad económica. Al promediar tasas de crecimiento de $7.93 \%$ entre 2003 y 2008, el sector industrial recuperó participación dentro del PBI, el cual creció a un promedio de 7.80 \% en dicho periodo. Tras una importante caída en 2009 de $7.26 \%$ para el producto industrial y de $5.92 \%$ para el PBI global, los mismos se recuperaron brevemente en 2010 y 2011 para luego volver a caer en 2012 y 2014 y ralentizar su marcha hacia finales de 2015 , lo que hizo que la participación sectorial en el PBI disminuyera de $18.4 \%$ en 2003 a $17.3 \%$ en 2015 .

El crecimiento del sector manufacturero en el periodo poscrisis de 2001 se sustentó en un incremento de la producción del conjunto de las actividades manufactureras [Azpiazu y Schorr, 2010]. No obstante, también puede advertirse que ciertas ramas industriales han experimentado un crecimiento más acelerado que otras (al menos en los primeros años posteriores a la crisis). Las actividades manufactureras que habían resultado fuertemente castigadas por la reestructuración neoliberal de los años noventa (textil e indumentaria, productos metálicos, máquinas y equipos, por mencionar algunas de las más importantes) han contribuido de forma significativa al crecimiento del sector en los inicios de la actual fase de reactivación industrial [Azpiazu y Schorr, 2010; Fernández y Porta, 2007]. El crecimiento de estas ramas respondió básicamente a la utilización

${ }^{5}$ En el crecimiento de este periodo, también ocupó un lugar central el precio de los commodities, sobre todo la soja. Su precio en el año 2002 era de aproximadamente 200 dólares estadounidenses (USD) por tonelada, en 2008 alcanzó 622 usD y en 2015 bajó a 340. 
de la capacidad ociosa instalada, aunque también la apertura de nuevas empresas incidió en su desenvolvimiento [Kulfas, 2009; Schorr, 2012].

Gráfica 4. Evolución de la producción manufacturera y el PBI (2003-2015) (índice base $2003=100$ )

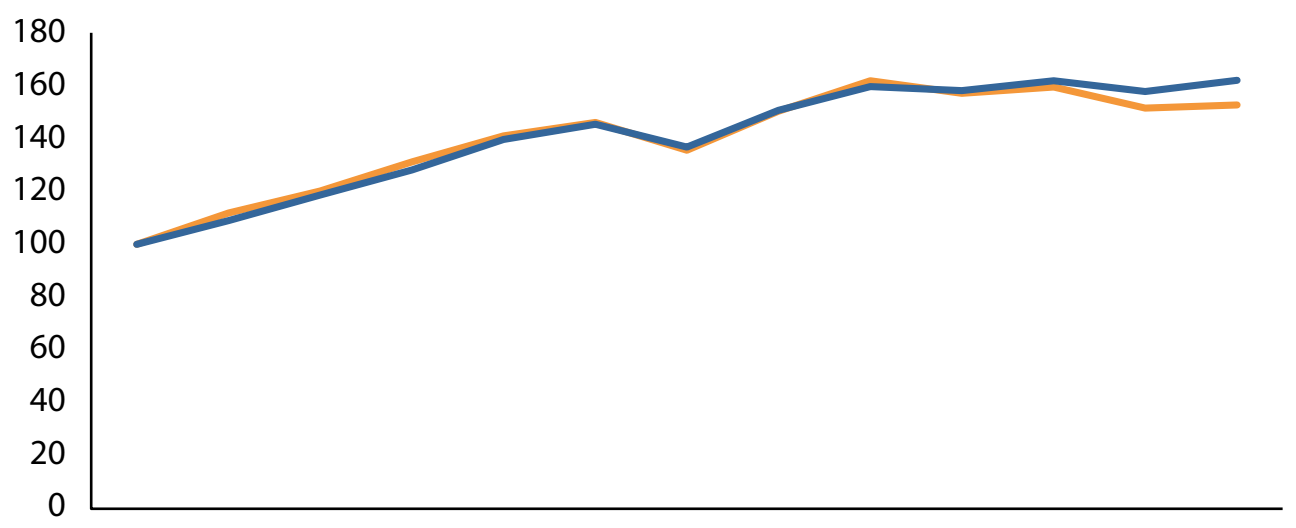

2003200420052006200720082009201020112012201320142015

Producto industrial $\longrightarrow \mathrm{PBI}$

Fuente: elaboración propia con base en información del Banco Mundial.

Sin embargo, tal crecimiento no modificó la composición intrasectorial de las manufacturas. Puede advertirse (cuadro 1) la persistencia de la especialización del sector en actividades que sustentan su competitividad en ventajas comparativas naturales y/o amparadas por un proteccionismo frívolo que crea "ventajas institucionales de privilegio" [Azpiazu y Schorr, 2010; Rougier y Schorr, 2012]. 
Cuadro 1. Evolución de la participación de las distintas ramas industriales dentro del producto bruto industrial (años 2005, 2010 y 2015) (\%)

\begin{tabular}{|c|c|c|c|}
\hline Ramas industriales & 2005 & 2010 & 2015 \\
\hline Elaboracióndeproductosalimenticiosybebidas & 24.69 & 23.95 & 25.49 \\
\hline Elaboración de productos de tabaco & 0.61 & 0.54 & 0.50 \\
\hline Fabricación de productos textiles & 3.11 & 2.91 & 2.68 \\
\hline Fabricación de prendas de vestir y pieles & 4.68 & 4.50 & 4.28 \\
\hline Cuero y artículos de cuero & 1.91 & 2.23 & 1.86 \\
\hline Madera y productos de madera & 2.07 & 1.61 & 1.44 \\
\hline Papel y de productos de papel & 3.56 & 3.34 & 3.13 \\
\hline Ediciones e impresiones & 3.59 & 3.91 & 3.17 \\
\hline Refinación de petróleo & 3.84 & 3.22 & 3.39 \\
\hline Sustancias y productos químicos & 12.04 & 12.37 & 14.17 \\
\hline Productos de caucho y plástico & 4.72 & 4.54 & 4.90 \\
\hline Otros productos minerales no metálicos & 4.01 & 4.21 & 4.58 \\
\hline Fabricación de metales comunes & 8.58 & 7.76 & 6.84 \\
\hline Productosdemetal,excluidosmaquinariayequipo & 5.23 & 4.88 & 4.16 \\
\hline Maquinaria y equipo & 4.67 & 6.12 & 5.87 \\
\hline Maquinaria de oficina & 0.35 & 0.46 & 0.48 \\
\hline Maquinaria y aparatos eléctricos & 1.84 & 1.62 & 1.63 \\
\hline Aparatosderadio,televisiónycomunicaciones & 0.43 & 0.91 & 1.66 \\
\hline Instrumentos médicos, ópticos & 0.91 & 0.99 & 0.85 \\
\hline Vehículos automotores & 4.39 & 5.33 & 4.20 \\
\hline Otros equipos de transporte & 0.65 & 0.48 & 0.35 \\
\hline Otras manufacturas & 3.97 & 3.49 & 3.48 \\
\hline Totales & 100.00 & 100.00 & 100.00 \\
\hline
\end{tabular}

Fuente: elaboración propia con base en datos del Instituto Nacional de Estadística y Censos (INDEC). 
En el año 2015, las ramas de alimentos y bebidas, sustancias y productos químicos, fabricación de vehículos automotores, refinación de petróleo ${ }^{6}$ y elaboración de metales comunes generaron más de la mitad (54.09\%) del producto manufacturero de la economía. Estas ramas industriales se caracterizan por presentar efectos limitados para la sofisticación y el dinamismo de la actividad manufacturera. La escasa capacidad para desarrollar encadenamientos productivos - por estar concentradas en los primeros eslabones de las cadenas de producción-, así como para impulsar de manera endógena el progreso técnico - dado que utilizan tecnologías maduras incorporadas en bienes importados de los países centrales-, ${ }^{7}$ no las habilita para convertirse en motores dinamizadores de una industria compleja y dinámica [Azpiazu y Schorr, 2010].

Además, estas actividades industriales presentan un elevado grado de concentración en un reducido grupo de actores: grandes empresas, muchas de ellas de capital extranjero, lo que vuelve aún menos virtuoso su desempeño en términos de especialización y dinamismo ${ }^{8}$ [Azpiazu y Schorr, 2010; Rougier y Schorr, 2012].

La participación de las grandes empresas manufactureras de la ENGE con el total de la producción industrial promedió 58 \% para el periodo 2003-2015.

Si analizamos el panel de la ENGE (cuadro 2), podemos advertir la importante gravitación de las ramas de producción alimentaria, química y petroquímica, y maquinaria, equipos y vehículos, dentro de la cual la automotriz tiene una participación relevante. Además, si consideramos la gráfica 5 podemos observar mayor participación de empresas de propiedad de capitales extranjeros que de nacionales. Si bien no se cuenta con estadísticas que permitan vincular directamente el tipo de actividad de las empresas del panel con el origen del capital de las mismas, no habría indicios para suponer que esta tendencia no se cumple para las empresas manufactureras.

${ }^{6}$ Es necesario destacar que este sector muestra una retracción sostenida durante el periodo, ligada al agotamiento de las reservas energéticas y la falta de inversiones [Costantino, 2017].

${ }^{7}$ Tanto bajo la forma de insumos, que se requieren en la producción, como de bienes de capital, empleados para realizar la misma.

${ }^{8}$ El posicionamiento monopólico u oligopólico de estos actores refuerza el carácter poco innovador que caracteriza dichas actividades y vuelve aún menos virtuoso su desempeño. Se puede considerar que, dada su capacidad de captar excedente de manera diferencial mediante la fijación de precios de monopolio, el gran capital no tiene mayores incentivos para procurar incrementar su rentabilidad mediante el desarrollo de prácticas innovativasschumpeterianas que permitan mejorar su productividad, competitividad y capacidad de agregación de valor. 


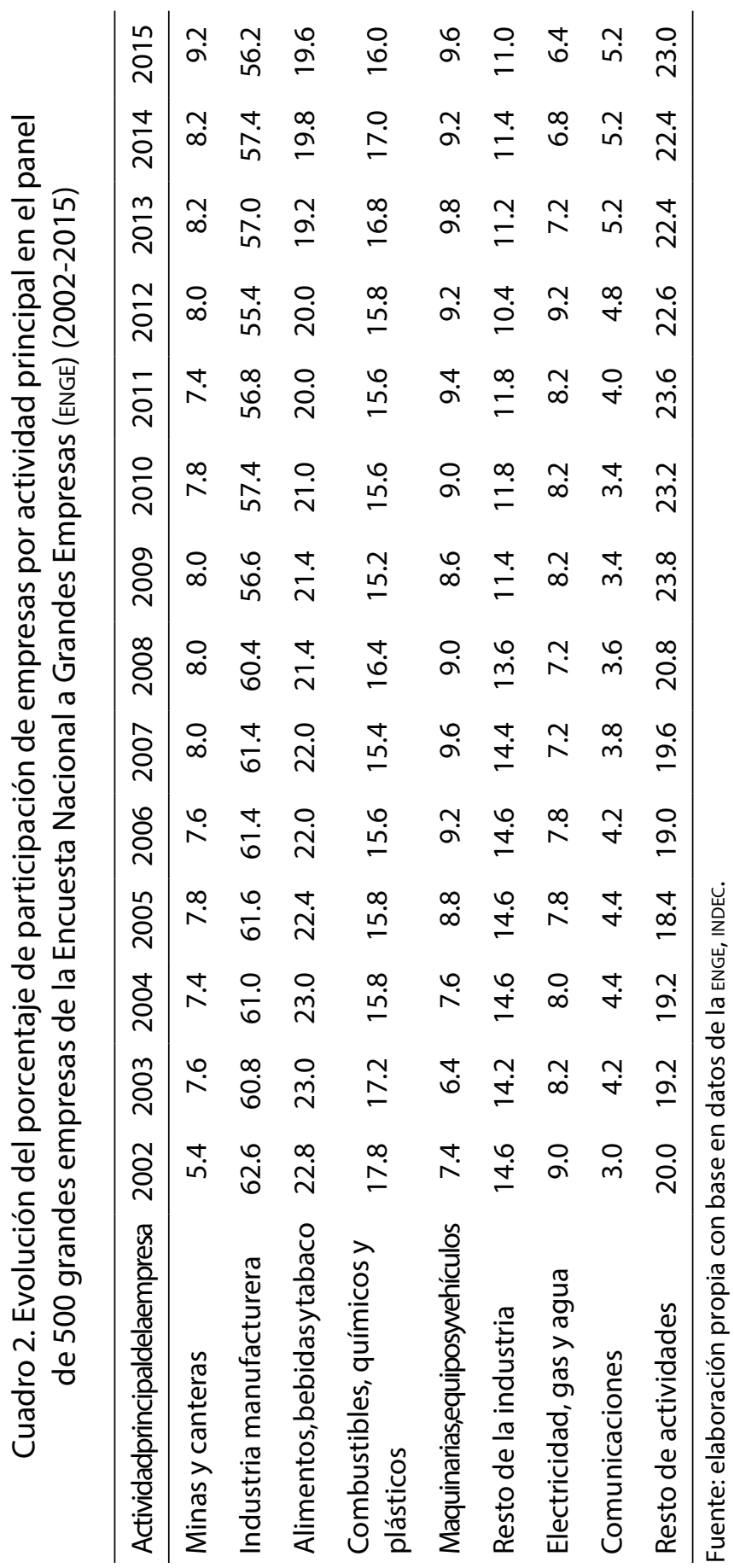




\section{Gráfica 5. Evolución de la cantidad de empresas de la ENGE por origen de capital (2002-2015)}

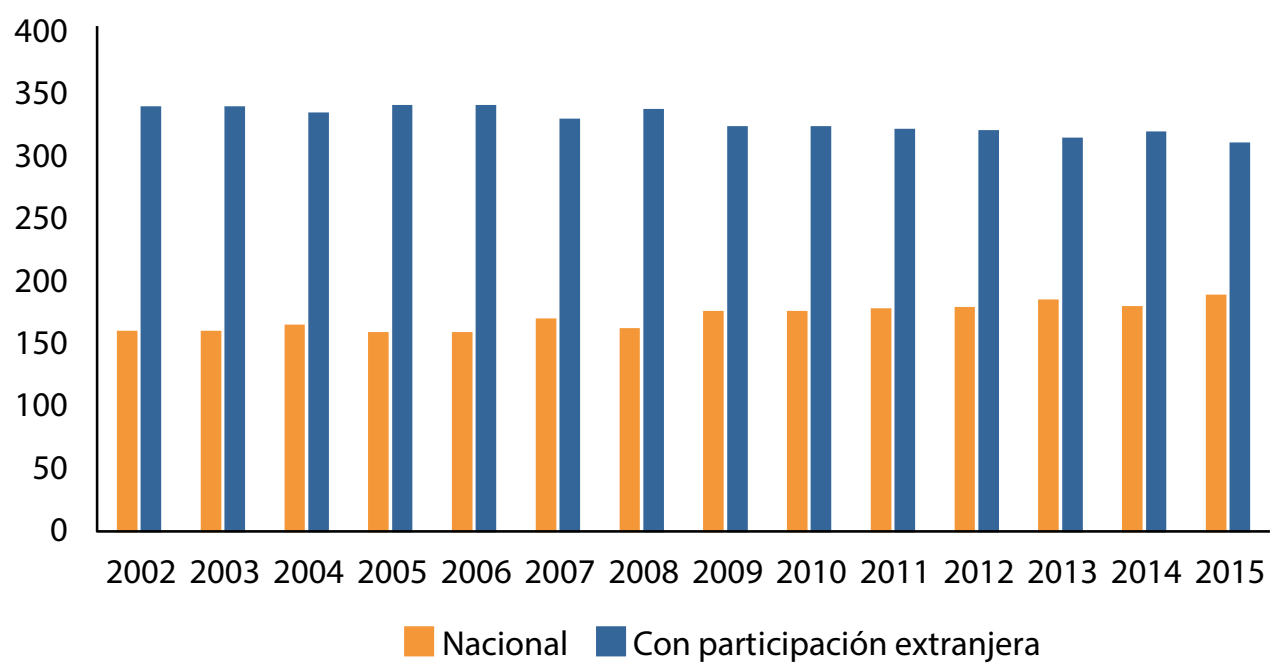

Fuente: elaboración con base en datos de la ENGE, INDEC.

Entonces, vemos así que el sistema productivo industrial se mantiene: a) orientado hacia la producción de materias primas y manufacturas centradas en el procesamiento de recursos naturales y/o amparadas en ventajas institucionales de privilegio; b) concentrado en un reducido grupo de grandes empresas, y c) extranjerizado. Por ende, no se ha podido avanzar en la consolidación de una estrategia de acumulación que mejore las condiciones de reproducción social internas y de inserción internacional sobre la base del desenvolvimiento de un complejo industrial endógeno, complejo y dinámico.

De acuerdo con lo desarrollado, luego de examinar los cambios en la correlación de fuerzas en el periodo, la estructura organizacional y la modalidad de implicación del Estado, se observa que la configuración del proyecto estatal kirchnerista no logró una estatalidad coherente y cohesionada ni desarrolló políticas públicas tendientes a generar una estrategia de acumulación centrada en lo productivo-industrial que tienda a propiciar el desarrollo. 
Luego de analizar el proyecto estatal neodesarrollista, a continuación examinamos las características del proyecto estatal bajo la gestión de Mauricio Macri (2015-2019). Como se mencionó, la victoria electoral de la Alianza Cambiemos significó el triunfo de aquellas posiciones que cuestionaban las modalidades de intervención del Estado en la esfera socio-económica y apelaban a los mecanismos del mercado para impulsar el crecimiento.

Para estudiar dicha experiencia, analizamos cómo se constituyó la correlación de fuerzas en ese periodo, qué características asumió la estructura estatal y sus modalidades de implicación, y cómo eso gravitó en la cada vez más importante pérdida de relevancia del sector industrial en la estrategia de acumulación en Argentina.

\section{Modificaciones en las correlaciones de fuerzas y los actores dominantes bajo el gobierno de la Alianza Cambiemos}

El triunfo electoral de la Alianza Cambiemos se acompañó de una redefinición de las relaciones de fuerza en la que determinados actores, con grados variables de incidencia, lograron imponer sus intereses en la agenda política. En relación con el periodo que se analizó antes, aquel modelo económico orientado a lo productivo fue desplazado finalmente por otro vinculado con la valorización financiera, con creciente importancia del capital transnacional, las fracciones relacionadas con la actividad agropecuaria y los grandes grupos económicos locales [Manzanelli et al., 2017].

De manera más precisa, los terratenientes pampeanos y los grupos económicos locales fueron recomponiendo sus demandas durante los últimos años del proyecto estatal configurado bajo el kirchnerismo, en particular luego del conflicto en torno a la Resolución 125 [Cantamutto y López, 2019]. La llegada de la Alianza Cambiemos al poder representó el triunfo de los actores que habían disputado el modelo económico del gobierno anterior [López y Cantamutto, 2017], centralmente de los actores económicos más concentrados. A su vez, las fracciones ligadas al capital extranjero también ganaron mayor relevancia en la escena política. Entre estas se distinguen las asociadas con el capital financiero internacional (los bancos 
trasnacionales), que adquirieron una posición dominante dentro del entramado de las fracciones más concentradas, y las empresas extranjeras no industriales, relacionadas con la producción y distribución de energía. Asimismo, esta reconfiguración de fuerzas posicionó a las pequeñas empresas y la clase trabajadora como los actores más vulnerables (o menos favorecidos) del periodo [Manzanelli et al., 2017].

Ahora bien, los magros resultados del desempeño económico agudizaron los conflictos de intereses no solo entre grupos y fracciones ganadoras y perdedoras del proyecto estatal configurado bajo la Alianza Cambiemos, sino también entre las fracciones que inicialmente se vieron beneficiadas por el mismo. En ese sentido, las ingentes ganancias de la fracción dominante vinculada con el sector financiero generaron rispideces con otras fracciones dominantes relacionadas con los servicios públicos y el sector energético, al tiempo que otros sectores como las cámaras industriales, la construcción, el comercio e incluso el sector agropecuario también manifestaron su disconformidad con el resultado de las políticas predominantes [Cantamutto y López, 2019].

\section{La reconfiguración de la organización estatal bajo la gestión de la Alianza Cambiemos}

En cuanto a la organización del Estado nacional, la gestión de la Alianza Cambiemos inició su periodo de gobierno ampliando la estructura estatal. El número de ministerios se incrementó de 11 a 23, lo mismo que la cantidad de secretarías (de 69 a 85), subsecretarías (de 165 a 204), direcciones nacionales (de 290 a 398) y direcciones generales (de 127 a 144) [Diéguez et al., 2019]. Las oficinas implicadas en la promoción de la actividad industrial se ubicaron en el Ministerio de la Producción, que se creó nuevamente a fines de 2015 y contó con cinco secretarías: Transformación Productiva, Industria y Servicios, Emprendedores y Pymes, Comercio e Integración Productiva.

A pesar del crecimiento de la estructura organizacional, la participación de la cartera de producción fue disminuyendo en el total de los gastos de la administración central durante los años 2015 a 2018 (gráfica 6). 
Gráfica 6. Evolución del gasto público del Ministerio de la Producción (2015-2018, \% del total)

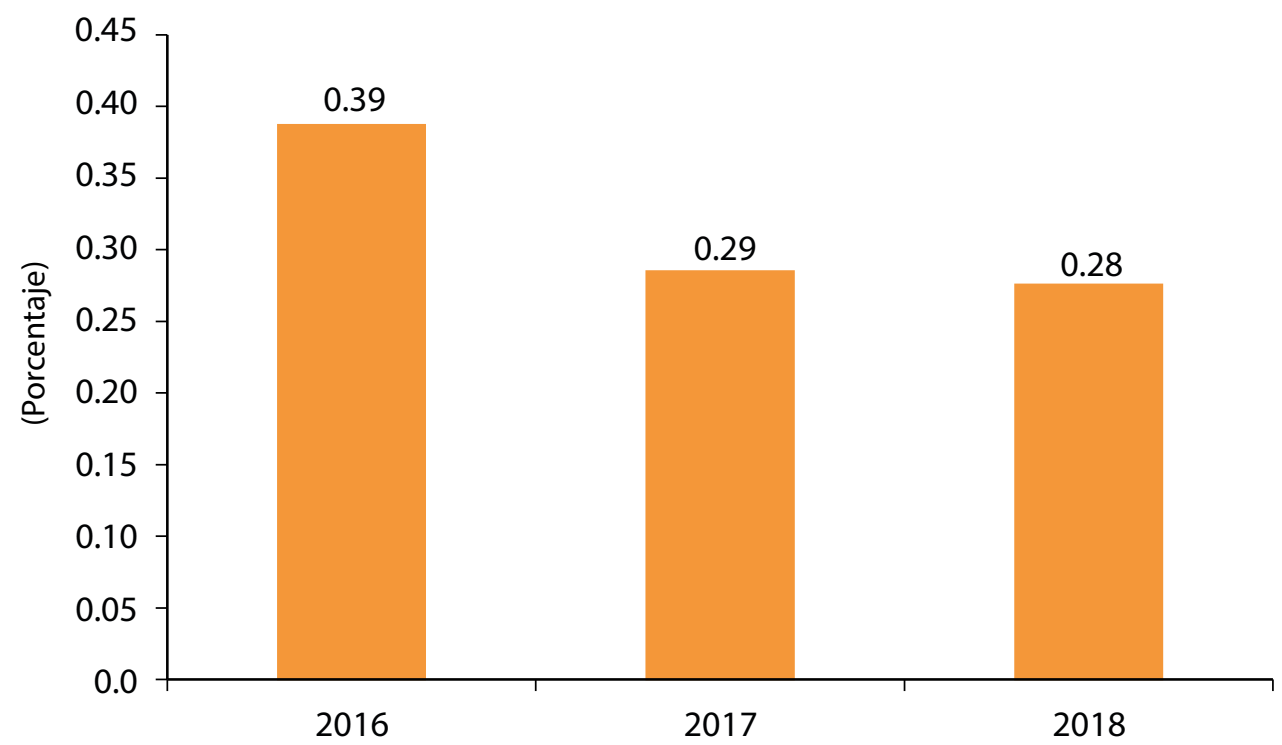

Fuente: elaboración propia con datos de la Oficina Nacional de Presupuesto del Ministerio de Economía de la Nación.

Por su parte, en el presupuesto de gastos de acuerdo con la finalidad también se observa una reducción en la categoría Servicios económicos, lo que evidencia una tendencia a la disminución de la intervención directa del Estado en los distintos sectores económicos en el periodo 2016-2018. También implica una importante baja en comparación con los últimos años del proyecto estatal bajo el neodesarrollismo. Así, mientras que en 2014 y 2015 representaba 41.09 \% y $33.15 \%$, respectivamente (gráfica 2), pasa a $18.22 \%$ en 2016 y llega a $12.83 \%$ en 2018 (gráfica 7). 


\section{Gráfica 7. Gasto público nacional por finalidades, porcentajes de participación (2016-2018)}

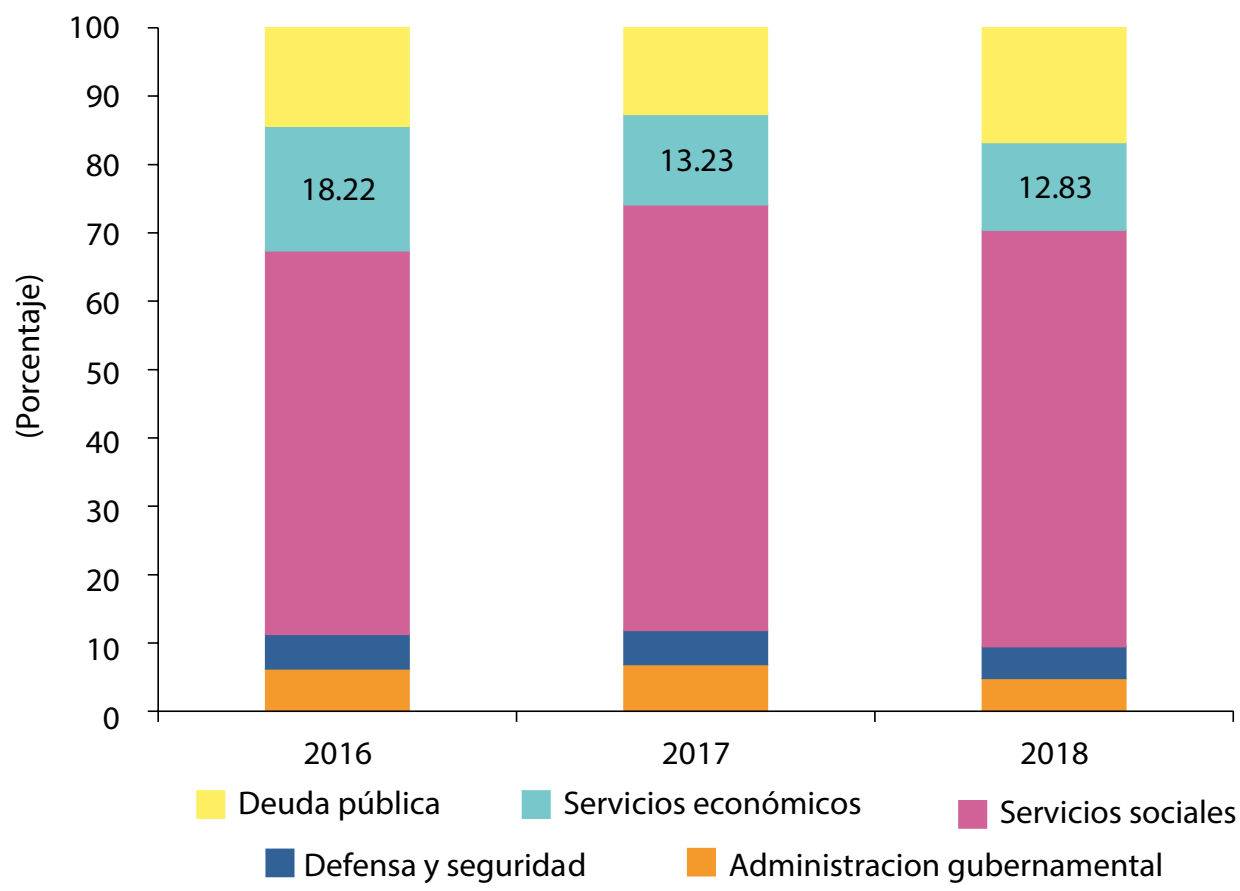

Fuente: elaboración propia con datos de la Oficina Nacional de Presupuesto del Ministerio de Economía de la Nación.

Por otro lado, cuando se examinan las categorías presupuestarias que componen la función Servicios económicos, se identifica una participación de Industria en torno a 2.50 \% (gráfica 8). Ese porcentaje es casi un punto mayor que el del periodo 2003-2015 (gráfica 3), pero cabe indicar que la reducción y pérdida de relevancia en el total de gastos de servicios económicos que se señaló en el párrafo anterior, da cuenta de la disminución del volumen absoluto de recursos destinados al fomento de las actividades económicas en general e industriales en particular.

Al igual que bajo el neodesarrollismo, la mayor parte de los recursos en servicios económicos se relaciona con las funciones de Energía, combustible y minería y con Transporte, que representan $89.24 \%$ del total del presupuesto a pesar de la reducción de los subsidios a los servicios públicos. 
Gráfica 8. Gasto público nacional en Servicios económicos desagregado por funciones (2015-2018)

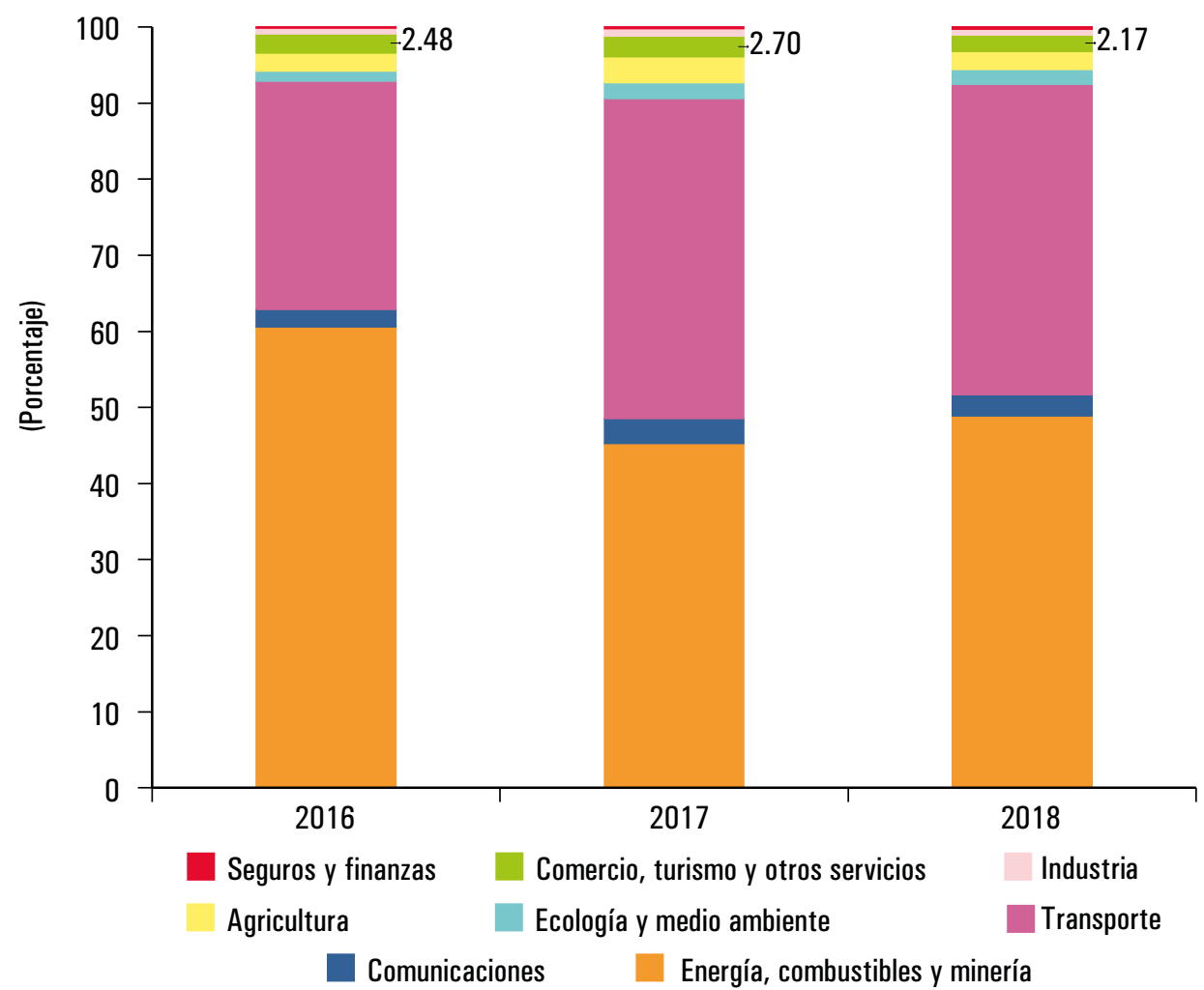

Fuente: elaboración propia con datos de la Oficina Nacional de Presupuesto del Ministerio de Economía de la Nación.

La poca relevancia presupuestaria del Ministerio de la Producción y de la función Industria evidenciada en esos tres años tuvo su correlato a nivel organizativo cuando en septiembre de 2018 se realizó un "reordenamiento estratégico [tendiente a] concretar las metas políticas diagramadas en materia de reducción presupuestaria" (decreto 801/2018). El objetivo de este reordenamiento era dar una señal de austeridad fiscal a los organismos internacionales de crédito [Diéguez et al., 2019] y cumplir con la meta de reducir el déficit fiscal (y mantener libre la flotación del dólar) acordada con el Fondo Monetario Internacional (FMI) [Miri, 2018; Ámbito, 2018]. 
Ese reordenamiento organizacional consistió en la eliminación de $10 \mathrm{mi}$ nisterios, hasta quedar un total de 13 hacia finales de 2018. Ello implicó que algunos ministerios tradicionales e históricos y otros más nuevos pasaran a ser secretarías de gobierno dentro de otras estructuras ministeriales (como son los casos de Salud; Trabajo y Empleo; Cultura; y Ciencia, Tecnología e Innovación Productiva). En este renovado esquema, el Ministerio de Producción se fusionó con el de Trabajo, por lo cual las áreas vinculadas con el fomento de las actividades industriales pasaron a depender del ahora denominado "Ministerio de Producción y Trabajo".

Esa fusión y pérdida de especificidad a nivel ministerial no significó una reducción de las secretarías, puesto que a las iniciales cinco (que se detallaron más arriba) se incorporaron la Secretaría de Política Minera y la de Simplificación Productiva. Solo esta última estaba relacionada con la actividad manufacturera y su finalidad fue la de "simplificar procesos y desburocratizar la administración pública para mejorar la competitividad y la integración de emprendedores y empresas al entramado productivo". ${ }^{9}$

Como lo evidenció el análisis de la estructura organizativa y la dotación de recursos presupuestarios, el fomento a la actividad industrial no tuvo un lugar preponderante en el proyecto estatal bajo la gestión de la Alianza Cambiemos. Ello está en consonancia con la modalidad de implicación desplegada que, como se detalla a continuación, no se orientó a incentivar el sector manufacturero para que ocupara un espacio relevante en la estrategia de acumulación.

\section{La modalidad de implicación del proyecto estatal bajo la Alianza Cambiemos}

Las principales políticas públicas que incidieron en la actividad productiva industrial durante la gestión de la Alianza Cambiemos no se orientaron a fomentarla. Precisamente, las más relevantes medidas económicas implementadas por Mauricio Macri configuraron un escenario poco propicio para el desarrollo de las actividades industriales. Entre ellas se destacan: la devaluación del peso de más de $300 \%$ desde diciembre de 2015 a junio de 2019, el incremento de los costos en la producción secundario al aumento

\footnotetext{
${ }^{9}$ Información disponible en <https://cutt.ly/fs99oPF>, fecha de consulta noviembre de 2019.
} 
del precio de los hidrocarburos (por la devaluación y por regulaciones sobre el precio) y la eliminación de los subsidios a las tarifas de servicios públicos [Costantino, 2019]. A este escenario se adiciona la política contractiva del Banco Central, que mantuvo muy elevadas las tasas de interés y desalentó las inversiones en el sector. Al mismo tiempo se tomaron diversas medidas que propiciaron la apertura comercial, se redujeron a cero los impuestos a las exportaciones de grano, carne y productos mineros, y se disminuyeron las retenciones a la soja [Costantino, 2019]. En conjunto, estas acciones se orientaron a mejorar la rentabilidad en los sectores primarios y los industriales procesadores de materias prima [Cantamutto y Schorr, 2016]. Por el lado de las importaciones, la apertura comercial se propició mediante el reemplazo de las declaraciones juradas anticipadas de importación por las licencias automáticas y no automáticas [Manzanelli et al., 2017].

En este sentido,

una economía con ajuste del gasto público, sostenida inflación, caída del consumo, apertura comercial y altas tasas de interés, con caída del producto y sumida en una política de endeudamiento que funge como mecanismo de financiamiento de la fuga de capitales, dista de conformar un paraíso productivo [Santarcángelo et al., 2019: 186].

En ese escenario poco propicio para el desarrollo del sector, las políticas específicas de fomento a la industria fueron limitadas en presencia y resultados. Los programas de fomento a las pymes pasaron a compartir su dependencia institucional con aquellos destinados a los emprendedores. De acuerdo con la información revelada, ${ }^{10}$ durante los años 2016-2018 se mantuvieron programas que venían del periodo anterior, como el Programa de Acceso al Crédito y la Competitividad (PACC Empresa), la asistencia técnica para la mejora de la productividad de pymes (Expertos) y el apoyo a los grupos asociativos (SPL). En julio de 2016 se sancionó una nueva ley de

${ }^{10}$ La misma se realizó vía <www.argentina.gob.ar/produccion> y mediante el análisis de resultados por programas y proyectos, correspondiente al tomo 2 de las cuentas de inversión de los años 2016, 2017 y 2018. Se hizo una solicitud de información pública al Ministerio de la Producción (exp2019-77140553 APN DGD) y la respuesta solo fue de las acciones que lleva adelante la Secretaría de Industria y Servicios, sin brindar datos de las acciones que dependen de la Secretaría de Emprendedores y Pymes. 
pymes (27.264), denominada Programa de Recuperación Productiva, y el decreto 1101/2016 que reglamentó los beneficios fiscales, impositivos e instrumentos de créditos destinados a las pymes. Sin embargo, de esas normativas no se han derivado políticas concretas para ampliar el crédito productivo [López, 2019].

Asimismo, se crearon los programas Ciudades para Emprender y el Club de Emprendedores y otras políticas vinculadas con el financiamiento de esas iniciativas (Fondo Semilla, Fondo Aceleración y Fondo Expansión), en sintonía con la Ley de apoyo al capital emprendedor (Ley 27349) de marzo de 2017.

De la Secretaría de Industria, sin realizar una descripción detallada, destacan los siguientes regímenes de promoción y programas: Compre Trabajo Argentino (Ley 27.437), Potenciar -orientado a la internacionalización de empresas-, el Programa de Desarrollo de Proveedores (Prodepro) y el Plan de Diseño. Respecto del sector automotriz, se sancionó una nueva ley para el desarrollo y fortalecimiento del sector (27.263) y se crearon algunos programas con muy magros resultados. ${ }^{11}$ Se mantuvo la normativa de promoción a la industria del software (Ley 26.922 de 2004), el régimen de bienes de capital, informática y telecomunicaciones, y el de aduana en factoría.

En relación con los regímenes de promoción regionales, el estímulo a las exportaciones por los puertos patagónicos quedó sin vigencia y el régimen de Tierra del Fuego se mantuvo.

El financiamiento productivo se vio afectado por las condiciones macroeconómicas ya indicadas y por la eliminación de algunas regulaciones, como la derogación del inciso " $k$ " que obligaba a las aseguradoras a invertir sus activos en la economía real y el desmantelamiento de las líneas de crédito para inversión productiva a tasa subsidiada (LicIP). Por otra parte, si bien la Carta Orgánica del Banco Central no fue reformada, ${ }^{12}$ tampoco se cumplió con lo establecido en la ley del año 2012 relacionada con el fomento del crédito productivo y con brindar mayor apoyo a las economías regionales y las pymes [López, 2019].

${ }^{11}$ A modo de ejemplo, citamos al denominado JuniOKM, que prevé descuentos al precio final de los autos, pero sin diferenciar entre origen local, Mercosur o extra zona. <https://cutt.ly/Ud92y82>.

${ }^{12} \mathrm{El}$ intento de formalizar la quita al Banco Central de la República Argentina de la facultad de orientar el crédito hacia el desarrollo se plasmó en el proyecto de ley INLEG-2019-19522714-APN-PTE. 
Por otro lado, en 2016 se anunció el Plan Productivo Nacional, cuyo fin era "integrar políticas transversales y sectoriales para crear más y mejores empleos". El mismo tiene como modelo productivo el caso de Australia, y a pesar de que se plantearon algunos pilares, no se implementó ninguna política o programa específico. De acuerdo con Fabrizio [2016: 11], en sintonía con otras políticas llevadas adelante por esta misma gestión, el citado plan se orienta a consolidar una estructura productiva industrial primarizada.

Como puede observarse, la modalidad de implicación del proyecto estatal bajo la Alianza Cambiemos no tuvo como eje el fomento del sector industrial. Si se consideran las principales medidas macroeconómicas, estas construyeron un escenario muy poco propicio para el desarrollo de la actividad manufacturera que no se revirtió con las políticas específicas orientadas al sector. La escasa significatividad y cantidad de los programas sectoriales, así como su orientación a la desregulación y desburocratización para el desarrollo del capital generaron magros resultados.

\section{La pérdida de relevancia del sector industrial}

Las diferentes políticas que comenzaron a aplicarse a partir de diciembre de 2015 afectaron negativamente la dinámica del sector manufacturero, como puede advertirse al analizar la gráfica 9 . A pesar del leve repunte que la actividad del sector tuvo en 2017 , la tasa de crecimiento fue de $-0.64 \%$ en promedio para el periodo 2015-2018. El decrecimiento del sector se tradujo en una merma de su participación relativa en el producto agregado de la economía.

En este contexto, es importante destacar que no todas las actividades manufacturares se vieron afectadas de la misma forma. La depreciación favoreció únicamente a pocas ramas orientadas a la exportación, en particular las vinculadas con la elaboración de productos alimenticios y bebidas (haciendo que su participación sectorial crezca, como puede advertirse en el cuadro 3). Por el contrario, las actividades que tenían el mercado interno como destino principal de su producción sufrieron un fuerte deterioro ante la importante retracción del consumo ocasionada por la caída de los salarios. 
Muchas actividades fueron afectadas también por la mayor apertura comercial, que aumentó la competencia de productos importados [Cassini, García y Schorr, 2019].

Gráfica 9. Evolución del producto industrial en umn constante y de su participación en el PBI

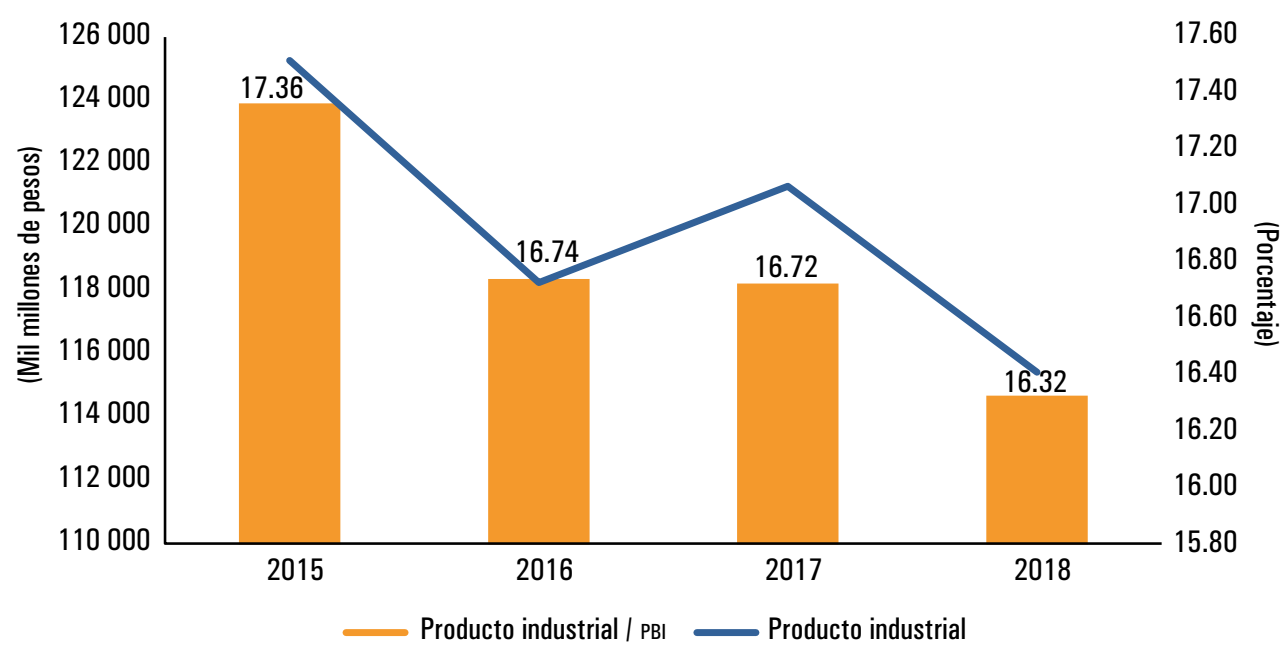

Fuente: elaboración propia con base en datos del Banco Mundial.

Esto reforzó el perfil de especialización sectorial que se ha venido consolidando a partir de la aplicación de las políticas neoliberales en el espacio nacional, amparado en ventajas comparativas de los recursos naturales o en ventajas institucionales de privilegio. En 2018, 56.5 \% de la producción manufacturera estaba vinculado con las ramas de alimentos y bebidas, sustancias y productos químicos, fabricación de vehículos automotores, refinación de petróleo y fabricación de metales comunes, las que, como ya se mencionó, poco contribuyen a la complejización y el dinamismo del sector. 
Cuadro 3. Evolución de la participación de las distintas ramas industriales dentro del producto industrial (2016-2018) (\%)

\begin{tabular}{lrrr}
\hline \multicolumn{1}{c}{ Ramas industriales } & 2016 & 2017 & 2018 \\
\hline Elaboracióndeproductosalimenticiosybebidas & 26.32 & 25.53 & 26.19 \\
Elaboración de productos de tabaco & 0.45 & 0.45 & 0.43 \\
Fabricación de productos textiles & 2.51 & 2.31 & 2.18 \\
Fabricación de prendas de vestir y pieles & 3.99 & 3.48 & 3.37 \\
Cuero y artículos de cuero & 1.80 & 1.56 & 1.61 \\
Madera y productos de madera & 1.39 & 1.44 & 1.49 \\
Papel y productos de papel & 3.16 & 3.09 & 3.21 \\
Ediciones e impresiones & 3.16 & 3.10 & 3.11 \\
Refinación de petróleo & 3.51 & 3.41 & 3.43 \\
Sustancias y productos químicos & 14.83 & 14.58 & 14.37 \\
Productos de caucho y plástico & 4.58 & 4.55 & 4.30 \\
Otros productos minerales no metálicos & 4.54 & 4.72 & 4.97 \\
Fabricación de metales comunes & 6.62 & 7.45 & 8.19 \\
Productosdemetal,excluidosmaquinariayequipo & 4.14 & 4.37 & 4.51 \\
Maquinaria y equipo & 6.33 & 7.00 & 5.92 \\
Maquinaria de oficina & 0.38 & 0.30 & 0.29 \\
Maquinaria y aparatos eléctricos & 1.54 & 1.49 & 1.44 \\
Aparatosderadio,televisiónycomunicaciones & 1.65 & 1.64 & 1.63 \\
Instrumentos médicos, ópticos & 0.72 & 0.73 & 0.76 \\
Vehículos automotores & 3.81 & 4.03 & 4.32 \\
Otros equipos de transporte & 0.30 & 0.35 & 0.27 \\
Otras manufacturas & 4.27 & 4.40 & 4.01 \\
Totales & 100.00 & 100.00 & 100.00 \\
\hline Fuente: & & & \\
\hline
\end{tabular}

Fuente: elaboración propia con base en datos del INDEC.

Además, las actividades industriales aún presentan un elevado grado de concentración. Ello se evidencia en la participación de las empresas manufactureras de la ENGE en relación con el producto industrial de la economía argentina, que se mantuvo en $58 \%$, al menos para 2017 , único dato estadístico disponible para el periodo en consideración. 
Podemos advertir, también, que en las ramas industriales más importantes del sector es donde se identifica mayor presencia de las empresas de la ENGE (cuadro 4), 59 y $57 \%$ de las cuales eran propiedad de capital extranjero para 2016 y 2017 , respectivamente.

Cuadro 4. Evolución de la participación de las distintas ramas de actividad dentro del panel de grandes empresas según la ENGE (\%)

\begin{tabular}{lrr}
\hline \multicolumn{1}{c}{ Actividad } & 2016 & 2017 \\
\hline Minas y canteras & 8.8 & 8.8 \\
Industria manufacturera & 55.2 & 53.8 \\
Alimentos, bebidas y tabaco & 19.2 & 20.0 \\
Textiles y cueros & 2.8 & 1.8 \\
Combustibles, químicos y plásticos & 16.2 & 16.0 \\
Mineralesnometálicos,metalesyproductosdemetal & 5.0 & 4.4 \\
Maquinarias, equipos y vehículos & 9.2 & 8.6 \\
Otras industrias de manufacturas & 2.8 & 3.0 \\
Electricidad, gas, agua, residuos y saneamiento & 8.2 & 8.4 \\
Construcción & 3.2 & 3.6 \\
Comercio & 8.4 & 8.0 \\
Transporte, correo y almacenamiento & 6.2 & 6.6 \\
Servicios de información y comunicaciones & 5.2 & 5.0 \\
Otras actividades & 4.8 & 5.8 \\
\hline Fuente: & & \\
\hline
\end{tabular}

Fuente: elaboración propia con base en datos de ENGE, INDEC.

En función de lo expuesto, después de analizar la correlación de fuerzas, la estructura organizacional y la modalidad de implicación del Estado, podemos advertir que el proyecto estatal configurado bajo la Alianza Cambiemos habilitó estrategias de acumulación que distan de viabilizar procesos de transformación estructural que impulsen el desarrollo. 
En este capítulo se analizó la forma que asumió el Estado bajo el kirchnerismo y el macrismo y la estrategia de acumulación resultante con base en la consideración de la relevancia de la modalidad de organización e implicación estatal para viabilizar una estrategia de acumulación centrada en la actividad industrial que habilite el desarrollo. Así mismo, a partir de considerar la relevancia de la modalidad de organización e implicación estatal para viabilizar una estrategia de acumulación centrada en la actividad industrial que habilite el desarrollo, se analizó la forma que asumió el Estado bajo el kirchnerismo y el macrismo y la estrategia de acumulación resultante.

Se evidenció que en el caso del neodesarrollismo, la correlación de fuerzas imperante se expresó en la configuración de una estructura estatal que experimentó un incremento de las instancias vinculadas con el desenvolvimiento del sector manufacturero, pero estas no ocuparon un lugar relevante (dada su poca participación presupuestaria). Del mismo modo, la modalidad de implicación, si bien reconoció un aumento del número de políticas específicas para el sector, se caracterizó por operar de forma fragmentada y descoordinada. Es así como la estrategia de acumulación resultante, a pesar de lograr un importante crecimiento manufacturero, se encontró lejos de avanzar en la dinamización y complejización del sector industrial, y quedó relegado centralmente a la explotación de recursos naturales.

A partir de 2015 se advirtió un cambio en la correlación de fuerzas que traccionó hacia la reconfiguración del proyecto estatal. En la estructura organizativa del Estado bajo la Alianza Cambiemos, las oficinas relacionadas con la industria ocuparon un lugar poco relevante, como en la experiencia anterior, aunque esa poca gravitación se agravó al perder la dependencia institucional específica y contar con aún menos recursos presupuestarios. Por su parte, la implicación estatal, expresada en las políticas y programas específicos hacia el sector industrial, disminuyó y se orientó de modo principal a reducir las regulaciones - avanzando en una desburocratización- con el fin de incentivar la inversión manufacturera. Como resultado de estos cambios tuvo lugar un proceso de fuerte contracción de la industria con su consecuente pérdida de relevancia en la estrategia de acumulación. 
En función de lo expuesto, puede observarse que las dos experiencias analizadas presentaron diversas correlaciones de fuerzas y contaron, en consecuencia, con distintos proyectos estatales que se tradujeron en disímiles estructuras organizativas y formas de implicación del Estado. No obstante, ninguna de ellas logró conformar una estatalidad coherente y cohesionada en la que las instancias vinculadas con el sector industrial tuvieran una participación relevante. Tampoco presentaron modalidades implicativas capaces de impulsar la conformación de un sector manufacturero nacional complejo y dinámico que impulse el desarrollo.

De este modo, luego de examinar las limitaciones del proyecto estatal bajo esas dos experiencias, resalta la importancia académica y política de considerar la conformación de la estructura estatal y de analizar las políticas públicas que de ella se derivan dada su relevancia en habilitar la salida de posicionamientos periféricos mediante la posibilitación de cambios en la estrategias de acumulación vigentes para lograr dinámicas de crecimiento con inclusión social.

REFERENCIAS

Ámbito [2018], "La Argentina y el FMI, una historia de deudas, crisis y búsqueda de credibilidad", en ámbito.com, Economía, 29 de mayo. <https:// cutt.ly/ms3tMAR>.

Amsden, Alice [1989], Asia's next giant: South Korea and late industrialization. Oxford, Oxford University Press.

[2004], "La sustitución de importaciones en las industrias de alta tecnología: Prebisch renace en Asia”, en Revista de la Cepal, abril, núm. 82, pp. 75-90.

Anglade, Christian y Carlos Fortin [1989], "Accumulation, adjustment and the autonomy of the State in Latin America", en Christian Anglade y Carlos Fortin (eds.), The state and capital accumulation in Latin America, vol. 2, Argentina, Bolivia, Colombia, Ecuador, Peru, Uruguay, Venezuela. Basingstoke, Palgrave Macmillan.

Araníbar, Antonio y Benjamín Rodríguez [2013], América Latina ¿del neoliberalismo al neodesarrollismo?, Buenos Aires, Siglo XxI. 
Azpiazu, Diego y Martín Schorr [2010], Hecho en Argentina. Industria y economía, 1976-2007. Buenos Aires, Siglo xxi Editores.

Baruj, Gustavo y Fernando Porta [2006], Politicas de competitividad en la Argentina y su impacto sobre la profundización del Mercosur. Documentos de Proyectos. Santiago de Chile, Cepal.

Baruj, Gustavo, Bernardo Kosacoff y Adrián Ramos [2009], Las políticas de promoción de la competitividad en la Argentina. Principales instituciones e instrumentos de apoyo y mecanismos de articulación públicoprivada. Documentos de Proyectos. Santiago de Chile, Cepal.

Basualdo, Eduardo [2011], Sistema político y modelo de acumulación. Ensayos sobre la Argentina actual. Buenos Aires, Cara o Ceca.

Brenner, Neil [2013], “'Glozalization’ as a State Spatial Strategy: Urban Entrepreneurialism and the New Politics of Uneven Development in Western Europe", en Jamie Peck y Henry Wai-Chung Yeung (comps.), Remaking the global economic-geographical perspectives. SAGE Publications Ltd.

Bresser-Pereira, Luiz Carlos [2006], "El nuevo desarrollismo y la ortodoxia convencional”, en Economía, México, Universidad Autónoma de México, vol. 4 , núm. 10.

[2007], "Estado y mercado en el nuevo desarrollismo", en Nueva Sociedad, Caracas, núm. 210.

Cantamutto, Francisco y Emiliano López [2019], “El programa imposible? El dilema entre el ajuste y la legitimidad al interior del bloque en el poder", en Paula Belloni y Francisco Cantamutto (coords.), La economía política de Cambiemos. Ensayos sobre un nuevo ciclo neoliberal en Argentina. Buenos Aires, Batalla de Ideas.

Cantamutto, Francisco y Martín Schorr [2016], "Timba agroexportadora". $<$ https://www.marcha.org.ar/timba-agro-exportadora/>.

Cassini, L., G. García Zanotti y M. Schorr [2019], "El poder económico durante el gobierno de Cambiemos: desempeños empresarios y lógicas de acumulación en una etapa de reposicionamiento de las diferentes fracciones del capital concentrado", en Paula Belloni y Francisco Cantamutto (coords.), La economía política de Cambiemos. Ensayos sobre un nuevo ciclo neoliberal en Argentina. Buenos Aires, Batalla de Ideas, pp.151-186. 
Chibber, Vivek [1999], "Building a Development State: The Korea Case Reconsidered", en Politics \& Society, vol. 27, núm. 3, pp. 309-346. [2003], Locked in Place. State-building and Late Industrialization in India. Princeton, Princeton University Press.

Costantino, Agostina [2017], "La estructura económica durante el kirchnerismo: ¿reprimarización o reindustrialización?", en Martín Schorr (coord.), Entre la década ganada y la década perdida. La Argentina kirchnerista. Estudios de economía política. Buenos Aires, Batalla de Ideas.

[2019], "Entre la estructura y la coyuntura: el comportamiento de los sectores económicos durante el gobierno de Cambiemos", en Paula Belloni y Francisco Cantamutto (coord.), La economía política de Cambiemos. Buenos Aires, Batalla de Ideas.

Couto, Bárbara [2010], "Desafíos para el Estado y los actores empresarios en la definición e implementación de la política industrial en Argentina", en Documentos de Investigación Social, IDAES, UNSAM, núm. 11.

Diéguez, Gonzalo et al. [2019], "GPS del Estado. Radiografía y balance de la Administración Pública Nacional 2015-2019", en CIPPEC, Buenos Aires. $<$ https://cutt.ly/Ys3rHA6>.

Evans, Peter [1995], Embedded Autonomy. States \& Industrial Transformation. Princeton, Princeton University Press.

[1996], "El Estado como problema y solución", en Desarrollo Económico. Revista de Ciencias Sociales, Buenos Aries, IDES, vol. 35, núm. 140.

Fabrizio, Rubén [2016], "Proyecto Productivo Nacional: Modelo CANGURO", en Industrializar Argentina, núm. 30.

Fernández Bugna, Cecilia y Fernando Porta [2007], "El crecimiento reciente de la industria argentina. Nuevo régimen sin cambio estructural", Bernardo Kosacoff (comp.), Crisis, recuperación y nuevos dilemas. La economía argentina 2002-2007. Santiago de Chile, Cepal.

Fernández, Víctor Ramiro [2017], La trilogía del erizo-zorro. Redes globales, trayectorias nacionales y dinámicas regionales desde la periferia. Barcelona, Anthropos-Siglo xxI Editores-Ediciones UNL.

Gaitán, Fabián [2013], El rescate del Estado. Los desafíos del desarrollo. Buenos Aires, Capital Intelectual. 
[2014], Auge, ocaso y resurgimiento de los estudios sobre desarrollo en América Latina. Santiago de Chile, Cepal.

Gallagher, Kevin, Roberto Porzecanski y Andrés López (eds.) [2008], Inversión extranjera directa y desarrollo sustentable. Lecciones desde las Américas. Grupo de Trabajo sobre Desarrollo y Medio Ambiente en las Américas.

García Puente, María Jimena [2016], Transformaciones del Estado y desarrollo. Capacidades estatales y desarrollo productivo industrial. El caso de la provincia de Santa Fe en el periodo 1990-2013, tesis, Universidad Nacional de Rosario.

García Puente, María Jimena, Carolina Lauxmann y Emilia Ormaechea [2019], "El Estado argentino y el desarrollo. Un análisis de la configuración e implicación estatal en la promoción industrial durante los años 2003-2015”, en Papeles del Centro de Investigaciones, vol. 9, núm. 29, en prensa.

Hersh, Adam y Christian Weller [2003], "Does Manufacturing Matter?", en Challenge, vol. 46, núm. 2, pp. 59-79.

Hikino, Takashi y Alice Amsden [1995], "La industrialización tardía en perspectiva histórica", Desarrollo Económico, núm. 35, pp. 3-34.

Jessop, Bob [1990], State Theory: Putting the Capitalist State in its Place. Pennsylvania, Pennsylvania State University Press.

[2008], El futuro del Estado capitalista. Madrid, Los libros de la catarata.

[2014], "El Estado y el poder", en Utopía y Praxis Latinoamericana, vol. 19, núm. 66, pp. 19-35.

[2017], El Estado. Pasado, presente, futuro. Madrid, Catarata.

Kohli, Atul [2004], State Directed-Development: Political Power and Industrialization in the Global Periphery. Cambridge, Cambridge University Press.

[2009], "States and economic development", en Brazilian Journal of Political Economy, vol. 29, núm. 2, pp. 212-227.

[2010], "Estado y desarrollo económico", en Documentos y Aportes en Administración Pública y Gestión Estatal, Universidad Nacional del Litoral, Santa Fe, núm. 12. 
Kulfas, Matías [2009], Las pymes argentinas en el escenario post convertibilidad. Políticas públicas, situación y perspectivas, Documentos de Proyectos, LC/W.272. Santiago de Chile, Cepal.

[2016], Los tres kirchnerismos. Una historia de la economía argentina 2003-2015. Buenos Aires, Siglo XxI.

Lavarello, Pablo [2017], “¿De qué hablamos cuando hablamos de política industrial?”, en Martín Abeles, Mario Cimoli y Pablo Lavarello (eds.), Manufactura y cambio estructural. Aportes para pensar la política industrial en la Argentina. Santiago de Chile, Cepal.

Lavarello, Pablo y Evelin Goldstein [2011], "Dinámicas heterogéneas en la industria de maquinaria agrícola argentina", en Problemas del Desarrollo. Revista Latinoamericana de Economía, México, Universidad Nacional Autónoma de México, vol. 42, núm. 166.

Lavarello, Pablo y Marianela Sarabia [2015], La política industrial en Argentina durante la década de 2000. Santiago de Chile, Cepal.

López, Emiliano y Francisco Cantamutto [2017], "El orden social kirchnerista entre la economía y la política”, en Martín Schorr (coord.), Entre la década ganada y la década perdida. La Argentina kirchnerista. Estudios de economía política. Buenos Aires, Batalla de Ideas.

López, Pablo [2019], "Instrumentos e instituciones para el financiamiento del desarrollo y la industria: avances y retrocesos en la Argentina reciente", en Voces del Fénix, año 9, núm. 76.

Mann, Michael [1991], "El poder autónomo del Estado: sus orígenes, mecanismos y resultados", en Zona Abierta, núm. 57/58.

Manzanelli, Pablo y Eduardo Basualdo [2016], "Régimen de acumulación durante el ciclo de gobiernos kirchneristas. Un balance preliminar a través de las nuevas evidencias empíricas de las cuentas nacionales", en Realidad Económica, núm. 304, pp. 6-40.

Manzanelli, Pablo, Mariana González y Eduardo Basualdo [2017], "La primera etapa del gobierno de Cambiemos. El endeudamiento externo, la fuga de capitales y la crisis económica y social", en Eduardo Basualdo (ed.), Endeudar y fugar. Un análisis de la historia económica argentina, de Martínez de Hoz a Macri. Buenos Aires, Siglo XXI.

Miri, Alfonso [2018], "El FMI aprobó un préstamo de us\$ 50.000 millones para la Argentina”, en Clarín.com, Economía, 7 de junio. <cutt.ly/ cgkVyvU>. 
Poulantzas, Nicos [2005 (1978)], Estado, poder y socialismo. México, Siglo XXI. Rougier, Marcelo y Martín Schorr [2012], La industria en los cuatro peronismos. Estrategias, politicas y resultados. Buenos Aires, Capital Intelectual.

Santarcángelo, Juan, Agustín Wydler y Juan Padín [2019], "Política económica y desempeño industrial en Argentina durante la Alianza Cambiemos: balance y perspectivas", en Revista de Ciencias Sociales, Bernal, Universidad Nacional de Quilmes, segunda época, vol. 10, núm. 35, pp. 171-188.

Schorr, Martín [2012], "Industria y neodesarrollismo en la posconvertibilidad", en Voces del Fénix, núm. 16, pp. 14-25.

Schorr, Martín (coord.) [2013], Argentina en la posconvertibilidad: ¿desarrollo o crecimiento industrial? Estudios de economía política. Buenos Aires, Miño y Dávila Editores.

Skocpol, Theda [1991], "El Estado regresa al primer plano: Estrategias de análisis en la investigación actual”, en Zona Abierta, núm. 57/58.

Stumpo, Giovanni y Diego Rivas [2013], "La industria manufacturera argentina 2003-2010. Reconstruyendo capacidades para enfrentar los desafíos del siglo xxi", en Giovanni Stumpo y Diego Rivas (comps.), La industria argentina frente a los nuevos desafios y oportunidades del siglo XXI. Santiago de Chile, Cepal.

Stubbs, Richard [2009], "What Ever Happened to the East Asian Developmental State? The Unfolding Debate", The Pacific Review 22 (1): pp. 1-22.

Szirmai, Adam [2013], "Manufacturing and economic development", en Adam Szirmai, Wim Naudé y Ludovico Alcorta (eds.), Pathways to Industrialization in the Twenty-First Century. New Challenges and Emerging Paradigms. Oxford, Oxford University Press.

Sztulwark, Federico [2010], "Políticas e instituciones de apoyo a las Pymes en la Argentina", en Carlo Ferraro y Giovanni Stumpo (comps.), Políticas de apoyo a las Pymes en América Latina. Entre avances innovadores $y$ desafios institucionales. Santiago de Chile, Cepal.

Varesi, Gastón [2010], "La argentina posconvertibilidad: modelo de acumulación”, en Problemas del Desarrollo. Revista Latinoamericana de Economía, vol. 41, núm. 161, pp. 141-164. 
Wade, Robert [1999], El mercado dirigido. La teoría económica y la función del gobierno en la industrialización del este de Asia. México, Fondo de Cultura Económica.

Wainer, Andrés [2018], "Economía y política en la Argentina kirchnerista (2003-2015)", en Revista Mexicana de Sociología, vol. 80, núm. 2, pp. 323-351. 


\title{
7. ESTADO ASOCIATIVO Y CADENAS DE VALOR EN MÉXICO AL INICIO DEL SIGLO XXI: EL CASO DE JALISCO
}

\author{
Paty Montiel* y Seyka Sandoval**
}

INTRODUCCIÓN

En el capitalismo del conocimiento, fase actual de desarrollo del modo de producción capitalista [Ordóñez, 2004], la coordinación social establecida y dirigida por el Estado se ve comprometida e impotente ante los retos de la sociedad [Messner, 1999]. La dinámica cada vez más sectorizada de la economía y la integración horizontal que impone el patrón industrial de la electrónica-informática y de las telecomunicaciones (SEIT) [Dabat y Ordóñez, 2009; Ordóñez y Bouchaín, 2011], del que dan cuenta las cadenas globales de valor (CGV), al mismo tiempo que exigen de la sociedad conocimientos especializados y sectorizados, dan voz a nuevos grupos con intereses sociales específicos y diferenciados que en la fase de desarrollo del capitalismo fordista-keynesiana no se dilucidaban.

La dinámica económica y social del capitalismo del conocimiento trasciende la escala nacional como el espacio prioritario de reproducción del capital al otorgar importancia a otras escalas geográficas como regiones subnacionales, supranacionales y globales. Así mismo, en el capitalismo del conocimiento, las concepciones de coordinación social jerárquico-estatales pierden eficacia ante el aumento de importancia, en el siglo XXI, de las organizaciones y asociaciones de diversa índole en ámbitos sociales y políticos,

* Doctora en Ciencias Políticas y Sociales por la unam y profesora de asignatura de la Facultad de Economía de la misma universidad.

** Doctora en Economía por la Facultad de Economía de la unam y profesora de Tiempo Completo Asociada C de la misma facultad.

Las autoras agradecen al PAPIIT IN307319"México frente a la revolución 4.0. Los sectores emergentes como pilares de desarrollo", el apoyo para realizar este capítulo. 
pero también económicos, y a distintos niveles, ya sea locales e internacionales [Puga y Luna, 2008].

La importancia de las organizaciones puede ser muestra del desgaste de la centralidad de las relaciones jerárquizadas y centralizadas del Estado, que experimenta una transformación para dar paso a relaciones y esquemas asociativos o acciones colectivas organizadas (ACO) que están conformando un nuevo modelo de coordinación social y de configuración del Estado distinto a como lo conocimos en el capitalismo fordista-keynesiano.

En este marco se inscribe la experiencia mexicana, cuya integración al capitalismo del conocimiento ha sido por la vía de desarrollo neoliberal, que colocó el diseño de la política económica en la línea del catching up a partir de la integración a los mercados internacionales y de la participación en las cadenas de valor, fragmentando espacialmente el accionar estatal y reconfigurando el Estado nacional en uno asociativo local y regional. La experiencia de Jalisco, de forma más específica la Zona Metropolitana de Guadalajara (ZMG), ilustra este hecho.

Desde las décadas de los sesenta y setenta, en el marco de la industrialización por sustitución de importaciones, el entonces nuevo patrón industrial -el de la industria electrónica- se instala con la llegada de las empresas trasnacionales Motorola, IBM y Burroughs, pero es en la década de los noventa cuando la ZMG se incorpora a la lógica de integración y up grading de las CGV por la apertura comercial que aceleró procesos ya presentes desde mediados del decenio de los ochenta. Las empresas y sus directivos representantes de la industria electrónica instalada en la región iniciaron procesos asociativos locales para competir en el mercado mundial y dieron impulso a la industria de las tecnologías de la información y desarrollo de software, y actualmente se involucran en acciones relacionadas con la industria 4.0 como el proyecto de la "Ciudad Creativa Digital”. Estas sucesivas ACo han configurado el sistema de generación y transferencia de conocimientos (SGTC) en Jalisco y a través de ello se observa una reconfiguración también de las relaciones del Estado.

Por lo tanto, el objetivo de este capítulo es mostrar que de la trayectoria mexicana en el neoliberalismo se desprende la experiencia en Jalisco sobre la reconfiguración del Estado en el siglo xxi, que con características de orden asociativo entre diversos y heterogéneos actores locales lleva a 
cabo diferentes ACO para dar forma a un sistema de generación y transferencia de conocimientos anclado al SEIT que le permitirá integrarse a las CGV disminuyendo los costos de transacción de la empresas trasnacionales (ET).

Para cumplir con el objetivo planteado, este capítulo abordará primero la integración de los empresarios a la vía neoliberal en México y su influencia en Jalisco para desarrollar una subvía con características asociativas que pondrá las condiciones para la integración de Jalisco a la globalización. En el segundo se analizarán, en el marco conceptual de sistemas de asociación compleja, las ACO ancladas al sEIT. En el tercer apartado se presenta la discusión de esta experiencia, sobre todo desde las CGV, con especial acento en la disminución de los costos de transacción que la estrategia asociativa de las ACO implica para el up grading, y en el cuarto se expone la propuesta de análisis y aportaciones sobre el Estado asociativo.

Vía de desarrollo neoliberal en México y asociativa en Jalisco

El concepto de vía alterna de desarrollo se enlaza con la doble historicidad del capitalismo industrial (como modo de producción y fase de desarrollo). Hace referencia al papel de la práctica político-social, definida por la modalidad que adopta la lucha de clases dentro del espacio de los Estados nacionales. La vía es el resultado de la lucha político-social y cultural que se obtiene como fuerza activa de dirección social que opera en los diferentes planos de la formación económico-social, pero la resolución de esa lucha debe atender a las "necesidades objetivas del desarrollo histórico-social en un contexto determinado" [Dabat, 1994: 44-45]; es decir, la vía debe dar cuenta de las pautas de crecimiento y desarrollo nacionales que la fase del capitalismo implica.

La vía alterna de desarrollo es una modalidad que los Estados nacionales asumen en consonancia con la fase, etapa o época en la que se ha desarrollado el capitalismo. Y en una época puede haber tantas modalidades como Estados nacionales existen, tantas vías como naciones, de allí el término "alterno"; sin embargo, eso ha quedado acotado por el poder hegemónico (entendido en el sentido gramsciano, en el cual se considera el ejercicio del poder por medio de la coerción pero también, y sobre todo, del consenso) que una 
nación es capaz de ejercer sobre el resto de naciones para implementar un sistema hegemónico de Estados.

Por ejemplo, en la fase de desarrollo anterior, del fordismo-keynesiano, pueden distinguirse tres vías de desarrollo nacionales en los países centrales. La vía del "fascismo" desarrollada antes de la Segunda Guerra Mundial en Alemania e Italia principalmente; la del "socialismo real", representada por el bloque de países soviéticos; y la del "americanismo" en Estados Unidos con influencia en Europa Occidental [Dabat, 1994: 45]. Mientras tanto, en los países en desarrollo, en particular en los de América Latina, la vía se caracterizó por el "corporativismo" de Estado (en México) y la estrategia económica de la industrialización por sustitución de importaciones (ISI); al mismo tiempo, los países del Este Asiático combinaron la IsI con una siguiente estrategia de industrialización orientada hacia las exportaciones (IOE) [Wade, 1999]. Todas estas vías de desarrollo nacional que se desplegaron después de la Segunda Guerra Mundial (menos el fascismo) compartían la característica de que el Estado era el pivote de coordinación económica y social: desde el Estado de bienestar en Europa y en menor medida en Estados Unidos, el Estado desarrollista en América Latina, con sus respectivas diferencias, al Estado más eficaz y autoritario del Este Asiático [Messner, 1999].

Hacia el capitalismo del conocimiento se han tenido que configurar otras vías de desarrollo conforme a las pautas de crecimiento y desarrollo económico que ello requiere. Se destacan la vía neoliberal, dirigida por Estados Unidos, que tendió a dominar Europa Occidental ${ }^{1}$ y América Latina a partir de la década de los ochenta; la vía asiática que han seguido los países del Este de Asia y China; y la vía escandinava (véase "El punto de partida y precisiones conceptuales: hacia un dispositivo analítico-propositivo" en la Introducción a la presente obra).

\section{Integración del empresariado al Estado neoliberal mexicano}

Entre las décadas de los ochenta y noventa, México emprende una vía de desarrollo neoliberal del capitalismo del conocimiento, la cual consiste en

\footnotetext{
${ }^{1}$ Europa Oriental se une a esta vía después de la desintegración de la Unión Soviética a inicios de la década de los noventa.
} 
articular elementos de la nueva base tecnológica-productiva en torno al SEIT con relaciones sociopolíticas corporativas surgidas de la Revolución Mexicana, pero reconfiguradas.

Ante la nacionalización de la banca en 1982, empieza un fuerte activismo empresarial. Entre las décadas de los ochenta y noventa, se identifican tres corrientes empresariales que influyeron en las decisiones de política pública y que dieron forma a la vía de desarrollo neoliberal mexicana.

La corriente liberal-conservadora, constituida por la Confederación de Cámaras de Comercio (Concanaco), la Confederación Patronal de la República Mexicana (Coparmex) y el Consejo Nacional Agrícola (CNA), promovía un nuevo modelo económico, político y social que asignara un papel de liderazgo a las empresas y protegiera al sector privado de las decisiones unilaterales del gobierno, así como un sistema político de partidos que en los hechos eran el Partido de la Revolución Institucional (PRI) y el Partido Acción Nacional (PAN). Con base en la afinidad ideológica de la Coparmex con el PAN, los líderes de esta corriente apoyaron la participación política de las empresas en este partido [Luna, 2004: 337]. El Estado prácticamente adoptó su programa económico durante los primeros años de la década de los ochenta y culminó con la privatización de las empresas estatales y la restitución de la banca al capital financiero nacional a mediados de las década de los noventa, lo cual reconfiguró a una clase agrominero-exportadora pero ahora como grupos financieros y financieros-industriales que habían desaparecido tras la nacionalización de la banca y que reaparecían luego de la privatización de empresas paraestatales [Ordóñez, 2017: 42].

En el contexto de finales de la década de los ochenta se levanta como fuerza opositora al PRI el Frente Democrático Nacional (FDN) ${ }^{2}$ liderado por Cuahtémoc Cárdenas, quien disputa las elecciones en 1988 y logra agrupar una importante fuerza política entre la población. Así mismo, la corriente liberal-conservadora pierde prestigio ante la segunda corriente, la liberalpragmática, que estaban organizando el Consejo Mexicano de Hombres

${ }^{2}$ Antecedente directo de lo que después sería el Partido de la Revolución Democrática (PRD), el FDN se compuso del Partido Auténtico de la Revolución Mexicana, el Partido Popular Socialista y el Partido del Frente Cardenista de Reconstrucción Nacional; luego se sumaron a la candidatura cardenista otras organizaciones más pequeñas como el Partido Social Demócrata, el Partido Verde Mexicano y más tarde el Movimiento al Socialismo, que estaba integrado por desprendimientos del Partido Socialista Unificado de México, el Partido Mexicano de los Trabajadores y el Partido Revolucionario de los Trabajadores [Alonso, 1993: 63; Wikipedia, 2018]. 
de Negocios (CMHN), la Asociación Mexicana de Instituciones Bursátiles (AMIB), la Asociación de Banqueros de México (ABM) y la Asociación Mexicana de Instituciones de Seguros (AMIS), y que hacia finales de la década de los ochenta tendrá un papel protagónico en la interlocución con el gobierno federal con miras a la entrada en el Acuerdo General sobre Comercio y Aranceles (GATT, por sus siglas en inglés) e incluso forma parte de la administración pública [Luna, 2004: 337]. Para este momento, hay una identificación entre la corriente liberal-conservadora y el PAN y de la corriente liberal-pragmática con el PRI.

Hacia la década de los noventa, las corrientes que dominan en el sector empresarial son la liberal-pragmática y una tercera, la liberal-crítica. Aunque frente a las negociaciones del TLCAN se alinean los grupos bajo la dominación de la liberal-pragmática, esta se divide por la exclusión de las negociaciones del capital financiero y su protección de facto [Luna, 2004: 343]. La corriente liberal-crítica se distingue por su composición y sus propuestas. Está formada por pequeños y medianos empresarios agrupados en la Cámara Nacional de la Industria de Transformación (Canacintra), la Concanaco, la Coparmex y el cNA que capitalizan los fallos de la política y los resultados económicos obtenidos a nivel nacional desde finales de la década de los ochenta; así empiezan a adquirir presencia entre las representaciones políticas del PAN a nivel regional. Entre sus descontentos está la situación de la pequeña empresa, así como de la industria enfocada al mercado interno y su inconformidad con las organizaciones centralizadas a nivel nacional [Luna, 2004: 341]. De aquí los triunfos electorales que en la década de los noventa consigue este partido en las gubernaturas estatales y Jalisco será uno de estos en 1995.

Para este momento, la alianza de la clase agrominera-exportadora y su evolución en facción industrial en conjunto con la tecnoburocracia dirigente del Estado se cristalizó con la desaparición del corporativismo empresarial en 1996 [Ordóñez, 2017: 43-44] al derogarse en la Ley de Cámaras de la Industria y del Comercio la obligatoriedad de que los empresarios pertenecieran a una cámara. En su lugar surgirán formas de organización que dejan de estar territorialmente centralizadas y cuya asociatividad se basará en la cooperación regional en relación con organizaciones internacionales.

La integración a la nueva fase se hace conforme a: a) una apertura indiscriminada, basada en la promoción de la inversión extranjera directa (IED) 
y de las exportaciones a partir de ventajas competitivas inferiores como bajos costos salariales y niveles medios y bajos de calificación de la fuerza de trabajo y de localización geográfica; b) ausencia a nivel nacional de promoción de procesos de aprendizaje tecnológico; c) falta de políticas de promoción industrial en sectores y ramas industriales específicas; d) ausencia de la promoción de redes productivas internas nacionales y de desarrollo de la empresa nacional; y e) fortalecimiento de los monopolios privados [Ordóñez, 2017: 35].

En estas condiciones, hacia finales de la década de los ochenta e inicios de la de los noventa México se integraba al mercado mundial: desde 1986 es miembro del GATT, en 1994 se incorpora al TLCAN y en 1995 se integra como miembro de la Organización Mundial del Comercio (OMc).

\section{Triunfo en Jalisco de la corriente empresarial "liberal-crítica"}

Las elecciones federales de 1988 fueron las primeras que mostraron la clara fractura que el régimen de "partido de Estado" ya presentaba desde 1968. ${ }^{3}$ Manuel Clouthier, candidato del PAN, resultaba una opción muy atractiva para sectores altos y medios de Jalisco; mientras que Cuauhtémoc Cárdenas, representante del frente de partidos de izquierda, fue ganando presencia entre los sectores populares y campesinos; Carlos Salinas de Gortari fue el representante del PRI. Finalmente las tres principales fuerzas político-electorales fueron el PRI, el PAN y el FDN. Los resultados de aquellas elecciones dieron a Cárdenas cerca de 23.8 \% de la votación en Jalisco pese al arraigo nulo que el candidato tenía en dicho estado, 30.7 \% a Clouthier del PAN y $42.5 \%$ a Salinas.

En 1995 el PAN capitalizó el voto de castigo al $\mathrm{PRI}^{4}$ y el triunfo en la gubernatura del estado fue para el ingeniero Alberto Cárdenas Jiménez, pues al descontento de los empresarios y de la sociedad se sumó el apoyo

${ }^{3}$ Si se consideran los movimientos sociales y sindicales que se expresan desde finales de la década de los sesenta, como el Movimiento Estudiantil de 1968, y en los años setenta, en la que las fórmulas económicas dejan de dar resultado para mantener el crecimiento económico de las décadas anteriores.

${ }^{4}$ La gubernatura anterior, encabezada por el PRI, ni siquiera concluyó su periodo de seis años; Guillermo Cosío Vidaurri fue obligado a dimitir después de las protestas contra la inseguridad que iniciaron en febrero de 1992. Además, la situación política y social se agravó ante la crisis económica del "error de diciembre" de 1994. 
de la Iglesia y la omisión de la Universidad de Guadalajara para apoyar al PRI [Valdez, 1996: 89-90]. Así, en 1995 Jalisco se convirtió en el cuarto estado en dejar de ser gobernado por el PRI ${ }^{5}$ y el PAN pasó de ser la "oposición leal" en Jalisco para convertirse en partido en el poder.

De acuerdo con cifras oficiales, en 1995 el pan obtuvo $52.5 \%$ de los votos para la gubernatura de Jalisco contra $37.09 \%$ del PRI y $3.98 \%$ del Partido de la Revolución Democrática (PRD). Además arrasó con los diferentes puestos de elección popular, sin que hubiese impugnaciones y desestabilidad política.

Este triunfo electoral del PAN sobre el PRI se debió a la relación que la corriente empresarial "liberal-crítica" mantuvo con el PAN de la entidad. La figura de Manuel Clouthier fue un antecedente importante en las elecciones nacionales de 1988; ya en la década de los noventa el acento que esta corriente ponía en las pequeñas empresas y en las industrias focalizadas en el mercado interno, su crítica al centralismo característico de las principales organizaciones a nivel nacional y la promoción de una nueva política industrial juntó una base de pequeños y medianos empresarios que encontró muchos simpatizantes en Jalisco. No obstante, las relaciones entre los empresarios y el gobierno no se establecerían como en la vía de desarrollo corporativista; si bien esta corriente encontró una base social importante, su régimen político no sería dominante como lo fue el PRI.

Por otra parte, en cuanto a la composición del gabinete de gobierno, el de Alberto Cárdenas destaca por la presencia de empresarios, en particular la figura de Sergio García de Alba, empresario con experiencia camaral en la Canacitra, que se integra a la Secretaría de Promoción Económica (Seproe) y quien ha sido reconocido como un parteaguas en la promoción económica de Jalisco en general y del seit en particular para esta entidad. A diferencia de lo ocurrido a nivel nacional respecto de la integración conforme a la apertura comercial indiscriminada y las varias ausencias

${ }^{5}$ En 1989, el PRI gobernaba las 32 entidades de la República Mexicana. Ya con la presidencia de Carlos Salinas de Gortari, en ese mismo año, Ernesto Ruffo, candidato del pAN, gana la gubernatura de Baja California. En 1991, en Guanajuato, Ramón Aguirre declina y no toma posesión, lo que propicia que el gobierno local nombre a Carlos Medina del PAN como gobernador interino. En 1992, el panista Francisco Barrio, que había impugnado las elecciones en Chihuahua en 1986, es electo gobernador; con él ya serían tres estados gobernados por el pan. Durante la presidencia del priista Ernesto Zedillo Ponce de León, Alberto Cárdenas Jiménez convierte Jalisco en el cuarto estado gobernado por el PAN [Ortiz, 2014: 124; Campos, s.f.]. 
en términos de política industrial e integración del mercado interno, en Jalisco se desarrolla una política industrial regional con características distintivas.

En 1996, se promulgó la Ley de Fomento Económico, que fue el marco para la creación del Consejo Estatal de Promoción Económica (CEPE). Este Consejo estuvo presidido por el gobernador, con la participación de la Seproe, las secretarías de finanzas, turismo y desarrollo urbano, los presidentes municipales de la zona metropolitana y de los municipios involucrados en los proyectos que se presentaron en el Consejo, pero también de los representantes del sector empresarial (Canaco, Coparmex y el Consejo de Cámaras Industriales de Jalisco-CCIJ) e incluso los representantes de los trabajadores (Confederación de Trabajadores de México -CTM-, Confederación Revolucionaria de Obreros y Campesinos -CROC-, Confederación Regional Obrera Mexicana -CROM). Este organismo fue un eje fundamental de política industrial que posibilitó la negociación entre gobierno, empresarios y trabajadores ante el nuevo escenario de apertura comercial [Chapa, 2013]. Durante su periodo fundó varios organismos públicos descentralizados (OPD) entre los que se encuentra el Consejo Estatal de Ciencia y Tecnología de Jalisco (Coecytjal) en el marco de la Ley de Fomento de Ciencia y Tecnología de 2000.

La gráfica 1 muestra claramente el incremento de la IED de Jalisco como proporción de la nacional para el periodo en que Alberto Cárdenas fuera gobernador; en 1994 representaba 0.6 y aumentó constantemente hasta alcanzar 7.69 \% en 2000. Para los periodos posteriores, la proporción de IED se mantuvo en una banda de $3 \%$ a $8 \%$, incluido el último periodo de gobierno del PRI, a partir de 2013.

Desde 1995 seguirían tres gubernaturas encabezadas por el PAN hasta 2013, en que regresaría el PRI; sin embargo, en este último periodo se fundó la Secretaría de Innovación, Ciencia y Tecnología (SICYT) ya anunciada por el gobierno anterior de González Márquez. 
Gráfica 1. Jalisco: inversión extranjera directa en relación con México

(1994-2017)

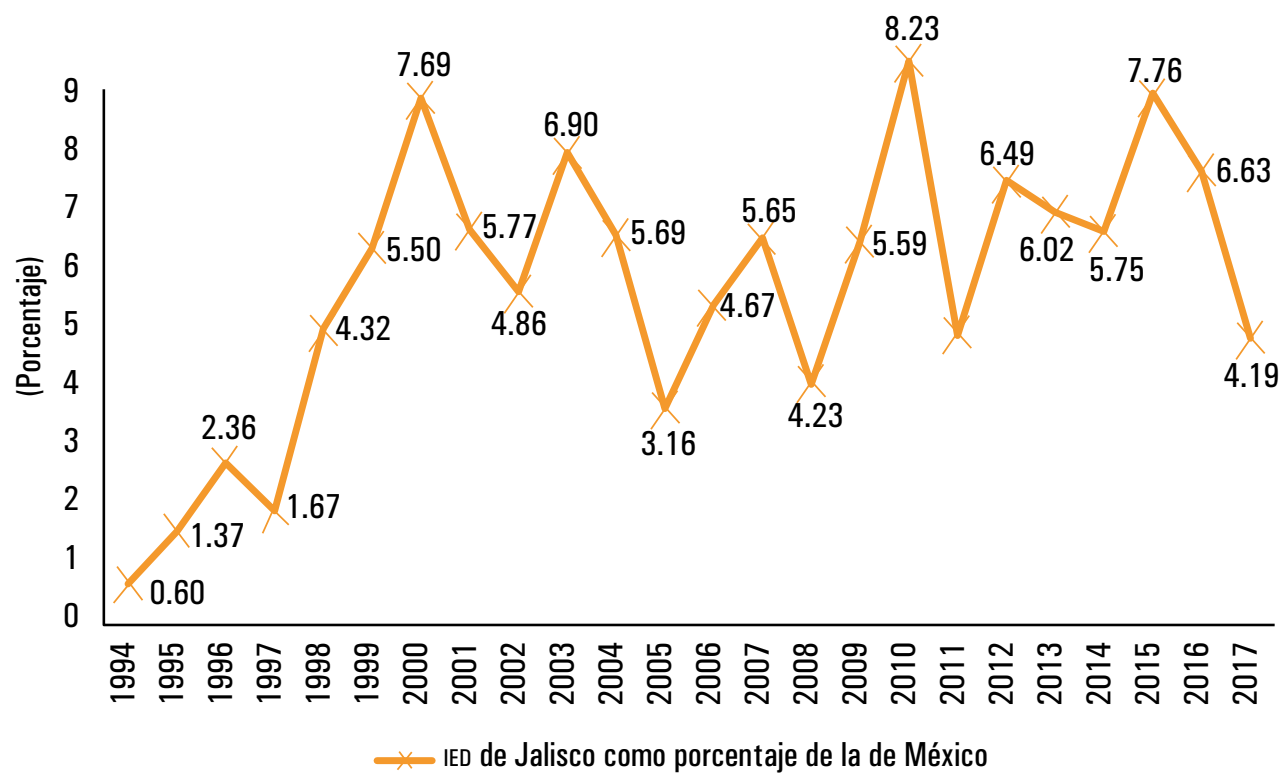

Fuente: elaboración propia con base en datos de la Dirección General de Inversión Extranjera, Secretaría de Economía.

ACCIONES COLECTIVAS ORGANIZADAS Y ACCIONES GUBERNAMENTALES

Por diferentes razones, el estado de Jalisco es considerado de desarrollo medio en el contexto general de México. Esta entidad se ubica en el centrooccidente del territorio de los Estados Unidos Mexicanos y su extensión ocupa el sexto lugar del país, con $80137 \mathrm{~km}^{2}$; no obstante, prácticamente desde la década de los setenta ha ocupado el cuarto lugar nacional en términos de población total, solo atrás del Estado de México, la Ciudad de México y Veracruz. En 2015 se reportaba una población de 7880539 personas, de las que $18.95 \%{ }^{6}$ cuenta con instrucción superior, mientras que a nivel

${ }^{6}$ Porcentaje de la población de 15 años y más. Aunque se coloca por arriba del nivel nacional, es superado por Aguascalientes (20.67), Baja California (19.38), Baja California Sur (21.05), Campeche (20.31), Coahuila (21.51), Colima (22.03), Ciudad de México (32.14), Nuevo León (24.17), Querétaro (21.15), Sinaloa (23.04), Sonora (21.94) y Tamaulipas (19.37) [Inegi, 2015]. 
nacional el porcentaje es 18.63 [Inegi, 2015]. Así mismo, es de los estados que en 1995 alcanzaba $8 \%$ de patentes solicitadas a nivel nacional según la residencia del inventor, mientras el Distrito Federal tenía 45 \% y Nuevo León, $13 \%$ [Conacyt, 2006]; para 2015 ya reporta $15 \%$, solo por detrás de la Ciudad de México (23\%), pero arriba de Nuevo León (13\%) [IMPI, 2017]. ${ }^{7}$ Respecto de su economía, Jalisco se caracteriza por ser un estado con diversidad productiva en alimentos, textiles y comercio al por menor. ${ }^{8}$

En el siglo xx Jalisco tuvo un fuerte antecedente en la industria eléctrica y luego electrónica con el asentamiento de empresas multinacionales (y después trasnacionales) aún dentro del patrón industrial petroquímico y metalmecánico de la época de la Isi. La entidad ha contado con condiciones económicas de localización, infraestructura y recursos humanos favorables por encima de la media del país que le permitieron recibir a las grandes ET de la electrónica con suma celeridad a partir de la década de los ochenta y los primeros años de los noventa; además, cuenta con una cultura empresarial regional y tradicional que se reprodujo bajo un esquema corporativo, pero diferente al de Nuevo León, por ejemplo. En cuanto a las condiciones políticas, este estado fue de los primeros en cambiar del régimen priista de gobierno hacia uno panista que puso énfasis en la atención de las necesidades de los pequeños empresarios.

Para los fines de este trabajo se identificaron las principales acciones gubernamentales y acciones colectivas organizadas, como asociaciones, las cuales debían cumplir con los siguientes criterios: a) relación con las actividades económicas del SEIT; b) participación definida y clara de diversos actores pertenecientes a sectores sociales distintos: empresarial, académico, gubernamental a nivel estatal y de las asociaciones público-privadas; c) planteamiento de metas u objetivos comunes; y 4) reglamentaciones de participación más o menos precisa.

El diagrama 1 presenta una propuesta de periodización de las acciones colectivas organizadas ancladas al sEIT. En primer lugar se considera el despliegue y la dinámica mundial del sEIT desde la década de los ochenta

${ }^{7}$ Se trata de las patentes solicitadas por entidad federativa de residencia del inventor, solicitudes hechas en el Instituto Mexicano de la Propiedad Intelectual (IMPI).

${ }^{8}$ Desde el periodo de la Colonia, su crecimiento económico se dio a partir de sus relaciones con la zona del Bajío [Alba Vega y Kruijt, 1988]. Eso lo ha dotado de un rasgo característico en el tipo de empresariado y las organizaciones que los aglutinaron, teniendo diversidad y heterogeneidad en sus organizaciones. 
hasta el periodo poscrisis de 2008-2009, así como la integración de México por la vía alterna nacional neoliberal. En segundo lugar, el asentamiento de este sector en Jalisco; desde sus antecedentes en la década de los sesenta hasta su complejización posterior a la crisis de 2008, su adopción y desarrollo ha sido por una subvía de desarrollo nacional asociativa. Finalmente, se han identificado tres acciones gubernamentales: la creación del Centro de Tecnologías de Semiconductores (CTS) en 1988, ${ }^{9}$ la fundación del Consejo Estatal de Ciencia y Tecnología de Jalisco (Coecytjal) en $2000^{10}$ y la Secretaría de Innovación, Ciencia y Tecnología (SICYT) hacia $2013,{ }^{11}$ así como cuatro acciones colectivas organizadas: la fundación de la Cámara Nacional de Industria Electrónica, de Telecomunicaciones y Tecnologías de la Información sección Occidente (Canieti-O) en 1992,12 y la creación

${ }^{9}$ Aunque no se profundizará en esta, se proporcionan datos distintivos. El cTs inicia operaciones en Guadalajara el 14 de noviembre de 1988, después de que el gobierno federal, a través de la Secretaría de Fomento y Comercio Industrial (Secofi), y la empresa IBм logran llegan a acuerdos luego de dos años de pláticas y negociaciones entre 1984 y 1986 (entrevista con Juan Milton Garduño Rubio, octubre de 2013). Y es que en el marco de la Ley para Promover la Inversión Mexicana y Regular la Inversión Extranjera se establecía que ninguna empresa extranjera podría ser dueña de $100 \%$ del capital, sino en proporción de $51 \%$ nacionales y $49 \%$ extranjeros (entrevistas con José Luis Leyva Montiel, octubre de 2013, y Juan Milton Garduño Rubio, octubre de 2013), por lo que las empresas de capital extranjero se vieron obligadas a crear empresas de coinversión con socios nacionales.

${ }^{10} \mathrm{Hacia}$ la década de los noventa, en México existían solo cuatro consejos estatales de ciencia y tecnología, y al final de esa década se habían sumado otros diez. Entre esos primeros consejos aún no figuraba el de Jalisco, que se fundará hasta 2000 con características distintivas muy claras en su origen y constitución. Primera característica distintiva: la Ley de Fomento; el Coecytjal se creará en el marco de la primera ley en ciencia y tecnología a nivel estatal en el país. Segunda característica distintiva: la visión de desarrollo económico y social; el Coecytjal pone el acento en el desarrollo económico y social, por lo que será un oPD sectorizado, hasta 2014, a la misma Secretaría de Promoción Económica (Seproe) del estado de Jalisco y no a la Secretaría de Educación Pública como varios actores sociales pensaban que debía ser. Tercera característica distintiva: la integración tripartita del Coecytjal incluyendo a los representantes de los sectores industrial y empresarial, así como a la academia y el gobierno en sus diferentes niveles.

11 Junto con Morelos, la Ciudad de México y Yucatán, Jalisco es el cuarto estado que cuenta con una secretaría dedicada a los temas de innovación, ciencia y tecnología de la entidad, pero Jalisco es la única entidad de la República Mexicana que tiene a la vez un Consejo Estatal en Ciencia y Tecnología, que data desde la Ley de Fomento a la Ciencia y Tecnología de 2000, y una Secretaría de Innovación, Ciencia y Tecnología, que fundó el gobierno priista en 2013.

${ }^{12}$ Los orígenes formales de la Canieti de Occidente se hallan en la entonces Cámara Nacional de la Industria Electrónica y de Comunicaciones Eléctricas (Caniece) creada en 1957 a nivel nacional; hacia 1997 esta se transformó en la Cámara Nacional de la Industria Electrónica de Telecomunicaciones e Informática (Canieti) y en 2007 adoptó su nombre actual de Cámara Nacional de Industria Electrónica, de Telecomunicaciones y Tecnologías de la Información, pero conservando sus siglas [Palacios, 2008: 34]. La Canieti de Occidente se funda formalmente en 1992; sin embargo, en ese primer momento solo incluye al estado de Jalisco, después abarcará toda la región occidente de México, que comprende hoy día los estados de Nayarit, Aguascalientes, 
de la Cadena Productiva de la Industria Electrónica (Cadelec) en $1998,{ }^{13} \mathrm{el}$ Instituto Jalisciense de Tecnologías de la Información (Ijalti) en 2002, ${ }^{14}$ aunque es hasta 2006 que se echa a andar, y la Ciudad Creativa Digital (CCD) en $2012^{15}$ pero que inició en 2013.

Ante la ausencia de un gobierno con características verticales y centralizadoras como las del Estado benefactor, la noción de acción colectiva amplía su significado: deja de ser una noción exclusiva para dar cuenta de los "movimientos sociales" y adquiere centralidad en el análisis de las organizaciones. Las relaciones entre los actores heterogéneos y diversos se decantan en acciones colectivas organizadas (ACO) o asociaciones mediadas por procesos de aprendizaje institucional, que a su vez les permiten generar y transmitir conocimientos, mismos que fortalecen las ACO; así mismo, cada Aco puede analizarse como una asociación compleja en sí misma. Desde esta perspectiva, las políticas públicas son el resultado de la participación de diversos actores por medio de las ACO, no solo del gobierno o de los sectores económicos, aunque sea de alguno de estos de donde provenga la iniciativa; la acción del gobierno (AG) se considera parte de las ACO.

Colima, Michoacán, Guanajuato y Jalisco. Será una de las primeras delegaciones fuera del centro del país. Originalmente, las primeras empresas que fundan la Caniece en Jalisco son en su mayoría trasnacionales estadounidenses, todas aglutinadas en la American Chambers of Commerce (Amcham, Cámara Americana de Comercio).

${ }^{13}$ La Cadena Productiva de la Industria Electrónica, A. C. (Cadelec) se fundó en 1997-1998 como una asociación civil cuya principal misión ha sido desarrollar la cadena de suministro de la industria electrónica instalada en Jalisco, creando y atrayendo proveedores locales, nacionales o internacionales [Palacios, 2008]. En su constitución participaron el gobierno de la entidad, así como IBM, Intel, HP, Jabil Circuit y Natsteel con fondos del Programa de Naciones Unidas para el Desarrollo (PNUD) y la gestión de la Fundación Mexicana para la Innovación y Transferencia de Tecnología en la Pequeña y Mediana Empresa (Funtec) de la Concamin. Además, nace en el contexto en el que al no estar obligados los empresarios a pertenecer a alguna cámara, estas se ven obligadas a cambiar sus estrategias de afiliación y una de ellas es la prestación de servicios, como la propia Funtec ya lo hacía.

${ }^{14}$ Haciendo una analogía, así como la Cadelec se convirtió en un brazo muy importante de Canieti-O con apoyo del gobierno estatal, el Instituto Jalisciense de Tecnologías de la Información (ljalti) se convirtió en un brazo ejecutor del Coecytjal con el apoyo de la industria y la academia, y por ello mismo nace ya con una autonomía política relativa mayor que la de la Cadelec. El ljalti nace en el contexto de la necesidad local de cambiar la industria hacia la estrategia del high value, low volume, pero también en la transición entre el final del gobierno de Alberto Cárdenas y el inicio del de Francisco Ramírez.

${ }^{15}$ En 2011, Guadalajara, Jalisco, compite contra otras ciudades mexicanas para albergar el proyecto y convertirse en la CCD de México; finalmente, el 30 de enero de 2012 es declarada sede de la CCD por el entonces presidente de México, Felipe Calderón Hinojosa. El objetivo fue detonar la industria creativa y multimedia articulándola con las industrias que ya existen en la entidad. Sin embargo, a modo de ver de algunos directivos de la industria, este se ha ido complejizando conforme se integran nuevos elementos. El proyecto en sí no solo busca detonar la industria, sino integrar a la ciudad "rescatando" el centro de Guadalajara. 
Diagrama 1. Periodización de las acciones colectivas organizadas y acciones gubernamentales que han configurado el SGTC anclado al SE-IT

\section{Despliegue y dinámica mundial del Sector Electrónico-Informático y de las Telecomunicaciones}

$\left.\left.\left.\begin{array}{l}\text { Despliegue } \\ (1980-2000)\end{array} \quad \begin{array}{c}\text { crisis dot } \\ \text { com } \\ (2001-2002)\end{array}\right\rangle \begin{array}{c}\text { Reestructuración } \\ (2002-2004)\end{array}\right\rangle \begin{array}{c}\text { Articulador y } \\ \text { dinamizador de la } \\ \text { economía } \\ (20008-2009)\end{array}\right\rangle$

Adopción e integración a traves de la Vía alterna de desarrollo nacional neoliberal en México

\section{Asentamiento y dinámica del SEIT en Jalisco}

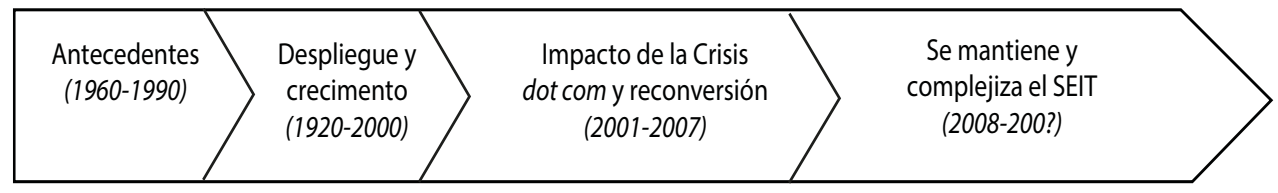

Adopción e integración a través de una Sub-vía de desarrollo nacional asociativa para la Configuración del Sistema de Generación y Transferencia de Conocimientos ancado al SEIT en Jalisco

\section{Inicia Configuración del Sistema (fines de la década de 1980 e inicios de 1990)}

Creación del CTS* (1988)

Creación de la Conieti-o (1992)

Creación de la Cadelec (1998)

\section{Configuración acelerada del Sistema (década del 2000)}

Creación del Coecytjal* (2000)

Creación del ljalti (2002)

Puesta en marcha de ljalti (2006)

Declaración de Guadalajara como

la CDD (2012)

\section{Configuración desacelerada} del Sistema (de 2013)

Creación de la Sicyt* (2013)

Puesta en marcha de la CCD (2013)

* Son acciones o resultados de acciones gubernamentales a nivel federal o estatal y, aunque no son actividades colectivas organizadas, se consideran en el estudio por ser acciones que han influido en la configuración del sistema y en relación directa con las actividades colectivas organizadas. Fuente: elaboración propia. 
La organización se define como una dimensión de la acción colectiva [Puga y Luna, 2008: 9-10] y las asociaciones como formas de acción colectiva organizada [Puga, 2005: 72], mismas que podrían definirse como un tipo de "arreglo social basado en una membresía libre que se coordina para el logro de ciertos objetivos" [Tirado, 2010: 22], y cuya forma de organización y toma de decisiones tienden a ser horizontales. Entre sus características destacan: a) los criterios flexibles de membresía por los que los participantes son heterogéneos con niveles significativos de diferenciación, b) los participantes son autónomos, c) pero los recursos son interdependientes, d) la distribución de la autoridad es dinámica y depende de la confianza y el prestigio, y e) existe una definición y redefinición de objetivos y metas que pueden ser conflictivas.

A continuación se presentan los casos de diferentes ACO y AG que están relacionadas directamente con el sEIT instalado en Jalisco.

En principio, la ACO se explica aquí por la ausencia de un gobierno con características verticales y centralizadoras como las del Estado benefactor, así como por la debilidad competitiva de los capitales locales y nacionales. Su función, para el caso de Jalisco, ha sido capitalizar tanto el proceso de aprendizaje tecnológico y organizacional como los conocimientos depositados en el personal de las ET y desatar procesos de aprendizaje institucional.

Los mecanismos de cohesión y comunicación de las ACo han sido la traducción, la confianza mutua y el liderazgo asociativo, que se acompañan de procesos de decisión mediados por la negociación y la deliberación racional.

\section{Mecanismos de comunicación y cohesión de las ACO}

La traducción puede definirse como la capacidad, ya sea individual o de la propia organización, para facilitar la comunicación y la comprensión entre individuos de diferentes organizaciones y generalmente tiene un papel importante en la colaboración [Luna y Velasco, 2003: 230]. Los factores que afectan la comunicación son desfases tanto en el lenguaje como en las orientaciones cognitivas, los intereses y las lógicas organizacionales, por lo que los niveles de operación de los traductores son: conocimientos, códigos, intereses, relaciones entre disciplinas y lógicas organizacionales. 
La Canieti-O se identifica en este caso como el primer espacio de traducción de diferentes actores relacionados directamente con el SEIT, de ET antagónicas en el mercado mundial, pero que cooperan en el ámbito local, de la academia y las empresas para formar recursos humanos, y del gobierno con las empresas y la academia para generar soluciones para la industria. También como organización traductora se encuentra la Cadelec, que ha sido el espacio de contacto entre las ET y las empresas locales, y de estas con el gobierno, cuyo periodo de mayor apogeo fue la primera década del siglo xxi. Por su parte, el Ijalti fue la respuesta de los actores del SEIT para anticiparse a la crisis del dot com y para crear mayor valor agregado local; su vinculación con el gobierno y la academia ha sido más evidente sobre todo con la creación del Consejo Estatal de Ciencia y Tecnología de Jalisco (Coecytjal) que, a pesar de ser un opD del gobierno, su organización hace posible el encuentro y el diálogo entre representantes de distintos sectores.

En los casos de las ACo estudiadas, se ha encontrado que los puestos en las direcciones generales son ocupados por personas que se han desempeñado en diferentes organizaciones, no solo de la industria, sino del gobierno y de la academia relacionada con el SEIT, lo cual facilita el conocer-quién a nivel de las SEIT, ya que cuentan con conocimiento e información acerca de "quién conoce qué” y "quién conoce cómo hacer qué” para llevar a cabo las propias acciones. La función de traducción de las ACO ha jugado un papel importante en el proceso de aprendizaje institucional.

La confianza mutua se define como el conjunto de las expectativas positivas sobre las acciones de los demás [Luna y Velasco, 2005: 129] y es compleja porque combina tres dimensiones o tipos: la calculada o estratégica, la del prestigio o capacidades y la personal o normativa.

La confianza mutua calculada o estratégica surge de estimaciones de costos y beneficios que la relación puede generar y que se originan en la interdependencia de los recursos [Luna y Velasco, 2005: 137]. Las ET del seIT se asocian a partir de la necesidad de generar condiciones más óptimas y competitivas para la industria local en el mercado global, tanto para realizar trámites administrativos que agilicen los procedimientos de importación/exportación, y seguidamente, allegarse recursos humanos calificados que el conjunto de la industria requiere, como para generar en conjunto volúmenes de demanda de insumos para atraer a grandes proveedores y 
con ellos IED. La confianza mutua calculada o estratégica es un impulso para que las ACo de la industria se lleve a cabo, como en el caso de la Canieti-O e incluso de la Cadelec; sin embargo, cuando los actores que participan provienen de diferentes sectores sociales, como es el caso del Ijalti y del proyecto de $\mathrm{CCD}$, la heterogeneidad de recursos de intercambio se incrementa y dificulta el cálculo de las pérdidas y las ganancias de los participantes en la interacción, lo cual eleva los costos de la negociación; por ello se requiere el papel de traductores para llegar a acuerdos, que en este caso se han identificado con los directivos de las ET que ocupan las presidencias de los consejos directivos, así como los propios directivos generales de dichas ACO.

Confianza mutua por prestigio o capacidades se refiere a la percepción acerca de las capacidades y competencias, así como del prestigio de los participantes, ya sean individuos u organizaciones [Luna y Velasco, 2005: 137]. Este tipo de confianza cobra importancia a partir del desempeño que cada una de las organizaciones -ya sean las mismas ET, organismos del gobierno o instituciones de educación superior (IES) - ha tenido en las mismas ACO, pero también estas últimas han generado ese tipo de confianza mutua con los participantes. Los resultados de las actividades que la Canieti-O se ha propuesto la colocan como un referente para los diferentes actores del SEIT; tal ha sido el caso del Ijalti, la Cadelec e incluso el Coecytjal. En cambio, el retraso en el proyecto de CCD ha mermado las expectativas positivas que la industria ha depositado en el gobierno.

Finalmente, la confianza personal o normativa se basa en normas, creencias y valores compartidos [Luna y Velasco, 2005: 138]. En el caso de Jalisco, esta dimensión es resultado de las interacciones basadas en la confianza mutua estratégica y por prestigio. Para los diversos actores relacionados con el SEIT, ya provengan de la industria, el gobierno o la academia, ha sido importante expresar en cada una de las ACO en que participan que el sector es lo más importante, por lo que entre más crezca y genere mayor valor agregado está bien para todos los participantes.

La relación entre la confianza mutua y la traducción es inversamente proporcional: a mayor confianza es menor la necesidad de traducción, y viceversa, a menor confianza, los requerimientos de la traducción son mayores. Esta relación se ha comprobado para las diferentes ACo. Mientras la Canieti-O no ha requerido traducción porque la confianza mutua entre 
los participantes se ha retroalimentado desde sus orígenes en Jalisco, en el proyecto de CCD han intervenido actores de diversos sectores para recuperar la confianza mutua entre los participantes.

En cuanto al mecanismo de cohesión por medio del liderazgo asociativo, no se basa principalmente en las leyes ni en la tradición ni en las supuestas cualidades personales del líder, sino en atributos menos tangibles pero con la misma importancia: el conocimiento de las personas y de los asuntos de que se trate, la iniciativa en los procesos de deliberación y negociación, las relaciones interpersonales e interinstitucionales, la capacidad de "traducción" y la habilidad para inspirar confianza [Velasco, 2014: 227]. Este tipo de liderazgo es el que han ejercido los diferentes directivos de las ET tanto al interior de la Canieti-O como en el resto de las ACO. La presencia de estos directivos en la Cadelec, así como en el Ijalti, el proyecto de la CCD y el propio Coecytjal ha posibilitado la colaboración con el gobierno de la entidad y con los actores provenientes de las IES.

Las ACO son espacios de comunicación constante cuyo principal recurso estratégico ha sido conocer-qué, conocer-por qué, conocer-cómo y conocerquién [Casas y Dettmer, 2008; Foray y Lundvall, 1998] en las dinámicas del mercado mundial para identificar restricciones, pero también para proponer posibles soluciones. Aunque los mecanismos de la confianza mutua, la traducción y el liderazgo asociativo han recaído principalmente en las funciones que los directivos y ejecutivos de las ET ejercen en el conjunto de los actores en cada una de las ACO, también ha sido nodal el accionar del Gobierno mediante el Coecytjal para involucrar a los actores de la academia e incluso de la industria tradicional de la entidad. El Coecytjal proyectó una política pública que consideró el SEIT como eje central de la política de ciencia y tecnología para proponer una articulación de la ciencia y tecnología con el desarrollo industrial de la entidad.

\section{Procesos de decisión de las Aco}

Como parte de los mecanismos de cohesión también se vislumbran los procesos de decisión, que están relacionados directamente con las características de las ACo en cuanto a que los participantes son heterogéneos y autónomos, pero los recursos son interdependientes; que la autoridad se 
determina por la confianza y el prestigio; que hay una redefinición constante de objetivos y metas; y que las decisiones tienden a tomarse en colectivo y por consenso.

En los casos presentados, las ACo tienen espacios colectivos para tomar decisiones. Los consejos directivos o asambleas generales son la norma en cada una de las ACo; aun los organismos del gobierno como el Coecytjal y la propia SICYT cuentan con espacios colectivos para la toma de decisiones y la consulta. Con excepción del consejo directivo de la Canieti-O, en el resto de espacios colectivos de decisión participan al menos representantes del gobierno y la industria, como en la Cadelec, y representantes de la academia, como el Ijalti, la CCD, el Coecytjal y la sicYT. La Canieti-O se desempeña en los consejos del resto de las ACO y las AG.

Luna y Velasco [2017] hablan de la actuación combinada de la negociación y la racionalidad deliberativa para tomar decisiones colectivas. La negociación es un proceso de compromisos, mientras que la racionalidad deliberativa es un proceso de convencimiento mutuo. El objetivo de la negociación es generar compromisos entre intereses en conflicto, pero interdependientes, por lo que los involucrados están más interesados en buscar compromisos que en diluir la relación, pero no hay reglas que resuelvan el conflicto de intereses. Por otro lado, la racionalidad deliberativa "se refiere al intercambio racional de argumentos para llegar a decisiones y soluciones razonables" [Luna y Velasco, 2009: 93]. El objetivo principal del proceso es convencer a los participantes, por lo que supone la definición colectiva de sus preferencias y los intereses estarán determinados por el debate.

Se ha encontrado que en los inicios de las ACO en las que el gobierno participa se efectúan con mayor frecuencia procesos de negociación. Por ejemplo, cuando el Ijalti se puso en marcha era importante hacer ver al gobierno que para lograr los financiamientos no se trataba de un organismo ni de la industria ni del gobierno; lo mismo sucede con la CCD, cuyos recursos económicos que la federación aportaría se condicionan al desarrollo mismo del proyecto. En estos dos casos, la industria igualmente aporta recursos financieros o en especie para llevar a cabo la colaboración. Los procesos de negociación del gobierno y la academia también tuvieron lugar cuando se fundó el Coecytjal para que este organismo no fuera 
sectorizado a la Secretaría de Educación sino a la de Promoción Económica de aquel entonces.

Pero una vez que las Aco están funcionando y que los consejos directivos se han establecido, los procesos de racionalidad deliberativa encuentran el marco de acción para llevarse a cabo. El cabildeo antes y después de las sesiones es importante, lo mismo que los espacios informales para compartir información. Destacan los eventos como el congreso anual de la Canieti-O, al que se convoca a todos los actores relacionados con el SEIT, ya sean de la academia, la industria y el gobierno. Los eventos que cada uno de los organismos organiza con la diferente participación de los actores también son importantes, como en su caso fue la Provelec organizada por la Cadelec y en la actualidad el Campus Party y el ITalent organizados por la SICYT. Todas las actividades formales de los consejos directivos y los eventos requieren tiempo y recursos para transmitir la información y llevar a cabo la discusión; se trata de costos que asumen cada una de las ACO para tomar las decisiones.

\section{LA DISCUSIÓN TEÓRICA QUE SE EXTRAE DEL CASO}

Desde una perspectiva de gobernanza de cadenas globales de valor [Gereffi et al., 2005], la experiencia del sector electrónico-informático y de las telecomunicaciones instalado en Jalisco se observa relativamente exitosa si se consideran los indicadores básicos de IED, el crecimiento de los empleos calificados y las remuneraciones. El aprendizaje institucional en materia de asociación que la experiencia arroja se interpreta como estrategias asociativas que dieron lugar a escenarios de ganar-ganar más allá del ámbito empresarial e involucran a actores gubernamentales, educativos y de la sociedad civil, lo que amplía las posibilidades de externalidades positivas.

De acuerdo con los datos que caracterizan la economía de Jalisco y la temporalidad en la que las ET en la rama se asentaron, se asevera que fue gracias a las características del territorio, la mano de obra y el entorno institucional que la posibilidad de inversión se abrió en primera instancia [Palacios, 2008]. Con base en la conceptualización de integración y up grading [Fernández-Stark y Gereffi, 2011; Gereffi y Hernández-Stark, 2016], lo anterior se interpreta como un entorno local que desarrolla 
potencialidades para generar vínculos estratégicos con las empresas líderes de la cadena de valor [Gereffi, 2001].

En esta línea de pensamiento, concentraremos la discusión en dos aspectos: primero, la construcción del proceso asociativo y su influencia en el diseño de la política pública para la entidad, y, segundo, la funcionalidad de las Aco para llevar a cabo la integración y el up grading.

\section{Estrategia asociativa para formular políticas públicas}

La experiencia en Jalisco destaca diversos elementos en términos de esta versión de Estado asociativo propio de la apertura comercial y los procesos de desindustrialización-industrialización funcional a los capitales extranjeros de los países desarrollados [Sturgeon, 2011], en México, particularmente estadounidenses.

La dimensión local de la estrategia de up grading resalta la importancia de las instituciones y los tomadores de decisiones, los cuales deberán ser capaces de identificar las restricciones de lo local en orden de desarrollar acciones que, superando dichas restricciones, puedan aprovechar las ventajas en el entorno global [Gereffi, 2001; Gereffi et al., 2005; Gereffi y HernándezStark, 2016]. A este respecto, los tomadores de decisiones no son actores predeterminados como agentes del gobierno; para el caso de Jalisco, se ha tratado de un conjunto de actores provenientes de distintos sectores sociales pero relacionados con las actividades económicas del sEIT que han influido en las políticas públicas por medio de ACO, siendo estas a la vez producto de las políticas públicas.

\section{Disminución de costos de transacción para la integración funcional trasnacional}

Las ACo han impulsado un entorno institucional local que en principio ha minimizado costos de transacción y coordinación relativos a la importación y exportación de bienes. La Canieti-O, formada por los principales directivos de las ET occidentales ubicadas en Jalisco, incorpora los intereses del capital nacional en la estrategia de las firmas trasnacionales mediante la participación del gobierno en los distintos niveles y las asociaciones empresariales locales. 
La política económica que observa la IED como motor de crecimiento económico y empleo se impone también en el seit en Jalisco. Lo local, con objeto de sobrevivir a la competencia global gestada en México entre los países asiáticos y Estados Unidos, se adhiere a las redes de proveeduría en una estrategia seguidora en la que como condición necesaria para competir debe integrarse a partir del cumplimiento de estándares internacionales en segmentos maduros de la cadena de valor [Sturgeon y Memedovic, 2011; Kawakami y Sturgeon, 2010; Sturgeon, 2011].

La asociación entre los actores, mediada por la Canieti-O, con la Cadelec, el Ijalti y luego la CCD, persigue en este contexto la conformación de una red que incorpora la generación de conocimiento local producido por universidades y cámaras, y aprovecha dicho conocimiento gracias a una estructura de reglas derivada de la relación de los actores, que no solo posibilita la explotación de dicho conocimiento sino que facilita los canales de comunicación y aprendizaje institucional, diseñando localmente una estrategia a partir de la cual las ET compiten globalmente.

Es importante destacar que la red local organizada por las firmas extranjeras incorpora, al mismo tiempo que autonomiza, la lógica de la política local. La asociación con el gobierno local y estatal expresa el interés del capital trasnacional por el territorio (ubicación geográfica), el marco institucional (reglas favorables a la reducción de costos en las transacciones comerciales internas y externas) y la mano de obra (a costo medio y susceptible de capacitar). Lo anterior se persigue en la medida en que la disciplina gubernamental local no interfiera con la estrategia global de competencia del segmento de la cadena de valor establecido en México, pero sí sume condiciones favorables.

La estrategia de reducción de costos totales (de producción y circulación, de transacción y coordinación) de las ET organiza, en el marco de las ACO, el entorno local como proveedor de espacio, conocimiento y mano de obra en un contexto regulatorio funcional a la reproducción del segmento de la cadena de valor en la que están insertas; la cooperación en este sentido no abre posibilidades de competencia entre capitales locales y extranjeros, sino de cooperación funcional en términos de que es el capital trasnacional el que ostenta el acceso a los flujos globales e "invita" a los actores locales a sumar esfuerzos en estrategias horizontales que arrojan, sin embargo, diversos grados de acceso y distribución inequitativa de los beneficios. 
Lo anterior encuentra limitantes. Después de la crisis del dot com aterrizaron en Jalisco las grandes contract manufactures proveedoras de las original equipment manufacturing (OEM) y original desing manufacturing (ODM) [Figueroa, 2019]. Las grandes proveedoras coartan la posibilidad de generar encadenamientos locales, pero también la propia dinámica de convergencia tecnológica del patrón industrial del SEIT en la competencia global obliga al sector a buscar ubicarse en segmentos de mayor valor agregado.

La estrategia asociativa de los directivos mexicanos de las ET ubicadas en México capitaliza las ventajas geográficas, institucionales y de mano de obra, con una mayor integración de los actores locales en la gestión del segmento productivo, y aunque ello ha generado derramas de conocimiento para los actores locales, esto no significa que el sector electrónico de Jalisco ofrezca evidencia de una vía distinta a los mecanismos de integración de la industria automotriz y aeroespacial, entre otras, que se identifican, como la electrónica, como los principales renglones exportadores, sin detonar encadenamientos productivos significativos con las empresas mexicanas.

\section{ESTADO ASOCIATIVO Y APRENDIZAJE INSTITUCIONAL}

Como se ha visto, los conocimientos y aprendizajes han sido fundamentales para activar tanto los mecanismos de cohesión y comunicación como los procesos de decisión de las ACo. En este sentido, los conocimientos son recursos fundamentales en las transacciones y colaboraciones entre los actores de las diversas ACO y los procesos de aprendizaje no se restringen al tecnológico y organizacional, sino que han sido a nivel institucional, lo cual da pauta para reconfigurar las relaciones entre los actores ya presentes en la fase del capitalismo fordista-keynesiano como el gobierno, las IES o la industria transnacional.

Los conocimientos a los que se ha hecho referencia interactúan entre sí, no son exclusivos del conocimiento científico, ni tampoco de la esfera de producción económica, sino que se generan en distintos sectores y ámbitos de la vida social; incluso puede tratarse de conocimiento tácito o de conocimiento explícito. Además, su proceso de aprendizaje, por el cual se transfiere y adquiere, ocurre por diferentes canales. 
El conocer-qué y el conocer-por qué son conocimientos más relacionados con el conocimiento explícito, codificado, que se adquiere de textos, bases de datos, etc., y que pueden ser contenidos en organizaciones prediseñadas para su producción y reproducción como las universidades y los centros de investigación. En Jalisco, la renovación de los planes y programas de estudios de las IEs ha corrido a cargo de cada una de ellas, pero la industria ha buscado influir en los contenidos desde la fundación de la Canieti-O. El impulso más fuerte vino con la creación del Coecytjal, la puesta en marcha del Programa Estatal de Ciencia y Tecnología de Jalisco (Pecytjal) 2001-2007 y en fecha reciente con la Red de Tecnológicos Mario Molina. Sin embargo, también se ha requerido producir ese tipo de conocimiento en las ACO, por lo cual ha sido exclusivo de las IES. En términos concretos, la Canieti-O y la Cadelec conocen-qué y cómo en el SEIT mundial, lo que les ha servido para actuar localmente en conjunto con el Coecytjal y después con la sicYT.

El conocer-cómo y el conocer-quién se adquieren en la práctica de la peculiar relación aprendiz-maestro o en la práctica cotidiana del aprender-haciendo o aprender-interactuando. Estos dos tipos de conocimiento están más relacionados con el conocimiento tácito o implícito. En particular conocer-quién, cuándo y dónde ha sido de nuestro particular interés analítico porque este tipo de conocimiento mezcla diferentes clases de habilidades, incluidas las sociales, requiere el conocimiento de diferentes disciplinas y tener acceso a las diferentes fuentes de conocimiento e información acerca de "quién conoce qué" y "quién conoce cómo hacer qué" [Foray y Lundvall, 1998: 116]; además, este tipo de conocimiento necesita de la habilidad para cooperar con diferentes tipos de personas y expertos, con un alto componente de conocimiento tácito. Conocer-quién combina información y relaciones sociales, por ello tiene una relación cercana con la función del traductor; este conocimiento implica no solo conocer quién posee el conocimiento específico para qué, sino también cómo obtener "traducciones" [Luna y Velasco, 2017: 139]. Este último tipo de conocimiento ha sido clave para llevar a cabo cada una de las ACO; consideramos que es el conocimiento que ha permitido la colaboración entre actores heterogéneos y que ha posibilitado, a su vez, los procesos de aprendizaje institucional.

En cuanto al aprendizaje, es el proceso por el cual se adquiere conocimiento, asimilándolo y estructurándolo, por lo que está condicionado al 
tipo y la complejidad del mismo [Rivera y Caballero, 2003: 14-15]. En ese sentido, el concepto de aprendizaje institucional resulta de utilidad para comprender la relación entre el conocimiento y las implicaciones que tiene para la reconfiguración de relaciones.

Además, consideramos que la institución proporciona continuidad y estabilidad al comportamiento colectivo, pero también al individual, como "el control colectivo de la acción individual" [Commons, 1931 citado por Johnson, 1992: 25] y como "hábitos de uso y costumbre" y "hábitos de pensamiento" [Veblen, 1919, citado por Johnson, 1992: 25]. La institución, por lo tanto, sería la "consecuencia del hábito" que guía el comportamiento individual en sociedad. De allí que se defina como el conjunto de hábitos y rutinas, reglas, normas y leyes que regulan las relaciones entre las personas y dan forma a la interacción humana, reducen la incertidumbre y dotan de la información necesaria para la acción colectiva e individual [Johnson, 1992: 25-27].

En el caso de Jalisco, los directivos de las ET han sido portadores de conocimientos de distintos tipos que les han permitido desatar procesos de aprendizaje institucional en diferentes ámbitos y niveles.

La naturaleza y la dinámica económica misma de SEIT impele a los directivos de las ET a diseñar estrategias en las que, en primer lugar, no considera como competencia los capitales nacionales mexicanos sino que, en el marco de disputa de los mercados internacionales, los capitales locales, grandes y pequeños son incorporados a la estrategia global de la reproducción de la IED en la entidad, en segmentos de proveeduría y en menor medida de diseño, así como a la propia reconversión industrial de la ET asentadas hacia actividades de mayor valor agregado. Por tanto, las relaciones al interior de la Canieti-O no están en función del capital y la influencia que cada dueño de empresa tiene, como pudo haber sido en la fase del capitalismo fordista-keynesiano, sino en función del conocimiento y recursos (IED, creación de empleos) que los directivos de empresa pueden generar para el sector y que, como consecuencia, pueden prometer al gobierno para conseguir su apoyo.

Este tipo de relaciones entre las empresas del SEIT se traslada a las siguientes ACO, como la Cadelec y el Ijalti. Modificar esas relaciones entre empresas y de ellas con el gobierno y las IEs es lo que denominamos aprendizaje institucional. Dejar de actuar de forma exclusiva por las ganancias de 
la empresa individual sino por la generación de los múltiples recursos del SEIT en conjunto implica cambiar las maneras de pensar de cada actor individual; requiere comprender que no se está trabajando en exclusiva para una empresa o para el gobierno o para alguna IEs, sino que al participar en cada ACo se es parte de una colectividad mayor. Por ejemplo, un actor es director de IBM pero también vicepresidente de Canieti-O y a la vez forma parte del consejo directivo de la Red de Tecnológicos Mario Molina.

Como correlato encontramos, después del primer lustro del sigo XXI, la incorporación de las necesidades de la estrategia trasnacional al diseño de política, en particular la conducción del desarrollo de la ciencia y la tecnología, así como el proyecto de la CCD, los cuales contribuyen al desarrollo competitivo de las redes de cooperación de capitales locales y trasnacionales en la estrategia global.

La experiencia de Jalisco como estrategia de aprendizaje institucional destaca claramente la introducción de nuevos actores en el diseño y la conducción de la política y acciones económicas tanto de los actores públicos como privados. La entrada de capitales extranjeros en el periodo de apertura rompe la relación tradicional entre los empresarios nacionales, el gobierno y los partidos políticos no solo para ampliar el número de actores que definen el entorno institucional actual, sino para ceder el liderazgo a los actores de las ET.

La asociación formalizada en cámaras y otras organizaciones, en participación con el gobierno, otorga a la estrategia una dimensión pública en la que el objetivo micro y mesoeconómico del capital transnacional, que está situado en la competencia global, adquiere un tono de "política pública" que "traduce" el interés individual en colectivo. En este sentido, el sGTC creado como resultado de una estrategia de asociación podría invisibilizar relaciones de poder entre los actores al concentrarse en la horizontalidad de la cooperación local, evitando observar la capitalización desigual de los resultados de dicha cooperación.

El aprendizaje institucional que explica la naturaleza asociativa del Estado para el caso del sEIT en Jalisco debe atender las diferencias en el análisis que implica la dimensión del SGTC versus la estrategia de segmento en la cadena global, las cuales si bien son complementarias, como en el caso que nos ocupa, no necesariamente superan las relaciones de 
subordinación entre el capital local-no integrado, desarrollándose en industrias maduras, y el capital trasnacional.

\section{CONCLUSIONES}

Este capítulo se ha enmarcado en la fase del capitalismo del conocimiento, cuyo tipo de Estado heredado de la fase anterior, el capitalismo fordistakeynesiano, es impotente ante los cambios que la actual fase implica.

Por lo anterior, dentro de la vía de desarrollo neoliberal que ha seguido México desde hace 40 años, se estudia el caso de Jalisco como un ejemplo de reconfiguración de las relaciones del Estado nacional, considerando que es una entidad en la que se asientan las ET propias del patrón industrial del capitalismo del conocimiento desde las décadas de los sesenta y setenta, el SEIT, y sus efectos políticos en la formulación de políticas públicas para la entidad.

Se ha expuesto que, gracias a la subvía regional sustentada en la corriente empresarial "liberal-crítica", en Jalisco se han impulsado cuatro ACO, mismas que han ido configurando el SGTC que se ancló al mismo despliegue y dinámica mundial del SEIT. La primea acción fue la Canieti-O, que aglutina las empresas del SEIT; seguida de la Cadelec, una asociación entre estas empresas y el gobierno; luego el Ijalti, que incorpora las IES con el objetivo de impulsar el sector de tecnologías de la información y comunicación y software; y por último el proyecto de CCD, el cual se inscribe dentro del intento de desarrollar elementos de la industria 4.0. Estas ACO se han acompañado de acciones gubernamentales como el Coecytjal y la SICYT, que han intentado trascender los cambios del SEIT a sectores económicos tradicionales de Jalisco y la sociedad. Cada una de las ACO representa un salto en la convergencia tecnológica que ha implicado el SEIT a nivel mundial y es una respuesta a las dificultades en el mercado global.

Se ha argumentado que las ACo han sido funcionales a la integración y el up grading al reducir los costos de transacción que las CGV implican; esos costos se absorben mediante los mecanismos de cohesión y comunicación de las ACo. La confianza mutua, el liderazgo asociativo y la traducción permiten integrar las acciones individuales en actividades colectivas, 
cuyos procesos de decisión, mediante la negociación y sobre todo la racionalidad deliberativa, les dan continuidad.

Los mecanismos de cohesión y comunicación, así como los procesos de decisión tienen como recurso clave el conocimiento y sus diferentes tipos. El aprendizaje institucional se ha servido de ellos para cambiar las relaciones entre los actores individuales y colectivos tendiendo a conformar un tipo de Estado no vertical ni centralizado al que hemos denominado Estado asociativo.

El Estado asociativo expresa en gran medida las estrategias de competencia de los capitales trasnacionales, las cuales trascienden las fronteras de las firmas para incorporar espacios y fuerza de trabajo e incidir en el entorno institucional local como parte de una lógica interdependiente de acumulación, en la que el conocimiento compartido entre agentes dentro y fuera de la cadena de valor se construye como insumo de la estrategia transnacional, la cual presenta al interior del espacio local una lógica asociativa que se constituye como base de la competitividad y competencia en el espacio global.

En este trabajo, destacamos el nuevo papel de las formas de Estado y su relación con capitales nacionales y trasnacionales en la generación de conocimientos que a modo de pool alimentan estrategias microeconómicas de las firmas trasnacionales en una relación no disciplinaria entre Estado y capital en la que, sin embargo, la interdependencia es asimétrica en un contexto en el que la atracción de la IED es condición de "éxito" económico para los países en desarrollo.

El caso del SEIT en Jalisco, si bien expone estrategias asociativas en las que las firmas locales pueden participar del pool de conocimientos que los acerca al aprovechamiento de las oportunidades de integración y escalamientos a partir de vínculos estratégicos, no ofrece evidencia que nos permita concluir que las ACO presenten oportunidades que nivelen el terreno de juego disminuyendo las asimetrías y abriendo oportunidades de encadenamientos significativas en la cadena electrónica e informática global para las empresas mexicanas. 
Alba Vega, C. y D. Kruijt, D. [1988], Los empresarios y la industria de Guadalajara, Guadalajara, El Colegio de Jalisco.

Alonso, J. [1993], El rito electoral en Jalisco (1940-1992). Zapopan, El Colegio de Jalisco.

Campos, R. [s. f. ], Las alternancias en México, cronología.

Casas, R., y J. Dettmer [2008], "Sociedad del conocimiento, capital intelectual y organizaciones innovadoras", en G. Valenti, M. Casalet, D. Avaro (eds.), Instituciones, sociedad del conocimiento y mundo del trabajo. México, Flacso-México, Plaza y Valdés, pp. 21-59.

Chapa García, J. [2013], Política industrial en Jalisco 1989-2001. Guadalajara, Centro Universitario de Ciencias Sociales y Humanidades, Universidad de Guadalajara.

Commons, J. [1931], "Institutional Economics", en American Economic Review, núm. 21.

Conacyt [2006], Informe General del Estado de la Ciencia y la Tecnología. México, Conacyt.

Dabat, A. [1994], Capitalismo mundial y capitalismos nacionales I. México, Fondo de Cultura Económica-Facultad de Economía, UNAM.

Dabat, A. y S. Ordóñez [2009], Revolución informática, nuevo ciclo industrial e industria electrónica en México. México, Casa Juan Pablos-Instituto de Investigaciones Económicas, UNAM.

Fernández-Stark , K. y G. Gereffi [2011], Manual de Desarrollo Económico Local y Cadenas Globales de Valor. Durham, Center on Globalization, Governance \& Competitiveness (CGGC), Duke University.

Figueroa López, A. [2019], Valle del silicio mexicano. Pasado, presente y futuro de la industria jalisciense de alta tecnología. Guadalajara, Canieti Occidente-Coecytjal.

Foray, D. y B. A. Lundvall [1998], "The knowledge-based economy: from the economics of knowledge to the learning economy", en D. Neef, G. Siesfeld y J. Cefola, eds., The economic impact of knowledge. Boston, Oxford, Johannesburg, Melbourne, New Delhi, Singapore, Butterworth Heinemann, pp. 115-121.

Gereffi, G. [2001], "Las cadenas productivas como marco analitico para la globalización”, en Problemas del desarrollo, vol. 32, núm. 125, pp. 9-37. 
Gereffi, G. y K. Hernández-Stark [2016], Global Value Chain: A primer. Carolina del Norte, Center on Globalization, Governance and Competitiveness, Social Science Research Institute.

Gereffi, G., J. Humphrey y T. Sturgeon [2005], "The governance of global value chains", en Review of International Political Economy, vol. 12, núm. 1, pp. 78-104.

IMPI [2017], IMPI en cifras 2017. <www.impi.gob.mx>.

Inegi [2015], Encuesta intercensal. México, Inegi.

Johnson, B. [1992], "Institutional learning", en B. A. Lundvall, National systems of innovation. Towards a theory of innovation and interactive learning. Londres, Pinter Publishers, pp. 23-43.

Johnson, B. y B. A. Lundvall [1994], "Sistemas nacionales de innovación y aprendizaje institucional”, en Comercio Exterior, agosto, vol. 44, núm. 8, pp. 695-704.

Kawakami, M. y T. Sturgeon [2010], "Global Value Chains in the Electronics Industry”, en O. Cattaneo, G. Gereffi y C. Sataritz, Global Value Chains in a Postcrisis World. Washington, DC, World Bank.

Luna, M. [2004], "Business and politics in Mexico", en K. J. Middlebrook, ed., Dilemmas of political change in Mexico. Londres, Institute of Latin American Studies, University of London, pp. 332-352.

[2009], "Las redes de acción pública como sistemas asociativos complejos: Problemas y mecanismos de integración", en REDES-Revista hispana para el análisis de redes sociales, diciembre, vol. 17, núm. 4, pp. 76-99.

[2017], Complex associative systems. Cooperation amid diversity. México, unam, Instituto de Investigaciones Sociales, Centro de Investigaciones Interdisciplinarias en Ciencias y Humanidades.

Luna, M. y J. Velasco [2003], "El vínculo entre las empresas y las instituciones académicas: La función de traducción y el perfil de los traductores", en M. Luna, Itinerarios del conocimiento: formas dinámicas y contenido. Un enfoque de redes. España, IIs, Antrhropos, pp. 229-258.

Luna, M. y J. Velasco [2005], "Confianza y desempeño en las redes sociales”, en Revista mexicana de sociología, enero-marzo vol. 67, núm. 1, pp. 127-162. 
Messner, D. [1999], "Del Estado céntrico a la 'sociedad de redes'. Nuevas exigencias a la coordinación social”, en N. Lechner, R. Millán y F. Valdés Ugalde, Reforma del Estado y coordinación social. México, Plaza y Valdés Editores, Instituto de Investigaciones Sociales-UnAM, pp. 77-121.

Ordóñez, S. [2004], "La nueva fase de desarrollo y el capitalismo del conocimiento: elementos teóricos", en Comercio Exterior, enero, vol. 54, núm. 1, pp. 4-17.

[2017], "Ciclo industrial, bloque histórico y facciones de capital en México", en Ensambles, otoño-invierno, vol. 3, núm. 6, pp. 31-52.

Ordóñez, S. y R. Bouchaín [2011], Capitalismo del conocimiento e industria de servicios de telecomunicaciones en México. México, Instituto de Investigaciones Económicas, UNAM.

Ortiz Barba, I. [2014], "Los liderazgos priistas ante la transición”, en A. Arellanos Ríos, Jalisco en su transición política. Zapopan, El Colegio de Jalisco, pp. 121-136.

Palacios Lara, J. J. [2008], Alianzas público-privadas y escalamiento industrial. El caso del complejo de alta tecnología de Jalisco, México. México, Cepal.

Puga, C. [2005], "Una doble mirada a las asociaciones: perspectivas teóricas y la experiencia mexicana”, en B. Arditi, ¿Democracia post-liberal?: el espacio político de las asociaciones. España, Anthropos, pp. 71-106.

Puga, C. y M. Luna (eds.) [2008], Acción colectiva y organización: Estudios de desempeño asociativo. México, Instituto de Investigaciones Sociales-UnAM.

Rivera Ríos, M. y R. Caballero Hernández [2003], "Los sistemas de innovación nacionales y la teoría del desarrollo", en Problemas del Desarrollo. Revista Latinoamericana de Economía, vol. 34, núm. 134, pp. 9-31.

Sturgeon, T. [2011], "De cadenas de mercancías (commodities) a cadenas de valor: construcciones teóricas en una época de globalización”, en Eutopía. Revista de Desarrollo Económico Territorial, noviembre, núm. 2, pp. 11-38. <https://doi.org/10.17141/eutopia.2.2010.1027>.

Sturgeon, T. y O. Memedovic [2011], Mapping Global Value Chains: Intermediate Goods Trade and Structural Change in the World Economy. Development Policy and Strategic Research Branch. Working paper 05/2010. Viena, United Nations Industrial Development Organization. 
Tirado, R. [2010], "De la asociación: características y problemas", en M. Luna y C. Puga (eds.), Nuevas perspectivas para el estudio de las asociaciones. Barcelona y México, Anthropos-Instituto de Investigaciones Sociales-UnAM, pp. 15-40.

Valdez Zepeda, A. [1996], "La metamorfosis de un régimen petrificado. Un acercamiento propositivo al estudio del cambio y la transición democrática en Jalisco", en Espiral. Estudios sobre Estado y sociedad, mayo-agosto, vol. I, núm. 6, pp. 81-110.

Veblen, T. [1919], "The place of science in modern civilization", The American Journal of Sociology, 11(5): 585-609.

Velasco, J. [2014], "Líderes y liderazgo en los sistemas asociativos complejos”, en S. Gordon y R. Tirado (eds.), El rendimiento social de las organizaciones sociales. México, Instituto de Investigaciones Sociales, UNAM, pp. 219-244.

Wade, R. [1999], El mercado dirigido. La teoría económica y la función del gobierno en la industrialización del este de Asia. México, Fondo de Cultura Económica.

Wikipedia [2018], Cuauhtémoc Cárdenas Solórzano.<https://cutt.ly/Xd94 $\mathrm{MPu}>.17$ de septiembre de 2018. 


\section{MUTACIONES DEL ESTADO EN LA PERIFERIA: EL ANCLAJE DEL CENTRO-OESTE FORMOSEÑO ENTRE LOS AÑOS NOVENTA Y EL NUEVO MILENIO}

Ernesto Fabián Giuliano*

INTRODUCCIÓN

Formosa es una de las jurisdicciones subnacionales que integran la denominada periferia rezagada [Vaca y Cao, 2004] de la Argentina. Este grupo de provincias, además de distinguirse por "su bajo desarrollo relativo, sus indicadores de deterioro social y una aguda dependencia del Sector Público" [Vaca y Cao, 2004: 73], presenta la especificidad de mostrar un "despliegue de las economías regionales [de] importancia secundaria frente al peso de las actividades rurales de neta subsistencia o del accionar de la Administración Pública”. En ellas, además, "se observan corrientes migratorias hacia las áreas centrales y deterioro en la participación relativa en el PBI" [Vaca y Cao, 2004:75]. Así, la economía de Formosa se caracteriza por producir bienes provenientes de las actividades intensivas en recursos naturales y por transitar un acentuado proceso de tercerización de la estructura de empleo, una escasa industrialización y "dependencia” de la región central del país y una vinculación "subordinada" dentro de la matriz productiva nacional trazada a partir de grandes empresas nacionales y extranjeras [Schorr et al., 2012: 55]. Configura, en tal sentido, un caso palmario de "periferia extrema" dentro de la formación social argentina. ${ }^{1}$

* Doctor en Ciencias Sociales, maestro en Gestión Territorial y Desarrollo, licenciado en Economía. Docente e investigador de la Facultad de Administración, Economía y Negocios (FAeN) de la Universidad Nacional de Formosa (UnaF). Correo electrónico: <giulianoernesto02@gmail.com>.

1 Tomamos la expresión de Stephen Bunker, que la utiliza para caracterizar "las regiones cuyos lazos económicos con el sistema mundial están basados casi exclusivamente en el intercambio de mercancías 
Las acciones acometidas por la élite estatal que comanda el Estado provincial han creado su propio sendero del proceso de neoliberalización entre los años noventa y el nuevo milenio ${ }^{2}$ con sus particularismos y llevado a una profundización y redefiniciones de este rasgo central de la formación social provinciana. En el presente trabajo, nos proponemos acercarnos sumariamente a estos procesos, que implicaron el acoplamiento fragmentario del Estado en el anclaje del centro-oeste, para lo cual organizamos la presentación en dos secciones. La primera está destinada al abordaje conceptual de la mutación del capitalismo, los cambios en la estatalidad focalizada en el caso formoseño, y en esa dinámica relacional, la emergencia de un conjunto de dispositivos regulativos específicos fragmentarios (DREF) que se proponen como políticas para alcanzar el desarrollo para las diferentes escalas: regional-local. En la segunda, nos dedicamos al objetivo propuesto: intentamos dar cuenta del desenvolvimiento que toman los DREF, estructurando un patrón regulativo escalar que va acoplándose en el centro-oeste formoseño, así como las lógicas de intereses que articulan y penetran, generando espacios de acumulación desiguales y en disputa. Finalmente, las conclusiones procuran articular los resultados observados en función del marco conceptual y el objetivo propuesto.

MutaCión del CAPITALISMO, CAMBIOS EN EL ESTADO A NIVEL FUnCIONAL Y ESPACIAL EN EL CASO FORMOSEÑO

La emergencia del denominado modo de desarrollo posfordista ha modificado la organización territorial de las formas de acumulación y del modo de regulación que relativizan el ámbito nacional y jerarquizan el global -local o regional- haciendo que los procesos de producción y acumulación

\footnotetext{
extraídas, esto es, de recursos que ocurren en la naturaleza y en cuya existencia o reproducción continuada no hay una intervención humana deliberada" [Bunker, 1984: 55]. Aduce que el carácter "extremo" le viene dado por "la baja proporción de capital y trabajo incorporados en el valor total de sus exportaciones y por el bajo nivel de encadenamiento con otras actividades y la organización social de la misma región" [Bunker, 1984].

${ }^{2}$ En este trabajo, el espacio temporal del nuevo milenio se extiende hasta 2015. En este año se cierra el ciclo del neodesarrollismo en la Argentina. Un ciclo caracterizado por el intento de reconstrucción de la autoridad estatal y el sostenimiento de ciertas actividades industriales, aunque en los hechos arrastró internamente las contradicciones que profundizaron su condición de economía periférica amalgamadas bajo el Consenso de Washington [Fernández y Seiler, 2015].
} 
del capital adopten patrones más dinámicos, flexibles, en redes e históricamente heterogéneos. Estos espacios emergen como los núcleos estratégicos de la reproducción material y se constituyen como la base territorial de la producción de capital.

En ese contexto, durante el punto culminante del neoliberalismo en los años noventa, nuestro país profundizó el proceso de ajuste y reformas estructurales impulsados por el denominado Consenso de Washington, las que se materializaron, entre sus principales políticas, en la reducción del Estado mediante la disminución de la planta de personal y de sus atribuciones reguladoras; la privatización de todas las empresas públicas y bancos de los Estados provinciales; la descentralización de funciones (educación y salud entre otros) desde el Estado Nacional a las provincias y de estas a los municipios; y la desregulación de todos los mercados para facilitar la movilidad de los capitales, la apertura del comercio internacional y el endeudamiento externo.

Esto es, se redefinieron los modos de relación y articulación del Estado con la sociedad civil, las modalidades (y objetivos) de intervención y sus formas organizativas, y se modificó el modelo de centralidad estatal ${ }^{3}$ y las estrategias de desarrollo que implicaron, para esta década, la desaparición total de la industrialización basadas en la sustitución de importaciones [Fernández y García, 2010]. De este modo, se dio lugar a una drástica modificación de la presencia del Estado en la dinámica de acumulación nacional, que en los hechos se tradujo en el paso de un "Estado de bienestar" a un "Estado subsidiario": "El primero fue paulatinamente retirándose de su función intervencionista y reguladora, a fin de liberalizar las relaciones económicas en un mercado abierto a las corrientes internacionales de bienes y dinero" [Rofman y Romero, 1997: 253].

$\mathrm{Al}$ calor de estas transformaciones y de modo concomitante con el dominio creciente de las reformas neoliberales, comenzó a desarrollarse un conjunto de contribuciones académicas originado en los países centrales. Estas contribuciones se agruparon dentro de la denominada nueva ortodoxia regional (NOR). Hacia mediados de los años noventa, esta perspectiva fue instalándose también en los países periféricos y la lectura

${ }^{3}$ También denominado matriz estadocéntrica y en el cual el Estado se convirtió en actor político, árbitro y, al mismo tiempo, arena de disputas por la distribución del ingreso y los conflictos sociales [Cavarozzi, citado por Fernández y García, 2010]. 
neoliberal del desarrollo capitalista se propagó de manera acrítica institucionalizándose de la mano de intelectuales e instituciones destacadas del mundo académico y supranacionales de nivel regional constituyéndose la NOR en una plataforma común.

Durante el transcurso de este periodo caracterizado por profundos cambios, como se viene explicando, Formosa estará signado por tres rasgos institucionales fundamentales: a) las modificaciones sucesivas en dos oportunidades de la Carta Magna de la provincia; b) la continuidad hegemónica del partido-Estado en la dirección política y administrativa del Estado; y c) a partir de los dos primeros, la implementación dominante del "modelo formoseño para el desarrollo provincial (MFDP)".

Estas características se comienzan a vislumbrar cuando los marcos legales e institucionales de Formosa se transforman en 1991 con la primera reforma constitucional durante la gestión del gobernador Vicente Bienvenido Joga, que le permitirá reelegirse (Art. 129 de la Constitución Provincial de 1991) repitiendo la fórmula para el cargo de vicegobernador con Gildo Insfrán. Dicha reforma constitucional consagrará nuevos institutos y derechos civiles, ${ }^{4}$ adelantándose a los que se incluyeron en la Constitución Nacional, reformada en 1994.

Pero a su vez es el comienzo de un poder hegemónico que tendrá su continuidad con la elección de Gildo Insfrán (1995-1999) y la cristalización del ideario redactado en el preámbulo de la Constitución de 1991: plasmar el modelo formoseño para un proyecto provincial, donde el grupo dominante, que encarnará política y económicamente ese proceso y al que denominamos partido-Estado, ${ }^{5}$ se convertirá desde entonces en un

\footnotetext{
${ }^{4}$ Sin pretender hacer un examen exhaustivo del texto constitucional, mostramos a manera de ejemplo los institutos que se incorporaron al texto constitucional: la Fiscalía de Asuntos Administrativos, el Consejo Económico y Social, y el Defensor del Pueblo. También se incorporan los derechos de los pueblos originarios, se protege el medio ambiente y recursos naturales, se consagran los derechos de los consumidores, los usuarios y las amas de casa, y se da amparo a las madres solteras desprotegidas, entre otros.

${ }^{5}$ La construcción de la hegemonía partido-Estado es liderada por la elite dirigente del Partido Justicialista local, en la que partido gobernante y Estado se mezclan, fusionan y conjugan con la impronta de conducciones personalistas desde el poder ejecutivo provincial, apoyada por dicha elite en articulación con grupos empresariales vinculados con la ganadería, la construcción, el empresariado forestal, comercial, gremial, los partidos políticos y las organizaciones sociales a los cuales abre la posibilidad de ocupar espacios de poder a nivel legislativo o ejecutivo. Política y electoralmente se forja a través de una herramienta clave: la Ley Provincial 657 sancionada el 1 de abril del año 1987 (que irá incorporando algunas modificaciones), conocida como Ley de Lemas.
} 
factor determinante para el asentamiento de espacios de acumulación vinculados con la explotación de los recursos naturales, como se observará.

Pese a que la Constitución provincial solo permitía una reelección (Art. $129^{6}$ de la Constitución Provincial de 1991) el Superior Tribunal de Justicia plasmará la interpretación de dicho artículo en la decisión de habilitar a Gildo Insfrán para que participe en las elecciones de dicho año, que lo consagrarán nuevamente gobernador para el periodo 1999-2003.

En el año 2001, el poder ejecutivo provincial (PEP) avanzará sobre el poder judicial al aumentar el número de la Corte local de tres a cinco miembros [Sued, 2006]. Hacia finales de 2002 se hacía evidente que el gobernador buscaba una nueva reelección en un ambiente social y económico convulsionado, dramático y teñido por las "emergencias económicas" a raíz de la situación de crisis que transcurría en el país y a nivel provincial.

Ese escenario fue crucial para la construcción de una arquitectura de leyes y arreglos escalares verticalizantes que facultarán con amplios poderes al ejecutivo provincial para decidir sobre el patrimonio del Estado. ${ }^{7}$ Junto a este plexo normativo, se prorrogan las leyes de emergencia económica 1.296 y 1.342 que ya se habían puesto en vigencia en la fase de la convertibilidad, las que desde entonces tendrán una continuidad

${ }^{6}$ El artículo 129 había habilitado al gobernador Vicente Joga en 1991 a una reelección de su mandato, participando de la fórmula nuevamente como vicegobernador Gildo Insfrán. Ello le permitió a este último sucederlo por un nuevo periodo (1995-1999) como gobernador, con la fórmula Gildo Insfrán-Floro Bogado. Ahora bien, como Insfrán ya había sido reelecto sucediendo al anterior gobernador, para 1999, según el artículo en cuestión, no estaba habilitado para presentarse a una nueva elección para ninguno de ambos cargos, sino con el intervalo de un periodo. Esta limitación constitucional es la que será sometida a la interpretación del Superior Tribunal de Justicia, el que con dos votos a uno negativo convalidó la decisión en un ambiente de gran presión política sobre los integrantes del poder Judicial de la provincia.

${ }^{7}$ Con la sanción de la Ley 1367 que adhiere a la ley nacional de emergencia económica 25.561 el poder ejecutivo provincial, se le otorgan poderes extraordinarios (Art. 10) que lo facultan a realizar todas las acciones, trámites, convenios, suscribir documentación, etc., que resulten necesarios, pudiendo, entre otras, modificar plazos, intereses, modalidades de pago, montos, y otros de las operaciones originales, comprendiendo las mismas los títulos públicos, bonos, letras de tesorería, préstamos, contratos de fideicomiso, etc., así como su negociación, canje, operaciones de pase, afectación en garantía y/u otras modalidades de operaciones financieras conforme a los usos y condiciones de mercado, del modo que resulte más favorable para el fisco y la economía provincial. Asimismo, se lo faculta a refinanciar y reprogramar las acreencias de cualquier naturaleza del Estado provincial que se mantenga con distintos organismos oficiales y/o entidades autárquicas, centralizadas, descentralizadas y/o persona física o jurídica. 
sistemática mediante la sanción de las leyes nacionales y provinciales que las prorrogarán durante todo nuestro periodo analítico. ${ }^{8}$

En ese escenario, la amplia mayoría de diputados oficialistas en la legislatura que seguía la marcha incesante del PEP en la acumulación de mayores atribuciones terminó facilitando la declaración de necesidad de la reforma constitucional abriendo los comicios a tal efecto el 1 de junio de 2003.

Un elemento clave que no puede soslayarse en este proceso es la aparición en el escenario político provincial del presidente Néstor Kirchner, quien había asumido como primer mandatario de la nación el 25 de mayo de dicho año. El 28 de ese mes, a solo cuatro días de los comicios para la elección a Convencionales Constituyentes, el presidente de la nación arribó a Formosa y manifestó su apoyo al proceso político que estaba en desarrollo y al gobernador Insfrán con la firma junto al PEP del Acta de Reparación Histórica (ARH).

De esta manera, tras ganar las elecciones el Partido Justicialista con $56 \%$, se instituye el ambiente de la reforma constitucional con amplia mayoría de dicho partido político, que impondrá la reelección ilimitada para todos los cargos electivos, ${ }^{9}$ lo que le permitirá a Gildo Insfrán acceder a un tercer (2003-2007) y luego un cuarto mandato (2007-2011), para continuar de manera ininterrumpida en el periodo 2011-2015. ${ }^{10}$ Desde la reforma de 1991 a la de 2003, el poder se centraliza en el Ejecutivo ${ }^{11}$ y se

${ }^{8}$ Así, por ejemplo, mediante la ley provincial 1.576 adhiere la Provincia de Formosa a la Ley nacional 26.729 que prorroga la vigencia de su similar 26.204, prorrogada a su vez por las leyes $26.339,26.456$ y 26.563 hasta el 31 de diciembre de 2013, que son las prórrogas de la Ley 25.561. Simultáneamente, a nivel mesorregional se prorrogan la vigencia de las leyes provinciales 1296, 1342, 1472, 1367, 1485, 1503, 1518, 1530 y 1544, así como la de todas las normas reglamentarias y aclaratorias dictadas en su consecuencia, manteniéndose el "estado de emergencia pública" durante el término establecido en la mencionada ley nacional.

${ }^{9}$ Abarcan los del poder legislativo y ejecutivo y los municipios. Arts. 105, 132 y 179 Constitución Provincial de 2003.

${ }^{10}$ En la actualidad, el gobernador ejerce un segundo mandato en el poder ejecutivo para el periodo 2019 a 2023.

${ }^{11}$ El Art. 65 delega al PEP la realización de las operaciones financieras, crediticias, de préstamos y bursátiles necesarias para asegurar el funcionamiento del Estado, las inversiones indispensables, la realización de obras públicas; atender las necesidades sociales, evitar los efectos que provocan las variaciones económicas y financieras; cubrir las necesidades del Tesoro Provincial; y asegurar el crecimiento económico y social provincial, afectando para ello los recursos correspondientes. Así, también, el pep es el encargado de realizar los "ajustes" en el presupuesto en caso de que este haya sido reconducido por falta de sanción de la Ley de presupuesto (Art. 62). 
debilitan el poder judicial y el poder legislativo ${ }^{12}$ con pérdida de protagonismo de este último.

Podemos observar, entonces, en un escenario de arreglos escalares verticalizantes y hegemónico, que la puesta en funcionamiento de la plataforma común, como bien lo señalan Peck y Tickell [1994], origina un doble vínculo entre las escalas ${ }^{13}$ territoriales: los ámbitos locales están determinados por las dinámicas globales y lo local se resignifica como configurador de los procesos globales. Sin embargo, esas relaciones son asimétricas e inestables -y más aún en territorios periféricos-, porque las estrategias locales, al favorecer la libertad de acción del capital, se inclinan a la voluntad de la competencia global. Así mismo, entre las regiones se alientan relaciones competitivas que consolidan y acentúan los procesos fragmentarios de reproducción socioespacial y de este modo provocan nuevos desequilibrios y desigualdades.

Hacia finales de 2001, llegó a su clímax la crisis del proceso neoliberal iniciado en Argentina más de dos décadas antes. Esto implicó la salida abrupta de la convertibilidad ${ }^{14}$, y más en general, un giro hacia una revalorización de la autonomía relativa del Estado para orientar el desarrollo

\footnotetext{
${ }^{12}$ Véase además <www.legislaturaformosa.gob.ar/constituciónprovincial.htm $>$. Mediante los incisos 4 y 5 del Art. 120, la legislatura provincial reduce su capacidad de control al PEP sobre operaciones de crédito que celebra, al que solo solicita un informe de dichas operaciones. A su vez debilita su independencia para definir sus pautas presupuestarias, las que quedan sujetas a las generales establecidas por el PEP. El Art. 170, inciso 6, en el mismo tenor, debilita presupuestariamente el poder judicial al definir su presupuesto según las pautas generales que se establecen en el presupuesto general desde el poder ejecutivo.

${ }^{13}$ Las "escalas" pueden interpretarse en una primera aproximación como constructos sociales. Como bien observa Smith Neil [González, 2005], "el punto vital es no tomar estas escalas simplemente por sentado, por muy evidentes que parezcan, sino entender sus orígenes, determinación y coherencia interna". Es decir, las escalas, como el Estado-nación, provincia, ciudad o cualquier otra, son, como dice Smith, "expresiones mismas de la organización de los procesos sociales". Con una observación más precisa, las entenderemos como "representaciones" impulsadas por los actores académicos, institucionales y económicos que despliegan estrategias destinadas a resolver su reproducción y los conflictos de poder a los que esas estrategias dan lugar. Ello conlleva el posicionamiento de una determinada organización espacial de las dinámicas económicas, sociales e institucionales, y a partir de ello, una configuración dada de las escalas -globales, nacionales y locales- y sus vínculos, en concordancia con esas estrategias [Fernández et al., 2012a: 28].

${ }^{14}$ La salida del régimen de la convertibilidad se materializa con la sanción de la Ley 25.561, que modificó de modo significativo el tipo de cambio real (por lo menos hasta el año 2008), alterando los precios relativos y desplazando el eje de la acumulación, principalmente, hacia los sectores productores de bienes transables [Azpiazu y Schorr, 2010].
} 
económico capitalista. En tal sentido, por lo menos algunas de las caraterísticas más ostensibles de las políticas macroeconómicas del paquete de medidas del neoliberalismo, "en su época de plenitud" [Jessop, 2010], esto es, las que fueron implementadas a comienzos de los noventa, fueron dejándose de lado aunque sin desaparecer radicalmente.

Ello ha implicado que el "neoliberalismo" no se haya desdibujado hasta hacerse irreconocible, y más sustantivamente, haya dado lugar a otro régimen de regulación distinto. Mirada bien de cerca, esta interpretación de un supuesto fin del neoliberalismo en Argentina (y en varios países latinoamericanos), diagnóstico que inclusive se trasladó al ámbito mundial después de la crisis económica global de 2008, no es convincente. En este sentido, Brenner, Peck y Theodore [2010: 22] sugieren que "más que la sentencia de muerte para el neoliberalismo, podemos estar viendo otro punto histórico de inflexión del mutante proceso de neoliberalización".

En efecto, estos autores ponen el acento en la deficiente conceptualización del "sistema regulatorio" al que se denomina "neoliberalismo", escrutando de manera crítica las asunciones insosteniblemente monolíticas sobre las que se descansan los diagnósticos de su defunción. La noción analítica clave que postulan es la de pensar el neoliberalismo más como un proceso de "neoliberalización", que como un estado o condición final. Así, entienden que la neoliberalización es un proceso contingentemente realizado y cambiante, cuyo núcleo reside en "la movilización del poder estatal para extender el dominio del mercado" [Peck y Tickell, 2003: 166].

Se trata, en tal sentido, de un "síndrome", de una lógica extendida a nivel global que se reproduce en lugares, territorios y escalas diversas. Según proponen Fernández y Cardozo [2012: 13], este síndrome encuentra su base en la reestructuración espacial y escalar del Estado, y el impulso de una nueva lógica funcional que desplaza la perspectiva "de bienestar" que promovió el Estado desarrollista hacia la promoción de una intervención "workfarista", asociada en primer término con una implicación orientada hacia la creación de ambientes productivos dinámicos, sustentados en la cualificación de la productividad laboral y la innovación empresarial. 
En otros términos, la representación escalar que otorgara centralidad a los ámbitos nacionales y cobertura protectora a la fuerza de trabajo y a los territorios periféricos, a través de sus elementos simbólicos y materiales, se vio socavada [Peck y Tickell, 1994], corriendo el eje de las estrategias de desarrollo, con foco en las escalas regionales/locales y su conexión articulada con el espacio global.

Es decir, la representación escalar posfordista se operativiza por medio de la jerarquización de un patrón bipolar sustentado tanto en la dimensión regional-local como la supranacional, colocando esos terrenos escalares como los ámbitos donde se corporizan las luchas y las respuestas a estrategias generadas en gran medida de forma externa a las mismas [Brenner, 2003] por medio de redes y flujos que las atraviesan y redefinen, a veces consolidando y otras creando nuevos procesos desigualadores tanto entre ellas como en su interior.

En línea con las ideas de la NoR, desde 2004 se implementa en Argentina el Plan Estratégico Territorial (PET) coordinado por el Ministerio de Planificación Federal Inversión y Servicios Públicos, por medio de la Subsecretaría de Planificación Territorial de la Inversión Pública; ${ }^{15}$ en él todas las jurisdicciones provinciales se articularon con una metodología homogénea, lineamientos e iniciativas de impacto territorial. Por su parte, el Consejo Federal de Inversiones, a través de su Línea de Trabajo sobre Planificación Estratégica Regional, ${ }^{16}$ asiste y acompaña las experiencias en los municipios, junto a las provincias interesadas, implementando los planes estratégicos de desarrollo local (PEDL).

${ }^{15}$ Si bien el PET surge en 2004 con el objetivo de concretar inversiones públicas y de equipamiento mediante una metodología homogénea de articulación y consensos entre equipos técnicos de nación, provincias, municipios, organizaciones civiles y cámaras empresariales, sus diferentes etapas se extienden hasta 2016. Desde 2015, la subsecretaría funciona en el ámbito del Ministerio del Interior, Obras Públicas y Vivienda. <www. planificacion.gob.ar/contenidos/2605>.

${ }^{16}$ La entidad acompañó el financiamiento de los planes estratégicos de desarrollo local en el territorio de Formosa. La coordinación, se operativizó con la Fundación Arandú de la provincia de Corrientes. <http://cfi.org. ar/accionar/lineas-de-trabajo/planificacion-estrategica-regional>. 


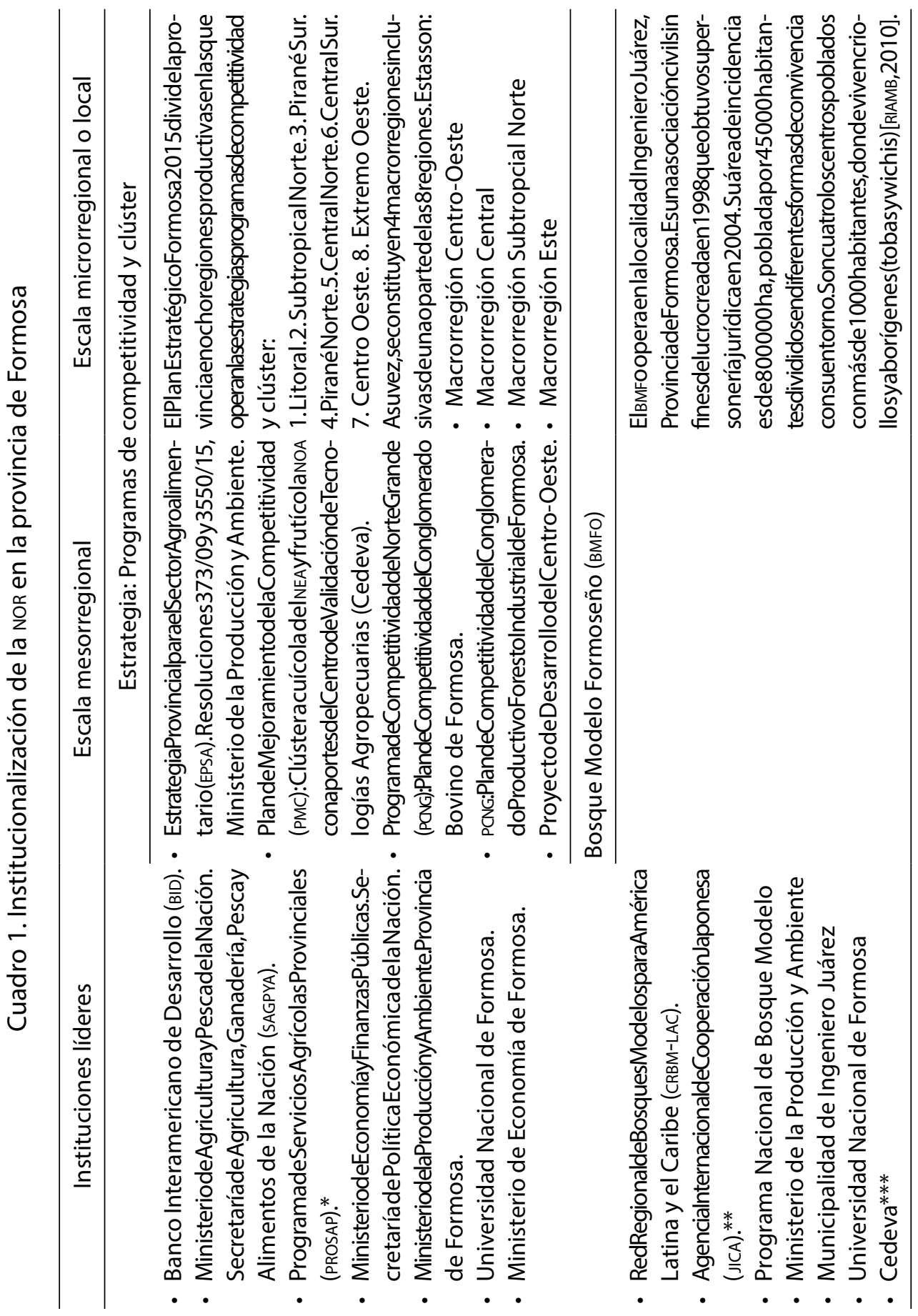




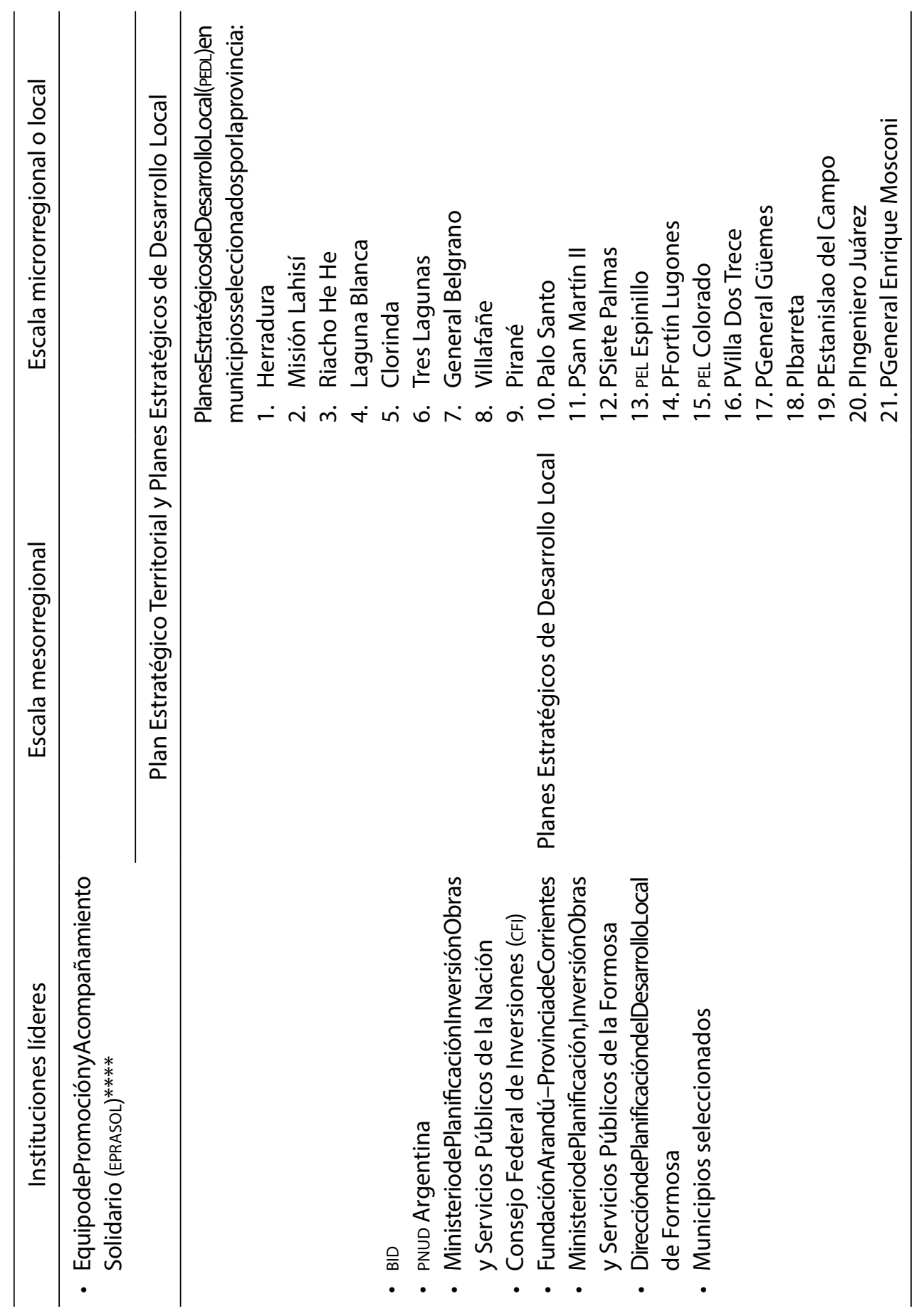




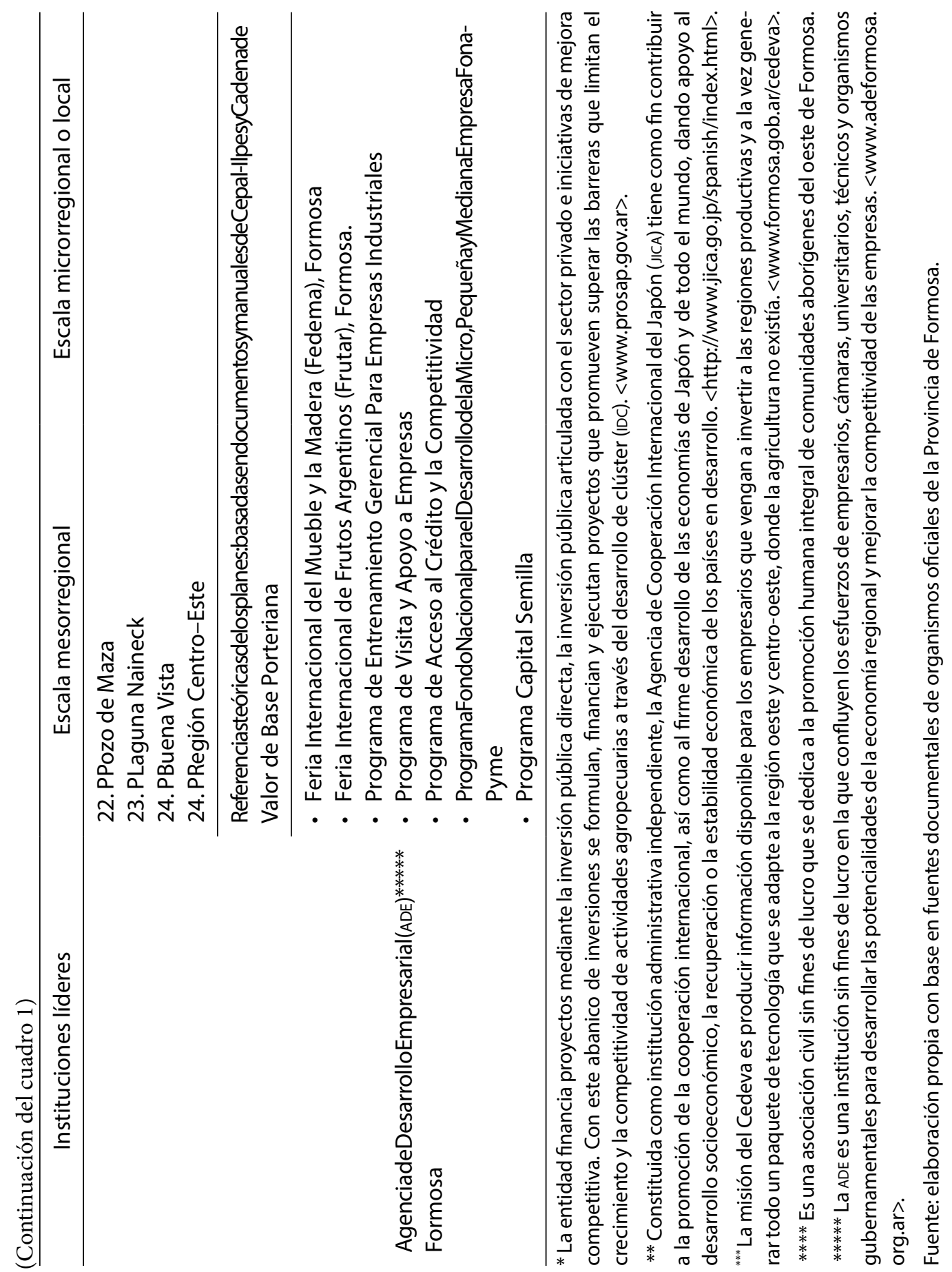


Durante este ciclo, de un neoliberalismo más complejo en el que se intenta posicionar al Estado con una impronta mayor, toda la dirigencia política y los decisores de política incorporan el lenguaje y las líneas de gestión pública basadas en la NOR como el camino inexorable para el desarrollo regionallocal competitivo e integrado al mundo. Es así que su implementación en el territorio ha implicado, en el marco de arreglos escalares verticalizantes y hegemónicos, el surgimiento a nivel mesorregional de espacios institucionales creados por la provincia, desde los cuales se ponen en práctica políticas funcionales a la nueva ortodoxia regionalista.

En el cuadro 1 presentamos la institucionalización de la NOR en la provincia de Formosa. Aquí nos detenemos solo en el detalle de las instituciones que lideran el proceso, proveniente de organismos internacionales, financieros supranacionales, instituciones gubernamentales y no gubernamentales.

También puede observarse el conjunto de dispositivos regulatorios específicos fragmentarios de políticas que operan a nivel de distintas escalas del territorio a los que denominamos DREF, reflejados por los programas de competitividad y desarrollo, iniciaciones de clústeres, plan estratégico territorial, planes estratégicos de desarrollo local, programas feriales, de entrenamiento gerencial y financiamiento al empresariado local.

La impronta de las políticas regionalistas-localistas afincadas en el espacio social formoseño nos habla, así mismo, del funcionamiento de un andamiaje de DREF con diferentes características y articulación de objetivos, pero que tienen como principio rector la construcción de espacios de acumulación (EA) inspirados en las líneas envasadas por la nueva ortodoxia de base "participativa", "universal" y "comunitarista". Esos EA son instancias de implicaciones fragmentarias público-privadas en las que operan las estrategias de lógicas de intereses en disputa, de actores económicos, políticos y sociales junto a los DREF, en las que se proyecta la atmosfera propicia a nivel regional-local para movilizar los engranajes de actividades económicas que propulsan la búsqueda de la rentabilidad y sustentabilidad para el desarrollo integrado al mundo.

Hacia el interior de estos procesos territoriales regionales-localesglobales, los fundamentos de la NOR, abigarrados en el proyecto neodesarrollista, vienen a recrear formas de intervención estatal asimilables al proceso de neoliberalización. Es decir, refuerzan el reescalonamiento espacial hacia abajo basado en la descentralización y la relativización de 
la escala nacional a través del PET y los PEDL, pero también desarticulan las tensiones sociales que producen las redes del capital global e impulsan hacia el interior de las microescalas de territorios en disputa un mensaje de construcción horizontal y participativo, que termina siendo funcional para esos intereses que acentúan las desigualdades en el territorio.

Sobre este punto específico, conviene recordar que ya Tickell y Peck señalaban tempranamente que

[el Estado neoliberal] ha demostrado una capacidad para metamorfosearse en una variedad de formas institucionales, para insinuarse dentro de un abanico de diferentes emplazamientos institucionales y absorber narrativas paralelas e incluso contendientes de reestructuración e intervención en respuesta tanto a contradicciones internas y presiones externas. El proyecto del neoliberalismo es consecuentemente plástico, evolutivo y cambiante [Peck y Tickell, 2003: 181].

Este mensaje, cuando se acepta de manera acrítica, implica a cambio la subordinación a una rejerarquización de las escalas subnacionales como espacios capaces de moldear su propia dinámica de desarrollo a partir de la articulación asociativa y cooperativa de actores económicos e institucionales, cohesionados y autorresponsables de su inserción en el escenario global.

Se abre con ello una nueva arquitectura regulatoria que Peck y Tickell denominan las formas reconstructivas, consensuadas o del roll out del proceso neoliberalizador, esto es, el despliegue de "nuevas formas estatales, nuevos modos de regulación, nuevos regímenes de gobernanza, con el objetivo de consolidar y manejar tanto la mercantilización como sus consecuencias" [Peck y Tickell, 2007: 33].

Como parte del proceso de redefinición del patrón socioeconómico espacial de la acumulación a partir del nuevo paradigma tecnoproductivo flexible y de globalización, el Estado-nación se transforma morfológica y funcionalmente lo mismo que sus escalas subnacionales, pero no desaparecen. De este modo, algunas funciones específicas se reubican en otros niveles de la organización estatal, otras se comparten o son desplazadas a actores no estatales y los objetivos, que antes eran internos, se expanden para incluir un rango extensivo de factores y procesos trasnacionales o extraterritoriales [Jessop, 2008]. 
Bob Jessop [1994: 263] denomina régimen schumpeteriano de workfare la emergente configuración del Estado. Se trata del "Estado de competencia", orientado funcionalmente a fomentar la flexibilidad, la competencia y la innovación; a crear, orientar y enriquecer las redes de economías nacionales y regionales generando procesos de articulación supra y subnacionales [Jessop, 2008].

Es justo esta perspectiva acerca del Estado la que se configura en Formosa mediante la implementación del MFDP. Un ambiente donde las fracciones del capital y los policy makers tienen el interés común de generar espacios propicios para la liberación de un conjunto de activos, incluida la fuerza de trabajo a un coste muy bajo, lo que posibilita mayores desigualdades y acentúa la acumulación del capital.

Así, estas acciones entramadas se dirigen a establecer nuevos marcos institucionales para movilizar las fuerzas productivas en relación con la reterritorialización del capital; a promover la competitividad al incentivar, crear, mantener y realzar fuerzas productivas específicas; y a regular las contradicciones sociopolíticas de la dinámica del capital [Brenner, 2003]. Es decir, cambia la modalidad de intervención estatal (y el sostenimiento estatal) por la modificación de la lógica y la dinámica espacial de la acumulación del capital. En esta dinámica surge un Estado destinado a dar soporte al desarrollo de procesos productivos y ser articulador de múltiples intereses público-privados, necesarios para ligar esos procesos con la generación y transferencia de conocimientos.

Ahora bien, esta concepción de Estado, como se observa, pone énfasis en las nuevas funciones implicadas en el campo productivo, pero a su vez se termina despegando de aspectos distintivos del Estado ford-keynesiano, como la redistribución para garantizar el bienestar social. Jessop ve en ello un desplazamiento del papel del Estado: desde el tipo de intervención reclamado por el sistema de acumulación fordista de administrar la demanda nacional a través de las medidas keynesianas y del Estado de bienestar hacia un papel preponderante en la promoción y fortalecimiento de la competitividad estructural de la economía nacional "dado el carácter irreversiblemente internacional del posfordismo" [Jessop, 1994: 257], reduciendo el papel del Estado en la administración de la demanda nacional e incrementándolo en la reestructuración constante y continua por el lado de la oferta. 
Peck y Tickell [1994] señalan también los límites que se generan cuando la regulación y las políticas públicas son planteadas exclusivamente desde la instancia local-regional -las cuales se hallan entregadas a la dinámica del capital global móvil y a la competencia por las fracciones de capital- ya que estas por sí solas tienen poco poder político para conducir esos procesos en un contexto de acumulación global y desregulado. ${ }^{17}$ En el mismo sentido, Jessop [2008] aporta que las instancias estatales subnacionales desprovistas de articulación con el Estado-nación, que dispone de una base fiscal para realizar modificaciones en esos ámbitos, no pueden por sí mismas generar transformaciones sustantivas en esas materias.

Podemos concluir parcialmente, entonces, que la reestructuración morfológica, el desarrollo de nuevas funciones y el modo de intervención del Estado implican un reacomodamiento de la forma de organización del poder y de las relaciones entre los actores que influye en la definición de sus políticas y en cómo se ejercen. Se añade a esto otro aspecto relevante, la redefinición de las funciones del Estado-nación, cuya centralidad estratégica se mantiene, pero reformulada y reestructurada por la proliferación de las escalas y sus dinámicas, y readaptada a la nueva lógica de acumulación y reproducción del capital y de su impacto en los territorios. En estos cambios en las formas de organización e implicación estatal, nos detendremos a continuación para acercarnos a la dinámica de acoplamiento que se fue desplegando mediante algunos de los DREF que presentamos en el cuadro 1 y que se vinculan con el espacio de acumulación denominado por Giuliano [2015: 147] anclaje del centro-oeste formoseño. Se analiza de modo sumario su desenvolvimiento y la estructuración de lógicas de intereses en disputa, los espacios donde operan las políticas de marquetización que favorecen selectivamente a determinados actores locales y extra-provinciales, las cuales consolidarán procesos territoriales con mayores desigualdades durante el neodesarrollismo, como nos disponemos a analizar a continuación.

\footnotetext{
${ }^{17}$ Los ámbitos locales poseen responsabilidad sin poder. Pero también agregamos, con escasos recursos y las instancias supranacionales poseen poder pero sin responsabilidad por las consecuencias sociales y económicas [Peck y Tickell, 1994]. Para lo cual agregamos, a los que se les giran recursos y "carecen de toda responsabilidad democrática real" [Jessop, 2008: 261].
} 
Analizamos a partir de aquí los elementos que consideramos la manifestación de las acciones institucionales que ejerce el Estado cuando decide articular estrategias de políticas relacionales en el espacio territorial del centro-oeste de Formosa. ${ }^{18}$ En este sentido, en dicho escenario encontramos marcos regulatorios y acciones institucionalizadas destinadas a la creación del ambiente proclive a la radicación de capitales privados.

Ahora bien, dichas acciones forman parte de un conjunto de marcos legales e institucionales en el que se ofrecen incentivos fiscales para el fomento de las inversiones privadas y el desarrollo económico y social (Ley provincial 777), así como leyes de venta especiales de tierra (leyes provinciales 1218 y 1321) y de afectación de estas, con destino a la radicación de inversiones (Ley provincial 1137). A estos marcos legales se les han adicionado espacios institucionales de articulación público-privado como son: los centros de validación de tecnologías agropecuarias (Cedeva) de Laguna Yema y Las Lomitas, planes de competitividad, el Programa de Colonización y Ordenamiento Territorial y Catastral de la Tierra Pública en el Oeste, la Agencia de Desarrollo Empresarial, la motorización del Bosque Modelo Formoseño y la instalación de infraestructuras básicas, como canales de agua -además de los vinculados con los ciclos de desborde y sequía del Bañado la Estrella-, caminos pavimentados y redes eléctricas.

Es decir, se trata de un patrón regulativo escalar que representa la continuidad y la reelaboración del proyecto neoliberal que se consolidó en los noventa por medio del roll back ${ }^{19}$ del Estado, pero que se combina luego de manera complementaria desde mediados de esta década con el roll out; una lógica de coproducción de políticas con los actores regionales, que imponen una extensión de los procesos de mercantilización de la tierra y

${ }^{18}$ El área que abarca tiene una superficie total de 2500000 ha y está comprendida entre los siguientes límites: al oeste, la línea Barilari; al norte, el río Pilcomayo y la República del Paraguay; al sur, el río Bermejo; y al este, la Ruta Provincial 26. Este perímetro incluye la totalidad de los departamentos Bermejo, Ramón Lista y Matacos, y una porción del departamento Patiño delimitada por la ruta provincial mencionada. <https://www. formosa.gob.ar/produccion/programas/desarrollointegral>.

${ }_{19}$ Alude al proceso de desmantelamiento o reducción del Estado de bienestar [Peck y Tickell, 2002, que se profundiza en los noventa en todo el territorio argentino, como anticipáramos. 
la explotación de recursos naturales mediante la implicación estatal que facilita un renovado y más complejo proceso de desarticulación fragmentante al momento de implicar la dinámica regional y que motorizan los engranajes de la NOR en su lógica de desarrollo con eje en lo regional-local-global.

Esa lógica desarticulada y fragmentaria es la que domina la implicancia estatal a nivel regional en el anclaje del Centro Oeste formoseño y la que contribuye a mantener inalterado el régimen de acumulación primarizado, generando dependencia con la región central del país, cuya vinculación es subordinada dentro de la matriz productiva nacional trazada a partir de grandes empresas nacionales y extranjeras.

En este sentido, nos ocupamos ahora del análisis de la frontera productiva agrícola-ganadera de la región en estudio y cómo ha operado en ella el patrón regulativo escalar al permitir, en su selectividad, la penetración de actores económicos que usufructúan estas estrategias que dominan la implicancia estatal, lo que genera espacios de acumulación primarizados. Esa dinámica relacional está vinculada con el proceso de corrimiento de la frontera productiva sojera en las regiones pampeanas y extrapampeanas y con la pamperización de la ganadería, ${ }^{20}$ que permitió que la producción pecuaria y otras actividades agrícolas alternativas se desplazaran a territorio formoseño y conllevó la penetración de capitales nacionales y extranjeros de perfil extractivista. Esa dinámica y otros procesos que presentamos a continuación consolidarán a su vez un espacio fragmentado, en disputa y desigual por los recursos naturales, en el que se ven involucrados actores diversos.

Por una parte, están las asociaciones de las comunidades indígenas y pequeños productores que denuncian al Estado por las infraestructuras de control del agua, a las que se suman otras comunidades originarias que se ven afectadas por los procesos de desmonte a raíz de la presión ganadera, forestal y de megainversiones proyectadas e iniciadas en el centro-oeste

\footnotetext{
${ }^{20}$ Entre los censos agropecuarios de 1988 y 2002, las provincias que mayor expansión tendrán en el cultivo de la soja serán las comprendidas en la región pampeana: Buenos Aires, Santa Fe, Córdoba y norte de La Pampa, y entre las extrapampeanas: Entre Ríos, Santiago del Estero, Chaco, Salta y San Luis [Codutti, 2005]. Dicho proceso no se detuvo, continuó en nuestro periodo de estudio. A su vez, el proceso de expansión de la ganadería se ha acompañado de un perfil de cría e invernada mucho más complejo que el predominante hasta entonces (de tipo extensivo), utilizando medios tecnológicos que han permitido la adaptación de las razas ganaderas a las condiciones agroecológicas del nuestro territorio.
} 
durante nuestro trayecto temporal, que afectan las tierras de pueblos originarios y criollos al modificar el espacio habitado por ellos.

Por otra, se hallan las asociaciones promovidas por el gobierno provincial mediante el plan piloto de afincamiento de explotaciones ganaderas con sistema silvo-pastoril ${ }^{21}$ y el Plan de Competitividad del Conglomerado Ganadero Bovino, así como las surgidas en articulación con agencias globales, como el Modelo Bosque Formoseño. Estas experiencias se funcionalizan en los principios de la NOR y sus estrategias de tipo bottom-up para moldear su propia dinámica espacial de desarrollo. En este sentido se conforman más de una decena de asociaciones de pequeños productores ganaderos que integrarán este proceso.

En efecto, en 1994 cobrará dinamismo la infraestructura diseñada en el Proyecto de Aprovechamiento Múltiple del Río Teuco-Laguna Yema, que se basaba en el aprovechamiento de los canales de agua abastecidos desde el río Bermejo, el cual se había iniciado en 1981 y luego fue propulsado en el Plan Trienal 1985-1987. Se trata, como anticipamos, de lo que hemos dado en llamar "anclaje espacial del centro-oeste de Formosa", que contará con otros dos pilares institucionales claves que le darán coherencia estructural: el Centro de Validación de Tecnologías Agropecuarias de Laguna Yema (Cedeva) y la Ley provincial 1137.

En este sentido, el aporte de agua procedente del río Bermejo y acopiada en el embalse de Laguna Yema de 14500 ha de superficie se proveerá con un canal a cielo abierto de $96 \mathrm{~km}$ de longitud (desde Laguna Yema hasta Las Lomitas), en cuyos laterales se empezarán a radicar las empresas, incentivadas además por las obras de pavimentación del tramo faltante de la ruta nacional 81 que se concretarán entre los años 2004-2008 y la llegada de la interconexión y los beneficios del régimen de diferimiento e incentivos impositivos.

Así mismo, la creación del primer Cedeva en Laguna Yema, localidad del Departamento Bermejo, aportará el contenido tecnológico del proyecto de desarrollo del centro-oeste, cuya función básica es generar información especializada acerca de los cultivos y la cría de animales caprinos y

${ }^{21}$ El plan aludido es la columna vertebral del Programa de Colonización y Ordenamiento Territorial y Catastral de la Tierra Pública, realizado íntegramente en el Instituto de Colonización y Tierras Fiscales de Formosa el 11 de enero de 2006. 
bovinos que responden a las particularidades de esa región típicamente semiárida y que al mismo tiempo impliquen el menor riesgo para los potenciales inversores que estén interesados en radicarse.

Puesto que la región circundante es semiárida con una geografía y unas características particulares en materia de agua y suelos, una de las primeras acciones de esta institución será la importación, desde 1998, de la experiencia israelí de sistemas de riego por goteo y por aspersión que serán instalados y supervisados por técnicos llegados desde ese país. Dichos sistemas serán utilizados luego por los principales grupos empresariales instalados en la región, como se observará.

La Ley provincial 1137, promulgada en diciembre de 1994, constituye el marco legal que establece el área definida para que progresivamente se vayan instalando los inversores, afectando como reserva para la ejecución de planes de colonización las tierras de dominio de la provincia colindantes con los canales construidos en los departamentos de Ramón Lista, Matacos, Bermejo y Patiño, que abarcan una superficie que se determinará con base en los $5 \mathrm{~km}$ contados desde ambas márgenes y a lo largo de todo el recorrido de los canales (Art. 1); ${ }^{22}$ esto totalizaría una superficie total aproximada de unas 100000 ha. En este contexto, el encargado de fijar los requisitos o condiciones en que se efectuarán la venta de las tierras comprendidas en la reserva y los planes para su colonización es el poder ejecutivo, sujeto a aprobación del legislativo (Art. 2).

\footnotetext{
${ }^{22}$ Es importante destacar que dicho artículo afectaba las tierras de propiedad provincial de conformidad con lo prescripto en los Artículos 40, incisos $2^{\circ}$ y 70, y 45 de la Constitución provincial del año 1991. El primero de los artículos otorga el papel protagónico al Estado, entre otros, para encauzar y fomentar la explotación racional de los recursos naturales. En este marco, el inciso $2^{\circ}$ establece como criterio que la distribución de la tierra debe ser equitativa, considerándola como bien de trabajo a los fines de su explotación racional, a un precio justo en relación con su rendimiento. En el inciso $7^{\circ}$ se establece que las condiciones en que se hará la reserva, venta o concesión de tierras que se encuentran en las zonas de influencia de obras de aprovechamiento hídrico deberán establecerse por ley especial. El Art. 45, por su parte, define la tierra rural fiscal como factor de la producción y establece las extensiones de 5000 ha como unidad productiva máxima, salvo excepciones que se precisen en una ley especial que las justifique.
} 
Mapa 1. Infraestructura del canal, el embalse "El Tuequito"

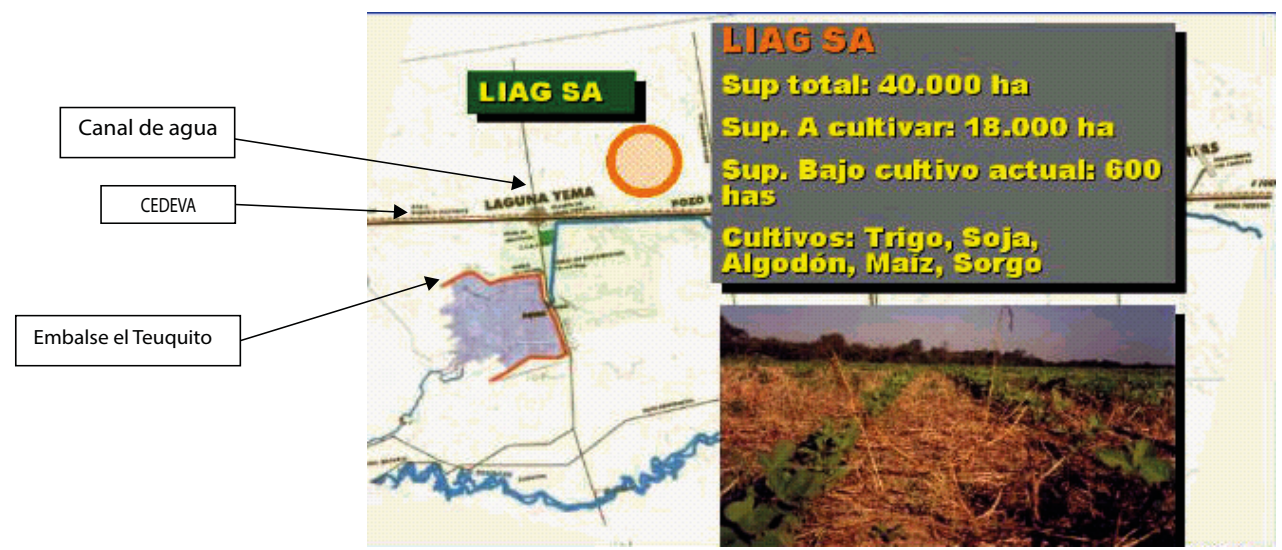

Fuente: Formosa Avanza-Gobierno de la Provincia de Formosa.

Con base en estos pilares, el afincamiento de sociedades empresariales agrícolas y ganaderas de capitales extranjeros y nacionales se hace evidente a partir de 1996. El caso emblemático se aprecia en el mapa 1, en el cual se observa la infraestructura del canal, el embalse "El Tuequito", el cEDEVA y las 40000 ha de tierras fiscales a LIAG Argentina, S. A., de capitales australianos, a través de la Ley provincial 1218 del año señalado.

$\mathrm{Al}$ respecto, Giuliano [2015: 148] da cuenta en el periodo que analizamos, de la llegada de empresas que se instalan en ambas márgenes del canal: Cotton Saurer S. A., Unitec Agro S. A., Grupo Eurnekian, Sumayen S. A., Agrocit S. A., Ciagro S. A., Laguna del Oeste S. A., Tejerina, Virasol S. A., Alma Gaucha, Cabañas Nuevo Milenium. Las actividades principales de estos capitales de origen extranjero y nacional extraprovinciales, gira en torno a los agronegocios, la ganadería bobina-bufalina y la cría de caprinos de raza y producción de semen, todos con destinos exportables a países del continente y la Unión Europea entre otros.

Otros casos significativos de venta de tierras realizadas por el estado provincial en los años 1999 y 2000 en este contexto son La Florencia Oeste y Ganadera Balado. La primera es un establecimiento privado de 60000 ha, sobre la Ruta Provincial 39, frente a la provincia de Chaco sobre el río Bermejo y colindante con la zona de influencia del Canal, que toma el agua de dicho río y lo conduce a las localidades de Ingeniero Juárez-Los 
Chiriguanos en el Departamento Matacos. El proyecto busca en veinte años el inicio de la producción, a partir de la reforestación, de quebracho blanco y colorado, algarrobo timbó, viraró y guayacán.

La segunda corresponde a la venta de una superficie de 6614 ha en el Departamento Patiño, a través de la Ley provincial 1321 del 6 de julio del año 2000, a favor de Daniel Alberto Balado, propietario de la empresa ganadera del mismo nombre.

Este proceso de anclaje de capitales y venta de tierras ha creado tensiones y conflictos debidos sobre todo a que el territorio en cuestión ha estado ocupado históricamente por pequeños productores criollos y/o comunidades indígenas y la adjudicación de las tierras a las empresas terminó lesionando los derechos de los más débiles.

Así, la solución a dicha situación por parte de las autoridades del estado provincial ha sido errática y a favor de los dueños del capital, siguiendo acciones de política que han ido desde la implementación de programas de reubicación de productores hasta la inacción de amigable componedor.

El primer tipo de acción correspondió a lo emprendido para el caso LIAG; el programa consistió en la reubicación de los productores criollos e indígenas en pequeñas parcelas con el compromiso de la empresa de realizar una serie de mejoras que luego serán reconocidas en términos de beneficios a favor de la firma extranjera por parte del Estado y este último construirá al inicio algunas viviendas del Programa Provincial de Asistencia Integral para los Pequeños Productores Agropecuarios (PAIPPA). ${ }^{23}$

El segundo se refiere a la seguida en el caso La Florencia. Allí el Estado permitió a los propietarios de la estancia seducir a la población criolla y la comunidad indígena Wichí con la posibilidad de participar en la explotación de la reforestación y capacitarse para tal fin. Dentro de la propiedad viven familias distribuidas en tres pueblos, algunas de las cuales aceptaron participar en el proyecto de reforestación. Otros viven en puestos

\footnotetext{
${ }^{23}$ En 1996, al adjudicarse las tierras a LIAG, S. A., los pobladores que estaban asentados históricamente en ella fueron ubicados en parcelas de 10 a 15 ha aledañas a la empresa; para ello se afectaron 101000 ha. La empresa se encargó de la construcción de 16 represas, $124 \mathrm{~km}$ de picadas interlotes, $67 \mathrm{~km}$ de picadas (caminos de accesos internos) y 107 ha de desbarejado. El costo de todo ello fue reconocido por el Estado y depositado en la cuenta corriente de la empresa [Bobadilla y Silva, 2004: 138-144].
} 
rurales y se dedican a la pequeña producción ganadera mediante la cría de vacunos y caprinos. ${ }^{24}$

La tensión y el conflicto se generaron cuando la empresa quiso avanzar sobre las propiedades de los criollos y las comunidades originarias para instalar viveros que utilizarían las aguadas para riego, lo que ocasionó la resistencia de los pobladores. Frente a estos hechos resulta relevante la postura relacional del Estado en manifestar su "desentendimiento" y declararse un "amigable componedor". Así lo expresaba el ingeniero Manuel Augusto Rodríguez, director del Instituto de Tierras Fiscales de la Provincia:

La estancia la Florencia [...] hasta 1903 o 1904 era propiedad de Bunge y Born[...] luego pasó por varias manos, inclusive fue de un tal Martínez de Hoz hasta 1970, y hace unos años fue adquirida por un hombre de apellido Bellsola[...] El campo fue vendido varias veces siempre para especulación financiera[...] el nuevo propietario, un tal Bellsola, habló conmigo hace un año y le dije: vos compraste un problema, un campo con toda la gente adentro, por lo tanto, el problema es tuyo con la gente, no sé cómo va a terminar esto, pero tiene más validez la gente que vive allí. El organismo que dirijo solo interviene como amigable componedor. ${ }^{25}$

Simultáneamente a estos procesos y producto de los desbordes que el río Pilcomayo genera en sus ciclos sobre el Bañado la Estrella, el estado provincial avanzará en 1997 en la construcción de infraestructuras de manejo del agua, ${ }^{26}$ que buscaban derivarla a la localidad de Las Lomitas, zonas aledañas y campos próximos, donde se pretendía desarrollar actividades productivas.

${ }^{24}$ Diario Clarín [2009], Suplemento rural, [en línea]. <https://cutt.ly/zd1aLRN>.

${ }^{25}$ Declaraciones del ingeniero Manuel Augusto Rodríguez, titular del Instituto de Colonización y Tierras Fiscales de la Provincia de Formosa, con fecha del 12 de septiembre de 2008 en el Diario El Comercial, transcritas en el Parte de prensa del Movimiento Campesino de Formosa - Frente Nacional Campesino titulado: "Latifundio La Florencia: tiempos de resistencia"; párrafo cuatro (4), <https://cutt.ly/6d1sRtU>. Consultado el 10/07/2020.

${ }^{26}$ La obra financiada con fondos del Banco Interamericano de Desarrollo (BID) apoyado por el gobierno nacional consistió en un terraplén elevado sobre las dos cuencas, la del río Salado y la del Bañado La Estrella, usando como traza a la Ruta Provincial 28. Esta elevación oscila, según las zonas, desde los $0.70 \mathrm{~m}$ en la parte norte, hasta unos $5 \mathrm{~m}$ en la zona de El Salado. El terraplén interrumpe en parte la dinámica cíclica y amplía de modo considerable la zona que ahora permanece constantemente inundada al oeste de dicha ruta [Brown et al., 2010: 104]. 
Esas decisiones fueron interpretadas como violaciones a los derechos de los pueblos originarios y de productores criollos, ${ }^{27}$ los que impulsaron una serie de denuncias que intentaron frenar la construcción. Este contexto de tensiones crecientes se profundiza en 2005 con la sanción a la Ley provincial 1.471, reglamentada por el Decreto 921/05. Así, el estado provincial, apelando al argumento del cuidado y preservación del agua dulce y de las condiciones ambientales del lugar, declara de dominio público el Bañado La Estrella más lo que pudiera incrementarse a futuro. Sin embargo, estos marcos regulatorios no detuvieron los reclamos y pedidos de inconstitucionalidad ${ }^{28}$ sin éxito de los pobladores afectados, que interpretaron que con esta regulación el estado provincial avanzaba en su potestad de confiscar tierras comunitarias indígenas y propiedades privadas criollas e incluso las adjudicaciones en venta en tanto derecho adquirido a titularizar la tierra, con destino al desarrollo clusterizado de producción bovina y agrícola, como anticipáramos en el cuadro 1.

A estas acciones se sumarán las generadas por las megainversiones globales de la Iniciativa para la Integración de la Infraestructura Regional Suramericana (IIRSA), ${ }^{29}$ que penetran el territorio del centro-oeste y ejercen una fuerte presión sobre la disponibilidad de recursos naturales para las poblaciones originarias, cuya habitualidad y vivencia se construye en torno a la tierra y la naturaleza, lo que ha generado la construcción de nuevos escenarios de tensiones y conflicto.

\footnotetext{
${ }^{27}$ Desde el inicio y hasta su finalización en 2007, la Federación Pilagá y la Asociación de Productores del Bañado La Estrella (Aprobae), junto con otros actores como Fundación Fungir y Amnistía Internacional, formularon informes, denuncias y acciones administrativo-jurídicas en contra de las obras. Reclamaron la inexistencia de consultas y consentimientos para su realización, así como el incumplimiento de pasos previos, como el estudio de impacto ambiental y audiencias públicas. La realización de la obra, pese a las denuncias, inundará de manera permanente tierras de dos comunidades pilagá (Campo del Cielo y el Descanso) y propiedades de particulares, ubicadas próximas a la Ruta Provincial 28. Luego, el gobierno comprará voluntades a integrantes de las comunidades indígenas, quienes extorsionados terminarán avalando las obras realizadas [Amnistía Internacional, 2010: 46-47].

${ }^{28} \mathrm{Al}$ respecto, puede consultarse: <https://cutt.ly/NgkZekE>. [Consulta: 10 de junio de 2017].

${ }^{29}$ Esta Iniciativa surgió en 2000 de una propuesta del BID, la Corporación Andina de Fomento (CAF) y el Fondo Financiero para el Desarrollo de la Cuenca del Plata (Fonplata), organismos que ofrecen préstamos para hacer las obras para alcanzar una inserción competitiva, eficiente y equitativa de nuestra región en el contexto de la globalización, diseñados y adaptados a los negocios y cadenas productivas agroalimentarias-ganaderas-forestoindustriales y energéticos extractivistas y exportadores a los mercados globales. En este sentido, Formosa es atravesada por el Eje Capricornio de la IIRSA, en la que se construyen los corredores bioceánicos y se proyecta la recuperación del ramal ferroviario C 25, el tendido de la red eléctrica y el Gasoducto del Nordeste Argentino.
} 
En este escenario disputado, el gobierno provincial impulsará dos líneas de política fragmentarias: operar como compartimentos estancos detrás del objetivo de avanzar y aumentar el volumen de las explotaciones ganaderas en este espacio territorial, y ser, a su vez, la fuente generadora de recursos económicos genuinos y sustentables. La primera de ellas será la emergencia de las tensiones por las obras de la Ruta Provincial 28 y su población objetivo son los productores criollos afectados. Allí se propondrán dos planes piloto para el afincamiento de explotaciones ganaderas con sistema silvopastoril, ${ }^{30}$ imitando expresamente, en una decisión verticalizante, la experiencia extranjera menonita ${ }^{31}$ desarrollada en el territorio paraguayo.

La segunda se encuadra en el Plan Estratégico Territorial-Formosa 2015 y dentro de él, en el marco del Plan de Competitividad del Conglomerado Bovino. Desde esta plataforma se avanzará en la conformación de más de una decena de asociaciones de pequeños productores en el centro-oeste con el fin de alcanzar el desarrollo de sus localidades.

En tanto que en una tercera línea de acción, pero escindida de las emprendidas por las estrategias espaciales antes enunciadas, en la localidad de Ingeniero Juárez y en coordinación con agencias globales, como el Centro Regional de Bosques Modelos para América Latina y El Caribe (CRBM-LAC) y la Agencia Internacional de Cooperación Japonesa (JICA), se implementará el Plan Estratégico Bosque Modelo Formoseño.

\footnotetext{
${ }^{30}$ Un sistema silvopastoril es aquel uso de la tierra y tecnologías en que leñosas perennes (árboles, arbustos, palmas y otros) son deliberadamente combinados en la misma unidad de manejo con plantas herbáceas (cultivos, pasturas) y/o animales, incluso en la misma forma de arreglo espacial o secuencia temporal, y en que hay interacciones tanto ecológicas como económicas entre los diferentes componentes [Young, 1987, apud Luccerini et al., 2013].

${ }^{31}$ Los menonitas conforman la corriente inmigratoria que llegó al Paraguay en tres oleadas (1927, 1929 y 1947) a partir de la decisión del gobierno paraguayo de colonizar los territorios del Chaco de este país. Se conformaron así tres colonias Menno, Fernheim y Neuland, respectivamente. "[...] Cuando en los años 60 los créditos otorgados permitían la mecanización progresiva, se comenzó a desmontar tierras para la ganadería, que se ha convertido hoy día en el pilar del desarrollo del Chaco" [Duerksen, 2011]. La experiencia que se plantea imitar en el plan formoseño es la de la colonia de Fernheim, conocida como Filadelfia, en la República del Paraguay.
} 
Mapa 2. Zona macro del plan de colonización

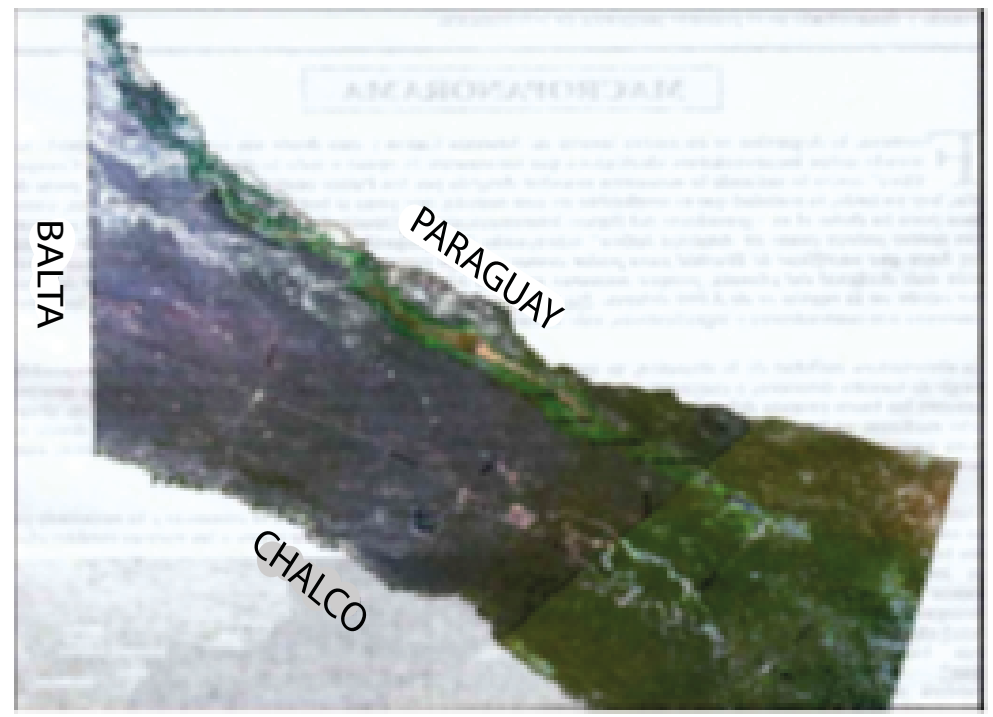

Mapa 3. Área piloto 1 de colonización

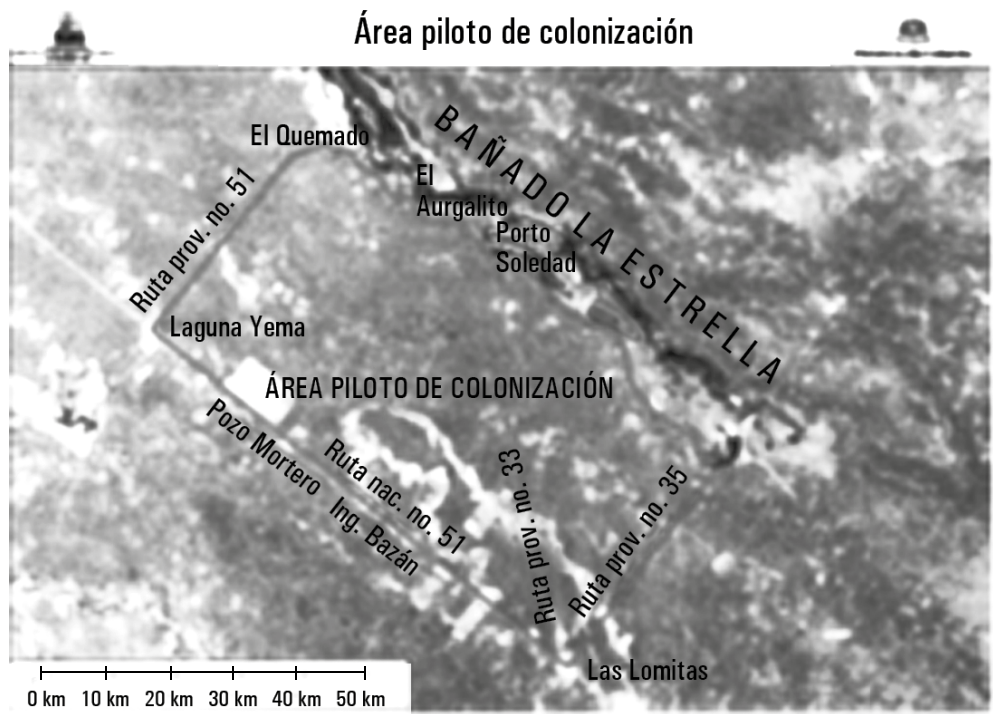

Fuente: Instituto de Colonización y Tierras Fiscales. Plan de Colonización y Ordenamiento Territorial y Catastral de la Tierra Pública, pp. 11 y 37. 
En efecto, en el año 2006 el Instituto Provincial de Colonización y Tierras Fiscales generó el plan piloto aludido con dos áreas de colonización, las cuales son los ejes vertebrales sobre los que se montó el Programa de Colonización y Ordenamiento Territorial y Catastral de la Tierra Pública en el oeste formoseño. Si bien este último contempla el tratamiento técnico en una zona macro de unos 2.2 millones de hectáreas, comprendida desde la Ruta Provincial 24 hasta la Línea Barilari, como se observa en el mapa 2 , el área piloto 1 de colonización (véase mapa 3 ) se ubica adyacente al territorio afectado por las obras de la Ruta Provincial 28.

Esta área piloto tiene una superficie estimada de unas 175000 hectáreas y sus límites son: la Ruta Provincial 28 al Este, el límite sur del Bañado La Estrella al Norte, la Ruta Provincial 37 al Oeste y la Ruta Nacional 81 al sur, todo ello al norte de los pueblos de Pozo Mortero y Las Lomitas. Incluye a unos 200 productores homogéneos, ${ }^{32}$ según las perspectivas del plan.

El área piloto 2 abarca una superficie de unas 26167 hectáreas y comprende a unos 26 productores, ${ }^{33}$ en la zona de La Diosa y San Marcos, anexa también al territorio del conflicto aludido. Se ubica dentro del área de la Sección 9a y la Colonia Juan Bautista Alberdi al este y oeste de la Ruta Provincial 28.

En términos generales, el Programa Integral de Colonización y Ordenamiento Catastral de la Tierra Pública en el oeste formoseño se presenta a los productores del Bañado la Estrella como la fuente cierta de ingresos sustentables, crecimiento y desarrollo, para lo cual se los induce explícitamente a seguir las experiencias "convalidadas" en la colonia paraguaya menonita conocida como Filadelfia. En este sentido, se utilizan como testimonios de validación empírica y exaltación de ello imágenes satelitales de Filadelfia y también de empresas de otras provincias que se instalan en el centro-oeste utilizando el mismo sistema de producción. El plan se

${ }^{32}$ Se trata de 200 explotaciones ganaderas. En el plan no se hace alusión a ninguna diferenciación entre ellas. Por el contrario, se avanza en las estimaciones de implantes de pasturas y cría de ganado bovino en proyección lineal. Programa de Colonización y Ordenamiento Territorial y Catastral de la tierra Pública [2006: 39-39].

${ }^{33}$ El programa abarcaba a 26 productores, identificados con apellido y nombre del productor, número de expediente iniciado en el Instituto de Colonización y Tierras Fiscales, y estratificado según la superficie de tierra ocupada y estado legal, es decir, que entre ellos hay productores con Adjudicaciones en Venta, Propiedad Particular, Permisos de Ocupación y fiscales [Programa de Colonización y Ordenamiento Territorial y Catastral de la Tierra Pública, 2006: 42]. 
describe como una muestra del éxito a imitar buscando convencer a los productores locales:

El área Filadelfia, a unos $150 \mathrm{~km}$ al norte del límite internacional República Argentina-Paraguay a la altura de Las Lomitas. Zona conocida como Colonia menonita. Han desmontado una superficie total de 2.500.000 hectáreas, donde mantienen unas 3.000.000 de cabezas de ganado vacuno, todo ello en un lapso de 30 años con lo que queda demostrado sobradamente la sustentabilidad de la técnica empleada, que justamente es similar a la que se propone implementar en el presente Proyecto de Colonización. [...] Si ellos lo han hecho, es posible reproducir el mismo modelo en la zona oeste de nuestra provincia [Programa de Colonización y Ordenamiento Territorial y Catastral de la Tierra Pública, 2006: 1-57].

Por su parte, el área piloto 2 cobrará dinamismo el 6 de enero de 2006 en el paraje La Diosa. Allí, por decisión del poder ejecutivo, se conformará una asociación de productores que llevará como nombre la fecha de su creación. La obtención de la personería jurídica prometía hacia delante mejores oportunidades mostrando el plan como un modelo productivo ganadero sencillo que genera por sí solo los ingresos que permitirán a los productores territoriales la continuidad del desarrollo del Oeste. Con este marco instituido, se afirmará finalmente que:

El modelo productivo ganadero con el sistema silvo-pastoril es el ideal para seguir desarrollando al Oeste formoseño. Su entendimiento es sencillo, todo se basa en implementar pasturas artificiales, mejor manejo de la hacienda y perfección de su genética, las demás necesidades (apotreramiento, corrales, baño, balanza, etc.) se irán concretando de por sí en el entendimiento de que la propia necesidad de los productores más el incremento notable de sus ingresos los habilitará para implementarlos [Programa de Colonización y Ordenamiento Territorial y Catastral de la Tierra Pública, 2006].

Bajo estos mismos principios que entienden que el desarrollo se enraíza solo con y desde las fuerzas productivas locales en idéntica convergencia con los fundamentados por la NoR, en 2010 se planteará en el Plan de Competitividad del Conglomerado Bovino como una segunda línea de trabajo consistente en la conformación de más de una decena de asociaciones de 
pequeños productores con objeto de conseguir el anhelado desarrollo en aquel territorio.

Este plan se había gestado con la alianza entre la Comisión Interna de la Sociedad Rural de Formosa llamada Cabañas Formoseñas y el Ministerio de la Producción, en convergencia con el Plan Estratégico Territorial de Formosa 2015. Aquí, a diferencia de la experiencia liderada por el Instituto de Colonización y Tierras Fiscales, el documento se presentará como un producto consensuado y participativo en el que se definen seis ejes estratégicos, nueve líneas de acción y catorce ideas de proyectos de apoyo a la competitividad. ${ }^{34}$

Así, desde los agrupamientos asociativos civiles, en línea con el primer eje estratégico del plan, se propulsa el engranaje para generar en el territorio un "sistema de producción primaria eficiente" mediante la producción forrajera para el engorde de los animales y la compra de maquinaria asociada. En este sentido la idea del proyecto es:

Con la formación de grupos asociativos de productores se logrará adquirir maquinaria que de otra forma sería dificultoso, por la magnitud de la inversión necesaria. Con esto se logrará realizar actividades tales como siembra y confección de reservas forrajeras [...]. Para el pequeño productor esta idea proyecto constituye la posibilidad de agregarle valor a su producción, tanto en una mejora de la calidad como así también en un aumento de los kilos de carne producidos. Para ello se contempla el armado de un campo con implantación de pasturas y apotreramiento adecuado ejecutado por una asociación de productores y asistido técnicamente por asesores del Plan Ganadero Provincial [Plan de Competitividad del Conglomerado Ganadero Bovino de Formosa, 2010: 40-42].

De este modo se reforzaba el direccionamiento y el liderazgo fijado por los intereses ganaderos dominantes que entienden el sistema primario y su cambio eficiente a partir de la consolidación de estos grupos particulares

${ }^{34}$ Los seis ejes estratégicos que se definieron a partir de una análisis de la matriz FODA (fortalezas, oportunidades, debilidades y amenazas) son: 1) sistema de producción primaria eficiente; 2) campos demostrativos; 3) sistema de comercialización de hacienda; 4) asistencia financiera; 5) capacidad y sanidad de faena; y 6) fortalecimiento institucional. Entre las nueve líneas de acción destacan: asociativismo, asistencia técnica, agregado de valor, capacitación, infraestructura extrapredial e instalaciones de faena. Para mayores detalles véase Plan de Competitividad del Conglomerado Ganadero Bovino de Formosa [2010: 39-52]. 
que presionan sobre los recursos naturales con el objetivo de convertir el territorio en praderas con implantaciones de pasturas y reservas forrajeras que serán funcionales a estos intereses ganaderos de mayor poder económico. Aunque aquí, a diferencia de las pruebas piloto antes analizadas, no se plantea explícitamente la "imitación" del sistema silvopastoril menonita.

En la municipalidad de Ingeniero Juárez, ${ }^{35}$ en tanto, se articulará con las agencias globales ${ }^{36}$ la implementación del Plan Bosque Modelo ${ }^{37}$ Formoseño de base conceptual canadiense y extendida a escala mundial. En Formosa se instituye en el año 2004 como una asociación civil integrada por instituciones ${ }^{38}$ gubernamentales y otras no gubernamentales, en tanto que las empresas con mayor poder económico en el territorio, como las petroleras, no participan de dicha experiencia. La asociación no cuenta con financiamiento propio, lo que constituye su principal debilidad [Red Iberoamericana de Bosque Modelo-RIAMB, 2004: 1-3].

Se trata, entonces, de una herramienta funcional a la NOR de estilo bottom-up y referente luego del Plan Estratégico de Desarrollo Local de Ingeniero Juárez [RIAMB, 2009: 12], cuya implicancia subnacional se acopla a la dinámica impuesta por los actores dominantes: hacia arriba, con las agencias globales aludidas, a través del financiamiento de distintos tipos de proyectos sujetos a sus directrices metodológicas de gestión; ${ }^{39}$ hacia abajo, en

${ }^{35}$ Ingeniero Juárez es la localidad ubicada en el oeste de la provincia de Formosa en el departamento Matacos.

${ }^{36}$ Entre ellas el Centro Regional de Bosques Modelos para América Latina y El Caribe (CRBM-LAC), la Agencia Internacional de Cooperación Japonesa (JІA) y el Programa Fondos Semillas de la Red Iberoamericana de Bosques Modelo.

${ }^{37}$ Bosque Modelo busca la asociación entre individuos, empresas privadas, ong y organismos estatales que, teniendo como meta el desarrollo sustentable de los ecosistemas boscosos, eleve el nivel y la calidad de vida de las comunidades o asentamientos, de bajos recursos como pauta fundamental [Red Iberoamericana de Bosque Modelo-rIAMB, 2009: 9-13].

${ }^{38}$ Entre estas instituciones encontramos: a) gubernamentales: la municipalidad de Ingeniero Juárez (cuyo Intendente preside el BMF), el Ministerio de la Producción y Ambiente, el Centro de Validación de Tecnologías Agropecuarias (Cedeva), el Instituto de Tecnología Agropecuaria (INTA), la Universidad Nacional de Formosa, la Administración de Parques Nacionales Reserva Natural Formosa, el Instituto de Programación de Acción Integral del Pequeño Productor Agropecuario (IPAIPPA), la Oficina de Empleo de Ingeniero Juárez y el Servicio Nacional de Sanidad y Calidad Agroalimentaria, (Senasa); b) no gubernamentales: la Asociación de Madereros, la Federación de Asociaciones de Productores del Extremo Oeste, la Comunidad Toba Qom' Lec, la Comunidad Wichí La Esperanza, la Comunidad Wichí El Mistolar y el Equipo para la Promoción y el Acompañamiento Solidario (Eprasol).

${ }^{39}$ Véase al respecto el trabajo de Ernesto Giuliano [2018: 259]. 
coordinación con las instituciones estaduales provinciales, colaborando en la construcción de nuevos actores que se alinean a la alianza ganadera con su principal fondo de sostenimiento financiero a la producción: el Fondo Fiduciario Provincial (FON.FI.PRo); organizando los primeros remates en la localidad de Ingeniero Juárez [Diario El comercial, 2012], o bien, asociando a productores caprinos o de las comunidades originarias para la producción apícola y la reforestación de algunas hectáreas de sus tierras. Esta lógica construida deviene del hecho de que las principales instituciones que componen y alimentan el BMF a escala regional-local (municipalidad de Ingeniero Juárez, Ministerio de la Producción y Ambiente, Cedeva) son las que sostienen el direccionamiento del espacio de acumulación basado en la explotación de los recursos naturales, fundamentalmente relacionado con la ganadería bovina y en menor medida con el ganado menor (como el caprino) o la producción apícola. En este sentido, por ejemplo:

El Bosque Modelo [...] colabora con la formación de nuevas asociaciones y participa de charlas para trabajar con estas. Es así que ha trabajado junto a productores en la Formación de la Federación de Productores del Extremo Oeste (FAPEO) que vincula diez (10) asociaciones de productores pecuarios con 250 socios en total. Estos son productores pecuarios del departamento de Matacos y Ramón Lista, y como logro tiene la organización del primer remate de hacienda de la zona mejorando de manera notable la rentabilidad de sus socios [RIAMB, 2010: 10].

O bien, ha colaborado de forma comprometida con el estado provincial en la elaboración de los corredores de áreas de conservación de parques protegidos, en conjunto con la zonificación y expansión de la superficie potencialmente explotable, definidos en el Plan de Ordenamiento Territorial de Formosa (Рот-For ${ }^{40}$ a partir de la puesta en vigencia de la Ley nacional 26.331 ${ }^{41}$ [Red Iberoamericana de Bosque Modelo-RIAMB, 2010: 9]. Es decir, los fondos y las estrategias que llegan al BMF desde la escala global,

${ }^{40}$ Al respecto puede consultarse Adámoli, Ginzburg y Torella [2009] en <https://cutt.ly/pd58arQ>. Allí se plantean tres zonas: 1) la occidental; 2) los corredores de conservación; y 3) la oriental. Las tres habilitan nuevas superficies de tierras, potencialmente explotables, hasta alcanzar unos 2.6 millones de hectáreas que sumados a las explotaciones actuales y por realizarse llegan a más de 3 millones de hectáreas.

${ }^{41}$ La ley es de ordenamiento de bosques nativos, la que obliga a las jurisdicciones a construir un plan de ordenamiento al respecto. 
nacional o provincial se orientan, en realidad, a un patrón regulativo verticalizante que se impone desde afuera de la localidad y en consecuencia son incongruentes con las necesidades de sus beneficiarios, quienes plantean:

Los cambios a realizarse deberán enfocarse en lograr mejores ajustes de los proyectos en los beneficiarios en pos de que los donantes cedan o depositen confianza en los ejecutores. Hemos tenido dificultades y consideramos que responden al diseño de los proyectos que se ajustan más a las necesidades del donante de controlar y monitorear los proyectos que a la de los beneficiarios, y a la hora de la ejecución notamos serias dificultades para la apropiación del proyecto [Red Iberoamericana de Bosque Modelo-RIAMB, 2009: 13].

Simultáneamente a estos procesos fragmentados y de gran presión sobre un territorio frágil desde lo ambiental y en sus recursos naturales [Gorleri, 1996] se amplían y consolidan los grupos de empresas nacionales y extranjeras, que desde mediados de los noventa comenzaban a afincarse en las márgenes del canal de agua Laguna Yema-Las Lomitas.

En tal sentido, en el año 2006 se suma a la empresa Garlisi Cereales, S. A., de los hermanos Gómez Luna, ${ }^{42}$ de la provincia del Chaco [Programa de Colonización y Ordenamiento Territorial y Catastral de la Tierra Pública, 2006: 31], a pocos kilómetros de Las Lomitas, la cabaña del empresario ganadero Juan Rolando Bunchich, ${ }^{43}$ que comprara dos mil hectáreas de tierra [Programa de Colonización y Ordenamiento Territorial y Catastral de la Tierra Pública, 2006: 29]. Así, se afincan la firma Proagro, S. A. ${ }^{44}$ [Programa de Colonización y Ordenamiento Territorial y Catastral de la Tierra Pública, 2006: 33] y la empresa de la provincia de San Juan Iceberg, S. A. ${ }^{45}$ En tanto que la firma Sumayen, S. A., será mostrada en los medios

${ }^{42}$ Dicha firma, adquirirá 15000 hectáreas en el área de colonización Las Lomitas-Bazán, con un proyecto de inversión de 9 millones de dólares con destino a la agricultura y la ganadería bovina mediante prácticas silvopastoriles.

${ }^{43}$ Se destina $50 \%$ a la implantación de pasturas artificiales para la cría de ganado bovino y el desarrollo de prácticas genéticas.

${ }^{44}$ El grupo empresario integra como inversores principales a los hermanos Cavigliaso, oriundos de Río Cuarto, Córdoba; Carlos Kerdinesnky, de Formosa, y la firma Winter Hermanos. Sobre un total de 8000 hectáreas, destinan 2000 a la producción de maní tipo confitería, la que se exporta íntegramente hacia la Unión Europea, Japón y China (Infocampo, "Maní, se afirma la producción en Formosa").

${ }^{45} \mathrm{Al}$ respecto, Ricardo Vailati (funcionario provincial a cargo del Cedeva - Laguna Yema) explica que: "La decisión [de la firma] de elegir a Formosa se tomó por la radicación en las proximidades de Las Lomitas de 
de información nacional, como desarrolladora de cultivos pocos tradicionales en la región, por ejemplo, los espárragos con destino de exportación a la Unión Europea. ${ }^{46}$

Por otra parte, en 2007 y después de un año de negociaciones con la empresa australiana LIAG S. A., el gobierno provincial decidirá quitar a la multinacional 30634 hectáreas porque no cumplió con las inversiones previstas en el proyecto. ${ }^{47}$ No obstante esta decisión negociada, la empresa continúa operando en la localidad de Laguna Yema, con una extensión de 9366 hectáreas.

\section{CONCLUSIONES}

A la luz de los procesos analizados se ha podido observar que la NOR no solo ha tenido una amplia y creciente penetración en el escenario latinoamericano, sino que además ha surcado con profundidad en escalas provinciales y municipales, como es el caso de Formosa. Su avance e ingreso no nada más ganaron espacio desde los análisis académicos, sino también en el cuerpo de instituciones forjadoras de políticas públicas del desarrollo local y la descentralización, donde la influencia del cuerpo teórico producido e introducido en los países centrales luego fue asimilada de manera acrítica tanto por organismos supranacionales que operan en la región como por las instituciones nacionales, provinciales y locales.

El anclaje del centro-oeste de Formosa muestra concretamente el despliegue de esta intervención. En esa dinámica, el acoplamiento de las políticas

empresas con tecnología de riego y con la infraestructura necesaria para poder llevar adelante el proyecto, [...] con destinos exportables a Inglaterra, Holanda y Alemania y el mercado interno con destino a Buenos Aires y Mendoza" (Diario La Mañana Formosa, Información General, 16-12-2008).

${ }^{46}$ Véase La Nación, "La ventaja de cosechar antes que todos", <https://cutt.ly/id1dfr2>.

${ }^{47}$ El Instituto de Colonización y Tierras Fiscales argumenta que se trató de una decisión que llevó un año de negociaciones al no haber dado cumplimiento cabal al proyecto original de inversión de 52 millones de dólares que preveía la puesta en producción de 18000 hectáreas y al no haber instalado una desmotadora de algodón, como se acordó inicialmente. Véase La Nación, secc. Economía, "Marcha atrás en una venta de tierras fiscales en Formosa. Liag deberá devolver 30.000 hectáreas compradas en 1996", 31 de diciembre de 2007. <https://cutt.ly/ $\mathrm{Td} 1 \mathrm{dnWs}>$. Así también, la venta de las tierras a dicha empresa a precios fiscales había generado la denuncia de diferentes organizaciones sociales y políticas que intentaron que adquiriera un costo político y social significativo. En la actualidad, la empresa continúa operando con una extensión de 9366 hectáreas, de las que más de 5000 operan bajo riego. 
públicas fragmentarias en el anclaje estudiado revela la puesta en juego de un conjunto de DREF y estrategias de actores diversos que van caracterizando el espacio de acumulación con elementos que marcan la selectividad de las políticas públicas, las tensiones y disputas por los recursos naturales.

Esa dinámica procesal, al trabajar institucionalizada con arreglos escalares verticalizantes y hegemónicos mediante políticas desarticuladoras y fragmentarias, genera un profundo proceso de reestructuración escalar del Estado funcional a la reproducción neoliberal y sus nuevas formas de mercantilización y subordinación. De allí que en contextos periféricos como los de Formosa resulta imprescindible conocer cómo opera dicho proceso, ya que al estar ausente del aparato discursivo de la Nor el papel que desempeñan las escalas, tampoco existe una centralidad puesta sobre el papel del Estado en dicha plataforma común.

Ello es producto de un patrón regulativo escalar que de manera fragmentaria, como venimos observando, cuando opera en el espacio, se funcionaliza a una lógica de intereses vinculados fundamentalmente con la alianza con los grupos ganaderos, de los agronegocios y de organizaciones globales que penetran y presionan a los actores más vulnerables, como las poblaciones originarias o los pequeños productores, los que quedan como sujetos de un camino que inyecta la promesa irresoluta de alcanzar el desarrollo endógeno y un mejor bienestar, según presagian los postulados de estas planificaciones de "consenso" y de base comunitarista-localista.

Sin embargo, su dinámica incorporada en el territorio, como se ha visto, genera relaciones jerárquicas de tamaño y poder, y decisiones sobre los recursos naturales que resultan asimétricas e inestables desde lo social, económico y político. De modo que el espacio se transforma, pero de manera desigual.

\section{Referencias}

Adámoli, Jorge, Rubén Ginzburg y Sebastián Torella [2009], POT-For. $<$ https://cutt.ly/pd58arQ>.

Amnistía Internacional [2010], "Exigimos respeto". Argentina: Los derechos de los Pilagás del Bañado la Estrella. <https://cutt.ly/OgkVdIS>. 
Azpiazu, Daniel y Martín Schorr [2010], "La industria argentina en la posconvertibilidad: reactivación y legados del neoliberalismo", en Problemas del Desarrollo. Revista Latinoamericana de Economía, México, Universidad Nacional Autónoma de México, abril-junio, vol. 41, núm. 161, pp. 111-139. <https://cutt.ly/KgkVhLX>.

Azpiazu, Daniel, Pablo Manzanelli y Martín Schorr [2011], "Concentración y extranjerización en la economía argentina en la posconvertibilidad (2002-2008)", en Cuadernos del Cendes, vol. 28, núm. 76, pp. 97-119.

Bobadilla de Gane, V. y Rafael A. Silva [2004], Formosa: recursos, ambiente y posibilidades para el desarrollo. Formosa, El Docente, pp. 138-144. Brenner, Neil [2003], “'Glocalization' as a State Spatial Strategy: Urban Entrepeneurialism and the New Politics of Uneven Development in Western Europe", en Jamie Peck y Henry Wai-chung Yeung (eds.), Remaking the Global Economy. Economic-Geographical Perspectives. Londres, Sage, pp. 197-215.

Brenner, Neil, Jamie Peck y Nik Theodore [2010], "After neoliberalization?", en Globalizations, vol. 7, núm. 3, pp. 327-345.

Brown, A. et al. [2010], Bitácora del Bañado la Estrella. Dinámica fluvial de un espacio compartido. <https://cutt.ly/Hs3DzSc $>$.

Bunker, Stephen [1984], "The exploitation of labor in the appropriation of nature", en Charles Bergquist (ed.), Labor in the Capitalist WorldEconomy. Londres, Sage, pp. 49-73.

Codutti, Raúl [2005], Consultoría, diagnóstico agrario y rural de la provincia de Formosa. Formosa, Ministerio de Economía y ProducciónProinder.

Diario El comercial [2012], "Exitoso tercer remate ganadero en Ingeniero Juárez", en Diario El comercial, Formosa, Argentina, 8 de agosto. $<$ www.elcomercial.com.ar/>.

Duerksen, M. [2011], "Los menonitas, protagonistas de la historia del Chaco y del Paraguay", en abc color, 12 de abril de 2011. <www.abc.com.py>. Fernández, Víctor Ramiro y Lucas Gabriel Cardozo [2012], "Nueva estatidad bajo la re-emergencia regional. La reelaboración del proyecto neoliberal y sus alteraciones en la periferia", en Revista Brasileira de Estudios Urbanos e Regionais, vol. 14, núm. 2, pp. 11-33. 
Fernández, Víctor Ramiro y María Jimena García Puente [2010], "Transformaciones Estatales ¿Cambio en sus funciones? Revisando perspectivas teóricas para analizar el Estado contemporáneo", en Revista de la Facultad de Ciencias Jurídicas y Sociales, vol. 1, núm. 8, pp. 137-48. Fernández, Víctor Ramiro, José Ignacio Vigil y Martín Seval [2012], "Explorando la región. Territorios, escalas y relacionalidades", en Revista de geografía Norte Grande, Santiago, mayo, núm. 51, pp. 21-41.

Fernández, Víctor Ramiro y Christian Rubén Seiler [2015], "Procesos de acumulación, industria y Pyme. El caso argentino y los límites del neodesarrollismo", en Sociedad y Economía, núm. 30, pp. 225-253.

Formosa 2015. El plan de inversiones que conduce a la visión de largo plazo. <https://cutt.ly/PgkVcG2>.

Giuliano, Ernesto F. [2015], Sociedades periféricas y multiterritorios. Análisis de la estructura social de Formosa en el ciclo 1980-2002. Buenos Aires, La Colmena.

[2018], Los cambios a nivel funcional y espacial del Estado y la estructura territorial productiva formoseña. Análisis del ciclo 1991-2012. Tesis, Facultad de Ciencias Sociales, Universidad de Buenos Aires.

González, Sara [2005], "La geografía escalar del capitalismo actual", en Geo Crítica. Scripta Nova. Revista electrónica de geografía y ciencias sociales. Barcelona, Universidad de Barcelona, vol. IX, núm. 189. $<$ http://www.ub.es/geocrit/sn/sn-189.htm>

Gorenstein, Silvia [2012], "Acumulación y desarrollo regional. Discusiones, enfoques y temas sobre la experiencia del norte argentino", Silvia Gorenstein (org.), ¿Crecimiento o desarrollo? El ciclo reciente en el norte argentino. Buenos Aires, Miño y Dávila.

Gorleri, Carlos [1996], "Auditoría del impacto ambiental de la actividad petrolera en el Oeste de la Provincia de Formosa". Monografía para la Maestría en Gestión Ambiental y Ecológica. Facultades de Arquitectura y Urbanismo, Ciencias Exactas y Naturales. Universidad Nacional del Nordeste, Corrientes, Argentina, pp. 1-25.

Jessop, Bob [2010], "What follow neo-liberalism? The deepening contradictions of US domination and the struggle for a new global order", en Robert Albritton, Bob Jessop y Richard Westra (eds.), Political economy and global capitalism. The 21st century, present and future. Londres, Anthem Press, pp. 67-88. 
[2008], El futuro del Estado Capitalista. Madrid, De la Catarata. [1994], "Post-fordism and the state", en Ash Amin (ed.), Post-Fordism. A reader. Malden, Mass., Blackwell, pp. 251-79.

Luccerini S, E. Subovsky y E. Borodowski [2013], "Sistemas silvopastoriles: una alternativa productiva para nuestro país”, en Apuntes Agronómicos, Facultad de Agronomía-Universidad de Buenos Aires, año 7, núm. 8.

Ministerio de Economía y Finanzas Públicas de la Nación [2006], Plan de Colonización y Ordenamiento Territorial y Catastral de la Tierra Pública. Plan de afincamiento de explotaciones ganaderas sistema silvopastoril con presupuesto, 2006. Instituto Provincial de Colonización y Tierras Fiscales, Provincia de Formosa. <https://cutt.ly/7gkVQY3>.

[2010], Programa de Competitividad del Norte Grande. Plan de Competitividad del Conglomerado Ganadero Bovino en la Provincia de Formosa.

Peck, Jamie [2002], "Economías políticas de escala: políticas rápidas, relaciones interescalares y workfare neoliberal", en Víctor Ramiro Fernández y Carlos Brandão, Escalas y políticas del desarrollo regional. Desafíos para América Latina. Buenos Aires, Miño y Dávila.

[2013], "Explaining (with) neoliberalism”, en Territory, Politics, Governance, vol. 1, núm. 2, pp. 132-157.

Peck, Jamie y Adam Tickell [1994], "Searching for a New Institutional Fix: the After-Fordist Crisis and the Global-Local Disorder", en Ash Amin (ed.), Post-Fordism. A reader. Malden, Mass., Blackwell, pp. 280-315. [2002], "Neoliberalizing Space", Oxford, Editorial Board of Antipode, pp. 380-404.

[2003], "Making global rules. Globalization or neoliberalization?", en Jamie Peck y Henry Wai-Chung Young (eds.), Making the global economy. Londres, Sage, pp. 163-181.

[2007], "Conceptualizing neoliberalism, thinking Thatcherism", en Helga Leitner, Jamie Peck y Eric Sheppard (eds.), Contesting neoliberalism. Urban frontiers. Nueva York, The Guilford Press, pp. 26-50. Programa de Colonización y Ordenamiento Territorial y Catastral de la Tierra Pública [2006], Instituto Provincial de Colonización y Tierras Fiscales, Provincia de Formosa. Argentina, pp.1-57. 
Red Iberoamericana de Bosque Modelo (RIAMB) [2014], consultado el 05/11/2015. <https://cutt.ly/5d1agg6>. [2013], 13 de noviembre de $2014<$ https://cutt.ly/Rd1azLJ>. [2010], 12 de octubre de $2011<$ https://cutt.ly/hd1avB6>. [2009], Bosque Modelo de Iberoamérica. Bosque Modelo Formoseño, pp. 9-13.

Rofman, Alejandro Boris y Luis Alberto Romero [1997], Sistema socioeconómico y estructura regional en la Argentina. Buenos Aires, Amorrortu. Schorr, Martín, Esteban Ferreira y Silvia Gorenstein [2012], "Complejos productivos con encadenamientos industriales en el norte argentino: algodón, azúcar y foresto-industria”, en Silvia Gorenstein (org.), ¿Crecimiento o desarrollo? El ciclo reciente en el norte argentino. Buenos Aires, Miño y Dávila.

Sued, Gabriel [2006], "Los secretos de Gildo Insfrán, el modelo de gobernante perpetuo", en La Nación. <www.lanacion.com.ar>.

Vaca, Josefina y Horacio Cao [2004], "La división regional del trabajo en la Argentina: nuevos elementos y tradicionales desequilibrios", en Realidad Económica, núm. 202, pp. 65-86.

Vailati, Ricardo [2008], "Merced al apoyo del Cedeva de Laguna Yema se tuvieron buenos rendimientos en cucurbitáceas". Diario La Mañana, Información General, publicado el 16 de diciembre. Formosa, Argentina. 


\title{
9. ESTADO, DESARROLLO Y MINERÍA EN AMÉRICA LATINA. INDAGACIONES SOBRE LAS CAPACIDADES DEL ESTADO PARA UNA ESTRATEGIA DE DESARROLLO' ${ }^{1}$
}

\author{
Alejandro Federico Casalis*
}

INTRODUCCIÓN

Los recursos naturales ocupan un lugar importante en los procesos de acumulación en América Latina, ya sea por su implicancia en la estructura económica y social como por su significación en términos políticos y espaciales. Constituyen el principal producto de intercambio de la región en el comercio internacional, pero también son un factor que ha condicionado las posibilidades de desarrollo de la misma tanto por la tendencia al deterioro de los términos de intercambio como por la especialización de la estructura productiva y la dependencia tecnológica y financiera del capital trasnacional asociadas con la explotación de los mismos.

* Licenciado en Ciencia Política por la Universidad de Buenos Aires (UBA), magister en Políticas Sociales por la Facultad Latinoamericana de Ciencias Sociales (Flacso) y posgraduado en Gestión y Control de Políticas Públicas de Flacso. Doctorando en Desarrollo Económico en la Universidad Nacional de Quilmes (UNQ). Es docente, investigador y coordinador técnico del área Estado y Políticas Públicas de Flacso, donde también se desempeña como secretario académico de la Maestría en Políticas Públicas para el Desarrollo con Inclusión Social y como coordinador académico del Diploma Superior en Desarrollo Local, Territorial y Economía Social. Es docente de grado en la Universidad Nacional de La Matanza y de posgrado en la Universidad Nacional de Quilmes y la Universidad Nacional de Tres de Febrero. Forma parte del comité de redacción de la Revista Estado y Políticas Públicas de Flacso. Sus temas de investigación remiten a Estado y desarrollo, desarrollo regional y minería, gobiernos locales y economía social y solidaria. Correo electrónico: <acasalis@flacso.org.ar>.

${ }^{1}$ Capítulo elaborado con base en la ponencia "Recursos naturales y desarrollo en América Latina. Límites y condiciones en un contexto posneoliberal" presentada en el taller "Alternativas al neoliberalismo en América Latina: explorando potencialidades y limitaciones del pensamiento latinoamericano sobre desarrollo", organizado por el Instituto de Investigaciones Económicas (IIEC-UNAM, México), el Instituto de Pesquisa e Planejamiento Urbano e Regional (IPPUR-UFRJ, Brasil) y el Instituto de Investigaciones en Estado, Territorio y Economía (IIETE-UNL, Argentina), y realizado del 23 al 25 de marzo de 2015 en la unAm, Ciudad de México. 
Durante la primera década del siglo xxi y hasta el año 2013, para la mayoría de los países de América Latina los recursos naturales (minerales, petróleo y productos agropecuarios) adquirieron renovada significación como fuente de acumulación y componente importante del financiamiento de las transformaciones políticas, económicas y sociales que estos países impulsaron. Asimismo, en América Latina se recuperó el debate acerca de la potencial contribución de estos al desarrollo y el aporte para impulsar procesos de industrialización e inclusión social y dotar al Estado de mayor autonomía en la toma de decisiones. Esto sucedió en un contexto más amplio como el fin del Consenso de Washington, la emergencia de las experiencias políticas nacionales y populares en la región y el pasaje de la globalización unipolar a la multipolar, lo cual generó novedosas condiciones para el desarrollo de América Latina. Sin embargo, estos procesos no estuvieron exentos de debates y contradicciones. Más aún, abrieron interrogantes acerca de la capacidad del Estado para generar procesos de acumulación sostenibles, revertir estructuras productivas primarizadas e imponer condiciones al capital trasnacional para sostener los procesos de desarrollo iniciados.

El objetivo de este capítulo es analizar los condicionamientos que el Estado enfrenta en América Latina para impulsar estrategias de desarrollo a partir de la utilización e industrialización de los recursos naturales, tomando como punto de referencia la minería. El artículo se organiza en tres partes. En la primera indagaremos en los principales planteamientos del estructuralismo latinoamericano, la teoría de la dependencia y el neoestructuralismo cepalino acerca del papel que asignan al Estado en relación con el uso de los recursos naturales para impulsar una estrategia de desarrollo. En la segunda parte, poniendo el foco específicamente en la desregulación del sector minero y la apertura a la inversión externa directa (IED) que se produjo a partir de fines de la década de 1980 en la región y en Argentina, daremos cuenta de las transformaciones del Estado y la erosión de sus capacidades en relación con una estrategia nacional de desarrollo. En la tercera parte analizaremos las debilidades que presenta el Estado en la periferia para orientar el proceso de desarrollo y señalaremos los límites que la minería pone de manifiesto en una estrategia de desarrollo de los gobiernos nacionales populares en América Latina cuando la construcción de capacidades estatales es acotada y limitada. Para ello, y con fines 
ilustrativos, se hará una breve referencia a Bolivia y Argentina por ser casos muy diferentes en cuanto a estrategia de desarrollo a partir de los recursos mineros. Finalmente, en las conclusiones se retoman los planteamientos centrales del pensamiento latinoamericano en lo que se refiere a la viabilidad de una estrategia de desarrollo basada en la explotación e industrialización de los recursos mineros, teniendo en cuenta los condicionamientos que operan sobre los Estados en la periferia en la fase actual de financiarización del capitalismo y con una función significativa como la que tienen las empresas trasnacionales en el sector en el marco de la globalización multipolar.

ESTADO, DESARROLLO Y RECURSOS NATURALES: PRINCIPALES PLANTEAMIENTOS

EN EL PENSAMIENTO LATINOAMERICANO

La tradición del pensamiento latinoamericano acerca de los recursos naturales es amplia y diversa. En este trabajo privilegiamos referir la tradición cepalina del estructuralismo latinoamericano, la teoría de la dependencia y el neoestructuralismo [Sánchez, 2019]. En todos los casos, identificaremos la consideración que estos enfoques y teorías tienen del Estado y la vinculación con los recursos naturales en relación con el desarrollo y el proceso de acumulación.

El estructuralismo latinoamericano señala que desarrollo y subdesarrollo corresponden a estructuras parciales, pero interdependientes, que componen un único sistema [Sunkel y Paz, 1970]. En el esquema centroperiferia, a América Latina le cabe el papel de una periferia productora de recursos naturales (alimentos y materias primas) que abastece al centro por medio del comercio internacional. Contrario a los planteamientos clásicos de la teoría económica que señalan que el fruto del progreso técnico tiende a distribuirse de forma equitativa mediante el comercio internacional y recomiendan la especialización en aquellos bienes y sectores en los que se disponga de ventajas comparativas, el estructuralismo latinoamericano postula que de perpetuarse esta situación de especialización en la producción y exportación de recursos naturales, lejos de desarrollarse, la periferia va a reproducir su situación de subdesarrollo. En esta perspectiva, salir de esta situación requiere un cambio estructural y la vía para ello es la industrialización mediante la acción del Estado [Prebisch, 1949]. 
Para el estructuralismo latinoamericano, la estructura socioeconómica de la periferia se caracteriza por:

i) especialización en bienes primarios y baja diversidad productiva (escasa complementariedad intersectorial e integración vertical); ii) niveles muy dispares de productividad intersectorial y oferta ilimitada de mano de obra con ingresos próximos a la subsistencia; y iii) estructura institucional (Estado, sector agrario y composición empresarial, entre otros) poco inclinada a la inversión y al progreso técnico [Bielschowsky, 2009: 175].

La especialización primaria de la estructura productiva en actividades de baja productividad, junto con un sector moderno y de alta productividad pero de escasa presencia en la economía, configura lo que se conoce como heterogeneidad estructural. Diversificar la estructura productiva mediante la industrialización implica realizar inversiones en simultáneo e incrementar el nivel de ahorro.

Pero la pregunta central para esta perspectiva era cómo se financiaba el desarrollo. Hasta la década de los sesenta, la respuesta de la Comisión Económica para América Latina y el Caribe (Cepal) indicaba que dicha función debía asumirla el Estado ${ }^{2}$ modernizando el sector primario para que aporte las divisas necesarias, genere demanda industrial y haga un uso eficiente del comercio internacional para impulsar el desarrollo. Prebisch señala que:

la industrialización de América Latina no es incompatible con el desarrollo eficaz de la producción primaria. Por el contrario, una de las condiciones esenciales para que el desarrollo de la industria pueda ir cumpliendo el fin social de elevar el nivel de vida, es disponer de los mejores equipos de maquinarias e instrumentos, y aprovechar prontamente el progreso de la técnica en su regular renovación. La mecanización de la agricultura implica la misma exigencia. La solución no está en crecer a expensas del comercio exterior, sino en saber extraer, de un comercio exterior cada vez más grande, los elementos propulsores del desarrollo económico [Prebisch, 1949: 4].

${ }^{2}$ Luego, a partir de la década de los sesenta y ante la evidencia de la dificultad para generar un nivel de ahorro suficiente para impulsar el desarrollo, la Cepal recomendó la apertura al capital externo. 
De este modo, como se infiere de la cita anterior, para el estructuralismo latinoamericano los recursos naturales cumplen la función de financiar el desarrollo industrial. Esto pone de manifiesto que la orientación del pensamiento estructuralista latinoamericano de un desarrollo "hacia adentro" no es incompatible con el desarrollo del sector primario, pero sí que supone la subordinación de los recursos naturales al desarrollo industrial. ${ }^{3}$

Finalmente, Prebisch indica que si bien América Latina no puede pretender generar desarrollo si solo sigue creciendo "hacia fuera" por medio de la exportación de productos primarios, ello no significa que:

la exportación primaria haya que sacrificarse para favorecer el desarrollo industrial [...] Si con el progreso técnico se logra aumentar la eficacia productora, por un lado, y si la industrialización y una adecuada legislación social van elevando el nivel de salario real, por otro, se podrá ir corrigiendo gradualmente el desequilibrio de ingresos entre los centros y la periferia, sin desmedro de esa actividad económica esencial [Prebisch, 1949: 11].

Esto evidencia que, para el pensamiento estructuralista latinoamericano, los recursos naturales no son incompatibles con la industrialización ya que aportan las divisas para financiarla, pero un aprovechamiento eficiente requiere subordinarlos a la estrategia de desarrollo. A pesar del aumento coyuntural del precio internacional de los bienes primarios, a largo plazo se verifica el deterioro de los términos de intercambio para realizar un aporte de divisas. Así mismo, el sector primario debe incrementar su productividad y eso requiere que sea modernizado. También, la inversión externa puede ser útil para elevar la productividad del sector primario, pero debe estar subordinada al proyecto de industrialización. El Estado ha de estimular el ahorro y utilizar las rentas que provienen del sector primario para incrementar la productividad del conjunto de la economía.

A finales de la década de los sesenta, la teoría de la dependencia señala que América Latina no ha podido salir del subdesarrollo porque en realidad

${ }^{3}$ De allí que desde la década de los sesenta, aunque ya habían sucedido algunas experiencias en la década anterior, se generan políticas para modernizar el sector primario [Bielschowsky, 2009]: reformas agrarias, expropiación de latifundios, control de los recursos petroleros y mineros mediante las políticas de nacionalización de empresas y la creación de empresas públicas, que se suman a las reformas fiscales y financieras para atraer capitales extranjeros. 
existe una estructura de dependencia entre el centro y la periferia que hace que estas relaciones sociales de dependencia se reproduzcan. De ese modo, el subdesarrollo no es una etapa anterior al desarrollo sino la condición del desarrollo de los países centrales [Dos Santos, 2003].

En el sector primario, y en particular en el minero, opera una lógica de economías de enclaves [Cardozo y Faletto, 1969]. El enclave es una expresión de la conformación de relaciones sociales asimétricas porque opera como una prolongación tecnológica y financiera de los países centrales hacia la periferia, y profundiza la relación centro-periferia porque extrae riqueza del territorio para sostener la acumulación económica y social en el centro, a la vez que genera un conjunto de relaciones sociales que perpetúan las condiciones económicas, sociales, políticas y culturales de subdesarrollo y dependencia. Además, pese a ser un "sector moderno", tiende a no actuar como agente de modernización transformando la estructura productiva, modificando el mercado de trabajo y propagando la innovación tecnológica más allá de las fronteras estrictas del enclave.

Los enclaves mineros tienen consecuencias negativas sobre la mano de obra y el grado de concentración del ingreso, ya que "en los enclaves mineros es reducido el nivel de ocupación, pero es alta la concentración de capital [...] y presenta cierta tendencia a un bajo nivel de distribución del ingreso desde el punto de vista de la economía nacional" [Cardozo y Faletto, 1969: 50]. Del mismo modo, tienen un carácter extractivo y están controlados por el capital extranjero, sin generar encadenamientos significativos con la estructura productiva y con un escaso aporte de divisas en relación con el nivel de importaciones que demandan y la remisión de utilidades que realizan.

La teoría de la dependencia muestra que los enclaves mineros generan límites para el desarrollo en tanto muestran la dependencia financiera que genera la exportación de recursos naturales ya que insume, en especial en el sector minero, grandes flujos de capital para financiar las importaciones. Además, implican demanda de divisas para remitir utilidades a las casas matrices; generan dependencia de las oscilaciones en el precio internacional de los commodities; profundizan la supeditación del capital trasnacional que opera en el sector; prolongan la dependencia tecnológica ya que los países productores de recursos naturales por lo general carecen de la tecnología, los insumos y los bienes de capital necesarios para explotar e industrializar 
los yacimientos; y dan lugar a un empresariado nacional subordinado al capital trasnacional y desplazado a los eslabones menos rentables del sector.

La globalización y el ascenso del neoliberalismo marcan un replanteamiento del pensamiento latinoamericano y esto se profundiza por las condiciones de endeudamiento de inicios de la década de 1980. En este contexto, se evidencian los problemas adicionales que la sustitución de importaciones genera, fundamentalmente en el abastecimiento de divisas para sostener el proceso industrial y dar cumplimiento al pago de la deuda externa [Leiva, 2008]. Los debates sobre el desarrollo son sustituidos por los del crecimiento y la apertura externa. El Estado, como agente principal del desarrollo, es desplazado por el mercado.

Fajnzylber, luego de analizar la evolución que ha tomado el sector primario (en particular agrícola) en comparación con el sector industrial en América Latina, sostiene que el

peculiar patrón de industrialización de América Latina ha desarrollado una relación con el sector agrícola que no solo se ha traducido en una competitividad internacional decreciente, sino que además no ha sido capaz de aprovechar plenamente las potencialidades del mercado que el sector agrícola le ofrecía [Fajnzylber, 1983: 234].

Esto lleva al autor a afirmar la relevancia del sector primario no solo para proveer divisas, sino para generar oportunidades de industrialización y agregado de valor en la industria siderúrgica, metalúrgica, metalmecánica, auto y agropartista, química y petroquímica, transporte y genética animal y vegetal, es decir, que el sector primario sea un estímulo para el desarrollo del sector industrial y de servicios. De allí que plantea una propuesta de "nueva industrialización" y recomienda no excluir los recursos naturales (sobre todo del agro) de las estrategias de desarrollo sino modernizarlos para que la producción exportable aumente, con la expectativa de que el comercio exterior genere más divisas y transforme las estructuras productivas primarizadas y los patrones de inserción internacional de la región en la división internacional del trabajo. ${ }^{4}$

\footnotetext{
${ }^{4} \mathrm{~A}$ pesar de los logros en la industrialización de algunos países de América Latina durante las décadas de los cincuenta y sesenta, ese esquema de relacionamiento de la periferia con el centro que describía el
} 
Con la consolidación del neoliberalismo, los recursos naturales pasan a ser materia de apropiación y penetración de las redes del capital trasnacional en el marco de las transformaciones del capitalismo en su etapa de "financiarización". En la región, los recursos naturales se convierten en el instrumento para la llegada de divisas tanto por el ingreso de la IED como por el aporte que realizan por las exportaciones. A partir de 1990, surge el enfoque neoestructuralista de la Cepal, que plantea una nueva estrategia de desarrollo. Se abandona la posición industrialista y se asume una orientación aperturista y la fusión del enfoque estructuralista con el schumpeteriano [Bielschowsky, 2009]. Hay un pasaje desde la intención de generar una modernización de la estructura productiva por la vía de la industrialización, con un papel central del Estado, a postular una modernización por la vía de la internacionalización de la economía y el aumento de las exportaciones -que para el caso de los países latinoamericanos son sus bienes primarios y los recursos naturales con mayor agregado de valor posible, pero bienes primarios al fin- como forma de financiar el desarrollo.

Este enfoque plantea la necesidad de aumentar la especialización productiva pero, a la vez, incorporar innovación tecnológica, es decir, que la nueva vía para producir el cambio estructural sea agregar valor a la exportación primaria [Cepal, 1990]. También recomienda la implementación de un conjunto de reformas del Estado que tiene como objetivo desregular y liberalizar la economía al capital trasnacional para aumentar la productividad y la competitividad, y considera la necesidad de generar políticas anticíclicas frente a la volatilidad financiera y el movimiento de capitales especulativos [Cepal, 1990]. Así mismo, se aconsejan reformas institucionales específicas para mitigar los efectos de la liberalización y compatibilizar equidad, gobernabilidad democrática y desarrollo económico [Cepal, 2000], pero lo cierto es que se abandona la estrategia estructuralista y se subordina a las lógicas que el neoliberalismo y la globalización imponen [Osorio, 2003].

En síntesis, a diferencia de la teoría basada en las ventajas comparativas, en esta "lectura" sobre el pensamiento latinoamericano que hemos

estructuralismo latinoamericano aún persiste, ahora bajo la forma de una inserción subordinada en las cadenas de valor global. Así lo señala la Cepal [2010] cuando dice que luego de la crisis financiera global de 2008, la mayoría de los países de la región se reprimarizaron a fines de la primera década del siglo xxı, principalmente por el aumento de la exportación de commodities y la penetración comercial de bienes industriales de China. 
realizado, los recursos naturales reciben una mirada crítica ya que se considera que su especialización productiva constituye un factor explicativo de la situación de subdesarrollo y dependencia de América Latina. El estructuralismo latinoamericano señala que el sector primario debe modernizarse y subordinarse a la estrategia de industrialización ya que aporta divisas y es un estímulo a la industrialización. Para la teoría de la dependencia, las economías de enclave constituyen las principales vías de la dependencia porque conforman una prolongación del centro hacia la periferia. Finalmente, con la consolidación del neoliberalismo, la perspectiva neoestructuralista planteará como estrategia de desarrollo la apertura e internacionalización de la economía con especialización productiva en recursos naturales y agregado de valor en los sectores que sea posible.

TRANSFORMACIONES EN EL ESTADO, DESREGULACIÓN DEL SECTOR MINERO Y LA APERTURA A LA IED EN LA REGIÓN Y EN ARgentina

En América Latina, el auge del neoliberalismo y las transformaciones del capitalismo a nivel mundial produjeron cambios en la capacidad de intervención del Estado en el proceso de acumulación y regulación de los recursos naturales. Uno de los más afectados por el proceso de liberalización y desregulación fue el sector minero. El Banco Mundial [1996] sostiene que los procesos de estatización de empresas realizados en la región en las décadas de los sesenta y setenta generaron un estancamiento en el sector minero y constituyeron la barrera principal al ingreso de capitales trasnacionales. En las décadas de 1980 y 1990, el Fondo Monetario Internacional (FMI) y el Banco Mundial (BM) comenzaron a recomendar -y también a establecer como condición para la firma de planes de estabilizaciónreformas económicas que liberalizaron el sector minero [Gutman, 2013].

Un conjunto de factores confluyeron para que el crecimiento del sector minero y su apertura al capital trasnacional ocurrieran. En primer lugar, los países de la región comenzaron a implementar reformas como la modernización de los regímenes mineros, el otorgamiento de mayor seguridad en los derechos mineros e incentivos tributarios a la inversión y marcos legales 
favorables, ${ }^{5}$ lo que en algunos países incluyó contratos de estabilidad tributaria por periodos prolongados, como el caso de Argentina. Como señala la Cepal [2013: 23], estos beneficios "se tradujeron en reglas de juego para la inversión minera altamente competitivas y que propiciaban condiciones fiscales más laxas en términos comparativos que las que existen en otras regiones mineras del mundo".

Entre las principales recomendaciones que el Banco Mundial [1996] venía realizando desde la década de 1980 destacan:

-Aspectos legales de la reglamentación minera:

a) Seguridad en la tenencia en cuanto a los derechos de concesión y la posibilidad de otorgarlos a terceros como garantía para obtener financiamiento.

b) Transparencia en los códigos mineros, lo que conlleva la eliminación de los criterios de elegibilidad discrecional para el otorgamiento de derechos.

c) Acceso a los recursos mineros, lo que implica que el Estado libere las tierras reservadas para prospección y explotación a las empresas estatales o paraestatales y que el acceso al capital privado sea en condiciones no onerosas.

-Régimen de inversión:

a) Acceso a divisas a valor de mercado para el pago de importaciones, reembolso de préstamos y repatriación de utilidades.

b) Eliminación del control de cambios para la venta y exportación de la producción a precios internacionales.

-Aspectos fiscales de la reglamentación minera:

a) Régimen equitativo tanto para los inversores como en comparación con otros países de la región, y también estable para asegurar que los impuestos se mantengan con escasa variación durante la vida del proyecto.

${ }^{5}$ Según la comparación internacional de 24 países mineros que realizaron Otto et al. [(2007) en Cepal, 2013: 23]: "Chile y la Argentina se encuentran en el $20 \%$ de los países con menor tasa de tributación efectiva y mayor rentabilidad privada". 
b) Tributación basada en el ingreso, nulas o bajas regalías, impuestos nulos o bajos a la importación de bienes de capital, eliminación de impuestos sobre los activos y sobre las utilidades, reembolso sobre el pago al impuesto al valor agregado.

-Reforma de las instituciones mineras públicas:

a) Modernización, aumento de la eficiencia y formación de los recursos humanos.

b) Abandono de las tareas de exploración, prospección, explotación y provisión de servicios por parte del Estado y cesión de las mismas al capital privado.

c) Que el sector público asuma la tarea de generar una política minera orientada al sector privado por medio de la cual promueva inversiones, administre derechos mineros y suministre información geológica.

Adicionalmente, el BM recomienda la promoción de la minería pequeña y mediana y la regulación en materia ambiental, pero estas reformas han tenido menor grado de desarrollo; en realidad se priorizaron las reformas orientadas al mercado y la inversión trasnacional. El Estado redujo su participación en la renta minera, asumió el papel de facilitador de la inversión privada y cedió a las empresas trasnacionales los espacios de mayor rentabilidad. En relación con la pequeña y mediana minería, la posición del BM es ambigua, porque si bien recomienda la promoción de las pequeñas y medianas empresas locales, al mismo tiempo indica que "la pequeña y mediana minería explote los pequeños yacimientos, a menudo, más complejos que no explotan las grandes empresas transnacionales" [Banco Mundial, 1996: xvii].

En términos del geógrafo David Harvey, podemos interpretar que las recomendaciones del BM tuvieron como objetivo generar la valorización de los recursos mineros y crear un "espacio" para la reproducción del capital. Harvey [2007] plantea que el proceso de acumulación capitalista implica la intensificación de las relaciones de producción y un despliegue geográfico del capital. Este proceso genera lo que dicho autor denomina estructuras geográficas [Harvey, 2007], es decir, mecanismos para la reproducción del 
sistema que condicionan los espacios geográficos donde opera el capital. ${ }^{6}$ Del mismo modo, Harvey [2005] señala que el capitalismo recurre a ajustes espacio-temporales para reorientar la sobreacumulación de capital hacia otras regiones. Para ello utiliza los siguientes mecanismos: a) la reorientación temporal de excedentes hacia proyectos de inversión de largo plazo; b) la reorientación espacial de los excedentes hacia la apertura de nuevos mercados, de nuevos sectores productivos y hacia la captación de nuevos recursos e inversión en mano de obra; o c) la combinación de los mecanismos antes mencionados.

La llegada de la IED dirigida hacia el sector minero de la región es parte de este proceso en tanto que se destinan excedentes al desarrollo de "un nuevo mercado" en una región donde hasta 1990 el capital trasnacional y el capital financiero habían permeado poco. La existencia de excedentes disponibles a nivel mundial fue canalizada por el sistema financiero hacia las empresas trasnacionales como préstamos a bajo costo. Así se ponen de manifiesto los ajustes espacio-temporales a los que recurre el capitalismo para mantener e incrementar la tasa de ganancia. El sector minero en América Latina, que comienza a ser desregulado, constituye un nuevo espacio para la expansión del capital mediante la llegada de IED y la entrada del sector en los circuitos de la especulación financiera por las variaciones en el precio internacional de los commodities.

En segundo lugar, el crecimiento acelerado que tuvo la minería en América Latina fue posible debido al surgimiento de nuevas tecnologías -procesos hidrometalúrgicos, pirometalúrgicos, ductos mineros, detección satelital y programas informáticos para evaluar los resultados de la exploración acotando el trabajo de campo- que permitieron explotar yacimientos de mineralización dispersa a menor costo. De lo contrario, esos yacimientos no hubieran podido explotarse con las tecnologías tradicionales [Moori y Bianco, 2003].

En tercer lugar, la existencia de precios internacionales relativamente bajos y estables durante las décadas de 1980 y de 1990 -cuando los organismos internacionales pusieron el tema en la agenda de las reformas

6 Para Harvey, lo mismo que para Lefevre [2013], el espacio constituye una relación social y como tal es socialmente producido por el proceso de acumulación, es decir, por las dinámicas y los sujetos que intervienen en dicho proceso. Para entender el funcionamiento de las estructuras geográficas es necesario observar las dinámicas que se generan en ellas. 
estructurales y se desreguló el mercado en América Latina- amplió la capacidad de imposición de condiciones favorables para las empresas trasnacionales al momento de realizar las reformas. De este modo, cuando a partir de 2003 se evidencia una tendencia en el mediano plazo al aumento en el precio de los minerales, las reformas ya estaban realizadas y la mayoría de las empresas trasnacionales instaladas en la región.

La Cepal [2013: 23] señala que la evolución de la inversión externa minera en la región indica que

entre 2000 y 2013 , la inversión mundial total en proyectos mineros se multiplicó casi por diez, al aumentar de 86.000 a 735.000 millones de dólares, de los que América Latina captó cerca del $30 \%$, seguida por América del Norte (principalmente Canadá), que concentró el $20 \%$, Oceanía (principalmente Australia), con el $17 \%$, y luego África (14\%) y Asia (10 \%) [Cepal, 2013: 23].

Salvo Chile, que posee la empresa pública Corporación Nacional de Cobre (Codelco) ${ }^{7}$ y Bolivia, que nacionalizó sus recursos durante el gobierno de Evo Morales, en la región el Estado tiene una baja participación en la renta minera por la falta de progresividad del sistema tributario y un marco regulatorio laxo para el capital privado. ${ }^{8}$ A diferencia del sector hidrocarburífero, en el que la explotación la realizan empresas públicas y la participación estatal en la renta petrolera en América Latina es mayor, la explotación minera generalmente se hace con base en concesiones y las empresas públicas mineras son una excepción, ${ }^{9}$ con lo cual el Estado relega

7 "La existencia de Codelco le permitió a Chile captar dos tercios del total de ingresos percibidos por la actividad minera debido, que controla aproximadamente un tercio de la producción nacional de cobre" [Cepal, 2013: 13]. Esto muestra la importancia que tiene para el desarrollo poseer una empresa pública que capte la renta minera.

${ }^{8}$ La Cepal [2013: 25] señala que en "los regímenes fiscales del sector minero en América Latina y el Caribe no se han incorporado instrumentos orientados a asegurar la participación progresiva del Estado en periodos de utilidades extraordinarias".

${ }^{9}$ En los regímenes a base de concesiones, el principal impuesto que cobra el Estado es el impuesto a las ganancias o a las utilidades declaradas y en menor medida las regalías, las cuales pueden centralizarse en el fisco o participarse a los gobiernos subnacionales. En Argentina, el aporte fiscal de la minería como porcentaje del aporte fiscal total en el periodo 2010 y 2012 fue de $1 \%$, mientras que en Perú fue de $12 \%$. En el mismo periodo, las regalías representaron casi $10 \%$, en tanto que en Bolivia $40 \%$ y en Colombia $50 \%$ [Cepal, $2013<$ Otto et al., 2007>: 29]. En el año 2007 un fallo de la Corte Suprema rechazó el intento del gobierno nacional de ampliar las retenciones a las exportaciones de oro y cobre por considerar que estaban amparadas en el régimen de estabilidad por 30 años que garantiza la Ley 24.196 de inversiones mineras. 
su participación en la renta minera a pesar de que la mayoría de los países tiene empresas petroleras estatales y por lo tanto cierta capacidad técnica, operativa y política adquirida que le permitiría lograr una participación más progresiva en la renta minera.

\section{Transformaciones en la minería en Argentina y políticas públicas}

A partir de la década de 1990, el sector minero en Argentina comenzó un proceso de transformación e internacionalización sustentado por la llegada de IED, en especial en cobre, oro, y en los últimos años, litio. ${ }^{10}$ Esto generó un cambio en la estructura productiva del sector, que hasta la década de los noventa se caracterizaba por: a) el peso decisivo de la producción del rubro "rocas de aplicación" y en menor medida de los minerales no metalíferos; b) una presencia mayoritaria de pequeños y medianos productores dependientes del mercado interno; y c) una balanza comercial sectorial deficitaria. Adicionalmente, la redistribución de la producción minera regional dio lugar a nuevas regiones antes marginales [Moori y Bianco, 2003].

El crecimiento de la minería en Argentina obedece a la adopción de un marco regulatorio funcional a la estrategia de inversión de las empresas trasnacionales mineras. ${ }^{11}$ Algunos de los beneficios más significativos para el capital trasnacional fueron: la desgravación en el pago de impuestos

${ }^{10}$ La IED pasó de representar 83 millones de dólares estadounidenses en 1992 [Moori y Bianco, 2003] a acumular un total de 12733 millones en el periodo 2007-2016 [Subsecretaría de Desarrollo Minero, 2017].

${ }^{11}$ La modificación al Código de Minería en el año 1993, que estableció que la nación y las provincias poseen la tenencia de las minas pero que no pueden explotarlas, por lo que ceden a los particulares dicha facultad (Arts. 8 y 9 del Código de Minería), la modificación a la Ley de Inversión Extranjera (mediante el decreto 1853 de 1993), la sanción de la Ley 24.196 de Inversiones Mineras en 1993, la Ley 24.224 de Reordenamiento Minero de 1993, la Ley 24.402 de financiamiento y devolución anticipada del IVA de 1994, la Ley 24.228 de Acuerdo Federal Minero de 1995, la Ley 24.498 de Actualización Minera de 1995, la Ley 24.585 de Protección Ambiental de 1995 y el Tratado de Complementación e Integración Minera Argentina-Chile de 1997. Estas modificaciones permitieron: la ampliación de la superficie máxima de exploración y explotación hasta 200000 ha; la eliminación de la prohibición de colindancia para facilitar la explotación de yacimientos con mineralización dispersa; el permiso para realizar un reconocimiento aéreo del terreno con fines mineros, por un tiempo y superficie acotada; la creación de catastros mineros provinciales y su homogeneización; y la armonización de los códigos de procedimientos mineros provinciales con vista a la conformación de un único código procesal. Además, se restablece el criterio de estabilidad del canon minero y se pautan sumas fijas, se fija el beneficio de estabilidad fiscal por 30 años y un tope a las regalías que pueden percibir las provincias, y se elimina la preferencia en cuanto al acceso al crédito oficial para pequeñas y medianas empresas mineras [Moori y Bianco, 2003]. 
indirectos; las exenciones en el pago del impuesto a las ganancias durante los primeros años de explotación y al pago de derechos de importación de bienes de capital, equipos, repuestos y accesorios; la depreciación acelerada para los bienes de capital y la doble deducción del monto invertido para estudios de factibilidad técnica-económica; y la introducción de un nivel máximo de regalías de $3 \%$ para las provincias -derecho que corresponde a la nación por la explotación de sus recursos naturales no renovables. ${ }^{12}$

Ese conjunto de leyes y beneficios tributarios constituyen ámbitos privilegiados de acumulación [Castellani, 2008], concepto que permite describir cómo ha sido la intervención económica estatal y el comportamiento de las empresas trasnacionales mineras. Castellani sostiene que estos "por su función constituyen una fuente de generación de cuasi rentas de privilegio, mientras que si se los define por su forma, pueden pensarse como un entramado de relaciones y/o prácticas de articulación entre actores del sector público y actores privados que se sostienen a lo largo del tiempo" [Castellani, 2008 apud Drulitzky, 2011: 9].

Una cuestión igualmente importante de señalar es que el crecimiento de la megaminería durante la década de 1990 se sirvió de las actividades de exploración y prospección que el Estado había realizado durante las décadas anteriores. En esto se pone de manifiesto la recomendación del BM que sostiene que el Estado debe actuar como "facilitador" de la inversión privada y "proporcionar un catastro de información geológica actualizada a la inversión transnacional" [Banco Mundial, 1996: xv]. El marco regulatorio e institucional se orientó a favor de la apropiación por parte del capital trasnacional del conocimiento socialmente producido (especialistas y profesionales formados pasan a desempeñarse en el ámbito privado), información y relevamientos geológicos efectuados previamente por el Estado, con lo cual se produce una reducción de las capacidades estatales [Evans, 1996; Fernández y García, 2013], tanto en "tiempo presente" como en una "proyección de pérdidas de capacidades estatales a futuro". El Estado pierde capacidades internas e infraestructurales -además se retira de las actividades de explotación y producción- y realiza una transferencia de funciones y capacidades hacia el mercado.

${ }^{12}$ Si bien el pago de regalías no registra niveles homogéneos en América Latina, Argentina es uno de los países que más bajo nivel de alícuota presenta. Además, para establecerlo se toma el valor de "boca de mina", lo que permite deducir los costos directos de explotación [Moori y Bianco, 2003]. 
Las transformaciones del marco regulatorio y fiscal dieron lugar a un crecimiento persistente del complejo minero de Argentina. Según datos de la Secretaría de Minería de la Nación [Casalis y Trinelli, 2013], las exportaciones entre 2002 y 2011 pasaron de 3056 millones de dólares a 16310 , registrando un acumulado de $434 \%$; los proyectos entre 2002 y 2011 se incrementaron de 18 a 614 , acumulando un crecimiento de $3.311 \%$; y las inversiones entre 2002 y 2011 crecieron de 541 millones de dólares a 11078 , lo que significa un aumento de 1948 por ciento.

El mismo fenómeno se replica a nivel subnacional. La minería constituye el principal complejo productivo ${ }^{13}$ y exportador de algunas de las provincias periféricas de Argentina, con significativa incidencia en el producto bruto geográfico ( $\mathrm{PBG}$ ), la recaudación, los puestos de trabajo y los aportes en materia de infraestructura. ${ }^{14}$ Así se muestra la relevancia que la actividad minera tiene en Argentina tanto para el Estado nacional como para las provincias caracterizadas tradicionalmente por tener estructuras productivas especializadas en productos primarios o de bajo nivel de industrialización vinculados a lo que se conoce como economías regionales [Casalis y Trinelli, 2013]. Por otra parte, esto se contrapone con el carácter extractivo que la actividad tiene y la baja participación estatal en la renta minera en relación con la que obtiene el capital privado. Por ejemplo, en el caso de la extracción de oro en San Juan, el Estado nacional obtuvo $30 \%$ en concepto de impuestos y regalías, el sector provincial $5.7 \%$ y el capital trasnacional 64.3\% en el periodo 2006-2010 [Basualdo, 2012].

Un análisis de la composición del sector muestra una presencia mayoritaria del capital trasnacional en la cadena minera y su ubicación en los eslabones de explotación, procesamiento, exportación, industrialización y elaboración de derivados de la materia prima. Las empresas mineras que operan en Argentina son fundamentalmente de Canadá, Estados Unidos, Suiza, Gran Bretaña, Japón, Australia y Sudáfrica, y su capital accionario

${ }^{13}$ Se entiende por complejos productivos "al conjunto de agrupamientos productivos de empresas (independientes o interdependientes) que pertenecen a un mismo sistema de input-output o cadena productiva (explotaciones agropecuarias, unidades industriales, comerciales, de servicios)" [Gorestein, 2012: 42].

${ }^{14}$ Por ejemplo, la provincia de Catamarca recibe más recursos fiscales provenientes de la minería que de la coparticipación federal. Así mismo, en el año 2011 la minería representó para esa provincia $94.8 \%$ de sus exportaciones, por un valor de 1436 millones de dólares, mientras que en San Juan significó $76.1 \%$ de las exportaciones, por un valor de 1885 millones de dólares [Casalis y Trinelli, 2013]. 
está compuesto por una compleja red de fondos de inversión, empresas de seguros, comercio exterior y la industria química, petroquímica, siderúrgica, farmacológica, automotriz, de telecomunicaciones, aeroespacial, electrónica, del vidrio y otros [Dirección de Economía Minera, 2017]. Los principales destinos de las exportaciones argentinas son Estados Unidos, Suiza, Alemania, China, Japón, Corea del Sur y Gran Bretaña, entre otros. Las empresas mineras, a su vez, operan en Argentina mediante filiales nacionales controladas por el capital trasnacional [Dirección de Economía Minera, 2017].

Los principales minerales de exportación son oro, plata, cobre, litio, molibdeno, plomo, hierro y zinc, entre los más representativos. El destino principal de la actividad es la exportación y no el mercado interno, y el carácter de la misma es altamente extractivo ya que se exporta con bajo nivel de industrialización local. Por otra parte, las empresas de origen nacional son en su mayoría de mediano y pequeño tamaño, con una participación subordinada en la cadena de valor. Se ubican en los eslabones menos rentables, proveen bienes y servicios de baja complejidad, y realizan las obras de infraestructura y las tareas de mantenimiento, con participación secundaria en la cadena de valor de la minería. ${ }^{15}$

Debilidades del Estado en la PeRIFERIA Y los límites que la minería MUESTRA EN UNA eStRATEGIA DE DESARROLLo de LOS GOBIERNOS NACIONALES POPULARES EN AMÉRICA Latina

A inicios del siglo XxI, entró en crisis el Consenso de Washington en América Latina. Esto ocurrió en un contexto global de ascenso de Brasil, Rusia,

\footnotetext{
${ }^{15}$ Algunas iniciativas intentan revertir la baja participación de las empresas locales como proveedores. San Juan creó por ley en 2013 un registro único de proveedores mineros el cual establece que $75 \%$ de la facturación anual de obras, bienes e insumos sea comprado a empresas provinciales o radicadas en la provincia y que $75 \%$ de la mano de obra que tomen sea local. Quienes no cumplan con ello recibirán una multa que va de 100000 pesos a un millón de pesos argentinos, cifra que, sin embargo, no parecería significativa para las empresas trasnacionales. También en la ley se aumentan $50 \%$ los impuestos a ingresos brutos y sellos a los proveedores que nos están inscritos en el registro con el objetivo de incrementar la tributación a nivel provincial. Por otra parte, el Ministerio de Industria de la nación creó en 2012 un foro de concertación, en el que participaron hasta 2015 las cámaras que agrupan a las empresas mineras y a los proveedores, para generar acuerdos de sustitución de importaciones, pero la incidencia fue limitada por las exenciones impositivas para la importación de bienes, repuestos e insumos que otorga la ley de inversiones mineras.
} 
India, China y Sudáfrica (conocidos como países BRICS), relocalización del proceso de acumulación en el sudeste asiático y el paso de la globalización multipolar a la unipolar [García y Ruiz, 2013]. En este marco, en la región emergieron gobiernos que recuperan tradiciones políticas de izquierda, nacionales populares e indigenistas [Sader, 2017 y 2015; Mouffe, 2013]. El Estado adquirió centralidad para orientar el proceso de acumulación y se recuperaron los debates acerca del desarrollo [García y Nosetto, 2006]. $\mathrm{El}$ aumento de los precios internacionales de los recursos naturales durante la primera década del siglo xxi hizo que estos últimos adquirieran notoriedad en la composición exportadora regional como fuente de acumulación para sostener los procesos de transformación política, económica y social implementados en la región durante esa misma década.

También dio lugar al surgimiento de críticas a los gobiernos nacionales populares de la región por impulsar estrategias "neoextractivistas" [Svampa, 2013; Gudynas 2012], por el riesgo de primarización de la estructura productiva ${ }^{16}$ y los problemas socioambientales que ocasiona la explotación no sustentable de los recursos naturales. A su vez, sin ser un tema específico de este capítulo, las críticas antes mencionadas tuvieron el acompañamiento y también fueron impulsadas y sostenidas por la acción colectiva y la movilización popular contra los procesos extractivistas en Ecuador, Bolivia, Perú, Brasil y Argentina, entre otros [Martínez, 2015; Cubillo et al., 2014; Merlinsky, 2013]. No obstante, hay diferencias sustantivas entre la extracción de recursos naturales en el marco de las reformas estructurales promovidas por el Consenso de Washington y la extracción de recursos naturales en un proceso de desarrollo de gobiernos nacionales populares que utilizan dichos recursos para impulsar la industrialización, agregar valor, ampliar derechos y fortalecer el sistema de seguridad social, entre otros [Tereschuk, 2013].

Tal vez el caso más significativo sea el de Bolivia, que basó su estrategia de desarrollo en la nacionalización de sus recursos naturales. Esto le permitió ampliar la participación estatal en la renta minera y mediante un manejo prudente del gasto público, en un marco de ampliación de derechos

${ }^{16}$ El sector minero registró entre 2003 y 2012, con excepción de 2008 y 2009, un aumento significativo de la rentabilidad y la inversión, pero también un elevado nivel de repatriación de utilidades. Además, puso de manifiesto la heterogeneidad estructural de la región. 
sociales e incipiente industrialización, sostener con mayor solvencia las transformaciones políticas, económicas y sociales que impulsó el gobierno de Evo Morales [García, 2017]. Un caso emblemático de este proceso lo constituye la explotación del litio, en la que Bolivia junto con Argentina y Chile poseen $80 \%$ de las reservas mundiales. Allí Bolivia desplegó una política propia de industrialización del recurso, desarrollo industrial y agregado de valor para la fabricación de baterías para la industria electrónica y automotriz [Nacif, 2012 y 2018]. ${ }^{17}$

Si bien Argentina, como describimos en la sección anterior, presenta uno de los marcos regulatorios más favorables al capital trasnacional, durante el periodo 2003-2015 logró una mayor participación estatal en la renta minera y desarrolló algunas políticas de ciencia y tecnología vinculadas con el desarrollo del sector. Entre las políticas públicas más destacadas pueden mencionarse la creación de la empresa Y-TEC de YPF y el desarrollo conjunto con el Consejo Nacional de Investigaciones Científicas y Tecnológicas (Conicet), la Universidad Nacional de Jujuy y el gobierno provincial en materia de litio; los proyectos de algunas empresas automotrices para la fabricación de baterías en Jujuy e iniciativas con la industria de la electrónica; la creación de empresas provinciales de minería y de la Organización Federal de Estados Mineros (OFEMI) ${ }^{18}$ algunas políticas del Ministerio de Industria de la nación, de la Secretaría de Minería y/o políticas provinciales destinadas al estímulo de la sustitución de importaciones y el desarrollo de proveedores locales con el objetivo de agregar valor en la cadena minera, generar empleo, diversificar la estructura productiva provincial, crear un registro de proveedores locales y estimular la mayor integración de la producción local y el desarrollo de nuevas tecnologías para la reducción del impacto ambiental, entre otros. Si bien los resultados alcanzados hasta 2015 eran incipientes, la mayoría de estas iniciativas fueron interrumpidas, paralizadas o desfinanciadas a partir de 2016 en el marco de las políticas de desregulación y apertura económica promovidas por el gobierno de Cambiemos en Argentina [Casalis y Trinelli, 2017].

\footnotetext{
${ }^{17}$ Este proceso parece interrumpirse con el golpe de Estado que sufrió Evo Morales en 2019.

18 La OFEMI es una organización creada en 2012 por las provincias mineras a instancias del gobierno nacional de la presidenta Cristina Fernández de Kirchner y disuelta en 2016 a instancias del gobierno nacional del presidente Mauricio Macri, cuando se reactivó el Consejo Federal Minero [Casalis y Trinelli, 2017].
} 
La región experimentó durante la primera década del siglo XxI un cambio cualitativo en cuanto al posicionamiento del Estado frente a los recursos naturales, considerándolos no solo como commodities susceptibles de ser intercambiables en el comercio internacional, sino también como un recurso estratégico [Fornillo, 2014] que bajo nuevas condiciones podría contribuir al desarrollo, agregar valor y diversificar la estructura productiva garantizando la sustentabilidad ambiental [Casalis y Trinelli, 2013; Schteingart y Coatz, 2015; Roger, 2018; Casalis, 2019]. No obstante, este proceso no estuvo exento de contradicciones, ni de las tensiones entre el corto plazo -sostener el producto bruto interno y financiar el gasto público-y el mediano y largo plazos -modificar la estructura productiva y aumentar la autonomía del Estado-; ni mucho menos resultó inmune a los cambios en el contexto externo -caída del precio internacional de los minerales- o la emergencia de problemas económicos propios, nuevas demandas de la ciudadanía, errores políticos y hechos de corrupción, como en Brasil, Ecuador, Chile y Argentina, que condicionaron y estancaron los procesos transformadores iniciados en la región y finalmente dieron lugar al triunfo de gobiernos conservadores que revirtieron los logros de los anteriores [Sader, 2017].

Un análisis crítico de la relación entre recursos naturales, minería y estrategias de desarrollo en América Latina lleva a reflexionar sobre la conformación del Estado en la periferia, la subordinación al capital trasnacional y la inserción actual en la globalización [Fernández y Ebenau, 2013]. Los avances y los retrocesos de los gobiernos nacionales y populares de la región durante el siglo xxI vuelven a posicionar el tema de las capacidades estatales en el centro del debate acerca de las estrategias nacionales de desarrollo y la necesidad de forjar bases más sólidas en las cuales anclar dichas experiencias.

En primer lugar, el sector minero está controlado mayoritariamente por el capital trasnacional; el Estado tiene una baja participación en la explotación de los minerales. Las empresas mineras trasnacionales operan bajo la lógica de la extracción, remiten divisas a las casas matrices y así profundizan la extracción y traslado de recursos desde la periferia al centro. $\mathrm{Su}$ objetivo no está puesto en contribuir con una estrategia de desarrollo, sino en la maximización de la rentabilidad. En ese sentido, la inversión y las 
exportaciones del capital privado están condicionadas a los ciclos de alzas y bajas en el precio internacional de los commodities, con lo que la contribución al producto bruto interno, impuestos, divisas y empleo que realiza la minería constituye una variable sobre la cual los Estados de la región tienen reducida capacidad de control e intervención si no muestran una acción decidida.

En segundo lugar, a pesar de la abundancia de recursos que la región posee, no controla el precio internacional de ninguno de sus minerales. El precio de los commodities depende de la evolución de los ciclos económicos a nivel mundial y está expuesto a las acciones especulativas del capital financiero. Los recursos naturales constituyen apéndices de la valorización del capital y la financiarización de la economía. Así mismo, los ciclos de alza generan presiones sobre el tipo de cambio y elevan los precios internos. Esto afecta la competitividad general del país y de las actividades productivas por el efecto del alza del tipo de cambio.

En tercer lugar, la persistencia de un marco regulatorio laxo, impuesto por los organismos internacionales a instancias del lobby de las empresas mineras durante el periodo de ascenso y consolidación del neoliberalismo, está fundado en los principios de liberalización, apertura y desregulación del sector, con pérdidas de capacidades regulatorias del Estado. De allí que dicho marco garantiza un sinnúmero de beneficios económicos, fiscales y ambientales que confieren a las inversiones mineras estabilidad de largo plazo. El Estado relega su capacidad de utilizar los recursos mineros para impulsar el desarrollo debido a una regulación poco favorable a la transferencia de tecnología y muy ventajosa para la IED en cuanto a la remisión de utilidades y la importación de bienes de capital, etc., la cual, al mismo tiempo, reduce la capacidad de intervención del Estado cuando este se rehúsa a retener una porción mayor de la renta minera a través de impuestos y regalías o bien mediante la creación de empresas públicas estatales.

En cuarto lugar, la minería es un sector que demanda cuantiosas inversiones para la explotación de los yacimientos. Para el Estado, a diferencia de otros sectores, la minería introduce el problema del financiamiento de largo plazo y la tensión política siempre permanente entre satisfacer demandas de corto plazo y privilegiar inversiones de mediano y largo plazos. Las dificultades de financiamiento y/o la disminución de reservas 
son los principales problemas que la región enfrenta para atender el financiamiento de la industrialización, el proceso de ampliación del sistema de seguridad social y las obras de infraestructura, y de manera simultánea destinar recursos para el desarrollo de la minería con mayor participación estatal. La contracara de este proceso es que la apertura y desregulación del sector a favor de la IED y la existencia de un andamiaje legal beneficioso para el capital trasnacional restringen la posibilidad de una mayor captura y retención de la renta minera a nivel nacional.

En quinto lugar, se trata de una cadena de valor global con múltiples ramificaciones hacia el sector financiero, sectores tecnológicos e industrias como la siderurgia, la química y petroquímica, la automotriz, la farmacológica, la electrónica, las telecomunicaciones y la aeroespacial. Por otra parte, es una cadena de valor que asigna un papel subordinado a las empresas locales; la participación de estas últimas está acotada a los eslabones menos dinámicos de la cadena de valor pero no así en la provisión de bienes de capital e insumos críticos en el proceso productivo. Del mismo modo, por el carácter extractivo y la exportación sin agregado de valor local, no genera encadenamientos hacia la fase de la industrialización y la producción de bienes de capital en el sector minero.

En sexto lugar, la minería incide sobre la estructura productiva de las regiones subnacionales donde opera. El sector minero es el de mayor productividad en relación con el resto de las actividades productivas regionales y desplaza al sector industrial y otras actividades primarias existentes de menor productividad. Es un caso paradójico porque, con la alta tecnificación y nivel salarial, la minería desplaza a la industria en su papel modernizador. Pero lejos de generar una transformación de la estructura productiva tiende a consolidar su perfil primario y dependiente de los recursos naturales a nivel subnacional.

En definitiva, la minería introduce tensiones y restricciones para el Estado en una estrategia de desarrollo que es necesario identificar. Por un lado, es una fuente potencial de acumulación para impulsar un proceso de desarrollo, dada la posibilidad de capturar parte de la renta minera, en un escenario regional de grandes reservas y precios internacionales razonables. Pero, por otro, consolida estructuras y dinámicas que resultan perniciosas para el desarrollo si no se modifican. 


\section{CONCLUSIONES}

Tanto el estructuralismo latinoamericano y la teoría de la dependencia como el neoestructuralismo cepalino han identificado, como analizamos en la primera parte del capítulo, los problemas que la dependencia de los recursos naturales genera para el desarrollo. Así mismo, concuerdan en que la función de proveedora de materias primas a nivel mundial asignado a la región estableció un modelo de inserción subordinado en la división internacional del trabajo que es necesario revertir. De allí que hayan puesto el eje en la industrialización como condición para el cambio estructural en América Latina (aunque señalado de forma muy tenue para el caso del neoestructuralismo, cuyo énfasis está puesto en la internacionalización de la economía y en el aumento de las exportaciones, en lo posible, con valor agregado, aunque esto último no es determinante en la estrategia de desarrollo).

En la segunda parte del capítulo examinamos cómo desde fines de la década de 1980 en América Latina y en Argentina a partir de 1990, el sector minero experimenta un proceso de desregulación y penetración de la inversión externa directa en el marco de un debilitamiento de las capacidades de regulación y de participación del Estado en la renta minera. La región pasa a ser un espacio de expansión del capital que permite sostener en términos de Harvey el proceso de acumulación en los países centrales mediante ajustes espacio-temporales del capital.

En la tercera parte del capítulo señalamos que durante la primera década del siglo xxi se produce en América del Sur un fuerte cuestionamiento al Consenso de Washington y la emergencia de gobiernos nacionales populares que impulsaron un incremento de la capacidad de regulación del Estado, la ampliación de derechos sociales y una búsqueda de mayor autonomía en la inserción regional y global, y tuvieron en la explotación minera una fuente de financiamiento de la estrategia de desarrollo. Se destacaron algunas iniciativas orientadas a una mayor participación estatal en la renta minera y políticas para la industrialización de los recursos y la promoción de políticas industriales y científico-tecnológicas. Sin embargo, los gobiernos nacionales populares no han logrado modificar la estructura productiva primarizada de la región, alterar las relaciones asimétricas de poder y cambiar el tipo de inserción en el comercio internacional. 
Los recursos naturales, y la minería en particular, constituyen un eje sobre el cual la región podría impulsar procesos de desarrollo. Pero se requiere, por un lado, comprender el funcionamiento del sistema capitalista en su fase actual de financiarización, los condicionamientos que enfrentan los Estados latinoamericanos en el ejercicio pleno de su soberanía y el papel que las empresas trasnacionales desempeñan en el marco de la globalización multipolar. Por otro lado, para impulsar una estrategia de desarrollo se torna necesario fortalecer las capacidades del Estado en relación con:

a) Cambios en el marco normativo para garantizar una mayor regulación económica y ambiental por parte del Estado y favorecer procesos de industrialización de los recursos naturales, sustitución de importaciones, integración local, transferencia tecnológica y desarrollo de industrias conexas a la minería como componentes de una estrategia nacional de desarrollo.

b) Ampliar la participación del Estado dentro de la renta minera mediante la creación de una empresa pública nacional (o en asociación con el sector privado pero manteniendo una participación estatal mayoritaria) para que desarrolle capacidades productivas, industriales, tecnológicas y de control, incremente la capacidad de negociación frente a las empresas trasnacionales y genere información propia del sector.

c) Identificar sectores estratégicos para la sustitución de importaciones, desarrollar una industria de bienes de capital para abastecer al sector minero y diversificar la estructura productiva para disminuir la dependencia de recursos no renovables en el mediano y largo plazos. Del mismo modo, transformar los recursos mineros en capital perdurable como inversiones en infraestructura, ciencia y tecnología, educación y calificación laboral de la población, creación de fondos estructurales para la reconversión productiva y el desarrollo de nuevos sectores industriales, entre otros.

Ahora bien, generar mecanismos que permitan orientar la explotación de los recursos naturales hacia el desarrollo y el cambio estructural no es un proceso automático. Se requiere incorporar el debate acerca de la 
explotación de los recursos mineros como un aspecto significativo del ejercicio de la soberanía porque las empresas trasnacionales que operan en la región forman parte de consorcios internacionales que actúan con una estrategia global y unificada, mientras que los países de la región presentan planes fragmentados, estructuras estatales débiles y políticas erráticas. A su vez, supone instalar la cuestión en la agenda subnacional, con la participación de los actores sectoriales y territoriales involucrados, para discutir alternativas de desarrollo en relación con modificar la estructura productiva regional, mejorar la inclusión social, ampliar los márgenes de autonomía del Estado frente a las empresas multinacionales e intereses económicos provinciales y garantizar la sustentabilidad ambiental con apoyo de las comunidades locales.

\section{REFERENCIAS}

Banco Mundial [1996], Una estrategia minera para América Latina y el Caribe. Washington, DC., Documento Técnico del Banco Mundial, núm. 345 .

Basualdo, Federico [2012], "Evolución y características estructurales de la minería metalífera en la Argentina reciente. La expansión de la actividad y el capital extranjero", en Martín Schorr (comp.), Los recursos naturales en la Argentina reciente. Minería, petróleo y agro pampeano. Buenos Aires, Editorial Atuel.

Bielschowsky, Ricardo [2009], "Sesenta años de la Cepal: estructuralismo y neoestructuralismo", en Revista de la Cepal, Santiago, abril, núm. 97.

Cardozo, Fernando y Enzo Faletto [1969], Dependencia y desarrollo. México, Siglo xxi Editores.

Casalis, Alejandro [2019], "Litio y desarrollo territorial en Argentina: políticas, actores y conflictos en torno a la explotación e industrialización", en Revista de Ciencias Sociales, segunda época. Bernal, Universidad Nacional de Quilmes, septiembre, núm. 36, pp. 13-36.

[2017], "Minería y modelo de desarrollo: sustentabilidad y capacidades estatales", Daniel García Delgado y Agustina Gradín, comps. Neoliberalimo tardío. Teoría y praxis, Buenos Aires, Flacso Argentina, pp. 133-146. 
Casalis, Alejandro y Arturo Trinelli [1990], Transformación productiva con equidad. La tarea prioritaria para América Latina y el Caribe. Santiago, Cepal.

[2000], Equidad, desarrollo y ciudadanía. Santiago, Cepal.

[2013], "El desarrollo territorial en la Argentina. Oportunidades y desafíos de la explotación de los recursos mineros (2002-2012)", en Revista Estado y Políticas Públicas, Buenos Aires, Flacso Argentina, octubre año 1, núm. 1, pp. 97-114.

Castellani, Ana [2008], "Ámbitos privilegiados de acumulación. Notas para el análisis del caso argentino (1976-1989)”, en Apuntes CECYP, Buenos Aires, núm. 14, pp. 139-157.

[2010], La hora de la igualdad. Santiago, Cepal.

[2013], Recursos naturales: situación y tendencias para una agenda de desarrollo regional en América Latina y el Caribe, Santiago, Cepal. Cubillo Guevara, Ana Patricia, Antonio Luis Hidalgo Capitán y José Andrés Domínguez Gómez [2014], "El pensamiento sobre el Buen Vivir. Entre el indigenismo, el socialismo y el posdesarrollismo", en Revista del CLAD Reforma y Democracia, núm. 60, pp. 27-58.

Dirección de Economía Minera [2017], Situación actual y perspectivas. Informe especial, marzo 2017. Dirección Nacional de Promoción Minera, Subsecretaría de Desarrollo Minero, Secretaría de Minería, Ministerio de Energía y Minería, Presidencia de la Nación, Buenos Aires.

Dos Santos, Teothonio [2003], La teoría de la dependencia. Balance y perspectivas. Buenos Aires, Plaza Janés.

Drulitzky, Alejandro [2011], "La relación entre el Estado y las empresas trasnacionales y su implicancia para el desarrollo. Claves para pensar el caso de la minería en la Argentina de la posconvertibilidad”, Documentos de investigación social. Buenos Aires, IDAEs/unsam, núm. 16.

Evans, Peter [1996], "El Estado como problema y como solución”, en Desarrollo Económico, vol. 35, núm. 140, pp. 529-562.

Fajnzylber, Fernando [1983], La industrialización trunca de América Latina. México, Editorial Nueva Imagen.

Fernández, Víctor Ramiro y Matthias Ebenau (comps.) [2013], Variedades de capitalismo entre centro y periferia. Miradas críticas desde América Latina. Buenos Aires, Miño y Dávila. 
Fernández, Víctor Ramiro y María Jimena García Puente [2013], "Estado, producción y desarrollo. Las capacidades nodales en una perspectiva latinoamericana", en Revista Estado y Políticas Públicas, Buenos Aires, Flacso, núm. 1, pp. 19-46.

Fornillo, Bruno [2014], “¿A qué llamamos Recursos Naturales Estratégicos? El caso de las baterías de litio en Argentina (2011-2014)", en Revista Estado y Políticas Públicas, Buenos Aires, Flacso, núm. 3, pp. 79-89.

Furtado, Celso [1966], Subdesarrollo y estancamiento en América Latina. Buenos Aires, Eudeba.

García Delgado, Daniel y Luciano Nosetto (comps.) [2006], El desarrollo en un contexto posneoliberal, Buenos Aires, Ciccus.

García Delgado, Daniel y María Cristina Ruiz del Ferrier [2013], "El nuevo paradigma. Algunas reflexiones sobre el cambio epocal", en Revista Estado y Políticas Públicas, Buenos Aires, Flacso, núm. 1, pp. 64-81.

García Linera, Álvaro [2017], “¿Fin de ciclo progresista o proceso por oleadas revolucionarias?", en Emir Sader (ed.), Las vías abiertas de América Latina: siete ensayos en busca de una respuesta: ¿fin de ciclo o repliegue temporal?, Caracas, Centro Estratégico Latinoamericano de Geopolítica (Celag)-Banco de Desarrollo Económico y Social de Venezuela (Bandes). Gorestein, Silvia (org.) [2012], ¿Crecimiento o desarrollo? El ciclo reciente en el norte argentino. Buenos Aires, Miño y Dávila.

Gudynas, Eduardo [2012], "Estado conservador y nuevos extractivismos: las ambivalencias del progresismo sudamericano", en Nueva Sociedad, núm. 237, 1/2012, pp. 128-145.

Gutman, Nicolás [2013], Argentina en la frontera minera. Buenos Aires, Ediciones del cCC.

Harvey, David [2005], "El 'nuevo' imperialismo: sobre reajustes espaciotemporales y acumulación mediante desposesión”, en Socialist register, Buenos Aires, Clacso.

[2007], "La geografía de la acumulación capitalista: reconstrucción de la teoría marxiana", Espacios del capital. Madrid, Akal.

Lefevre, Henry [2013], El espacio social. España, Capitán Swing.

Leiva, Fernando [2008], "Towards a critique of Latin American Neostructuralism”, en Latin America Politics and Society, vol. 50, núm. 4, pp. 1-25. Martínez Alier, Joan [2015], "Ecología política del extractivismo y justicia socio-ambiental”, en Revista Interdisciplina, vol. 3, núm. 7, pp. 7-73. 
Merlinsky, Gabriela (comp.) [2013], Cartografías del conflicto ambiental en Argentina. Buenos Aires, Ciccus.

Moori Koenig, V. y C. Bianco [2003], Industria minera; Estudio 1 EG.33.6; Préstamo BID 925/OC-AR, Pre II. Coordinación del estudio: Oficina de la Cepal -ONU en Bs. As. a solicitud de la Secretaría de Política Económica, Ministerio de Economía de la Nación.

Mouffe, Chantal [2013], Agonistics: thinking the world politically. Londres, Verso.

Nacif, Federico [2012], "Explotación de litio en Argentina y Bolivia: bloques sociales y modelos de desarrollo", Ponencia presentada en las Jornadas de Economía Crítica, Universidad Nacional de Cuyo, 2013, Mendoza, Argentina.

[2018], "El abc del litio sudamericano. Apuntes para un análisis socio-técnico", en Revista de Ciencias Sociales, segunda época, Bernal, Universidad Nacional de Quilmes, septiembre, núm. 34, pp. 49-67.

Osorio, Jaime [2003], "El neoestructuralismo y el subdesarrollo. Una visión crítica", en Nueva Sociedad, Caracas, núm. 183, 1-2, pp. 134-150.

Otto, J. et al. [2007], Royalties mineros, un estudio global de su impacto en los inversionistas, el gobierno y la sociedad civil. Santiago, Ediciones Universidad Católica de Chile.

Prebisch, Raúl [1949], "El desarrollo económico de América Latina y alguno de sus problemas", Santiago, Cepal, <https://cutt.ly/pdqH4mD>. Roger, Diego [2018], "Almacenaje de energía y transición energética: alternativas en un horizonte de desarrollo tecnológico e industrial nacional", en Revista de Ciencias Sociales, segunda época, Bernal, Universidad Nacional de Quilmes, septiembre, núm. 34, pp. 17- 47.

Sader, Emir (coord.) [2017], Las vías abiertas de América Latina: siete ensayos en busca de una respuesta: ¿fin de ciclo o repliegue temporal? Caracas, CELAG- BANDES.

[2015], "La ultraizquierda fracasó", en Página 12, 12 de enero, Buenos Aires, Argentina.

Sánchez, Jeannette (coord.) [2019], Recursos naturales, medioambiente y sostenibilidad. 70 años del pensamiento de la Cepal. Santiago, Cepal, onU. Schteingart, Daniel y Diego Coatz [2015], “¿Qué modelo de desarrollo para Argentina?", en Boletín Informativo de Techint, Buenos Aires, núm. 349. 
Subsecretaría de Desarrollo Minero [2017], Competitividad y atractividad de inversiones de la minería argentina. Buenos Aires, Subsecretaría de Desarrollo Minero, Ministerio de Energía y Minería, Presidencia de la Nación.

Sunkel, Osvaldo y Pedro Paz [1970], El subdesarrollo latinoamericano y la teoría del desarrollo. México, Siglo XxI.

Svampa, Maristella [2013], "Consenso de los commodities y lenguajes de valoración en América Latina", en Nueva Sociedad, Buenos Aires, marzo-abril, núm. 244, pp. 30-46.

Tereschuk, Nicolás [2013], "Commodities y estrategias de desarrollo. ¿Qué hacer con las materias primas?", en Le Monde Diplomatique, Buenos Aires, edición 168, junio, pp. 8-9. 



\section{PARTE III}

TRANSFORMACIONES SUBNACIONALES Y DESAFÍOS URBANO-REGIONALES BAJO EL PROCESO DE REESTRUCTURACIÓN MULTIESCALAR DEL CAPITALISMO Y LOS CAMBIOS EN LA REGIÓN 



\section{POLÍTICAS NACIONALES DE DESARROLLO REGIONAL EN AMÉRICA LATINA: LECCIONES Y RETOS DE LOS AÑOS 2000}

Fábio Lucas Pimentel de Oliveira*

INTRODUCCIÓN

\section{Antecedentes y contexto histórico}

Los años setenta representaron un "cambio de época" hacia la hegemonía financiera, reflejada en las estrategias empresariales, en las políticas macroeconómicas de la mayoría de los países del planeta y en los territorios. Desde entonces, la "glocalización" impulsa el desplazamiento de actividades alrededor del mundo bajo la combinación del paradigma de acumulación flexible de capital y la métrica de los parámetros financieros de rentabilidad [Harvey, 1990; Chesnais, 1994; Swyngedouw, 2010].

Se trata de un proceso al que los países de América Latina se vinculan de modo particular, insertándose bajo características estructurales que les son peculiares: dependencia de recursos financieros externos para lograr equilibrio macroeconómico; relaciones comerciales basadas en la exportación de productos primarios y/o de bajo valor agregado e importación de productos finales dotados de alto grado tecnológico; incapacidad para superar la heterogeneidad estructural entre sectores productivos modernos y rezagados, y por ende, débil articulación intersectorial en los sistemas económicos [Ffrench-Davis, 2010].

* Instituto de Pesquisa e Planejamento Urbano e Regional, Universidade Federal do Rio de Janeiro, Brasil. 
La adecuada integración entre enfoques que combinan economía política, geografía crítica y planificación permite afirmar que las interacciones entre el patrón de inserción internacional y las estructuras socioeconómicas de los países del continente van a determinar estrategias nacionales y generar efectos territoriales específicos.

¿Cómo entonces reaccionaron los gobiernos de la región en cuanto al intento de orientar los procesos de desarrollo regional?

La búsqueda de respuestas debe arrancar de consideraciones acerca de la ejecución de políticas económicas luego del cambio en el proceso de acumulación de los años setenta, y más importante, de la crisis fiscal y financiera que acometió a todas y cada una de las naciones de América Latina en los ochenta, cuando se inicia el proceso de neoliberalización.

La adhesión, temprana o tardía, de los países latinoamericanos a los preceptos del Consenso de Washington puso en marcha la dinámica de la neoliberalización, que se concretó en los procesos de roll back y roll out [Peck y Tickell, 2002].

Desde principios de la década de los noventa, la actuación pública coincidió con la reversión de la concepción desarrollista que había prevalecido en los últimos 40 años en la región. Emergieron prácticas de eficiencia, transparencia y búsqueda de metas en la gestión pública, variables típicamente empresariales que cualificaron el concepto de Estado mínimo y terminaron por omitir el neoliberalismo realmente existente en América Latina. Las cuestiones macroeconómicas (monitoreo de la tasa de cambio y la tasa de interés, manejo de superávits fiscales, equilibrio de la balanza de pagos, etc.) se convirtieron rápido en prioridad.

Solo en los años 2000 volvió la preocupación por el desarrollo económico en los principales países de la región, es decir, con aspectos relacionados con la dimensión social, a los que se añadió el tema ambiental. Eso sin que la estructuración macroeconómica erigida en los años noventa hubiera sido superada [Cepal, 2012a] y de cierta manera reproduciendo los requerimientos del roll out, esto es, ensamblando sistemas político-institucionales adecuados a la neoliberalización.

En cuanto al aparato institucional público vinculado con la cuestión territorial del desarrollo, Riffo [2013] ha demostrado que transitó desde el enfoque de las agencias nacionales, predominante entre los años sesenta y mediados de los setenta, hacia estrategias basadas en proyectos con impacto 
territorial a partir de mediados de la década de los setenta, para luego expresar la concepción de desarrollo endógeno. Esta última ganó fuerza exactamente en el contexto de crisis fiscal y financiera de los Estados latinoamericanos en los años ochenta.

La emergencia generalizada del neoliberalismo en América Latina en los años noventa conllevó al reforzamiento del localismo y a la adopción de estrategias autonomistas por parte de los agentes públicos y privados de los territorios en función de la completa ausencia y/o la inefectividad de políticas e instituciones dedicadas al desarrollo regional desde la escala nacional en los países de la región. Además, las grandes empresas empezaron a dictar la espacialidad del desarrollo y a sacar provecho de la competencia entre lugares.

No por coincidencia, el hecho de que los Estados nacionales retomaran la agenda regional es producto del inicio de los años 2000 bajo gobiernos que se enmarcaron en una posición crítica de los planteamientos neoliberales hasta entonces vigentes. Esta reorientación se ha propuesto sobre el reconocimiento de un cada vez más necesario cambio estructural de las economías latinoamericanas, mediante el cual se generarían mejores condiciones de vida y mayor equidad social. Esa propuesta ganó especial enfoque en términos territoriales dadas las desigualdades espaciales existentes [Cepal, 2012a; Silva, 2010].

La reconsideración de la dimensión espacial, parte constitutiva de las estrategias de desarrollo socioeconómico de un grupo importante de países de la región, ${ }^{1}$ se basó en distintas concepciones teóricas, anticipadas por interpretaciones múltiples sobre el proceso reciente de acumulación capitalista, las inherentes desigualdades sociales, la sustentabilidad ambiental y modelos institucionales de diseño, financiamiento y ejecución de los planes.

Los documentos que oficializaron las políticas reconocen la tendencia hacia un nuevo escenario geopolítico. Afirman que promover un despliegue regional de las capacidades gubernativas resultará de la interacción entre los principales agentes sociales en la escala mundial, nacional y territorial. Para lograr éxito en términos de ejecución, consideraron que

1 Se consideraron los siguientes casos nacionales y sus respectivos documentos de políticas regionales: Argentina, Brasil, Colombia, Ecuador y Perú. Estos documentos están indicados en las referencias bibliográficas. 
el dinamismo económico proporcionado por ese arreglo multiescalar es fundamental para proponer ciertos avances en materia de gobernanza [Cepal, 2015].

Puesto que toda política pública se inscribe en una determinada y concreta dinámica social, y en cierta forma, intenta domeñarla y modificarla, para así intentar avanzar hacia el cumplimiento de ciertos objetivos a los que se supone que dicha dinámica no conduce per se, los modelos y las estrategias que constituyen el fundamento de las Políticas Territoriales necesariamente tendrían que ser concebidos en concordancia con las específicas condiciones histórico-estructurales de las realidades en que se van a aplicar [De Mattos, 1989: 2].

Así, cada país trató de destacar su entendimiento de los procesos económicos internacionales y de concebir las políticas como la capacidad del Estado de orientar el dinamismo económico bajo lineamientos que juzga conveniente para su sociedad, apuntando los factores internos a enfatizar, a saber, económicos, políticos, sociales, institucionales, ambientales, etcétera.

A la luz de lo que fue expuesto y con el propósito de extraer lecciones importantes de la experiencia de la primera década de los 2000, este artículo intenta no solo dar a conocer los principales rasgos de las políticas, sino también evaluar el grado de coherencia y los límites que poseen, a la luz de sus propias referencias, para su ejecución en el contexto histórico de principios del siglo XXI.

Por tanto, además de esta introducción, está dividido en cuatro secciones. En la primera, contempla una descripción de los rasgos generales de políticas de desarrollo regional propuestas en América Latina en aquel contexto, identificando sus aspectos clave. De estos referentes deriva una lectura crítica en la segunda sección, la cual aporta consideraciones que van desde las posibilidades de ejecución hasta los principales límites y brechas. La tercera sección se dedica a apuntar elementos con los que se propone cualificar la discusión: el rescate del estatuto del subdesarrollo, la multiescalaridad en las políticas, la actuación del mercado en las regiones, las capacidades estatales y el grado de participación social articulado con el proceso de planificación, es decir, expresado en términos de gobernanza territorial. Las consideraciones finales sintetizan los principales hallazgos 
de la investigación, apuntando los desafíos aprendidos con la experiencia de políticas regionales en los años 2000 en América Latina, imaginándolos útiles a su (re)diseño bajo el contexto de profundización de la financiarización y el subdesarrollo.

LOS PRINCIPALES RASGOS

Antes de empezar la descripción de los casos nacionales, conviene decir que se tomó en cuenta una tipología de políticas y estrategias de desarrollo regional estructurada por Cuadrado-Roura [2012] con base en ciertas características del histórico institucional vinculado con la temática. Se trata de una clasificación dual: el primer grupo, constituido por políticas orientadas hacia la búsqueda por eficiencia, se restringe a los aspectos económicos y tuvo una temporalidad bien enmarcada en el contexto de los años ochenta y noventa, en línea con el avance de la ola neoliberal en América Latina. El segundo grupo de políticas fue concebido con miras a promover la equidad y se orientó hacia aspectos como el bienestar social, la provisión de servicios públicos capaces de igualar las condiciones de vida en los distintos territorios de un país, etc. Su contextualización temporal es cíclica, es decir, fue concebido por primera vez en los años inaugurales de las políticas regionales y en los 2000 volvió al debate revestido de orientación ético-social.

Si se tiene en cuenta la ascensión de gobiernos progresistas en la primera década del siglo xxI, era de esperarse la predominancia, entre las políticas analizadas, del enfoque de la equidad, sobre todo porque se intentaba superar el periodo "sin políticas", o mejor dicho, el contexto en el que la actuación del Estado fue funcional a la acumulación, confirmando las tendencias y estrategias privadas.

En el ámbito de esa doble clasificación, a continuación se hace una síntesis de los aspectos principales de las políticas referenciada en las dimensiones siguientes: concepción teórica, correspondencia subnacional con la lógica global, escala de intervención, grado de descentralización y modo de operacionalización de la estrategia.

En cuanto a las concepciones teóricas, se verifica la combinación de distintas interpretaciones acerca de los procesos de desarrollo regional, 
que van desde el enfoque de la cohesión territorial (Brasil), basado en la experiencia europea de desarrollo; de la nueva geografía económica (Colombia) y los aportes de Paul Krugman y el Banco Mundial; de la teoría de la base de exportación (Perú), de Douglas North; y de concepciones que más bien se deben a la regionalización de cuestiones nacionales, como el desarrollismo (Argentina).

También se mencionó una estrategia neoestructuralista que busca aprovecharse de ventanas de oportunidad para trasladar una economía exportadora hacia una economía de base tecnológica-industrial. No es una casualidad que en algunos de los documentos esté registrada la importancia de promover la competitividad territorial, incluyendo estrategias inspiradas en la idea de clústers, de Michael Porter.

Se anota, además, la noción de empoderamiento social y de equidad (Ecuador) mediante la transferencia de recursos y competencias hacia los niveles subnacionales de gobierno y ampliación de la participación social, con menciones a los estudios de Milton Santos y J. L. Coraggio. Las políticas también se presentan como instrumentos habilitados para contribuir a la disminución de la pobreza, y en algunos casos la miseria se toma como elemento analítico para el diseño de acciones públicas.

Desde el punto de vista del concepto de región, es común que las políticas lo asuman como el nivel subnacional de intervención pública en el que impactarán los condicionantes de niveles más amplios. Ecuador, a su vez, incorpora nociones más complejas, como las ideas de construcción social o un enfoque relacional de la producción del espacio. Otras políticas llegan a abstraer las relaciones sociales con miras a tornar el recorte espacial operacional en estrategias orientadas por concepciones estrictamente económicas, como parece ser el caso argentino.

A su vez, la identificación de los condicionantes de la globalización y el reclamo por una orientación activa y renovada de la acción pública recomiendan cualificar el patrón de inserción periférico latinoamericano. Por ello, las políticas se detienen en las potencialidades internas de cada país, poniendo énfasis en elementos alineados con el paradigma de acumulación flexible (tecnología, recursos humanos, actuación en sectores intensivos en conocimiento y capital), los cuales serían capaces de impulsar la actividad económica. En general se reconoce que los factores de dinamismo 
tienen origen internacional y su adecuada promoción estaría vinculada con las capacidades productivas locales.

En lo que respecta a las escalas de intervención, hay un énfasis muy claro en el propósito de hacer una adecuada división de atribuciones entre el gobierno central y los gobiernos subnacionales, sean países federativos, como Brasil, o no. De cualquier manera, ese planteamiento de las políticas presupone la articulación de estrategias nacionales de desarrollo y su regionalización con lo que está pasando en la economía mundial, enmarcando un papel distinto de las políticas en comparación con el contexto de los años noventa.

En realidad, uno de los rasgos más notables en las políticas se refiere a la capacidad de entregar a la sociedad una oferta de servicios públicos de calidad. Para ello se plantea la descentralización político-administrativa coordinada por el Estado nacional por medio de la transferencia de competencias desde el nivel central de gobierno hasta los gobiernos subnacionales, lo que requiere el despliegue de capacidades técnicas locales y el envío de recursos financieros. En Ecuador, la descentralización está planteada como antecedente para la desconcentración productiva, hecho que enseña una creencia considerable en el reto de que las capacidades institucionales puedan viabilizar un desarrollo menos desigual.

Sin embargo, de los factores de competitividad asociados con la acumulación flexible antes mencionados, la oferta de infraestructura es el modo predominante de intervención en la agenda pública regional. Llega a ser, en el caso de Argentina, "la" estrategia, en el sentido de que todas las dimensiones restantes serían activadas luego de una constitución infraestructural más adecuada a los requisitos nacionales e internacionales. En otros casos, la infraestructura tiene una función importante por ser considerada el medio por el que podrá efectuarse la estrategia de desarrollo regional.

Como alternativa a ese patrón económico de operacionalización de la política está la lógica de empoderamiento y participación social. En general, el fortalecimiento de la democracia debe tomarse como un objetivo y la política entenderse como el instrumento según el cual puede consolidarse la participación de la sociedad en la dirección de la planificación espacial del desarrollo, considerando, por supuesto, un adecuado alineamiento institucional relativo a la organización político-administrativa descentralizada. 
Algunas políticas reconocen la función social en términos de la resolución de conflictos para la elección de metas y estrategias locales, mientras que otras toman el conflicto como solucionado ex ante y lo entienden como ruido al momento de tomar decisiones estratégicas.

INSUMOS PARA EL DEBATE CRÍTICO

La consulta de los documentos de las políticas nacionales de desarrollo regional posibilita la interpretación de aspectos poco destacados o que más bien podrían haber sido mejor enfatizados. Se trata de una tarea útil para cualificar las propuestas y anticipar eventuales límites de aplicación práctica.

En términos teóricos, los aportes generales que enmarcan el propio concepto de región definen una actuación imprecisa. No se está haciendo referencia a la multiplicidad de casos analizados, que conllevaría a variadas formas de concebir el espacio subnacional para entonces determinar cómo ocurrirá la intervención pública sobre él. El tema es que al nivel intrapolítico, es decir, en las propias políticas, con frecuencia se notan inadecuaciones entre la base conceptual, el diagnóstico regional y la estrategia diseñada para orientar la intervención. Era de esperarse, por lo menos, que hubiera una línea rectora que asegurase la coherencia entre esas etapas constitutivas de la estrategia pública. Las matrices teóricas a las que recurrieron las políticas confirman que la estrategia y el discurso no concuerdan y con eso emerge la incoherencia entre la idea, la acción y el diagnóstico de la realidad que se quiere cambiar.

Obsérvese la notable influencia de la corriente de pensamiento conocida como nuevo regionalismo. Según sus aportes, "los procesos/estrategias locales y regionales tienen capacidad, por sí mismos, para configurar las dinámicas globales y determinar -desde esa base territorial- el destino de las regiones bajo las nuevas formas de competencia" [Fernández et al., 2008].

Derivada de las experiencias de desarrollo regional de los países centrales, es una concepción que no tiene aplicación automática y perfectamente reproducible en la realidad latinoamericana. Asimismo, algunos gobiernos de la región, con diferentes grados de aceptación, han convertido 
sus planteamientos teóricos en orientación estratégica para concebir y planificar sus políticas. La preferencia por la oferta de infraestructura y la búsqueda de competitividad como prácticas públicas centrales y la ampliación del grado de inserción como objetivo general materializan la influencia del nuevo regionalismo.

Más importante que cuestionar el peso teórico-interpretativo de esa línea de pensamiento es advertir que la acción estatal inspirada en ella auspicia una peligrosa selectividad territorial sin que se combatan las diferenciaciones espaciales, conforme lo presenta la mayoría de los documentos. Así que, al parecer, es muy difícil concebir una estrategia de desarrollo capaz de revertir el cuadro de disparidades regionales existente cuando el diagnóstico de la realidad no concibe el espacio en cuanto el producto de una interacción social compleja, determinada desde los intereses situados en la escala global.

Uno de los caminos para la superación de esa insuficiencia pasa por considerar las estructuras productivas internas de los territorios. No todas las políticas mencionan esa dimensión y cuando lo hacen se nota que prevalece un carácter tangencial. Es muy importante identificar cuál ha sido, cuál es y cuál podrá ser la función de los agentes privados en la dinámica territorial, tomando en cuenta sobre todo el vínculo directo que los principales grupos empresariales poseen con los agentes globales de acumulación, alejándolos de proposiciones nacionales.

Considerar lo anterior demanda cuestionar cuál es la verdadera efectividad de la política pública en términos de influir o determinar el desarrollo regional. Bajo narrativas que involucran a los gobiernos en temas "prioritarios", como el mantenimiento del equilibrio macroeconómico, el problema regional se convierte en accesorio, o en los casos más radicales, está fuera de la agenda. En ese sentido, deben tenerse en cuenta las capacidades gobernativas nacionales para ejecutar la política.

Tal dimensionamiento requiere una concepción de Estado que va más allá de la que plantea la simple intervención de matriz keynesiana. Es necesario añadir elementos analíticos acerca de cómo se conducen y ejecutan las políticas públicas identificando alineamientos teóricos y políticos concretos de las acciones correspondientes [Dunham, 1978].

Además, en los años 2000 la preocupación por el desarrollo regional y local ya no era específica de los actores involucrados o comprometidos 
exclusivamente con el tema. Desde principios de los años noventa, hubo una filiación al desarrollo regional de la cuestión ambiental, de los cambios en el medio rural, de los avances en ciencia y tecnología (innovación y territorio), del fomento a las pequeñas y medianas empresas y sus arreglos locales, de la oferta de enseñanza superior y del combate a la pobreza. Esa multiplicidad de asuntos, radicada en distintos organismos de gobierno e instituciones públicas y privadas, conforma lo que algunos estudiosos llamaron políticas implícitas de desarrollo regional [Araújo, 2012].

Cada una de ellas despliega estrategias específicas de regionalización, en general sin coordinación con instancias estatales superiores. De ello resulta un inescapable carácter disperso de iniciativas y de asignación de recursos financieros y un potencial conflicto entre agentes sociales para consolidar decisiones consideradas de interés apenas parcial. Así que es fundamental conjugar el enfoque espacial de la escala nacional (más cercana de la nacional) y la escala local (más cercana del terreno), además de la transversalidad de las acciones públicas.

Lo anterior -no considerar las capacidades públicas y privadas en interacción o en conflicto-implica desconocer los límites de la intervención espacial. Hace falta que las políticas determinen si existen articulaciones productivas internas o una tendencia hacia la fragmentación de los espacios nacionales en función de vínculos más fuertes con el exterior, y principalmente, las características de la interacción de esa estructura productiva con la organización capitalista mundial.

Casi ninguna de las políticas considera el papel fundamental de los agentes privados para que las acciones públicas resulten efectivas. No se identifica el modo predominante de acumulación de capital, qué empresas, sobre todo industriales, fueron subsumidas por la lógica de acumulación financiera y/o cuáles permanecen estancadas en ganancias basadas en la renta de la tierra y en la extracción de recursos naturales. Lo que sí es cierto es que los agentes privados han sido efectivos en las determinaciones regionales en América Latina.

\section{ELEMENTOS PARA CUALIFICAR LA DISCUSIÓN}

Lo discutido antes indica que el planteamiento de políticas de desarrollo regional en América Latina en los años 2000 tuvo en cuenta: a) el contexto 
económico actual y la inserción de América Latina en él; b) la cuestión escalar y la consecuente adecuación de las políticas a las estrategias nacionales, más allá del localismo; c) las necesarias consideraciones sobre las estructuras económicas; d) las dimensiones institucional y financiera que dan soporte a la política; y e) la participación social en las directrices del desarrollo y como parte de un modelo de gobernanza, teniendo en cuenta las restricciones de la dimensión local y la vinculación con políticas de carácter nacional (a ejemplo de la macroeconómica y/o las sectoriales).

\section{El contexto geoeconómico y la reafirmación del subdesarrollo}

El contexto histórico actual puede caracterizarse por la puesta en marcha de un cambio geopolítico mundial, de lo cual resultaría la pérdida de importancia de relaciones del tipo "centro-periferia" en pro de relaciones multilaterales de tipo "sur-sur" impulsadas esencialmente por China. El liderazgo de este país se debe a la industria, demandante de distintos tipos de insumos para la producción y ofertante de manufacturas baratas. El gobierno chino desempeña un papel fundamental en la definición de estrategias competitivas para añadir aún más valor en su terreno [Cepal, 2012b].

No obstante, la nueva conformación geopolítica todavía no representa un cambio estructural auspicioso para América Latina. Las pautas de exportación y los flujos de capital correspondientes a la relación chino-latinoamericana no indican transformaciones de gran significado, por el contrario: la tendencia es el reforzamiento cualitativo de la lógica centro-periferia anterior [Cepal, 2012b]. Es decir, la región continuó experimentando considerable vulnerabilidad comercial y financiera.

Además, no es de todo correcto decir que el alza de precios provocada por la demanda china entre 2004 y 2011 solo tuvo efectos benéficos; en el caso brasileño, por ejemplo, ese efecto, si bien favoreció la actividad de exportación y le permitió alcanzar una buena capitalización, tuvo efectos inflacionarios asociados con la valorización de la tasa de cambio, lo que afectó a la sociedad en general y el cálculo económico de inversiones productivas. Lo mismo había ocurrido, entre los años sesenta y setenta, con Venezuela y las ganancias relacionadas con la exportación de petróleo [Furtado, 2008]. 
Ese cuadro es aún más dramático para los países que dependen básicamente de las exportaciones para generar renta: en estos casos, la vulnerabilidad vinculada con una eventual caída de los precios internacionales comprometería el desempeño del país y generaría dificultades desde el punto de vista de la actuación estatal sobre la economía.

Otros efectos internacionales se relacionan con los flujos de capital. Acerca de ese tema deben hacerse dos comentarios adicionales. Primero, desde un nivel más amplio y estructural hay que considerar que en la región no existen políticas públicas diseñadas de forma apropiada (o que sean efectivas) para seleccionar los flujos de capital que se direccionan hacia ella, es decir, no hay un control de los flujos que haga que prevalezcan los de capitales productivos en desmedro de los de capitales especulativos. Segundo, los países de América Latina se han desempeñado como grandes receptores de capitales chinos y eso significa que la competencia ya no es solo en términos de comercio internacional, sino también en términos productivos, mediante la implementación de parques manufactureros [Cepal, 2012b].

Por otra parte, merece la pena considerar el condicionante quizás más importante de la inserción externa de los países del continente: la influencia y principalmente la competencia de Estados Unidos en América Latina. Es decir, además de que las relaciones internacionales sur-sur no comporten alteraciones cualitativas relevantes, tampoco se olviden los efectos de la hegemonía financiera representada por el dólar estadunidense y del lobby protector ejercido por el gobierno de Estados Unidos siempre que conviene a su estructura productiva.

En ese sentido, debe alertarse que los planteamientos y estrategias sugeridos para la ejecución de políticas regionales de desarrollo, ya sea por medio de la oferta de infraestructura o según una orientación hacia procesos tecnológicos-industriales y de desarrollo de habilidades basadas en el conocimiento, hacen imprescindible considerar estos determinantes externos para enmarcar la particularidad latinoamericana. Condiciones geopolíticas, el tiempo histórico y la influencia de la economía global son completamente distintos en el continente latinoamericano en relación con lo que ha prevalecido en otros lugares y tiempos históricos [Chang, 2002].

Aunque se reconozca la pluralidad de situaciones, el subdesarrollo económico congrega el conjunto de países de América Latina bajo un solo estatuto. 
A la inversa de lo que ha ocurrido en el desarrollo de las naciones hoy industrializadas y directoras, el paso de la infancia a la adolescencia económica no se presenta en las nuestra como producto de una evolución gradual, en que el edificio va elevándose paulatinamente, desde los cimientos hasta las terminaciones. Aparece, más bien, como un salto, una mutación, en que no solo se trata de quemar con relativa celeridad ciertas etapas, sino que también se intenta desviar el curso de la marcha tradicional [Pinto, 1991: 59].

Si esa concepción es válida, la "quema de etapas" para "desviar el curso de la marcha tradicional" significa generar, desde especificidades propias, las condiciones para superar los reflejos estructurales de la condición multiescalar del subdesarrollo. Es fundamental romper con la concepción de evolucionismo o de convergencia en relación con los países centrales, porque en América Latina no existen ni institucional ni económicamente las mismas condiciones constitutivas que existieron en los países centrales.

En ese sentido, De Mattos (1988), Furtado (1996) y Coraggio (1994) afirman que, para una sociedad subdesarrollada, el sendero hacia el desarrollo pasa por el conflicto de intereses, única posibilidad de que las capacidades nacionales sean efectivamente reorientadas hacia la generación y consecuente apropiación de los frutos de la actividad económica, convirtiéndolos en ganancias sociales. No hay espacio, pues, para la convergencia en relación con patrones de imposible alcance si no es precedida por un verdadero, doloroso y difícil cambio de estructuras.

\section{La multiescalaridad en las políticas regionales}

No es posible acercarse a la complejidad de la cuestión regional en América Latina sin considerar sus especificidades socioeconómicas, sintetizadas por Pinto [2008] bajo el concepto de estilo de desarrollo. Solamente a partir de tales consideraciones se puede comprender mejor y concebir políticas capaces de escapar de una concepción abstracta y a-espacial, evitando el peligro de reproducir experiencias llevadas a cabo en otras realidades.

Por ello es de gran importancia tener en cuenta la cuestión escalar. Al considerar el contexto económico internacional, las políticas contemplan las múltiples escalas que inciden en el proceso de desarrollo regional. Sin 
embargo, ese referencial analítico parece tomarse sin dominio efectivo, el que impide su posicionamiento como mediación acerca de la transmisión de los efectos de doble vía entre global, nacional y local.

Son pocas las políticas que logran vincular los procesos que ocurren en los diversos niveles escalares. Por ello resultan estrategias desarticuladas en relación con las realidades que anticipan conocer, como si la parte pudiera extraerse del todo sistémico. Al recurrir metodológicamente al aislamiento de una parte específica (las regiones bajo análisis) de un todo para establecer referencias a un promedio, se suelen plantear políticas involucradas con la convergencia hacia un dudoso tipo ideal, ignorando las relaciones jerárquicas entre diversas espacialidades. Se omite, pues, la sincronía existente en los marcos de una división del trabajo a nivel nacional condicionada por la inserción subordinada a la lógica global y que alcanza lo local [Massey, 1984].

Además, en algunas políticas también se propone una vinculación escalar dual (global-local) que en las publicaciones se reconoce por el excesivo localismo, concepción que prescinde del Estado nacional al privilegiar la autonomía subnacional. Ese tipo de enfoque no explica, por ejemplo, cómo y dónde se define el poder económico sobre determinado espacio y tampoco deja claras las condiciones que determinan su inserción a nivel regional, nacional y mundial. Bajo una globalización que se profundizó en las últimas décadas, a menudo el comando de la dinámica territorial no es local y ni siquiera nacional. Es decir, las posibilidades de desarrollo económico no necesariamente están contenidas en las regiones donde se quieren adoptar políticas.

La visión escalar tiene gran amplitud explicativa. Permite entender los impactos derivados de la reorientación de los procesos tecnológicos-industriales resultantes del desplazamiento de actividades económicas alrededor del mundo, y también qué papel han jugado los agentes sociales -Estados, mercado y sociedad-para impulsar procesos nacionales de desarrollo [Smith, 1990].

Debe advertirse que no es suficiente medir el nivel de rezago de una región A y proponer el recorrido de un camino de desarrollo con base, por ejemplo, en "ventajas comparativas locales" para que llegue a cierta condición deseada, equivalente a aquella que goza la región B. Eso llevaría a la conclusión de que las políticas recurrirían a un enfoque normativo que 
no está pautado en la comprensión de las relaciones jerárquicas entre diversas espacialidades.

Ese es, con precisión, el problema. Gran parte de las políticas entiende la cuestión regional en los términos del nivel de la convergencia, alejándose de las necesarias mediaciones histórico-estructurales que pueden y deben ser rescatadas para constituir el cuadro de condicionantes multiescalares que determina la espacialidad del desarrollo, para luego sacarle una concepción estratégica correspondiente.

\section{La estructura económica: dimensionando el poder privado}

Aunque partan del supuesto de la multiescalaridad, muchas de las políticas lo hacen con el sentido de reseñar eventos ocurridos en la escala supralocal, omitiendo, por ejemplo, los impactos de la actuación de entes empresariales, mediante "políticas privadas", sobre las regiones.

La marginación de los agentes de mercado -empresas locales, trasnacionales, etc.- lleva al entendimiento de que hay una sobreestimación del poder de intervención público al mismo tiempo que una subestimación de la capacidad privada de determinar el desarrollo regional.

Así, debe darse atención especial a las distintas fracciones de capital, es decir, empresas (y empresarios) de variados tamaños, con distintos perfiles sectoriales, capacidades competitivas, diferentes grados de inserción externa, mayor-menor interacción con otras empresas y gremios patronales, etc., si se quiere integrar un análisis que se proponga reflejar la realidad y luego subsidiar un diseño adecuado de intervención pública.

También hay que destacar cómo se promoverá la interacción de la política territorial diseñada con el desarrollo productivo regional y en este ámbito cómo actúan las fracciones de capital cuyas actividades impactan sobre el territorio. La ausencia de consideraciones acerca de los agentes de mercado hace que se suponga una adhesión homogénea con las acciones estatales. Al no considerar las particularidades de la dimensión privada, las políticas no tienen en cuenta las distintas capacidades empresariales no solo de interferir, sino también de determinar intervenciones más efectivas que la propia política estatal. 
De eso resulta una potencial desarticulación de estrategias y una tendencia a una vinculación más efectiva entre "islas de dinamismo", exploradas a menudo por grandes empresas, y los procesos globales, saltando la escala y las estrategias nacionales, como solía ocurrir en el periodo de industrialización en América Latina.

Más aún, en general las fracciones de capital con origen en América Latina, antes que innovadoras y progresistas, configuran una clase empresarial que tiende a explorar actividades económicas alejadas de los requerimientos de la competencia oligopolista [Cardoso, 1963].

La preferencia por los dictámenes de los procesos mercantiles de acumulación hace que las iniciativas de Estado sean aún más fundamentales, desde que la naturaleza relacional del sector público permita que se induzca la sociedad a un proceso de desarrollo basado en las necesarias disrupciones promocionadas por la innovación, por la competencia amplia y por el avance de las fuerzas productivas. $\mathrm{O}$ sea, el aparato público no debe contener o tolerar narrativas escalares, al mismo tiempo que promueva la elevación de la competitividad económica de los países y respectivas regiones [Vainer, 2001; Mazzucato, 2018].

Por ello no puede asumirse ex ante que las empresas van a reaccionar de la misma forma en relación con las políticas estatales impulsadas desde los más distintos segmentos gubernamentales. La cuestión, pues, es concebir una política que pueda garantizar, mediante el adecuado conocimiento de hacia quién está dirigida, la efectividad del cambio estructural que, se afirma, es tan necesario y que hace tiempo se persigue.

\section{Las capacidades estatales: dimensiones institucional y financiera}

El aludido tema de las estructuras de capital más bien tiene que ver con otras tipologías de política. De hecho, la conducción del desarrollo regional depende de la articulación con formas complementarias de actuación del Estado, de organismos sociales e instituciones en general.

La complejidad que ha envuelto el tema impone la necesidad de que se contemplen las cuestiones institucional y financiera relativas a la ejecución de las políticas regionales. Especial relevancia se atribuye a las capacidades estatales, enfatizando una mirada intragubernamental. Sin 
embargo, las pocas referencias a otras estrategias y acciones de gobierno que poseen impacto espacial indican que la dispersión de iniciativas cuyos propósitos no se refieren específicamente al territorio, lejos de constituir una ventaja o un reconocimiento de la importancia de la temática, dificulta la coordinación estatal de las intervenciones espaciales.

Así es que pierde fuerza el discurso de retomar la capacidad estatal para enfrentar las presiones de procesos globales bajo una estructura coordinada desde el nivel nacional. Eso se expresa en la mayor efectividad de los resultados de las iniciativas dispersas en comparación con aquellos de las políticas regionales, hecho que puede llevar a cuestionamientos acerca de su necesidad.

La otra dimensión igualmente importante tiene relación con la estructura financiera que sostiene la ejecución de las políticas. Con la descentralización político-administrativa como eje central, el gobierno central debería compartir con los gobiernos subnacionales la responsabilidad de la adecuada oferta de bienes y servicios públicos mediante apoyo técnico y asignación de recursos. Para eso es fundamental conocer el origen de los recursos financieros involucrados en la política (quién la financia), su distribución entre los entes nacionales y subnacionales (para quién) y el objetivo relacionado con su ejecución (la vinculación con el proyecto nacional de desarrollo).

En gran parte de las políticas se aclaran los dos últimos puntos y se presentan con detalles, pero en muchos casos no se menciona al origen de los fondos que van a financiar la política nacional de desarrollo regional. La vinculación presupuestaria con reformas de difícil y larga ejecución, como la tributaria, hace que la política quede atrapada. En otras palabras, la dimensión financiera demuestra ser uno de sus principales límites, pues sin ella queda comprometida la concertación sociopolítica de ejecución de las iniciativas estratégicas, entre ellas la descentralización.

\section{La participación social en las directrices del desarrollo}

Los efectos prácticos de la descentralización y de las políticas con impacto territorial del sector público están expresados en las condiciones socioeconómicas de la realidad local. De ahí que su efectividad suele ser monitoreada, en general, por medio de diagnósticos que integran las dimensiones 
social, económica, institucional, ambiental, etc. Es esa vinculación entre las capacidades estatales, el conocimiento de las dinámicas socioeconómicas locales y las relaciones, impactos e influencias de lo "extra-local" lo que permite apuntar cuáles son los principales condicionantes del desarrollo espacial.

Tómese, por ejemplo, el caso de las regiones exportadoras. La generación de los recursos económicos que sostienen las capacidades estatales de estos espacios está limitada, en primer término, por los ciclos de precios internacionales y por la tasa de cambio, excepto en condición de monopolio. Además, los periodos de baja de precios pueden convertirse en un límite dinámico, teniendo en cuenta que no hay control efectivo sobre la magnitud del excedente económico generado en las actividades exportadoras, los enlaces sectoriales posibles y sobre las decisiones empresariales acerca del uso de tales ganancias.

Así que no tiene sentido concebir una estrategia de desarrollo regional derivada de acciones aisladas de los territorios sin que se la vincule con políticas macroeconómicas y sectoriales y con las decisiones privadas con impacto territorial. Esa creencia fue avalada por las notables fallas del localismo de los años noventa, en las que predominaron intervenciones focales incapaces de enfrentar las imposiciones del contexto económico internacional, pero sigue alimentando el imaginario y las narrativas de políticas públicas.

De todas maneras, uno de los logros de las políticas regionales debe expresarse en la profundización de la participación social en los procesos de planificación y los arreglos de gobernanza territorial. La pérdida de coordinación, por el Estado, de iniciativas con impacto territorial y los cambios en la interacción con las estructuras de capital privadas requieren la participación social de nuevas formas de organización en una estructura institucional igualmente renovada.

Esa sería la manera de garantizar que los beneficios del crecimiento fueran distribuidos según los requerimientos sociales, enmarcando la superación de las barreras al desarrollo puestas, en primer término, por las asimetrías y brechas que definen distintas condiciones de vida en los territorios. Por ende, la convergencia idealizada resultaría, además, en la percepción de que se están haciendo efectivas las iniciativas de cohesión social [Cepal, 2015]. 
De cualquier manera, no puede perderse de vista el recrudecimiento de conflictos originados en la tendencia de imposiciones "desde afuera" de directrices de desarrollo en desmedro de las aspiraciones sociales o de cualquier plan nacional, ignorando las especificidades y reivindicaciones de la sociedad de la región. Esa realidad no idílica asume, entre otras, la forma de eliminaciones e impactos ambientales irreversibles. Además, implica el esfuerzo de mejoramiento de coordinaciones institucionales, ya sea en términos estatales (es decir, entre los diversos niveles de gobierno) o sociales.

En síntesis, una incipiente participación social resultaría en pro de la lógica que preside los intereses de la acumulación capitalista; es decir, la planificación presentaría la tendencia a asegurar ganancias privadas sin dotarse de cualquier carácter social que esté más allá de la generación de empleos.

\section{CONCLUSIONES}

El propósito de esta sección es reiterar los puntos juzgados imprescindibles para apoyar un enfoque renovado del desarrollo regional latinoamericano basado en una mirada abarcadora de dimensiones destacadas y no contempladas en las políticas.

Una de las lecciones que puede extraerse de los documentos consultados es la necesaria articulación multiescalar -es decir, procesual y relacional- de las instancias global, periférica (latinoamericana), nacionales y regionales, capaz de aportar a los territorios un adecuado entendimiento de los efectos internacionales, macroeconómicos, sectoriales y ambientales de la estrategia de desarrollo diseñada. Para ello es crucial avanzar hacia concepciones teóricas coherentes y operacionales para la política. De igual manera, es necesario tener en cuenta los propósitos del proyecto nacional de desarrollo y cómo ese proyecto se refleja en términos espaciales.

Hubo consenso en torno al hecho de que la ausencia del Estado nacional resultó en la ampliación de la heterogeneidad espacial que siempre ha caracterizado a los territorios en América Latina. La tendencia de ampliación de los rezagos entre regiones dinámicas y estancadas llevó a 
una vinculación directa de ciertos locales con los procesos globales, manteniéndose como un importante desafío.

Quedó clara la necesaria y efectiva cualificación de la actuación del Estado nacional bajo tres dimensiones: a) coordinador jurídico-institucional de la descentralización; b) inductor de los avances económicos espaciales mediante políticas con efectos territoriales, superando la fragmentación y la ausencia de coordinación; y c) promotor de disrupciones productivas que contribuyan a elevar el nivel de competitividad del mercado.

A la adecuada adopción de un enfoque multiescalar debe añadirse el rescate del Estado nacional para que puedan hacerse las mediaciones con el proceso hegemónico de acumulación que prevalece desde los años setenta en el mundo y que sigue vigente luego de la crisis de 2008. Asimismo, definir la interacción entre el tipo de acumulación vigente al nivel global y las economías nacionales, considerando cómo se inserta el continente latinoamericano en el contexto internacional, pasa por identificar el papel fundamental que las estructuras de capital juegan en esa dinámica.

Por fin, el reclamo por una cultura de participación social en los procesos públicos de decisión requiere la combinación del aprendizaje con experiencias centralistas y localistas para que se logren transmitir, desde arriba hacia abajo (y al revés), las directrices estratégicas de las políticas en observancia a los intereses de la sociedad.

\section{REFERENCIAS}

Araújo, T. B. [2012], A questão regional no Brasil hoje. Campinas, Unicamp. Cardoso, F. H. [1963], El empresario industrial en América Latina: Brasil. NU. Cepal. Mar del Plata, Argentina. Periodo de Sesiones (10: 6-18 mayo 1963). <https://cutt.ly/Odwfggk>.

Cepal [2012a], Cambio estructural para la igualdad. Una visión integrada del desarrollo. Trigésimo cuarto periodo de sesiones de la Cepal. Santiago, Cepal.

[2012b], La República Popular China y América Latina y el Caribe: diálogo y cooperación ante los nuevos desafíos de la economía global. Santiago, Cepal. 
[2015], Estrategias y politicas nacionales para la cohesión territorial: estudios de caso latinoamericanos. Santiago, ILPES.

Chang, Ha-Joon [2002], Kicking away the ladder: development strategy in historical perspective. Londres, Anthem.

Chesnais, F. [1994], La mondialisation du capital. París, Syros.

Coraggio, J. L. [1994], Territorios en transición: crítica a la planificación regional en América Latina. Toluca, Universidad Autónoma del Estado de México.

Cuadrado-Roura, J. R. [2012], "Las políticas de desarrollo regional y el conflicto eficiencia-equidad", en ILPEs, Desarrollo regional en América Latina: el lugar importa. Santiago, Cepal, ILPES, pp. 57-78.

De Mattos, C. [1989], Reestructuración social, grupos económicos y desterritorialización del capital. El caso de los países del Cono Sur. Serie IEU/ILPES 13, Santiago.

[1988], Comentarios a un artículo de Sergio Boisier (mimeo). Santiago, ILPES.

Dunham, D. M. [1978], “¿Qué hacen los teóricos del desarrollo regional después de la medianoche?". IX Curso de Planificación Regional del Desarrollo. Santiago de Chile.

Fernández, V. R., A. Amin y J. I. Vigil [2008], Repensando el desarrollo regional. Contribuciones globales para una estrategia latinoamericana. Buenos Aires, Miño y Dávila.

Ffrench-Davis, R. [2010], "Macroeconomics for development: from 'financierism' to 'productivism'”, en Cepal Review, diciembre, núm. 102, pp. 7-26.

Furtado, C. [2008], Ensaios sobre a Venezuela: subdesenvolvimento com abundância de divisas. Río de Janeiro, Contraponto.

[1996], O mito do desenvolvimento econômico. Sao Paulo, Paz e Terra.

Harvey, D. [1990], The Condition of Postmodernity: An Enquiry into the Origins of Cultural Change. Cambridge, Blackwell.

Massey, D. [1984], Spatial divisions of labor: social structures and the geography of production. Nueva York, Methuen.

Mazzucato, M. [2018], The entrepreneurial state: debunking public vs. private sector myths. Penguin Books.

Peck, J. y A. Tickell [2002], Neoliberalizing Space. Oxford, Blackwell Publishers. 
Pinto, Aníbal [2008], "Notas sobre los estilos de desarrollo en América Latina", en Revista de la Cepal, Santiago, diciembre, núm. 96.

[1991], América Latina: una visión estructuralista. México, UNAM.

Riffo, L. [2013], "50 años del ILPES: evolución de los marcos conceptuales sobre desarrollo territorial", Serie Desarrollo Territorial, núm. 15. Santiago, Chile: Cepal. <https://cutt.ly/0dwki7v>.

Silva, I. [2010], Panorama del desarrollo territorial en América Latina y el Caribe. Santiago, Cepal.

Smith, N. [1990], Uneven Development: Nature, Capital, and the Production of Space. Athens, University of Georgia Press.

Swyngedouw, E. [2010], “'Globalización o glocalización? Redes, territorios y reescalamiento", en V. R. Fernández y C. A. Brandão (coords.), Escalas y políticas del desarrollo regional. Desafíos para América Latina. Buenos Aires, Miño y Dávila.

Vainer, C. B. [2001], "As escalas do poder e o poder das escalas: o que pode o poder local?", en Cadernos IPPUR, agosto-diciembre, año XV, núm. 2.

DOCUMENTOS NACIONALES CONSULTADOS

\section{Argentina}

Plan Estratégico Territorial Avance II: Planificación Estratégica Territorial - 1a ed. (v.1 y 2). Buenos Aires, Ministerio de Planificación Federal, Inversión Pública y Servicios, 2011.

Plan Estratégico Territorial Bicentenario 1816-2010-2016. Buenos Aires, Ministerio de Planificación Federal, Inversión Pública y Servicios, 2010.

Brasil

A PNDR em dois tempos: a experiência aprendida e o olhar pós-2010. Ministério da Integração Nacional (MI). Brasília, DF: SPDR, 2010.

Política Nacional de Desenvolvimento Regional: proposta para discussão. Ministério da Integração Nacional. Brasília, DF: SPDR/SPR, dezembro de 2003. 


\section{Colombia}

Bases del Plan Nacional de Desarrollo 2010-2014. Bogotá, DF: DNP, 2011.

Visión Colombia II Centenario: Fortalecer la Descentralización y Adecuar el Ordenamiento Territorial. Bogotá, DF, Departamento Nacional de Planeación, 2007.

\section{Ecuador}

Código Orgánico de Organización Territorial, Autonomía y Descentralización (COOTAD). Quito, Ministerio de Coordinación de la Política y Gobiernos Autónomos Descentralizados, febrero de 2011.

Plan Nacional de Descentralización 2012-2015. Quito, Secretaría Nacional de Planificación y Desarrollo (Senplades), 2012.

Plan Nacional para el Buen Vivir 2009-2013: Construyendo un Estado Plurinacional e Intercultural. Quito, Senplades, 2009.

Perú

Plan Bicentenario: el Perú hacia el 2012. Lima, Centro Nacional de Planeamiento Estratégico, marzo de 2011.

Propuesta de Plan Nacional de Regionalización y Descentralización (2012-2016). Secretaría de Descentralización, Presidencia del Consejo de Ministros. Lima, Secretaría de Descentralización, 2012. 



\title{
11. ENFERMEDAD HOLANDESA REGIONAL-SUBNACIONAL EN LA AMÉRICA DEL SUR DEL SIGLO XXI: CASOS REGIONALES EN BRASIL, COLOMBIA Y PERÚ
}

\author{
Luis E. Reina-Bermúdez, ${ }^{*}$ Didier Alejo-Barrera, ${ }^{* *}$ \\ Robson Dias da Silva*** y Lino Santa****
}

INTRODUCCIÓN

Los recientes cambios en la dinámica del comercio internacional de América Latina han generado una recomposición de los sectores productivos subnacionales. Con los auges de los commodities, entre los periodos 2003-2008 y 2009-2014, los países productores se vieron beneficiados por los ingresos por regalías, enfrentándose, no obstante, a presiones por la reestructuración de sus sectores económicos que terminaron afectando su desarrollo económico y social.

Estos cambios generaron efectos diversos sobre el desarrollo de los sectores industriales. Algunos, como el textil, vieron su crecimiento estancado a largo plazo, mientras que la construcción, por su parte, inicialmente experimentó un crecimiento acelerado durante el auge para después sufrir también un estancamiento. Por el contrario, otros sectores no lograron despegar y quedaron en el atraso por no poder generar procesos de exportación. La teoría de la enfermedad holandesa subnacional y la maldición de los recursos naturales explicaron la mayoría de los efectos.

\footnotetext{
* Universidad Nacional Abierta y a Distancia. Corporación Pluridesarrollo, Colombia.

** Universidad Nacional Abierta y a Distancia. Corporación Pluridesarrollo, Colombia.

*** Universidade Federal Rural de Rio de Janeiro. Tesorero de la Regional Studies Asociation - LA, Brasil.

**** Centro Nacional de Planeamiento Estratégico - Ceplan, Perú.
} 
Esta investigación es un estudio comparado entre tres países latinoamericanos que busca indagar la relación entre el auge de los recursos naturales y su incidencia en la composición de la estructura productiva partiendo de un análisis basado en las teorías que vinculan los recursos naturales y el desarrollo, como la enfermedad holandesa.

Para entender los efectos se realiza un estudio de corte transversal. Tras esto, se hace un análisis de las series de tiempo del producto interno bruto (PIB) por sectores para Colombia, Brasil y Perú a partir de tasas de crecimiento y tasa de crecimiento geométrica teniendo en cuenta tres periodos claves: a) desde el inicio de la serie hasta la crisis mundial de 2008; b) desde el final de 2008 hasta la crisis del petróleo de 2014; y c) desde el final de 2014 hasta el final de cada serie de tiempo. Por último, se comparan el contexto y los resultados de cada país, y se reflexiona sobre los aspectos que generaron una mayor profundización del problema o su contención en el tiempo.

La investigación resalta los efectos de los auges de recursos naturales a nivel subnacional, lo que permite entender los cambios para las zonas productoras de petróleo y cómo estas sufren una recomposición de sus estructuras productivas que termina generando un desequilibro regional y un crecimiento económico no armónico. Este es uno de los efectos en el largo plazo de la explotación y auge de recursos naturales, suscribiéndose a lo que se conoce como la maldición de los recursos naturales.

EL VÍNCULO ENTRE RECURSOS NATURALES Y DESARROLLO: UNA REVISIÓN GENERAL

Es necesario aclarar que la enfermedad holandesa subregional es solo uno de los posibles marcos teóricos para abordar la relación problemática entre desarrollo y dotación de recursos naturales. Existen otros como el staple trap, la apropiabilidad o la misma maldición de recursos naturales que Richard M. Auty ha enunciado en varios de sus artículos y libros [Auty, 2001a, 2001b, 2007, 2015 y 2017].

Desde luego, si se examinan juiciosamente diversas ideas sobre la relación de desarrollo y dotación de recursos naturales, se encuentran vínculos tanto positivos como negativos. Las nociones iniciales de desarrollo, como el Big Push, la trampa del crecimiento atado y la hipótesis de 
la apropiabilidad [Auty, 2001b], analizan diversos aspectos de las dinámicas generadas por la presencia de recursos naturales en un país o una región. En el campo de la economía del desarrollo, ya se han estudiado estos efectos en América Latina; Prebisch [1950] y Furtado [1979] son unos de los principales autores en esta área. Estos autores sustentaron las tesis de deterioro de los términos de intercambio y de la existencia de centros y periferias mundiales, respectivamente. En contraparte, Harold Hotelling [1931] desarrolló un modelo de precios crecientes de las materias primas, argumentando que al ser finitas las cantidades que pueden extraerse en el planeta, los precios de productos mineros tenderían a subir a largo plazo. Esos desarrollos teórico-empíricos fueron incorporados, junto con los efectos propios de la enfermedad holandesa, en la denominada maldición de recursos naturales, versión más conocida actualmente entre todos estos desarrollos teóricos relativos a los efectos de la dotación de recursos naturales.

Resulta ineludible la referencia al modelo teórico inicial de Corden y Neary [1982], quienes plantearon los efectos de la enfermedad holandesa pero con un supuesto muy importante: el pleno empleo derivado del salario, un supuesto bastante poco plausible para las realidades del mercado laboral con alto desempleo, informalidad o subempleo de los de América Latina. En presencia de pleno empleo, se genera la expectativa de unas dinámicas que implican que los sectores transables comienzan a perder competitividad, es decir, no venden en el exterior.

De igual modo, el supuesto anterior es poco plausible dada la especialización del sector, incluso dado el nivel de tecnología específica que se ha requerido desarrollar y usar, en especial en el caso brasileño. Esto lleva a considerar la postura de Stijns [2003], que indica cuatro efectos, con una perspectiva empírico-analítica más amplia que está en concurrencia con el retraso del establecimiento de Estados desarrollistas, tal como fue planteado por Peter Evans y Leandro Wolfson [1996].

En concreto, Stijns [2003], basado en el artículo seminal de Corden y Nearby [1982], indica que, primero, el hallazgo de reservas de recursos naturales y su posterior explotación acarrean fuertes incrementos en las exportaciones de recursos naturales debido al bajo nivel de eslabonamiento de las economías latinoamericanas [Hirschman, 1977], lo que se traduce en un bajo nivel de transformación de la materia prima en la 
región productora. El segundo efecto: en un ambiente de libre flotación del precio de la moneda local frente a las divisas se presenta una apreciación de la moneda local, es decir, los nuevos soles, pesos o reales aumentan su valor frente al resto de monedas.

Como tercer efecto, y como consecuencia de lo antes mencionado, se comienzan a disminuir las ganancias de las exportaciones, y por tanto, estas empiezan a decaer (los productos transables dejan de destinarse a exportación). El cuarto efecto consiste en que esto puede generar una contracción del sector industrial. Al mismo tiempo, comienza a ser más rentable para los capitalistas invertir en los sectores no transables (servicios y construcción), acelerando su crecimiento y participación en la estructura económica de la región y/o del país

El aspecto problemático de esto es la inestabilidad del tipo de cambio que conlleva ciclos de enfermedad holandesa. En la parte negativa del ciclo de enfermedad holandesa, los sectores manufactureros no reaccionan con la suficiente rapidez para generar exportaciones, empleo e ingresos fiscales, lo que obliga a realizar reformas fiscales [Reina, 2019]. Esto acarrea problemas de planeación privada y pública a mediano y largo plazos.

Estos problemas de planificación pública generan atrasos en el progreso socioeconómico de los países y constituyen la maldición de recursos naturales [Reina et al., 2018]. Esta maldición ocurre, precisamente, porque existen dotaciones importantes de recursos naturales [Auty, 1993], recursos que desincentivan el establecimiento de medidas auténticamente desarrollistas [Auty, 2001b].

De hecho, para Jefrey Frankel [2012] los ciclos de enfermedad holandesa constituyen un posible origen de la maldición de recursos naturales, lo que se refleja en dos efectos ligados a los precios. El primero indica una tendencia en el largo plazo a que los precios de los commodities disminuyan. El segundo tiene que ver con una creciente volatilidad de los precios.

Asimismo, los otros dos efectos del auge de los recursos mineros están ligados al desempeño de los sectores productivos. Un efecto indica el incremento sostenido de sectores no transables (construcción y servicios, entre otros). El segundo se refiere a una mayor inestabilidad de los anteriores sectores no transables, los cuales crecen con el auge y entran en profundas crisis con el agotamiento (económico y/o físico), es decir, sufren por los ciclos de enfermedad holandesa. 
Por último, los otros dos efectos están ligados al entorno institucional y social: uno hace referencia a la inestabilidad de los derechos de propiedad y el deterioro institucional ligado a decisiones anárquicas y concentración de poder, y otro alude a un entorno social más conflictivo donde se agravan las peleas entre los diferentes actores sociales.

\section{Marco contextual colombiano}

La legislación colombiana ha venido evolucionando y adaptándose para lograr una adecuada asignación de los recursos de regalías provenientes de la explotación de hidrocarburos con miras a su desarrollo social y económico. Estos cambios en lo legislativo implicaron una evolución institucional que se cristalizó en lo que ahora se denomina (nuevo) Sistema General de Regalías [Rettberg et al., 2014].

La regulación de la explotación de recursos mineros en Colombia comienza con la expedición de la Ley 20 de 1969, que estableció el principio de propiedad absoluta de la nación sobre las minas y yacimientos de hidrocarburos. Posteriormente, con el decreto legislativo 2310 se modificó el régimen de concesiones petroleras para permitir contratos de exploración y explotación de hidrocarburos por medio de asociaciones con la nación.

Esto se reforzó y amplió en la Constitución de 1991, la cual reiteró que la propiedad sobre productos minerales, hidrocarburos y energéticos es del Estado. De igual forma, creó la obligación del pago de regalías a los entes territoriales donde se encuentren los yacimientos mineros o energéticos y otorgó derechos a regalías en favor de los puertos marítimos y fluviales por donde se transporten dichos recursos o productos derivados del petróleo. En el mismo sentido, creó un fondo de regalías, el cual tiene participación de los municipios productores. Dichos municipios con regalías tenían algunas de estas con un destino específico para la promoción de la minería, la preservación del ambiente y el financiamiento de proyectos regionales de inversión definidos como prioritarios en los planes de desarrollo.

La anterior legislación duró 11 años en aplicación. Después fue modificada por el Acto Legislativo 5 de 2011 el cual creó el actual sistema de regalías, identificado como el Nuevo Sistema General de Regalías (nuevo 
SGR). Este sistema mantiene los derechos de propiedad mencionados al mismo tiempo que otorga derechos al gobierno central para designar objetivos, fines, administración, ejecución, control, uso eficiente y destinación de los ingresos provenientes de la explotación de los recursos naturales no renovables precisando las condiciones de participación de sus beneficiarios. De igual modo, generó un proceso tanto de distribución nacional de los ingresos de las regalías como de diversificación y cambió la destinación específica para el financiamiento de proyectos para el desarrollo social, económico y ambiental de las entidades territoriales; al ahorro para su pasivo pensional; para inversiones físicas en educación, inversiones en ciencia, tecnología e innovación; para la generación de ahorro público; y para la fiscalización de la exploración y explotación de los yacimientos y conocimiento y cartografía geológica del subsuelo [Colombia, Congreso de la República, 2019].

El nuevo sistema general de regalías estableció unas reglas de distribución diferentes y creó fondos [Moyano y Wright, 2016] que democratizaron las regalías para que $100 \%$ de las entidades territoriales de Colombia las usaran.

El sistema de regalías nuevo implicó mejoras en tres ámbitos: a) la distribución o cobertura de los recursos; b) la equidad territorial, pues se tiene en cuenta la pobreza relativa en la asignación; y c) la estabilidad mediante la creación de fondos de mediano plazo para activar en caso de choques [Bonet y Urrego, 2014].

\section{Marco contextual de Brasil}

Pese a que en los ámbitos académicos brasileros se ha discutido acerca de la importancia del petróleo en las décadas de los cuarenta y cincuenta, la producción nacional de hidrocarburos solo adquirió un peso a partir de la década de los setenta, cuando se comenzaron a explotar reservas de petróleo y gas en la plataforma oceánica del estado del Río de Janeiro. Desde entonces, los caminos de la industria petrolera han sido determinantes para la dinámica económica nacional y de la región productora.

El estado de Río de Janeiro entró al presente siglo respondiendo por más de $80 \%$ de la producción brasilera de petróleo y rápidamente ganó 
relevancia dentro del escenario nacional por cuanto resulta receptor de las rentas oriundas de la explotación extractiva. La compañía de petróleo pública Petrobras pasó a detentar cada vez mayor poder de decisión sobre la cantidad de inversión nacional, posicionándose como piedra angular de la dinámica económica de Río de Janeiro.

Dos puntos representan importantes cambios en la industria brasilera de petróleo. La entrada en vigor del nuevo marco regulatorio del petróleo en 1997 (conocido como Ley del petróleo) y el descubrimiento de nuevos campos y reservas de petróleo en aguas ultraprofundas en la capa presal del litoral del estado de Río de Janeiro en el periodo de 2007. En relación con el primero, destaca la modernización de las relaciones productivas dentro del territorio nacional al capacitar a Petrobras en el desarrollo tecnológico más robusto con el objetivo de responder a los desafíos de la producción offshore. También es importante señalar la reglamentación de las rentas compensatorias por la explotación de petróleo, las regalías, la cual permitió su repartición entre los entes de la federación impactados por la industria.

En relación con el segundo, resaltan las grandes proyecciones originadas con la expansión de las reservas probadas y potenciales. La capa presal pasó a ser vista, desde su anuncio en 2007, como una oportunidad sin precedentes para el desarrollo productivo y social nacional, además de reposicionar Brasil entre los grandes productores de petróleo y gas. El descubrimiento de pre-sal ${ }^{1}$ coincide con el óptimo periodo de expansión de los precios internacionales de los commodities, lo que aumentó más aún la posición estratégica que la industria petrolera ya detentaba en la matriz productiva brasilera.

Además, la ampliación de la producción física, la expansión de las inversiones y los mejores precios convirtieron Río de Janeiro y sus municipios productores en grandes receptores de regalías, lo que conllevó a una inédita situación en las finanzas públicas locales de presupuestos elevados y planteó preocupaciones sobre un futuro periodo pospetróleo y los efectos de una posible enfermedad holandesa.

\footnotetext{
1 Se refiere a la capa geológica que está debajo de una masa de sal en profundidad, donde existen reservas de yacimientos de petróleo.
} 
El estado de Río de Janeiro se tornó el gran centro de inversión nacional desde entonces. Dado que es una industria intensiva en capital, la industria del petróleo, liderada por Petrobras, hizo de Río de Janeiro el principal receptor de inversiones públicas y privadas entre los estados de la federación brasilera en las dos primeras décadas del presente siglo. Estos factores, junto con las inversiones urbanas necesarias para la recepción de grandes eventos deportivos y culturales, tornaron Río de Janeiro en el eje central de la política neodesarrollista del periodo.

El fin del superciclo de los commodities, junto al escenario de inestabilidad política que tuvo inicio con Petrobras, condujo a la casi completa paralización de las inversiones de la industria del petróleo en Río de Janeiro, arrastrando a otros sectores dependientes de sus compras y colocando al Estado en una situación productiva y fiscal precaria. Por cuenta de este escenario, el estado de Río de Janeiro enfrenta, desde 2014, una severa crisis económica y fiscal que inclusive llevó al gobierno de este estado a decretarse en calamidad financiera. Así mismo se paralizaron las inversiones públicas y privadas en servicios básicos en áreas centrales, como salud, educación y seguridad.

\section{Marco contextual de Perú}

El desarrollo económico y social de Perú está ligado a la explotación de recursos naturales; el mayor generador de divisas es la exportación de oro, cobre y plata, entre otros. El gobierno de Alberto Fujimori abrió mayores oportunidades a la inversión extranjera en el sector minero con la creación de la Ley de Promoción al Sector Minero mediante el Decreto Legislativo 708: en este decreto se declaró de interés nacional la promoción de la inversión en el sector. Por otro lado, la participación de los gobiernos locales en los beneficios obtenidos de los recursos mineros se estipuló en el año 1996 por medio de Decreto Supremo (DS 88-95-EF), el cual tuvo vigencia hasta junio de 2002. Con el objetivo de mejorar la participación de los gobiernos regionales y locales en el sector, el gobierno peruano aprobó también la Ley de Canon ${ }^{2}$ (Ley 27506). En ella se establece el canon que

\footnotetext{
${ }^{2}$ Canon debe entenderse en el sentido de reglas sobre las cantidades de dinero que se cobran a quienes desarrollan actividades mineras.
} 
hace referencia a la participación efectiva y adecuada de la que gozan los gobiernos regionales y locales del total de los ingresos y rentas obtenidos por el Estado por la explotación económica de los recursos naturales [Congreso de Perú, 2001]; se consideran cinco tipos de cánones: minero, hidrocarburos (determinación del canon petrolero y gasífero), hidroenergético, pesquero y forestal (cuadro 1).

Cuadro 1. Constitución de los cánones en Perú

\begin{tabular}{ll}
\hline Canon & \multicolumn{1}{c}{ Constitución del canon } \\
\hline Minero & $\begin{array}{l}50 \% \text { deimpuestoalarentaquepaganlasempresasminerasporelaprovechamientoderecursos } \\
\text { mineros (metálicos y no metálicos). }\end{array}$ \\
Petróleo & $\begin{array}{l}\text { Distribuciónespecialdeacuerdoconlalegislacióndelosdepartamentosdondeseencuentrala } \\
\text { explotación del recurso. }\end{array}$ \\
Gasífero & $50 \%$ de impuesto a la renta y regalías que percibe el estado por la explotación. \\
\hline
\end{tabular}

Fuente: Ley del Canon 27506.

Como se observa en el cuadro 1, la constitución del canon minero y otros, excepto el petrolero, se modificó con la nueva ley, pasando de una distribución de 20 \% (periodo 1996-2002) a una de 50 \% con la nueva Ley de Canon [Arellano, 2008]. Esta misma ley permitió la participación de las regiones en la distribución del canon, en cuanto las universidades públicas lo hacen desde 2004 por medio de la Ley 28077 (vigencia julio a diciembre de 2004). El actual criterio de distribución está regido por la Ley 28322. El diagrama 1 muestra la distribución del canon minero.

De acuerdo con el diagrama 1, con base en la Ley 28322 el canon minero para las entidades territoriales (municipalidades y departamentos) corresponde a $50 \%$ de las utilidades empresariales del sector. Con dicho canon se estimulan inversiones en lo que respecta a cadenas productivas sostenibles, en especial con $30 \%$ que es destinado para el desarrollo productivo.

En lo que respecta al canon y sobrecanon petrolero -constituido por $12.5 \%$ del valor de la producción que obtiene el Estado por la explotación de petróleo, gas natural asociado y condensados-, Loreto, Ucayali, Piura, Tumbes y la provincia de Puerto Inca en Huánuco son los departamentos que gozan de dichos ingresos. 
Diagrama 1. Distribución de las utilidades mineras y canon entre los gobiernos regionales y locales y las universidades

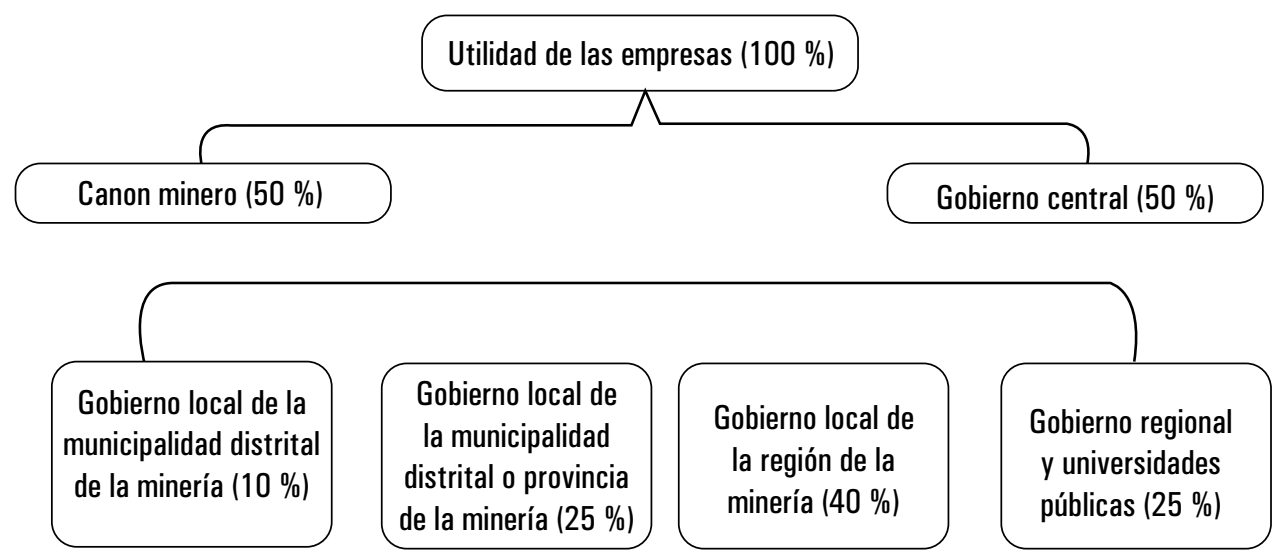

Fuente: elaboración propia con base en las normas de distribución del canon de la Ley 28322.

Recapitulando los contextos y precedentes en la década de los noventa

Revisar las estructuras económicas de las regiones al interior de estos países llevaría necesariamente a plantear la enorme disparidad regional existente en Perú, condición compartida con Colombia y Brasil en la década de los noventa [Silva, 2003]. Según Silva, en la década precedente los departamentos que presentaron un dinamismo económico importante basado en recursos naturales en Perú fueron Pasco, Arequipa, Cuzco y Cajamarca. Mientras tanto, otros quedaron rezagados dependiendo del sector primario, como Amazonas, Apurimac y Puno. Paralelamente, Ancash sufrió un proceso de desindustrialización, al mismo tiempo que Loreto y Tacna se quedaban rezagados en términos de PIB per cápita con otros departamentos de Perú, pese a que el sector minero es importante allí.

Aunque el sector minero haya sido importante en la economía peruana gracias a los precios de los minerales y al mayor volumen producido, la transferencia hecha a los gobiernos locales ha llevado a que las autoridades no agencien de forma adecuada los recursos, los cuales deberían destinarse para proyectos de inversión y no para gastos corrientes. Sin embargo, existe evidencia de que los recursos se destinan para gastos relacionados 
con los apoyos sociales y los sueldos de los funcionarios [Maldonado, 2011]. Esto ha llevado a que muchos gobiernos sean poco democráticos [Kahhat, 2016], lo cual coincidiría con la explicación según el grado de apropiabilidad que menciona Auty [2001].

Además, la falta de planificación y concertación con las comunidades locales ha provocado que, con base en cuestionamientos ambientales, sociales y políticos, estas hayan paralizado la ejecución de aproximadamente 15 proyectos desde 2008 , generando una pérdida de 21.5 millones de dólares de inversiones.

\section{Metodología}

Las regiones analizadas fueron: Orinoquía en Colombia, que abarca los departamentos de Meta, Casanare, Vichada y Arauca; la región Sur en Perú, que comprende Arequipa, Apurímac, Cusco, Moquegua, Puno y Tacna; y para Brasil, el estado federado de Río de Janeiro. Dada la naturaleza de los diferentes periodos de tiempo estudiados para cada país, a continuación se describe el tratamiento estadístico realizado a cada serie de tiempo. Para todos los países se tomaron los datos del PIB a precios corrientes por sectores económicos reportados por las entidades oficiales que, para el caso de Colombia fue el Departamento Administrativo Nacional de Estadística (DANE); para Perú, se utilizó información del Instituto Nacional de Estadística e Informática (INEI) y para Brasil, los datos reportados por el Instituto Brasileiro de Geografía y Estadística (IBGE). Se estructuraron cinco sectores: a) agropecuario; b) minería; c) manufacturas; d) construcción; y e) servicios. Se calculó la participación porcentual del sector dentro del PIB regional, así como las tasas de crecimiento de los sectores.

\section{El caso de la región colombiana de la Orinoquía}

La producción petrolera se concentra en la Orinoquía, donde en fecha reciente se ha hecho un esfuerzo por mostrar los impactos de la actividad petrolera en las regiones; estos estudios son especialmente descriptivos y 
están restringidos por lo corto de las series estadísticas a nivel departamental [Martínez et al., 2017; Martínez, 2018].

Martínez y Delgado [2018] presentan unos hallazgos producto de las percepciones de cerca de 80 representantes del sector petrolero y de la Federación Nacional de Departamentos y Municipios. Esto permitió obtener una imagen del funcionamiento del esquema de distribución de regalías actual.

Sin embargo, para analizar los cambios en la estructura productiva a largo plazo es necesario entender las dinámicas de crecimiento de los cinco sectores económicos señalados en la metodología del presente capítulo.

Para la región de la Orinoquía, en Colombia, la cual abarca los departamentos de Meta, Casanare, Arauca y Vichada, se encontró que el sector minero presenta una alta tasa de crecimiento, en especial para los años 2007-2008, de 55\%, para 2010-2011 alcanzó su punto máximo de $65 \%$ para luego decrecer hasta $31 \%$ en 2016-2017 y finalmente recuperarse en el último periodo analizado. Este comportamiento evidencia un auge en el sector minero, sobre todo impulsado por el petróleo (gráfica 1).

La dinámica del petróleo impulsó varios sectores como la construcción, la cual, un año después del crecimiento del sector minero, alcanzó 37 \% de crecimiento en el periodo 2008-2009. La misma situación, pero con un menor ritmo, se observó en los periodos 2010-2011 y 2012-2013, cuando llegó a $19 \%$. La dinámica de este sector está estrechamente ligada al sector de la minería y cuando esta cayó después de 2014, la construcción decreció hasta $20 \%$, recuperándose al final del periodo al mismo tiempo que la minería. Situación diferente pasa con el sector de los servicios, que muestra un crecimiento promedio de $9 \%$ en el periodo de estudio evidenciado.

Situación contraria muestran los sectores agropecuario y manufacturero. Como se observa en la gráfica 2, al inicio del auge en 2007-2008, tanto el sector agropecuario como el manufacturero crecían a un ritmo de 29 y $16 \%$, respectivamente. Sin embargo, en la medida en que el auge se sostiene en el tiempo, ambos sectores comienzan a disminuir su ritmo de crecimiento: el sector manufacturero llegó a decrecer 7 \% el agropecuario $15 \%$, ambos en el periodo 2013-2014. Una vez que el auge finalizó, ambos sectores comenzaron a retomar su senda positiva. 


\section{Gráfica 1. Tasas de crecimiento de la Orinoquía, Colombia}

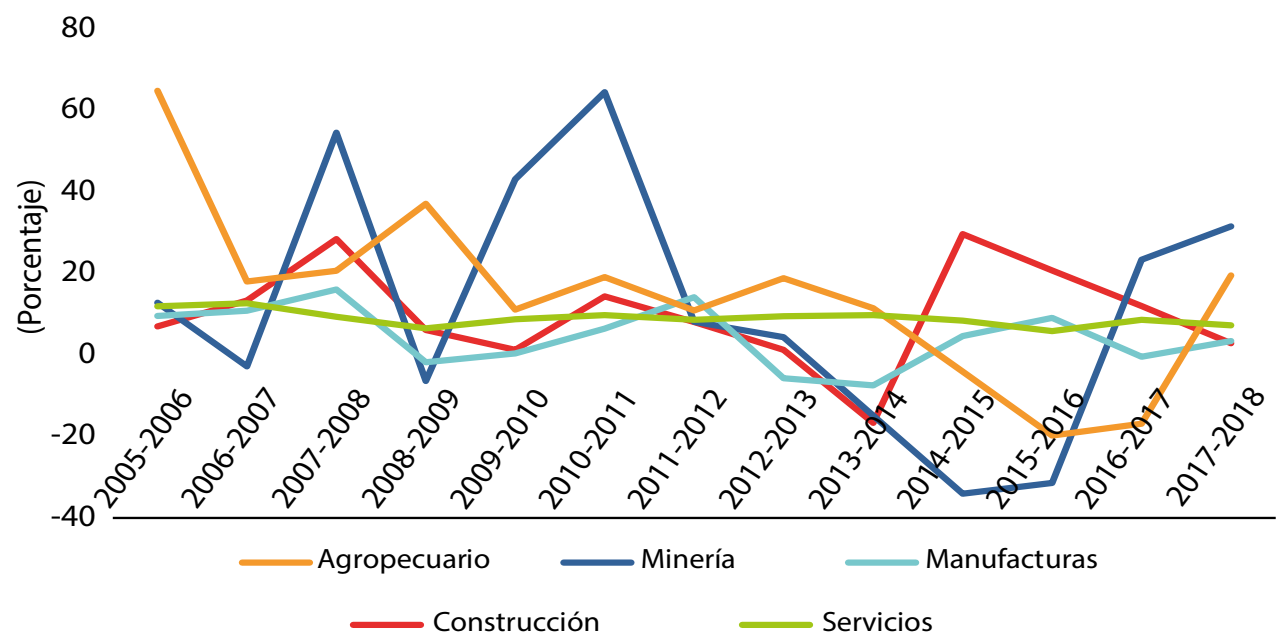

Fuente: elaboración propia a partir de datos del DANE.

Se analiza en las series de tiempo el proceso de desarrollo de los diferentes sectores económicos para indagar los efectos sobre la estructura económica. Para el caso de Colombia, existe información desde antes del año 2005 y ya en este periodo la región Orinoquía tenía explotaciones de petróleo (diagrama 2). No obstante, se venían adelantando incipientes procesos de desarrollo de las manufacturas, las cuales representaban $4 \%$ de su estructura productiva. De igual modo, el sector de construcción también estaba despegando y apenas representaba $1 \%$ de la estructura productiva, mientras que los servicios equivalían a $32 \%$ y el sector minero a 52 por ciento.

En el transcurso de los años siguientes (diagrama 3), la región Orinoquía vivió un intenso boom de petróleo, lo que hizo que se creara una estructura económica completamente ligada a este recurso, con $62 \%$ de su estructura productiva dedicada a la minería. A la par de este sector se desarrolló la construcción, que en este periodo representó $6 \%$. Por el contrario, el sector agropecuario representó apenas $6 \%$ de la producción y la incipiente industria manufacturera solo $1 \%$, convirtiéndose en sectores que perdieron el dinamismo que venían mostrando en años pasados. De igual modo, el sector servicios, aunque perdió su participación en la estructura productiva, continuó creciendo a buen ritmo impulsado por el boom de los recursos naturales. 

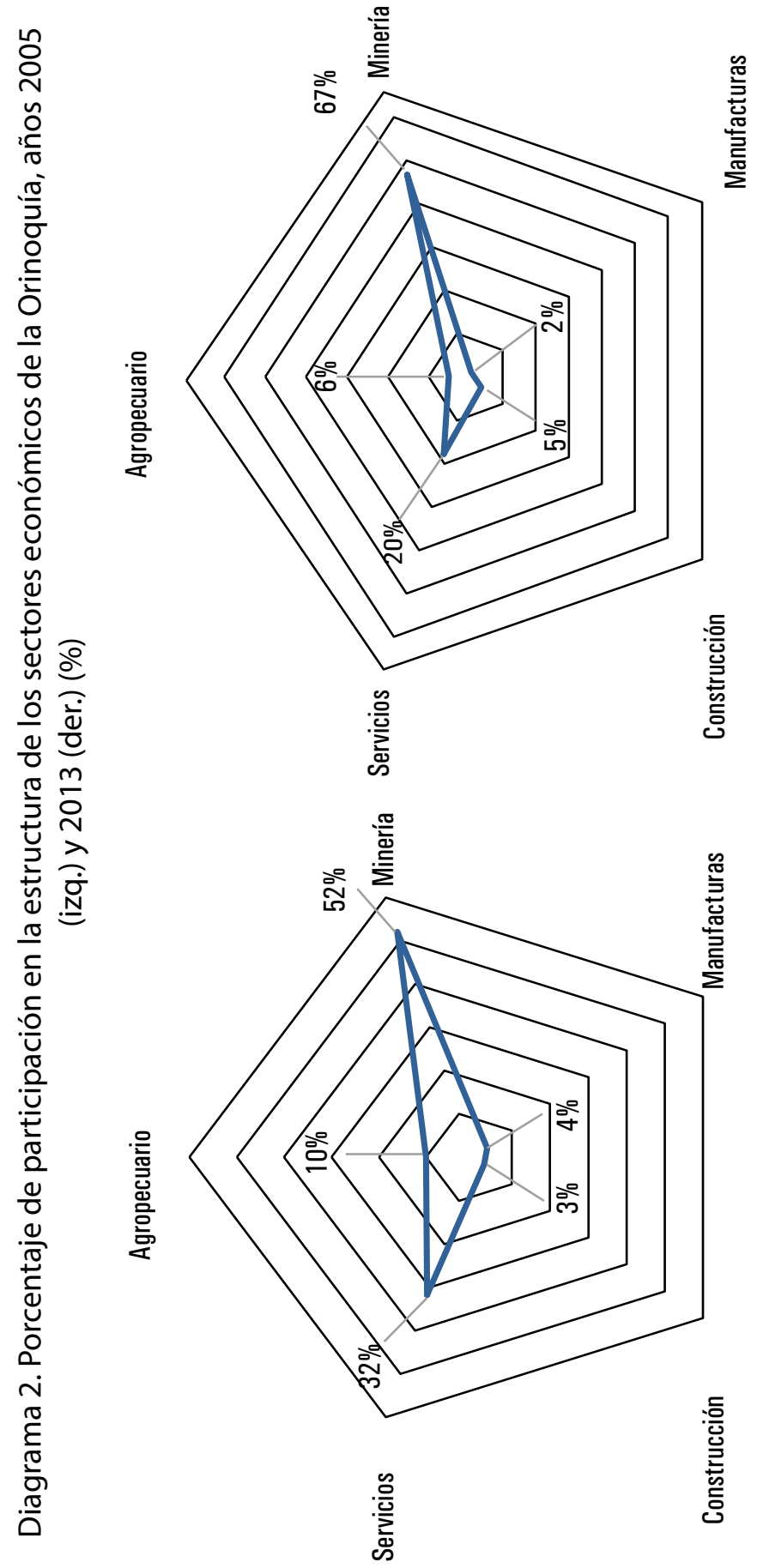

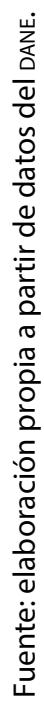


Diagrama 3. Comparativo en porcentaje de la evolución de los sectores económicos en la región Orinoquía, Colombia

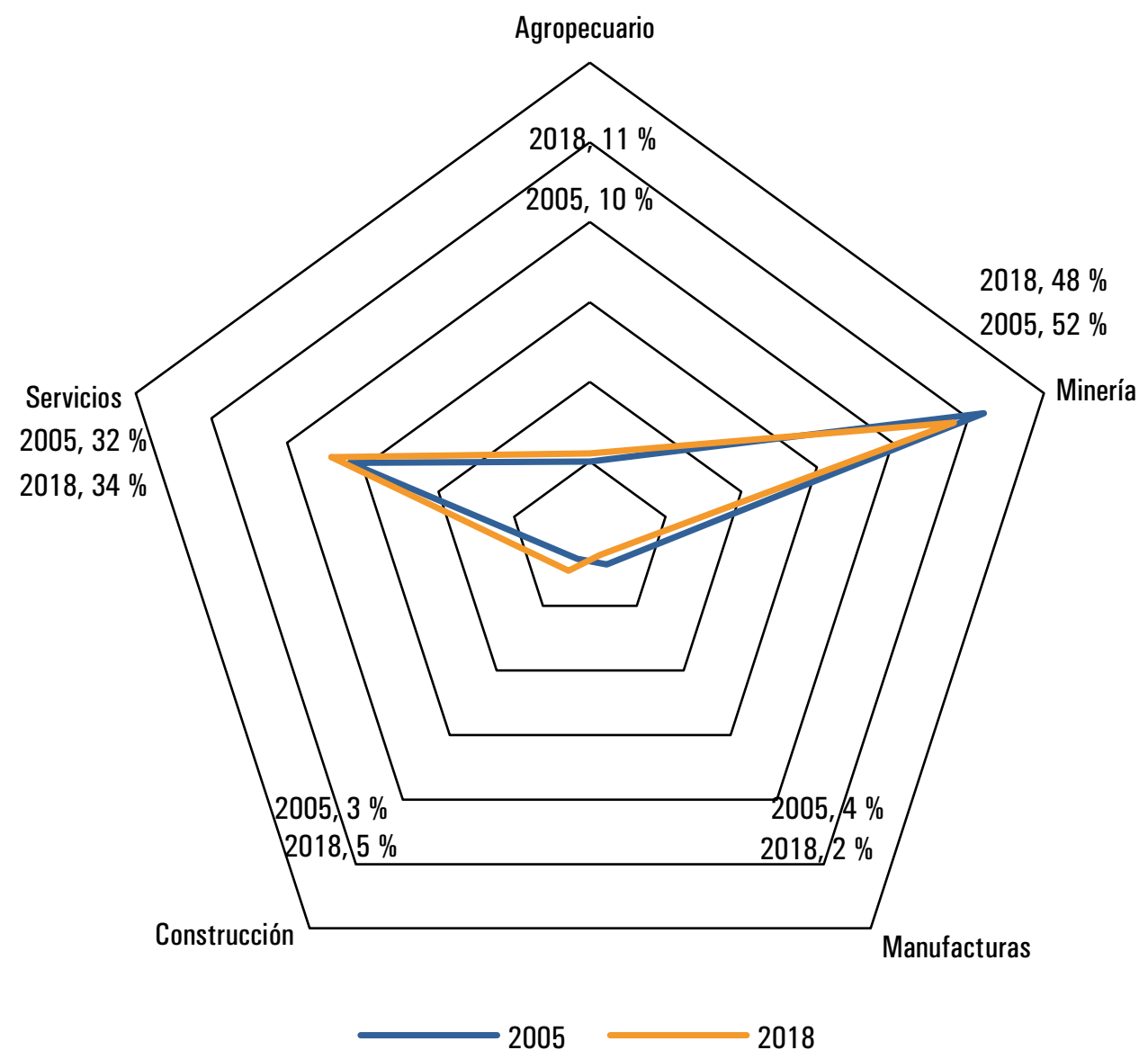

Fuente: elaboración propia a partir de datos del DANE.

Al realizar el comparativo de la evolución al finalizar la serie y teniendo en cuenta que en 2014 se generó una crisis mundial ligada al petróleo que afectó a todos los minerales, encontramos que algunos sectores ganaron dinamismo durante el auge del sector minero. Este fue el caso de los sectores no transables, como los servicios y la construcción, los cuales crecieron y se convirtieron en factores importantes dentro de la estructura productiva. Lo contrario ocurrió con los sectores manufacturero y agropecuario. 
El primero de estos, que al inicio mostraba crecimiento, decreció en el tiempo y representó apenas $1 \%$ al finalizar el periodo. El crecimiento del sector agropecuario también disminuyó durante el auge, pero logró recuperarse una vez terminado este periodo.

\section{El caso de la región brasileña de Río de Janeiro}

Para Brasil se estudió la región de Río de Janeiro en el periodo 20022016. Se analizó la información de los cinco sectores de la región, la cual presenta una situación del todo diferente a las otras dos regiones señaladas (gráfica 2). La región de Río de Janeiro tiene un desarrollo mayor del sector de servicios y es más turística; no obstante, en el fondo marino se encontraron grandes reservas de petróleo que lo convirtieron en el mayor estado petrolero de Brasil.

Lo anterior se ve reflejado en las dinámicas del sector minero, el cual presentó un periodo de auge entre 2009 y 2012 en el que creció a una tasa de $36 \%$. Por otro lado, los sectores transables, como las manufacturas, evidenciaron un despegue positivo de $38 \%$ para luego marcar una tendencia decreciente hasta llegar $2 \%$. El sector agropecuario mostró decrecimientos después del inicio del auge del sector minero, en los periodos 2004-2005 y 2009-2010. En contraste, este mismo sector tuvo un crecimiento de $39 \%$ en un momento de auge de $36 \%$ de la minería.

Por otro lado, los sectores no transables, como los servicios, pasaron de tener un crecimiento negativo de $11 \%$ a alcanzar un crecimiento promedio de $10 \%$ en el periodo de estudio. Este sector es el más desarrollado de esta región y su motor principal. El sector de la construcción mostró un crecimiento en el periodo 2007-2008, cuando también se presentó un incremento del sector minero. Un periodo después, en 2008-2009, el sector de la construcción creció a 32 por ciento. 
Gráfica 2. Histórico de tasa de crecimiento de la región de Río en Brasil

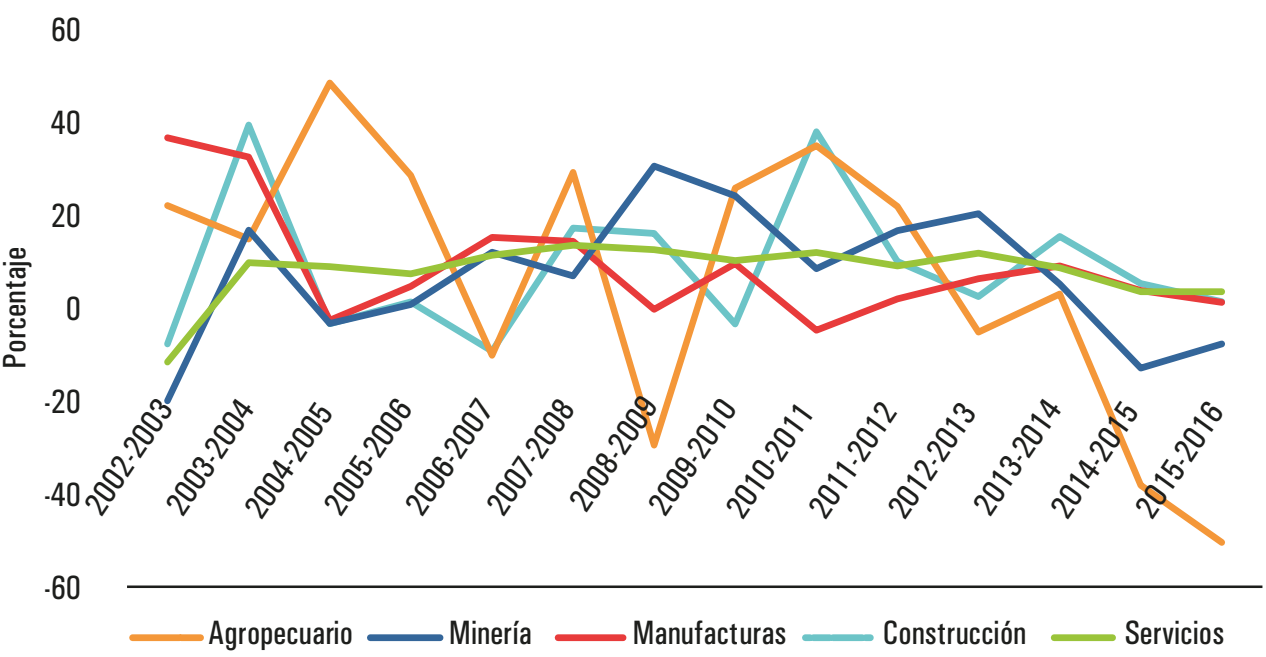

Fuente: elaboración propia a partir de datos del IBGE.

Se observa que la estructura productiva de la región de Río de Janeiro (diagrama 3) tiene un fuerte desarrollo de su sector terciario: el sector de los servicios representa $76 \%$ de su economía. El sector agropecuario solo representa $1 \%$, mientras que sectores como la construcción y la manufactura dan cuenta de $6 \%$ de la estructura productiva. El sector de la minería representa $11 \%$ para el año inicial de 2002.

Por el contrario, para el año de mayor intensidad, que fue 2005 para el sector minero energético, encontramos que este representó $21 \%$ de la estructura productiva de la región; el sector de servicios constituyó $66 \%$, el sector de manufactura, 9 \% y el de construcción, 4 por ciento.

Se observó que el sector minero, que inicialmente representó $11 \%$, decreció 50 \% y se ubicó en $6 \%$ de participación en el PIB regional (diagrama 4). Los sectores transables, como la agricultura, no tuvieron gran variación y mantuvieron su participación alrededor de $1 \%$. El sector manufacturero apenas creció $7 \% \mathrm{y}$, por otro lado, un sector no transable como la construcción decreció a 1 por ciento. 

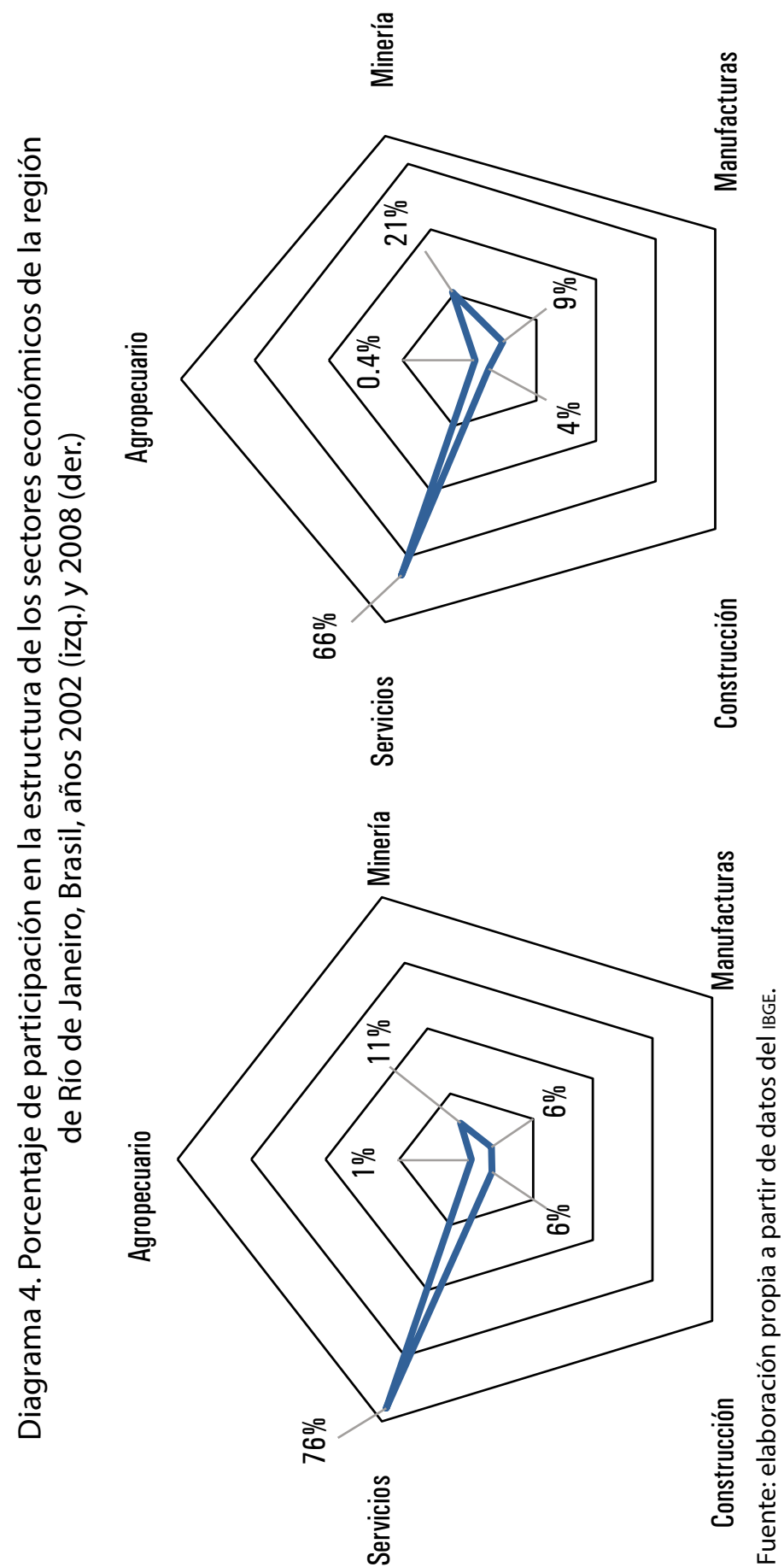
Diagrama 5. Comparativo en porcentaje de la evolución de los sectores económicos en la región Río de Janeiro, Brasil

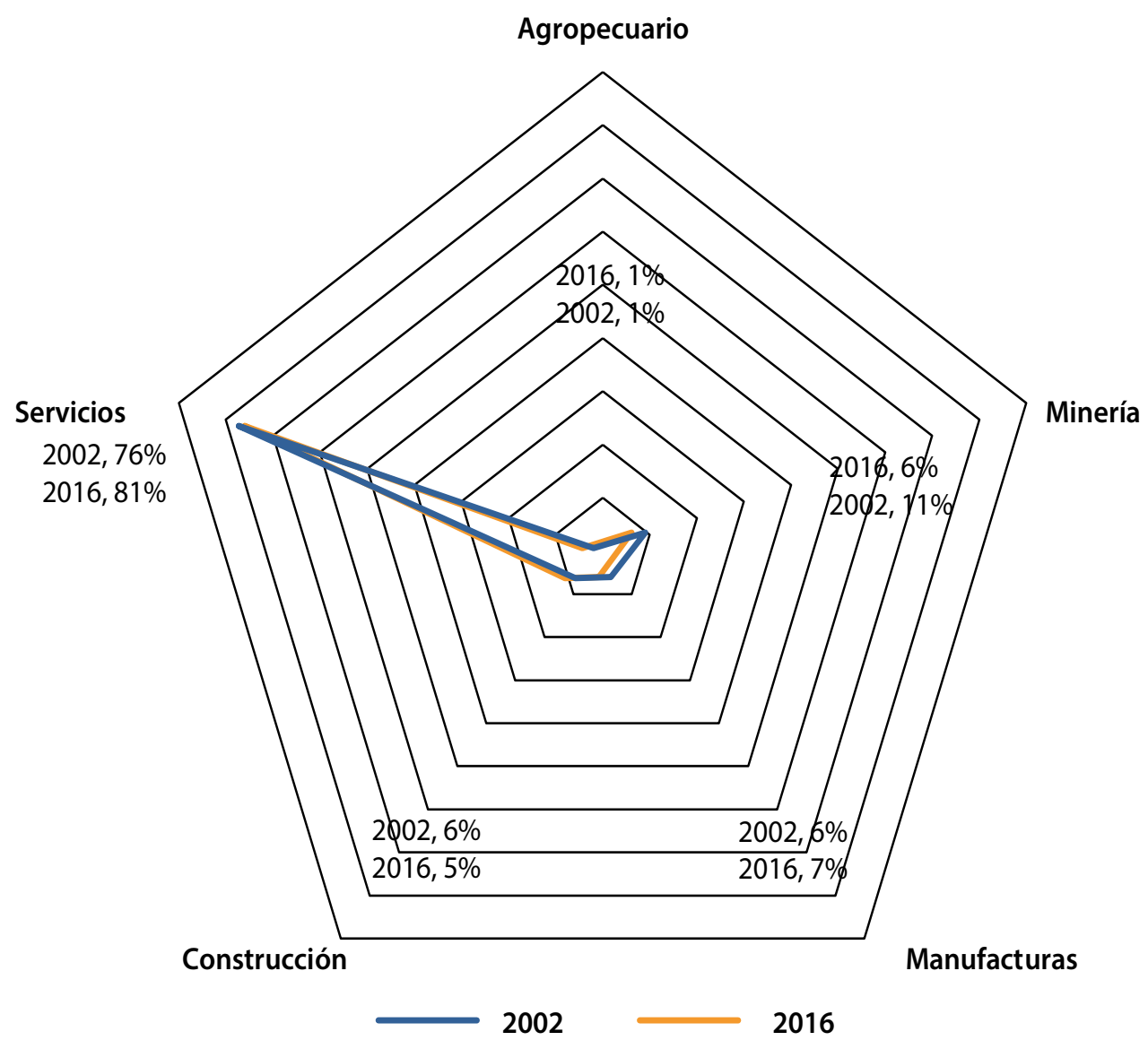

Fuente: elaboración propia a partir de datos del IBGE.

El caso de la región Sur peruana

Para Perú se realizó un análisis de la región Sur, ${ }^{3}$ una región exportadora de cobre y oro principalmente. Se estudiaron los cinco sectores económicos

${ }^{3}$ Abarca Arequipa, Apurímac, Cusco, Moquegua, Puno y Tacna. 
en el periodo 2007-2017 y se observó que el sector minero presentó un auge entre 2009-2010 y 2015-2016, llegando a tasas de crecimiento de 40 a 51 por ciento.

Asimismo, el sector agropecuario mostró cambios en su tendencia de crecimiento. Entre 2007 y 2012, el promedio de crecimiento era de $12 \%$ y disminuyó a la mitad (6 \%) entre 2012 y 2017 con etapas de decrecimiento en 2009-2010. De igual modo se encontró que cada vez que se presentó un incremento en la minería, el ritmo de crecimiento del sector agropecuario disminuyó; por ejemplo, en el periodo 2009-2010, este último creció apenas 3 por ciento.

Gráfica 3. Histórico de tasa de crecimiento de la región Sur de Perú

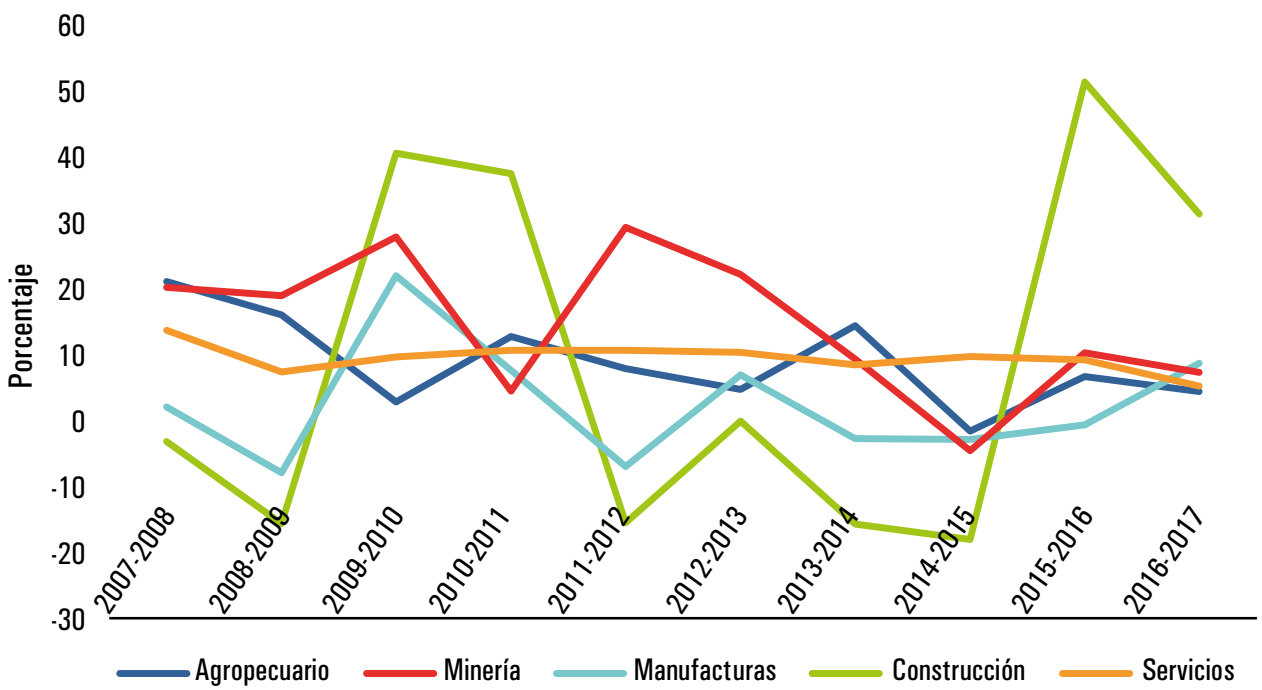

Fuente: elaboración propia a partir de datos del INEl.

El sector manufacturero mostró un comportamiento similar al agropecuario. En un primer momento, entre 2007-2012, creció a un ritmo de $3 \%$ para luego disminuir dicho ritmo a $1.8 \%$. Como el sector agropecuario, la manufactura también tuvo una disminución del crecimiento con los auges de la minería, pasando de tasa de crecimiento de $22 \%$ en 20092010 a $7 \%$ en $2011-2012$. 
Por su parte, los sectores no transables, como el sector de la construcción, mostraron un comportamiento independiente de los auges, con una tendencia de crecimiento siempre positiva. Algo similar sucedió con el sector servicios, que exhibió un comportamiento relativamente estable de $9 \%$, en promedio, durante el periodo de estudio.

En 2007, la región Sur de Perú mostró una distribución de la estructura productiva más compacta, por la que se evidenció un mayor desarrollo del sector de las manufacturas y de servicios que en la región colombiana. El auge generó una distribución de 33 \% para la minería, 14 \% para la manufactura, $37 \%$ para los servicios, $9 \%$ para el agropecuario y $7 \%$ para la construcción. Una vez que la crisis de 2014 inició, se generó la reversión de la distribución productiva (diagrama 5): la minería decreció a $17 \%$ y el sector manufacturero a $12 \%$. Por el contrario, el sector no transable de la construcción, que al principio representó poco más de $5 \%$, creció en el periodo posterior al auge hasta alcanzar $10 \%$. El sector de servicios mostró una participación constante de $42 \%$, en promedio, lo que indica que este sector no tenía fuertes relaciones con la minería.

$\mathrm{Al}$ realizar el comparativo entre el año inicial y el final de la serie para rastrear los cambios en la distribución productiva de la región se identificó que en 2007 hubo una participación del sector minero de $31 \%$ en la región Sur del Perú; esta participación disminuyó a 27 \% para el año final 2015. Por otro lado, cuando analizamos los sectores que se ven afectados por la enfermedad holandesa, hallamos que el sector agropecuario mantuvo su participación porcentual, con $9 \%$ en ambos periodos. El sector manufacturero, por su parte, en el año inicial tuvo una mayor participación de $17 \%$ y para el año final de 2015 se ubicó en 10 por ciento.

En contraste, los sectores no transables aumentaron su participación. En el año inicial, la construcción representaba $5 \%$ y dobló su participación al cabo de 10 años. Por último, el sector de servicios, que inicialmente tenía una participación de 38 \%, llegó a representar 44 \% de la distribución productiva de la región al final de la serie. 

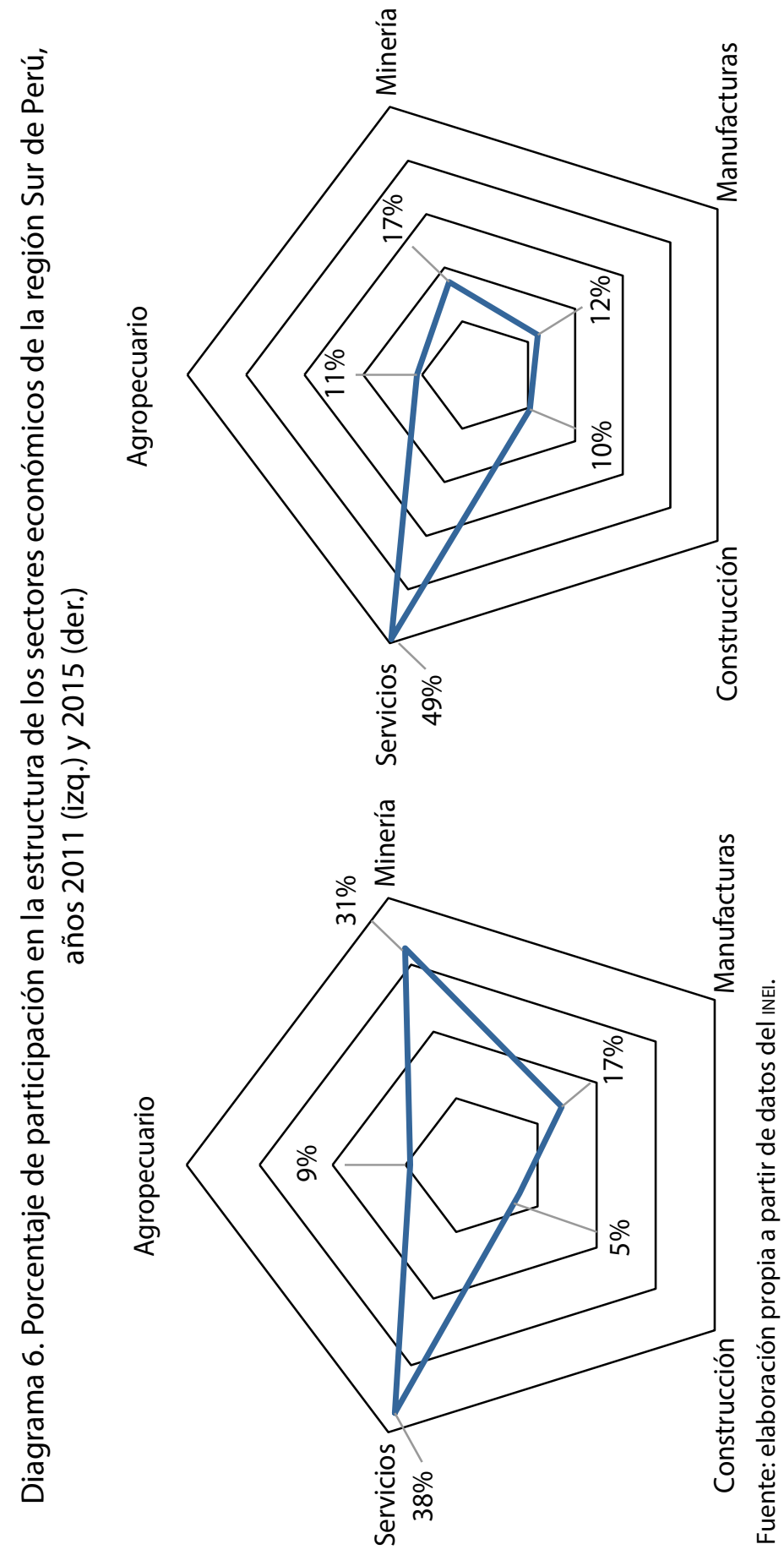
Diagrama 7. Comparativo en porcentaje de la evolución

de los sectores económicos en la región Sur de Perú

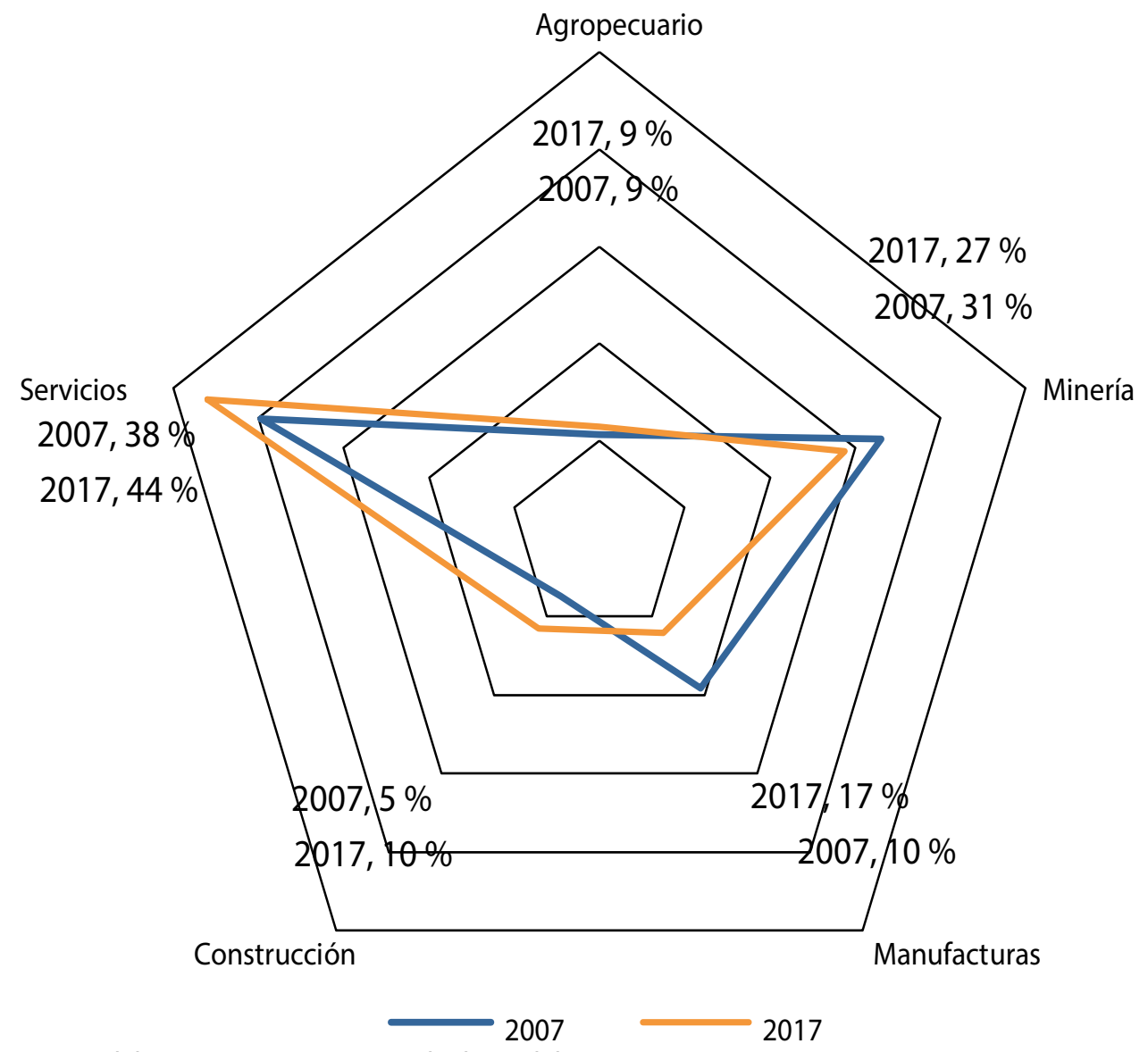

Fuente: elaboración propia a partir de datos del INEI.

Comparativo de tasas de crecimiento geométrico

Ahora analizaremos el promedio de la tasa de crecimiento geométrico de los cinco sectores (cuadro 2). Para el caso de la minería en las diferentes regiones, rastreamos un promedio de crecimiento geométrico en el primer periodo de $7 \%$ para Colombia, el cual llega a $9 \%$ y al final del periodo, 
después de la crisis petrolera, decae a -2\%. Algo similar sucede con Brasil, que en el primer periodo alcanza $7 \%$ y en el segundo tramo analizado llega hasta $8 \%$, para terminar con un promedio de $-25 \%$. Por el contrario, la región Sur de Perú tuvo inicialmente un crecimiento negativo de $-5 \%$, aunque en el siguiente periodo se recuperó y alcanzó 7 \%, y terminó el último periodo con un crecimiento de 9 por ciento.

En el caso de los sectores transables, como el agropecuario, vemos un promedio de crecimiento de $7 \%$ para Colombia, para luego, en el periodo del auge, llegar apenas a $1 \%$ y para el último periodo recuperarse hasta $8 \%$. Algo semejante ocurre con la región Sur de Perú, en la cual se registra un promedio de crecimiento de $9 \%$ durante el decaimiento del sector minero, en la medida em que el auge de los minerales surge se ubica en el segundo periodo en $3 \%$ y termina con un crecimiento de 2 por ciento.

Para el otro sector transable como es la manufactura, vemos el mismo comportamiento: en el periodo inicial un crecimiento de $4 \%$ para la Orinoquía colombiana, luego un ritmo mínimo en el periodo del auge de $1 \%$ para finalizar con $2 \%$. La misma historia se identifica para Brasil, que en el periodo inicial arrancó con un crecimiento de $7 \%$, luego de $3 \%$ y termina el periodo de análisis con $2 \%$. Por el contrario, Perú mostró un inicio de $-2 \%$, se recuperó para el periodo de auge, aunque a niveles mínimos de $3 \%$, y finalizó en 1 por ciento.

Los sectores no transables mostraron un comportamiento diferente para la Orinoquía colombiana. Allí, el sector de la construcción exhibió una dinámica fuerte de $16 \%$, en el periodo del auge se moderó y se ubicó en $7 \%$ y terminó con $-3 \%$. Es diferente para la región Sur de Perú, que al inició tuvo un promedio de crecimiento de $9 \%$, se aceleró un poco durante el auge y llegó a $10 \%$ para finalmente descolgarse a $2 \%$ después del auge. Brasil no experimentó un comportamiento diferente al de Perú, el cual inició con promedios de crecimiento pequeños de $3 \%$ y al momento del auge se dispararon a $8 \%$ y terminaron en terreno negativo de -5 por ciento.

En el sector servicios se observó un comportamiento similar en las tres regiones con promedio de crecimiento cercano a $5 \%$. Por ejemplo, Colombia llegó a crecer en los dos primeros periodos a $5 \%$ y al final decayó a $4 \%$. Perú también creció a $5 \%$ en los dos primeros periodos y finalizó en $4 \%$. Brasil inició creciendo $4 \%$, en el momento del auge subió a 5 \% y finalizó con $3 \%$. 
Como puede verse, este sector no sufrió grandes cambios en ninguna de las tres regiones.

Cuadro 2. Tasas de crecimiento geométrico promedio comparado de las regiones (\%)

\begin{tabular}{|c|c|c|c|c|}
\hline Región & Sector & $2005-2008$ & $2009-2013$ & 2014-2018 \\
\hline \multirow[t]{5}{*}{ Orinoquía,Colombia } & Agropecuario & 7 & 1 & 8 \\
\hline & Minería & 7 & 9 & -2 \\
\hline & Manufacturas & 4 & 1 & 2 \\
\hline & Construcción & 16 & 7 & -3 \\
\hline & Servicios & 5 & 5 & 4 \\
\hline Región & Sector & $2007-2008$ & $2009-2013$ & 2014-2017 \\
\hline \multirow[t]{5}{*}{ Sur de Perú } & Agropecuario & 9 & 3 & 2 \\
\hline & Minería & -5 & 7 & 9 \\
\hline & Manufacturas & -2 & 3 & 1 \\
\hline & Construcción & 9 & 10 & 2 \\
\hline & Servicios & 5 & 5 & 4 \\
\hline Región & Sector & $2002-2008$ & $2009-2013$ & 2014-2016 \\
\hline \multirow[t]{5}{*}{ RíodeJaneiro,Brasil } & Agropecuario & 4 & 6 & 2 \\
\hline & Minería & 7 & 8 & -25 \\
\hline & Manufacturas & 7 & 3 & 2 \\
\hline & Construcción & 3 & 8 & -5 \\
\hline & Servicios & 4 & 5 & 2 \\
\hline
\end{tabular}

Fuente: elaboración propia. 
Las regiones analizadas evidencian diferentes momentos de desarrollo económico inicial, lo que resulta importante para rastrear los efectos de la enfermedad holandesa. Por ejemplo, la región de Río de Janeiro, con una economía fuertemente tercerizada, no sufrió mayor convulsión con el auge porque su estructura productiva respondía mayoritariamente al comercio. Para el caso de Perú, se identificó que al inicio había un alto grado de desarrollo del sector textil, el cual comenzó a decrecer durante el auge y no logró una recuperación posterior. Algo similar sucedió con el sector agropecuario en Colombia, el cual tenía una mayor participación antes del auge del petróleo en 2005, misma que se fue perdiendo con el auge para recuperar parcialmente su dinamismo al final de este. Cabe también anotar que el sector textil de la región de Colombia nunca logró crecer.

Cuando se presenta un auge de un recurso natural, este modifica la estructura productiva de la región destruyendo, disminuyendo el ritmo o impidiendo que se desarrollen los demás productos transables. Esto se evidenció en cada región de los diferentes países analizados: los sectores transables crecieron rápidamente durante el auge, mientras que el ritmo de crecimiento de los no transables decreció o disminuyó. Una vez finalizado el auge, los no transables se estancaron o decrecieron y los transables, aunque crecieron en algunos casos, no volvieron a recuperar su dinamismo anterior. El impacto fue negativo - para la productividad-de los diferentes factores de producción: tierra, trabajo y capital, ocasionando disminución de la competitividad a nivel internacional vía precios. Esto porque los factores de producción continúan con unas rentas esperadas altas, dificultando nuevos emprendimientos.

El caso de Río de Janeiro, una región con una gran economía centrada en el sector servicios, permite deducir que entre más grande y diversificada sea la economía, menos trastornos se generarán en la estructura productiva durante un auge. Resultados similares a los encontrados por Weber [2014], Tsvetkova y Partridge [2016: 82], y Weinstein, Partridge y Tsvetkova [2018] demuestran que los efectos de la enfermedad holandesa son menos fuertes en regiones metropolitanas que en aquellas más rurales (menos diversificadas y con menor tamaño económico). 
El caso de Perú exhibe cierta diversidad de esa dependencia regional de recursos naturales ya que nunca han tenido una participación de la minería superior a un tercio de su economía, lo que les permite mantener tasas de crecimiento sectorial. Sin embargo, en Colombia la participación llegó a ser de la mitad de la producción regional, favorecida en gran medida por un PIB de menor tamaño y con casi nula participación del sector manufacturero.

ReferenCiAs

Arellano, Javier [2008], "Resurgimiento minero en Perú: ¿una versión moderna de una vieja maldición?", en Colombia Internacional, núm. 67, pp. 60-83.

Auty, Richard M. [1993], Sustaining Development in Mineral Economies: The Resource Curse Thesis. Londres, Routledge, 272 pp.

(ed.) [2001a], Resource abundance and economic development. Londres, Oxford University Press, $360 \mathrm{pp}$.

[2001b], "The political economy of resource-driven growth", en European Economic Review, vol. 45, núm. 4-6, pp 839-846.

[2007], Patterns of rent extraction and deployment in developing countries: implications for governance, economic policy and performance. Londres, Palgrave Macmillan, 577 pp.

[2015], The political basis of the resource curse. Handbook on the Economics of Natural Resources. Reino Unido, Edward ElgarPublishing's, $140 \mathrm{pp}$.

[2017], "Natural resources and small island economies: Mauritius and Trinidad and Tobago", en The Journal of Development Studies, Reino Unido, Frank Cass Publishers, vol. 53, núm. 2, pp. 264-277.

Bonet, J. et al. [2014], Efectos del nuevo Sistema General de Regalías sobre el desempeño fiscal municipal: un análisis dosis-respuesta. Documentos de trabajo sobre economía regional. Bogotá, Banco de la República, 51 pp. Bonet, J., y J. Urrego [2014], El Sistema General de Regalías: ¿mejoró, empeoró o quedó igual? Documentos de trabajo de economía regional. Bogotá, Banco de la República, 55 pp. 
Bonilla, Miguel Palomino et al. [2015], "El costo económico de la no ejecución de los proyectos mineros por conflictos sociales y/o trabas burocráticas", IPE. <https://cutt.ly/bgkVK05>.

Colombia, Congreso de la República [2019], Ley 5 de 2011. Bogotá, Congreso de la República de Colombia.

Corden, W. M., y J. P. Neary [1982], "Booming sector and de-industrialisation in a small open economy", en The Economic Journal, Londres, Oxford Academic-Royal Economic Society, vol. 92, núm. 368, 825-848.

Congreso de Perú [2001], "Ley canon LEY N²7506", en Gaceta del Congreso de Perú, Lima, Perú.

Departamento Nacional de Planeación [2019], Guía de distribución de los recursos del sistema general de regalias entre fondos y beneficiarios. Bogotá, DNP.

Evans, Peter y Leandro Wolfson [1996], "El Estado como problema y como solución”, en Desarrollo económico, Buenos Aires, JSTOR, enero-marzo, vol. 35, núm. 140, pp. 529-562.

Frankel, J. A. [2012], The natural resource curse: A survey of diagnoses and some prescriptions. Cambridge, Faculty Research Working Paper Series. John F. Kennedy School of Government, Harvard University. $<$ https://cutt.ly/2gkVVfX>. 14 de marzo de 2020.

Furtado, Celso [1979], Teoria e Política do Desenvolvimento Econômico. 7. ed. Sao Paulo, Editora Nacional, 344 pp.

Grupo Propuesta Ciudadana [2007], Vigilancia de las industrias extractivas 2004-2006. Reporte nacional núm. 5. Lima, Grupo Propuesta Ciudadana, $110 \mathrm{pp}$.

Hirschman, A. O. [1977], "A generalized linkage approach to development, with special reference to staples", en Economic development and cultural change. Chicago, The University of Chicago Press Journals, núm. 25, pp. 67-88.

Hotelling, Harold [1931], "The Economics of Exhaustible Resources", en Journal of Political Economy, Chicago, The University of Chicago Press Journals, vol. 39, núm. 2, pp. 137-75.

Instituto Peruano de Economía (IPE) [2017], "Indicador Compuesto de la Actividad Económica”. Lima, Peru. <www.ipe.org.pe/portal/15044/>. 14 de marzo de 2020. 
Instituto Nacional de Estadística e Informática (INEI) [2015], "Panorama de la economía peruana 1950-2015 (año base 2007)”. Lima, Perú. $<$ https://cutt.ly/qgkV1e2>, 14 de marzo de 2020.

Kahhat, Farid [2016], "Las industrias extractivas y sus implicaciones políticas y económicas", en Revista de ciencia política y gobierno, Lima, Facultad de Ciencias Sociales dela PUCP. doi.org/10.18800/rcpg.201601.007

Lira, I. S. [2003], Disparidades, competitividad territorial y desarrollo local y regional en América Latina. Santiago, Cepal, 84 pp.

Maldonado, S. [2011], Boom minero y corrupción de funcionarios públicos de los gobiernos locales en el Perú: Evidencia de un experimento natural. Berkeley, Centro de Estudios para el Desarrollo y la Participación (Cedep), 86 pp.

Martínez, A. y M. Delgado [2018], Estudio sobre el impacto de la actividad petrolera en las regiones productoras de Colombia. Caracterización departamental Meta.

Martínez, A., J. Núñez y M. Delgado [2017], Estudio sobre el impacto de la actividad petrolera en las regiones productoras de Colombia, núm. 016042, Fedesarrollo.

Moyano, L. y P. Wright [2016], "Regalías y pobreza en el caribe colombiano: ¿momento para una alternativa focalizada?", Revista de Economía Institucional, 18, 34, junio 2016, pp. 201-227. doi: 10.18601/01245996. v18n34.12

Olarte, E. [2007], La economía política peruana de la era Neoliberal 19902006. Lima, Pontificia Universidad Católica del Perú, 87 pp.

Prebisch, Raúl [1950], The economic development of Latin America and its principal problems. Santiago, Cepal. <https://cutt.ly/ugkZnzK>, 10 de diciembre de 2019.

Reina-Bermúdez, Luis Eduardo [2019], "Efecto de la volatilidad del precio del petróleo en la economía global", en Filosofía en Red-Evento continuo del programa de Filosofía UNAD. Bogotá, 3 de julio.

Reina-Bermúdez, Luis Eduardo, Didier Alejo-Barrera y Neider Devia Merchan [2018], "Análisis regional de Colombia y su maldición de recursos naturales: cambios institucionales tardíos", en EURE (Santiago), enero, vol. 44, núm. 131. 
Rettberg, Angelika, Juan Felipe Ortiz-Riomalo y Sandra Yáñez-Quintero [2014], "Legislando minas. Breve recuento de la legislación minera en Colombia (1829-2001)". Documentos Cede. Bogotá, Universidad de los Andes.

Silva Lira, I. [2003], Disparidades, competitividad territorial y desarrollo local y regional en América Latina, Ilpes.

Stijns, Jean-Philippe [2003], "An empirical test of the Dutch disease hypothesis using a gravity model of trade", en EconPapers, Munich, agosto, núm. 1.

Tsvetkova, A., y M. D. Partridge [2016], "Economics of modern energy boomtowns: do oil and gas shocks differ from shocks in the rest of the economy?", en Energy Economics, Ámsterdam, Elsevier, núm. 59, pp. 81-95.

Weber, J. G. [2014], "A decade of natural gas development: the makings of a resource curse?", en Resourse and Energy Economics, Chicago, Elsevier, núm. 37, pp. 168-183.

Weinstein, A. L., M. D. Partridge y A. Tsvetkova [2018], "Follow the money: Aggregate, sectoral and spatial effects of an energy boom on local earnings", en Resources Policy, núm. 55, pp. 196-209. 


\title{
12. INTEGRACIÓN SUDAMERICANA, PROYECTOS DE GRAN ESCALA Y GLOCALIZACIONES: LA ENCRUCIJADA DE LA HIDROVÍA PARAGUAY-PARANÁ Y EL CORREDOR BIOCEÁNICO CENTRAL EN EL SEGUNDO CICLO EXTRACTIVISTA
}

\author{
Gisela Ariana Rausch* y Estefanía Szupiany**
}

INTRODUCCIÓN

Este trabajo integra dos investigaciones que las autoras tienen en curso; el objetivo principal es reflexionar analíticamente y con perspectiva histórica acerca del papel de los proyectos de gran escala ${ }^{1}$ (PGE) durante la fase del capitalismo iniciada en las últimas décadas del siglo xx, en el contexto de la llamada integración sudamericana. Este proceso político-

* Doctora en Historia, Facultad de Humanidades y Artes, Universidad Nacional de Rosario. Investigadora Adjunta en el Instituto de Estudios Críticos en Humanidades, Rosario/Consejo Nacional de Investigaciones Científicas y Técnicas (Conicet), Centro Universitario Rosario de Investigaciones Urbanas y Regionales (curdiuR). Desarrolla el proyecto de investigación: "Proyectos de gran escala, paisajes hidrosociales y políticas de territorio: la Hidrovía Paraguay Paraná y el puente Rosario-Victoria en la conformación de territorios periféricos de extracción". Es docente en la Facultad de Arquitectura, Diseño y Urbanismo, Universidad Nacional del Litoral y coordinadora del área: "Agua y megaproyectos" en la red internacional WATERLAT GOBACIT. Correo electrónico: <gsrrsch@gmail.com>.

** Doctora en Arquitectura por la Facultad de Arquitectura Planeamiento y Diseño, Universidad Nacional de Rosario. Becaria posdoctoral en el Consejo Nacional de Investigaciones Científicas y Técnicas (Conicet) con sede en el Instituto de Humanidades y Ciencias Sociales del Litoral (IHusco Litoral). Desarrolla el proyecto de investigación: "Integración territorial y reconfiguraciones locales. Las nuevas conexiones viales entre Santo Tomé, Santa Fe y Paraná". Es docente en la Facultad de Arquitectura, Diseño y Urbanismo, Universidad Nacional del Litoral. Correo electrónico: <eszupiany@gmail.com>.

${ }^{1}$ Con este concepto se busca la diferenciación respecto de los grandes proyectos, los cuales conformaron uno de los núcleos de la planificación de intervención estatal durante gran parte del siglo xx. El concepto de PGE busca hacer visible la complejidad específica de los proyectos posteriores a la reestructuración capitalista de finales del siglo, lo cual se desarrolla en este trabajo. 
territorial fue impulsado a finales del siglo pasado en algunos países de América Latina, a partir del acuerdo Mercosur (1991) y luego fue reforzado y ampliado por la Iniciativa para la Integración Regional Sudamericana (IIRSA-Cosiplan) (2000). El mismo requirió una materialización territorial que consistió en una red de proyectos infraestructurales orientados a impulsar la explotación de ciertos elementos de la naturaleza -concebidos como recursos y demandados por el mercado internacional-en los diferentes países del subcontinente con el objetivo de exportarlos a los centros de producción mundial.

En Argentina, el mayor énfasis exportador estuvo puesto en los agronegocios ${ }^{2}$ en especial en el monocultivo de soja desde el ingreso de la semilla genéticamente modificada en $1996 .^{3} \mathrm{~A}$ partir de ese acontecimiento, que se acompañó de la incorporación de tecnología y una nueva manera de producción agrícola (la empresarial), la estructura agraria del país fue transformándose de manera progresiva y se expresó en la conformación de una nueva organización territorial a partir de la emergencia de nuevas jerarquías espaciales. El área cerealera argentina, encabezada por el polo agroexportador Gran Rosario ${ }^{4}$ (provincia de Santa Fe) y el puerto de Buenos Aires, cobró especial relevancia dentro del modelo adoptado.

Nuestro trabajo se propone estudiar el caso de la ciudad de Santa Fe y su territorio de expansión -o Gran Santa Fe (GSF)- ${ }^{5}$ cuyo papel en el esquema general mencionado es relativamente menor-debido sobre todo

\footnotetext{
${ }^{2}$ Se hace referencia a la forma empresarial de producción agraria. Los agronegocios constituyen un sector productivo; la agroindustria, una cadena de actores y relaciones; $y$ el sistema agroalimentario, un modelo global de una cadena productiva [Malassis, 1975].

${ }^{3}$ Si bien el modelo se consolidaría después de 2000 (impulsado por la demanda internacional), puede decirse que durante los noventa se sentaron las bases (normativas, administrativas, proyectuales) para su despliegue. Asimismo, la comercialización de soja transgénica fue autorizada por el Ministerio de Economía y Obras y Servicios Públicos [Resolución № 167, 1996]. Esta resolución, que en su momento no tuvo repercusiones mayores, modificó la estructura agraria de Argentina con el tiempo.

${ }^{4}$ Este polo incluye localidades del Departamento San Lorenzo hacia el norte de Rosario y Villa Gobernador Gálvez hacia el sur de la ciudad; es considerado el polo agroexportador más grande del mundo, sobrepasando al Distrito Aduanero de Nueva Orleans (Estados Unidos).

${ }^{5}$ La ciudad de Santa Fe, capital de la provincia homónima ubicada en la región Centro-Este de la República Argentina, representa el centro administrativo, funcional y de servicios con mayor jerarquía del continuum urbano denominado GSF; con una población total de 490171 habitantes (según el Censo Nacional de Población, Hogares y Viviendas 2010). Su patrón territorial de crecimiento responde a la prolongación de vías circulatorias en distintas direcciones, incluida su extensión a las localidades vecinas de Monte Vera y Recreo al norte; Santo Tomé y Sauce Viejo al suroeste; y San José del Rincón y Arroyo Leyes al este.
} 
a que no posee puerto natural-, aunque su ubicación geográfica se considera estratégica por ser el puerto más continental de la Hidrovía ParaguayParaná (HPP). Esto ha provocado, desde los años noventa, intensos debates y discusiones que aún ocupan amplios espacios en la prensa local, en particular lo referente a las obras de infraestructura que se creen necesarias para conectar el puerto de la ciudad con el esquema internacional de un modo económicamente eficiente.

Asimismo, el GSF constituye un nodo donde se encuentran el mencionado corredor fluvial HPP y el eje vial conocido como Corredor Bioceánico Central ( $\mathrm{CBC}$ ). La HPP consiste en una vía de navegación norte-sur que corre desde Brasil (Mato Grosso) hasta el océano Atlántico (Uruguay); mientras que el CBC define un eje vial en sentido este-oeste que atraviesa la HPP y conecta los frentes oceánicos Atlántico-Pacífico, desde Porto Alegre (Brasil) hasta la región de Coquimbo (Chile). Ninguno de estos proyectos se ha concretado en su totalidad y su funcionamiento es parcial sujeto a las obras infraestructurales existentes. El cruce de la HPP y el CBC tiene lugar en plena zona cerealera de Argentina, y como mencionamos antes, uno de los puntos de convergencia entre las rutas (fluvial y terrestre) se encuentra entre las ciudades de Santa Fe y Paraná (capital de Entre Ríos). ${ }^{6}$ Las infraestructuras que ahora posibilitan dicho encuentro son: la Autovía Ruta Nacional 168, el Túnel Subfluvial Hernandarias, las avenidas Alem y 27 de Febrero, la Avenida Circunvalación de Santa Fe, la Autopista Provincial 01, la Autovía Ruta Nacional 19 y el puerto de Santa Fe. Para este último existe un demorado proyecto que propone su traslado a una zona con mejores posibilidades de funcionamiento. También existe un proyecto de puente entre Santa Fe y Paraná que complementaría el tráfico del túnel subfluvial y posibilitaría mayor flujo de transporte. ${ }^{7}$

Por otra parte, se encuentran en preparación los pliegos para la reprivatización de la HPP en el tramo argentino -que vence en 2021-por donde pasa entre 60 y $80 \%$ de la carga destinada a exportación. ${ }^{8}$ Este proceso implica una nueva licitación del consorcio que lo tiene a cargo, ${ }^{9}$ junto con

${ }^{6}$ Otro cruce entre la HPP y el CBC se halla entre las ciudades Rosario y Victoria, a través del puente homónimo.

${ }^{7}$ Este proyecto, que los diferentes gobiernos de Santa Fe han promovido desde la década de los noventa, tampoco se ha concretado.

${ }^{8}$ Los porcentajes varían según los momentos y las fuentes.

${ }^{9}$ Desde 1995, el consorcio que opera en el tramo argentino es Hidrovías, S. A., integrado por la empresa belga Jan De Nul N. V. y las nacionales Kocourek S.A. y EMEPA, S. A. [Decreto 253, 1995]. 
algunas propuestas de obras concentradas principalmente en aumentar la profundidad del río para posibilitar que las embarcaciones de mayor calado completen la carga. ${ }^{10}$ La situación antes mencionada, junto a los intereses expresados por el gobierno de China -principal comprador de la producción argentina de soja- de aumentar la demanda cerealera y obtener la concesión de la vía navegable [Punto Biz, 2018; Perfil, 2019], a lo que se suma que en marzo de 2019 el gobierno nacional aprobó la importación del evento biotecnológico para el cultivo de soja proveniente del mencionado país, ${ }^{11}$ evidencia el peso que el país asiático está teniendo en el territorio. Estos intereses conforman una coyuntura que nos exigen, como mínimo, algunas reflexiones en torno a las consecuencias territoriales y socio-ecológicas de casi 20 años de vigencia de este modelo agroexportador en Argentina.

Escribimos este artículo en medio de una América Latina convulsionada, donde los sectores hegemónicos más conservadores intentan sostener un modelo político-económico que ha dejado excluidos a amplios sectores que componen el cuerpo social y hoy manifiestan sus demandas en el espacio urbano. Los últimos hechos de violencia militar (en Ecuador, Chile y Bolivia, por ejemplo) y las luchas de intereses diversos y reclamos sociales constituyen el síntoma de un modelo en crisis y refuerzan la exigencia de un análisis de los efectos del mismo en sus múltiples aspectos y escalas de materialización. En tal sentido, este trabajo se inscribe en dicho marco general, con la idea de realizar un aporte en el campo de los estudios urbanos, y en particular, en aquellos centrados en las singularidades de los países de América Latina. Sin ánimos de exhaustividad o totalidad, se pretenden plantear algunos interrogantes a partir de la participación que tienen los PGE en el esquema internacional y de sus efectos espaciales en los ámbitos regionales y locales. Se parte de una mirada que intenta superar, por un lado, la economicista-eficientista, bajo la cual los proyectos estudiados fueron y continúan siendo promovidos, y por el otro, los estudios circunscritos a efectos (o impactos) meramente locales, o al contrario, solo sistémicos de los grandes proyectos. Con base en estas dos intenciones, se propone analizar:

${ }^{10}$ Actualmente, los buques portacontenedores no completan carga debido a la profundidad del río (10 pies desde zona de Confluencia hasta Santa Fe, 25 pies hasta Puerto San Martín y 35 pies hasta el océano Atlántico). En reuniones y presentaciones públicas se habla de llevar la profundidad a 40 a 42 pies.

${ }^{11}$ A cargo de la empresa Beijing Dabei Nong Biotechnology (DBN) [Resolución 17, 2019]. 
a) las condiciones histórico-geográficas que hicieron posible la emergencia de ambos PGE durante la década de los noventa; b) el papel de este tipo de proyectos en vinculación con el lugar asignado internacionalmente a los países de América Latina como productores de materia prima; c) las discusiones y legitimaciones, en el ámbito local y regional, en torno a los mismos en relación con las ideas de integración, crecimiento económico y desarrollo regional; y d) las transformaciones espaciales asociadas con ambos proyectos. Este último aspecto se analizará de manera general en relación con los anteriores, por cuanto las investigaciones más profundas y minuciosas se encuentran aún en curso.

Resulta necesario aclarar que la HPP y el CBC han tenido grados de desarrollo diferentes en el área estudiada y las transformaciones derivadas de su progresiva implementación también han tenido grados distintos de materialización. Asimismo, mientras que las obras asociadas al CBC desencadenaron efectos urbanos -evidenciados en transformaciones espaciales en el GSF-, el funcionamiento de la HPP se vincula sobre todo con el área de cultivo sojero y las transformaciones urbanas más evidentes se han dado en Rosario y su área de influencia [Schweitzer, 2016]. En Santa Fe, las discusiones en torno a la implementación de la HPP se han referido principalmente a dos infraestructuras: el puerto, que exigía su traslado hacia una localización más ventajosa económicamente; y la construcción de la obra hidroeléctrica Proyecto Paraná Medio. Ambas obras no se han concretado.

Adoptando estrategias de indagación histórica basadas en el análisis documental, nuestro trabajo propone una elaboración con enfoque crítico y multiescalar en el que convergen los aportes teóricos de la geografía humana, los estudios urbanos y regionales y la ecología política.

En el primer apartado, se desarrolla un marco teórico estructurado en tres conceptos que, a nuestro entender, posibilitan la lectura de la problemática general: la idea de integración y su significado en el marco de la IIRSA, el concepto de PGE y el de glocalización; en el segundo apartado se presenta una sinopsis de la IIRSA como marco general infraestructural de la HPP y el CBC. En dos apartados subsiguientes, se exponen las características principales de los proyectos estudiados, y en el quinto se desarrollan las transformaciones urbanas y discusiones derivadas de las infraestructuras asociadas con ambos PGE en el ámbito del GSF. Finalmente, se formulan algunas reflexiones a modo de conclusión. 
INTEGRACIÓN REGIONAL, PROYECTOS DE GRAN ESCALA Y TERRITORIALIDADES GLOCALES. LAS CONDICIONES de partida de la Hidrovía Paraguay-Paraná y el Corredor Bioceánico Central

El ciclo del capitalismo que inició a finales del siglo xx, conocido como proceso de globalización ${ }^{12}$ o de capitalismo mundial integrado (CMI) [Guattari y Rolnik, 2013], introdujo un nuevo orden en el sistema mundo que consistió en nuevas jerarquías económico-territoriales, acompañadas por una nueva configuración de las relaciones territorio-autoridad ${ }^{13}$ [De Mattos, 1989; Dicken, 2003; Harvey, 2004; Sassen, 2010], junto a un rediseño de la división territorial global del trabajo [Ciccolella et al., 1994; Fernández, 2018]. Algunos autores han interpretado estas transformaciones como un pasaje de las antiguas relaciones centro-periferia a una configuración trasnacional de la economía, redistribuyendo los papeles de los diferentes sectores económicos mundiales. En dicha distribución, se asignó a los países de América Latina el lugar de cantera de extracción de recursos naturales por parte de empresas multinacionales, con centro en el llamado Norte Global. Este papel, expresado en la noción de reprimarización de la economía, ${ }^{14}$ consistió en desarrollar un modelo económico basado en la producción y exportación de bienes primarios, como metales, petróleo y granos; en Argentina la cadena de la soja es uno de los complejos productivos más relevantes [Reboratti, 1990, 2010; Pengue, 2000; Teubal, 2006; Vidosa, 2017]. Para algunos autores [Alimonda, 2006; Gudynas, 2009; Acosta, 2012; Seoane y Algranati, 2013; Svampa y Viale, 2014], con este modelo económico se inició un segundo ciclo extractivista, ${ }^{15}$ que se dio a llamar neoextractivismo. El extractivismo puede entenderse como una modalidad de acumulación basada en la extracción de elementos de la naturaleza a gran escala (tendiente al agotamiento del recurso) y en la que destaca la asimetría entre

12 Utilizamos la definición de globalización propuesta por Brenner [1999: 435] que hace referencia a un "proceso dialéctico a través del cual el movimiento de mercancía, capital, dinero, personas e información a través del espacio geográfico es permanentemente expandido y acelerado, al tiempo que son producidas, reconfiguradas y/o transformadas infraestructuras espaciales relativamente fijas que posibilitan tales movimientos de aceleración".

${ }^{13}$ Estas nuevas relaciones fueron posibilitadas por el ascenso de los capitales privados a sectores que tradicionalmente pertenecían a los Estados nacionales [Sassen, 2010].

${ }^{14}$ Haciendo referencia a una vuelta a la producción primaria de exportación, luego de un periodo (a mediados del siglo xx y hasta la década de los ochenta) cuyo objetivo estuvo puesto en el desarrollo industrial.

${ }^{15}$ El primero estaría ubicado en el siglo xIX. 
quienes operan como extractores de materias primas (en general, países de economías centrales) y quienes ofrecen los recursos no procesados para la exportación ${ }^{16}$ [Acosta, 2012]. Esta dinámica depredadora no puede considerarse una novedad, sino que forma parte de la misma dinámica capitalista que ya Marx [2004 (1867)] había observado en el momento histórico que denominó de acumulación originaria. Sin embargo, los mecanismos y las formas a partir de los cuales esta dinámica de acumulación por despojo se mantiene y reproduce en el tiempo adopta variantes según el momento histórico. ${ }^{17}$ En la nueva configuración mundial, surgida a finales del siglo xx, las áreas ricas en bienes de la naturaleza fueron conectadas a los centros de producción global, proceso que ha sido calificado por Acosta [2012] como determinismo geográfico y ecológico. En este determinismo, las redes tecnológicas de transporte de mercadería han tenido una función clave al posibilitar tanto la aceleración como la territorialización (o fijación) de los capitales globales [Harvey, 1985; Brenner, 1999].

En los países del Cono Sur, la reactivación de los procesos de integración se llevó adelante a través del Mercosur ${ }^{18}$ (1991). El mismo abrió un ciclo de regionalismo abierto (neoliberal) que Sanahuja [2008-2009] ubica entre 1990 y 2005. Este periodo estuvo orientado a la inserción internacional de los actores estatales y no estatales en el mercado internacional en torno a tres áreas económicas (Europa, Norteamérica y Asia Oriental), mediante políticas de liberalización económica intrarregional, de baja protección externa [Sanahuja, 2008-2009]. Durante la década de los noventa, este tipo de regionalismo fue promocionado bajo la idea de integración regional, término que tomó un carácter específicamente económico. Es decir, mientras la idea de integración regional de corte estructuralista ${ }^{19}$-promovida por

${ }^{16}$ Como puede verse, el término extractivismo evidencia las relaciones económicas desiguales entre países, mientras que primarización hace referencia solo a un tipo de modelo económico. Por ello, en este trabajo se utilizará extractivismo.

${ }^{17}$ Laval y Dardot [2015] ensayan las diferencias entre los mecanismos de apropiación territorial en el momento de la acumulación originaria, y los llevados adelante en el siglo xxI.

${ }^{18}$ Acuerdo firmado en 1991 por Brasil, Argentina, Paraguay y Uruguay. Posteriormente se incorporó Bolivia.

${ }^{19}$ Según Laredo [1994: 131] “El pensamiento liberal en que se ha basado la teoría clásica de la integración, propicia la abolición de barreras aduaneras, el libre comercio y la ampliación de los mercados como instrumentos conducentes a la reducción de los costos y al aumento de la productividad. Mientras que el pensamiento estructural, basándose en la observación de la realidad internacional caracterizada por la asimetría, la competencia entre desiguales y la profundización de las brechas, enfatiza en los fenómenos estructurales desestimados por el pensamiento liberal como fundamento de la integración". 
los gobiernos de los países de América Latina ${ }^{20}$ durante las décadas de los sesenta y setenta- colocaba el énfasis en los aspectos políticos de la misma ${ }^{21}$ con posterioridad al Consenso de Washington (1989) -y en pleno proceso de implementación de políticas neoliberales-, la integración se enfocó en los aspectos económicos (áreas de libre comercio y unión aduanera, principalmente).

En este nuevo contexto, las infraestructuras, y en especial los PGE, posibilitaron la territorialización de los procesos, ${ }^{22}$ habilitando la mayor circulación de mercaderías junto a la conexión de áreas consideradas nichos de extracción con los centros económicos mundiales.

Con PGE no se hace referencia a artefactos meramente técnicos de gran tamaño, sino a objetos tecnológicos complejos, conformados por elementos heterogéneos que actúan en varias dimensiones y escalas. Así, un PGE se compone de aspectos técnicos, políticos, económicos, normativos, ecológicos y sociales, entre otros. Los PGE involucran una variedad de actores (privados, civiles no gubernamentales y gubernamentales) e impactan a diferentes escalas (local, nacional, regional, internacional). Para el antropólogo Lins Ribeiro, los PGE

tienen características estructurales que les permiten ser tratados como "expresiones extremas" del campo del desarrollo: el tamaño del capital, territorios y cantidad de personas que controlan; su gran poder político; la magnitud de sus impactos ambientales y sociales; las innovaciones tecnológicas que crean frecuentemente; y la complejidad de las redes que ellos engendran” [Lins, 2007: 178].

Debido a sus impactos ambientales y sociales -sigue el autor- "los PGES muestran con claridad el desequilibrio de las relaciones de poder entre poblaciones locales y outsiders desarrollistas" [Lins, 2007: 178].

${ }^{20}$ Aquí no nos detendremos en las teorías de la integración, para ampliar, puede verse: Balassa [1964]; Laredo [1984, 1990 y 1994].

${ }^{21}$ El Tratado de la Cuenca del Plata (1969), que no llegó a concretarse en políticas, es un ejemplo. Para ampliar sobre las formas que tomó el regionalismo durante las décadas de los sesenta y setenta y posterior al Consenso de Washington, véase Fuentevilla [2018].

${ }^{22}$ Brenner [1999] interpretó que ante la desterritorialización del capital y la aceleración en los flujos (de dinero, personas, imágenes, etc.) propios de la globalización, se ha producido un proceso de reterritorialización consistente en la aparición de nuevas escalas y formas de organización territorial. 
Asimismo, los PGE se caracterizan por la transversalidad territorial, sorteando múltiples fronteras entre países (por ejemplo, geográficas y legales), propiciando, por un lado, las vinculaciones espaciales del capital que la coyuntura histórica les exige para su reproducción, y por el otro, provocando fragmentación socioespacial y conflictos entre diferentes intereses y actores en distintos órdenes (político, económico, ecológico, simbólico, social). Puede decirse, entonces, que estos proyectos definen redes territorialidades complejas y multiescalares en las que convergen diversos intereses.

La reconfiguración de los territorios y de las relaciones espaciales ocasionada por la implementación de PGE puede leerse a la luz del concepto de glocalización aportado por Swyngedouw [1992 y 2004]. Este concepto intenta colocar en relieve el carácter socioespacial, multiescalar y conflictivo en el que se ha dado el proceso de integración de la economía mundial, donde se configuran nuevas relaciones dinámicas entre los ámbitos locales y globales. Dicho de otro modo, la glocalización implica un proceso dinámico en el que lo que se considera local se encuentra configurado e indisociablemente vinculado -y en conflicto- con procesos de orden global. En tal sentido, consideramos relevante estudiar los PGE como artefactos multidimensionales y multiescalares que activan procesos de glocalización.

Asimismo, los grandes proyectos de infraestructura de los últimos años en América del Sur se orientaron básicamente a: acelerar el transporte interoceánico, casi siempre operado por empresas multinacionales; conectar regiones productivas (en Argentina, Noroeste, Nordeste, Cuyo y Córdoba); y facilitar la vinculación entre los grandes centros de producción y consumo y a su vez la de estos con los puertos exportadores (corredores viales Sao Paulo-Buenos Aires, Porto Alegre-Rosario y Cuyo-Córdoba). En este marco, la IIRSA constituyó el programa territorial infraestructural principal para llevar adelante dichos objetivos.

IIRSA: ENTRE LA INTEGRACIÓN SUDAMERICANA Y LAS OPORTUNIDADES EXTRACTIVISTAS

La iniciativa de integración económica, conocida como IIRSA, puede considerarse una manifestación de la voluntad de sectores económicos hegemónicos de organizar de forma tecnológica los flujos de capital y de extracción de elementos de la naturaleza en América Latina para su exportación a los centros de producción global. Como ha señalado Delgado Ramos [2012], 
los países de este continente cuentan con minerales de gran uso y especialmente valorados por el mercado internacional, tales como bauxita, cobre, litio y níquel, y a esto se le suman las áreas propicias para la explotación forestal y monocultivo. Por tanto, desde la dimensión meramente económica, la creación de la IIRSA es una red para la articulación productiva del territorio, pero si se amplía el campo de observación a las dimensiones sociecológicas y geopolíticas, puede considerarse una red de extracción y transporte ágil de elementos de la naturaleza, con consecuencias relevantes para las poblaciones afectadas. Los objetivos económicos y estratégicos del programa territorial pueden observarse en dos documentos que consideramos antecedentes de IIRSA y provienen de diferentes organismos.

El primero es un documento de la $\mathrm{CAF}^{23}$ (uno de los organismos financiadores principales de los proyectos de infraestructura de IIRSA) en el que su presidente declara:

Hace seis años la institución que presido puso en marcha un Plan de Acción para la Participación de la CAF en Proyectos de Infraestructura Física e Integración Fronteriza; ambicioso programa cuya principal finalidad es la de contribuir -mediante una acción mancomunada- al desarrollo sostenible de nuestros pueblos, a través de la redimensión de un sector que no solo permite ampliar el espacio económico regional y aprovechar mejor los recursos y ventajas comparativas, sino que genera los componentes para una inserción competitiva en la economía mundial [Corporación Andina de Fomento, 1998: 2].

El segundo, que en realidad se publicó dos años antes que el de la CAF, se trata de un resumen elaborado por la United States Trade and Development Agency a partir de una serie de conferencias realizadas en Brasil entre noviembre y diciembre de 1995. Allí se presentaba un programa de propuestas de infraestructuras para distintos países de América del Sur coincidente en términos generales con el posterior de IIRSA. ${ }^{24} \mathrm{El}$ evento se denominó Surface Transportation Project Opportunities in South America y estaba destinado a "exportadores, desarrolladores y empresas financieras de Estados Unidos” [US TDA, 1995: 1, traducción de autores].

${ }^{23}$ Por ese entonces la CAF era la Corporación Andina de Fomento, actualmente se denomina Banco de Desarrollo de América Latina.

${ }^{24}$ En Argentina, entre los proyectos considerados "oportunidades" se encontraba el Puente RosarioVictoria, la modernización del Puerto Rosario y la HPP. 
Mapa 1. "Oportunidades" en América Latina

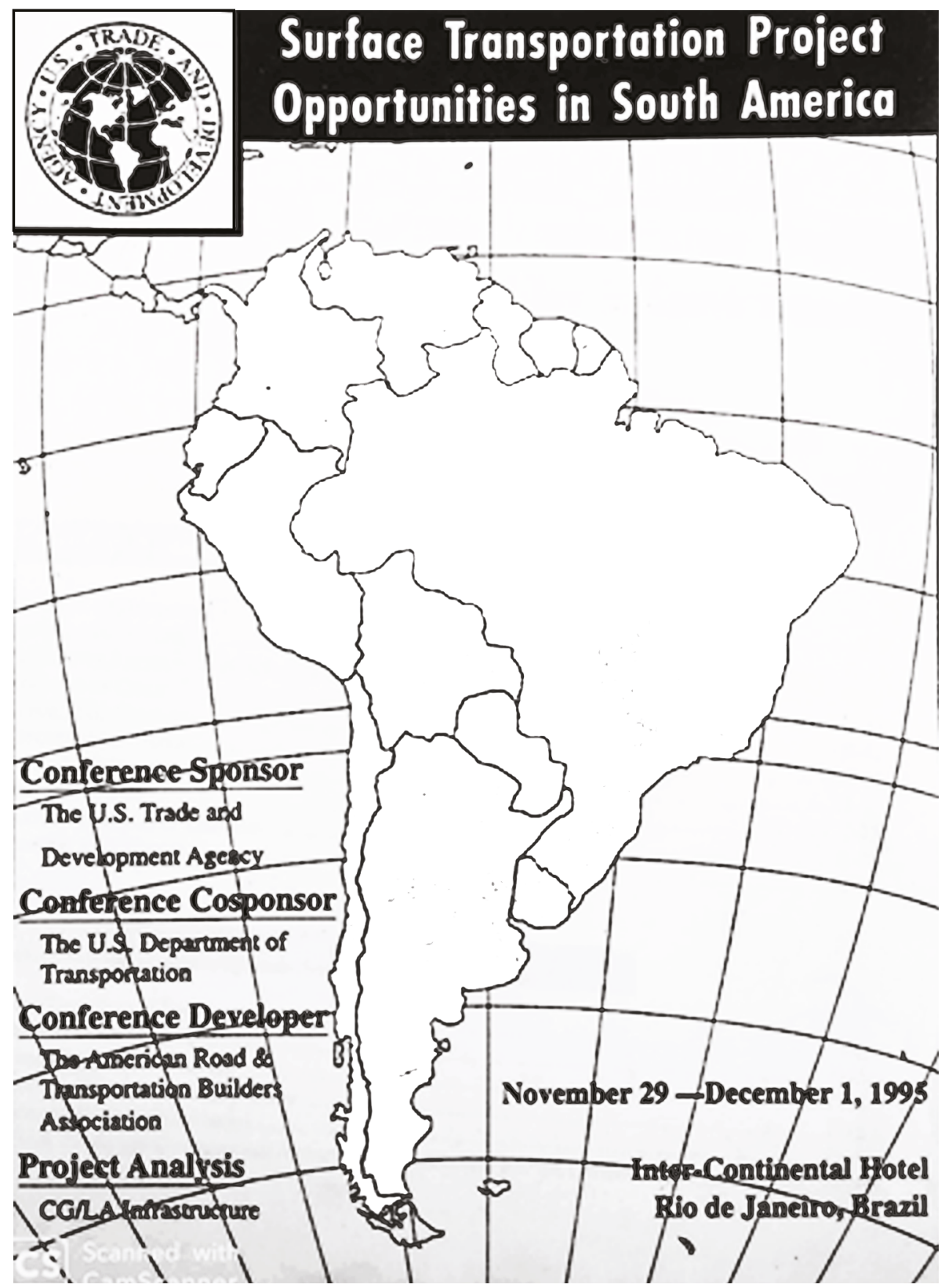

Fuente: US TDA [1995: tapa]. 
Según se exponía en el documento, el objetivo era proveer una combinación sólida de conceptos y datos básicos acerca de las oportunidades de inversión en los países suramericanos para "posicionar de la mejor manera los negocios" en dicha área [US TDA, 1995: 1, traducción propia]. El "hecho sorprendente respecto de América del Sur" -señalaba el documento-residía en el "modo en que las economías estaban siendo energizadas", y en dicho proceso, las infraestructuras "prometían crear recursos de ventajas comparativas para los países y las regiones". Y continuaba: "El sueño de la antigua era, de mover montañas, está llegando a su fin", haciendo referencia a que se avecinaba una época de menores esfuerzos económicos para los países del subcontinente.

Figura 1. Tipos de proyectos de infraestructura en América Latina

U.S. TDA Surface transportation proyect opportunities in South America Proyect Profiles

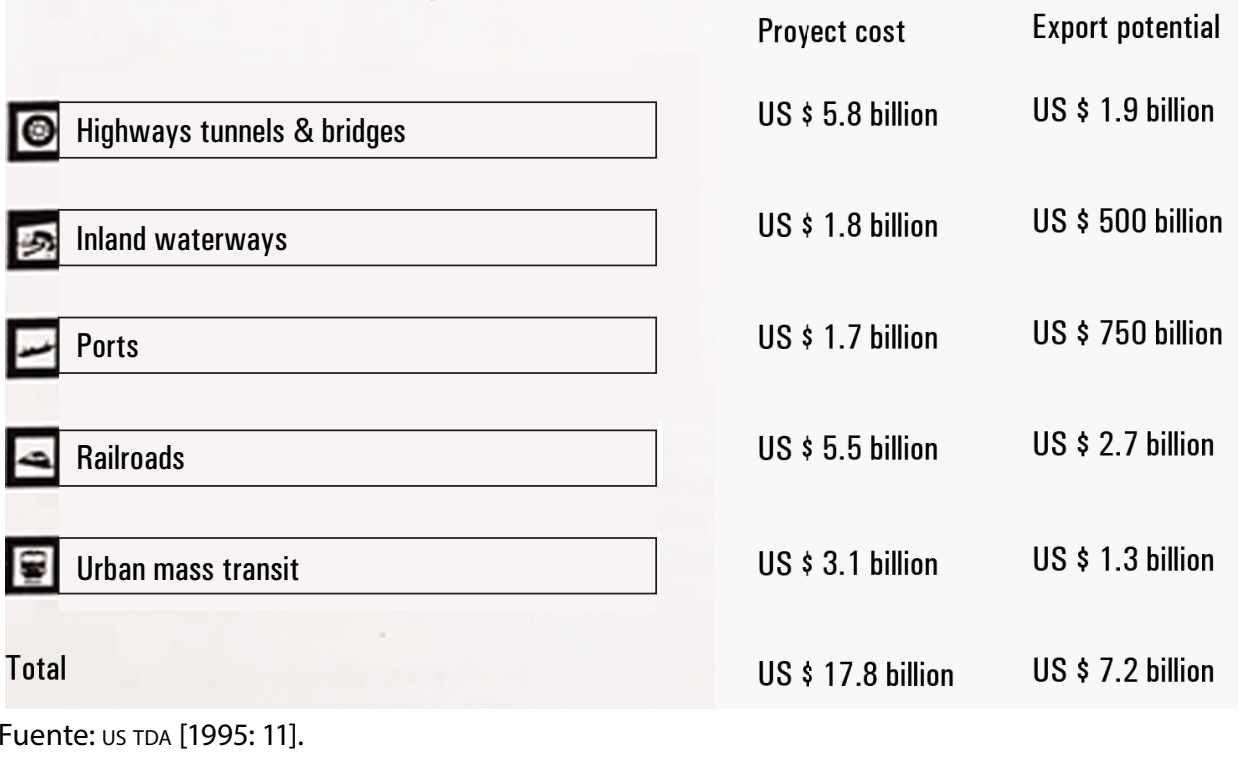


En el mapa 1 y la figura 1 pueden observarse con claridad los objetivos netamente económicos de los proyectos infraestructurales que se proponían, los cuales significaban ingentes oportunidades de negocios para el sector empresarial estadounidense hacia mediados de la década de los noventa. Como se dijo más arriba, este documento puede considerarse un antecedente relevante del programa que después sería sistematizado y ampliado en la IIRSA.

La IIRSA se creó en el marco de la Primera Reunión de Presidentes Sudamericanos celebrada en Brasilia en el año $2000^{25}$ con una cartera de más de 300 proyectos infraestructurales en áreas de energía, comunicaciones y transporte. El propósito principal era alentar obras de infraestructura, que aquí concebimos como PGE, para el desarrollo del Área de Libre Comercio (ALCA). Esta iniciativa fue coordinada a través de tres instancias: a) un comité de dirección ejecutiva, compuesto por autoridades gubernamentales de cada país; b) un comité técnico, integrado por el Banco Interamericano de Desarrollo (BID), la Corporación Andina de Fomento (CAF) y el Fondo Para el Desarrollo de la Cuenca del Plata (Fonplata); y c) grupos técnicos ejecutivos, coformados por funcionarios y expertos designados por los gobiernos suramericanos.

En 2009, la Iniciativa se sumó al Consejo Suramericano de Infraestructura y Planeamiento (Cosiplan) de la Unión Suramericana de Naciones (Unasur), cuyo tratado constitutivo fue aprobado en 2008. Con esto se iniciaba una nueva etapa en el proceso de integración física y en 2011 se incorporó al Cosiplan como su foro técnico.

Durante sus primeros 10 años (2000-2010), la IIRSA aplicó la metodología de planificación territorial indicativa, la cual consistió en organizar el territorio suramericano y ordenar la cartera de proyectos -vinculada con la concreción de infraestructura de transporte, energía y comunicaciones- a partir de la identificación de 10 ejes de integración y desarrollo (EID): Andino, Andino del Sur, Capricornio, Hidrovía Paraguay-Paraná, Amazonas, Escudo Guayanés, Del Sur, Interoceánico Central, Mercosur-Chile y Perú-Brasil-Bolivia (mapa 2). Entre ellos se incluyeron los dos PGE aquí

${ }^{25}$ La reunión estuvo conformada por los 12 países independientes de América del Sur, integrantes, al mismo tiempo, de la Comunidad Andina y del Mercosur: Argentina, Bolivia, Brasil, Chile, Colombia, Ecuador, Guyana, Paraguay, Perú, Surinam, Uruguay y Venezuela. 
analizados: la HPP como un EID en sí mismo y el CBC en el marco del Eje Mercosur-Chile. La consolidación del CBC se proyectó en el marco del Plan de Acción Estratégico 2012-2022.

\section{Mapa 2. Ejes de integración y desarrollo}
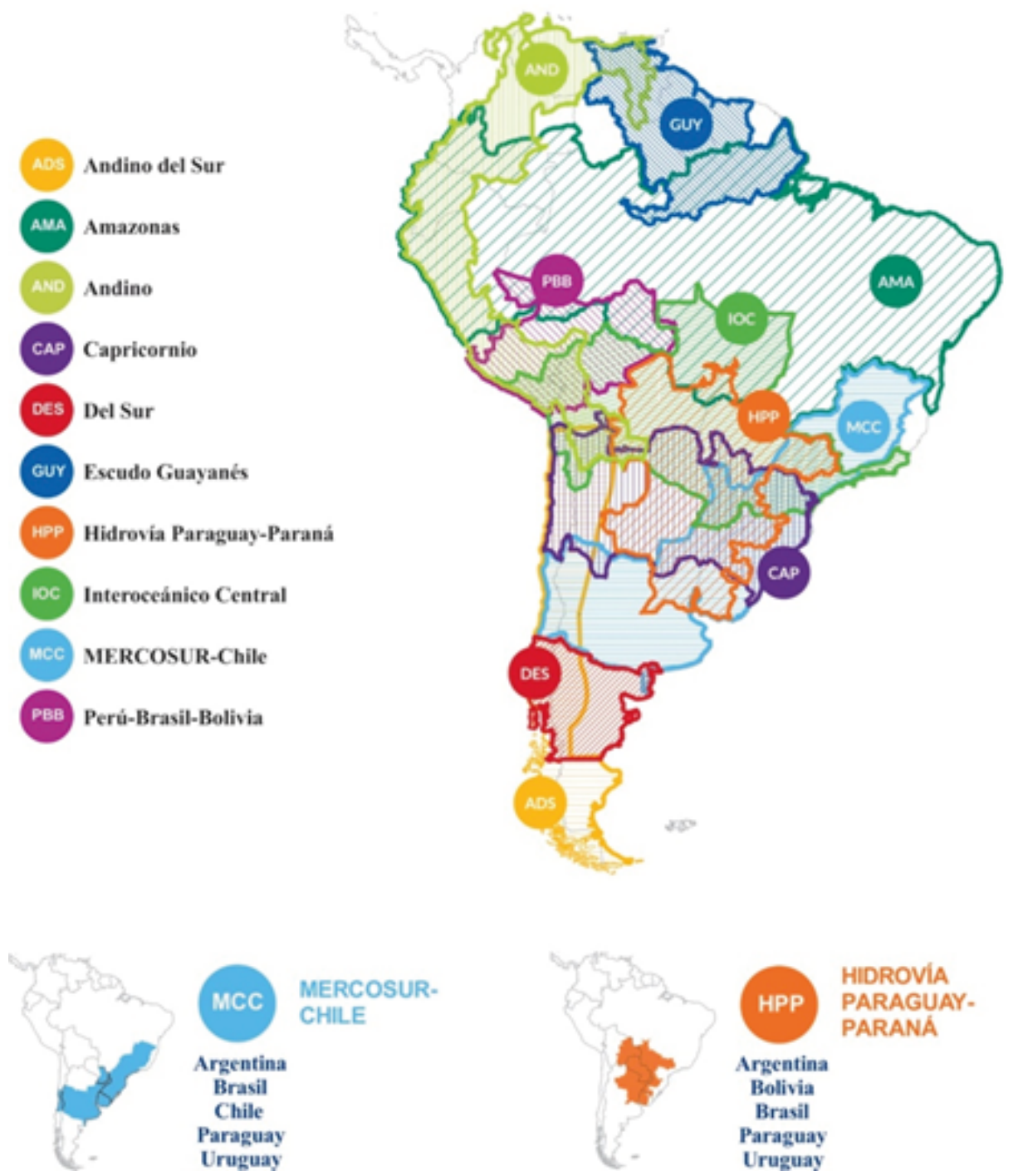

HIDROVIA

PARAGUAY.

PARANÁ

Fuente: Unasur-Cosiplan [2017: 129-131]. 
Como puede observarse en el mapa 2, la IIRSA define -mediante un plan infraestructural- una nueva geografía en la gran región suramericana. Inscrita en el contexto del mercado internacional, posee una función estratégica respecto de los requerimientos históricos del capital al configurar una trama compleja (concretada parcialmente aún) consistente en puntos de extracción de diversos materiales demandados por el mercado y las vías de conexión (terrestres, fluviales y oceánicas) que, en definitiva, conducen a los centros globales de producción.

Implementando la "Columna vertebral" del Mercosur. La hPp durante la década de los noventa

La HPP integra el actual programa de la IIRSA, aunque el interés de los países de América del Sur por realizar acciones conjuntas e impulsar una vía de navegación a lo largo de los ríos Paraguay y Paraná tiene sus antecedentes en el Tratado de la Cuenca del Plata, firmado en 1969 entre Brasil, Argentina, Bolivia, Paraguay y Uruguay. Los objetivos de tal iniciativa estaban puestos en conformar una gran región de desarrollo basada en la producción industrial, acorde con las políticas de sustitución de importaciones que los países llevaban adelante por ese entonces. Dicho tratado no redundó en acciones concretas hasta que, en 1988, a partir de una reunión en Canela (Brasil), los ministros de Transporte de dichos países expresaron su voluntad de impulsar la Hidrovía Paraguay-Paraná [Comité Intergubernamental Hidrovía, 1988: 1].

Esta nueva iniciativa se daba en un momento histórico totalmente diferente al de las décadas precedentes: en el plano político, los Estados nacionales iniciaban la reforma de su estructura tradicional para dar lugar a una nueva racionalidad capitalista conocida como neoliberalismo. Esta nueva racionalidad significó la introducción de la lógica de la competencia y el modelo de la empresa en la economía, la sociedad y en el mismo Estado [Laval y Dardot, 2013], y para el caso de la HPP significó la hegemonía de los sectores privados (en su mayoría multinacionales) en las decisiones y gestiones para impulsarla y ponerla en funcionamiento. En el plano técnico, hacia la década de los noventa las demandas del mercado internacional se perfilaban en franco ascenso y la nueva lógica empresarial basada en la eficiencia exigía medios de transporte de mayor tamaño, 
en adecuación a la nueva logística. Para el caso de la HPP, dicha reestructuración implicó que la vía navegable fuera modificada para adecuarse a los buques oceánicos ${ }^{26}$ (graneleros y portacontenedores, entre otros) y el transporte multimodal.

El proyecto técnico original de la HPP consistía en obras principales de dragado y señalización a lo largo de $3.442 \mathrm{~km}$ de río, junto a la rectificación del cauce en los tramos con meandros más pronunciados. El objetivo era posibilitar la navegación de buques comerciales todos los días del año, es decir, independientemente del régimen periódico de inundación-sequía característico. Por último, las obras de rectificación en el área Pantanal no se realizaron ante la decisión del gobierno brasileño, en 1998, de retirarse del proyecto. ${ }^{27}$ Según expresaba la CAF en 1998, el área de influencia comprendida por el proyecto se estimaba en $720000 \mathrm{~km}^{2}$, con una población calculada en más de 40 millones de habitantes hacia finales de la década de los noventa [CAF, 1998: 181].

Según la ejecución de los proyectos, la HPP fue dividida en tres tramos: Puerto Cáceres-Corumbá, Corumbá-Santa Fe y Santa Fe-Océano Atlántico. El tramo en territorio argentino quedó bajo competencia del gobierno nacional hasta 1995 y el resto de la hidrovía quedó bajo la administración del Comité Intergubernamental HPP (СıH). ${ }^{28}$ Desde 1995, como ya se mencionó, el tramo argentino fue concesionado al consorcio Hidrovías, S. A.

Las actividades de transporte a lo largo de la HPP están enmarcadas jurídicamente en el Acuerdo de Las Leñas (1992). ${ }^{29}$ En el mismo se estableció la libertad de transferencia de carga trasbordo, depósito de mercadería y navegación, excepto el tránsito de buques de guerra y otras actividades sin fines de lucro. El acuerdo también reconoció que cada país ejerce soberanamente como responsable en la ejecución de las obras dentro de su territorio, en la forma que crea más conveniente y de acuerdo con el cronograma y plan director definido.

${ }^{26}$ Durante la década de 2000 , se realizaron varias obras de profundización de la hidrovía con este fin.

${ }^{27}$ Pantanal es un humedal especialmente rico en biodiversidad y cultura, $y$, al mismo tiempo, de extrema fragilidad ecológica [Dunne et al., 1997]. El gobierno brasileño, respondiendo a la solicitud de organizaciones ambientalistas y sociales para no llevar adelante las obras y considerando el riesgo que las mismas significaban para el humedal, se retiró en 1998 del proyecto HPP [Diario La Capital, 21/03/1998: 7].

${ }^{28}$ Creado en 1987 bajo la Resolución 210 de Santa Cruz de la Sierra (Bolivia). Dicha resolución establecía la HPP como un programa prioritario para el desarrollo de los países adscritos.

${ }^{29}$ Países participantes: Argentina, Brasil, Paraguay y Uruguay. Fecha de adopción: 25 de mayo de 1992, aprobado el 25 de octubre de 1995 por Ley Mercosur 24.578, entrada en vigor: 20 de julio de 1999. 


\section{Mapa 3. Ubicación de la HPP en América del Sur}

The Hidrovía Paraguay-Paraná Proyect

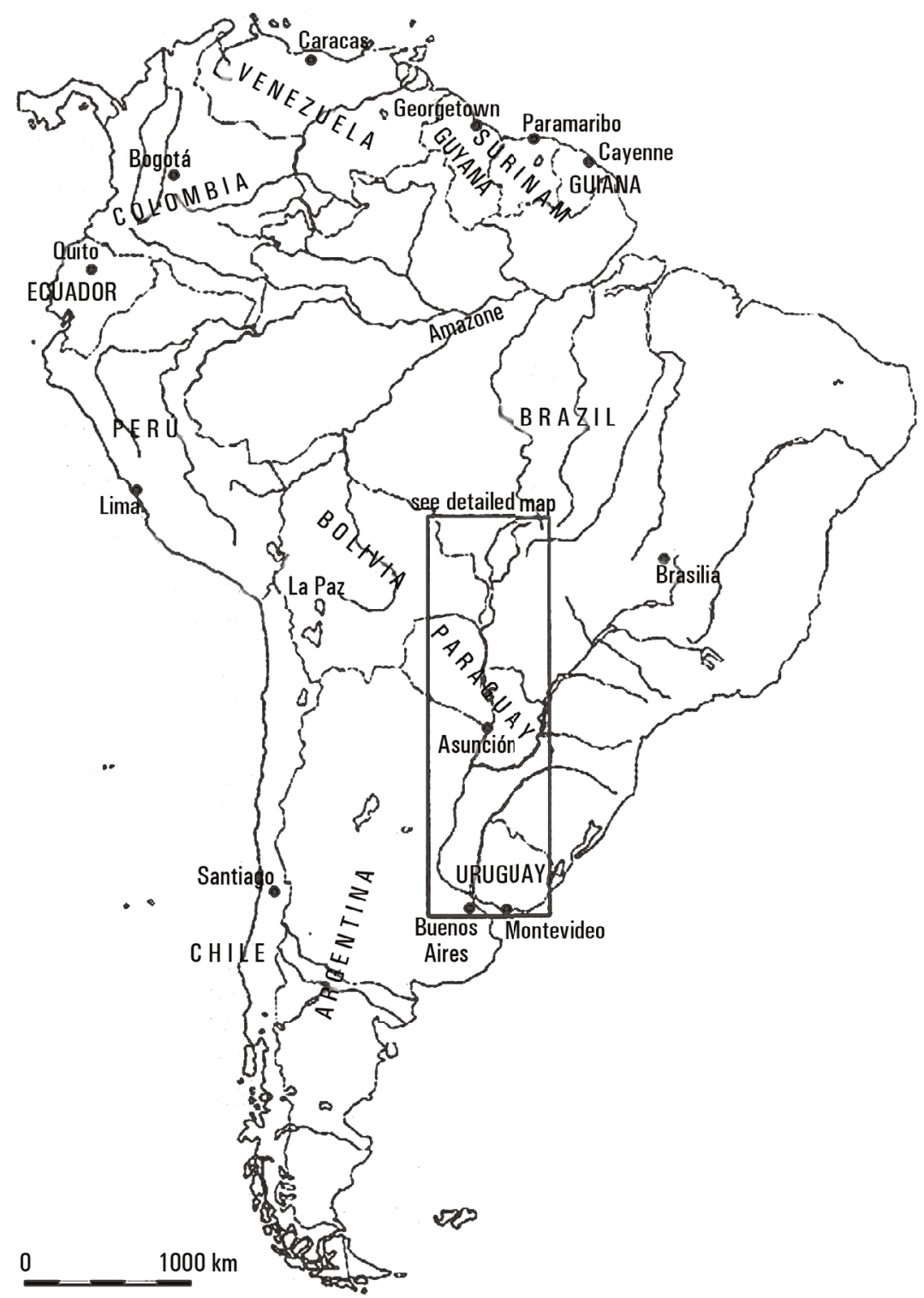

Fuente: Loveras Rivas [1997]. 
Mapa 4. La HPP en tramos, con terminales portuarias

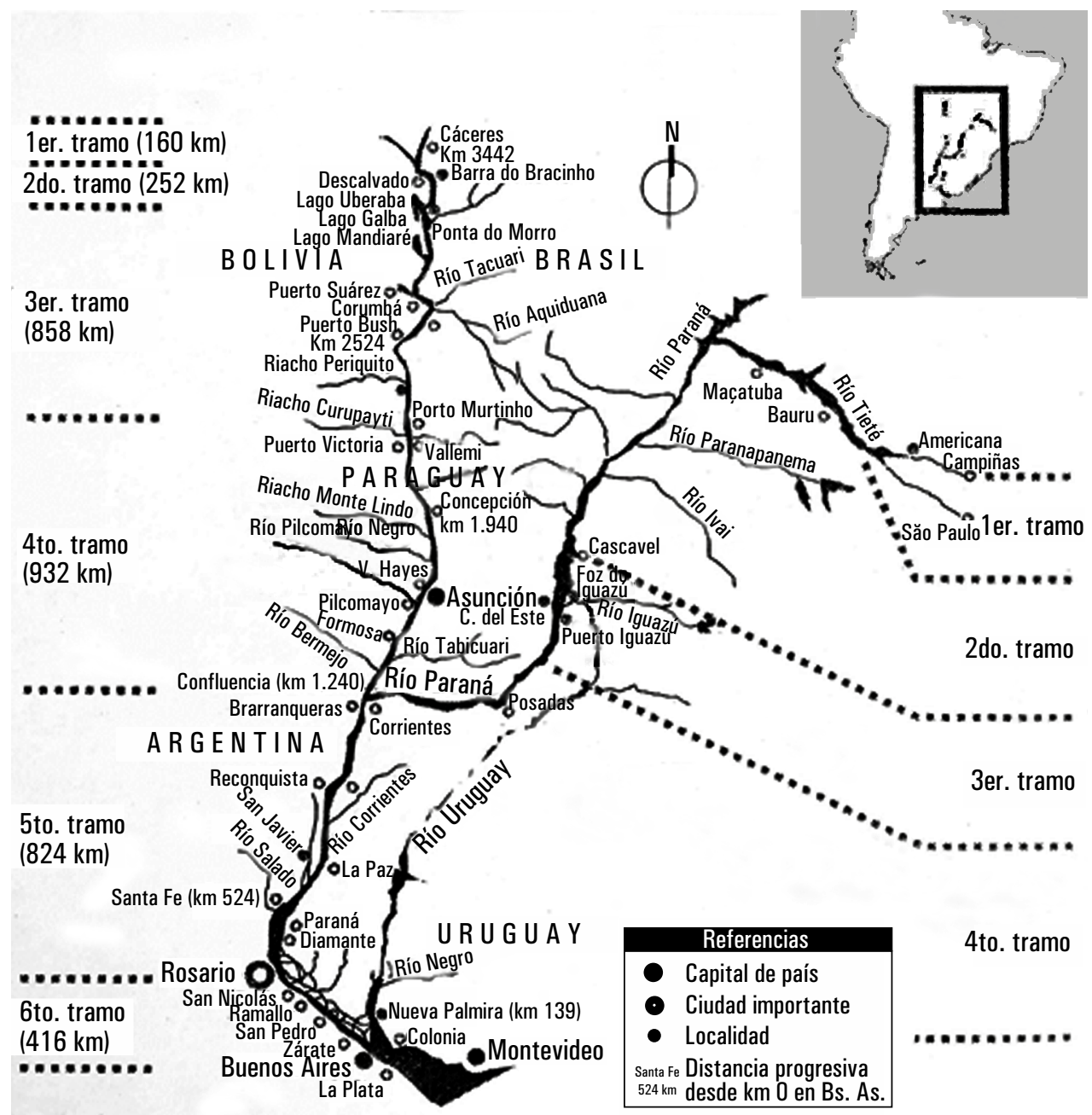

Fuente: Diario La Capital [7/6/1998: 7].

La financiación de la HPP estuvo a cargo del BID y el Programa de Naciones Unidas para el Desarrollo (PNUD). En 1996, el Fonplata comenzó a administrar los recursos económicos del BID y dio impulso a las obras proyectadas. Dicho impulso se debía, en gran parte, a que estaban finalizadas 
las evaluaciones de factibilidad técnica y de impacto ambiental encargadas a las consultoras Hidroservice Luis-Berger, S. A. (1994) y TaylorGolder-Consular-Connal, respectivamente (1994). En el año 2000, la HPP se integra a la IIRSA, si bien el CIH e Hidrovías, S. A. se mantienen como el organismo y la empresa, respectivamente, para cada tramo, de gestión de la misma.

La importancia comercial que se asignó a la HPP fue la de constituir una vía de transporte que atraviese cinco países por el corazón mismo de América del Sur, promocionándose como un eje de exportación de diversos productos como hierro (de Bolivia) y granos agroindustriales (principalmente soja, maíz y trigo) provenientes de Bolivia, Paraguay, una zona del Mato Grosso y Argentina. Según la Empresa Brasileira de Pesquisa Agropecuaria (Embrapa), entre 2015-2016 el área sembrada correspondiente a esta región superaba los 32 millones de hectáreas y la producción de soja era de unos 96 millones de toneladas. Asimismo, a partir de dicha dinámica se han generado zonas especializadas en el procesamiento y producción de derivados de soja, como es el caso del polo agroexportador en el área Gran Rosario ya mencionado. Pero además de conectar en el sentido norte-sur y hacia la desembocadura del océano Atlántico, las conexiones transversales constituyen vías de salida interoceánicas.

\section{La conexión interoceánica: el cbc Coquimbo-Porto Alegre}

En términos generales, un corredor bioceánico ( $\mathrm{CB}$ ) consiste en un espacio de comunicación intermodal que articula distintos puntos y regiones, extendiéndose de manera transversal entre dos cuencas oceánicas con el objetivo de acortar distancias para la agilización del intercambio comercial. ${ }^{30}$ A partir de redes existentes -viales, ferroviarias y fluviales-, los CB articulan y complementan la infraestructura de transporte con el propósito de optimizar el flujo y el movimiento de mercancía y personas hacia las entradas y salidas ubicadas en los márgenes de ambas cuencas.

\footnotetext{
${ }^{30}$ Los CB pueden asimilarse en tanto formas contemporáneas a aquellas otras grandes intervenciones a lo largo de la historia, proyectadas con el mismo objetivo de acortar distancias para el intercambio comercial: el Canal de Suez, entre el Mar Mediterráneo y el Mar Rojo (1869); el Ferrocarril Transcontinental, en Estados Unidos (1869); el Ferrocarril Transandino Central, entre Argentina y Chile (1910); y el Canal de Panamá, entre el mar Caribe y el océano Pacífico (1914), entre otros.
} 
La noción de CB comenzó a difundirse en la década de los noventa al ser promocionada como estrategia para el desarrollo geopolítico de los países suramericanos respecto de la cuenca del Pacífico y en el marco de la progresiva consolidación del Mercosur. En particular, los informes Okita I en 1987 y Okita II en $1997^{31}$ validaron la generalización del concepto de CB en Argentina al tiempo que surgieron iniciativas -por parte de diversos actores públicos y privados- respecto de la definición de sus trazados. Entre ellos se priorizaron tres ejes transversales este-oeste en el territorio nacional: el Corredor Bioceánico Norte-Eje Capricornio-, el Corredor Bioceánico Central (CBC) -Medialuna fértil del Mercosur- y los Corredores Bioceánicos de la Patagonia [Consejo Federal de Inversiones, 2014].

El CBC consiste en una franja de territorio que atraviesa, por un lado, las regiones Central de Chile y Cuyo de Argentina, territorio destacado por sus recursos mineros, energéticos y forestales y sus actividades vitivinícolas y frutihortícolas; y por el otro, las regiones Centro de Argentina y la conformada por el territorio del Uruguay junto al estado brasileño de Rio Grande do Sul, regiones destacadas por sus actividades agrícolas en grandes extensiones [Hermida, 2017]. Antes de la definición formal del Eje Mercosur-Chile por parte de la IIRSA, esta franja geográfica había sido distinguida por el Instituto de Investigaciones Económicas de la Bolsa de Comercio de Córdoba en función de las oportunidades que ofrecía en un sentido económico. El instituto describía el CBC "como una red de regiones entrelazadas por el asentamiento de los conglomerados productivos y las cadenas de valor de mayor peso en Sudamérica, capaces de potenciar el intercambio comercial y las inversiones" [Hermida, 2017: 14].

La infraestructura del CBC está conformada por un complejo multimodal de cargas que responde a la articulación y combinación del siguiente esquema intermodal (desde la cuenca del Pacífico hacia la del Atlántico):

${ }^{31}$ Los informes Okita I y II son investigaciones elaboradas por expertos japoneses en el marco de la Agencia de Cooperación Internacional del Japón (JICA) a solicitud del gobierno argentino. Ambos estudios abordan diagnósticos y estrategias de desarrollo con el objetivo de incrementar la competitividad y la exportación a Asia de los productos argentinos. De acuerdo con lo expuesto por Aldo Ferrer [1991: 519], el primer informe: "Aborda su objeto de estudio desde una perspectiva heterodoxa compatible con la experiencia histórica del Japón y sugiere, con excepción de la crítica cuestión de la deuda externa, una estrategia distinta de la recomendada por otros centros de poder internacional y los organismos multilaterales de financiamiento". 
puertos en la Región Central de Chile, pasos cordilleranos, red vial y ferroviaria, HPP, puertos fluviales y marítimos en Argentina, cruces sobre los ríos Paraná y Uruguay, puertos de Uruguay y Brasil [CFI, 2014]. Entre las obras a desarrollar, el túnel de Agua Negra en la cordillera de los Andes representa la obra vial de mayor relevancia y complejidad tanto por su ejecución física como por su definición política y territorial. ${ }^{32}$

En el marco de este esquema reticular, hacia la década de los noventa comenzó a jerarquizarse en el territorio argentino un eje en particular: el CBC Coquimbo-Porto Alegre de infraestructura, básicamente, vial. Este eje de comunicación se extiende a lo largo de $2.472 \mathrm{~km}$ desde el puerto de Porto Alegre (Brasil) hasta el puerto de Coquimbo (Chile), atravesando la Región Centro -Entre Ríos, Santa Fe y Córdoba-y las provincias de La Rioja, San Juan y Corrientes (Argentina).

Tras la reforma constitucional de 1994 y la posibilidad de integrar provincias en regiones dentro de la organización política del territorio nacional (Arts. 124 y 125), las provincias de Santa Fe, Córdoba y Entre Ríos conformaron la Región Centro. ${ }^{33}$ Entre las acciones más relevantes, la incorporación de la región en el proceso de consolidación del CBC Coquimbo-Porto Alegre se convirtió en uno de los proyectos centrales de las agendas públicas y privadas de cada provincia. En torno a ello, se creó el Comité Ejecutivo de Seguimiento a favor del fortalecimiento del cBC, foro al que se sumó la provincia de San Juan ${ }^{34}$ y en el que la representatividad del sector privado comenzó a ocupar un lugar central en la observación del proceso:

${ }^{32}$ El proyecto del Túnel Binacional Agua Negra se ubica en la frontera argentino-chilena y une la provincia argentina de San Juan y la región chilena de Coquimbo. Consiste en dos túneles paralelos de 13.9 km cada uno, separados en unos 50 metros aproximadamente [Unasur-Cosiplan, 2016]. En el año 2010, a partir de acuerdos binacionales, se creó la Entidad Binacional para el Proyecto de Túnel de Baja Altura del Paso de Agua Negra (Ebitan), con el objetivo de avanzar hacia la concreción de las obras.

${ }^{33}$ En 1998, las provincias de Córdoba y Santa Fe firmaron el Tratado de Integración Regional, al que se adhirió la provincia de Entre Ríos en 1999.

${ }^{34}$ Dicho comité se creó en el marco de la 1a. Jornada de Debate Corredor Bioceánico Central, celebrada en el Paraninfo de la Universidad Nacional del Litoral el 3 de noviembre de 1998. El encuentro contó con la participación aproximada de 180 representantes de distintas instituciones de las provincias de Santa Fe, Córdoba, Entre Ríos y San Juan [Unión Industrial Santa Fe, 1999]. 


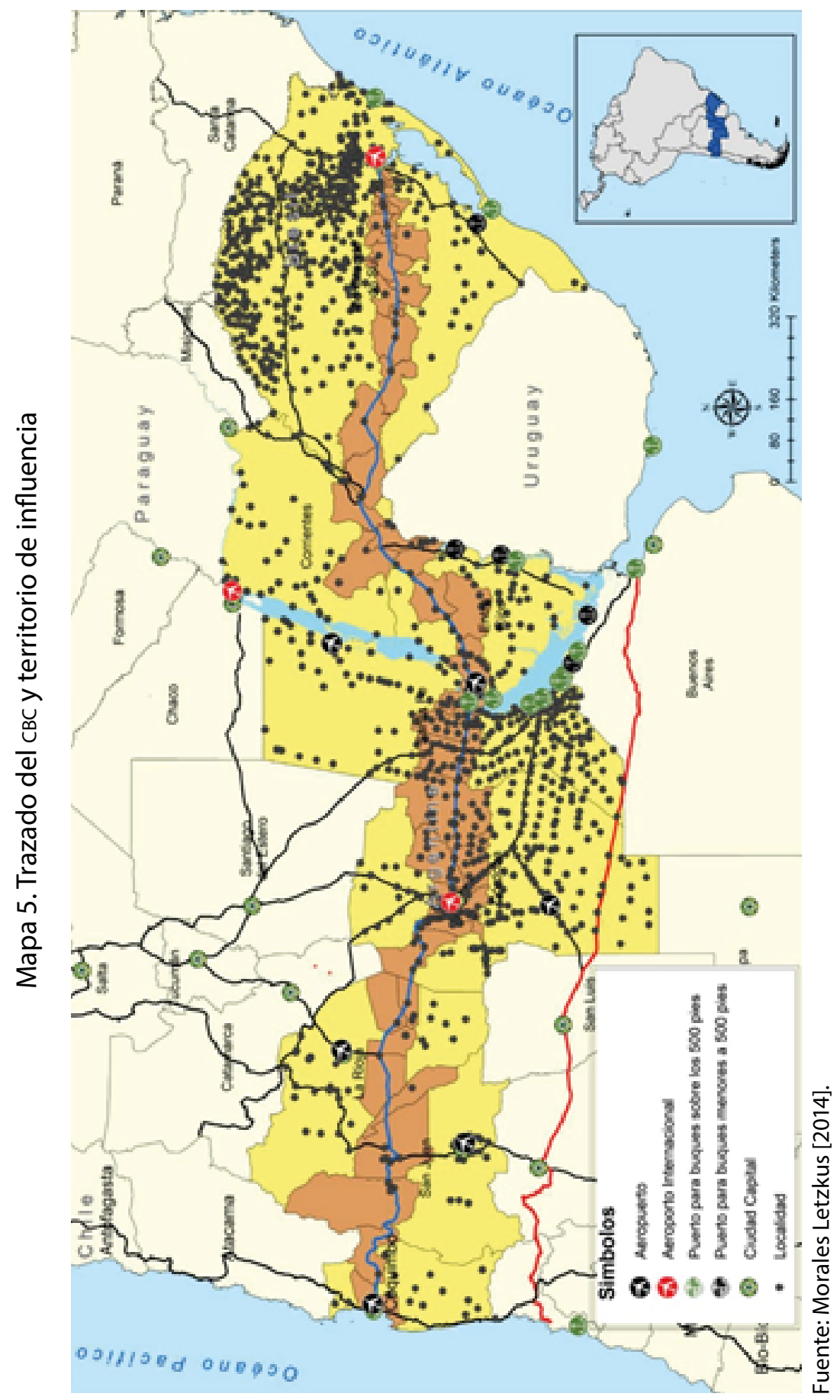


Por el camino del enfoque sistemático del concepto corredores, se llega a la problemática de la región como marco analítico donde se desenvuelven los aspectos institucionales, económicos y sociales. Esto permite pasar de la idea del corredor como una cuestión vial, a la del corredor como un eje centralizador de las decisiones y acciones públicas y de coordinación de acciones de los actores sociales y económicos [Unión Industrial Santa Fe, 1999].

Entre los órganos que componen la Región Centro, específicamente en el marco del Consejo de la Sociedad Civil, se encuentra el Foro de Entidades Empresarias y de la Producción de la Región Centro. ${ }^{35}$ Este foro, que agrupa a las entidades empresarias "más representativas", en el año 2015 derivó en la creación de la Red para el Desarrollo del CBC, afirmando que "Casi dos décadas lleva este proyecto de unidad, que hoy empieza a tomar forma tangible desde la iniciativa privada con la generación de estos espacios y puntos de encuentro, con acciones concretas" [Foro de Entidades Empresarias de la Región Centro, 2015: 1]. De esta manera comenzó a evidenciarse la centralidad asumida por el sector privado en el proceso de consolidación del CBC Coquimbo-Porto Alegre, con una fuerte participación de las bolsas de comercio y empresarios de diversos rubros, al mismo tiempo que se manifestó el papel subsidiario y de acompañamiento asumido por los gobiernos y las entidades públicas.

Glocalizaciones en la encrucijada hPp-CBC. Metamorfosis urbana, Debates locales Y LA ESPERA POR LA INSERCIÓN PORTUARIA

Como se mencionó antes, hasta el momento las obras proyectadas vinculadas tanto con la HPP como con el CBC se han concretado parcialmente. En lo que atañe a nuestra área de estudio, el cBC ejerce sus funciones de conector utilizando las infraestructuras existentes en el GSF, que se complementan con algunas remodelaciones y obras nuevas realizadas. Respecto de la HPP, el acceso al puerto de Santa Fe -como ya señalamos- plantea dificultades para las empresas interesadas en usarlo. Si bien esta ciudad se ubica geográficamente en un punto estratégico respecto del corredor

\footnotetext{
${ }^{35}$ Asimismo, integran dicho Consejo el Foro de Organizaciones del Trabajo de la Región Centro, el Foro de Profesionales de la Región Centro y el Foro de Universidades, Ciencia y Técnica de la Región Centro.
} 
fluvial, las instalaciones portuarias actuales son limitadas en dimensiones y equipamiento para la carga de buques oceánicos. Las características del río en esa zona exigen permanentes obras de dragado y mantención, con altos costos y resultados insuficientes en relación con las expectativas de los sectores exportadores. En este sentido, el proyecto de traslado del puerto santafesino a una ubicación próxima al cauce principal del río Paraná y más cercana a Entre Ríos se ha convertido en una demanda frecuente de dichos sectores (empresarios, la Bolsa de Comercio y funcionarios públicos, entre otros).

La encrucijada HPP-CBC correspondiente al GSF está conformada por una serie de proyectos, algunos de los cuales consisten en remodelaciones (adecuaciones, ampliaciones, etc.) de infraestructuras existentes, al tiempo que otros constituyen obras nuevas, como el mencionado proyecto del nuevo puerto. Entre las obras ejecutadas se encuentran: Av. Circunvalación Oeste, tramos 1 y 2 (1994-1997); Av. Circunvalación Oeste, tramo 3 (2004-2012); Av. 27 de Febrero y Leandro Alem (2004-2005); Autovía Ruta Nacional (RN) 168 (2007-2011); y Autovía RN 19 (2008-2011). Mientras que los proyectos que aún no se han concretado son: puente Santa Fe-Paraná, traslado nuevo puerto de Santa Fe y puente Santa Fe-Santo Tomé. Estos últimos han sido objeto de intensos debates y ansiadas esperas por diversos sectores sociales de la ciudad.

Durante la década de los noventa, un proyecto asociado con la HPP que disparó acalorados debates fue el Proyecto Hidroeléctrico Paraná Medio. Esta represa, que retomaba con algunas modificaciones un proyecto anterior de la dictadura militar, prometía asegurar la cantidad de energía suficiente para la inserción de la región en el mercado internacional. Finalmente, y luego de dos años de movilizaciones por parte de organizaciones ambientalistas de Santa Fe y Paraná en oposición, la represa no se construyó. ${ }^{36}$

A continuación se ofrece una descripción de los procesos de concreción de cada uno de los proyectos mencionados, junto a las discusiones locales surgidas en torno a su implementación.

${ }^{36}$ Aquí no nos detendremos en este proyecto, para ampliar puede verse Arach [2003] y Rausch [2018]. 
Mapa 6. Infraestructuras que conforman la encrucijada HPP-CBC en el GSF

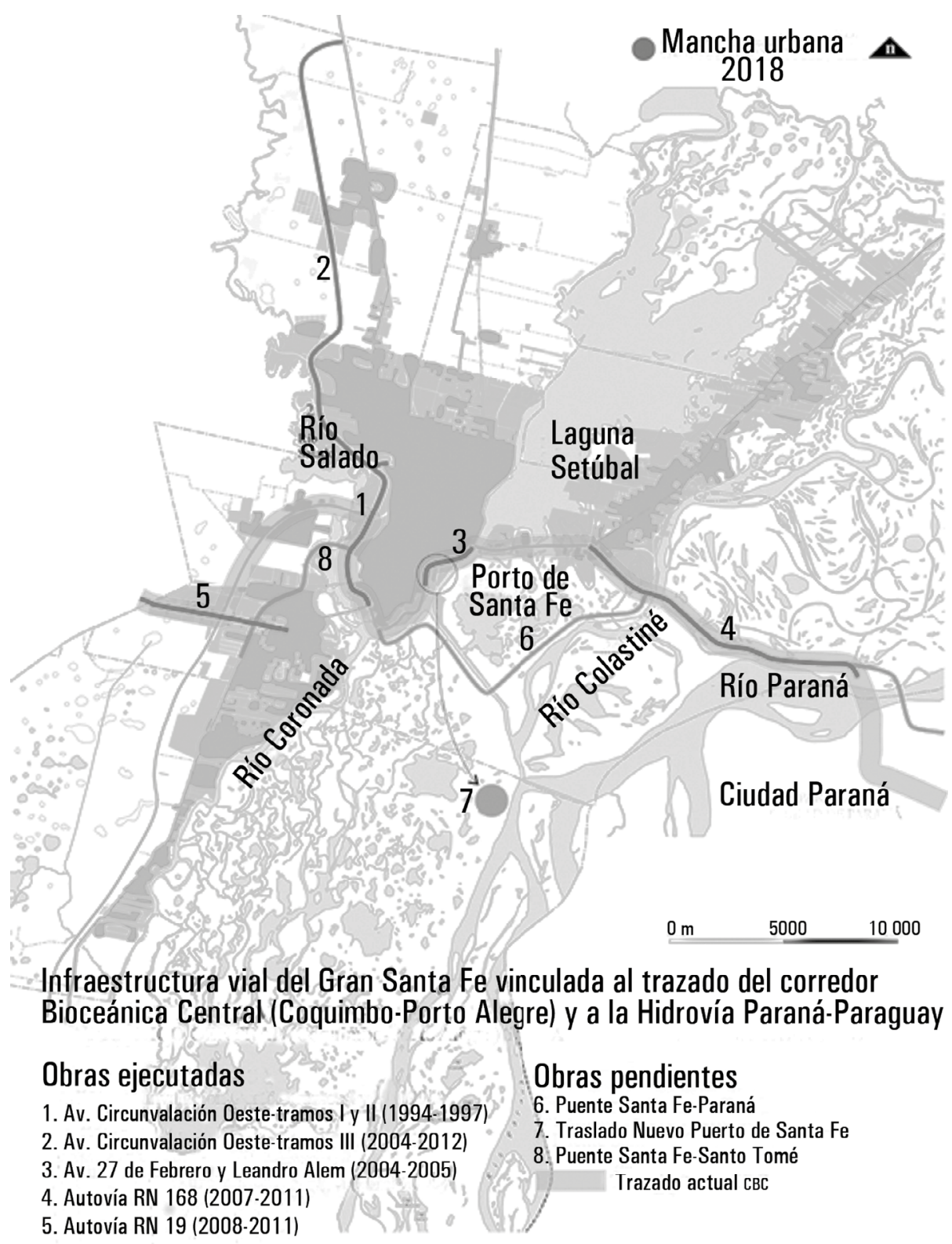

Fuente: elaboración propia. 
Avenida Circunvalación Oeste, tramos I y II (1994-1997) y tramo III (2004-2012)

La Avenida Circunvalación Oeste se originó en las primeras obras de defensa hídrica construidas a la vera del río Salado; no obstante, a esta función defensiva se sumó, más tarde, la de vía contenedora del tránsito vehicular de carga. De este modo, ante las indefiniciones y demoras respecto a la construcción del nuevo puente vial Santa Fe-Santo Tomé, el trazado de la circunvalación junto al puente de la Autopista Rosario-Santa Fe se convirtió en uno de los segmentos urbanos del CBC. Su ejecución fue prevista en tres tramos claramente diferenciados, con una extensión total aproximada de $30 \mathrm{~km}$. Mientras los tramos I y II fueron ejecutados entre 1994 y 1997, el tramo III se inició en el año 2004, luego de la catástrofe hídrica de 2003, y quedó habilitado en 2012.

Ahora bien, si se examinan su diseño e implementación respecto del entorno urbano, el predominio de su carácter funcional y de servicio por sobre el potencial paisajístico de la ribera oeste devino en la materialización de su trazado como una barrera y un límite urbano. Su emplazamiento a "espaldas" del río Salado puede interpretarse como el desaprovechamiento de una oportunidad para la integración urbana de los barrios del oeste, en particular si se piensa en la posibilidad de convertir los bañados del río Salado en espacios públicos de uso colectivo destinados al intercambio de grupos sociales y a la revalorización de un sector urbano postergado desde siempre. Durante las últimas décadas del siglo xx, se verificaron en la ciudad de Santa Fe movimientos internos de población que impulsaron una mayor ocupación de los barrios emplazados en las cercanías de los bañados del Salado. Esta tendencia de expansión avanzó sobre tierras, en muchos casos fiscales, ubicadas en áreas bajas, de riesgo hídrico, y desprovistas de infraestructura de servicios sanitarios y urbanos adecuados. ${ }^{37}$

${ }^{37}$ El crecimiento de la ciudad de Santa Fe se originó desde el extremo sureste, en vinculación con el trazado fundacional y el curso de la laguna Setúbal, hacia el norte y el oeste. En relación a esta última direccionalidad, la mancha urbana avanzó a lo largo del siglo xx sobre terrenos anegadizos pertenecientes a los bañados del río Salado, generando una creciente vulnerabilidad social y espacial que se profundizó en las últimas décadas. De las 20000 personas que se sumaron a la ciudad en el periodo 1991-2001, alrededor de 18000 se radicaron en el oeste, manteniendo una tendencia iniciada en la década anterior [Gioria, 2009]. 
Así fue consolidándose uno de los sectores urbanos más desfavorecidos en términos socioespaciales en la ciudad. Este proceso se dio en un contexto muy particular de Argentina, luego de media década de aplicación de políticas neoliberales acorde con las medidas pautadas en el Consenso de Washington. El ajuste fiscal, la destrucción del estado social y la incorporación de la lógica empresarial en las áreas agrícolas [Svampa, 2005] fueron algunos factores que provocaron el aumento de la pobreza y desplazamientos poblacionales de dos tipos: por un lado, desde las zonas agrícolas hacia los centros urbanos por parte de los sectores que quedaban fuera del sistema productivo "modernizado"; y por el otro, desplazamientos hacia las periferias de aquellos sectores sociales que se volvían incapaces de solventar los costos de la vivienda en otras áreas con mejores servicios en el interior de las ciudades. Tal es el caso del borde oeste de la ciudad de Santa Fe.

\section{Avenidas 27 de Febrero y Leandro Alem (2004-2005)}

Tras la habilitación del tramo sur de la Avenida Circunvalación en 1969, su prolongación hasta el puente sobre la laguna Setúbal se había reducido tan solo a obras de pavimentación y mejorado de las calzadas durante la década de los setenta. No obstante, la intensificación del tránsito vehicular de escala tanto regional como nacional y el aumento paulatino de la movilidad internacional a partir de la incorporación de la ciudad al CBC impulsaron la redefinición del trazado de las avenidas 27 de Febrero y Leandro Alem. Ambas bordean al puerto de Santa Fe y empalman con la RN168 (hacia el este) y con la Autopista Rosario-Santa Fe (hacia el oeste, a través de los tramos I y II de la Avenida Circunvalación Oeste). El proyecto de remodelación fue elaborado por la Dirección Provincial de Vialidad (DPV) y licitado por el gobierno provincial a mediados de 2003. El mismo consistía en la habilitación de una multitrocha de ocho carriles, con una longitud total de $2650 \mathrm{~m}$, comprendidos entre el principio del tramo sur de la Avenida Circunvalación y el intercambiador de acceso al Puente Oroño [GPSF, 2003].

Sin embargo, el proyecto desató una serie de polémicas. En primer lugar, la ejecución de la obra requería talar una gran cantidad de especies 
arbóreas de gran tamaño (alrededor de 300); esto generó una rotunda oposición por parte de algunas entidades ambientalistas santafesinas. En segundo lugar, surgieron otras críticas al proyecto, las cuales se fundamentaron en la barrera urbana que produciría esta "gran trocha de cemento" entre el sector costero y la ciudad, ante la posibilidad de reconversión del área portuaria en un nuevo escenario urbano. ${ }^{38}$ Por último, la crítica se dirigió hacia el modo en que se había gestionado el proyecto: centralizado en el gobierno provincial y sin la participación de otras entidades como las universidades, los colegios profesionales, las cámaras industriales y comerciales, entre otras.

Frente a estas posturas críticas, los "defensores del ensanche" justificaban la importancia y urgencia de la obra para potenciar la integración territorial de la ciudad, y al mismo tiempo, "preservar" su histórico lugar geográfico como "nudo de comunicaciones" frente a la temida competencia con la ciudad de Rosario, que para entonces se perfilaba como el mayor centro agroexportador del país. En palabras de autoridades estatales locales: "Mientras tanto, esta vía de comunicación ya no admite más demoras si es que pretendemos que no nos saquen del mapa y ya nadie pase por Santa Fe" [Diario La Capital, 8/12/2003]. Tras una serie de modificaciones al proyecto original, la obra se inició a principios de 2004 y quedó definitivamente habilitada al tránsito hacia finales de 2005. Pese a los cambios hechos a su trazado y de los intentos posteriores por conectar ambos márgenes de la avenida (puente peatonal, semaforización), el acceso a la zona portuaria, comercial y costera se redujo al uso del automóvil, lo que dejó sin efecto los reclamos y sugerencias mencionados.

\section{Autovía RN 168 (2007-2011)}

$\mathrm{Al}$ inicio de los años ochenta, la Autovía 168 solo se había concretado en su primer tramo, entre la laguna Setúbal y el intercambiador con la RP1. La ejecución del segundo tramo (entre dicho intercambiador y el acceso al Túnel Subfluvial) no se concretó sino hasta el nuevo siglo, casi cincuenta años más tarde de anunciada la conversión de la RN168 en autovía, por

${ }^{38}$ Para ampliar sobre la reconversión del puerto santafesino y sus nuevos usos, puede verse Fedele [2011]. 
la década de los sesenta. La obra se concretó en dos etapas: la primera de ellas concluida en el año 2008, comprendió el tramo extendido entre el intercambiador con la RP1 y el acceso al puente sobre el río Colastiné con una extensión aproximada de $3.7 \mathrm{~km}$. La segunda etapa, extendida entre el río Colastiné y el acceso al Túnel Subfluvial, comprendía una extensión de $9 \mathrm{~km}$. La obra se licitó a fines de 2006, en función del anteproyecto elaborado por la Dirección Nacional de Vialidad (DNV), los trabajos se iniciaron a mediados de 2007. Esta vez, además de la construcción de dos nuevos carriles y 1600 metros de puentes aliviadores, el mayor desafío tecnológico y de ejecución consistió en el ensanche del puente ubicado sobre el río Colastiné. Finalmente, la inauguración de este último tramo se concretó en 2011, quedando concluida la Autovía 168 [Diario El Litoral, 1/02/2011].

A diferencia del tramo anterior, extendido entre la laguna Setúbal y el intercambiador de la RP1, el tramo comprendido entre dicho intercambiador y el río Paraná mantuvo las condiciones naturales de su emplazamiento, a excepción de las transformaciones, no menores, que ocasionó el trazado de la RN 168 sobre el curso fluvial. ${ }^{39}$ Sin embargo, en el tramo comprendido entre el intercambiador y el río Colastiné se consolidaron dos de los barrios que hoy integran el Distrito La Costa de la ciudad de Santa Fe: La Guardia y Colastiné Sur. Dos barrios de baja densidad demográfica cuya principal característica es una insuficiente infraestructura de servicios sanitarios y una alta vulnerabilidad hídrica.

Autovía RN 19 (2008-2011)

Luego de la pavimentación de la RN 19, entre 1935 y 1942, las intenciones de convertirla en autopista datan de finales de la década de los sesenta, en el marco de una serie de obras tendientes a definir el sistema vial

${ }^{39}$ Al respecto, Bertuzzi [2015: 150-151] explica: “La autovía Santa Fe-Paraná significa la construcción de dos carriles paralelos a los dos existentes, llegando a cuatro vías. Se trata de un terraplén con arenas locales refuladas por una draga, ubicada en cursos de agua cercanos [...] La concepción original de la ruta es la de un terraplén continuo, realizado por tramos, con aliviadores de pequeñas luces coincidentes con los cursos de agua más estables, sin dimensionar cabalmente que con su construcción se estaba generando una gran estructura-dique perpendicular al normal escurrimiento de las aguas del sistema del río Paraná. Es sin duda la construcción de mayor impacto sobre el área y al mismo tiempo la que mayor vulnerabilidad genera para sus habitantes, porque no solamente disminuye la capacidad de drenaje, sino que retiene el agua en las grandes crecientes al norte de la ruta". 
(integrado por la Autopista Rosario-Santa Fe, la Avenida Circunvalación Sur, el Puente Viaducto Oroño, la Autovía 168, el Puente Colastiné y el Túnel Subfluvial) que conectaría la ciudad de Santa Fe con la región y el país [Diario El Litoral, 5/10/1970]. A pesar de haberse dado a conocer por parte del gobierno de la provincia un informe de los antecedentes y algunos avances evidenciados por el proyecto, la obra no se iniciaría -y solo parcialmente- sino hasta varias décadas después; en concreto, hasta el año 2008.

Por aquel entonces, el gobierno de la Provincia de Santa Fe inició las gestiones para construir el tramo comprendido entre la ciudad de Santo Tomé (desde el kilómetro 0, en la intersección con la RN 11) y la localidad de San Francisco (intersección con la RN 158), con una extensión aproximada de $136 \mathrm{~km}$. Entre las justificaciones del proyecto, la obra sería de vital importancia para el sistema o conjunto de infraestructura de transporte que liga las economías del Mercosur y Chile, en el contexto de la rehabilitación y mejoramiento del CBC:

Las obras que configuran el Proyecto RN 19 mejorarán las condiciones de tránsito con origen y destino en la región, y del pasante generado desde el Este en las provincias mesopotámicas, Brasil y Uruguay; y desde el Oeste, en las provincias de Córdoba, Noroeste del país, Cuyo y Chile. Se espera que el Proyecto aporte a la competitividad de la economía regional al proveer infraestructura para una logística más eficiente. Del mismo modo se espera que facilite la complementación de las estructuras productivas locales vinculándolas entre sí y facilitando su acceso a los mercados. Además, se espera que aporte a disminuir significativamente la tasa de accidentes en la propia ruta e incrementar las posibilidades de la actividad turística en la misma [GPSF, 2006: 2].

A pesar de tratarse de una ruta de jurisdicción nacional, tanto el proyecto como la ejecución estuvieron a cargo del gobierno de la Provincia de Santa Fe y contaron con aportes del Banco Mundial, como parte del Préstamo para la Reforma del Estado Provincial. Iniciadas en 2008, las obras de la autovía en el tramo correspondiente al territorio de Santa Fe quedaron inauguradas a mediados del año 2011. Respecto del tramo comprendido entre San Francisco y la capital de la Provincia de Córdoba (156 km), la reconversión de la RN 19 en autovía se inició en 2017 y su finalización se prevé para finales de 2020. 
Por otra parte, si se considera el tramo de acceso a la ciudad de Santo Tomé, entre el kilómetro 0 y el kilómetro 3, puede observarse la consolidación de un espacio mixto donde la autovía tiene la pretensión de convertirse en una avenida de penetración urbana. A lo largo de esa extensión, comprendida entre la intersección de la RN 19 con la Avenida Luján (al este) y con la AP01 (al oeste), se ha materializado un espacio superpuesto en el que algunas pocas viviendas coexisten con clubes, comercios, industrias, galpones y depósitos. Un espacio en el que las vías del tren (ubicadas a la altura del kilómetro 1.5), los semáforos y los cruces a nivel morigeran las altas velocidades que caracterizan este tipo de autovías.

\section{El Puente Santa Fe-Paraná (PSFP)}

Este proyecto comenzó a ser impulsado en la década de los noventa como parte de las obras de infraestructura vinculadas al Mercosur: "La construcción de este complejo constituye una de las aspiraciones de entidades intermedias y dirigentes de la capital santafesina interesados en adaptar las obras de infraestructura de la zona en el marco del desarrollo del Mercosur y el corredor bioceánico" [Diario La Capital, 15/10/1998].

Desde mediados de dicha década, en la prensa santafesina es frecuente encontrar voces entusiastas sobre su construcción y reuniones entre los gobernadores de las provincias involucradas. El objetivo con el cual se promocionaba era ofrecer un alivio al tránsito del Túnel Subfluvial que para entonces se consideraba saturado. En 1998, los gobernadores presentaron el estudio de prefactibilidad, que señalaba que la iniciativa se enmarcaba "dentro de la intención de las dos provincias de hacer avanzar una de las versiones del corredor bioceánico: el que nace en Coquimbo, Chile, y después pasa por San Juan, San Francisco (Córdoba), Santa Fe, Paraná, para desembocar en el sur de Brasil" [Diario La Capital, 17/10/1998]. De aquí surgiría la "arista conflictiva" - como aparece referida en la prensa- de esta obra, ya que significaba una potencial competencia para la empresa concesionaria del puente Rosario-Victoria (PRV): ${ }^{40}$ el grupo italiano Impregilo.

${ }^{40}$ Este puente conecta las mismas provincias pero más al sur, entre las ciudades de Rosario (Santa $\mathrm{Fe}$ ) y Victoria (Entre Ríos). Hacia fines del siglo xx, Rosario se perfilaba como polo agroexportador y el puente significaba una obra crucial para ello. Esta obra se inauguró en 2003. 
Por ese entonces, este proyecto no se había concretado y su impulso estaba rezagado respecto del proyecto santafesino. Asimismo, en los pliegos del PRV, Impregilo estableció una cláusula que determinaba compensaciones económicas en caso de disminuir el tráfico por alguna obra alternativa. De este modo, el PSFP era considerado una competencia para la conexión del sur provincial y por este motivo algunos funcionarios declaraban lo contrario: "esta alternativa es complementaria y no competitiva con el puente Rosario-Victoria, al cual se le asignan similares características, además de la importancia que reviste en materia internacional" [Diario La Capital, 5/10/1999].

Durante la década posterior, el proyecto del PSFP fue retomado por los distintos gobiernos provinciales y por las autoridades locales de ambas ciudades; no obstante, el llamado a licitación pública nacional para la contratación de la consultora encargada del proyecto ejecutivo se concretó en 2014. Dos años más tarde, la empresa ATEC S. A., contratada por la DNV, dio a conocer el anteproyecto del nuevo enlace vial, cuyo lugar de emplazamiento generó una serie de disputas. De las ocho trazas sugeridas inicialmente, la empresa descartó aquella impulsada por el municipio y por diversas instituciones y fuerzas productivas de la ciudad de Santa Fe, cuya traza preferente se extendería en las cercanías a la futura reubicación del puerto proyectado. Tras un largo periodo de intenso debate, la traza definitiva se resolvió a favor de esta última, cuya ejecución fue incluida en el Plan General de la Nueva Red de Autopistas y Rutas Seguras. ${ }^{41}$ A pesar de estos avances, la obra quedó postergada de nuevo.

\section{El nuevo puerto de Santa Fe}

La problemática del puerto de Santa Fe es una constante de alcances históricos en los debates locales sobre intercambio comercial. Con la reconversión económica de la década de los noventa y el ascenso del transporte

\footnotetext{
${ }^{41}$ Dicho plan se enmarcaba en la Ley 27.328 sancionada por el gobierno nacional en el año 2016. La misma consiste en la implementación de un sistema de contratos de participación público privada (PPP) cuya modalidad de financiamiento incluye inversiones privadas y la consecuente explotación de las redes viales mediante mecanismos de concesión. No obstante, el gobierno nacional dio de baja el programa ppp a finales de 2018.
} 
multimodal como medio privilegiado para el traslado de commodities, las remodelaciones portuarias estuvieron al corriente en aquellas ciudades que pretendían insertarse en las dinámicas globales. Los sectores políticos y empresariales de la ciudad de Santa Fe no estuvieron exentos de formular tales pretensiones, que se orientaron a pensar en una nueva localización para el puerto histórico, como se dijo antes, más propicia al ingreso de buques oceánicos y barcazas que circulan por la HPP.

En 1998, el Ente Administrador Puerto de Santa Fe ${ }^{42}$ contrató a ingenieros pertenecientes a la Facultad de Ciencias Hídricas de la Universidad Nacional del Litoral para realizar un estudio de tres alternativas para la localización de la terminal multipropósito. El criterio regente para la selección de alternativas fue una localización que funcionara como puerto natural, es decir, sin los requerimientos de mantención permanente de las vías de acceso, como ocurre con el puerto histórico [Prendes, 1998]. En dicho estudio, se presentaron nueve alternativas de localización para el nuevo puerto, cuyo proyecto proponía ocupar unas 20 hectáreas de superficie en las que se disponen un puerto granelero, una planta de almacenamiento de combustibles e instalaciones suficientes para las actividades de carga y descarga de buques oceánicos.

El derrotero del proyecto siguió los lineamientos de gran parte de los proyectos de la ciudad: años y décadas de discusiones, ${ }^{43}$ con mayor o menor intensidad en el impulso según la oferta de financiamiento y las campañas políticas -donde estas iniciativas adquieren relevancia discursiva- 0 bien adaptándose a los cambios en las estrategias económicas a escala nacional.

REFLEXIONES FINALES Y CONCLUSIONES

La sistematización y el análisis multiescalar hasta aquí desarrollados sobre las infraestructuras que forman parte de la encrucijada HPP-CBC en

${ }^{42}$ Entidad administradora del puerto de Santa Fe desde 1994 según convenio firmado por el gobernador (Santa Fe, PE. Acta de transferencia de la Administración y explotación portuaria de la Provincia de Santa Fe a favor del Ente Administrador Puerto Santa Fe, 29 de marzo de 1994).

${ }^{43}$ En 2016, por ejemplo, el gobierno de la provincia decidió estudiar nuevamente el tipo de terminal que es conveniente, luego de una licitación fallida [Punto Biz, 25/10/2016]. 
el GSF han tenido como objetivo general colocar en evidencia el papel estratégico (económico y geopolítico) que las mismas poseen en un contexto amplio, vinculado con una exigencia histórica del capital: conectar áreas ricas en elementos de la naturaleza - por lo general ubicadas en los países económicamente periféricos- con los centros de producción global. Así, por ejemplo, la producción de soja proveniente de Paraguay, Bolivia y Argentina concurre en el polo agroexportador rosarino, donde recibe una serie de procesamientos para su destino al mercado internacional (sobre todo a China).

En tal esquema, el GSF está atravesado por diversas conexiones, materializadas en infraestructuras que, por un lado, vinculan su territorio a nivel regional y continental, y por el otro, han provocado fragmentaciones y conflictos socio-espaciales en la escala urbana. Esto último se hizo evidente en la controvertida obra de las avenidas Leandro Alem y 27 de Febrero, concebidas estrictamente en un sentido funcional-económico que resultó en la fragmentación de un área de alto valor histórico y paisajístico para la ciudad, además de la tala de un importante -y también histórico- conjunto arbóreo. Lo mismo ha ocurrido con las obras en la Avenida Circunvalación Oeste, llevadas a cabo en un sector excluido de la ciudad, caracterizado por un alto grado de riesgo hídrico y exento de políticas de planificación urbana, donde tampoco se ha trascendido la mera función económica de la vía como conector regional. De este modo, se ha perdido la oportunidad de cualificar e integrar los barrios del oeste en tanto nexo urbano entre la ciudad y el río Salado. Asimismo, la concreción de la RN 19, lejos de convertirse en una avenida de penetración urbana hacia el oeste de la ciudad de Santo Tomé, resultó en un espacio urbano donde la superposición de actividades ha quedado supeditada a la dinámica de los flujos extralocales.

Esta relación conflictiva entre las infraestructuras de escala regional e internacional y los usos urbanos puede encontrar algún hilo de inteligibilidad a partir de la observación de los objetivos con que se han concebido las obras. En efecto, las infraestructuras analizadas se han proyectado, en el esquema de la IIRSA, con intenciones meramente funcionales-económicas y desde una perspectiva eficientista empresarial que no contempló otros ordenes existentes en la ciudad (la movilidad del peatón y los usos 
de la escala local, por ejemplo), ni otros valores, como los culturales-históricos y paisajísticos, más propios de una concepción de espacio vivido que de un espacio exclusivamente del capital global. De ahí gran parte la emergencia de conflictos entre diferentes sectores sociales cuyos intereses y miradas sobre las obras difieren. El caso de la adecuación de las avenidas Leandro Alem y 27 de Febrero a las necesidades del mercado internacional y la controversia que generó es particularmente elocuente.

Asimismo, en un momento histórico caracterizado por la racionalidad neoliberal, la competencia entre ciudades con el objetivo de atraer inversiones ha sido un movilizador de acciones estatales orientadas a la construcción de PGE y la adecuación de infraestructuras que posibiliten tal objetivo. Esta dinámica quedó manifiesta en la polémica entre funcionarios de Santa Fe y Rosario a partir de la construcción del Puente Santa Fe-Paraná y el Puente Rosario-Victoria, respectivamente. Tal es así que ambas ciudades, durante la década de los noventa, disputaron su hegemonía en el marco del trazado del CBC con la intención de monopolizar el tráfico de commodities en la región.

Finalmente, interesa destacar que a pesar de la concepción continental o global con que los PGE y otras infraestructuras fueron concebidas o remodeladas en sus objetivos, ha sido la escala local la arena principal donde los conflictos y las disputas tuvieron lugar. Así como pueden observarse los efectos locales de las dinámicas globales en las zonas de extracción de elementos de la naturaleza (por ejemplo, que se agote o contamine un río por el uso indiscriminado por parte de una explotación minera), también dichas dinámicas provocan conflictos en los ámbitos urbanos que atraviesan en su materialización infraestructural. Las fragmentaciones en el espacio urbano, los distintos reclamos sociales por preservar el espacio vivido y las reconfiguraciones de la trama urbana constituyen efectos concretos del encuentro conflictivo entre las distintas lógicas que organizan los flujos de mercancías, de información y de población. Dicha conflictividad deja en evidencia, por un lado, la condición intensamente política de los PGE, y por el otro, el papel clave del estado (municipal, provincia y nacional) a la hora de posibilitar, mediante las políticas que define, cuáles sectores sociales tendrán lugar en la producción social del espacio y en la apropiación de los recursos naturales. 
Un especial agradecimiento a la ingeniera Elba Stancich por facilitar documentos valiosos de su archivo particular, que conformaron gran parte de nuestras fuentes.

REFERENCIAS

Acosta, Alberto [2012], "Extractivismo y neoextractivismo: Dos caras de la misma maldición”, en Grupo Permanente de Trabajo sobre Alternativas al Desarrollo, Más allá del desarrollo. Quito, Fundación Rosa Luxemburg/Abya Yala, pp. 83-118.

Alimonda, Héctor [2006], "Una nueva herencia en Comala. Apuntes sobre la ecología política latinoamericana y la tradición marxista", en $\mathrm{H}$. Alimonda (comp.), Los tormentos de la materia. Aportes para una ecología política latinoamericana. Buenos Aires, Clacso, pp. 93-122.

Arach, Omar [2003], "Ambientalismo, Proyectos de Gran Escala y Transnacionalidad. El caso de la Coalición Ríos Vivos y la oposición a la Hidrovía del Mercosur", en Avá, Posadas, Universidad Nacional de Misiones, núm. 4, pp. 35-51.

Balassa, Bela [1964], Teoría de la integración económica. México, Uteha. Bertuzzi, María Laura [2015], Marcas en el paisaje. Permanencias y ausencias como pautas de interpretación del territorio ribereño. Tesis, Universidad Politécnica de Catalunya, Barcelona.

Brenner, Neil [1999], "Globalisation as Reterritorialisation: The Re-scaling of urban Governance in the European Union”, en Urban Studies, Glasgow, Reino Unido, University of Glasgow, vol. 36, núm. 3, pp. 431-451.

Ciccolella, Pablo, Elsa Laurelli y Alejandro Rofman [1994], Integración latinoamericana y territorio. Transformaciones socio-económicas, políticas y ambientales en el marco de las políticas de ajuste. Buenos Aires, UBA/CEUR.

Comité Intergubernamental Hidrovía [1988], Acta del 25 de noviembre de 1988. 
Consejo Federal de Inversiones-Foro de Entidades Profesionales de la Región Centro [2014], Sistematización de estudios vinculados a la hidrovía Paraná-Paraguay-Uruguay, Córdoba, Argentina, Centro de Ingenieros de Córdoba.

Cosiplan (Consejo Suramericano de Infraestructura y Planeamiento de Unasur), <http://iirsa.org/>.

Corporación Andina de Fomento (CAF) [1998], Los ríos nos unen. Integración fluvial suramericana, Bogotá, Colombia, CAF.

De Mattos, Carlos [1989], "Reestructuración social, grupos económicos y desterritorialización del capital. El caso de los países del Cono Sur", en Eure, Santiago de Chile, Pontificia Universidad Católica de Chile, vol. 16, núm. 47, pp. 61-90.

Decreto 253, Vias Navegables. Poder Ejecutivo Nacional, Buenos Aires, Argentina, 21 de febrero.

Diario El Litoral, 5/10/1970. "Autopista en discusión”, p. 4.

1/02/2011. "La presidenta dejó inaugurada la autovía que une a las ciudades de Santa Fe y Paraná". <https://cutt.ly/bd6q4HF>.

Diario La Capital, 21/03/1998. "Critican el proyecto de la Hidrovía Paraguay-Paraná”, p. 7.

, 7/06/1998. "La ruta de la soja del Mercosur", p. 7.

, 15/10/1998. "Avanza el proyecto del puente para unir Santa Fe y Paraná”, p. 6.

, 17/10/1998. "Obeid y Busti aceleran el paso por el puente Santa Fe-Paraná”, p.7.

, 5/10/1999. "Construirán un puente para unir Santa Fe con Paraná", p. 6.

8/12/2003. "Polémica en torno a una importante obra vial en la ciudad de Santa Fe". <https://cutt.ly/Cd6wqMc>.

Delgado Ramos, Gian Carlo [2012], "Extractivismo minero, conflicto y resistencia social", en Realidad Económica, Buenos Aires, IADE, enerofebrero, núm. 265, pp. 60-84.

Dicken, Peter [2003], Global Shift: Reshaping the global economic map in the 21st Century. Londres, Sage.

Dunne, Thomas et al. [1997], Proyecto Hidrovía Paraguay-Paraná. Informe de una evaluación independiente, Washington, DC, EDF/CEBRAC. 
Fedele, Javier [2011], "Puertos sin barcos. El espacio urbano en el proceso de reconversión de usos del área portuaria de Santa Fe", en Área, Buenos Aires, Universidad de Buenos Aires, núm. 17, pp. 37-53.

Fernández, Víctor Ramiro [2018], La trilogía del erizo-zorro. Redes globales, trayectorias nacionales y dinámicas regionales desde la periferia. Buenos Aires, Anthropos/unL.

Ferrer, Aldo [1991], "Perspectivas heterodoxas en el Informe Okita acerca de la economía argentina", en El Trimestre Económico, México, Fondo de Cultura Económica, julio-septiembre, vol. 58, núm. 231, pp. 497-520.

Foro de Entidades Empresarias de la Región Centro [2015], "Se creó la red para el desarrollo del Corredor Bioceánico Central”, Primer Encuentro Institucional y Empresarial del Corredor Bioceánico Central Coquimbo-Porto Alegre, San Juan, Argentina, 25 y 26 de febrero de 2015. Fuentevilla, Cristian [2018], "La integración regional en la perspectiva del IIRSA y la pertinencia geopolítica de la energía entre 2005 y 2009”, en Millcayac, Mendoza, Universidad Nacional de Cuyo, septiembrefebrero, vol. 5, núm. 9, pp. 305-320.

Gioria, Blanca [2009], La construcción del espacio geográfico de la ciudad de Santa Fe 1573-2007. Santa Fe, Argentina, Ministerio de Innovación y Cultura, Gobierno de Santa Fe.

Gobierno de la Provincia de Santa Fe (GPSF) [2003], Licitación de la obra de remodelación de las Avdas. 27 de Febrero y Leandro Alem de Santa Fe. $<$ https://cutt.ly/nd6wyzD>.

(GPSF) [2006], Estudio Socio Ambiental, Ruta Nacional $N^{\circ}$ 19, Tramo: $R N N^{\circ} 11-R N N^{\circ} 158$ (Capítulo 1). Santa Fe, Argentina, Ministerio de Obras, Servicios Públicos y Vivienda, DPV.

Guattari, Felix y Suely Rolnik [2013], Micropolítica. Cartografías del deseo. Buenos Aires, Tinta Limón.

Gudynas, Eduardo [2009], "Diez tesis urgentes sobre el nuevo extractivismo. Contextos y demandas bajo el progresismo sudamericano actual", en A. Acosta, Extractivismo, política y sociedad, Quito, CAAP (Centro Andino de Acción Popular) y ClaEs (Centro Latinoamericano de Ecología Social), pp. 187-225.

Harvey, David [1985], "The geopolitics of capitalism", en D. Gregory y J. Urry (eds.), Social Relations and Spacial Structures. Londres, Macmillan, pp.128-163. 
[2004], Spaces of Neoliberalization: towards a theory of uneven geographical development. Heidelberg, University of Heidelberg.

Hermida, Raúl [2017], "El túnel de Agua Negra y el Corredor Bioceánico Central", en Revista de la Bolsa de Comercio de Rosario, Rosario, BCR, núm. 1530, pp. 12-20.

Laredo, Iris [1984], "La integración regional en el actual contexto mundial", en Revista Integración Latinoamericana, Buenos Aires, BID-INTAL, enero-febrero, vol. 9, núm. 87, pp. 26-41.

[1990], Modelos y estrategias de integración. La Plata, Instituto de Integración, UNLP.

[1994], "Del deterioro y la asimetría hacia una nueva inserción de América Latina en el sistema internacional", en P. Ciccolella (ed.), Integración latinoamericana y territorio. Transformaciones socioeconómicas, políticas y ambientales en el marco de las políticas de ajuste. Buenos Aires, CEUR/UBA, pp. 115-140.

Laval, Christian y Pierre Dardot [2013], La nueva razón del mundo. Ensayo sobre la sociedad neoliberal. Barcelona, Gedisa.

[2015], Común. Ensayo sobre la revolución en el siglo xxı, Barcelona, Gedisa.

Ley 24.578 [1995], Mercado Común del Sur. Gobiernos de la República Argentina, República Federativa de Brasil, República del Paraguay y República Oriental del Uruguay, 25 de octubre de 1995.

Lins Ribeiro, Gustavo [2007], "Poder, redes e ideología en el campo del desarrollo", en Tabula Raza, Bogotá, Universidad Colegio Mayor de Cundinamarca, enero-junio, vol. 6, pp. 173-193.

Loveras Rivas, M. [1997], The Hidrovia: reinventing the wheel, Países Bajos, Macula/IUCN.

Malassis, Louis [1975], "Groupes, complexes et combinants agroindustriels: methods et concepts”, en Economies et Societés, París, ISMEA, septiembre-octubre, núm. 9.

Marx, Karl [2004 (1867)], El Capital, México, Siglo xxi.

Morales Letzkus, Cristian [2014], Potencialidades económicas y de negocios del Corredor Bioceánico Central (CBC) Coquimbo-Porto Alegre. Chile, Gobierno Regional de Coquimbo, Proyecto FIC-R (Fondo de Innovación para la Competitividad). 
Pengue, Walter [2000], Cultivos transgénicos. ¿Hacia dónde vamos?, Buenos Aires, Lugar Editorial.

Perfil, 28/07/2019, "Preocupación de EE.uU. por una firma china que busca entrar en la Hidrovía. <https://cutt.ly/wd6wsa1>.

Prendes, Héctor [1998], Compendio del estudio realizado por la Facultad de Ingeniería y Ciencias Hidricas de la Universidad Nacional del Litoral. Anteproyecto de Terminal Multipropósito. Santa Fe, Argentina, Ente Administrador Puerto Santa Fe.

Punto Biz, 25/10/2016, "Puerto de Santa Fe: volverán a estudiar qué tipo de terminal conviene construir". <https://cutt.ly/od6wkUI>.

, 17/12/2018, "Holding chino quiere quedarse con el dragado de la Hidrovía". <https://cutt.ly/2d6wTCT>.

Rausch, Gisela [2018], "Proyectos hidráulicos, ambientalismos y re-escalamiento territorial: la disputa en torno a la construcción del Proyecto Paraná Medio en el proceso de neoliberalización de Argentina, 19951997", en Revista de Geografía Norte Grande, Santiago de Chile, Pontificia Universidad Católica de Chile, núm. 69, pp. 169-190.

Reboratti, Carlos [1990], "Agribusiness y reestructuración agraria en la Argentina”, en E. Laurelli y J. Lindenboim (comps.), Reestructuración económica global. Efectos y políticas territoriales. Buenos Aires, CEUR, pp. 147-164.

[2010], "Un mar de soja. La nueva agricultura en Argentina y sus consecuencias", en Revista de Geografía Norte Grande, Santiago de Chile, Pontificia Universidad Católica de Chile, núm. 45, pp. 63-76.

Resolución 17 [2019], Ministerio de Producción y Trabajo. Secretaría de Alimentos y Bioeconomía, Buenos Aires, Argentina, 26 de febrero de 2019. 167 [1996], Ministerio de Economía y Obras y Servicios Públicos. Secretaría de Agricultura Pesca y Alimentación, Buenos Aires, Argentina, 25 de marzo de 1996.

Sanahuja [2008-2009], "Del regionalismo abierto al regionalismo post-liberal. Crisis y cambio en la integración regional en América Latina y el Caribe, en Alfonso Laneydi Martínez, Lázaro Peña y Mariana Vázquez. Anuario de la integración de América Latina y el Gran Caribe, 7. Buenos Aires, Coordinadora Regional de Investigaciones Económicas y Sociales (CRIES). 
Sassen, Saskia [2010], Territorio, autoridad y derechos. De los ensamblajes medievales a los ensamblajes globales. Buenos Aires, Katz.

Schweitzer, Mariana [2016], Transporte y producción del territorio en el litoral portuario del sur de la provincia de Santa Fe. Tensión entre estrategias globales y transformaciones locales. Tesis, Universidad Nacional de Buenos Aires, Facultad de Arquitectura Diseño y Urbanismo, Buenos Aires, Argentina.

Seoane, José y Clara Algranati [2013], "El sabor amargo del crecimiento económico: la expansión del modelo extractivo entre 2003 y 2007”, en J. Seoane, E. Taddei y C. Algranati, Extractivismo, despojo y crisis climática, Buenos Aires, Herramienta/El Colectivo/GEAL, pp.61-81.

Svampa, Maristella [2005], La sociedad excluyente. La Argentina bajo el signo del neoliberalismo. Buenos Aires, Taurus.

Svampa, Maristella y Enrique Viale [2014], Maldesarrollo. La argentina del extractivismo y el despojo, Buenos Aires, Katz.

Swyngedouw, Erik [1992], “The Mammon quest: 'glocalisation', interspatial competition and the monetary order -the construction of new scales”, en M. Dunford y G. Kafkalas (eds.), Cities and regions in the new Europe. Nueva York, Belhaven, pp. 39-67.

[2004], "Globalisation or glocalisation? Networks, territories and re-scaling", en Cambridge Review of International Affairs, Cambridge, University of Cambridge, vol. 17, núm. 1, pp. 25-48.

Teubal, Miguel [2006], "Expansión del modelo sojero en la Argentina. De la producción de alimentos a los commodities", en Realidad Económica, Buenos Aires, IADE, núm. 220, pp. 71-94.

Unasur (Unión de Naciones Suramericanas), <www.unasursg.org/>.

Unasur-Cosiplan [2016], Túnel Binacional Agua Negra. Programa Territorial de Integración, Buenos Aires, Argentina, Secretaría сСт CosiplanIIRSA, INTAL.

[2017], Informe de Actividades 2017, Buenos Aires, Argentina, Foro Técnico IIRSA.

Unión Industrial Santa Fe [1999], "Corredor Bioceánico Central-Porto Alegre-Coquimbo", Conexión Industrial. Publicación de la Unión Industrial de Santa Fe, Santa Fe, Argentina, vol. 3, núm. 11, pp. 20-21. 
Us TDA (United States Trade and Development Agency) [1995], Surface Transportation Project Opportunities in South America, Río de Janeiro, Brasil, Us TDA.

Vidosa, Regina [2017], "Inserción internacional de un régimen de acumulación periférico: el complejo de la soja en la Argentina durante la posconvertibilidad”, en A. García (coord.), Territorio y políticas públicas en el sur. Dinámicas socioeconómicas en la Argentina y Brasil a principios del siglo XXI. Buenos Aires, Biblos, pp. 177-194. 